

The publications of the Museum of Zoology, University of Michigan, consist of two series-the Occasional Papers and the Miscellaneous Publications. Both series were founded by Dr. Bryant Walker, Mr. Bradshaw H. Swales, and Dr. W. W. Newcomb.

The Occasional Papers, publication of which was begun in 1913, serve as a medium for original papers based principally upon the collections of the Museum. The papers are issued separately to libraries and specialists, and, when a sufficient number of pages have been printed to make a volume, a title page, table of contents, and index are supplied to libraries and individuals on the mailing list for the entire series.

The Miscellaneous Publications, which include papers on field and museum techniques, monographic studies, and other contributions not within the scope of the Occasional Papers, are published separately, and as it is not intended they will be grouped into volumes, each number has a title page and, when necessary, a table of contents. 


\title{
A Systematic Review of the Harvest Mice (Genus Reithrodontomys) of Latin America
}

\author{
BY \\ EMMET T. HOOPER
}

ANN ARBOR

UNIVERSITY OF MICHIGAN PRESS

JANUARY 16,1952 
. 


\section{CONTENTS}

PAGE

Introduction $\ldots \ldots \ldots \ldots \ldots \ldots \ldots \ldots \ldots \ldots \ldots \ldots \ldots \ldots \ldots \ldots \ldots \ldots$

Materials ............................. 8

Acknowledgments $\ldots \ldots \ldots \ldots \ldots \ldots \ldots \ldots \ldots \ldots \ldots \ldots \ldots \ldots \ldots$

Methods ................................. 9

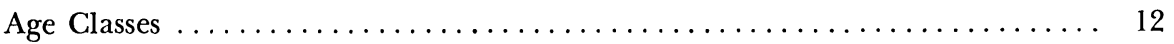

Pelages $\ldots \ldots \ldots \ldots \ldots \ldots \ldots \ldots \ldots \ldots \ldots \ldots \ldots \ldots \ldots \ldots \ldots \ldots \ldots$

Breeding Habits $\ldots \ldots \ldots \ldots \ldots \ldots \ldots \ldots \ldots \ldots \ldots \ldots \ldots \ldots \ldots \ldots \ldots$

Topography and Nomenclature of the Molar Teeth $\ldots \ldots \ldots \ldots \ldots \ldots \ldots$

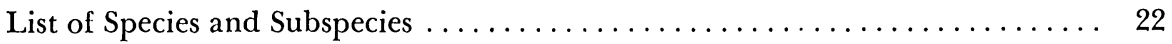

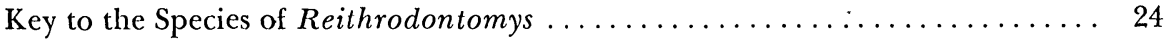

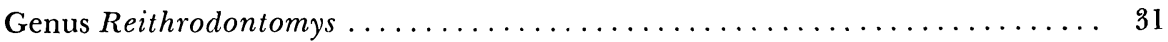

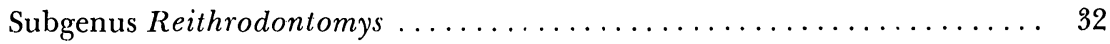

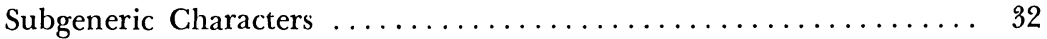

Reithrodontomys montanus ................... 34

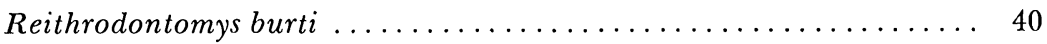

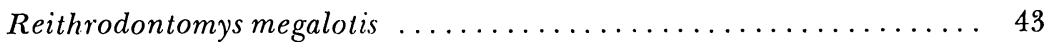

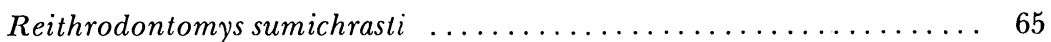

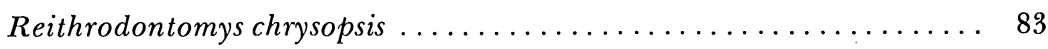

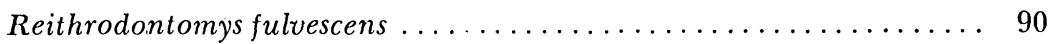

Reithrodontomys hirsutus .................... 123

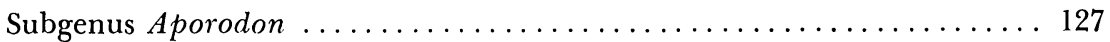

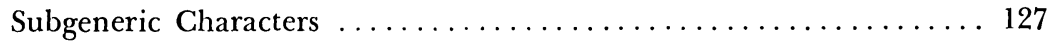

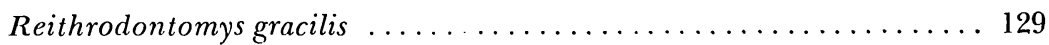

Reithrodontomys darienensis $\ldots \ldots \ldots \ldots \ldots \ldots \ldots \ldots \ldots \ldots \ldots$

Reithrodontomys mexicanus ................... 138

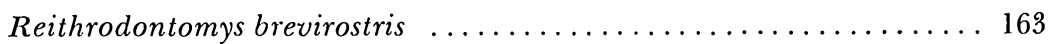

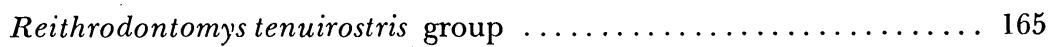

Reithrodontomys microdon $\ldots \ldots \ldots \ldots \ldots \ldots \ldots \ldots \ldots \ldots \ldots \ldots$

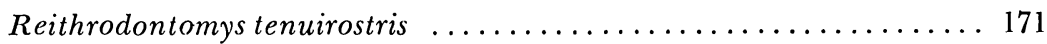

Reithrodontomys rodriguezi $\ldots \ldots \ldots \ldots \ldots \ldots \ldots \ldots \ldots \ldots \ldots \ldots$

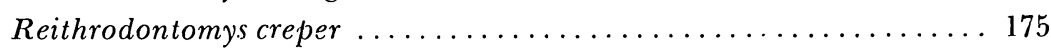

Configurations of the Molar Teeth $\ldots \ldots \ldots \ldots \ldots \ldots \ldots \ldots \ldots \ldots \ldots$ 
Size, Altitude, and Latitude $\ldots \ldots \ldots \ldots \ldots \ldots \ldots \ldots \ldots \ldots \ldots \ldots \ldots$

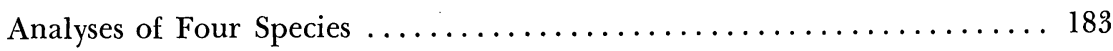

Summary and Conclusions $\ldots \ldots \ldots \ldots \ldots \ldots \ldots \ldots \ldots \ldots \ldots \ldots \ldots \ldots \ldots \ldots$

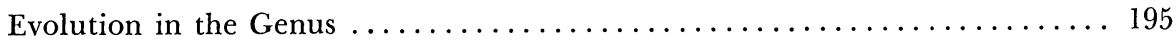

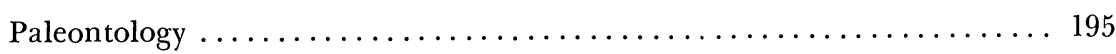

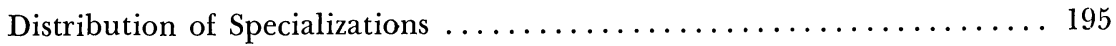

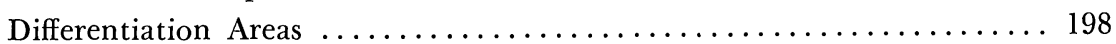

Estimate of Phyletic Development in the Genus ............... 199

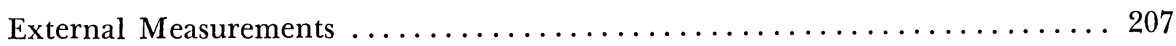

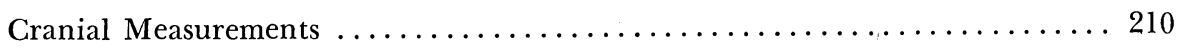

Currently Recognized Forms of Reithrodontomys not Reviewed in Detail in this

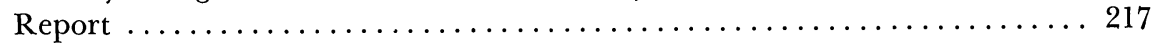

Gazetteer ........................................ 220

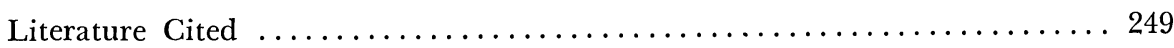




\section{ILLUSTRATIONS}

\section{PLATES}

(Plates I-IX follow page 255)

PLATE

I. Schematic diagram of the interrelationships of the species of Reithrodontomys.

II, III. Dorsal and ventral aspects of crania of species inhabiting western México.

IV, V. Dorsal and ventral aspects of crania of species inhabiting central México.

VI, VII. Dorsal and ventral aspects of crania of species inhabiting northern Central America.

VIII, IX. Dorsal and ventral aspects of crania of species inhabiting southern Central America.

\section{FIGURES IN THE TEXT}

FIGURE

PAGE

1. Diagrams of the cranium to illustrate cranial measurements............ 10

2. Diagram of an enamel pattern of the molar teeth of Reithrodontomys........ 21

3. The first and second lower molar teeth of Reithrodontomys humulis and R. burti.. 24

4. Occlusal view of right upper molar row of Reithrodontomys humulis, $R$. megalotis,

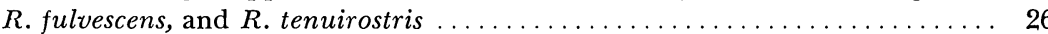

5. Occlusal view of left lower molar row of Reithrodontomys humulis, $R$. megalotis,

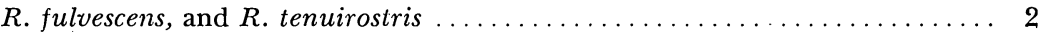

6. Profile of cranium of Reithrodontomys microdon and $R$. mexicanus......... 28

7. Three types of occlusal pattern of the third left upper molar tooth of Reithro-

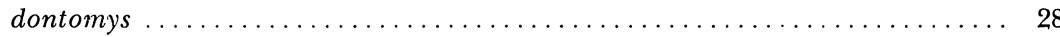

8. Three types of occlusal pattern of the third left lower molar tooth of Reithrodon-

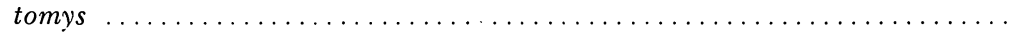

9. Dorsal aspect of the forepart of the cranium of Reithrodontomys sumichrasti, $R$.

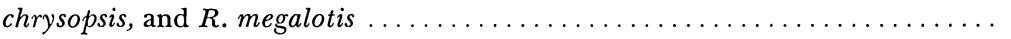

10. Diagram of the palate and pterygoid region of Reithrodontomys sumichrasti and

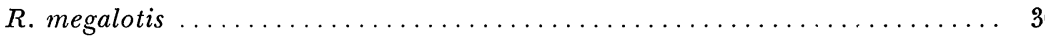

11. Graph of cranial lengths of specimens of Reithrodontomys megalotis........ 45

12. Graph of molar row lengths of specimens of Reithrodontomys megalotis . . . . . 46

13. Histogram correlating length of skull and color of underparts in specimens of

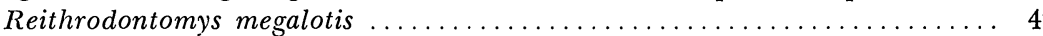

14. Histograms showing skull lengths of specimens of Reithrodontomys chrysopsis and R. sumichrasti

15. Histograms showing tail lengths of specimens of Reithrodontomys chrysopsis and

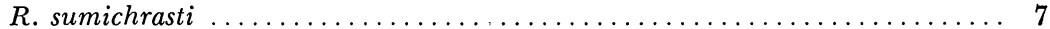

16. Graphs of the condition of mesolophs in the molar teeth of Reithrodontomys..... . 179

17. Correlation of length of skull and length of head and body in Reithrodontomys

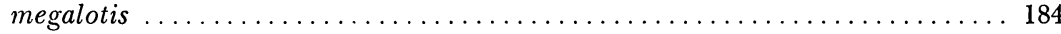

18. Graph of the relationship of cranial length to altitude in Reithrodontomys fulves-

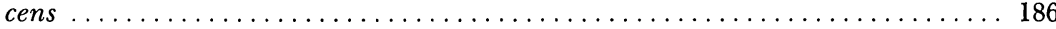


19. Graph of the relationship of cranial length to altitude in Reithrodontomys sumichrasti

20. Graph of the relationship of cranial length to latitude in Reithrodontomys sumichrasti .............................................. 188

21. Graph of the relationship of cranial length to altitude in Reithrodontomys mexicanus ................................................ 189

22. Graph of the relationship of cranial length to altitude in Reithrodontomys megalotis ............................................ 190

23. Graph of the relationship of cranial length to latitude in Reithrodontomys mega-

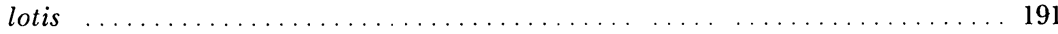

24. Variation in the occlusal pattern of the third molar teeth of Reithrodontomys megalotis, $R$. fulvescens, and $R$. mexicanus . . . . . . . . . . . . . . . . 216

\section{MAPS}

1. Distribution of Reithrodontomvs montanus and R. burti ................ 36

2. Distribution of Reithrodontomys megalotis ...................... 51

3. Distribution of Reithrodontomys sumichrasti . ..................... 66

4. Distribution of Reithrodontomys chrysopsis ........................ 84

5. Distribution of Reithrodontomys fulvescens $\ldots \ldots \ldots \ldots \ldots \ldots \ldots \ldots \ldots \ldots$

6. Distribution of Reithrodontomys hirsutus . . . . . . . . . . . . . . . . . 125

7. Distribution of Reithrodontomys gracilis and R. darienensis . . . . . . . . . 131

8. Distribution of Reithrodontomys mexicanus ......................... 141

9. Distribution of Reithrodontomys brevirostris $\ldots \ldots \ldots \ldots \ldots \ldots \ldots \ldots \ldots \ldots \ldots$

10. Distribution of Reithrodontomys microdon and $R$. rodriguezi ............ 168

11. Distribution of Reithrodontomys tenuirostris and R. creper .............. 172

12. Distribution of the Recent species of Reithrodontomys . . . . . . . . . . . . . . . . 202 


\section{A SYSTEMATIC REVIEW OF THE HARVEST MICE (GENUS REITHRODONTOMYS) OF LATIN AMERICA *}

\section{INTRODUCTION}

HARvest mice of the genus Reithrodontomys are small long-tailed rodents with deeply grooved upper incisors. They are assigned to the subfamily Cricetinae. They are known from Pleistocene deposits of North America and now occur over much of southern North America and in the northern part of South America. Their altitudinal range extends from below sea level in Death Valley of California to over 13,000 feet on the mountains of México and Central America. Ecologically they usually are associated with grasses or other low herbage in a wide variety of habitats and climates, as, for example, in marine or fresh-water marshlands and on dry, well-drained uplands in temperate climates; on hot, sandy deserts among xerophytic vegetation; on the border of tropical forests in humid lowlands; and in cool, coniferal forests up to timber line on high mountains. Within that extensive geographic, altitudinal, and ecologic range there are 17 species of harvest mice. Some of the species are monotypic and are restricted in distribution to essentially one habitat type in a few small areas. Others range widely in diverse environments and have evolved numerous geographic races.

The mice of this genus have been known to science since 1841, when Audubon and Bachman described the little harvest mouse of the eastern United States, now known as Reithrodontomys humulis. Contributions concerning this group of rodents to 1914 have been summarized by Howell (1914) in his taxonomic review of the genus. That and other important reports made since 1914 are referred to in the species accounts in the present paper. No separate section is devoted to the taxonomic history of the genus.

I have studied all known species of the genus and have arrived at a concept of their affinities. This concept and the facts that are the basis for it are set forth in this report. The species of México (excluding Baja California), Central America, and South America have been of greatest interest because that region, particularly México and Central America, is the focal area for species of harvest mice. Moreover, the region apparently has been of paramount importance throughout the evolution of the genus. I have studied the species of that region in detail and have included accounts of their distribution and variation. Less attention has been given to the species or parts thereof that are found outside Latin America. No detailed accounts are given of variation in the species humulis and raviventris or of variation in those parts of the

* Accepted for publication 29 March 1951. 
species megalotis and montanus that occur in Canada, the United States, or Baja California, although the characteristics and apparent relationships of each of these species are described. More detailed statements of the characteristics of $R$. humulis and $R$. raviventris are given elsewhere (Hooper, 1943, 1944).

Two major divisions and several lesser divisions of the genus are here recognized. The 2 major phyletic lines, or subgenera, are known by the names Reithrodontomys and Aporodon. Each consists of at least 2 important branches or species groups. Those of Reithrodontomys are known by the names megalotis and fulvescens and those of Aporodon are termed the mexicanus and tenuirostris groups. The megalotis group consists of 9 species, of which 7 are Recent and 2 are fossil. The various affinities of the species of the megalotis group suggest that 3 minor phyletic lines are represented in the group. These might be termed the humulis, megalotis, and sumichrasti groups, but none of these is quite equivalent to any other species group of the genus. There are 2 species in the fulvescens group, 4 in the mexicanus group, and 4 in the tenuirostris group. Each of these systematic levels is considered an evolutionary stage as well as a convenient level in a taxonomic system.

\section{MATERIALS}

Specimens of the 56 forms treated in this report total 3111. They consist principally of conventional study skins and skulls, which are in institutional and private collections as listed below and as indicated by appropriate symbols in the lists of specimens examined. Specimens for which the source is not indicated are in the University of Michigan Museum of Zoology.

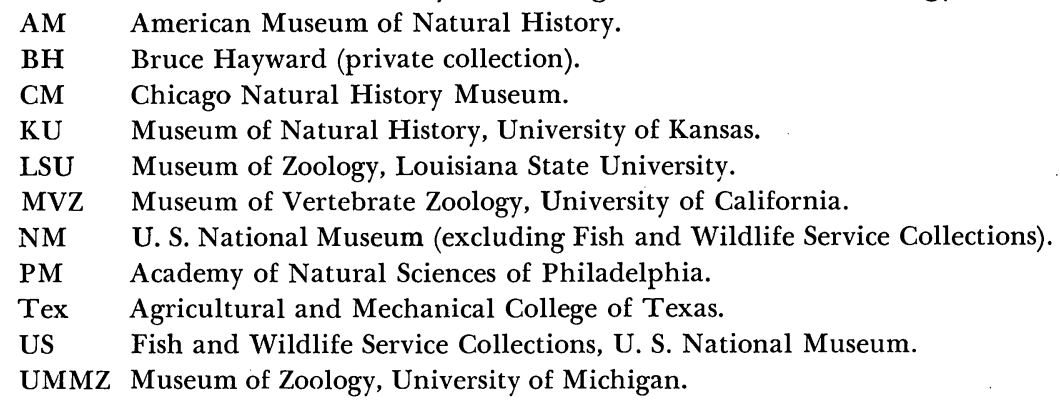

\section{ACKNOWLEDGMENTS}

The custodians of these collections have been exceedingly co-operative in providing specimens and information. To them and to those on the curatorial staffs to whom fell the tasks of packing, shipping, receiving, and checking the specimens obtained on loan, I extend hearty thanks. Without the full co-operation of F. A. Ulmer, Jr. and R. K. Enders, an important series of specimens collected by Enders and associates in Panamá could not have been 
studied. The inconveniences caused Mr. UImer are appreciated. Enders, O. P. Pearson, and G. G. Goodwin kindly supplied certain information on collecting localities and habitats in Central America. Monsieur P. Revilloid, director of the Museum of Natural History of Geneva, Switzerland, graciously provided photographs and information that permitted an appraisal of the type specimens of $R$. mexicanus and $R$. sumichrasti. Dr. H. O. Wagner has been of great assistance in more ways than can be enumerated. His work has filled in many gaps in our knowledge of the habits and distribution of mammals in México. His many efforts in my behalf and his companionship and stimulating comments while we were in the field will long be remembered. The aid of C. O. Handley, Jr., W. B. Quay, H. A. Spencer, and L. de la Torre is also gratefully acknowledged. Handley and Quay helped with many routines. De la Torre and Spencer prepared the photographs. In my opinion they achieved excellent results.

The drawings and maps were prepared by William A. Brudon, artist for the Museum of Zoology, University of Michigan. His excellent work would be a credit to any report.

Financial support for field investigations and for the publication of this report was provided in part by the Horace H. Rackham School of Graduate Studies of the University of Michigan.

\section{METHODS}

Measurements of total length, tail vertebrae, hind foot, and ear are those recorded by the collector, unless otherwise indicated. I measured the skulls, using parallel-jawed calipers graduated in tenths of millimeters and aided by 7-power magnification in a dissecting microscope. The limit of error in determining each cranial measurement is $\pm 0.1 \mathrm{~mm}$., excepting the measure of breadth of the brain case. The contour of the brain case did not permit the use of the same points in all skulls; the error in determining the breadth of the brain case is slightly greater than $\pm 0.2 \mathrm{~mm}$. in some specimens. Details of the molar teeth were determined with the aid of 15-power magnification in a dissecting microscope. That magnification, and none less than that, permitted me to see clearly all topographic details of the teeth. The cranial dimensions are illustrated in Figure 1. They are as follows:

Skull length.-The greatest length of the skull as measured between 2 vertical planes, one just touching the tips of the nasals, the other marking the posterior limits of the skull. The skull rests, bullae and incisor tips down, on the laboratory table.

Zygomatic breadth.-The greatest spread of the zygomatic arches, measured on the squamosal bones at a right angle to the long axis of the skull.

Breadth of brain case.-The greatest breadth of the brain case posterior and superior to the zygomatic arches. 
Depth of cranium.-The distance from the dorsal limits of the brain case to a horizontal plane passing through the incisor tips and the ventral borders of the auditory bullae. In determining this distance I placed the skull on a glass microscope slide. One jaw of the calipers was placed on the lower surface of the slide and the other on the dorsalmost surface of the cranium. The reading thereby obtained included the depth of the slide; subtracting the depth of the slide yielded the depth of the cranium.
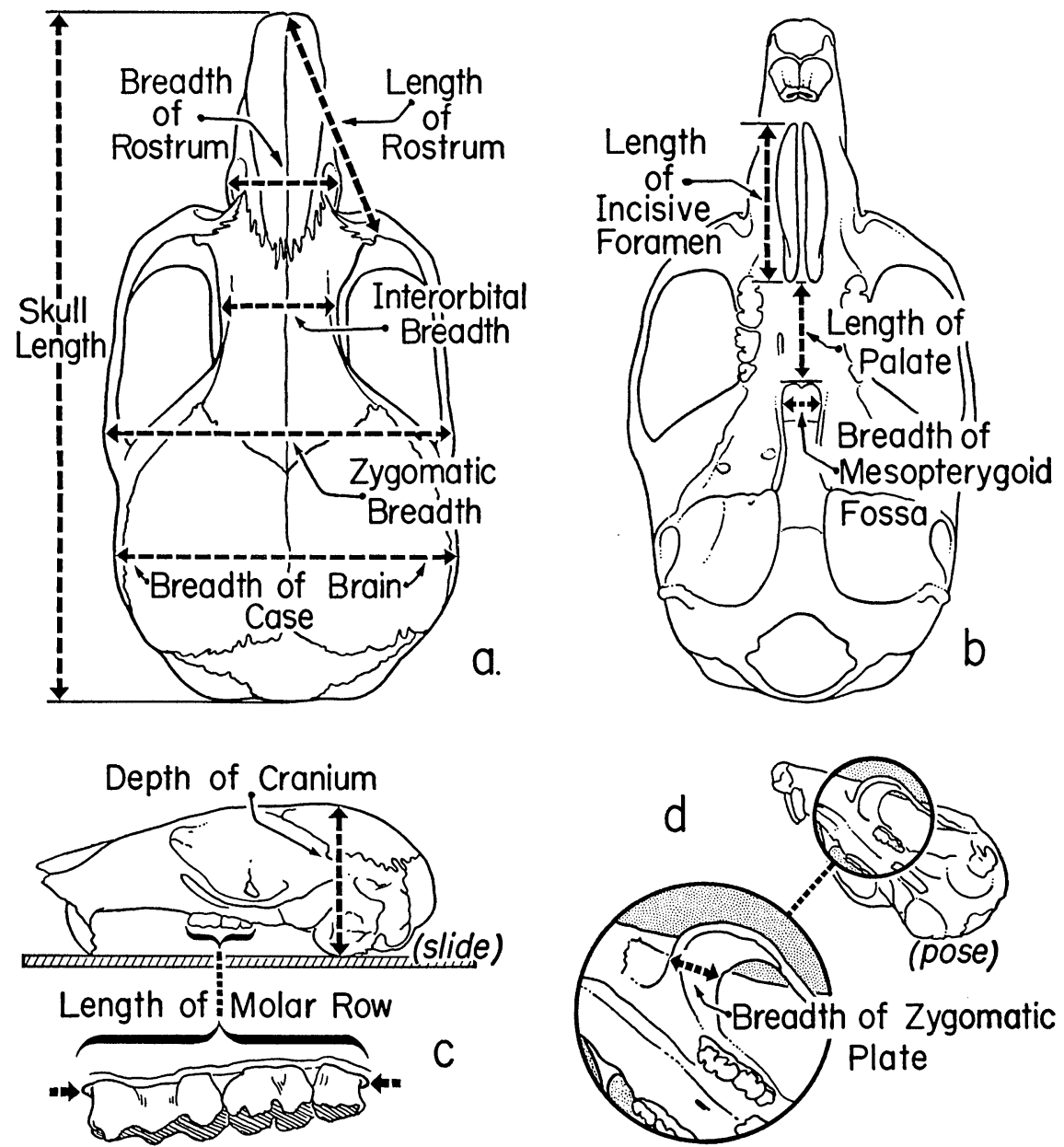

Fig. 1. Dorsal $(a)$, ventral $(b)$, and lateral $(c$ and $d$ ) aspects of the cranium of Reithrodontomys to illustrate cranial dimensions. For explanation of dimensions see text.

Interorbital breadth.-The least diameter of the frontal bones between the orbital fossae.

Breadth of rostrum.-The greatest transverse breadth of the rostrum, in- 
cluding the unbroken bony nasolachrymal capsule, anterior to the zygomatic plate.

Length of rostrum.-The distance in a straight line from the shallow notch that lies lateral to the lachrymal bone (on the superior orbital border of the zygomatic arch), anteromedially to the tip of the nasal on the same side of the skull.

Length of palate.-The least length of the hard palate between the mesopterygoid fossa and the incisive foramina.

Length of molar row.-The greatest length of the alveolar space of the upper molar row; not necessarily the distance from the anterior border of $\mathrm{M}^{1}$ to the posterior border of $\mathrm{M}^{3}$.

Length of incisive foramen.-The greatest length of one of the incisive foramina. The right foramen was measured whenever possible.

Breadth of zygomatic plate.-The least transverse diameter of the zygomatic plate of the maxilla (maxillary septum), from anterior to posterior borders.

Breadth of mesopterygoid fossa.-The greatest transverse diameter of the anterior half of the mesopterygoid (interpterygoid) fossa. Measured with expansive calipers on the ventral rim of the fossa, near the border of the hard palate.

Cranial proportions are expressed in terms of cranial depth, unless otherwise indicated. Thus, the statement that the rostrum is relatively longer in subspecies $a$ than it is in subspecies $b$ means that the ratio of length of rostrum to depth of cranium is larger in $a$ than in $b$. None of the differences in cranial proportions that are said to contrast subspecies or species have been tested statistically. Such differences between subspecies are slight at best; those -which distinguish species may be more pronounced.

No distinction as to sex has been made in the analyses. Hall (1946: 498) and Dalquest (1948: 325) indicated that females average larger than males in their samples of $R$. megalotis from the western United States. If the sexes differ in the measurements employed in the present study, the differences are not readily apparent. In the generally small samples here available such differences must be obscured by individual variation. The possibility of sexual differences in measurements was investigated in detail in the series of $R$. sumichrasti from Los Esesmiles, El Salvador. A sample of 20 males was compared statistically with a sample of 20 females. In each measurement the mean value for the males is essentially identical with that for the females. The probability that the sexes differ in any of the dimensions is exceedingly low. If sexual differences are present in those dimensions, they are not evident in the samples. Other samples were not accorded statistical treatment. In no species described here, however, does sexual dimorphism in the measurements, if present at all, appear to be sufficient to warrant separating the sexes in the analyses. 
Capitalized color terms are from Ridgway (1912). All color comparisons were made in natural light which passed to the laboratory table through windows which were behind the observer. The areas under direct observation, whether on a study skin or on Ridgway's plates, were masked off from adjoining areas insofar as was possible.

\section{AGE CLASSES}

In analysis of the study material each specimen was assigned to one of 5 age levels. In this report the 5 levels are condensed to 3 and designated juvenile, subadult, and adult. These age categories are systematic working tools. They do not necessarily correspond to similarly named levels that are based on the sexual age of the animals. The 2 sets do roughly correspond, however. All specimens herein referred to as juveniles appear to be sexually immature. All adults apparently are sexually mature. The subadults are approaching or have recently attained sexual maturity. The age groups are based on traits of the study skin and skull. Nestlings and other immature individuals that are in juvenile pelage or are assuming the subadult coat comprise the juvenile age group. The skull of each is fragile, the sutures between the bones are incompletely closed, the rostral segment is comparatively short, and the molar teeth, if completely emerged, are unworn. Juveniles were not employed in detailed comparisons of species or races. Subadults are in subadult pelage or are molting that pelage. The skull resembles that of the adult, but the bones are less completely coalesced, the brain case is relatively higher, the zygomatic arches are slighter anteriorly, and the rostrum is shorter. The molar teeth are completely emerged; $\mathrm{M}^{3}$ shows slight wear. The third group consists of adult and senile animals. The bright adult pelage has been acquired. The cranial bones are well ossified and closely coalesced, the rostral segment is relatively long, the zygomatic arches are strong, and the molar teeth are well worn. The dentine of all primary cusps is occlusally confluent.

Young adult animals are perhaps most satisfactory for analyses of geographic variation. In them racial characteristics are readily seen in both skin and skull. Senile individuals generally are unsatisfactory. They are usually in ragged pelage, the skull often is misshapen, and the original dental pattern is not discernible on the excessively eroded molar teeth. The bulk of collections consists of specimens of subadult age. Usually, few adults and juveniles are represented. A series of 114 specimens of $R$. sumichrasti from 6 collecting localities in the mountains of central Chiapas illustrates the age frequencies observed in many collections. These specimens were obtained by one collector within a period of 3 weeks in late November and early December. Whether all trapped individuals were saved and are included in the series is not known. I have reason to believe that most of the individuals procured are included. It is probable, therefore, that the series accurately represents age classes in the 
populations, or at least in that part of the populations which came to the traps in those localities at that season of the year. Eleven per cent (13 individuals) are classed as adults, 61 per cent (69 individuals) as subadults, and 28 per cent (32 individuals) as juveniles. Only 5 per cent of the juveniles are of nestling age. The remaining 23 per cent appear to be almost as old as the youngest subadults. Thus, about three-fourths of the series consists of animals that are of medium age and one-fourth consists of both young and old animals. The age composition of this series seems typical of many series.

\section{PELAGES}

In their life cycle mice of the genus Reithrodontomys apparently assume at least 3 pelages: a juvenile, a subadult or postjuvenile, and an adult pelage. After each of these pelages a partial or complete molt intervenes; the juvenile fur is lost and is synchronously replaced by the subadult fur and later the subadult pelage is replaced by the adult coat. In addition to those 3 stages there appears to be at least one annual replacement of the adult pelage. The types of pelage in Reithrodontomys are essentially similar to those in Peromyscus as described by Collins (1923). The process in replacement, however, appears to differ in the 2 genera and it probably is not exactly the same in all species of Reithrodontomys.

The foregoing and the following statements pertaining to molt and regrowth of hair in Reithrodontomys are based on an analysis of conventional study skins. The statements are subject to the qualifications inherent in any study in which characteristics of growth in a living animal are inferred from dead material. Such inferences need the support of experimental data. The basic rhythm in pelage renewal apparently is similar in all species of the genus. In each species the juvenile, subadult, and adult pelages are assumed in sequence. Whether or not the process in replacement is identical in all species cannot be determined from the present study skins; minor differences in the process between or among species cannot be detected. The process appears to be fundamentally the same at least in fulvescens, mexicanus, sumichrasti, and humulis, samples of which were analyzed in detail.

Young which are ready to leave the nest have a long dense coat composed of an abundance of long guard hairs and shorter cover hairs. The guard hairs are blackish and monocolor, or are translucent distally. The cover hairs are banded much as in subsequent pelages; they are plumbeous basally, buffy subterminally or terminally, and sometimes dusky terminally. The buffy band is exceedingly narrow, however. The many long guard hairs and the fine, soft cover hairs make the upper parts woolly in appearance. Compared with subsequent coats the juvenile pelage is always dark and dull. In the heavily pigmented species and races it is blackish dorsally. In the paler forms it is drab or gray. 
The subadult or postjuvenile pelage is quite different from the juvenile pelage. The hairs have a coarser texture similar to that in the adult. The pelage is contrastingly colored. The buffy hues, subdued in juveniles, are prominent in subadults. The bands containing those colors are wider, and the buffy hues are more intensely buffy. Distinctive markings, such as an eye ring, auricular spot, dorsal stripe, or lateral line, are well defined. The subadult pelage resembles the adult coat more than it resembles the juvenile.

The adult pelage is the brightest of the 3 pelages. Distinctive markings attain their full expression in adults. The buffy hues are conspicuous, contributing more to the total color of the fur mass than they do in the other pelages. They are also more intense and appear to be nearer the red end of the spectrum. The black guard hairs of the upper parts, although obscuring the buffy bands and deepening the tone of the pelage particularly in the deeply pigmented forms, nevertheless appear to contribute less to the total coloration than in the other pelages.

The molt that accompanies the acquisition of the subadult pelage appears to be the most uniform and complete of the molts. In the process most if not all of the juvenile fur is shed as new fur is acquired. There appear to be 2 centers from which the molt proceeds, a principal one on the venter and a secondary one on the forehead or muzzle; the latter center, however, may merely mark the first appearance on the head of the molt wave that has progressed from the ventral center. The molt first appears on the ventral surface, where it forms an expanding ellipse. In most of the skins representing this stage the entire ventral surface is molting. The ellipse expands symmetrically, encroaching about equally on both sides and both flanks, and proceeds dorsally. These dorsally progressing areas meet in the middle of the back. The middorsal molt area so formed spreads anteriorly and posteriorly. Replacement of the fur on the rump is usually completed before replacement on the head. The molting area on the muzzle and forehead expands posteriorly to meet the anteriorly progressing molt of the back. The 2 meet dorsally either on the crown or on the neck. Laterally, they meet on the cheeks. In some instances replacement begins on the snout or forehead before the back has started to molt.

The molt sequence associated with the appearance of the adult pelage in general resembles that of the juvenile-subadult molt, but details are obscured by great individual variation. The variations seem real, but may be artifacts of inadequate samples. These variations are concerned with timing or sequence of molting areas, with symmetry in replacement, and with extent and continuity of molt. There is apparently more than one center where molt begins. The variation in timing is produced by the different times at which the molting centers start in relation to one another. Insofar as can be seen in the material at hand, molt may begin in any one center; other centers may not 
always take part. Replacement is less symmetrical than in the juvenile-subadult process. Molt on one side of the body is often more advanced than on the opposite side. The molt may not extend to some areas or may be slow in doing so. For example, the fur of the belly apparently is not replaced in all individuals, and areas on the crown and rump are slow to receive the molt. Replacement areas on the back, venter, and head, which are 3 centers evident on some individuals, apparently expand unequally and at different rates in different individuals. The pattern in relation to the molt centers appears to be as follows: Molting on the head usually begins on the forehead or muzzle and ends on the crown or neck. The belly may not always molt; when it does, the molt progresses in much the same manner as in the juvenile-subadult molt. Replacement on the back usually starts middorsally and progresses in all directions. Thus the peripheral areas, namely, the shoulders, neck, sides, hips, and finally rump, may be the last to molt. In some examples, however, all of these areas molt synchronously.

The mode of replacement of the adult pelage is not well understood. The number of annual replacements and the molt pattern in each process cannot be determined conclusively from the specimens at hand. It seems clear that there is one annual molt. There are numerous examples in which adult pelage is being replaced on various parts of the body. Moreover, the great differences in some species between adult summer and adult winter pelage suggest that there may be 2 annual molts. The seasonal differences are most apparent where there are well-defined wet and dry seasons which correspond respectively to the summer and winter periods of high latitudes. The pelage differences seem too great to be accounted for in any other manner than by renewal of the fur. Whether the entire adult coat is replaced annually cannot be determined from the specimens.

Most of the molting adults from México and northern Central America represent the months January through March and late June through July, which might indicate that molting occurs principally near the beginning of the dry season and again in the wet season. Most of the specimens available, however, were collected in these months; consequently, it is not known whether the incidence of molt is significantly greater in those 2 periods. The number and position of molting areas in adults are notable in their lack of uniformity. In the specimens patches of fur on the neck, a flank, one or both sides, or on the back are being replaced but seemingly with no relationship to one another. A distinct molt line may be present or there may be no superficial evidence that new hair is emerging among the old. The conclusions reached are that ( 1 ) there is at least one annual molt, in which the new adult fur replaces the old, (2) in some species and climates adult replacement is biannual and partial or complete, and (3) the process of adult replacement is more irregular than is the assumption of the subadult and adult pelages. 
Consideration of pelages is of great importance in the comparison of closely related forms or of samples of a species. Geographic variation in pelage traits can be reliably appraised only when variation of other sorts, such as that associated with age and season, can be taken into account. Two samples from widely separated localities, each representing a different pelage, may easily be assumed to represent different forms. The differences between summer and winter pelages and between subadult and adult pelages are of the same sort and degree as those that distinguish geographic races. Without knowledge of variation in the population they can readily be so interpreted. The differences between subadult and adult pelages require especial attention. They are sometimes obscure. In the comparisons of geographic samples of a species they may become insidious.

\section{BREEDING HABITS}

Nests.-The breeding habits of $R$. megalotis are best known. Predominantly terrestrial in habit, the species usually nests on the surface of the ground under bushes, matted grass, or weeds. The nests are globular in shape with at least one opening on the lower side. They are constructed of plant fibers and consist of an inner layer of soft material, such as "down" from cattails (Bailey, 1931: 165), fine grass, or pappi. Two nests described by Smith (1936: 274) were well-woven structures about 3 inches in diameter. The single opening of each was about one-half inch in diameter and was lined with plant pappi, the same material that lined the interior of the nest. The cup of the nest was about 2 inches in diameter. Nests described by Dalquest (1948: 326) were 3 inches in internal diameter; some of them, presumably made by harvest mice, were cuplike with an opening above.

In writing of harvest mice in general Howell (1914: 10) stated that nests are often placed some distance above ground in vines, bushes, or low trees. He cited instances of nests situated several feet above ground in clusters of grain stalks, in old woodpecker holes in fence posts, and on cornstalks. All of these records pertain to species that are principally terrestrial in habit. The nesting habits of the scansorial kinds, for example $R$. mexicanus, $R$. microdon, and $R$. tenuirostris, are unknown.

REPRoduction.-In $R$. megalotis mating takes place in all months of the year, but breeding seasons probably are especially pronounced where there are clear-cut winter and summer periods. In the specimens at hand, pregnancies are indicated for each month of the year except February and November. Bailey (1936: 19) reported embryos for almost every month in specimens from Oregon. Smith (1936: 276) recorded pregnant females in California for each month except January and March. Bailey (1931: 163-65) noted embryos in specimens from New Mexico representing the months January, May, June, September, October, and December. Dalquest (1948: 326) found embryos in 
March and April in harvest mice in Washington. Hall (1946: 500) examined 101 sexually mature females from Nevada, representing the months January and April through October. The 22 that contained embryos were collected in the months May through August. No embryos were found in the 23 specimens representing January, April, September, October, and November. These data suggest that in Nevada breeding is mainly limited to spring and summer months. In his material from California Smith (loc. cit.) noted 2 peaks in the incidence of pregnant females, one in April and another of lesser importance in October, indicating 2 breeding seasons in California. Whether there are definite breeding seasons in megalotis in central México, where the climate is moderate the year around, is not known.

The gestation period in megalotis was determined by Svihla (1931: 364) to be 23 or 24 days. The youngest age at which her captive animals were found to breed was 4 months and 8 days. The number of embryos, as determined from published accounts and field records at hand, varies from 1 to 7 ; the average is 4 . The young are suckled from 3 pairs of mammae, 1 pair pectoral and 2 pairs inguinal in position. The young described by Smith (1936) were born helpless. They began to walk on the tenth day; their eyes were open on the eleventh day but were not fully functional until the thirteenth day. They were weaned when 3 weeks old.

Few data on reproduction in other species in the genus are available. Each of 2 female specimens of $R$. montanus reported by Hibbard (1938: 176) contained 5 embryos; one specimen was collected in April, the other in November. An embryo count and a breeding season similar to those for $R$. megalotis are suggested. In the series of $R$. fulvescens from México and Central America there are evidences of breeding (lactation, embryos, or very young juveniles) for almost all the months represented by specimens. The material is inadequate for determining whether there are breeding periods. A specimen of fulvescens from El Salvador contained 5 embryos. In one from Veracruz there were 3 embryos. The number of embryos in $R$. sumichrasti may be less than in $R$. megalotis. In 13 pregnant females of sumichrasti the maximum number of embryos is 4 . Counts of fetuses in 9 females from southern Jalisco follow: 4 (1 specimen), 3 (4 females), and 2 (4 individuals). Pregnant or lactating females of $R$. sumichrast $i$ from the highlands of central México were collected in March, April, and June. There were 3 embryos in a specimen from western Panamá trapped in September.

There are few data on the species chrysopsis, hirsutus, and creper. A sexually mature female chrysopsis obtained in Distrito Federal in June contained 4 embryos. Of 2 pregnant females collected on March 16 on the Volcán de Toluca, México, one contained 4 young, the other had several small embryos. A specimen of $R$. hirsutus trapped in May in southeastern Nayarit contained 4 embryos. A specimen of $R$. creper trapped in Panamá in September con- 
tained 2 embryos. Another obtained there in November was lactating.

In $R$. mexicanus breeding apparently takes place in most months of the year, as in $R$. megalotis. If there are definite breeding seasons they are not indicated by the data at hand, which, however, are few and do not cover all months. Seven females from El Salvador had recently been nursing; those specimens represent the months November, February, March, and April. Five nestling juveniles, also from El Salvador, were obtained on December 12, 13, and 20. Two nursing females from Costa Rica were collected on December 4 and July 4, respectively. A nursing female from Prusia, Chiapas, was trapped on April 2; all other specimens from Prusia taken in March and April are juveniles or subadults. Two specimens of mexicanus from Panamá contained embryos; there were 3 in one specimen and 2 in the other.

\section{TOPOGRAPHY AND NOMENCLATURE OF THE MOLAR TEETH}

The dental nomenclature used here is mainly derived from 2 sources. The terminology used for the cusps and ridges is that of Wood and Wilson (1936). The names applied to the enamel grooves and folds are those of Hershkovitz (1944). His terminology, because of its simplicity and clarity, should become standard for the molar teeth of cricetine rodents when the primary aim is to designate the topographic location of the folds. When the intent is to trace dental homologies of cricetines with other mammals, other terminology may be desirable. Homologies of the folds are suggested by the position of the fold with respect to a cusp or ridge; identical names do not necessarily indicate homologous parts.

Figure 2 is a schematic diagram of the most complex and complete enamel pattern of the molar teeth of Reithrodontomys. Each species group in the genus Reithrodontomys has a topographic pattern characteristic of that group, and some individual species within a group are characterized by patterns peculiar to them. Those characteristics are discussed under appropriate headings elsewhere in this report. Individual variations in each type of pattern are numerous. The topographical parts of the molar teeth and some variations observed in them are described in the following pages.

\section{CUSPS AND RIDGES}

Anterocone (id).-The anterocone (id) varies in size and shape in each species. It may be divided into 2 conules or may appear as a single prominent cone. Internal folds may be present or absent and may be distinct from or coalesced with the anterior cingulum and anteroloph (id).

Anterior cingulum.-The anterior cingulum of the lower molars is at best an inconspicuous ridge separated from the metaconid by a small fold; in $\mathrm{M}_{2-3}$, it may be absent. In $\mathrm{M}^{1-3}$ of some species it is a distinct loph, often equal in prominence to the other lophs of the tooth. It may decrease in height and width toward the margin of the tooth or its size may be greater at the 
margin than medially. At an advanced stage of wear it disappears as a distinct structural detail.

Anterolophid.-The anterolophid is distinct on all teeth. It is best developed in $M_{1}$ and smallest in $M_{3}$ where it often loses its identity at an early stage of wear. In the species humulis the anterolophid of $\mathrm{M}_{1}$, and usually of $\mathrm{M}_{2}$, extends posteriorly along the labial border of the protoconid and joins a labial cingulum that may extend to the posterolateral border of the tooth.

Principal cones.-In $\mathrm{M}_{1-2}^{1-2}$ individual variations in the relative sizes and shapes of the principal cusps are similar to those observable in other cricetines, such as in the genus Peromyscus. The relative positions of those cusps differ slightly among individuals; they differ importantly between species. They are almost opposite in position in some species and are alternate in location in other forms. In $M \frac{3}{3}$ variation in the principal cusps is much greater. The protocone (id) may exceed all other cusps in size and constitute as much as one-half the crown area of the tooth. In some species the paracone is the largest cusp of the $\mathrm{M}^{3}$; in other species it is scarcely larger than the anterior cingulum. The hypocone is the largest cusp of the posterior half of $\mathrm{M}^{3}$. It is smaller than the protocone and after slight wear of the tooth is often continuous with it. The metacone is not a prominent cusp of $\mathrm{M}^{3}$ in the genus Reithrodontomys. It may be entirely absent or may appear as a relatively low crest or style on the labial side of the hypocone or posterior cingulum. In a worn tooth it is usually completely coalesced with the hypocone and posterior cingulum. It is best developed in the subgenus Aporodon and in $R$. hirsutus and $R$. fulvescens of the subgenus Reithrodontomys. The hypoconid constitutes the bulk of the posterior half of $\mathrm{M}_{3}$. It usually occupies a more lingual position than the hypoconid of $\mathrm{M}_{1-2}$. It may even lie on the lingual side of the tooth, posterior to the metaconid, in the position occupied by the entoconid in $\mathrm{M}_{1-2}$. The entoconid in $\mathrm{M}_{3}$ is a distinct cusp or expanded loph in some species; in other species it either is absent or appears as a low style which is visible as a distinct detail only in a young tooth. In all species it merges with the posterior cingulum and hypoconid at an early stage of wear.

Mesoloph (id), mesostyle (id).-Mesolophs (ids) and mesostyles (ids) are characteristic structures in the teeth of some species. When most complete, the mesoloph (id) extends to the labial margin of each molar tooth; there it: terminates as a distinct mesostyle (id). Complete mesolophs usually maintain their identity until a late stage of wear. In a second group of species the mesoloph is as high lingually as the other lophs of the tooth. Labially it is a low, usually barely perceptible ridge. A mesostyle (id) may or may not be present. In a third group of species these accessory styles and lophs are usually absent; rarely, a low mesoloph that may or may not extend to the margin of the tooth may be present, and a mesostyle (id) may be present or absent. In all species a mesostyle (id) may occur entirely independently of the mesoloph (id), or, as is usually true where a complete mesoloph (id) is present, it may 
be the terminal vertical ridge of the mesoloph (id). The size of the styles is inconstant within a species and within the teeth of an individual. Mesostyles usually persist for much of the lifetime of the tooth.

Enteroloph, enterostyle, ectolophid, ectostylid.-These lophs and styles occur sporadically in most species of Reithrodontomys; they are usual in species of Aporodon. When present, they are smaller than the corresponding lophs and styles on the opposite side of the tooth and usually occur only when mesolophs (ids) are also present. A loph and a style, one or both, may occur in one tooth and be absent in others in the row.

Posterior cingulum.-The posterior cingulum is best developed in the lower molars. In the upper teeth it is small and is usually distinct only in an unworn tooth; with wear it merges with the metacone. In the lower molars it normally is a prominent structure of the posterior part of the tooth, maintaining its identity to a late stage of wear. In $M_{3}$ its size and shape vary; it may be developed as a distinct, long process of the hypoconid or it may be absent. In a worn $M_{3}$ it is usually continuous with, and indistinguishable from, the hypoconid and entoconid.

FOLDS

Major fold.-In $\mathrm{M} \frac{1-2}{1-2}$ the major fold is always a deep open valley. With wear of these teeth it recedes toward the margin and disappears, usually

Upper Molars
1. Anterocone
a. Anterolingual conule
b. Anterolabial conule
2. Anterior cingulum
3. Anteroloph
4. Protocone
5. Paracone
6. Mesoloph
7. Mesostyle
8. Enteroloph
9. Enterostyle
10. Hypocone
11. Metacone
12. Posterior cingulum

\section{NAMES OF CUSPS}

\section{Lower Molars}

(1)


without having ever been separated from the marginal enamel. In $M \frac{3}{3}$ it is much reduced or is absent. In species wherein it is well developed, it may appear as an enamel island at a late stage of wear.

Minor fold.-The minor fold lies between the protocone (id) and the anteroloph (id). In the upper teeth it is well developed only in $\mathrm{M}^{1}$. In $\mathrm{M}^{2}$ and $\mathrm{M}^{3}$, at greatest development, it is represented as an inconspicuous crease in
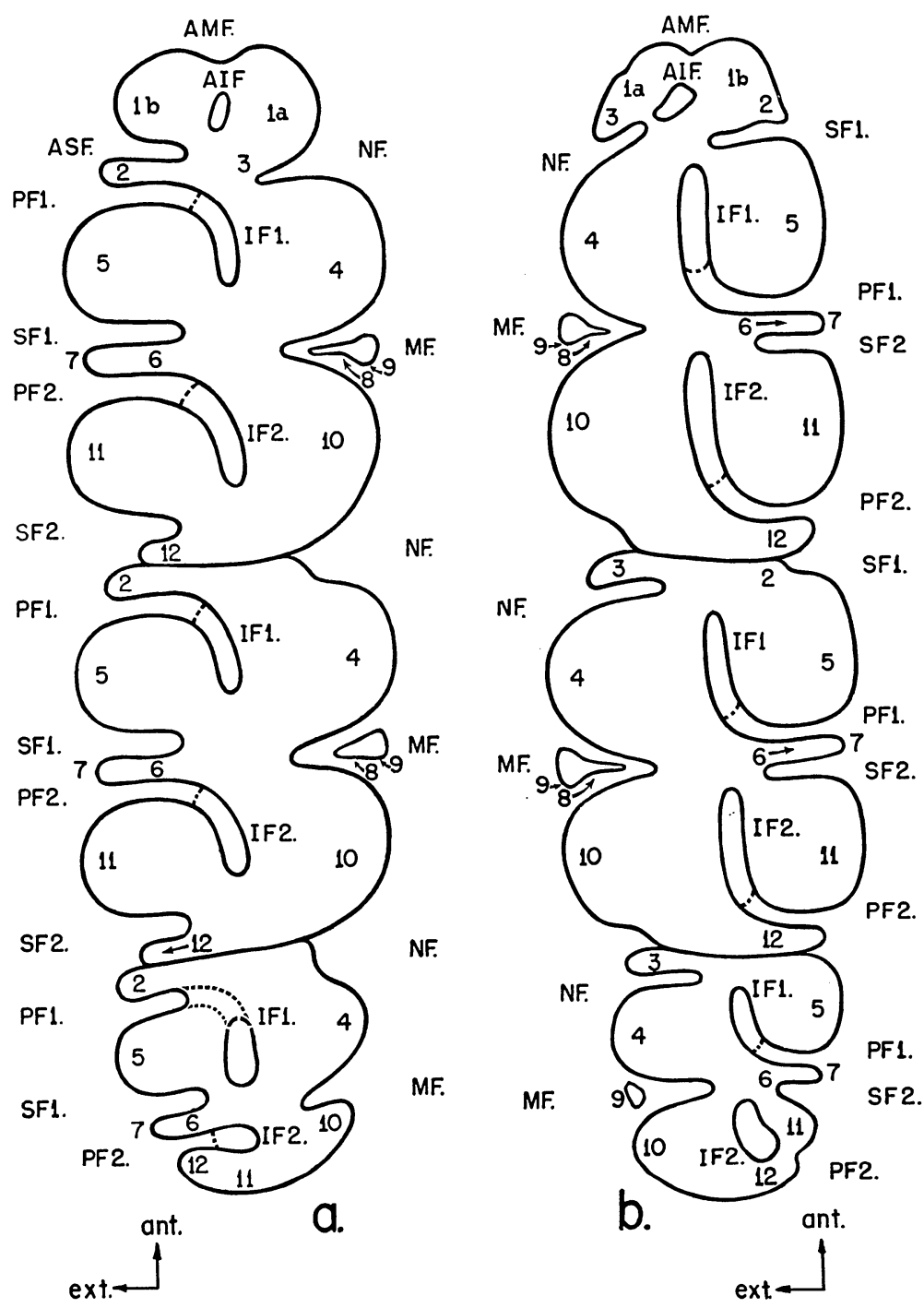

Fig. 2. Stylized diagram of a complex enamel pattern of $(a)$ upper and $(b)$ lower molar teeth of Reithrodontomys. For explanation of symbols see opposite page and text. 
the anterior face of the protocone. In the lower molars it is a prominent fold in each tooth except in $\mathrm{M}_{3}$ in some species.

Primary folds.-In $\mathrm{M} \frac{1-2}{1-2}$ of all species the primary folds are prominent folds. Their relative lengths differ in $\mathrm{M} \frac{3}{3}$. The first primary fold lies between the paracone, labially, and the anterior cingulum and protocone, lingually, and in $\mathrm{M}_{1-3}$ between the metaconid and protoconid. The second primary fold is anterior and lingual to the metacone, and in the lower molars it separates the entoconid from the hypoconid; in $\mathrm{M}_{3}$ of some species it is indistinct or lacking. Each primary fold may be divided by a septum into internal and external parts. At late stages of wear the internal fold appears as an enamel island.

Secondary folds.-The secondary folds vary greatly in length and depth, associated with the length of the mesoloph (id). The first secondary fold lies between the paracone and mesoloph and in $\mathrm{M}_{1-3}$ between the metaconid and the anterior cingulum. The second secondary fold separates the posterior cingulum and metacone, and in $\mathrm{M}_{1-3}$ it separates the mesolophid and entoconid. Secondary folds are well developed only in those species that have mesolophs (ids). The second secondary fold in $\mathrm{M}^{1-3}$ and the first secondary fold in $\mathrm{M}_{1-3}$ are always short; often they are absent. Any enamel peninsula or island formed from a secondary fold is usually short-lived, disappearing after slight wear. The anterosecondary and anteromedian folds occur only in $M_{1}^{1}$. They are always much shorter than the primary folds. They are well developed only in those species wherein there are also strong secondary folds.

Internal folds.-Each internal fold has an external counterpart from which it apparently was derived. In some instances the internal and external parts are continuous in an unworn tooth. As the tooth wears the 2 become separate, the internal part forming an enamel island and the external part becoming an enamel peninsula. In other individuals the 2 are separated by enamel, and they are discrete in the unworn as well as in the worn tooth. The internal folds and their external counterparts are as follows: The anterointernal fold of $\mathrm{M}^{1}$ apparently is derived from the anteromedian fold in some individuals and from the minor fold in others; in $\mathrm{M}_{1}$ it apparently is derived from the anteromedian or the first secondary fold. The first and second internal folds are internal parts, respectively, of the first and second primary folds. The anterointernal fold will usually disappear at an early stage of wear. The first and second internal folds, on the other hand, usually remain for most of the life of the tooth.

\section{LIST OF SPECIES AND SUBSPECIES OF REITHRODONTOMYS SUBGENUS REITHRODONTOMYS}

megalotis group:

Reithrodontomys simplicidens Brown Reithrodontomys pratincola Hibbard
Reithrodontomys humulis virginianus Howell

Reithrodontomys humulis humulis Audubon and Bachman 
Reithrodontomys humulis merriami Allen

Reithrodontomys burti Benson

Reithrodontomys montanus albescens Cary

Reithrodontomys montanus montanus Baird

Reithrodontomys montanus griseus - Bailey

Reithrodontomys megalotis pectoralis

Hanson

Reithrodontomys megalotis dychei Allen Reithrodontomys megalotis caryi Howell

Reithrodontomys megalotis aztecus Allen

Reithrodontomys megalotis megalotis Baird

Reithrodontomys megalotis saturatus Allen and Chapman

Reithrodontomys megalotis alticolus Merriam

Reithrodontomys megalotis arizonensis Allen

Reithrodontomys megalotis zacatecae Merriam

Reithrodontomys megalotis amoles Howell

Reithrodontomys megalotis ravus

Goldman

Reithrodontomys megalotis longicaudus Baird

Reithrodontomys megalotis distichlis von Bloeker

Reithrodontomys megalotis limicola von Bloeker

Reithrodontomys megalotis catalinae Elliot

Reithrodontomys megalotis peninsulae Elliot

Reithrodontomys raviventris raviventris Dixon

Reithrodontomys raviventris halicoetes Dixon

Reithrodontomys sumichrasti sumichrasti de Saussure

Reithrodontomys sumichrasti nerterus Merriam

Reithrodontomys sumichrasti luteolus Howell
Reithrodontomys sumichrasti dorsalis Merriam

Reithrodontomys sumichrasti modestus Thomas

Reithrodontomys sumichrasti australis Allen

Reithrodontomys sumichrasti vulcanius Bangs

Reithrodontomys chrysopsis chrysopsis Merriam

Reithrodontomys chrysopsis perotensis Merriam

fulvescens group:

Reithrodontomys fulvescens fulvescens Allen

Reithrodontomys fulvescens canus Benson

Reithrodontomys fulvescens griseoflavus Merriam

Reithrodontomys fulvescens toltecus Merriam

Reithrodontomys fulvescens aurantius Allen

Reithrodontomys fulvescens intermedius Allen

Reithrodontomys fulvescens tropicalis Davis

Reithrodontomys fulvescens difficilis Merriam

Reithrodontomys fulvescens tenuis Allen

Reithrodontomys fulvescens nelsoni Howell

Reithrodontomys fulvescens mustelinus Howell

Reithrodontomys fulvescens infernatis Hooper

Reithrodontomys fulvescens helvolus Merriam

Reithrodontomys fulvescens amoenus Elliot

Reithrodontomys fulvescens chiapensis

Howell

Reithrodontomys hirsutus Merriam

\section{SUBGENUS APORODON}

mexicanus group:

Reithrodontomys gracilis gracilis Allen and Chapman
Reithrodontomys gracilis anthonyi

Goodwin

Reithrodontomys gracilis pacificus Goodwin 
Reithrodontomys gracilis harrisi Goodwin

Reithrodontomys darienensis Pearson

Reithrodontomys mexicanus mexicanus de Saussure

Reithrodontomys mexicanus scansor Hooper

Reithrodontomys mexicanus howelli Goodwin

Reithrodontomys mexicanus orinus Hooper

Reithrodontomys mexicanus ocotepequensis Goodwin

Reithrodontomys mexicanus lucifrons Howell

Reithrodontomys mexicanus cherriei Allen

Reithrodontomys mexicanus potrerograndei Goodwin

Reithrodontomys mexicanus garichensis Enders and Pearson
Reithrodontomys mexicanus milleri Allen

Reithrodontomys mexicanus eremicus Hershkovitz

Reithrodontomys mexicanus söderströmi Thomas

Reithrodontomys brevirostris Goodwin

tenuirostris group:

Reithrodontomys microdon wagneri Hooper

Reithrodontomys microdon albilabris Merriam

Reithrodontomys microdon microdon Merriam

Reithrodontomys tenuirostris Merriam Reithrodontomys rodriguezi Goodwin Reithrodontomys creper Bangs

\section{KEY TO THE SPECIES OF REITHRODONTOMYS}

\section{GEOGRAPHIC RANGE IN THE UNITED STATES}

In M3 first primary fold as long as or longer than the second primary fold; each usually extends more than halfway across the tooth (Figs. 4c, 24b); major fold clearly visible; worn occlusal surface of left tooth $\mathbf{E}$-shaped (Figs. 7a, 24b). In $\mathbf{M}_{3}$ major fold as long as or longer than first primary fold; each usually extends more than halfway across the tooth (Figs. $5 c, 24 b b$ ); worn occlusal surface of left tooth S-shaped (Figs. 8a, 24bb) R. fulvescens, p. 90
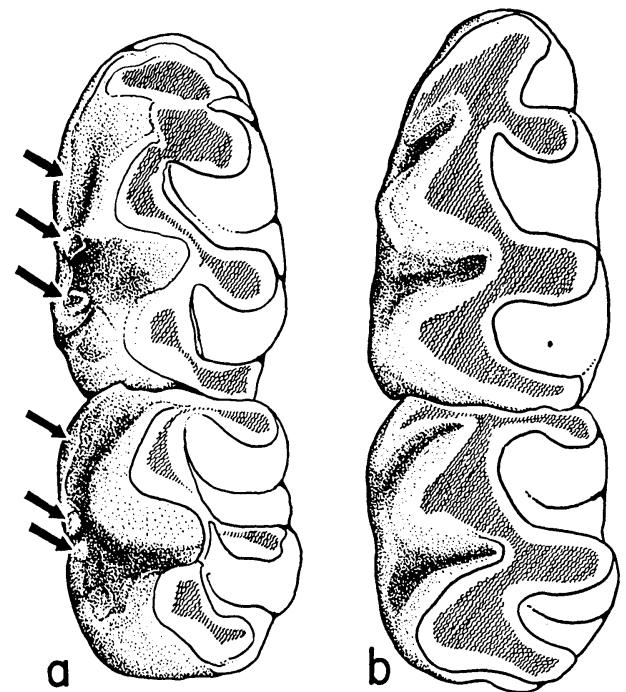

Fig. 3. (a) A distinct labial ridge with cusplets on $\mathrm{M}_{1-2}$ as seen in $R$. humulis. (b) A faint labial ridge on $\mathbf{M}_{1-2}$ as seen in $R$. burti. 
In M3 first primary fold distinctly shorter than the second primary fold; it does not extend halfway across the tooth (Figs. $4 a, b ; 24 a$ ); major fold indistinct (a small indentation on the lingual side of the tooth) or completely absent; worn occlusal surface of left M3 C-shaped (Figs. 7b, 24a). In $\mathbf{M}_{3}$ major fold shorter than first primary fold, usually not extending halfway across the tooth (Figs. $5 a, b ; 24 a a$ ); worn occlusal pattern of left tooth C-shaped (Figs. $8 b, 24 a a) \ldots \ldots \ldots \ldots \ldots \ldots \ldots \ldots \ldots \ldots \ldots \ldots \ldots$

2(1') A distinct labial shelf or ridge, often with distinct cusplets, on $\mathbf{M}_{1-2}$ (Figs. $3 a, 5 a$ ). In M1 and especially in M2, major fold and second primary fold tend to coalesce on the longitudinal mid-line of the tooth, isolating the anterior cusps (protocone and paracone) from the posterior cusps (hypocone and metacone) (Fig. 4a). Range southeastern United States ...................... humulis, p. 217

2' No distinct labial ridge on $\mathrm{M}_{1-2}$ (Fig. $5 b$ ). In M1-2 major fold and second primary folds meet but do not coalesce on the mid-line; instead, they form a loph or commissure that extends from the hypocone to the paracone; the protocone and paracone thus are connected by a loph with the hypocone and metacone (Fig. 4b). Range outside of the southeastern United States $\ldots \ldots \ldots \ldots \ldots \ldots \ldots \ldots \ldots$

$3\left(2^{\prime}\right) \quad$ Brain case narrow (maximum breadth $9.6 \mathrm{~mm}$. in specimens examined). Rostrum short and broad. Tail shorter than head and body. Range Great Plains and southwestern United States . . . . . . . . . 34

3' Breadth of brain case of adults usually over $9.5 \mathrm{~mm}$. Rostrum longer and narrower. Tail length about equal to, or longer than, head and body length . . . . . . 4

$4\left(3^{\prime}\right) \quad$ Fur of upper parts long, dense, and heavily pigmented. Ears blackish. Habitat salt marshes bordering San Francisco Bay, California ......... raviventris, p. 220

4' $\quad$ Fur of upper parts shorter and less dense. Color of upper parts varying from pale buff to reddish brown. Ears buffy or fuscous; when fuscous, the inferior inner and superior outer parts of the ear are darker than the rest of the ear. Habitat excludes salt marshes bordering San Francisco Bay............. megalotis, p. 43

\section{GEOGRAPHIC RANGE IN MÉXICO}

Second primary fold well developed in $\mathbf{M}_{3}$ (often appearing as an oval internal fold); $\mathrm{M}_{3}$ essentially a smaller replica of $\mathrm{M}_{2}$ (Figs. $5 d, 24 c c$ ). Mesolophs and mesostyles in M1-2 and usually in all other molar teeth (Figs. 4d, 5d). Zygomatic plate scarcely or not at all broader than mesopterygoid fossa (sometimes distinctly broader than fossa in gracilis). Mesopterygoid fossa approximately as broad as either pterygoid fossa (sometimes markedly narrower than pterygoid fossa in gracilis).

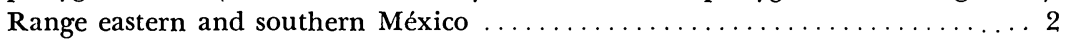

2(1) Zygomata weak, particularly anteriorly. Brain case deep and broad; its breadth scarcely less than zygomatic breadth (Fig. $6 a$ ). Breadth of zygomatic plate less than $1.5 \mathrm{~mm}$. Rostrum long and narrow (Fig. $6 a$ ). Ear length, as measured from notch on fresh specimen, scarcely less than length of hind foot. Habitat moist forests, generally above 8500 feet in central and southern México...... microdon, p. 168 Zygomata strong, usually $0.5-1.0 \mathrm{~mm}$. broader than brain case (Fig. $6 b$ ). Breadth of zygomatic plate of adults $1.4 \mathrm{~mm}$. or more. Rostrum relatively broad and short (Fig. $6 b$ ). Ear length usually 3 or $4 \mathrm{~mm}$. less than length of hind foot. Habitat dry to

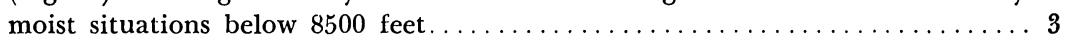

$3\left(2^{\prime}\right) \quad$ Skull length usually less than $22.0 \mathrm{~mm}$.; if more than $22.0 \mathrm{~mm}$., then length of incisive foramina less than $4.0 \mathrm{~mm}$. Frontals flat and broad interorbitally. Upper surface of hind feet whitish or dusky. Habitat tropical lowlands of southern México R. gracilis, p. 129

Skull length of adults usually more than $22.0 \mathrm{~mm}$.; if less, then length of incisive foramina more than $4.0 \mathrm{~mm}$. Frontals strongly constricted and not markedly flat 
and broad interorbitally. Upper surface of hind feet dusky. Habitat mountains and valleys at elevations above 1000 feet .............. mexicanus, p. 138 $l^{\prime} \quad$ Second primary fold indistinct or absent in $M_{3}$, the tooth different in form from $\mathbf{M}_{2}$ (Figs. $5 a-c, 24 a a, b b$ ). No mesolophids in $\mathbf{M}_{1-3}$. Mesolophs and mesostyles present or absent in M1-3 (Fig. $4 a-c$ ); when present, the mesolophs are usually unequal in length on the several teeth and usually do not extend to the labial border of the tooth. Zygomatic plate broader than mesopterygoid fossa. Greatest breadth of mesopterygoid fossa usually $1 / 2$ to $3 / 4$ that of either pterygoid fossa. Range not confined to eastern and southern México

$4\left(1^{\prime}\right) \quad$ In M3 first primary fold as long as or longer than second primary fold; each extends more than halfway across the tooth (Figs. $4 c, 24 b$ ); major fold well developed, some-
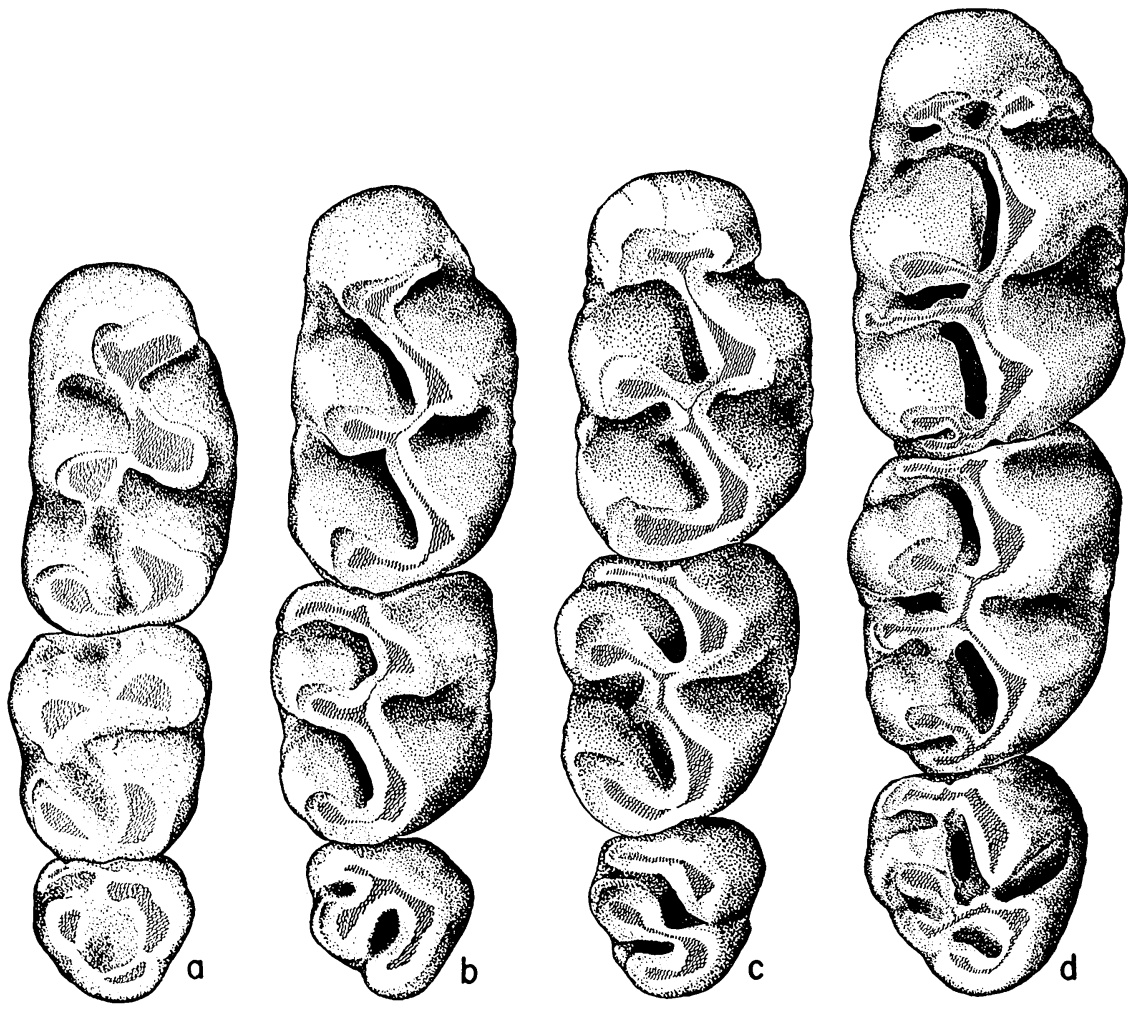

Fig. 4. Occlusal views of right upper molar rows of 4 species of Reithrodontomys: (a) humulis, (b) megalotis, (c) fulvescens, (d) tenuirostris. For names of folds and cusps see Figure 2.

times continuous with first primary fold; worn occlusal surface of left tooth E-shaped (Figs. 7a, 24b). In $\mathrm{M}_{3}$ major fold at least as long as the first primary fold (Figs. 5c, 24bb); worn occlusal surface of enamel of left tooth S-shaped (Figs. 8a, 24bb)

5(4) Zygomatic breadth more than $11.9 \mathrm{~mm}$. Interorbital breadth more than $3.4 \mathrm{~mm}$. Supraorbital border sharp-angled or beaded. Tail scarcely or not at all paler ventrally than dorsally. Duskiness of tarsi extending to the upper surfaces of the hind feet R. hirsutus, p. 123 
5' Zygomatic breadth less than $11.9 \mathrm{~mm}$. Interorbital breadth less than $3.4 \mathrm{~mm}$. Supraorbital border comparatively smooth, perhaps elevated but not ridged or beaded. Tail paler ventrally than dorsally, usually sharply bicolor. Upper surface of hind feet whitish or buffy, not dusky. .

R. fulvescens, p. 90

In M3 first primary fold shorter than second primary fold (Figs. $4 a, b ; 24 a$ ); major fold indistinct, at best a broad, shallow indentation on the lingual face of the tooth; worn occlusal surface of left tooth C-shaped (Figs. 7b, 24a). In $\mathbf{M}_{3}$ major fold shorter than first primary fold (Figs. $5 a, b ; 24 a a$ ); worn occlusal surface of left tooth C-shaped (Figs. $8 b, 24 b b$ )

$6\left(4^{\prime}\right) \quad$ Breadth of brain case more than $10.7 \mathrm{~mm}$. Tail length more than $90 \mathrm{~mm} . \ldots \ldots 7$

$7(6) \quad$ No buffy hairs anywhere on inner surfaces of ears. Ears 17-19 mm. in length, measured from notch to tip on fresh specimen. Mesolophs in $\mathrm{M}^{1}$ or $\mathrm{M}^{2}$, or both, usually
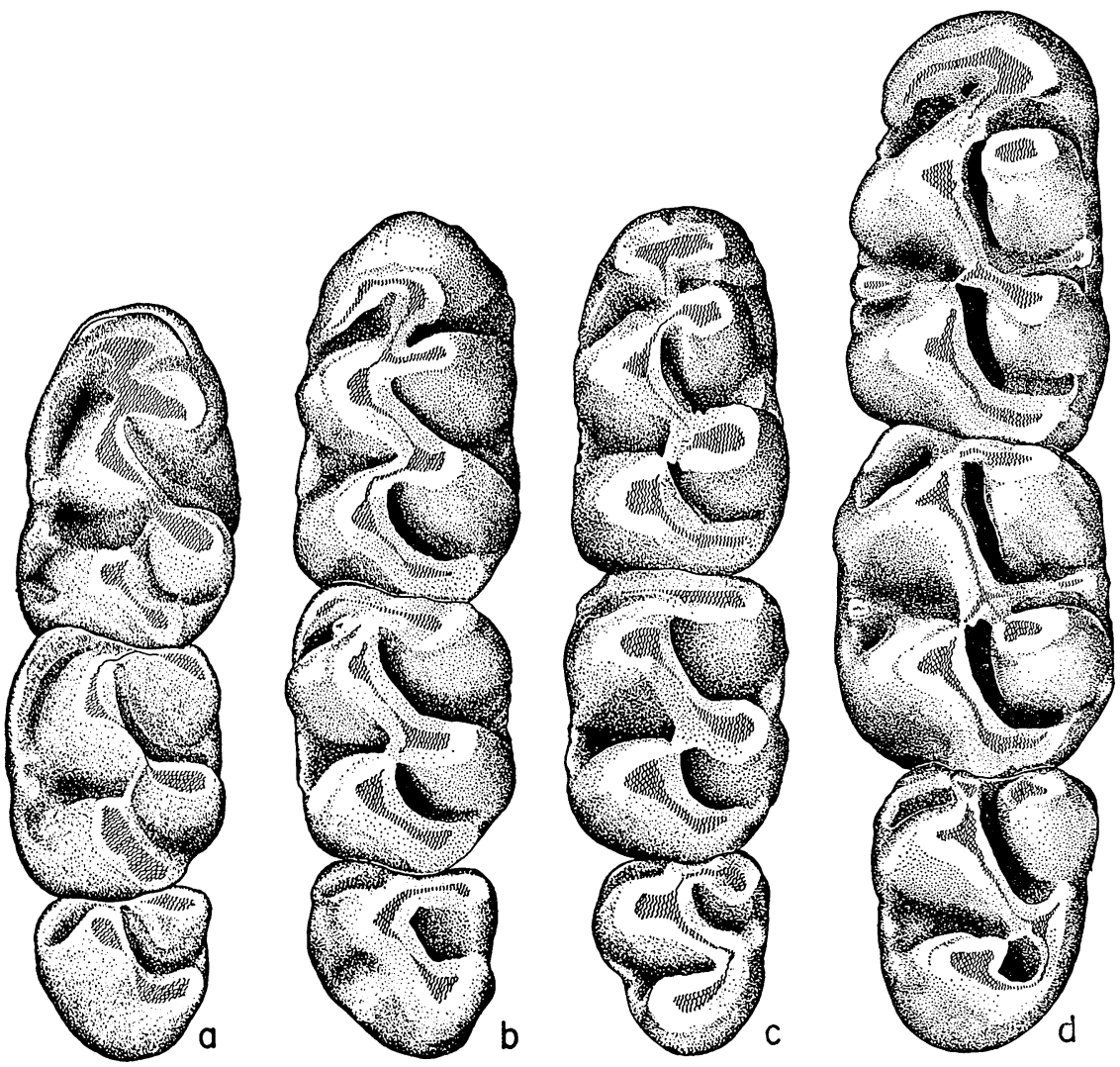

Fig. 5. Occlusal views of left lower molar rows of 4 species of Reithrodontomys: (a) humulis, (b) megalotis, (c) fulvescens, (d) tenuirostris. For names of folds and cusps see Figure 2.

unequal in length and not always reaching the labial margin of the tooth. Rostrum long and narrow. Interorbital area strongly constricted, hourglass-shaped (Fig. 9b). A distinct zygomatic notch (Fig. 9b). Habitat above 9000 feet in highlands of central México R. chrysopsis, p. 83 At least a few buffy hairs on inner surfaces of ears. (Note: a microscope sometimes required.) Ears less than $18 \mathrm{~mm}$. in length, measured when fresh. Mesolophs usually 
absent in all molar teeth, sometimes present in M1-2. Rostrum and interorbital area broader and zygomatic notch slight (Fig. 9a). Habitat at elevations below 9000 feet in central and southern México.

R. sumichrasti, p. 65
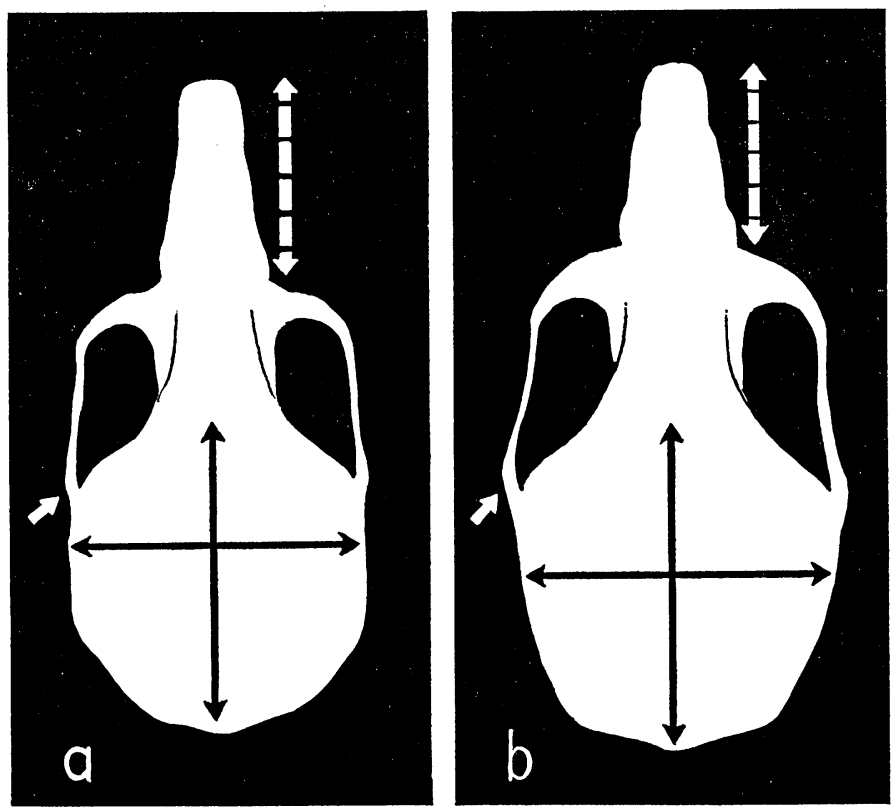

Fig. 6. (a) Long narrow rostrum, weak zygomatic arches, and broad brain case (its breadth scarcely less than zygomatic breadth), as seen in $R$. microdon. (b) Shorter and broader rostrum, strong zygomatic arches, and broader brain case as seen in $R$. mexicanus.
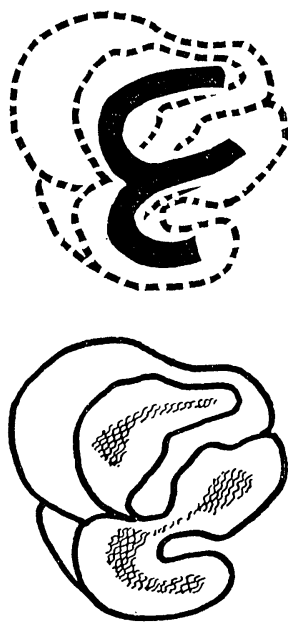

a
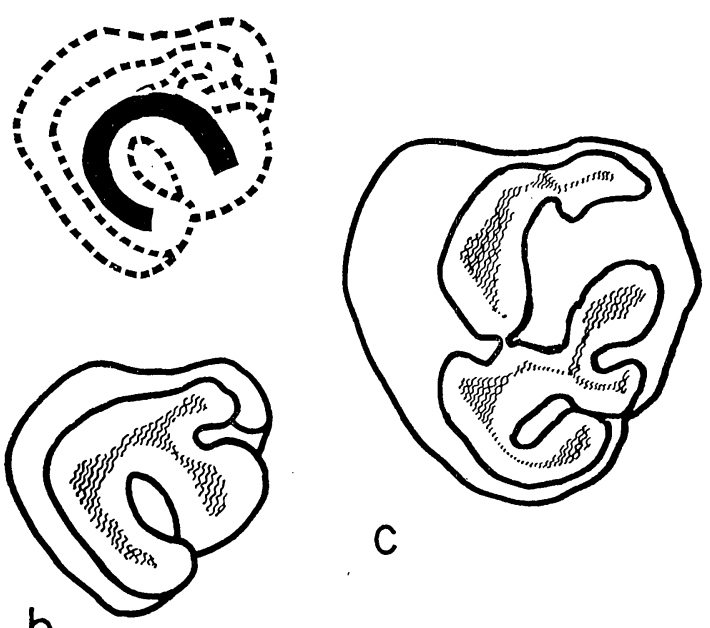

C

Fig. 7. Occlusal pattern of left M3: $(a)$ E-shaped, $(b)$ C-shaped, and $(c)$ complex, similar to the pattern of M2. 
Breadth of brain case less than $10.7 \mathrm{~mm}$. Tail length less than $100 \mathrm{~mm}$., usually

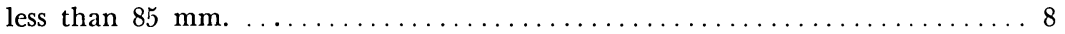

$8\left(6^{\prime}\right) \quad$ Tail shorter than head and body $\ldots \ldots \ldots \ldots \ldots \ldots \ldots \ldots \ldots \ldots \ldots \ldots$

9(8) Tail length less than 95 per cent of head and body length. Total length of adults less than $140 \mathrm{~mm}$. Breadth of brain case usually less than $9.8 \mathrm{~mm} \ldots \ldots \ldots \ldots 10$
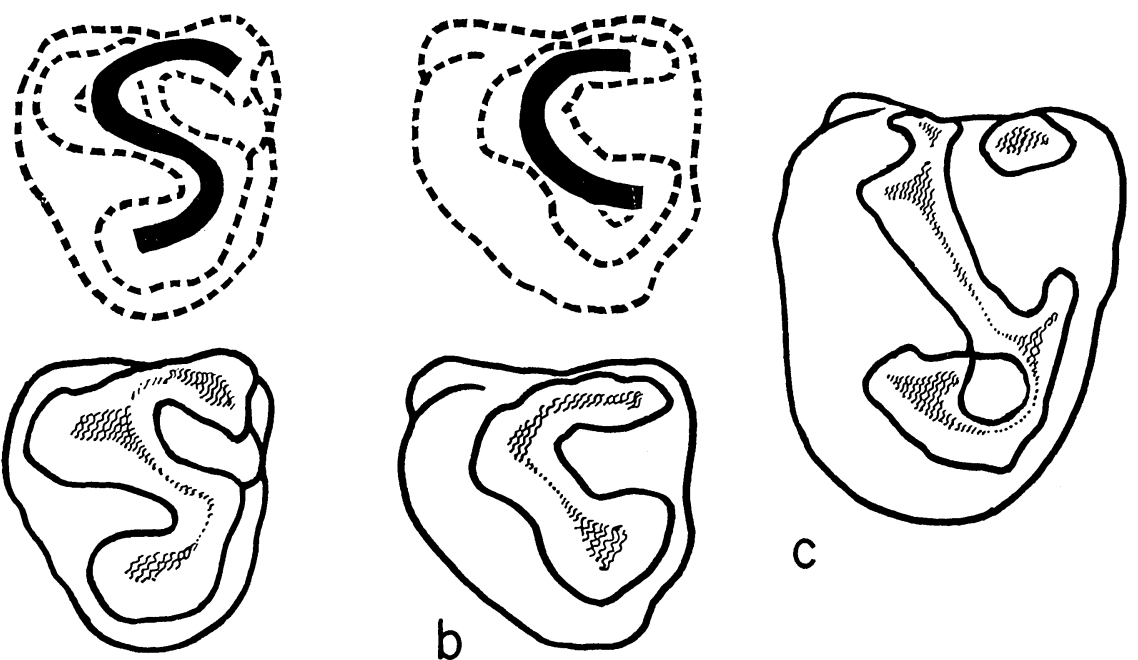

a

Fig. 8. Occlusal pattern of left $\mathrm{M}_{3}:(a)$ S-shaped, (b) C-shaped, and (c) complex, similar to the pattern of $\mathrm{M}_{2}$.

10(9) A faint labial ridge on M1-2 (Fig. 3b). Tarsi entirely whitish or with only a thin longitudinal line of dusky. Preauricular and postauricular areas and head bright buffy. Habitat on coastal plain in Sonora............... burti, p. 40 No labial shelf on $\mathbf{M}_{1-2}$ (Fig. $5 b$ ). Tarsi extensively dusky, the dusky part scarcely or not at all smaller than the whitish part. Head and preauricular and postauricular areas grayish buff. Habitat outside of coastal plain in Sonora . . R. montanus, p. 34

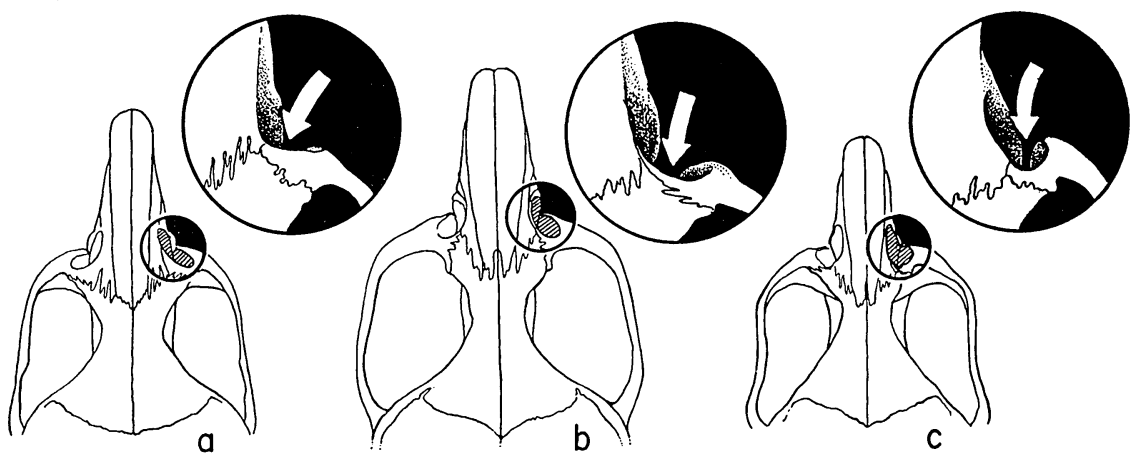

Fig. 9. (a) A moderately broad interorbital area and rostrum and a slight zygomatic notch (sumichrasti). (b) A long narrow rostrum, strongly constricted interorbital area, and distinct zygomatic notch (chrysopsis). (c) A shorter rostrum, moderately constricted interorbital area, and anteroposteriorly deep zygomatic notch (megalotis). 
9' Tail length over 90 per cent of head and body length. Total length of adults more than $130 \mathrm{~mm}$. Breadth of brain case more than $9.6 \mathrm{~mm} . \ldots \ldots$. . megalotis, p. 43

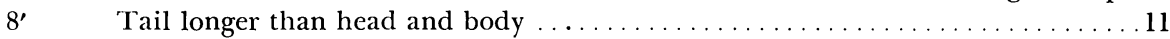

$11\left(8^{\prime}\right)$ Zygomatic notch anteroposteriorly shallow, the keel of the zygomatic plate scarcely visible when the skull is viewed from directly above (Fig. $9 a$ ). Breadth of mesopterygoid fossa more than $1.0 \mathrm{~mm}$. and about equal to expanse of palate between posterior palatine foramina (Fig. 10a). Tail length over $75 \mathrm{~mm}$., usually greater than $85 \mathrm{~mm} . \ldots \ldots \ldots \ldots \ldots \ldots \ldots \ldots \ldots \ldots \ldots \ldots \ldots \ldots$ sumichrasti, p. 65

11' A distinct zygomatic notch, the keel of the zygomatic plate clearly visible when viewed from directly above (Fig. $9 c$ ). Breadth of mesopterygoid fossa less than 1.3 $\mathrm{mm}$. and narrower than the distance between posterior palatine foramina (Fig. 10b). Tail length usually less than $85 \mathrm{~mm}$ R. megalotis, p. 43
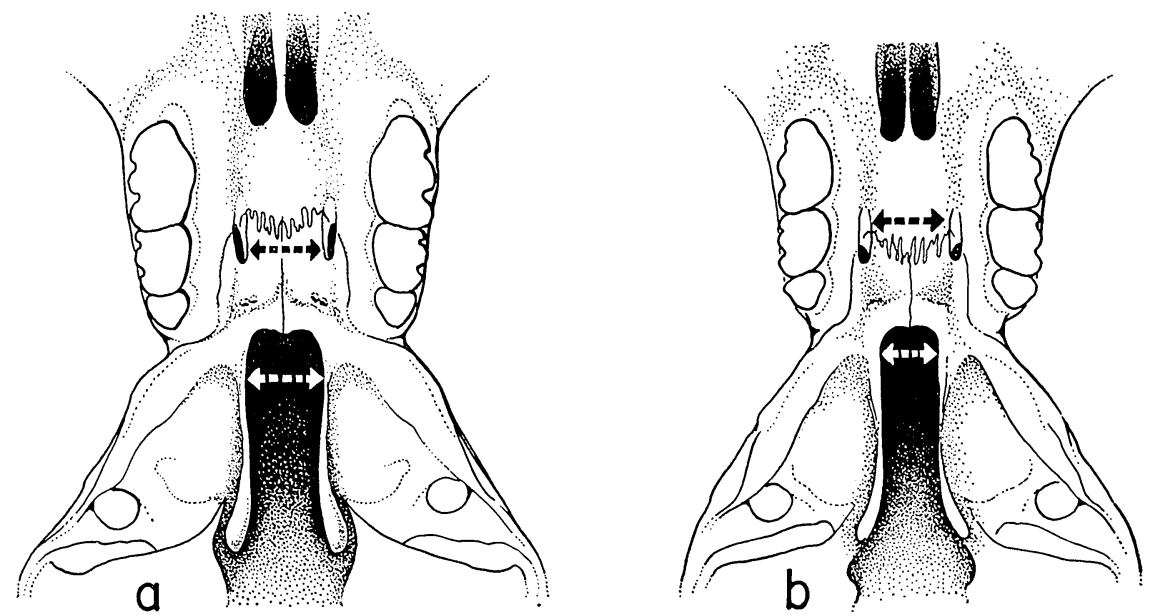

Fig. 10. (a) A moderately broad mesopterygoid fossa, its breadth about equal to breadth of palate between posterior palatine foramina. (b) A narrow pterygoid fossa, its breadth less than breadth of palate between posterior palatine foramina.

III. GEOGRAPHIC RANGE IN CENTRAL AND SOUTH AMERICA Second primary fold indistinct or absent in $\mathrm{M}_{3}$, the tooth different in form from $\mathrm{M}_{2}$ (Figs. $5 a-c ; 24 a a, b b)$. No mesolophids in $\mathbf{M}_{1-3}$. Mesolophs and mesostyles rarely present in $\mathrm{M}^{1-3}$; when present the mesolophs are usually unequal in length on the several teeth and do not attain the labial border of the tooth (Fig. 4a-c). Zygomatic plate broader than mesopterygoid fossa. Mesopterygoid fossa narrower than either pterygoid fossa

In M3 first primary fold as long as or longer than second primary fold; each extends more than halfway across the tooth (Figs. 4c, 24b); major fold well developed, sometimes confluent with first primary fold; worn occlusal surface of left tooth E-shaped (Figs. $7 a, 24 b$ ). In $\mathrm{M}_{3}$, major fold at least as long as first primary fold (Figs. $5 c, 24 b b$ ); worn occlusal surface of left tooth S-shaped (Figs. 8a, 24bb) ....

R. fulvescens, p. 90 In M3 first primary fold shorter than second primary fold (Figs. $4 a, b ; 24 a$ ); major fold indistinct, at best a broad, shallow indentation on the lingual face of the tooth; worn occlusal surface of left tooth C-shaped (Figs. $7 b, 24 a$ ). In $\mathbf{M}_{3}$ major fold shorter than first primary fold (Figs. $5 a, b ; 24 a a$ ); worn occlusal surface of left tooth C-shaped (Fig. $8 b) \ldots \ldots \ldots \ldots \ldots \ldots \ldots \ldots \ldots \ldots \ldots \ldots \ldots \ldots \ldots \ldots$ sumichrasti, p. 65 1' Second primary fold well developed in $\mathrm{M}_{3}$, usually appearing as the posterior one 
of 2 internal folds (Figs. $8 c, 24 c c$ ); $\mathrm{M}_{3}$ essentially a smaller replica of $\mathrm{M}_{2}$ (Fig. $5 d$ ). Mesolophs and mesostyles in M1-2 and usually in all other molar teeth (Fig. $4 d$ ). Zygomatic plate scarcely or not at all broader than mestopterygoid fossa. Mesopterygoid fossa about as broad as either pterygoid fossa $\ldots \ldots \ldots \ldots \ldots \ldots \ldots \ldots$

$3\left(1^{\prime}\right) \quad$ Length of hind foot 22-26 mm. Length of molar row $3.9-4.5 \mathrm{~mm} \ldots \ldots \ldots \ldots$

4(3) Interorbital breadth more than $4.0 \mathrm{~mm}$. Length of rostrum more than $9.0 \mathrm{~mm}$. Habitat above 7500 feet in mountains of Costa Rica and Panamá. R. creper, p. 175

4' Interorbital breadth less than $4.1 \mathrm{~mm}$. Length of rostrum less than $9.2 \mathrm{~mm}$. Habitat above 8000 feet in mountains of Guatemala ........... tenuirostris, p. 171

3' Length of hind foot less than $22 \mathrm{~mm}$. Length of molar row less than $3.9 \mathrm{~mm} . \ldots 5$

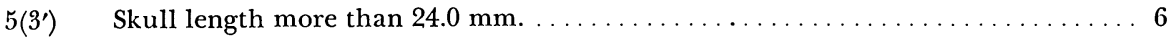

6(5) Breadth of zygomatic plate less than $1.5 \mathrm{~mm}$. Zygomatic breadth less than $12.0 \mathrm{~mm}$. and about equal to breadth of brain case. Depth of brain case more than $9.2 \mathrm{~mm}$.

$R$. rodriguezi, p. 174

6' Breadth of zygomatic plate $1.5 \mathrm{~mm}$. or greater. Zygomatic breadth more than 12.0 $\mathrm{mm}$. and about $0.5-1.0 \mathrm{~mm}$. greater than breadth of brain case. Depth of brain

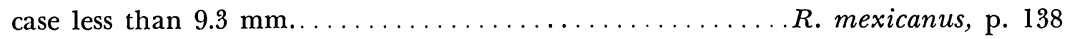

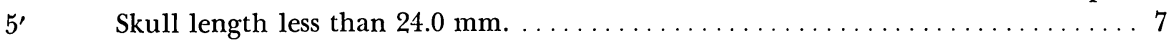

$7\left(5^{\prime}\right) \quad$ Brain case highly inflated. Zygomatic breadth scarcely greater than breadth of brain case. Rostrum long and narrow (Fig. 6a). Habitat above 8500 feet in the mountains of Guatemala .......................... microdon, p. 168

$7^{\prime} \quad$ Brain case moderate. Zygomatic breadth about $0.5-1.0 \mathrm{~mm}$. greater than breadth of brain case; rostrum broader (Fig. 6b). Habitat not restricted to mountains of

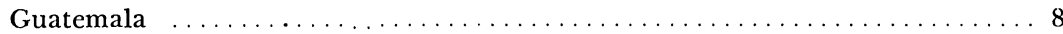

$8\left(7^{\prime}\right) \quad$ Length of rostrum less than $7.0 \mathrm{~mm}$. Length of incisive foramen less than $4.0 \mathrm{~mm} .9$ 9(8) Upper surfaces of hind feet dusky. Habitat lowlands of eastern Panamá.........

R. darienensis, p. 137

9' Upper surfaces of hind feet whitish or dusky. Habitat north of Panamá

R. gracilis, p. 129

$8^{\prime} \quad$ Length of rostrum more than $7.0 \mathrm{~mm}$. Length of incisive foramen more than

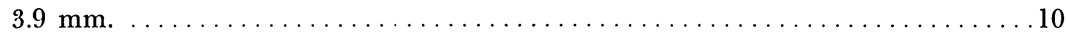

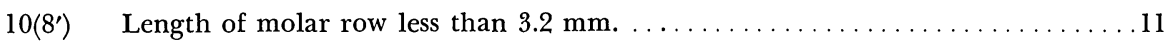

11(10) Depth of brain case less than $8.6 \mathrm{~mm}$. Dorsal surface of skull comparatively flat. . 12

12(11) Upper surfaces of hind feet dusky. Fur of upper parts long and dusky. Tail length greater than $100 \mathrm{~mm}$. and about 150 per cent of length of head and body. Breadth of zygomatic plate of adults less than $1.5 \mathrm{~mm}$. Habitat humid highlands of Costa Rica $\ldots \ldots \ldots \ldots \ldots \ldots \ldots \ldots \ldots \ldots \ldots \ldots \ldots \ldots \ldots \ldots \ldots \ldots \ldots \ldots \ldots \ldots$ brevirostris, p. 163

12' Upper surfaces of hind feet whitish or lightly dusky. Fur of upper parts bright reddish buff and moderately short. Tail length usually less than $105 \mathrm{~mm}$. and less than 140 per cent of length of head and body. Breadth of zygomatic plate more than 1.5

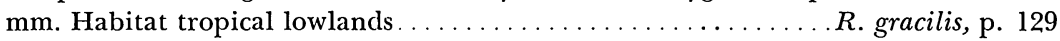

11' Depth of brain case more than $8.4 \mathrm{~mm}$. Dorsal surface of skull convex.........

R. mexicanus, p. 138

$10^{\prime} \quad$ Length of molar row more than $3.2 \mathrm{~mm} \ldots \ldots \ldots \ldots \ldots \ldots \ldots \ldots \ldots$

$13\left(10^{\prime}\right)$ Length of skull less than $22.5 \mathrm{~mm}$. Depth of skull less than $8.5 \mathrm{~mm}$. Tail length usually less than $105 \mathrm{~mm}$. Habitat tropical lowlands. . . . . . . R. gracilis, p. 129

13' Length of skull of adults more than $22.0 \mathrm{~mm}$. Depth of brain case more than 8.3 $\mathrm{mm}$. Tail length of adults rarely less than $100 \mathrm{~mm}$. Habitat above 3000 feet.....

GENUS REITHRODONTOMYS GIGLIOLI

R. mexicanus, p. 138

Mus Linnaeus, Audubon and Bachman, 1841: 97; 1842: 306; 1849: 103, and 1851: 103 (humilis, carolinensis, Lecontii); Schinz, 1845: 176 (Lecontii, humilis). 
Reithrodon Waterhouse, LeConte, 1853: 410, 413 (Mus Lecontei Bachman $=$ Reithrodon Lecontei); Baird, 1857: 447 (N. Amer. forms different from S. Amer. forms); de Saussure, 1860: 109 (R. mexicanus); 1861: 3 (R. sumichrasti); Tomes, 1861: 284 (R. longicauda in Guatemala); Lilljeborg, 1866: 16 (N. Amer. species should form a distinct group).

Reithrodontomys Giglioli, 1874: 326 (original description, no species mentioned); Merriam, 1892: 26 (antedates Ochetodon Coues); Allen, 1893: 79 (first use with species); Miller and Rehn, 1901: 95 (Mus lecontii Audubon and Bachman $[=$ R. humulis Audubon and Bachman] selected as type of genus); Osgood, 1907: 50 (Hesperomys cherriei Allen $=$ Reithrodontomys cherriei); Howell, 1914: 13 (Reithrodon megalotis Baird designated as type to replace Mus lecontii Audubon and Bachman, designated by Miller and Rehn in violation of opinion 46 of Int. Comm. Zool. Nomen.).

Ochetodon Coues, 1874: $184^{1}$ (original description, separating N. Amer. species-from California south to Guatemala-from S. Amer. Reithrodon Waterhouse); Merriam, 1892: 26 (antedated by Reithrodontomys Giglioli); Winge, 1924: 13 (not distinct from Rhithrodon Waterhouse).

Hesperomys Waterhouse, Allen 1891a: 211 (description of Reithrodontomys cherrii as Hesperomys (Vesperimus) cherrii); Winge, 1924: 135 (includes N. Amer. species of Rhithrodon Waterhouse).

Rhithrodontomys Giglioli, Elliot, 1901: 494, and subsequent publ. (nec Reithrodontomys); Winge, 1924: 127, 135 (identical with Hesperomys Waterhouse).

Aporodon Howell, 1914: 13, 63 (original description, as a subgenus of Reithrodontomys); Winge, 1924: 127 (should be included with Calomys Waterhouse).

Reithrodon Waterhouse, Winge, 1924: 135 (N. Amer. species should be placed in Hesperomys Waterhouse).

Characters of the genus are given by Howell (1914: 13-14) and Ellerman (1941: 378) and are not repeated here. Subgeneric characters are presented under the subgenera.

\section{SUBGENUS REITHRODONTOMYS GIGLIOLI}

TyPE.-Reithrodon megalotis Baird, Howell, 1914: 13.

\section{Subgeneric Characters}

External.-There are no external characters entirely peculiar to the subgenus. Size of body and skull varies from the smallest to among the largest in the genus (range in length of hind foot about 14-22 mm.). Coloration and characteristics of the pelage vary; some forms have long, soft fur and are deeply pigmented dorsally and ventrally; others have pale, rather hispid pelage. Tail also varies in length and coloration; bicolor and clothed with long hairs which tend to obscure the scales in most species. Forefeet and hind feet typically white or pale buffy dorsally; sometimes dusky in chrysopsis and sumichrasti. Ears monocolored or varicolored, varying from the smallest to the largest in the genus.

${ }^{1}$ Both Reithrodontomys Giglioli and Ochetodon Coues date from 1874. The date of publication of Coues' description apparently is 15 December 1874, when, according to the title page of the 1874 volume of the Proceedings, pages 153-200 were mailed. Mr. J. A. G. Rehn assures me (in litt.) that the information on the title page may be considered reliable. Giglioli's description appeared earlier, probably early in July. In the parts of the Bollettino that contained the description there is a printed reference to 15 June 1874 , which precludes publication earlier than that date. Those parts of the Bollettino are recorded in the files of the Royal Geographical Society, London, as having been received 16 July 1874 (fide G. R. Crowe, librarian of the Society, in litt. dated 1 January 1949). 
CRANIAL.-Outstanding cranial characters are seen in anterior-posterior proportions of the skull and in zygomasseteric structures. Forepart of skull (anterior to interorbital constriction) about equal in length to rear part. Brain case moderately inflated, extending laterally slightly beyond anterolateral limits of zygomatic arches. Zygomatic notch present. Incisive foramina usually relatively long-longer than hard palate. Zygomatic plate much broader than mesopterygoid fossa, except in hirsutus. Mesopterygoid fossa narrow, its width about equal to crown length of $\mathbf{M}^{2}$. Pterygoid fossae large, each usually well over twice as broad as mesopterygoid fossa, except in hirsutus. Hamuli of pterygoids only slightly inflated and scarcely or not at all reflexed laterad. Angular process of mandible strongly inflected mediad and then dorsad, forming a broad deep fossa. Zygomasseteric musculature distinct from that in Aporodon (Rinker and Hooper, 1950).

Dental.-Outstanding diagnostic characters are in $\mathrm{M} \frac{3}{3}$ (Figs. 4, 5, 16). Cusps of all molar teeth alternate in position in all species but humulis, in which they are usually opposite. Primary and secondary folds of $\mathrm{M}^{1-2}$ usually retain their connection with the marginal enamel throughout life of tooth; separated early as internal folds in $\mathrm{M}_{1-2}$. Anterior cingulum of $\mathrm{M}^{1}$ indistinct or absent. Mesoloph (id) and mesostyle (id) present or absent in $\mathbf{M}^{1-2}$; absent in $\mathrm{M}_{1-2}$ and $\mathrm{M} \frac{3}{3}$ (sometimes present in hirsutus). Enterolophs and ectolophids absent on all teeth. Posterior cingulum absent or but slightly developed on upper molars; present on lowers. Enterostyles and ectostylids present or absent in $\mathrm{M}^{1-2}$; absent in $\mathrm{M} \frac{3}{3} . \mathrm{M}_{3}^{3}$ distinctive; pattern of 2 types, one peculiar to fulvescens and hirsutus, the other characteristic of other species in the subgenus.

$\mathrm{M}^{3}$ in fulvescens and hirsutus: Oval and of medium size for the genus, its crown length about equal to one-half that of $\mathrm{M}^{2}$; hypocone large and distinct from protocone throughout life of tooth; paracone large, about size of protocone; metacone usually present but separate from hypocone only in unworu tooth, thereafter appearing as a large posterior cingulum; minor fold indistinct or absent, as on $\mathrm{M}^{2}$; major fold present, but relatively shorter than in $\mathrm{M}^{2}$ and retained to a late stage of wear of the tooth; first and second primary folds, the only labial folds of the tooth, of approximately equal length and depth. With wear each fold may retain its connection with the marginal enamel or be separated as one of the 2 enamel islands. $M_{3}$ similar in occlusal pattern to $\mathrm{M}_{2}$; protoconid and hypoconid of about equal size; metaconid smaller than either; entoconid low-crowned and coalescing with the hypoconid to form a continuous, sinuous loph from the protoconid to the hypoconid; no posterior cingulum; major fold deep and long, extending to the entoconid, and maintaining its identity for the life of the tooth; minor fold short and shallow; first primary fold deep, slightly shorter than the major fold, and remaining as an external fold or an internal island to a late stage of wear; no other folds present. 
$\mathrm{M} \frac{3}{3}$ in all other species of the subgenus small and oval, the crown length usually less than one-half that of $\mathrm{M}_{2} \frac{2}{2}$. In $\mathrm{M}^{3}$ hypocone well developed, scarcely smaller than protocone and fusing with protocone at an early stage of wear; paracone small-about size of hypocone; metacone and posterior cingulum absent; lingual folds (major and minor) at best indistinct and disappearing early in the life of the tooth; 2 folds present on the labial side of the tooth, namely the first and second primaries; first primary fold shallow and short, about one-half the depth and length of the second primary; second primary fold deep and long-longer than radius of the tooth-and retained with wear as the one central enamel island of the tooth. $\mathbf{M}_{3}$ : Protoconid, metaconid, and hypoconid of about equal size; entoconid absent, or present as an inconspicuous style on the flank of the hypoconid; posterior cingulum absent; labial folds (major and minor) absent, or shallow and short, becoming indistinct at an early stage of wear; first primary fold deep and long-the only lingual fold and the only principal fold of the tooth-and retained as an enamel island in late stages of wear.

\section{Reithrodontomys montanus Baird}

(Maps 1, 12; Pls. II, III)

Mice of the species $R$. montanus have been known since 1855 when the species was first described, but the status and relationships of the species remained obscure for about eighty years. The nomenclatural history is given in detail by Benson (1935). Only bare essentials need be recounted here. Baird (1855: 335) based his description of montanus on one specimen collected somewhere between Missouri and the Pacific Coast; he stated that it came from the Rocky Mountains at latitude 38 degrees. Later (1857: 186) he gave the latitude as 39 degrees. Allen (1895a: 123) determined the type locality to be the upper part of the San Luis Valley, Saguache County, Colorado. In the period 1857 to 1935 montanus received varied treatment. Some authors doubted its validity as a full species (e.g. Coues, 1874, 1877). Most authors endorsed it as a tenable kind (e.g. Allen, 1893, 1895a; Howell, 1914) but did not correctly associate the characters of the type specimen with those of comparatively well-known populations. In 1935 Benson clarified the situation. After studying the specimens that are essential for assessing the status of montanus, he concluded that montanus is specifically distinct from megalotis and is conspecific with albescens and griseus. Howell (1935) and other authors have accepted Benson's conclusions. Some (e.g. Hibbard, 1938, 1944, and Hill and Hibbard, 1943) continued to regard montanus as specifically distinct from albescens and griseus. Hill and Hibbard (1943) thought that montanus is possibly the nominal form of the megalotis group of forms.

I concur with Benson. The type specimens of montanus, albescens, and griseus are examples of the same species. $R$. montanus is the oldest valid name and, therefore, it is the name for that species. The type of $R$. megalotis is 
specifically distinct from each of the aforementioned types. It is an example of the species long known under the name megalotis. Thus name and populations are correctly aligned.

There is no good reason known to me to doubt the type locality of montanus, as determined by Allen (1895a: 123). The fact that no other specimens have been collected in San Luis Valley, although several experienced collectors have sought them especially, cannot be taken as proof that the species is absent there. The species apparently is rare throughout the intermontane region (the region ranged by the subspecies montanus); it is an occasion of note when a specimen of the species is collected there. Accordingly, it is not surprising that topotypes of montanus have not been forthcoming.

Three geographic races of $R$. montanus are currently recognized. They are defined principally on characters of coloration.

Distribution.-Great Plains and intermontane valleys and plateaus from South Dakota south over most of Nebraska, Kansas, Oklahoma, Texas, New Mexico, and at least the eastern half of Colorado to northern Durango, México. Much of the known range lies at an elevation of 2000 to $4000 \mathrm{feet}$, but the species inhabits areas 3000 to 4000 feet higher in the Rocky Mountains and descends to an altitude of about 1000 feet in eastern Kansas, Oklahoma, and Texas. San Luis Valley, Colorado, about 7500 feet in elevation, is the highest record of occurrence to my knowledge.

Habitat.-Published accounts and habitat notes at hand indicate that $R$. montanus occurs predominantly on uplands where the vegetative cover is sparse, consisting largely of short grass and other low-growing plants, and where the substrate is well drained and often sandy. $R$. megalotis also occurs in the region inhabited by $R$. montanus. It is found principally in denser cover and in more moist situations, such as in growths of tall grass and weeds, in stream-side thickets and fence rows, on bottom lands around bogs, and at the edges of forests.

Comparisons.-The species needs detailed comparison with burti, megalotis, and humulis. Other species are quite different. All species of Aporodon are distinguished from it by the characters of the subgenus. $R$. sumichrasti and $R$. chrysopsis are much larger and are distinct in many other features of skin and skull. $R$. fulvescens has a much longer tail and different third molars, both upper and lower. $R$. burti has paler tarsi, larger ears, and a larger zygomatic notch; the 2 species are compared in detail in the accounts of burti. $R$. humulis is distinguishable from $R$. montanus in characters as follows: More deeply pigmented upper parts, the colors dark browns and grays; blackish, monocolor ears, no brightly colored preauricular tuft or postauricular spot; longer brain case (best seen in postorbital area); broader mesopterygoid fossa; narrower zygomatic notch. The lower molars are particularly diagnostic. In humulis the labial part of $\mathrm{M}_{1-2}$ consists of a distinct and usually broad ridge or shelf that extends continuously from the hypoconid to the 


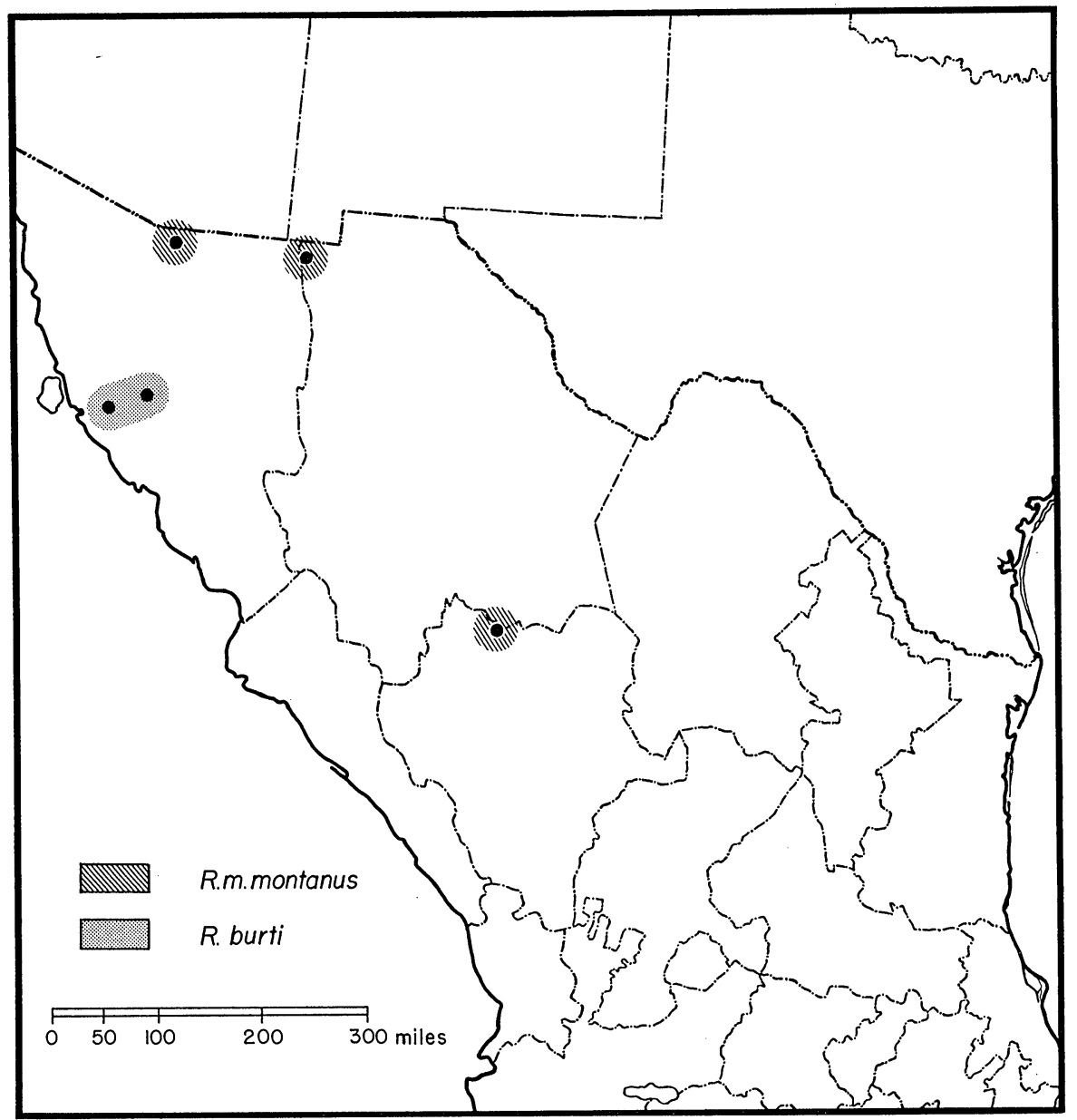

MAP 1. Distribution of Reithrodontomys montanus montanus and Reithrodontomys burti in México, as determined from specimens examined.

anteroconid (Figs. $3 a, 5 a$ ). Conulids arise from the shelf or ridge. The largest of these usually lies lateral to, and is basally a part of, the protoconid. Such ridges, shelves, and distinct conulids are at best indistinct in montanus; in most specimens they are absent.

$R$. montanus and $R$. megalotis are not easily distinguished, particularly on the Great Plains where some characters of megalotis parallel those of montanus. In that region the 2 species are similar in size, coloration, and in most cranial proportions. In megalotis, however, the tail usually is relatively longer and the ear larger; the brain case broader (over $9.6 \mathrm{~mm}$. in most specimens examined from the region); rostrum longer and relatively narrower, the nasolachrymal capsule usually relatively smaller; and the molar teeth are slightly different. In montanus the cusps are shorter, and the enamel folds 
tend to be distinctive. Described herewith are characteristics of those folds in $\mathrm{M}^{1-2}$, where they are best seen. The principal folds on the labial side of each of those teeth (first and second primary folds) are broad and long, making the primary cusps appear farther apart than in megalotis. The mesial parts of those folds lie approximately on the longitudinal mid-line of the tooth. The lateral parts between anterocone and paracone and between paracone and metacone tend to be $\mathrm{U}$-shaped (in lateral profile), exposing a broad, flat expanse of enamel between those cones. The principal lingual fold (major fold) also is broad and U-shaped at its base. In megalotis the labial folds are narrow and their floors tend to be $\mathrm{V}$-shaped. Their mesial parts usually extend diagonally, rather than anteroposteriad. The principal lingual fold also is narrow and V-shaped.

RELATIONSHIPS. $-R$. montanus is one of the generalized species of the genus. It is small and short tailed. The bony parts of the skull show no marked specializations and its teeth are simple in pattern. It apparently is adjusted to semiarid conditions, and, if present knowledge of its ecological and geographic distribution is sufficiently complete to make the induction reliable, its range of environmental tolerance is narrow compared with that of megalotis, for example.

Its affinities are with megalotis and humulis, and burti is probably an immediate offshoot from it or from montanus-like stock. It resembles megalotis in many external and cranial features. Although some of the similarities, particularly those of coloration and size, may be parallel responses to similar environments, many other details make it reasonably clear that the 2 species are closely related. Affinities with humulis appear to be somewhat more distant but still closer than with other species of the genus except megalotis and burti. The short-crowned molar teeth with their broad, U-shaped primary folds, a tendency toward dome-shaped cusps, and a trace of a labial ridge on $\mathrm{M}_{1-2}$ point toward a relationship with humulis. These characteristics have their maximum development in humulis. They are less well expressed in montanus and burti. They are not seen in other species of the genus.

\section{Reithrodontomys montanus montanus Baird}

Reithrodontomys montanus Baird, 1855: 335; 1857: 449.

Ochetodon montanus, Coues, 1874: 186; 1877: 130.

Reithrodontomys montanus, Allen, 1893: 80; 1895a: 123; Howell, 1914: 24; 1935: 143.

Reithrodontomys albescens griseus, Howell, 1914: 24 (part); Bailey, 1931: 165 (part).

Reithrodontomys montanus montanus, Benson, 1935: 139.

Reithrodontomys montanus griseus, Benson, 1939: 147.

TyPE.-Skull and mounted skin; U. S. Nat. Mus. No. $\frac{441}{1306}$. Colorado, Saguache County, upper end of San Luis Valley; collected in 1853 by F. Kreutzfeldt.

Distribution.-Intermontane plains and valleys of southern Colorado, western New Mexico, trans-Pecos Texas, and northwestern México. Known 
range from Saguache County, Colorado, south to the vicinity of Agua Prieta, northeastern Sonora, and Canutillo, northern Durango. Vertical range from 4000 feet at Agua Prieta to about 7500 feet in San Luis Valley, Colorado.

Habitat.-Apparently arid, short-grass plains and slopes. Specimens at hand were collected in situations as follows: On a short-grass plain (Canutillo). In sacatón (near Agua Prieta). In sparse grass on a stony mesa (near Fort Davis). On a grassy slope (6000 feet elevation on Mt. Locke). Each of the aforementioned localities is represented by one specimen of montanus. $R$. megalotis was abundant at the latter 2 collecting stations.

Characters.-Size: Small (see measurements). Tail shorter than head and body (its length 71-94 per cent of head and body length in the specimens examined). Ear small and rounded (its length from notch to tip, measured on fresh skin, averages $14 \mathrm{~mm}$. in the specimens at hand).

Color: Adult summer pelage (July specimen from Socorro, New Mexico): Upper parts pale buff, lightly sprinkled with black; all hairs Dark Mouse Gray proximally; cover hairs between Pinkish Buff and Light Pinkish Cinnamon distally; guard hairs black terminally and Pale Pinkish Buff subapically, some without the buffy band. Vertebral stripe diffuse and indistinct. Buffy hues least obscured by black overlay on cheeks, lower sides, flanks, and in a spot behind and in a tuft before each ear. Pinnae clothed with blackish and Pinkish Buff hairs, the black predominant on the inferior inner and superior outer borders. Underparts whitish, the hairs of throat white throughout, the remainder white or Pale Pinkish Buff distally, Dark Mouse Gray at bases. Worn adult summer pelage (August specimen from Brewster County, Texas): Grayer dorsally than in fresh pelage, the buffy hues less prominent, and the vertebral stripe narrower and more sharply defined. Fresh subadult winter pelage (March specimen from Jeff Davis County, Texas): Upper parts distinctly grayer, the buffy hues slightly more yellowish than Pinkish Buff and the black overlay more pronounced than in the adult pelage. No fresh adult winter pelages at hand.

Skull: Similar in size and most cranial proportions to that of burti. Brain case narrow, strongly depressed posteriorly. Zygomata strong anteriorly, the anterior and posterior zygomatic diameters about equal. Frontals strongly constricted interorbitally, the interorbital diameter much less than breadth of rostrum. Rostrum short and broad, nasolachrymal capsule often highly inflated. Nasals flat and broad posteriorly, scarcely broader anteriorly. Zygomatic notch distinct, the anteroposterior diameter greater than the frontal diameter. Zygomatic plate broad, its breadth usually more than twice that of mesopterygoid fossa. Pterygoid fossae broad, greatest diameter of each 2 to 3 times that of mesopterygoid fossa, and their anterior parts usually deeply excavated. Palate usually longer than molar row, mesopterygoid border convex, straight, or concave, pterygoid borders sloping abruptly into the ptery- 
goid fossae. Auditory bullae moderately inflated, usually relatively smaller than in megalotis. Molar teeth rather short-crowned, much as in humulis. Pattern of $\mathrm{M} \frac{3}{3}$ as in other species of the subgenus Reithrodontomys. Anterocone (id) flat anteriorly, not divided into distinct conules (ids). Enamel folds of $\mathrm{M} \frac{1-2}{1-2}$ broader than in other species of the genus except humulis, primary cusps therefore appearing far apart. Second labial (second primary) and large lingual (major) folds in $\mathrm{M}^{1-2}$ particularly broad, a broad expanse of enamel usually visible between protocone and hypocone and between paracone and metacone; mesial part of the second primary fold lies approximately on longitudinal mid-line of tooth.

Comparisons.-Compared with griseus (specimens of montanus from transPecos Texas and central New Mexico; examples of griseus from northern Texas and eastern Oklahoma): Upper parts paler and more buffy in all pelages, the ground color Pinkish Buff to Light Pinkish Cinnamon in adult winter pelages and Light Pinkish Cinnamon in adult summer coats (compared with Light Pinkish Cinnamon in winter and Pinkish Cinnamon in summer pelages of griseus); less black overlay in montanus; vertebral stripe about equally apparent in the 2 races. Ears and dorsal tail stripe paler, less blackish. No racially significant differences noted in size or cranial proportions.

REMARKs.-As here understood $R$. m. montanus is restricted to the mountainous parts of southern Colorado, New Mexico, western Texas, and northwestern México. To the east it grades into griseus, as evidenced in specimens at hand from Lincoln and Curry counties, New Mexico, and Martin, Briscoe, Bailey, and Hemphill counties, Texas. Those specimens are between montanus and griseus in coloration. They are less blackish and more buffy dorsally than are specimens from Cooke County, northern Texas, and Rogers County, eastern Oklahoma, and they average slightly darker and more reddish than the examples from México, trans-Pecos Texas, and western New Mexico. They are here assigned to griseus, although they could be included in the subspecies montanus almost as well.

I consider the specimens from Cooke County, Texas, and Rogers County, Oklahoma, to be typical of griseus. In them the dark, reddish buff dorsal coloration, diffuse blackish dorsal stripe, and other characters that are ascribed to that race (Howell, 1914: 23) are well seen. They contrast markedly with specimens of montanus from México, trans-Pecos Texas, and western New Mexico. This fact is the principal reason for inferring that griseus may be a tenable race and may not be identical with montanus as intimated by Benson (1935: 141) and Howell (1935: 143). Conclusive statements concerning this, however, can come only from thorough study of variation in the species montanus, which is not attempted here. A prime purpose of the present cursory assessment of geographic variation in the species is to determine 
the correct subspecific name for the Mexican populations. In so doing I have examined 96 specimens from various parts of the species' range, a far from adequate sample for a definitive study of variation in the species. The sample is sufficient, however, to suggest that: (1) The populations of (a) the sandhill region of Nebraska and South Dakota and (b) those of eastern Kansas and Oklahoma and northeastern Texas are subspecifically distinct from each other and from (c) the populations of western New Mexico, trans-Pecos Texas, and northwestern México. (2) The populations in southern Texas (San Antonio, the type locality of griseus) and those in western Oklahoma (Woods County) are intermediate in characters between those to the east and west; they are more similar to those toward the east. (3) All samples here studied of those populations represent the same species to which the oldest valid name, montanus, applies.

Subspecific names are available for the populations mentioned above. The names albescens and griseus clearly are applicable respectively to the northern and eastern populations. The subspecific name montanus is here restricted tentatively to the populations of northern México, southwestern Texas, and western New Mexico. I assume that topotypes, when available, will closely resemble samples of the southwestern populations. There are geographical reasons but no complete morphological reasons for this assumption.

Specimens examined.-Nine from the following localities: México. Durango: $3 \mathrm{mi}$. SW Canutillo, $6300 \mathrm{ft}$., 1 (MVZ). Sonora: $18 \mathrm{mi}$. S Agua Prieta, 4000 ft., 1 (MVZ); 14 mi. S Nogales, 3500 ft., 1 (US).

United States. Colorado: Saguache Co., San Luis Valley, 1 (NM). New Mexico: Sandoval Co., Sandoval, 2 (MVZ). Socorro Co., $3 \mathrm{mi}$. N Socorro, 1 (MVZ). Texas: Brewster Co., west of Glass Mts., l. Jeff Davis Co., Fort Davis, 1; Mt. Locke, $6000 \mathrm{ft}$., 1.

\section{Reithrodontomys burti Benson \\ (Maps 1, 12; P1s. II, III; Fig. 3)}

Reithrodontomys burti is a small, pale, short-tailed form known only from a few localities on the arid coastal plain of central Sonora. Superficially it resembles $R$. megalotis and particularly $R$. montanus of the same region, but details of its morphology indicate that probably it is not a geographic race of either of those species or of any other known species of Reithrodontomys.

CHARACTERS AND COMPARISONS.-The skin and skull of burti are described under appropriate headings below. Characters that distinguish burti from montanus, megalotis, and fulvescens (the other species of Reithrodontomys known from Sonora) are emphasized here. $R$. burti differs from each of those species in the following features: Preauricular tuft and postauricular areas bright buffy, strikingly distinct from the surrounding areas; in the other 
species the circumauricular and surrounding areas are similar in color. Cheeks bright buffy, the hairs whitish or narrowly plumbeous basally (cheeks grayish buff, the hairs plumbeous basally, in the other species). Ankles completely white or white with a fine, longitudinal, dusky stripe (dusky stripe broad, its breadth exceeding that of the white stripe in montanus, megalotis, and fulvescens). Tail stripe narrow and indistinct rather than distinctly dusky, broad, and sharply demarked. Zygomatic notch exceedingly long anteroposteriorly (broader than long in the other species). A more or less distinct enamel ridge on the labial border of $\mathrm{M}_{1-2}$, that ridge extending from the anterolophid to the hypoconid and producing a "humpbacked" frontal profile of the protoconid (ridge absent-a trace of it in montanus-and protoconid evenly convex labially in the other species).

Compared further with montanus, burti has larger ears (see measurements), a greater interorbital diameter of the frontals, and a broader zygomatic process of the maxilla. In burti the palate slopes gradually into the pterygoid fossae; the fossae are shallow anteriorly. In montanus the posterior border of the palate more often gives way abruptly to the deeply excavated anterior parts of the pterygoid fossae. Benson (1939: 148) stated that the baculum of burti is longer and less curved than that of montanus. Compared further with megalotis, burti has a longer tail (70 to 97 per cent of head and body length compared with 94 to 114 per cent in specimens of megalotis from the region), a narrower brain case (see measurements), and a relatively longer palate.

$R$. fulvescens has a much longer tail (see measurements), buffy ears (readily seen internally), a broader mesopterygoid fossa, and unique third molars.

Relationships. $-R$. burti appears to be a relict species derived from the ancestral stock that gave rise to montanus, megalotis, and humulis. It bears closest resemblance to montanus, as evidenced by many external and cranial features common to both, but certain characters indicate a direct relationship to humulis. The brain case of burti is narrow and long and the frontals are broad between the orbits, much as in humulis. Similarities in $\mathrm{M}_{1-2}$ may be more significant of relationships. In humulis the labial part of each of those teeth consists of a distinct and often broad shelf or ridge that extends from the anterior part of the tooth to the hypoconid. From it arise one or more conulids, the largest of which usually is lateral to, and basally is part of, the protoconid. A similar ridge occurs in burti, and the protoconid is lightly cleft or indented, appearing "humpbacked" in profile. In some specimens the indentation is pronounced and the protoconid is clearly divided into a medial conid and a smaller lateral conulid. The ridge or shelf is much broader and the differentiation of conid and conulid is distinctly more clear-cut in humulis than in burti. In this discussion of relationships, these dental similarities in the 2 species seem important. 


\section{Reithrodontomys burti Benson}

Reithrodontomys burti Benson, 1939: 147.

Type.-Adult male, skin and skull; Mus. Vert. Zool. No. 83001; México, Sonora, Río Sonora, Rancho de Costa Rica; collected 3 May 1938 by Margarito Delgadillo; original No. 5400, Seth B. Benson.

Distribution.-As now known, the coastal plain of central Sonora, México. Known vertical range 300-600 feet.

Habitat.-Apparently desert grassland. Specimens were trapped in situations as follows: In sparse dry grass with scattered mesquite, palo verde, and palo fierro on a sandy plain (11 mi. W Hermosillo). In a field of wheat stubble (Rancho de Costa Rica).

Characters.-Size: Small; in specimens examined range in hind foot length 16-17 mm., in total length $116-136 \mathrm{~mm}$., in weight 8.2-12.7 grams, in skull length 19.4-21.3 mm. Tail short, 70-97 per cent of head and body length in specimens examined.

Color: Fresh adult pelage (topotypes collected in May): Upper parts Pinkish Buff to Light Pinkish Cinnamon, darkened slightly with black dorsally but essentially pure in a line low on the sides; hairs of back black distally, Pinkish Buff to Light Pinkish Cinnamon subapically, and Dark Plumbeous basally; most guard hairs colored as underfur, a few without the median buffy band. Circumauricular areas conspicuously different in color from back, the hairs Pinkish Buff or Pale Pinkish Buff throughout. Cheeks Pinkish Buff to Pinkish Cinnamon, the hairs white or narrowly Plumbeous basally. Circumorbital area the color of the cheeks. Hairs of throat white throughout, those of remainder of underparts Dark Plumbeous basally, the basal band narrow, well obscured by the long white terminal part. Pinnae Hair Brown, clothed internally and externally with dusky, buffy, and whitish hairs, the latter 2 types predominant. Tarsi white, or at most with a fine line of dusky hairs on the medial surface. Feet white. Tail faintly bicolor, whitish below and Drab above, the Drab stripe narrow (its width about one-third or one-fourth the diameter of the tail) and indistinctly demarked from the adjoining white area.

Subadult pelage (topotypes collected in May): Similar to that of adult but upper parts duller and grayer, the buffy bands paler (Pinkish Buff to Pale Pinkish Buff), particularly on the head, shoulders, and sides. Fresh winter pelage unknown.

Skull: Elongate and narrow. Brain case narrow. Frontals flat dorsally, comparatively broad interorbitally. Zygomata broadly spread, anterior and posterior diameters about equal. Maxillary process of zygomatic arch a comparatively broad plate. Zygomatic plate broad, as in megalotis. Zygomatic notch exceedingly large, its anteroposterior length usually greater than its breadth. Incisive foramina broadest at middle, scarcely narrower posteriorly, 
extending well beyond first molars. Palate slightly concave anteroposteriorly, its mesopterygoid border convex and usually with a distinct process and its pterygoid borders comparatively flat and merging evenly, without abrupt descent (when viewed ventrally), into the pterygoid fossae. Mesopterygoid fossa moderate in breadth, decidedly broader than either incisive foramen. Each pterygoid fossa about twice as broad as the mesopterygoid fossa. Bullae moderate in size. Upper molars similar to those of montanus, the major and primary folds broad, and the pattern simple, without accessory styles or lophs. Anterocone undivided, its anterior face flat. General pattern of lower molars simple and much as in megalotis and montanus, but labial border of $\mathrm{M}_{1-2}$ distinctive (see Relationships above).

Remarks.-The principal diagnostic characters of burti are the bright buffy cheeks, preauricular tufts and postauricular spots, pale tarsi, long, broad zygomatic notch, and slight enamel ridge on the first and second lower molars. Present data indicate that it is a monotypic species. There is no evidence that it interbreeds with other forms, although many of its traits are matched in $R$. montanus. Its range is inadequately known. A small, pale specimen from Guaymas that Burt (1938: 52) tentatively referred to R. m. megalotis is probably an example of burti. I have not examined the specimen.

Specimens examined.-Twenty-three from the following localities in Sonora, México: 11 mi. W Hermosillo, 600 ft., 3 (MVZ); Rancho de Costa Rica, 300 ft., 20 (MVZ).

\section{Reithrodontomys megalotis}

(Maps 2, 12; Pls. II-V; Figs. 4, 5, 9-13, 16, 17, 22-24)

R. megalotis is a prevalent species; it has a large range and it is abundant in most parts of that range. It is found predominantly in open situations outside of forests and is at home in cultivated areas. It probably has profited from man's agricultural practices. Its range overlaps that of at least 8 other species (Map 12). It is the only species of the genus that inhabits the far western United States and Baja California, excepting $R$. raviventris which is restricted to the salt marshes of central California. In parts of the Great Plains it occurs with $R$. montanus. Farther south its geographical range overlaps variously that of fulvescens, sumichrasti, chrysopsis, hirsutus, mexicanus, and microdon. There are records of occurrence of megalotis with each of these species.

Sixteen geographic races of the species are currently recognized. Five of these are represented on the mainland of México. They are not equally distinct from one another. The races megalotis and saturatus stand in greatest contrast, while alticolus and saturatus are but slightly differentiated from each other. The forms that live in the comparatively cool highlands, namely saturatus, alticolus, amoles, and zacatecae, have dark, reddish pelages. In 
megalotis, which inhabits the more arid and generally lower Central Plateau and northwestern deserts of México, the pelage is pale and buffy.

The interrelationships of the Mexican races of $R$. megalotis require detailed comment. The forms saturatus and alticolus are morphologically close, and intergradation of the 2 is evident in the material studied. The status of amoles is not clear. The form is known from only 3 specimens, all from the type locality. Those resemble examples of zacatecae, and the 2 forms may prove to be identical. In any event, in their morphology amoles and megalotis appear to be conspecific and herein are so treated, although evidence of interbreeding of the 2 is now lacking.

The interrelationships of saturatus and zacatecae are unusual in the genus. Howell (1914: 39) indicated that the forms intergrade in the state of México but that they maintain their identity farther west where their ranges overlap in Jalisco and Michoacán. He recorded both forms from the same locality. Present evidence indicates that the forms indeed do overlap in range, but that there is little, if any, interbreeding between them, at least in the areas now sampled. The small ears and skulls of specimens from "Salazar, Toluca Valley, etc.," México, which Howell took as evidence of intergradation are instead individual variations within the known range of variation of saturatus. All but one of those specimens are juveniles.

Both saturatus and zacatecae are mesic highland forms. They inhabit the moderately cool and moist mountains and valleys that skirt the arid Central Plateau of México; saturatus ranges in the Sierra Madre Oriental and the volcanic highlands of central México; zacatecae occupies the upper slopes of the Sierra Madre Occidental. For much of their extent (Map 2) their ranges are separated by that of megalotis, which inhabits suitable places on the intervening arid Plateau and with which both forms apparently interbreed. The ranges of saturatus and zacatecae meet in Jalisco and Michoacán and in adjoining states to the north where the ridges of the Sierra Madre Occidental intersect the central volcanic highlands.

All samples of the species from Veracruz, Puebla, México, and extreme eastern Michoacán are typical of saturatus. In them there are no characters that are peculiar to zacatecae or that evidence intergradation of saturatus and zacatecae. The samples from central and western Michoacán and Jalisco, however, are variously mixed in regard to the characteristics of saturatus and zacatecae. Those from Ameca, the mountains south of Guadalajara, Ocotlán, and Zamora are typical saturatus. The samples from El Nevado de Colima and Cerro Tancitaro are good zacatecae. In the series from the vicinity of Volcán Parícutin (San Juan, Angahuan, Corupo, and Patambán), Nahuatzin, and Pátzcuaro the characters of both saturatus and zacatecae are evident. In those and in other specimens from Jalisco and Michoacán, however, the characters of saturatus and zacatecae do not appear to be combined in the same 
individual. In each the characters are predominantly or exclusively those of one form or the other. Each specimen is assignable to one or the other of the 2 forms; few are intermediate.

Each sample of each form was analyzed in regard to central tendencies of 3 characters that distinguish saturatus from zacatecae. Some of the results are shown in Figures 11-13. These figures illustrate the central tendencies in length of skull, length of molar row, and color of the underparts, not only for the aforementioned samples but also for certain other representative

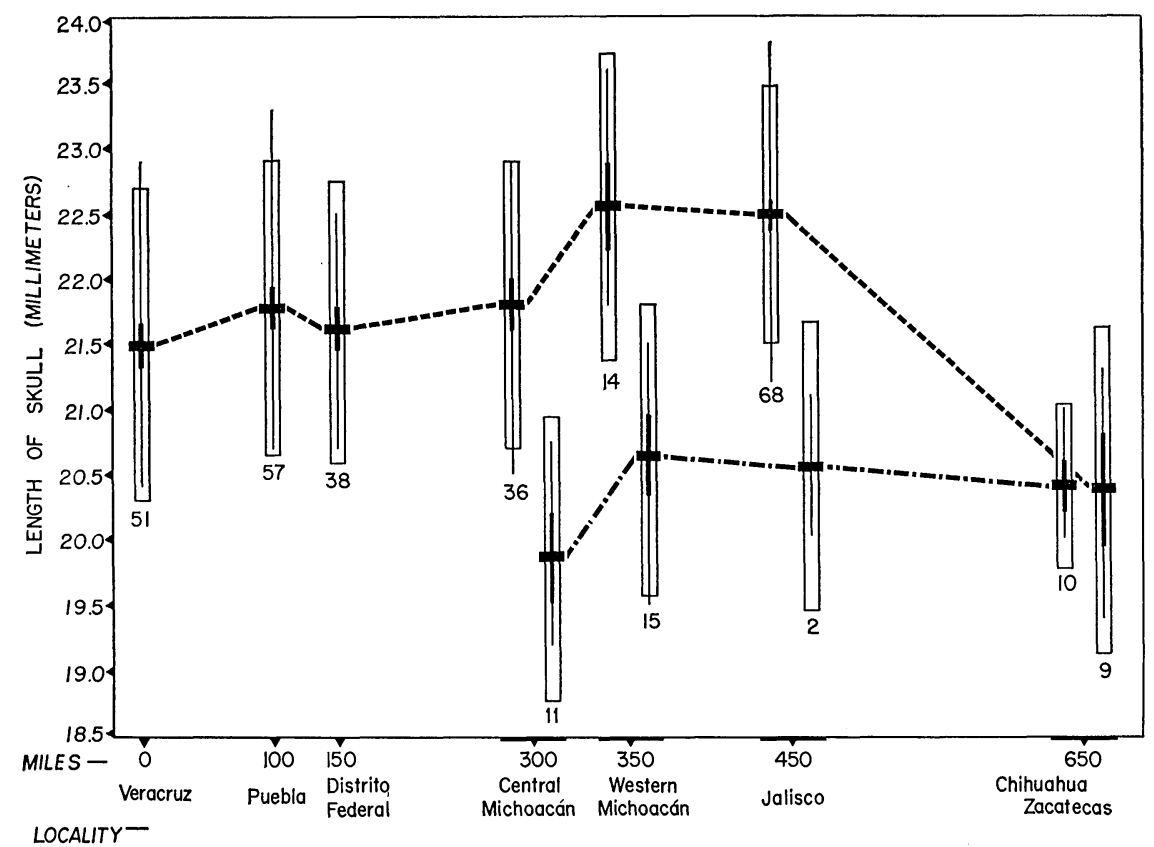

Fig. 11. Cranial lengths of specimens of Reithrodontomys megalotis from central and northern México. The samples constitute a transect that extends from central Veracruz westward to Jalisco, thence northward to Chihuahua. The upper series of rectangles and lines represents samples of $R$. m. saturatus. The means of those samples are connected by a broken line which terminates at the extreme right at the mean of a sample of $R$. m. megalotis. The lower bank of rectangles represents samples of $R . m$. zacatecae. The range in cranial length for each sample is indicated by the length of the light line; the vertical bar on that line extends for 2 standard errors each side of the mean; the open rectangle marks off 2 standard deviations on each side of the mean; the number of items in the sample is noted below the rectangle.

series of $R$. megalotis. They constitute a transect that extends from Veracruz westward to Jalisco, thence northward to Durango and Chihuahua. Approximate mileages between the localities represented are indicated in Figures 11-12.

In these figures lengths of the skull and lengths of the upper molar row 
are indicated on the ordinate. The range in each sample is indicated by a vertical line, the mean by a heavy cross bar, and 2 standard errors each side of the mean by a vertical bar on the vertical line. The open rectangle demarks 2 standard deviations above and below the mean. The number of specimens in each sample is noted below the rectangle. The upper series of rectangles and lines represents samples of $R$. m. saturatus. The means of those are connected by a broken line, which at the far right terminates at the mean of a sample of R. m. megalotis from northwestern México. The lower bank

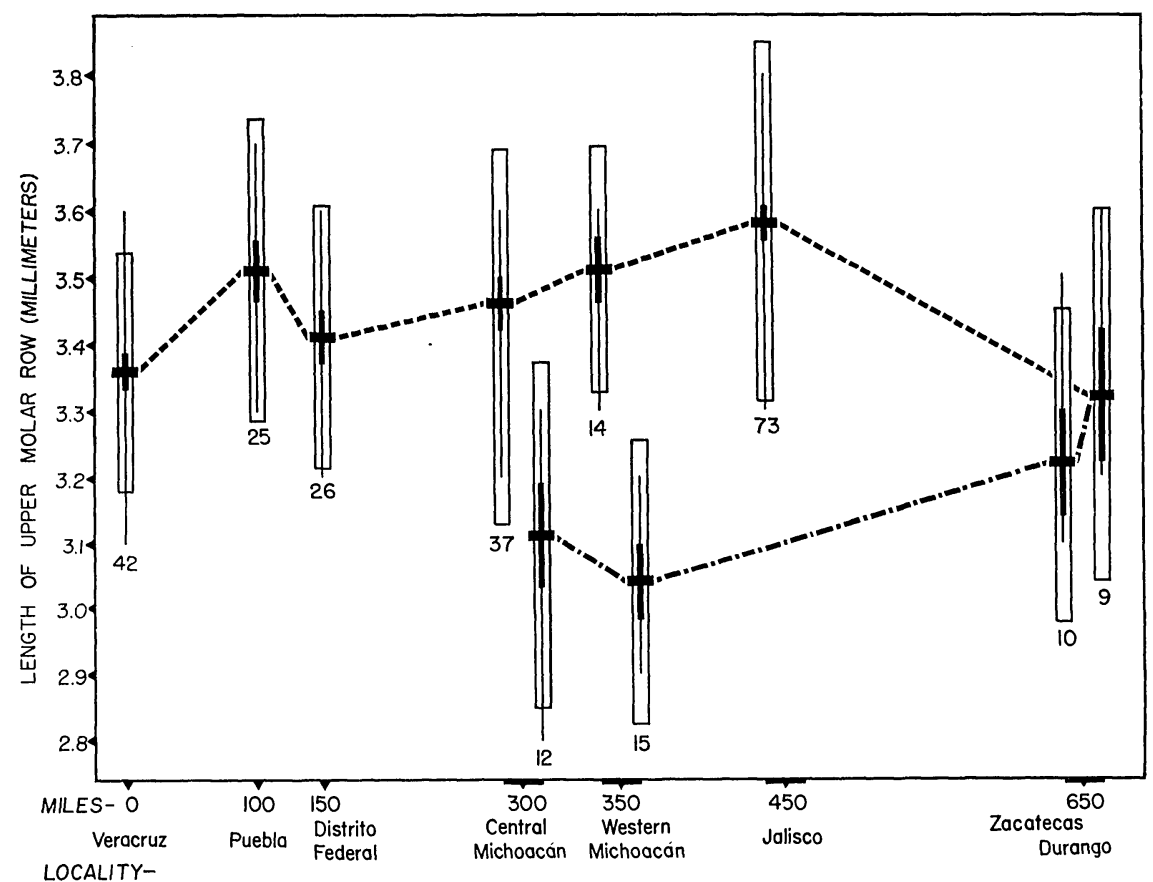

Fig. 12. Molar row lengths of specimens of Reithrodontomys megalotis from central and northern México. The samples constitute a transect extending from central Veracruz westward to Jalisco, thence northward to Chihuahua. The upper series of figures represents samples of $R$. m. saturatus. The broken line that connects their means terminates at the extreme right at the mean of a sample of $R . m$. megalotis. The lower bank of rectangles represents samples of $R$. m. zacatecae. For further explanation see Figure 11 and text.

of rectangles and lines represents the samples of $R$. m. zacatecae from Michoacán and Jalisco. A broken line connects each mean with the mean of a sample of zacatecae from northwestern México and, terminally, with the mean of a sample of $R$. m. megalotis.

The mean cranial lengths are similar in the samples of saturatus from Veracruz, Puebla, Distrito Federal, and central Michoacán. So are the mean molar row lengths. The means are larger in the samples from western Michoacán and Jalisco. They grade away from, rather than toward, the mean values 
obtaining in the samples of zacatecae from the region. If the samples include numerous intergrades-intermediates between zacatecae and saturatus-the means should approach each other rather than diverge, and the distinct bimodality indicated by the upper and lower series of rectangles would be unexpected. Two standard deviations each side of the mean, demarked by each rectangular box, include approximately 95 per cent of the individuals,

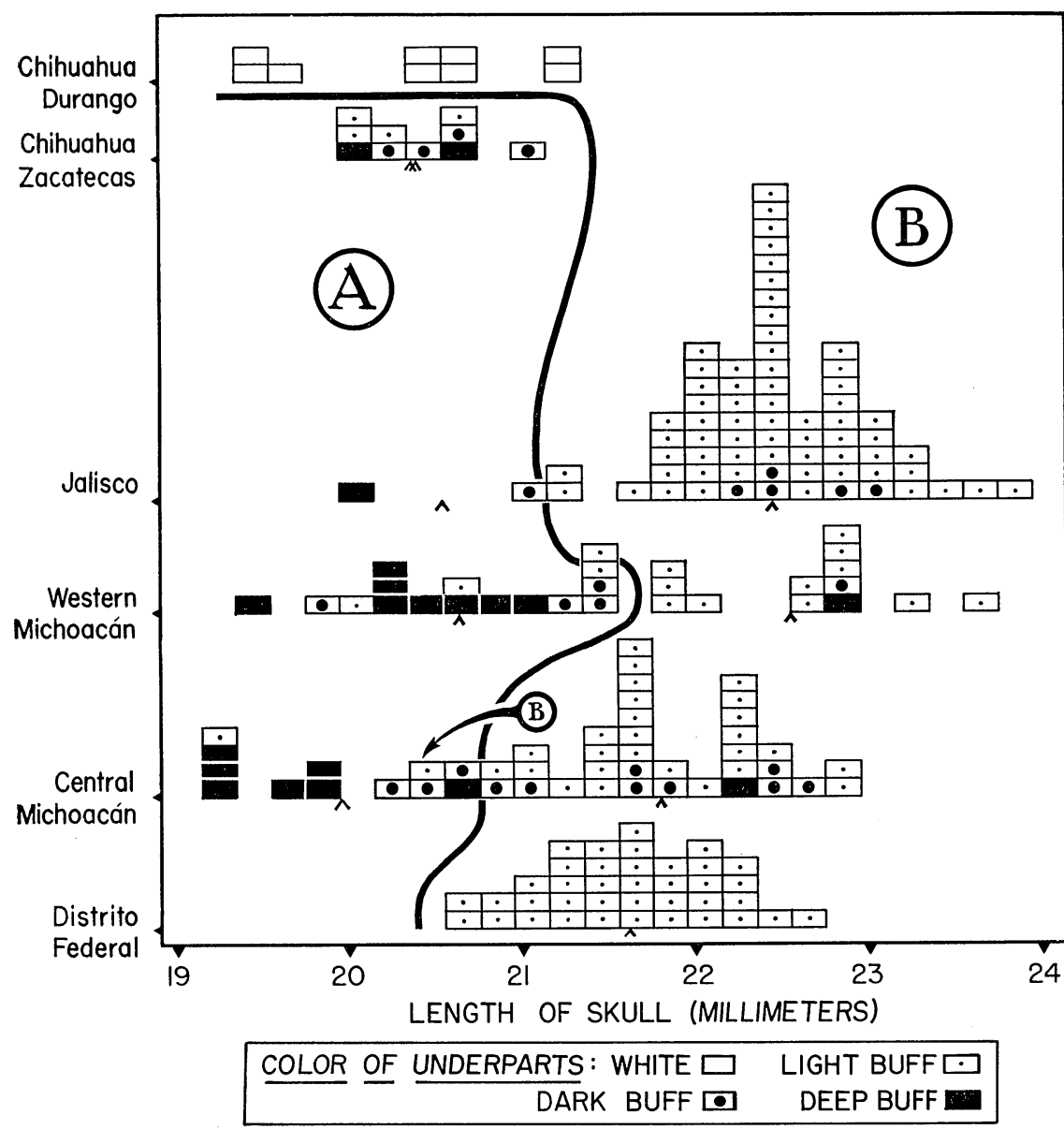

Fig. 13. Histograms correlating length of skull and color of underparts in specimens of Reithrodontomys megalotis from central and northern México. The samples represent a transect extending from Distrito Federal westward to Jalisco, thence northward to Chihuahua. Each rectangle represents a specimen; the cranial length of the specimen is indicated on the abscissa, and an estimate of the tone of its underparts is designated by a symbol within the rectangle. The open rectangles at the top of the figure represent specimens of $R . m$. megalotis from Chihuahua and Durango. Area B includes specimens of $R$. m. saturatus. Area $\mathrm{A}$ includes specimens of $R$. m. zacatecae and one specimen of saturatus (indicated by arrow). The wedge-shaped marks indicate the mean skull lengths of the 10 samples represented. 
if distribution of the values in accordance with the normal curve is assumed. There is slight vertical overlap between the rectangles, and inferentially between the values for the populations of which these are samples. It seems highly probable that in length of skull and length of molar row the upper and lower series represent different forms between which there appears to be little or no intergradation. If the forms interbreed, evidence of that interbreeding is not shown clearly in length of skull or of molar row in the samples at hand.

Figure 13 correlates length of skull and color of the underparts in individual specimens. The specimens of megalotis are small and light-bellied. Those of zacatecae are small and most are heavily pigmented ventrally. A few have light buffy underparts, but there is no higher percentage of them in the samples from Jalisco and Michoacán than there is in Chihuahuan and Zacatecan samples. The specimens of saturatus are large and most are light buffy ventrally. A few are dark buffy and a smaller number are deep buffy. The incidence of the heavy ventral pigmentation is greater in the samples from Jalisco and Michoacán (wherein the presence of intermediates between saturatus and zacatecae is suspected) than it is in the sample from Distrito Federal, where only typical saturatus occurs. It is not greater, however, than in the samples from Puebla and Veracruz, areas farther to the east and away from the known range of zacatecae. Thus the number of dark-bellied specimens in the samples of saturatus from the area of suspected intergradation is no greater than is to be expected in saturatus. If the forms interbreed, a higher incidence of large dark-bellied specimens would be expected in the intergrading area.

In summary, present evidence indicates that the ranges of zacatecae and of saturatus overlap and interdigitate in Jalisco and Michoacán. The forms appear to maintain their identity there and to be more distinct in size than they are in other parts of their ranges. If the forms intergrade, either evidence of it is not clearly indicated in the specimens at hand or the data from the specimens have been misinterpreted. The forms appear to be connected reproductively only through $R$. m. megalotis.

Distribution.-The geographic range of $R$. megalotis exceeds that of any other species in the genus. It also extends farthest north. It spans about 35 degrees of latitude, from the Okanagan Valley in southern British Columbia to southern Oaxaca. Eastern limits are in southwestern Wisconsin. Western limits are the shores of the Pacific Ocean and Santa Catalina Island, California. The vertical range is also extensive. In California altitudes of capture extend from 250 feet below sea level in Death Valley, the lowest record, to 11,500 feet in the White Mountains. Highest records of occurrence are farther south in México, where the species has been found near timber line (about 13,000 feet) on the volcanoes of Orizaba and Popocatépetl. Most records are for altitudes less than 9000 feet. 
Habitat.-The species megalotis lives under a wide variety of environmental conditions, such as those obtaining in deserts, in humid salt marshes along the seacoast, and in cool pine and oak forests on mountains. To judge from habitat notes and published accounts, it is generally most abundant in rather dense growths of grass, forbs, and other low-lying vegetation near water, as in meadows, marshes, and stream valleys and in fence rows and on ditch banks in cultivated areas. Usually it is absent from heavy forests, although it commonly inhabits grassy and brushy clearings in forests. In the highlands of central México it occurs predominantly on sacatón plains, grass- and sedge-covered meadows, and in grassy or weedy clearings among pine and oak forests. In the arid region of northern México it is found in grass and weeds along streams or in stream beds, along irrigation ditches, and in sparse grass among catclaw, mesquite, and yucca. In Washington it occurs on sagebrush flats, on sand dunes, in thick riverside jungles, in cattail and tule marshes, and in other dense growths of grass and weeds (Dalquest, 1948: 326). In Nevada it is found principally in grassy places near water (Hall, 1946: 499). Grinnell (1933: 169) reported its occurrence in many habitats, most of which are zonally below the yellow-pine belt. In Kansas it occurs principally in valleys and in bottom lands, along wooded fence rows, in weed patches bordering woods, and in other moist situations (Hibbard, 1944: 78).

Comparisons.-The comparatively short bicolor tail and whitish feet and the broad zygomatic plate and pterygoid fossae, simple molariform teeth (without well-developed mesolophs), incomplete $\mathrm{M} \frac{3}{3}$, and other characters of the subgenus Reithrodontomys distinguish megalotis from all species of Aporodon. Within the subgenus Reithrodontomys, raviventris and montanus are perhaps most similar to megalotis; chrysopsis, sumichrasti, humulis, fulvescens, and hirsutus are more distantly removed morphologically. I find no absolute characters that will distinguish megalotis and montanus. $R$. megalotis of central and southern México is quite distinct from $R$. montanus of northern México and the Great Plains in size of body, ear, tail, skull, and in characters of coloration. In the arid parts of northern México it is much smaller and paler and more like montanus. For further comparisons of the 2 species see the accounts of $R$. montanus.

$R$. fulvescens and $R$. megalotis exhibit parallel modifications geographically. For example, both are large and dark in the highlands of central México and small and pale in the northern deserts, and examples of the species often are superficially similar. The structure of the third upper and lower molars will distinguish the 2 species; insofar as is known, the characters of those teeth are absolutely diagnostic. In addition, the tail of fulvescens is usually longer, the zygomatic notch shallower, and the mesopterygoid fossa broader than in megalotis of the same region (see measurements).

In the highlands of central and southern México the range of megalotis 
overlaps that of sumichrasti, and examples of each species have been collected in the same trap line, although the 2 species typically occupy different habitats. In that region the 2 species are similar in coloration, both having long, reddish brown fur dorsally, buffy underparts, brownish or blackish ears with few or many buffy hairs, and pale hind feet. Megalotis, however, lacks dusky hairs on the hind feet (the duskiness of the tarsus often extending onto the metatarsus in sumichrasti). Its ears are smaller, and the tail is shorter, rarely exceeding $90 \mathrm{~mm}$. and usually less than $80 \mathrm{~mm}$. in both subadult and adult specimens (rarely less than $80 \mathrm{~mm}$. and usually well over $90 \mathrm{~mm}$. in sumichrasti). The skull is smaller (readily seen in breadth of brain case). The zygomatic notch is broad and anteroposteriorly deep (equally broad but distinctly shallower in sumichrasti, Fig. 9) and the mesopterygoid fossa is absolutely and relatively narrower (see measurements). The teeth of the 2 species are generally similar. The posterior border of the paracone of $\mathrm{M}^{1-2}$ is evenly rounded in megalotis, as in most other species of the subgenus Reithrodontomys. In contrast, in many but not all specimens of sumichrasti there is a keel on the posterolabial border of the paracone; it is often fused with the mesostyle. When present, this structure alone suffices for distinguishing sumichrasti from all other species in the genus.

$R$. chrysopsis resembles megalotis externally, particularly in the mountains of central México where both species occur. In contrast to megalotis, chrysopsis has large ears (over $16 \mathrm{~mm}$. in length when fresh and measured from the notch) in which there are no buffy hairs; a longer tail (rarely less than $80 \mathrm{~mm}$., usually over $90 \mathrm{~mm}$. in adults); a broader, deeper brain case (see measurements); a broader mesopterygoid fossa; much larger auditory bullae and molar teeth; and well-developed mesolophs in $\mathrm{M}^{1-2}$.

$R$. humulis and $R$. hirsutus are quite different from megalotis. $R$. humulis is smaller, has smaller ears, a scantily haired tail, broad short rostrum, broad mesopterygoid fossa (scarcely narrower than either pterygoid fossa), and different molar teeth. In humulis the primary cusps of $\mathrm{M}^{1-2}$ are oval in shape and widely separated by broad major and primary folds; $\mathrm{M}_{1-2}$ bear an external shelf from which often arise distinct conulids (Fig. 5); these structures are absent in megalotis. $R$. hirsutus is larger (see measurements), has a narrow zygomatic plate, broad mesopterygoid fossa, and mesolophs in $\mathrm{M}^{1-2}$. Both megalotis and hirsutus occur at Ameca, Jalisco.

ReLATionships.-Morphologically and ecologically $R$. megalotis occupies a position between montanus on the one hand and chrysopsis and sumichrasti on the other. ( $R$. raviventris is excluded in this comparison.) Closest affinities of megalotis appear to be with montanus. Both are comparatively unspecialized kinds, montanus being the more generalized of the two. They are small and short-tailed, and they have small ears. The skull is comparatively generalized, with broad zygomatic plates and pterygoid fossae; the angle of the 


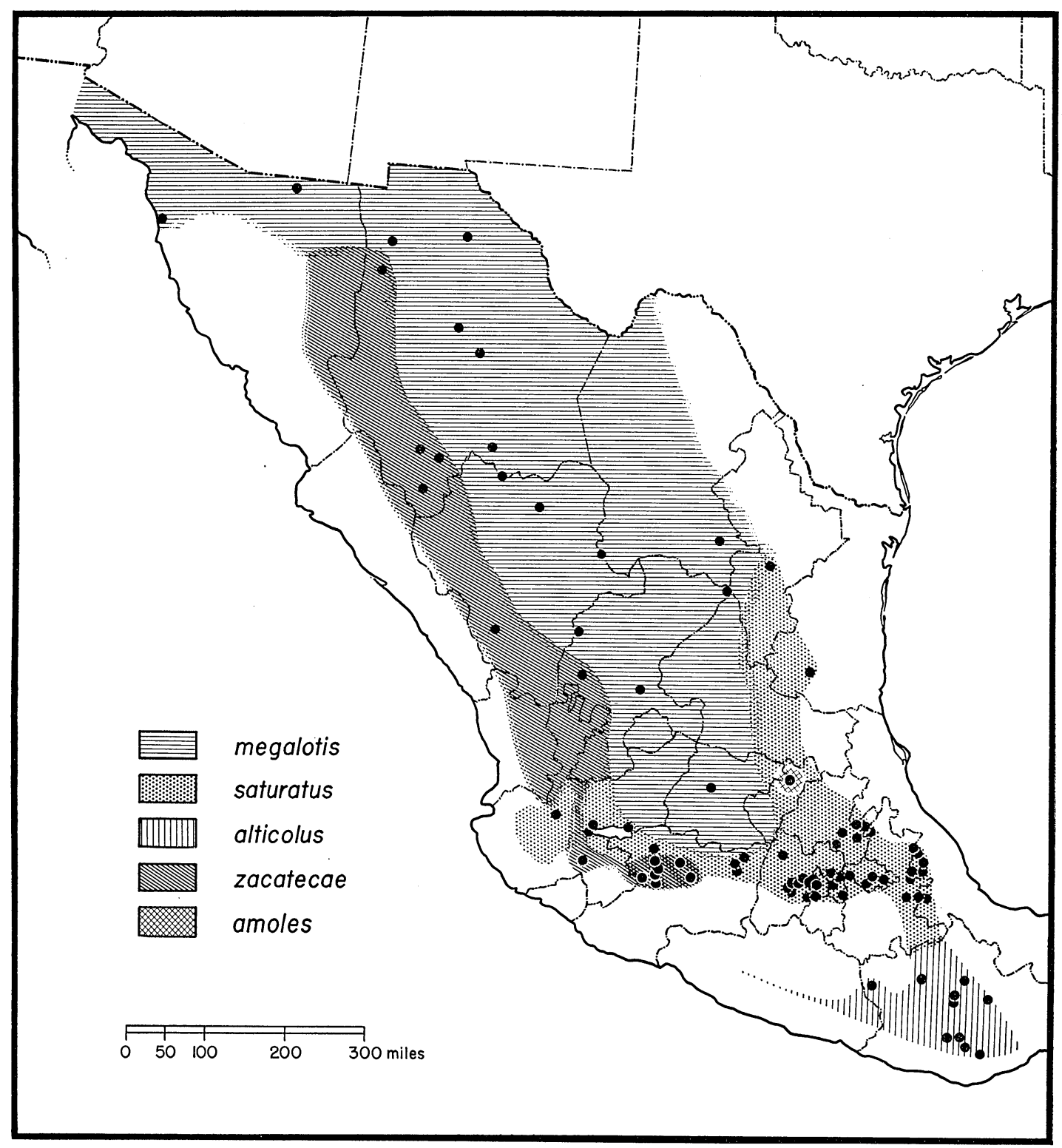

MAP 2. Distribution of subspecies of Reithrodontomys megalotis in Latin America (excluding Baja California), as determined from specimens examined. 
ramus is strongly deflected. These structures reflect large internal pterygoid muscles and perhaps a generalized masseteric complex (Rinker and Hooper, 1950). The molar teeth are comparatively simple, usually without accessory enamel loops and cusps. Both species are typically inhabitants of open grassy hills and plains in temperate climates, montanus occurring largely in drier, well-drained and more open situations and megalotis living chiefly in more moist situations where the plant cover is denser and often composed of arborescent species.

Affinities of megalotis with chrysopsis and sumichrasti appear fairly close but are more distant than with montanus. All of these species are derivable from a common morphotype. Montanus and megalotis lie nearer that stem form than do chrysopsis and sumichrasti when the species are ranked according to amount of specialization. Compared with megalotis, chrysopsis and sumichrasti are large of body and skull. They have large ears and a long tail. In them the brain case is broad and deep and the rostrum long and narrow, approximating but by no means equaling the extreme condition seen in microdon and creper. The zygomatic plate is relatively narrower and the zygomatic notch consequently shorter than in megalotis. The pterygoid fossae are relatively smaller and the mesopterygoid fossa is correspondingly broader, reflecting differences in the internal pterygoid muscles. The molar teeth are more complex; more often there are accessory lophs and styles between the primary cusps. All of these characteristics are here interpreted as specializations of chrysopsis and sumichrasti in advance of megalotis.

Although megalotis superficially resembles fulvescens, probably many of those resemblances are parallel responses to similar environments. Certain features, notably the enamel pattern of $\mathrm{M}_{3}^{3}$ and the bony parts of the zygomasseteric structure, suggest that the 2 species are separate morphologically and probably represent distinct evolutionary lines within the subgenus Reithrodontomys.

The trenchant differences between megalotis and humulis strongly suggest that the 2 are more distantly related than are megalotis, raviventris, and montanus. The elongate skull, broad frontals, comparatively broad mesopterygoid and narrow pterygoid fossae, and the peculiar structure of the molar teeth set humulis apart from those species. Evolutionary connection of megalotis with humulis apparently is through montanus or a montanuslike form.

\section{Reithrodontomys megalotis megalotis Baird}

Reithrodon megalotis Baird, 1857: 451.

Reithrodontomys megalotis, Allen, 1893: 79; 1895a: 125.

Reithrodontomys megalotis deserti Allen, 1895a: 127. Nevada, Nye County, Oasis Valley. [A synonym of megalotis, fide Howell, 1914: 26, and Hall, 1946: 499.]

Reithrodontomys megalotis sestinensis Allen, 1903: 602. México, Durango, Río Sestín, $7500 \mathrm{ft}$. 
Reithrodontomys megalotis nigrescens Howell, 1914: 32. Idaho, Payette County, Payette. [A synonym of megalotis, fide Hall, 1946: 499, and Dalquest, 1948: 326.] Reithrodontomys megalotis megalotis, Howell, 1914: 26. Reithrodontomys fulvescens tenuis, Howell, 1914: 47 (part).

TyPe.-Skull; U. S. Nat. Mus. No. 2281; between Janos, Chihuahua, and San Luis Springs, Grant County, New Mexico; collected by C. B. Kennerly; date unknown; specimen catalogued in November 1855 (Poole and Schantz, 1942: 346).

Distribution.-Great Basin of the western United States and northern México from the lower part of the Okanagan Valley of British Columbia south and east through Oregon and California, southern and western Idaho, Nevada, Arizona, and the western half of Utah to the central part of the Mexican Plateau. Known range in México from the vicinity of Puerto de Lobos and Cananea, northern Sonora, southeast on the Plateau and in the foothills of the Sierra Madre to the vicinity of Guanajuato. Known vertical range in México from approximately sea level at Puerto de Lobos, Sonora, to approximately 8500 feet near Guanajuato, Guanajuato.

HaвiтAт.-Grassy places, brushy thickets, and tracts of sedges and rushes in arid and semiarid regions; found predominantly near permanent water, but there are records of specimens collected on the desert far from water. The specimens from La Sauceda were collected in sacatón. The example from Puerto de Lobos was obtained on sand dunes. No other ecological information on the Mexican specimens is at hand. Specimens from the southwestern United States, near México, provide information on places of occurrence of R. m. megalotis as follows: In sparse grass, scattered catclaw, and mesquite (near Portal, Cochise Co., Arizona). On a grassy meadow beside a stream lined with sycamores and walnuts (Pinery Canyon, Chiricahua Mts., Arizona). In grassy washes; along irrigation ditches; and among Yucca and Chrysothamnos on sand dunes (Otero Co., New Mexico). In a salt-cedar thicket near the Rio Grande (El Paso Co., Texas). On grass-covered slopes, $6000 \mathrm{ft}$. on Mt. Locke; on a stone-covered mesa near Fort Davis (Jeff Davis Co., Texas).

Characters.-Size: Small; in a series of 15 subadults and adults from western Texas, range in hind-foot length $16-18 \mathrm{~mm}$., in head and body length 58-75 mm., in length of cranium 19.6-21.2 mm. Pinnae rounded in outline, measuring about $14 \mathrm{~mm}$. from notch in fresh specimen. Tail short, its length about that of head and body (tail length 94-120 per cent of head and body length in the 15 specimens).

Color: Adult summer pelage (August specimens from Cochise County, Arizona): General coloration of upper parts warm tan, of underparts and feet white, and of ears and upper side of tail drab; back scarcely darker than the sides. Cover hairs of upper parts Pinkish Cinnamon distally, CinnamonBuff subapically and Dark Mouse Gray basally. Hairs of throat white throughout and of pectoral area Pinkish Cinnamon distally and Dark Mouse 
Gray basally; remainder of underparts white distally and Dark Mouse Gray basally. Pinnae clothed with black and Pinkish Cinnamon hairs both externally and internally, the black hairs concentrated on the inferior inner margin. Forefeet and hind feet entirely white. Tail bicolor, Hair Brown dorsally, white ventrally.

Adult winter pelage (March and April specimens from western Texas): Upper parts decidedly paler and grayer than in summer, the general coloration grayish buff, the gray concentrated on the shoulders and foreback, the buff predominant on cheeks, rump, and sides. Cover hairs Cinnamon-Buff distally, Pinkish Buff subapically, and Deep Mouse Gray for the remainder of their length. Guard hairs apparently longer and perhaps more abundant than in summer pelage. Buffy hairs of ears paler (about Pinkish Buff). Underparts as in summer.

Subadult pelages (localities as above) essentially like the respective summer or winter pelages, but duller dorsally (apparently less of buffy hues present).

Skull: Brain case oval in dorsal outline, about as broad as it is long. Frontals strongly constricted interorbitally, with low supraorbital ridges in old skulls. Rostrum moderately long and narrow. Zygomatic arches strong, their spread almost as broad anteriorly as posteriorly. Zygomatic notch large, its anteroposterior and transverse dimensions about equal. Zygomatic plate broad (about twice as broad as the mesopterygoid fossa). Mesopterygoid fossa narrow, its smallest breadth about one-half the greatest breadth of either pterygoid fossa. Mesopterygoid border of bony palate straight or convex. Incisive foramina narrow and long, their posterior borders usually lying posterior to plane of first upper molars. Molar teeth small, the length of the row $3.5 \mathrm{~mm}$. or less, which is about equal to the length of the hard palate and about $1 \mathrm{~mm}$. less than the length of the incisive foramina. Molars simple, without mesolophs. Sphenopalatine vacuities large (about as long as molar row) and oblong.

REMARKs.-The pale buffy head, back, and sides, buffy ears, whitish underparts without a strongly buffy pectoral spot, short tail, and moderate size are the principal diagnostic characters of $R$. m. megalotis. It is a well-marked race and in México its characters apparently are comparatively uniform throughout the range here ascribed to it. Specimens from Durango, including examples from near the type locality of sestinensis, are easily lost in series from northern Sonora and the southwestern United States. The race occurs in the arid foothills of the Sierra Madre Occidental and Oriental and discontinuously in the interlying basin. There are few records of occurrence for eastern Chihuahua and central and northern Coahuila (Map 2), a region consisting predominantly of deserts. Evidence of direct connection of the populations of the Big Bend segment of Texas with those in the Sierra 
Madre Oriental and Occidental is lacking. Intergradation with saturatus is indicated by a specimen from Lulú, extreme eastern Zacatecas, and by examples from the mountains near Galeana, west-central Nuevo León. The latter specimens are referred to saturatus on the basis of their darker upper parts, buffy venter, and long tail. The example from Lulú is more similar to typical megalotis and accordingly is identified with that race.

The interrelationships of megalotis and zacatecae are not entirely clear, and they will remain obscure until more specimens are forthcoming from middle elevations on the eastern slopes of the Sierra Madre Occidental. The few specimens at hand from those slopes indicate that the 2 forms intergrade. Two examples from the vicinity of García, northwestern Chihuahua, and La Unión, southwestern Chihuahua, are indistinguishable in size and cranial dimensions from typical megalotis (examples from Sonora, Arizona, and New Mexico). In color of upper parts and underparts they resemble topotypes of zacatecae. An example from Sombrerete, Zacatecas, is intermediate in coloration. Intermediate also is a specimen from Ranchería, southwestern Chihuahua; its tail is relatively long and the molar teeth are small as in topotypes of zacatecae. These instances are interpreted here as evidence of intergradation of megalotis and zacatecae. Topotypes of zacatecae themselves are paler than the specimens from Jalisco and Michoacán, in which the dark coloration, small size, small molar teeth, and other diagnostic characters of zacatecae are best seen. A specimen from Santa Rosa, Guanajuato, here referred to megalotis, could be identified with zacatecae almost as well.

Specimens Examined.-Forty-one from the following localities in México: Chihuahua: Casas Grandes, 4800 ft., 4 (US); Chihuahua, 4700 ft., 2 (US); 5 mi. SE Chihuahua, 5250 ft., 3 (MVZ); 2 mi. W Parral, 6200 ft., 5 (MVZ); 7 mi. W El Saúz, Cañón del Potrero, 5750 ft., 1 (MVZ); 2 mi. W Villa Ahumada, $4200 \mathrm{ft} ., 3$ (MVZ). Coahuila: Jimulco, $4100 \mathrm{ft} ., 3$ (US); Saltillo, 4800 ft., 1 (US); Sierra Guadalupe, 1 (US). Durango: 3 mi. SW Canutillo, 6300 ft., 1 (MVZ); 14 mi. E Zarca, 6650 ft., 1 (MVZ). Guanajuato: Santa Rosa, $8200 \mathrm{ft}$. ?, 1 (US). Sonora: 5 mi. N Cananea, $4750 \mathrm{ft} ., 1$ (MVZ); Cienega Well, $50 \mathrm{ft}$. ?, 3 (NM); Nogales, $4000 \mathrm{ft}$., 1 (MVZ); $15 \mathrm{mi}$. NNE Cananea, La Sauceda, 4700 ft., 6 (MVZ); Puerto de Lobos, near sea level, 1 (MVZ); 20 mi. S U. S. Boundary, Sonora mesa, $100 \mathrm{ft} ., 1$ (US). Zacatecas: $3 \mathrm{mi}$. N Lulú, 5500 ft., 1 (MVZ); 8 mi. W, 1 mi. N Sombrerete, 7800 ft., 1 (KU).

\section{Reithrodontomys megalotis saturatus Allen and Chapman}

Reithrodontomys saturatus Allen and Chapman, 1897b: 201.

Reithrodontomys saturatus cinereus Merriam, 1901: 556. México, Puebla, Chalchicomula.

Reithrodontomys megalotis saturatus, Howell, 1914: 36 (part); Davis, 1944: 391; Hooper, 1947: 48; Hall and Villa, 1949c: 455; 1950: 190.

Reithrodontomys fulvescens intermedius, Hooper, 1947: 48 (part).

Reithrodontomys megalotis zacatecae, Hall and Villa, 1949c: 456 (part); 1950: 191 (part). 
Type.-Adult male; Amer. Mus. Nat. Hist. No. $\frac{12502}{10812}$; México, Veracruz, Las Vigas, 8000 feet elevation; collected 26 April 1897 by Frank M. Chapman.

Distribution.-Highlands of central and eastern México. Known range from the vicinity of the Volcán de Orizaba, west-central Veracruz, west to Ameca, central Jalisco, and north in the Sierra Madre Oriental to the neighborhood of Galeana, west-central Nuevo León. Vertical range from 3500 feet in the mountains near Gómez Farías, Tamaulipas, to timber line (about 13,000 feet) on the volcanoes Popocatéptl and Orizaba.

HaвiтAт.-Grass, forbs, and other low-lying cover along streams, in meadows, brushy lands, open forests, and cultivated areas; predominantly near water in the pine-oak zone, locally in grassy openings in humid broadleaf evergreen forests. Following are a few situations in which specimens were trapped:

In Veracruz: In tall grass at edge of pine forest (near Perote). In open stands of grass and Baccharis on a rocky bank of a stream in pine forest $(10,000 \mathrm{ft}$., at the lower edge of the fir belt on the Cofre de Perote); in a fence row of Baccharis and grass that separated a small sedge-covered marsh from grazed meadow and open pine forest $(10,300 \mathrm{ft}$. on the Cofre); in sparse grass at the edge of pine forest (10,700 ft. on the Cofre). Common among bunch grass, Baccharis and alder at edge of a pedregal and a forest of long featheryleaf pine (11/2 mi. E Las Vigas).

In the central highlands: In grass and brush in an area formerly dominated by pine and oak (Apulco). Abundant in grass and brush bordering oat fields; uncommon in near-by dry, oak-covered slopes (Rancho Córdoba). Uncommon at edge of second-growth fir forest $(11,400 \mathrm{ft}$. on Volcán de Toluca). Common in cultivated bottom lands near mouth of Cañon Contreras (near Mexico City); rare above 8500 feet in fir forest on cool, moist, north-facing slopes of the canyon. Fairly common at edge of sacatón plains and in adjoining dry forest of oak, madrone, and pine with brushy understory (Km. 46 , México-Acapulco highway near La Gima). In open stand of Baccharis and blue-eyed grass between a meadow and a pine-fir forest; on the border of a plowed field and a pine-fir forest; near a pile of slash under a fir tree at the edge of a fir forest (Cerro San Andrés). In dense grass ( $1 \mathrm{ft}$. high) at edge of a pine forest (Mil Cumbres). Abundant in bunch grass in a large meadow (diameter about 1 mile) surrounding a lake in pine-fir zone; less abundant in grass, brush, and young fir between fir forest and cultivated lands (10 mi. SE Pátzcuaro). In a stand of bunch grass ( $4 \mathrm{ft}$. tall) and Baccharis in a cutover pine forest ( 2 mi. $S$ Corupo).

In Tamaulipas: Variously in dense and sparse vegetation and in rock piles occurring in a clearing in a humid, oak-sweetgum forest (Rancho del Cielo).

Comparisons.-Compared with megalotis (topotypes of saturatus; speci- 
mens of megalotis from Jeff Davis and Presidio counties, Texas): Larger (see measurements). Tail length similar in the 2 forms (averaging longer than head and body in specimens examined). Much more intensly pigmented dorsally and ventrally, upper parts brown, compared with pale buff in megalotis, and underparts buffy instead of white; pectoral area dark buffy (see detailis below). Cranium similarly proportioned to that of megalotis but larger and relatively deeper, larger auditory bullae and slightly longer and narrower rostrum.

Details of coloration, for comparison with description of megalotis given in the accounts of that subspecies, follow. Winter pelage (specimens from Altotonca, Veracruz): Upper parts a mixture of black and Pinkish Cinnamon, the black forming a broad distinct dorsal stripe, the Pinkish Cinnamon purest on shoulders and low on sides where it forms a more or less distinct lateral line; basal bands of hairs Blackish Mouse Gray. Hairs of underparts Blackish Mouse Gray basally and Pale Pinkish Cinnamon distally, but those of throat white throughout, and those of pectoral area Cinnamon or Pinkish Cinnamon distally. Pinnae Fuscous, clothed internally and externally with black and Pinkish Cinnamon hairs, the black hairs concentrated on inferior inner and superior outer surfaces. Tail sharply bicolor-blackish above and white below-or tricolor, the dorsal black stripe bordered on each side with a fine Pinkish Cinnamon line. Ankles dusky bordered by Pinkish Cinnamon; hind feet white or Pale Pinkish Cinnamon. Forefeet white, sometimes Pale Pinkish Cinnamon. Summer pelage (specimens from Las Vigas): As winter pelage but upper parts darker, the buffy ground color nearer Cinnamon and the black overlay more extensive; underparts a deeper tone of buff.

REMARKs. $-R$. m. saturatus is the largest and one of the darker forms of the species. It inhabits the comparatively humid highlands of central México. R. $m$. alticolus, a slightly differentiated form of the highlands of Oaxaca, approaches it closely in both size and coloration. Two other subspecies are almost as intensely pigmented. These are $R$. m. zacatecae of the Sierra Madre Occidental and $R$. m. longicaudus of California, Oregon, and Washington. Specimens from the humid parts of the range of those 2 forms, for example zacatecae from western Michoacán and longicaudus from the vicinity of San Francisco Bay, California, are essentially identical in color with specimens of saturatus from Veracruz or Puebla.

Variations in the skins and skulls of saturatus reflect slight differences between populations and great variability among individuals at each locality. The intense pigmentation is characteristic of all samples. In coloration the skins from Jalisco are similar to skins from Distrito Federal, México, and Veracruz. Those from eastern Puebla, including topotypes of cinereus, may average slightly paler dorsally than most other series of saturatus, but they are matched in strictly comparable pelages by topotypes of saturatus; there- 
fore cinereus should be regarded as a synonym of saturatus, as Davis (1944: 391) pointed out. A slight geographical gradient in size of body and of skull is indicated. Its slope is low and its direction is from west to east across the volcanic highlands. Maximum size obtains in the specimens from Jalisco and northwestern Michoacán (Figs. 11, 12).

The broad range in variation within populations is seen in both skin and skulls. The pelages clearly illustrate the variations. The subadult pelage is less brightly colored and more buffy than is the adult. Fresh pelages are more blackish dorsally and buffy ventrally than are worn pelages. A similar contrast obtains between pelages of the wet and the dry seasons. Fresh adult pelages of the wet season (most specimens collected in July and August are typical) are rich reddish brown and blackish dorsally and buffy ventrally. Fresh pelages of the dry season (all typical specimens at hand were collected in the period December-March) are paler and grayer dorsally, a quality particularly conspicuous on the foreback and shoulders. There is less black in the upper parts, and the buffy bands have more yellow in them. The underparts are pale buffy. Abrasion and fading produce shorter fur of various tones of buff and gray. The result of these several factors, and others not mentioned, is an impressive array of various colorations in single samples of saturatus.

The specimens from Jalisco and northwestern Michoacán resemble examples of $R$. s. nerterus in size and pelage coloration. In those of nerterus, however, the tail is longer, sparsely haired (the scales clearly visible), and indistinctly bicolor or monocolor. There are often dusky hairs on the upper surface of the hind feet. The ears are larger. The brain case and mesopterygoid fossa are broader, the zygomatic notch is shorter, and the molar teeth are larger.

For discussion of the interrelationships of saturatus and zacatecae, see the general accounts of the species $R$. megalotis.

The specimens from Galeana, Nuevo León, are distinctly paler dorsally and slightly smaller than specimens of saturatus from the central highlands and from southwestern Tamaulipas. Their underparts are buffy. In external and cranial characters they are between saturatus and megalotis but nearer saturatus. The specimens from the vicinity of Gómez Farías deserve mention. They have cinnamon underparts and small molar teeth, with short mesolophs in $\mathrm{M}^{1-2}$. The tail length as recorded on the specimen tags averages greater than in other series of $R$. megalotis from México. The large value for tail length may be an artifact of measurement by the collector of the specimen. If the measurements are valid the populations represented by the specimens should be recognized by a different name.

I have examined the cranial fragments of Reithrodontomys from San Josecito Cave, Nuevo León, reported by Cushing (1945: 182). At least 30 
individuals are represented in the samples. Nineteen of the crania are fairly complete. They consist of parts of the rostrum, anterior roots of the zygomata, upper jaws with dentitions, and frontal segments of the cranium. In 8 specimens at least one upper incisor is in place and in 11 examples at least one molar is in position. All upper molars except left $\mathrm{M}^{3}$ are present in one specimen. The samples were recovered from talus. Their geological age, therefore, can not be known precisely.

Only one species is represented, apparently. That species is similar to, and probably identical with, $R$. megalotis. Its characters especially resemble those of the populations of $R$. megalotis that inhabit the region of the cave today. The range in variation in the cave specimens is matched in samples of $R$. megalotis from the localities 12 miles north of Galeana and Rancho del Cielo. The dentitions of the samples are similar. Like the Galeana and Cielo specimens, but unlike specimens from other parts of the range of $R$. megalotis, the cave examples have mesolophs in $\mathrm{M}^{1-2}$. The mesolophs are unequal in length. In most of the first and second upper molars found in the samples the mesolophs are short and blunt, extending less than halfway to the labial border of the tooth. In $\mathrm{M}^{1-2}$ of one specimen the mesolophs attain the border of the tooth. In other details in the configuration of the molar teeth the samples likewise resemble one another. They are also closely comparable in size and in proportions of the cranium. Following are means and standard errors of 6 cranial measurements of the samples from (1) San Josecito Cave and (2) Galeana and Rancho del Cielo, respectively: Interorbital breadth, $3.03 \pm .04,2.98 \pm .03$; breadth of zygomatic plate, $1.94 \pm .04,1.91 \pm .03$; length of alveolus of molar row, $3.39 \pm .03$, 3.31 \pm .02 ; length of hard palate, $3.39 \pm .04,3.29 \pm .05$; length of incisive foramen, $4.59 \pm .05,4.51 \pm .03$; breadth of mesopterygoid fossa, $0.92 \pm .04,0.99 \pm .02$. The probability is exceedingly slight that the two series, and the populations they represent, differ in any of these measurements. And in the absence of any other distinguishing characters it seems probable that at least in cranial features the specimens from San Josecito, Rancho del Cielo and Galeana represent the same species and likely the same subspecies.

Specimens examined.-Five hundred and forty from the following localitıes in México: Distrito Federal: Colonia del Valle, 7500 ft., 2 (CM); Cañón Contreras, 10,400 ft., 1; Contreras, 8500-9500 ft., 40 (11 CM); Huipulco, 7600 ft., 3 (MVZ); San Ángel, pedregal, 2 (CM); San Gerónimo, pedregal, 7800 ft., 2; near Santa Rosa, 10,500 ft., 4 (CM). Hidalgo: Apulco, 7200 ft., 2; Real del Monte, $9000 \mathrm{ft} ., 2$ (US); $6 \mathrm{mi}$. SW Pachuca, $8400 \mathrm{ft}$., 1 (Tex); Tulancingo, $7000 \mathrm{ft} ., 11$ (1 US). Jalisco: $1 \mathrm{mi}$. WSW Ameca, $4000 \mathrm{ft}$., 10 (KU); Cerro Viejo de Cuyutlán, 8500-9700 ft., 75 (74 KU, l MVZ); $27 \mathrm{mi}$. S and $12 \mathrm{mi}$. W Guadalajara, 11 (KU); vicinity of Ocotlán, $5000 \mathrm{ft} ., 7$ (3 KU, $1 \mathrm{CM}, 3 \mathrm{US}$ ). México: 5 mi. E Amecameca, 9600 ft., 1 (MVZ); Atlacomulco, $8200 \mathrm{ft} ., 1$; 
Lerma, 8500 ft., 3 (US); Lago Zempoala, 9400 ft., 3 (Tex). Rancho Córdoba, 8200-8700 ft., 40 (8 CM); vicinity of Río Frío, 9500-10,500 ft., 17 (11 Tex); Salazar, 10,000 ft., 6 (US); 3 mi. NW Texcoco, $7600 \mathrm{ft}$., 2 (Tex); Toluca Valley, 9000 ft. ?, 2 (US); 15 mi. SW Toluca, 10,000 ft., 1 (MVZ); N and NW slope Volcán Popocatépetl, 10,800-13,000 ft., 9 (MVZ); N slope Volcán de Toluca, 1 (US); W slope Volcán de Toluca, 11,400ft., 1. Michoacán: 10 mi. NW Ciudad Hidalgo, Cerro San Andrés, 9400 ft., 5; 2 mi. S Corupo, 7700 ft., 3; near Mil Cumbres, $8000 \mathrm{ft}$., 1; Nahuatzin, $8500 \mathrm{ft} ., 8$ (US); vicinity of Pátzcuaro, 3-4 mi. N, 6700 ft., 4 (MVZ); 31/2-5 mi. S, 7800-7900 ft., 31 (MVZ); 9 mi. SE, 8000 ft., 4 (MVZ); 10 mi. SE, 9200 ft., 26; Sabaneta, 8000 ft., 3 (MVZ); 2 mi. NNW San Juan, 7700 ft., 1; 1 mi. N Zamora, 5500 ft., 12 (MVZ). Morelos: Huitzilac, 3 (US); kilometer 46, Mexico City-Acapulco highway, 10,000 ft., 7. Nuevo León: $12 \mathrm{mi}$. N Galeana, $7000 \mathrm{ft} ., 5$. Puebla: Beristain, 7000 ft., 17; Chalchicomula, 8400 ft., 5 (US); Honey, 6200 ft., 4 (1 CM); Huauchinango, $5000 \mathrm{ft} ., 1$ (US); Lago Salado, 8000 ft., 2 (Tex); Río Atlati, 8700 ft., 20 Tex); Volcán de Orizaba, 1 (US). Tamaulipas: 5 mi. NW Gómez Farías, Rancho del Cielo, 3500 ft., $(14 \mathrm{BH})$. Tlaxcala: Apixaco, $7800 \mathrm{ft} ., 2$ (US); Huamantla, $8200 \mathrm{ft}$., 1 (US); 5-8 mi. SW Tlaxcala, $7500 \mathrm{ft} ., 2$ (Tex). Veracruz: near Altotonca, $6000 \mathrm{ft} ., 30$ (17 CM); N slope Cofre de Perote, 10,000-10,700 ft., 12 (3 Tex); Cofre de Perote, 3 (US); Guadalupe Victoria, $8300 \mathrm{ft} ., 1$ (Tex); Jalacingo, 5500-6000 ft., 18 (6 CM); vicinity of Las Vigas, 7500-8400 ft., 24 (13 US, 2 Tex); Perote, 8000 ft., 6 (3 US); Volcán de Orizaba, timber line, 2 (CM); Xuchil, 12 (CM).

\section{Reithrodontomys megalotis alticolus Merriam}

Reithrodontomys saturatus alticolus Merriam, 1901: 556.

Reithrodontomys megalotis alticolus, Howell 1914: 37.

Reithrodontomys megalotis saturatus, Howell, 1914: 37.

Type.-Adult male, skin and skull; U. S. Nat. Mus. Biol. Surv. Coll. No. 68392; México, Oaxaca, Cerro San Felipe, elevation 10,000 feet; collected 24 August 1894 by E. W. Nelson and E. A. Goldman; original No. 6623.

Distribution.-Highlands of Oaxaca and probably of Guerrero. Known range from the vicinity of Tamazulapan and Cerro Zempoaltepec south to Tlapacingo, at west, and to Miahuatlán and Ozolotepec, at east. Vertical range from 4700 feet at Ejutla to 10,000 feet on Cerro San Felipe.

Habitat.-Apparently similar to that for saturatus. Specimens were collected in situations as follows: In stands of grass ( $1 \mathrm{ft}$. in height) growing between a cornfield and bamboo thickets along a river (Miahuatlán). Among grass and forbs adjoining cultivated areas near a river (Ejutla). In grass along a stone fence between cornfields; none taken in near-by pine-oak forests (Ixtlán). Among grass, brush, and willow trees adjoining milpas and a river (Oaxaca City). Among grass, brush, and a few oaks bordering orange and banana groves and alfalfa and cornfields (Sola de la Vega). 
Comparisons.-Compared with saturatus (specimens of alticolus from Miahuatlán and Ejutla; topotypes of saturatus): Not significantly different in external measurements. Upper parts less blackish and more reddish, the buffy bands between Pinkish Cinnamon and Vinaceous-Cinnamon in adult fresh summer pelage and near Orange-Cinnamon or Tawny in adult worn pelage of either summer or winter. Underparts averaging paler, whitish or Pale Pinkish Buff, pectoral area varying from Light Pinkish Cinnamon to Cinnamon. Coloration otherwise similar. Skull narrower and slighter in build. Brain case narrower (see measurements). Supraorbital border usually evenly curved (a slight supraorbital ridge or sharp-angled shelf usually seen in saturatus).

REMARKs.-The narrow brain case, gently sloping (ventrad) supraorbital border and reddish-buff dorsal coloration are the prinicpal diagnostic characters of alticolus. The reddish hues are best seen in pelages that evidence wear, wherein the black tips of the hairs have been reduced. These and the other characters that distinguish alticolus from saturatus are slight when compared with the differential features of saturatus and megalotis. Nevertheless they seem worthy of recognition. They are best developed in the specimens from southern Oaxaca (Miahuatlán and Ejutla) and less clearly seen in those from localities to the north (Ixtlán and Cerro San Felipe). The latter group approaches saturatus geographically and morphologically. The type specimen of alticolus is in this group. It is morphologically atypical of alticolus. A skull from Oaxaca City has an unusually large brain case, short rostrum, slight zygomatic notch, and broad mesopterygoid fossa.

Specimens Examined.-Sixty-seven from the following localities in Oaxaca, México: Cerro San Felipe, 10,000 ft., 1 (US); Cerro Zempoaltepec, $7700 \mathrm{ft}$. ?, 4 (US); Ejutla, 4700 ft., 4; Sierra Juárez, Ixtlán, 6000 ft., 5; La Parada, about 8000 ft., 2 (US); Miahuatlán, 5100 ft., 9; Oaxaca, 5100 ft., 19 (3 CM, 8 US); m.ts. 15 mi. SW Oaxaca, $9300 \mathrm{ft}$. ?, 2 (US); 3 mi. N Ozolotepec, 10,000 ft., 1 (US); Sola de la Vega, $5000 \mathrm{ft} .$, 17; Tamazulapan, somewhere between 6500 and $7500 \mathrm{ft} ., 1$ (US); Tlapacingo, $5200 \mathrm{ft}$. ?, 2 (US).

\section{Reithrodontomys megalotis zacatecae Merriam}

Reithrodontomys megalotis zacatecae Merriam, 1901: 557; Howell, 1914: 39; Hall and Villa, 1949c: 456 (part).

Reithrodontomys megalotis obscurus Merriam, 1901: 558. México, Chihuahua, Sierra Madre near Guadalupe y Calvo.

Reithrodontomys colimae, Allen, 1906: 249 (fide Howell, 1914: 39).

Reithrodontomys megalotis zacatecae, Hall and Villa, 1949c: 456 (part); 1950: 191 (part).

Type.-Adult female, skin and skull; U. S. Nat. Mus. Biol. Surv. Coll. No. 91910; México, Zacatecas, Sierra de Valparaíso; collected 6 December 1897 by E. W. Nelson and E. A. Goldman; original No. 11859.

Distribution.-Sierra Madre Occidental of western México. Known range 
from the vicinity of Colonia García, northwestern Chihuahua, south to the Nevado and Volcán de Colima and the vicinity of Pátzcuaro, Michoacán. Known vertical range from approximately 6000 feet at Los Conejos, Michoacán, to 8500 feet at Nahuatzin, Michoacán.

Habitat.-Apparently similar to that for $R$. m. saturatus. Specimens were collected in situations as follows: In sparse bunch grass, bracken, and other ferns that formed the understory in a selectively cut pine forest (near Apo on Cerro de Tancítaro). Among grass, a few forbs, and sparse brush in open pine-oak forests (near Volcán Parícutin). In sparse grass and forbs in a hillside field bordering an oak-pine forest (El Nevado de Colima).

Comparisons.-Compared with megalotis (specimens of zacatecae from Sierra de Valparaíso; specimens of megalotis from Jeff Davis and Presidio counties, Texas): Similar in size of body and skull. Tail longer on the average (119 per cent of head and body in 7 specimens of zacatecae compared with 104 per cent in 15 examples of megalotis). Much darker and more reddish dorsally and ventrally, the dorsal fur reddish brown and the ventral fur pinkish buff compared with pale buffy gray dorsally and white ventrally in megalotis. In adult winter pelage upper parts a mixture of black and Pinkish Cinnamon, the black concentrated in a dorsal line, the Pinkish Cinnamon purest on sides, forehead, and cheeks. Underparts Light Pinkish Cinnamon, becoming Pinkish Cinnamon between forelegs. Hairs of throat white throughout, those of other parts of body Blackish Mouse Gray basally. Pinnae Fuscous, covered with black and Pinkish Cinnamon hairs, the black concentrated on inferior inner and superior outer surfaces. Tail Fuscous dorsally, white ventrally. Feet white, as in all known forms of megalotis in México. Subadult winter pelage paler and grayer than adult, the buffy bands of the upper parts Light Pinkish Cinnamon or Pinkish Buff. (Compare with color description of megalotis in the accounts of that form.) Molar teeth and zygomatic notch smaller, and zygomatic plate narrower.

Compared with saturatus (topotypes of zacatecae; topotypes of saturatus): Smaller. Tail averages longer (119 per cent and 108 per cent of head and body length, respectively, in 7 specimens of zacatecae and 12 specimens of saturatus). In both subadult and adult winter pelages, ears, upper side of tail, head, sides, and back paler, the dorsal stripe not as black and the buffy bands of the hairs less rufescent in hue. Underparts tending to be a deeper more reddish hue of buff. Cranium smaller (see measurements of depth of cranium and breadth of brain case, in particular). Molar teeth smaller. Rostrum and incisive foramina shorter.

Compared with arizonensis (topotypes of zacatecae; topotypes of arizonensis): Insofar as can be determined from the scanty material at hand, the 2 subspecies differ only in coloration. That of zacatecae is darker dorsally and 
ventrally; the buffy hues are similar but the black overlay is much heavier dorsally. Underparts decidedly more buffy.

Remarks. $-R$. m. zacatecae is a well-marked form. Its dark dorsal coloration, buffy underparts with darker buffy pectoral spot, moderately long tail, and small molar teeth distinguish it from megalotis. Its small size and small teeth, to mention only 2 of the diagnostic characters, set it apart from saturatus. It inhabits the higher and cooler parts of the Sierra Madre Occidental. Records of occurrence indicate that it is found principally above 7000 feet, in the oak-pine zone. $R$. m. megalotis inhabits the flanks of the Sierra Madre and adjoining parts of the intermontane plateau. Data indicating that the 2 forms intergrade are not as full as are desired. Specimens from the vicinity of Colonia García, northwestern Chihuahua, and an example from La Unión, southwestern Chihuahua, are darker dorsally and more buffy ventrally than specimens considered typical of megalotis from lower elevations to the east and north. In coloration they are referable to zacatecae; cranially they are not significantly different from typical megalotis. A specimen from Ranchería, southwestern Chihuahua, has a relatively long tail and small teeth as seen in zacatecae. It is also more buffy ventrally and slightly darker dorsally than examples of megalotis from lower elevations in Chihuahua; nevertheless it is distinctly paler than topotypes of zacatecae. Specimens from the mountains near Guadalupe y Calvo, which were the basis for the name obscurus, are like topotypes of zacatecae externally. Cranially they are between zacatecae and megalotis, nearer the latter in size of skull.

There are 4 molariform teeth, instead of the usual 3, in the right upper jaw of one specimen. $\mathrm{M}^{1-3}$ are normal in position and shape. The extra tooth lies immediately anterior to $\mathrm{M}^{1}$ in the position where $\mathrm{Pm}^{4}$ might be. It is small and peglike in form. Its crown height is about equal to that of $\mathbf{M}^{1}$. On the occlusal surface the enamel is slightly indented on the anterior face of the tooth and is slightly folded shallowly on the posterior face. The specimen (Mus. Vert. Zool. No. 100247) was collected 4 miles south of Pátzcuaro, Michoacán. This is the only instance known to me of supernumerary teeth in Reithrodontomys.

As here understood zacatecae is recognized principally by its reddish-brown upper parts, cinnamon underparts, small size, relatively long tail, small brain case, small molar teeth, slight zygomatic notch, moderately narrow zygomatic plate, and broad mesopterygoid fossa. Those characters are best seen in the specimens from the southern part of the range of zacatecae in Jalisco and Michoacán. On the average, examples from localities to the north are less intensely pigmented dorsally and ventrally; the brain case, molar teeth, and zygomatic plate average slightly larger.

The interrelationships of zacatecae and saturatus are discussed in detail 
above. Where the forms meet in Jalisco and Michoacán there apparently is little or no panmixia of their populations (Figs. 11-13). Specimens of both zacatecae and of saturatus are at hand from the vicinity of Pátzcuaro, Nahuatzin, and Volcán Parícutin. Populations of saturatus appear to separate the populations of zacatecae in Michoacán and Jalisco from those in Zacatecas and areas to the north. If the 2 forms interbreed freely, they do so in areas not sampled at this time. Present evidence indicates that intermixture of the 2 forms is uncommon.

Specimens eXAmined.-Fifty-five from the following localities in México: Chihuahua: 9 mi. SE Colonia García, 8200 ft., 2 (MVZ); Sierra Madre near Guadalupe y Calvo, somewhere between 7000 and $9000 \mathrm{ft} ., 3$ (US); $6 \mathrm{mi}$. N Guachochic, La Unión, 8400 ft., 1 (MVZ); 12 mi. E Guachochic, Ranchería, $6250 \mathrm{ft}$., 1 (MVZ). Durango: El Salto, somewhere between 7600 and $8400 \mathrm{ft}$., 2 (US). Jalisco: N slope El Nevado de Colima, $7300 \mathrm{ft}$., 2. Michoacán: $3 \mathrm{mi}$. (by road) E Angahuan, $8000 \mathrm{ft}$., 2; 81/2-9 mi. (by road) E Angahuan, $8000 \mathrm{ft}$., 2; Cerro Tancítaro, $1 \mathrm{mi}$. N Apo, $7000 \mathrm{ft}$., 5; 4 mi. WSW Uruapan, Los Conejos, 6000 ft., 1; Nahuatzin, 8500 ft., 2 (US); 3 mi. NE Volcán Parícutin, $7200 \mathrm{ft} .$, 1; 3 mi. N Volcán Parícutin, San Juan, 7200 ft., 1; 2 mi. NNW San Juan, 7700 ft., 2; Patambán, 4 (US); 31/2-5 mi. S Pátzcuaro, 7800-7900 ft., 12 (MVZ); 9 mi. SE Pátzcuaro, 8000 ft., 1 (MVZ). Zacatecas: Sierra de Valparaíso, 8200-8700 ft., 13 (US).

\section{Reithrodontomys megalotis amoles Howell}

Reithrodontomys amoles Howell, 1914: 40.

Type.-Adult female, skin and skull; U. S. Nat. Mus. Biol. Surv. Coll. No. 81234; México, Querétaro, Pinal de Amoles: collected 20 September 1896 by E. W. Nelson and E. A. Goldman; original No. 10169.

Distribution.-Known only from the vicinity of Pinal de Amoles, Querétaro.

Habitat.-Two specimens from Amoles were trapped in the following situations: One under vines and herbs growing in an abandoned cornfield in a barranca and the other among brush and herbs on a rocky slope.

Comparisons.-Compared with saturatus (topotypes of amoles; topotypes of saturatus): Similar in coloration. Smaller in all measurements of skin and skull except length of tail and breadth of mesopterygoid fossa. Tail relatively longer (the length respectively 117, 123, and 125 per cent of head and body length in the 3 topotypes). Brain case shallower and narrower (see measurements). Mesopterygoid fossa similar in breadth in the 2 forms, thus relatively broader in amoles. Molar teeth and auditory bullae smaller.

Compared with megalotis (topotypes of amoles; specimens of megalotis from western Texas): Similar in length of head and body and in size of ear. Tail much longer (averages 122 per cent of head and body length, compared 
with 104 per cent in 14 specimens of megalotis). Summer pelage much darker, back predominantly blackish, and sides Cinnamon to Pinkish Cinnamon, with a light admixture of black. Underparts varying from bright Pinkish Cinnamon to Pale Pinkish Cinnamon, pectoral area slightly darker in tone. Tail and ears as in saturatus, darker than in megalotis. Feet white. Cranium similar in length but narrower and shallower in amoles (well seen in zygomatic breadth, depth of cranium, and breadth of brain case); zygomatic plate narrower (see measurements); zygomatic notch anteroposteriorly shorter; mesopterygoid fossa broader; molar teeth smaller.

Compared with zacatecae (topotypes of arnoles; specimens of zacatecae from western Zacatecas and Durango): Similar in coloration, upper parts of amoles possibly slightly more blackish and reddish. Similar in length of head and body, length of ear and tail, and in most dimensions of the cranium. Brain case narrower and shallower.

REMARKs. $-R$. amoles was described from one specimen collected in 1896. In 1949 Dr. H. O. Wagner made especial efforts to obtain additional topotypes and in several hundred trap nights succeeded in trapping 2 specimens. All statements herein regarding amoles are based on those 3 specimens and, accordingly, are highly tentative. $R$. amoles is most similar to $R$. zacatecae and especially to the segment of zacatecae found in Michoacán and southern Jalisco. The characters that distinguish topotypes of amoles from the specimens in Michoacán and Jalisco are few and slight. When the range of variation of amoles is better known it may coincide closely with that of zacatecae of Michoacán and Jalisco. The forms zacatecae, amoles, and arizonensis are all characterized by moderately dark coloration, small size, relatively long tail, and small molar teeth. They form a group distinct from megalotis and saturatus. The group approaches the specific level of differentiation, and in some areas it appears to be reproductively isolated from megalotis and saturatus (see Figs. 11-13 and accounts of the species megalotis for further discussion of this point).

Specimens examined.-México, Querétaro, Pinal de Amoles, approximately 7500 ft., 3 (1 US).

\section{Reithrodontomys sumichrasti}

(Maps 3, 12; Pls. II-IX; Figs. 9, 10, 14-16, 19, 20)

The status, relationships, and full extent of the range of $R$. sumichrasti have been obscure since the species was first described in 1861, a period of over ninety years. The species has been confused repeatedly with other species of the genus and has received a lion's share of scientific names applied to samples from various parts of its range. Specimens have been identified erroneously as megalotis, fulvescens, and chrysopsis. Other specimens were the basis for the descriptions of rufescens, nerterus, otus, seclusus, luteolus, 


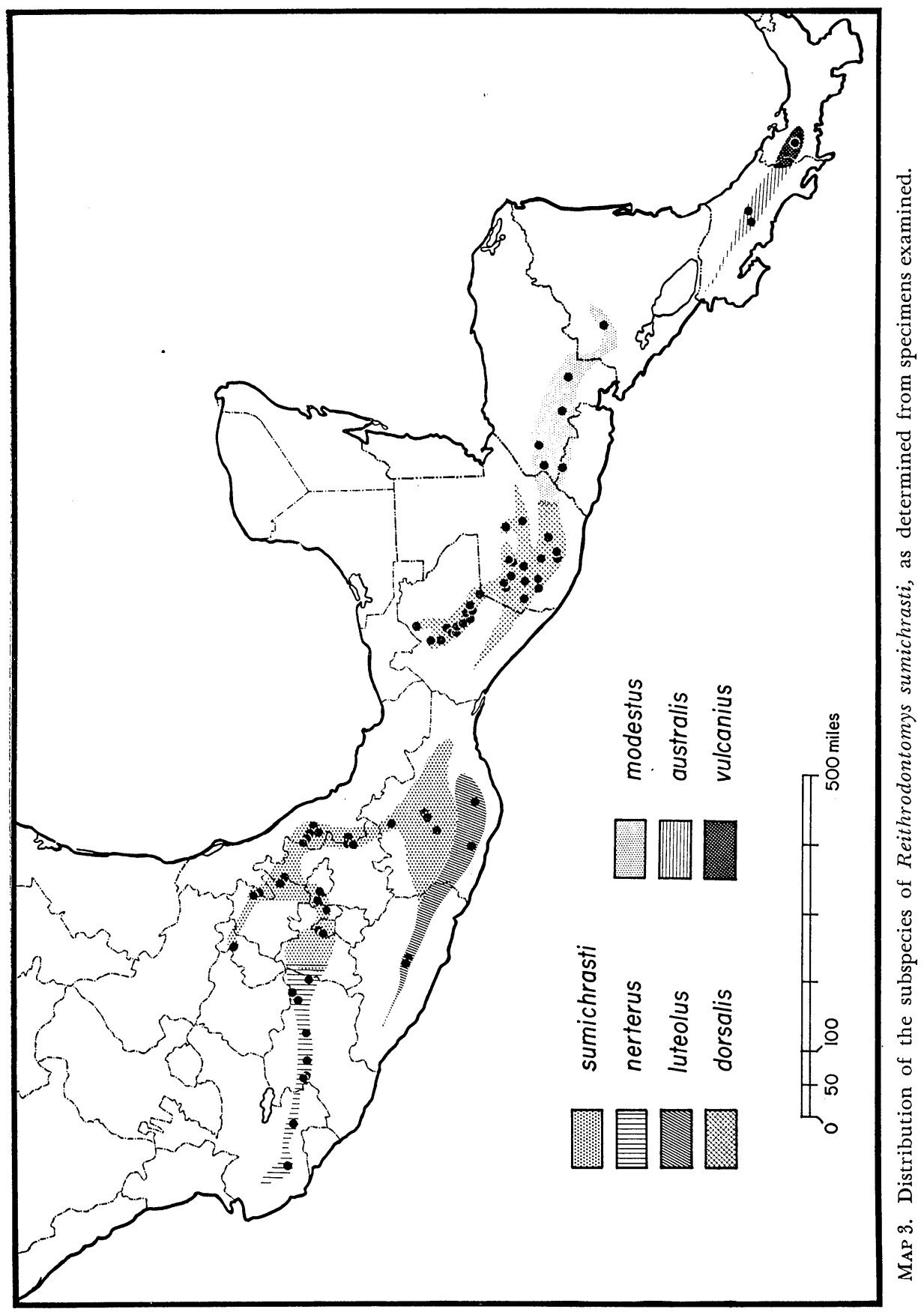


alleni, dorsalis, underwoodi, modestus, australis, and vulcanius. Some of these names are clearly synonyms. Seven of them designate the geographic races that are recognized here.

When Howell (1914: 50) reviewed the genus, he had the original description and photographs of the type specimen of $R$. sumichrasti. He determined to his satisfaction that the type is an example of the subgenus Reithrodontomys. He was not sufficiently certain of the specific identity of the form, however, to use the name for one of the currently recognized species. He listed sumichrasti in the synonymy of $R$. fulvescens difficilis, but indicated that it might not belong there.

I have at hand a photograph of the skull of the type specimen and measurements of it and of the skin. These were generously supplied by Dr. P. Revilloid, director of the Museum of Natural History of Geneva. It is clear that the type is referable to the subgenus Reithrodontomys, as Howell pointed out. It is not conspecific with $R$. fulvescens, however. The characters of $\mathrm{M} \frac{3}{3}$ rule out fulvescens and also exclude all species of Aporodon. It is equally clear that the type is conspecific with either megalotis or rufescens (as heretofore known). In order to associate sumichrasti with one or the other of those 2 species, the photographs and other data were compared in detail with specimens of megalotis and rufescens from west-central Veracruz. Specimens from west-central Veracruz were selected because the type specimen of sumichrasti probably came from that area. The following characters were considered most important in indicating the identity of sumichrasti: In $\mathrm{M}^{1-2}$ of the specimen there are short blunt mesolophs bounded anteriorly by a short, anteromedially directed first secondary fold. Such an arrangement is usual in rufescens and uncommon in megalotis. $\mathrm{M}^{3}$ is small and oval in shape, more closely resembling rufescens than megalotis. The mesopterygoid fossa is broad and the auditory bullae are small in relation to size of skull; in these characters the type fits better with rufescens than with megalotis. In $\mathrm{M}^{1-2}$, particularly in $\mathrm{M}^{2}$, the paracone is not evenly rounded posteriorly but is keeled on its posterolabial margin; the keel projects into the second primary fold. This is common in rufescens; insofar as is known, megalotis has no such keel. In the mountains of Veracruz the 2 species are similar in size and in many other characters. Incomplete specimens from the region often are difficult to identify. Present evidence, however, appears to be sufficient to correctly connect the type specimen with the species heretofore known as $R$. rufescens. Accordingly, it is necessary to relegate rufescens to the synonymy of sumichrasti, the oldest applicable name.

Mirador, Veracruz, is suggested as the type locality of sumichrasti. The species occurs in that area and Sumichrast, who obtained the type specimen, is known to have stopped in Mirador at Sartorius' ranch (see accounts of $R . m$. mexicanus for additional information). 
Genetic variability in $R$. sumichrasti appears to be well scattered through the populations of the species. There are great seasonal and age differences and few clear-cut geographic trends in morphological traits. The broad range in individual variation is well seen in the several large samples, for example in those from the Volcán de Chiriquí, Panamá, from Los Esesmiles, El Salvador, from several localities in Chiapas, and from the Nevado de Colima, Jalisco. In the samples from the Nevado, there are long narrow skulls and short broad skulls, broad and narrow brain cases, large and small teeth and auditory bullae, pale buffy upper parts and dark reddish-brown upper parts, dusky feet and white feet, long and short and monocolor or bicolor tails, and correspondingly striking variations in other parts. Considering extremes, one might suspect that more than one species is represented in the sample. The presence therein of all essential degrees of intermediacy renders that hypothesis untenable, however. It strongly indicates that the observed variations in the sample are those of individuals of one species but of various ages and representing various stages of pelage wear and replacement.

In tone of coloration the races of sumichrasti may be arranged in 2 groups. Within each group the color deepens geographically from north to south. The races sumichrasti, dorsalis, australis, and vulcanius are dark-colored forms. In each there is an abundance of black dorsally which largely obscures the cinnamon ground color. Thus, the upper parts are blackish and dull. The underparts are similarly somber. The tips of the hairs are tinted but the bands are narrow and the broad plumbeous bands show through and contribute strongly to the tone of the underparts. Of these 4 races australis and vulcanius are the most somber and sumichrasti is the palest. The races nerterus, luteolus, and modestus comprise a group which is brighter in color. In them there is less black dorsally and the cinnamon-tinted bands of the hairs of the underparts obscure the blackish basal bands. The result is a distinctly brighter and on the average more buffy coat in those races. Of the 3 forms, nerterus is the palest and modestus the darkest.

Distribution.-Highlands of central and southern México and Central America, from the Sierra de Autlán and El Nevado de Colima, Jalisco, and Amoles, Querétaro, south to the Volcán de Chiriquí, Panamá. Most records of occurrence are within the altitudinal range 5000-9000 feet. Known vertical range extends from approximately 4000 feet at Orizaba, Veracruz, Las Margaritas, Chiapas, and Altos Escazú, Costa Rica, to 10,000 feet near Ozolotepec, Oaxaca, 11,300 feet on Volcán de Chiriquí, Panamá, and 13,200 feet on Volcán Tajumulco, Guatemala.

Habitat.-The species has a broad ecologic range, in keeping with the extent of its vertical range. It occurs in both subtropical and temperate climates. The type of substrate on which it lives varies from dry, rocky and sandy soil to marshy and other perennially wet ground. Three situations in 
which it is found are: sparse cover in oak and pine forests, sacatón, and lush growths in cloud forests. To judge from trapping records, it is most abundant and apparently thrives in cool and moist situations, such as along streams and in cool, humid forests. Of all species in the subgenus Reithrodontomys it most closely qualifies as a subtropical species.

Its geographic, vertical, and ecologic ranges overlap those of several other species of the genus, and there are many instances of capture of specimens of sumichrasti and of other species of Reithrodontomys in the same area. For example, the species is recorded with mexicanus, rodriguezi, and creper from the Volcán de Chiriquí, Panamá. In Guatemala it is found variously with tenuirostris, microdon, mexicanus, fulvescens, and gracilis. In México examples of the species have been collected in the same trap line in which specimens of one or more of the following species also were trapped: microdon, chrysopsis, megalotis, fulvescens, and mexicanus. The broad vertical and ecological ranges of sumichrasti partly account for the fact that sumichrasti occurs with many other species of harvest mice. Moreover, the species is centrally located geographically and ecologically. Its geographic range encompasses the metropolis of Reithrodontomys. More species occur within the geographic limits of its range than within the range of any other species in the genus. It occupies a geographically intermediate position between northern and southern species. Its vertical and ecological positions are also intermediate, lying between those of species that live in cool, moist situations at high altitudes and those of other species that are adjusted to hot and dry conditions of tropical or temperate lowlands.

In ranking the species of the subgenus Reithrodontomys on the basis of altitudinal, climatic, and vegetational belts in which they live, I would place $R$. sumichrasti below chrysopsis and above megalotis. $R$. chrysopsis inhabits the cool, moderately moist fir belt on the upper slopes of the mountains. $R$. sumichrasti lives at lower elevations in the pine-oak zone and in the adjoining, more humid, broadleaf evergreen belts. It apparently thrives in moderately heavy and often brushy cover in forested areas where the temperatures are moderate and where there are frequent rains, fogs, or clouds. R. megalotis typically occurs in more open, although not necessarily drier, situations, such as grasslands, meadows, and fence rows along open fields; it ranges to lower altitudes than do the other 2 species.

Comparisons.-In the subgenus Reithrodontomys, sumichrasti stands between chrysopsis and megalotis in size of body and skull. On the basis of size alone some specimens of sumichrasti may be indistinguishable from small individuals of chrysopsis or large examples of megalotis. Differential characters of chrysopsis and sumichrasti are given in Table I and Figures 14 and 15. Color of the pelage of $R$. sumichrasti is Cinnamon or tones thereof. Seasonal and age differences in coloration are greater than those apparently related 
directly to geography. These differences are described in detail elsewhere. In general, adult pelages of both dry and wet seasons are reddish brown or blackish dorsally and cinnamon ventrally. In coloration the northern races of sumichrasti resemble $R$. chrysopsis chrysopsis and $R$. fulvescens difficilis; resemblances of wet-season pelages of chrysopsis and sumichrasti are particularly striking. Upper surfaces of the hind feet vary from whitish through buffy to dusky; the dusky area varies in size and intensity. There is some evidence that duskiness of the hind feet is characteristic in the wet months of the year.

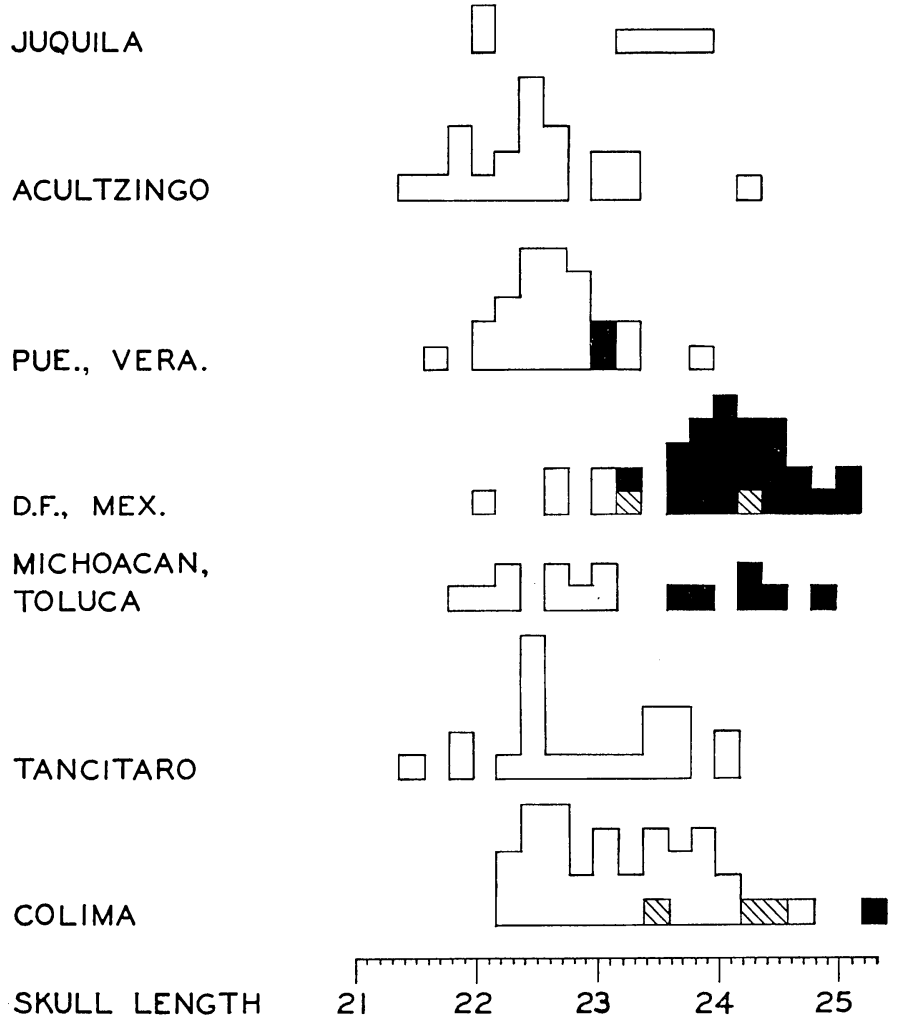

Fig. 14. Skull lengths (in $\mathrm{mm}$.) of specimens of Reithrodontomys chrysopsis and $R$. sumichrasti from México. Each black square represents a specimen of chrysopsis and each open square indicates a specimen of sumichrasti; a shaded square represents 2 specimens, one of each species.

Relationships.-Cranial and dental characters of sumichrasti indicate clearly that the species belongs in the subgenus Reithrodontomys. It is a specialized species in contrast to montanus, burti, humulis, megalotis, and raviventris, which are considered generalized kinds. Its large body and skull, long scantily-haired tail, long broad rostrum, short broad zygomatic notch, broad mesopterygoid fossa, and the tendency toward a complex molar pat- 
tern constitute evidences of specialization. On the basis of amount of specialization sumichrasti and chrysopsis may be considered to comprise a "weak" species group. The affinities of that group are clearly with the megalotis group of species, rather than with the fulvescens group. The closest living relatives of sumichrasti appear to be chrysopsis and megalotis, to judge from the morphology of those species. Both chrysopsis and sumichrasti may have evolved from primitive megalotis-like stock. Facts of their morphology are compatible with that hypothesis.
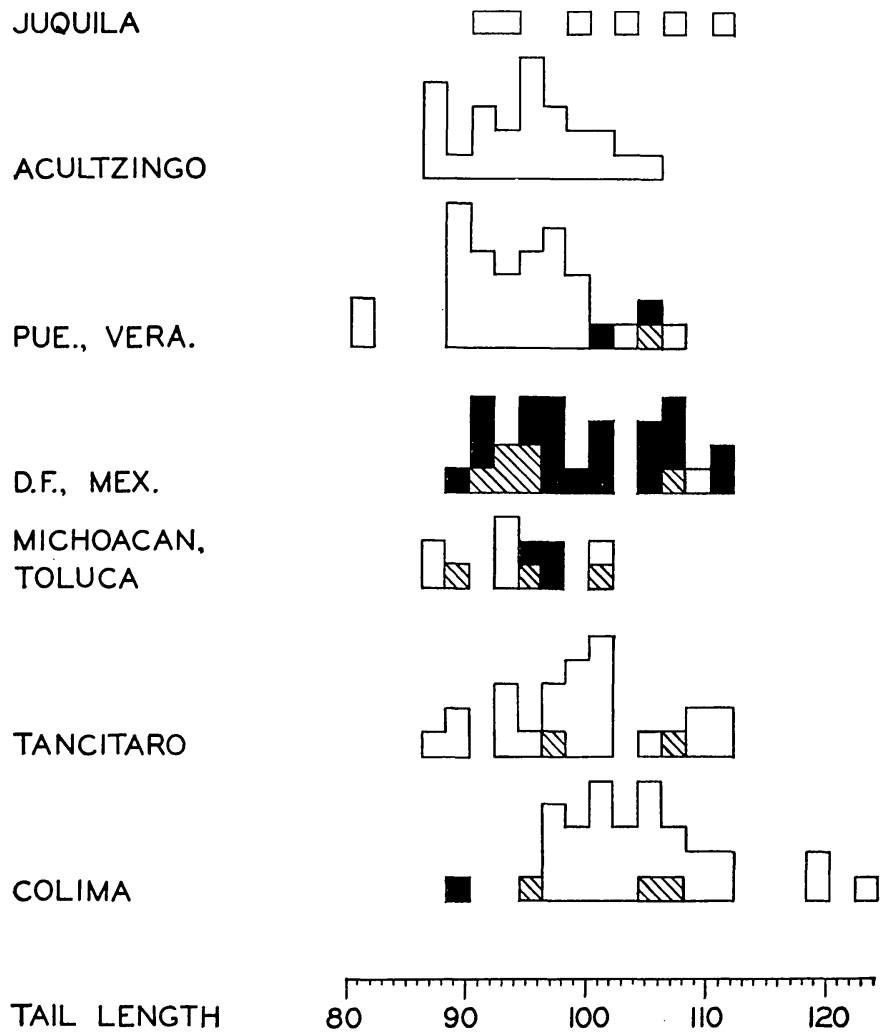

Fig. 15. Tail lengths (in mm.) of specimens of Reithrodontomys chrysopsis and R. sumichrasti from parts of México. Each black square represents a specimen of chrysopsis and each open square indicates a specimen of sumichrasti; a shaded square represents 2 specimens, one of each species. In specimens from Cerro de Tancítaro and El Nevado de Colima the tail length of sumichrasti tends to exceed that of chrysopsis.

\section{Reithrodontomys sumichrasti sumichrasti de Saussure}

Reithrodon sumichrasti de Saussure, 1861: 3.

Ochetodon sumichrasti, Coues, 1874: 186 (sp. proband.).

Reithrodontomys rufescens Allen and Chapman, 1897b: 199. México, Veracruz, Jalapa, $4400 \mathrm{ft}$. Reithrodontomys rufescens rufescens, Howell, 1914: 56. 
Reithrodontomys fulvescens difficilis, Davis, 1944: 392; Howell, 1914: 51 (part). Reithrodontomys fulvescens toltecus, Davis, 1944: 392 (part); Hooper, 1947: 49 (part).

Type.-Male, skin and skull; Mus. Hist. Nat. Genève No. $\frac{531}{3}$; México (herewith fixed at Mirador, Veracruz); purchased from Sumichrast.

Distribution.-Mountains of southeastern México-in Veracruz, Puebla, Hidalgo, Querétaro, México, Distrito Federal, and Oaxaca. Known range from Amoles, Querétaro, and Molango, Hidalgo, southeast to Cerro San Felipe, Oaxaca. Known vertical range from about 4000 feet at Orizaba, Veracruz, to 9500 feet in the vicinity of San Bartolomé, near Mexico City.

HaBitat.-Stands of grass, brush, or forbs within and bordering temperate and subtropical pine and oak forests; principally in areas frequently bathed by clouds and rain. Specimens were collected in situations as follows: Eight feet above ground in a fir tree among pines and oaks at the lower edge of the fir belt; on a rocky south-facing slope among oaks and pines (Cañón Contreras). In an oak forest (Hacienda Córdoba). On the border of oak forests and cornfields (Cerro San Felipe). In woods; at the edge of a field (La Cumbre). In a pine forest; in vegetation bordering pine forest and pastureland (Huauchinango). Among alder, ferns, moss, and grass in a humid canyon; among brush, grass, and pines (Amoles). In stone walls bordering cornfields within oak forests (Acultzingo). In various places at the lower edge of the oak and pine forests where they merge with more tropical forests (Altotonca and Teziutlán). Among sparse brush and grass on the upper slopes of a humid tropical canyon (Jalapa).

Characters.-Size: Medium; head and body length of adults rarely less than $75 \mathrm{~mm}$., the maximum $88 \mathrm{~mm}$. in specimens examined; hind foot rarely less than $18 \mathrm{~mm}$., the maximum $21 \mathrm{~mm}$. Tail long, the observed range 81-113 $\mathrm{mm}$. in subadults and adults. Ear moderate, varying from 13 to $17 \mathrm{~mm}$., the average about $15 \mathrm{~mm}$. Skull large, the observed range in total length in subadults and adults $21.5-24.3 \mathrm{~mm}$. Molar teeth moderate in size, the range in length of molar row 3.2-4.0 mm., the average $3.6 \mathrm{~mm}$.

Color: As described for $R$. s. nerterus (the samples of which more completely represent the gamut of ages and seasons than do those of sumichrasti) except for differences as follows: In adult pelage of dry season (February specimens from Huauchinango) upper parts somber, not as bright as in nerterus, ground color similar in the 2 forms (near Cinnamon or Pinkish Cinnamon) but hair bands providing that color apparently narrower in sumichrasti, the black bands thus contributing relatively more to the tone of the upper parts. Underparts much less brightly colored, the buffy bands of about the same hue in both forms (near Pinkish Cinnamon) but bands apparently narrower in sumichrasti. Whatever the cause, the underparts of sumichrasti are distinctly duller, less buffy, than those of nerterus. Adult pelage of wet season (August specimens from Amoles): Dorsal area much as 
in nerterus; sides duller in sumichrasti, the cinnamon bands narrower and thus contributing relatively less than the black bands to the mass coloration of the sides. Underparts duller, mass coloration Light Pinkish Cinnamon in sumichrasti and bright Cinnamon or Pinkish Cinnamon in nerterus. Subadult pelages matching closely in the 2 subspecies, but again upper parts and underparts of sumichrasti slightly more somber than in nerterus.

Skull: Brain case of moderate size (see measurements); its shape more similar to that of megalotis and chrysopsis than to that of species of Aporodon. Frontal bones broad, in old individuals often forming a narrow postorbital shelf. Rostrum broad and long (see measurements), consistently broader than interorbital constriction. Zygomata broad and strong, much less fragile than in Aporodon. Zygomatic notch broad and anteroposteriorly shallow, shallower than in all other species of the subgenus Reithrodontomys. Zygomatic plate broader than mesopterygoid fossa. Pterygoid fossae moderately broad, the size of each between that seen in mexicanus and that in megalotis. Auditory bullae moderate: relatively much smaller than in megalotis, slightly smaller than in chrysopsis, and larger than in hirsutus and mexicanus. Incisive foramina long and narrow, as in chrysopsis and megalotis. Posterior palatine foramina small oval slits. Sphenopalatine vacuities large, usually as large as the crown surface of the molar row. Molar teeth much as in megalotis; but in $\mathrm{M}^{1-2}$ they are unlike those of megalotis in that a short, blunt mesoloph is often present; it is bounded laterally by a short anteriorly projecting secondary enamel fold. In further contrast the posterolateral face of the paracone in $\mathrm{M}^{1-2}$ of sumichrasti is often keeled dorsoventrally; the keel may be fused with a mesostyle. This character is best seen on $\mathrm{M}^{2}$. It is entirely peculiar to sumichrasti, insofar as is known.

Remarks.-The specimens from western Puebla, México, and Distrito Federal are intermediate in characters between sumichrasti of Veracruz and nerterus of Jalisco and Michoacán. In none is the venter as bright as in the brightest nerterus; however, one of 5 adult pelages and 3 of 6 subadult pelages from Distrito Federal fall within the range established by the specimens from Michoacán and Jalisco. The examples from Acultzingo average slightly paler than those from other localities in Veracruz; the difference is probably seasonal rather than racial. Three examples from La Cumbre, Oaxaca, agree with luteolus topotypes in color of underparts. Their rather blackish upper parts and their cranial characteristics require that they be assigned to sumichrasti rather than to luteolus. Other specimens from Oaxaca also fit best with sumichrasti of Veracruz.

SPECIMENS EXAMINED.-One hundred and fifty-three from the following localities in México: Distrito Federal: vicinity of Contreras, 8500-9300 ft., 14; San Bartolomé, 9500 ft., 1. Hidalgo: Molango, 5400 ft., 14; Zacualtipán, 6000 ft., 18. México: Hacienda Córdoba, 8600 ft., 1. Oaxaca: Cerro San Felipe, 
7200-7500 ft., 3; 5 mi. NE Cerro San Felipe, La Cumbre, 9000 ft., 3 (MVZ); mts. 15 mi. SW Oaxaca, somewhere between 8800-9500 ft., 1 (US); Reyes, somewhere between 6700 and 10,200 ft., 3 (US). Puebla: Honey, $6200 \mathrm{ft}$., 1; Huauchinango, 5000 ft., 10 (3 CM, 3 US); Río Atlati, 8700 ft., 1 (Tex); Teziutlán, $6000 \mathrm{ft}$., 8 (2 CM). Querétaro: Amoles, somewhere between 7500 and 9500 ft., 7 (1 US). Tlaxcala: 5 mi. SW Tlaxcala, $7500 \mathrm{ft}$., 1 (Tex). Veracruz: vicinity of Acultzingo, $7000 \mathrm{ft}$., 29 (9 CM, $1 \mathrm{KU}$ ); Altotonca, $6000 \mathrm{ft} ., 9$ (5 CM); Las Vigas, $8500 \mathrm{ft}$., 3 (KU); Jalacingo, 5500-6000 ft., 8 (5 CM, $1 \mathrm{KU}$ ); vicinity of Jalapa, $4500 \mathrm{ft}$., 8 (3 AM, $1 \mathrm{KU}, 1 \mathrm{US}$ ); vicinity of Jico, between 4500 and 6500 ft., 8 (US); Maltrata, $6000 \mathrm{ft} ., 1$ (US); Orizaba, $4000 \mathrm{ft} ., 1$ (US).

\section{Reithrodontomys sumichrasti nerterus Merriam}

Reithrodontomys colimae nerterus Merriam, 1901: 551; Howell, 1914: 60.

Reithrodontomys levipes otus Merriam, 1901: 555. México, Jalisco, foothills of El Nevado de Colima, $6500 \mathrm{ft}$.

Reithrodontomys otus, Howell, 1914: 55.

Reithrodontomys chrysopsis seclusus Hall and Villa, 1949a: 163 (part); 1949b: 173 (part); 1949c: 459 (part); 1950: 195 (part). México, Michoacán, Cerro Tancítaro, $7800 \mathrm{ft}$.

Type.-Subadult female, skin and skull; U. S. Nat. Mus. Biol. Surv. Coll. No. $\frac{33680}{45715}$; México, Jalisco, foothills of El Nevado de Colima, $6500 \mathrm{ft}$., elevation; collected 21 April 1892 by E. W. Nelson and E. A. Goldman; original No. 2514.

Distribution.-Mountains bounding the southwestern part of the Mexican Plateau, in the states of Jalisco and Michoacán. Known range from the Sierra de Autlán, Jalisco, east to Macho de Agua, extreme eastern Michoacán. Known vertical range from 5300 feet at Uruapan, Michoacán, to 9500 feet on the Nevado de Colima, Jalisco.

HaвiтAT.-Grassy and brushy areas in pine-oak forests and locally in fir forests. Specimens were obtained in situations as follows: In a thicket of Salvia and Alnus bordering a bunch-grass meadow (grass 2-3 ft. high) and a pine-oak forest (Sierra de Autlán). In a dense growth of Salvia, Lupinus and other shrubs (average height 4-8 ft.) in a recently cut pine-fir forest; among ferns, moss, sedges, and shrubs in a perennially moist canyon (NW slopes of Nevado de Colima). Among Salvia, Ceanothus, Lupinus, and other shrubs in a mixed hardwood and coniferal forest-oaks, madrone, pines, and other trees (NE slopes of Nevado de Colima). In a thicket of brush and vines along a fence at the lower border of pine-oak forests (foothills west of Ciudad Guzmán). In dense growths of forbs, bunch grass (3 ft. in height), and shrubs near a creek in a pine-oak forest; in brush bordering a wheat field and an oak, pine, and fir forest (Cerro Tancítaro). In dense brush bordering a pineoak forest and grassland (Uruapan). In brush and among lava boulders in a pine-oak forest (6 mi. S Pátzcuaro). In Baccharis, elderberry, grass, and among young pine and fir trees at the edge of a meadow; in tall grass near 
a creek; in an oak forest; among forbs and grass along a creek in a pine forest (Cerro San Andrés). In a pine-fir forest (30 mi. E Morelia).

Characters.-Color: Fresh adult pelage of dry season (March specimens from the Nevado de Colima): Upper parts a mixture of cinnamon and black, the former predominant on the sides and cheeks and the latter on the head and back; distal one-third of cover hairs slightly more buffy than Cinnamon or Pinkish Cinnamon; basal two-thirds Dark Plumbeous to PlumbeousBlack, nearer the latter; the many long guard hairs Plumbeous-Black basally, black medially, and pale gray or colorless apically. Entire underparts bright cinnamon, that color most vivid in the pectoral area; basal one-half of the fur varying from Dark Plumbeous to Plumbeous-Black, distal half between Cinnamon and Clay Color or Pinkish Cinnamon and Cinnamon-Buff. Muzzle and circumorbital area Fuscous or black. Pinnae Fuscous or Fuscous-Black, always with some, and often with many, buffy hairs on their internal and external surfaces. Tail Fuscous or Fuscous-Black dorsally and either paler ventrally or monocolor. Ankles and wrists Fuscous. Upper surface of hind feet white, Cinnamon, Pinkish Cinnamon, or Fuscous; in most specimens, however, white or Pinkish Cinnamon with a narrow dorsal Fuscous stripe extending from the ankle for about one-third of the distance to the base of toes; toes white. Fresh adult pelage of wet season (June and July specimens from Cerro Tancítaro): Similar to that of dry season but upper parts much darker because of a slightly deeper ground color (about Cinnamon) and a greater abundance of black guard hairs, particularly on head and back; tail scarcely paler ventrally than dorsally.

Fresh subadult pelage of dry season (March specimens from the Nevado de Colima): In general, duller than adult pelage. Ground color of the upper parts slightly paler in tint, nearer Pinkish Cinnamon and Cinnamon-Buff than Cinnamon and Clay Color, hair bands of that color apparently narrower than in adults. Underparts also appearing less vivid, nevertheless Cinnamon or Pinkish Cinnamon as in adults. Fresh subadult pelage of wet season (late June specimens from Cerro Tancítaro): As described immediately above, but upper parts much darker; back and head blackish.

CoMPARISONS.-Compared with sumichrasti (specimens of nerterus from El Nevado de Colima; specimens of sumichrasti from Jalapa and Las Vigas); Similar in body size and in most cranial proportions. Tail averages longer (105 mm. compared with $92 \mathrm{~mm}$.), but this difference not significant when applied to the total sample of each race. Pelage coloration brighter; this difference best seen on the sides and especially on the underparts. Zygomatic plate narrower and zygomatic notch shallower.

REMARKs.-The bright cinnamon sides and underparts constitute the principal basis for recognition of nerterus. The moderately narrow zygomatic plate and shallow zygomatic notch characterize all series of nerterus except 
the series from Cerro Tancítaro. Those specimens are not separable from sumichrasti of Veracruz in the 2 characters. The bright coloration of the sides and underparts is fully developed in the specimens from Tancítaro, however, and in all other series from Michoacán and Jalisco. When due consideration is given to age and pelage condition, I cannot separate the series from central and western Michoacán from the series from Jalisco without recourse to the locality labels. $R$. s. nerterus grades into $R$. s. sumichrasti in eastern Michoacán and western México. The eastern limit of the range of nerterus is here considered to be near the México-Michoacán state line. (Map 3.)

Two species are represented in the series of specimens that formed the basis for the description of seclusus. Twenty of those specimens, including the holotype, are examples of $R$. sumichrasti. Two are specimens of $R$. chrysopsis. The differences between the 2 series are real, indeed, but they distinguish full species, not subspecies. The original description of seclusus is published both in English and in Spanish (Hall and Villa, 1949a, 1949b). The Spanish version was published on 18 September 1949 (fide Hall, in litt.), the English account on 23 August 1949. The latter has priority and, therefore, establishes the name. The specimens from Cerro Tancítaro closely resemble topotypes of nerterus. The forms seclusus and nerterus are not separable subspecifically; seclusus, therefore, is relegated to the synonomy of nerterus.

$R$. otus also is a synonym of nerterus. The type specimen is clearly an example of $R$. sumichrasti nerterus and not of $R$. fulvescens or of $R$. hirsutus, the species with which otus was compared by Howell (1914: 56). The type specimen and other examples from the lower edge of the pine zone on the Nevado (listed below as the foothills west of Ciudad Guzmán) are slightly paler than those from higher elevations in the fir-pine belt. The differences, however, are far from sufficient for formal subspecific recognition.

Specimens examined.-One hundred and forty from the following localities in México: Jalisco: El Nevado de Colima, foothills W of Ciudad Guzmán, 6500 ft., 10 (3 US); NE slopes, 7300 ft., 7; NE slopes, 7500 ft., 5; NW slopes, 8000 ft., 37; NW slopes, 9500 ft., 1; Sierra de Autlán, 7000 ft., 1; 9000 ft., 4. Michoacán: Cerro Tancítaro, $6000 \mathrm{ft}$., 5 (GM); $7800 \mathrm{ft}$., 10 (CM); NW slopes, 1 mi. N Apo, 7000 ft., 14; NW slopes, 31/2 mi. ENE Apo, 9000 ft., 6; undetermined elevation, 5 (CM); 8 mi. WNW Ciudad Hidalgo, 8000 ft., 2; 9 mi. WNW Ciudad Hidalgo, 8700 ft., 1; 10 mi. NW Ciudad Hidalgo, Cerro San Andrés, $9400 \mathrm{ft}$., 5; 10 mi. ESE Zitácuaro, Macho de Agua, 8000 ft., 2 (MVZ); 30 mi. E Morelia, 8500 ft., 3 (MVZ); Mil Cumbres, 9200 ft., 1; 31/2 mi. S-9 mi. SE Pátzcuaro, 7800-8000 ft., 18 (15 MVZ); 2 mi. W Pátzcuaro, 7700 ft., 1 (MVZ); Uruapan, 5300 ft., 2. 


\section{Reithrodontomys sumichrasti luteolus Howell}

Reithrodontomys rufescens luteolus Howell, 1914: 57.

Reithrodontomys alleni Howell, 1914: 59. México, Oaxaca, mountains near Ozolotepec, $10,000 \mathrm{ft}$.

Type.-Adult female, skin and skull; U. S. Nat. Mus. Biol. Surv. Coll. No. 71558; México, Oaxaca, Juquila, 5000 ft. elevation; collected 28 February 1895 by E. W. Nelson and E. A. Goldman; original No. 7579.

Distribution.-Sierra Madre del Sur of Guerrero and Oaxaca. Known range from Omilteme, Guerrero, east to the vicinity of Ozolotepec, Oaxaca. Known altudinal range from 5000 feet at Juquila to $10,000 \mathrm{ft}$. in the mountains near Ozolotepec.

HaBITAT.-Presumably similar to that for sumichrasti and nerterus, namely brushy and grassy areas in cloud forests and mesic oak-pine forests. A specimen from Omilteme was trapped under a pile of pine slash in an open pine forest.

Comparisons.-Compared with sumichrasti (topotypes of luteolus; topotypes of sumichrasti): Similar in size. Coloration brighter, nearer that of nerterus than that of sumichrasti. Upper parts more rufescent, ground color similar in the 2 forms (near Cinnamon), but that color less strongly intermixed with black on cheeks and sides in luteolus, those parts thus brighter and standing in stronger contrast to the blackish middorsal area. Underparts near Pinkish Cinnamon or Light Pinkish Cinnamon, but appearing slightly more brilliant than in sumichrasti. Brain case flattened dorsally and shallow posteriorly (more evenly convex in dorsal profile in sumichrasti).

Compared with nerterus (topotypes of luteolus; topotypes of nerterus): Similar in size. Coloration of dry season pelage similar, but ground color of upper parts a slightly deeper shade of Cinnamon (between Cinnamon and Sayal Brown); sides and cheeks as brightly colored as in nerterus; underparts similar. Pelage of wet season unknown. Zygomatic plate broader and zygomatic notch deeper, on the average. Brain case more flattened dorsally and shallower posteriorly.

REMARKs.-The dorsally flat and posteriorly shallow brain case constitutes the principal morphological basis for the recognition of luteolus. It is a weakly characterized form, and its traits cannot be appraised satisfactorily from the few specimens at hand. Present evidence indicates that $R$. alleni is a synonym of $R$. s. nerterus. In the type specimen, a skin and incomplete skull of an old male, the complex of characters peculiar to $R$. sumichrasti are evident; no qualities therein suggest a different species. Moreover, insofar as it is complete the skull resembles skulls of topotypes of luteolus, and the pelage coloration falls within the range of variation to be expected in luteolus.

Specimens examined.-Seventeen from the following localities in México: Guerrero: Omilteme, somewhere between 6000 and $8700 \mathrm{ft} ., 3$ (US); $3 \mathrm{mi}$. W 
Omilteme, $8200 \mathrm{ft}$., I (MVZ). Oaxaca: Juquila, $5000 \mathrm{ft}$, 12 (US); 3 mi. N Ozolotepec, La Cieneguía, 10,000 ft., 1 (US).

\section{Reithrodontomys sumichrasti dorsalis Merriam}

Reithrodontomys dorsalis Merriam, 1901: 557; Howell, 1914: 61; Goodwin, 1934: 36.

Trpe.-Adult male, skin and skull; U. S. Nat. Mus. Biol. Surv. Coll. No. 77009; Guatemala, Dept. Totonicapán, Calel; collected 14 January 1896 by E. W. Nelson and E. A. Goldman; original No. 9112.

Distribution.-Mountains of Chiapas and Guatemala. Known range from Pueblo Nuevo, Chiapas, southeast to the vicinity of Salamá and San Rafael, Guatemala. Vertical range from 4000 feet at Las Margaritas, Chiapas, to approximately 13,200 feet on Volcán Tajumulco, Guatemala.

HABITAT.-This form occurs in a wide variety of habitats in the subtropical and temperate highlands. It is found in open stands of grass and scrub oak on dry, rocky hillsides, in sparse cover in pine-oak forests, in brush and grass along streams and ponds, and in wet, lush growths in cloud forests. To judge from trapping records, it is most abundant in dense stands of grass, weeds, and brush, such as are found in abandoned fields or burned or cutover areas, and in moist situations in cloud forests and oak-pine forests. Specimens were collected in situations as follows: Among moss-covered boulders in a cutover, heavily-grazed pine and cypress forest; in a damp, dense growth of moss, grass, and woody perennials that formed the understory of a second-growth pine forest (Chemal). In dense, moist, ground cover in a cloud forest; in grassy openings and bracken jungles in a wet deciduous forest; in bunch grass at the edge of a wheat field in an open pine forest (Nebaj). In dry, shrubby growth; in a damp deciduous forest; and in a moist pine forest (Cotzal). In a grassy clearing in a cloud forest (Finca Montserrat). In a coffee grove (Yepocapa). In grass at the edge of a clearing in a cloud forest (La Jolla Grande). In lush, moist vegetation at the base of a cool, northwest-facing slope in the cloud forest belt; among ferns and rushes in an alder thicket along a stream (Chajul). In grass in a dry scrub-oak forest (Jocopilas). In sparse grass among oak scrub on a heavily grazed hillside (Salamá). Among brush and rocks in pastureland; in brush in a dry oak forest; in an oak cloud forest (San Cristóbal). In grass and brush along cornfields (Las Margaritas, Amatenango, and San Francisco Solano). In brush and grass under oaks, junipers, and pines; in hedges bordering a swampy pasture; in brush and grass bordering a river (Teopisca). In grass under junipers and oaks; in a thicket of Salvia at the border of a cornfield (San Rafael). Under a tangle of brush and vines in a pasture near a lake (San José).

Comparisons.-Compared with luteolus (specimens of dorsalis from southeastern Chiapas; specimens of luteolus from Juquila, Oaxaca): Averaging slightly smaller in body and skull size. Tail shorter (averages $85 \mathrm{~mm}$. in a 
series of 42 specimens of dorsalis and $101 \mathrm{~mm}$. in 6 specimens of luteolus). Coloration much more somber. Upper parts more blackish, the dorsal stripe distinct; ground color slightly more reddish in hue and deeper in tone (near Cinnamon or Sayal Brown). Underparts also duller, the hairs with a narrow distal band of Pinkish Buff or Pinkish Cinnamon which usually fails to obscure the broad Blackish Plumbeous basal band; pectoral area Cinnamon. (In luteolus, underparts bright Pinkish Cinnamon, the distal bands better obscuring the Blackish Plumbeous basal bands; pectoral area slightly more intense than remainder of underparts.) Brain case narrower and cranium relatively deeper than in luteolus; mesopterygoid fossa absolutely and relatively narrower.

Compared with sumichrasti (specimens of dorsalis from southeastern Chiapas: examples of sumichrasti from Acultzingo, Veracruz): Similar in size and coloration, the upper parts of dorsalis, however, blacker and with a more distinct dorsal stripe. Tail shorter (averages 115 per cent of head and body length in 42 specimens of dorsalis and 132 per cent in 24 specimens of sumichrasti). Molar teeth and hard palate smaller; crania of the 2 forms otherwise closely similar.

REMARKs.-The dark dorsal coloration is a principal diagnostic character of dorsalis, distinguishing it from all neighboring races of the species. The characters of dorsalis are best developed in the specimens from Chiapas and western Guatemala. In those from central Guatemala-from San Rafael, San Pedro Yepocapa, Sierra Santa Elena, and San Pedro Jocopilas-the upper parts average slightly paler, the brain case shallower, and the molar teeth smaller. In these features the specimens approach examples of modestus from El Salvador.

Howell (1914: 61) recognized that dorsalis and rufescens [= sumichrasti] were morphologically close, but he chose to treat them as separate species because in his material he saw no evidence that dorsalis intergrades with rufescens or luteolus. There is now ample evidence of intergradation, through individual variation, of dorsalis and sumichrasti; they can best be treated as conspecific. It is improbable that their populations are continuous at the present time. The low country of the Isthmus of Tehuantepec is a partial, if not complete, barrier to these highland forms.

Two specimens from Teopisca are unlike the remainder of the specimens of $R$. sumichrasti. They are pinkish gray (near Dark Mouse Gray or Deep Mouse Gray) dorsally and ventrally. The pelages resemble the gray color phase seen in some races of Peromyscus maniculatus. One is a breeding female and the other is a subadult male.

Specimens EXAmined.-Three hundred and fifty-seven from the following localities: Guatemala. Alta Verapaz: Cobán, 4500 ft., 5 (CM). Baja Verapaz: 6 mi. NE Salamá, 5400 ft., 3 (US). Chimaltenango: Volcán Acatenango, Finca 
Montserrat, 5700 ft., 1 (CM); San Pedro Yepocapa, 4800 ft., 2 (CM); 4 mi. E Yepocapa, La Jolla Grande, 5700 ft., 1 (CM); Sierra Santa Elena, 9500 ft., 2 (CM). El Quiché: 21/2 mi. SW Chajul, 6400 ft., 6 (US); 31/2 mi. NE Cotzal, 4600 ft., 6 (US); 3-4. mi. SE Nebaj, 8200 ft., 19 (US); 3 mi. NW San Pedro Jocopilas, $7200 \mathrm{ft}$., 7 (US). Huehuetenango: Chemal, 10,500-11,000 ft., 8 (US); Hacienda Chancol, somewhere between 9000 and 11,000 ft., 29 (US); 'Todos Santos, 10,000 ft., 10 (US). Quezaltenango: Volcán Santa Maria, between 9000 and 11,000 ft., 4 (US); Zunil, 7000 ft., 3 (US). Sacatapéquez: Finca San Rafael, 6900 ft., 8 (CM). San Marcos: Volcán Tajumulco, 10,400-13,200 ft., 3 (CM). Totonicapán: Calel, 10,800 ft., 22 (US).

México. Chiapas: Amatenango, $5200 \mathrm{ft}$., 24; Canjob, somewhere between 5300 and $6500 \mathrm{ft}$., 2 (US); vicinity of Comitán, $5200 \mathrm{ft}$., 27 (US); mts. $21 \mathrm{mi}$. NW Comitán, 8000 ft., 4 (US); Las Margaritas, 4000 ft., 9; Pinabete, somewhere between 7500 and $8800 \mathrm{ft}$., 8 (US); Pueblo Nuevo, $5500 \mathrm{ft}$., 2; San Cristóbal, 7000 ft., 17; near San Cristóbal, somewhere between 8000 and 9500 ft., 5 (US); 6 mi. SE San Cristóbal, 7300 ft., 4 (MVZ); San. Francisco Solano, 5000 ft., 23; San Gregorio, 6500 ft., 1 (CM); 28 mi. ESE Comitán, San José, 4900 ft., 1 (MVZ); San Rafael, 5000 ft., 21; Tenejapa, 7800 ft., 2 (US); Teopisca, $5500 \mathrm{ft}$. and $6700 \mathrm{ft}$., 35 (6 US); Tumbalá, 5000-5500 ft., 33 (US).

\section{Reithrodontomys sumichrasti modestus Thomas}

Reithrodontomys modestus Thomas, 1907: 163; Allen, 1908: 654; 1910: 98.

Reithrodontomys australis modestus, Howell, 1914: 63.

Reithrodontomys dorsalis underwoodi Goodwin, 1937: 2. Honduras, Dept. Ocotepeque, Monte Verde, 4500 feet.

Reithrodontomys australis underwoodi, Goodwin, 1942: 158.

Type.-Adult male; British Museum; Nicaragua, Prov. Jinotega, near Jinotega, elevation 4650 feet; collected 20 January 1906 by M. G. Palmer; original No. 29.

Distribution.-Interior highlands of El Salvador, Honduras, and northwestern Nicaragua. Known range from Los Esesmiles, El Salvador, and Monte Verde, Honduras, east to the vicinity of Jinotega and San Rafael del Norte, Nicaragua. Vertical range from 4500 feet at Monte Verde to 8000 feet on Los Esesmiles.

Habitat.-Brush and grass in oak-pine and cloud forests. The specimens from Cerro Uyuca were collected in guatál (an abandoned field grown to blackberry and other shrubbery) situated between a cloud forest and a pine forest; the specimens were trapped about 100 yards below the cloud forest. On Los Esesmiles the species was common in the oak and pine zone up to the edge of cloud forests; notes on specimen tags indicate places of capture as follows: In brush on the banks of a stream; in grass in a pine forest; under roots of a tree on a stream bank; in a brushy ravine between grassy slopes; in a ravine in a wheat field; and at the edge of a cloud forest. 
Comparisons.-Compared with doralis (specimens of modestus from Los Esesmiles; examples of dorsalis from southeastern Chiapas): Similar in size. Coloration brighter dorsally and ventrally owing to a slightly paler and more pinkish ground color (near Pinkish Cinnamon rather than between Cinnamon and Sayal Brown as in dorsalis) and a less heavy overlay of black; dorsal stripe narrower and less blackish. Underparts varying in color, as in other races of sumichrasti; in most specimens of modestus entire underparts bright Pinkish Cinnamon, that color concentrated in the pectoral area (in most specimens of dorsalis the pectoral area is Cinnamon and the remaining underparts are Light Pinkish Cinnamon or Pinkish Buff). Auditory bullae and molar teeth absolutely and relatively smaller; cranium shallower and more flattened dorsally (as seen in dorsal profile).

REMARKs.-The shallow cranium, small molar teeth, and small auditory bullae are the principal diagnostic characters of modestus. These features are seen in all series of specimens examined from El Salvador and Honduras. They also obtain in the examples from Nicaragua, insofar as they can be seen in that material, which is poorly preserved and fragmentary. In the series from those 3 countries the color of the pelage averages brighter (less blackish) and more pinkish than in the samples of the species from Guatemala, Chiapas, Costa Rica, and Panamá. The specimens from El Salvador are the brightest of the lot. They stand in greatest contrast to specimens of dorsalis from Chiapas and western Guatemala, where the characters of that race apparently are best developed.

Present material permits the recognition of only one geographic race of R. sumichrasti in Honduras, El Salvador, and Nicaragua. There are at hand topotypes of underwoodi and specimens from a locality about 15 miles southeast of the type locality of modestus; for purposes of comparison the latter may be considered to be topotypes. Relying on those topotypes and on the original description of each of the forms, I find no characters that indicate that modestus and underwoodi are subspecifically separable. The characters fall within the range of variation established by the large series of specimens from Los Esesmiles, El Salvador. There are cranial and external features, the former more clearly defined than the latter, common to all series from the 3 countries. There is no good reason to assume that they represent more than one recognizable race. Accordingly, underwoodi should be relegated to the synonymy of modestus, the older applicable name.

One locality record listed below is questionable. The specimen listed from Savala, Nicaragua, probably was not collected at Savala if that locality lies in the Atlantic lowlands as indicated by Allen (1910). I have not located Savala.

SPECIMENS EXAMINED.-One hundred and thirty from the following localities: El Salvador. Chalatenango: Los Esesmiles, 6200-8000 ft., 92 (MVZ). 
Honduras. La Paz: Humuya [= Muya, 4000 ft. ?], 20 (AM). Lempira: Cementerio, $5300 \mathrm{ft}$., 1 (AM). Francisco Morazán: Cerro Uyuca, $6100 \mathrm{ft} ., 3$. Ocotepeque: Monte Verde, $4500 \mathrm{ft} ., 3$ (AM). Nicaragua. Jinotega: near San Rafael del Norte, about 5000 ft., 10 (AM). Savala (?), 1 (AM).

\section{Reithrodontomys sumichrasti australis Allen}

Reithrodontomys australis Allen, 1895b: 328; 1904: 45.

Reithrodontomys australis australis, Howell, 1914: 62; Goodwin, 1946: 383.

Type.-Adult; Amer. Mus. Nat. Hist. No. $\frac{11291}{9555}$; Costa Rica, Prov. Cartago, El Volcán de Irazú; collected in June, 1892, by George K. Cherrie.

Distribution.-The Cordillera Central and Cordillera de Talamanca in Costa Rica. Known range confined to El Volcán de Irazú and to other mountains near San José, Costa Rica.

Habitat.-Presumably similar to that for dorsalis.

Comparisons.-Compared with modestus (specimens of australis from El Volcán de Irazú; examples of modestus from Los Esesmiles): Similar in size. Tail shorter; on the average scarcely longer than head and body in australis (its length about 120 per cent of that of head and body in modestus). Coloration somber, the upper parts of adults a mixture of black and Pinkish Cinnamon, the former making a distinct blackish stripe; underparts Light Pinkish Cinnamon becoming Pinkish Cinnamon in the pectoral area. Upper parts of subadults much darker in australis than in modestus, the black predominant; color of midback near Fuscous or Fuscous-Black. (In both adults and subadults of modestus the buffy hues rather than black are predominant both ventrally and dorsally; the pelage of modestus is therefore markedly brighter.) Crania closely similar, but palate and auditory bullae smaller in australis and zygomatic plate narrower.

REMarks.-The specimens of $R$. sumichrasti from Costa Rica are separable from those from Honduras and El Salvador in coloration, tail length, length of palate, and size of bullae. They are distinguished from Panamá specimens in tail length, breadth of rostrum, length of palate, and size of molar teeth. The sample from Costa Rica, however, is small. Because the species $R$. sumichrasti is so variable individually, little confidence can be placed in estimates derived from small samples. As now understood vulcanius is quite distinct from modestus. Australis is less distinct from either of those forms, yet its characters, as now observed, are not entirely intermediate between vulcanius and modestus. It is for this reason that 2 southern races of sumichrasti are here recognized. Larger samples, especially from Costa Rica, may indicate that there is only one recognizable race in Costa Rica and Panamá.

SPEcimens EXAMINED.-Nineteen from the following localities in Costa Rica: Cartago, slopes of El Volcán de Irazú, 18 (17 US, l CM). San José, Altos Escazú, 4000 ft., 1 (CM). 


\section{Reithrodontomys sumichrasti vulcanius Bangs}

Reithrodontomys australis, Bangs, 1902: 37.

Reithrodontomys australis vulcanius Bangs, 1902: 38.

Reithrodontomys australis australis, Howell, 1914: 62 (part); Goldman, 1920: 84.

TYPe.-Adult male, skin and skull; Mus. Comp. Zool. No. 10281; Panamá, Prov. Chiriquí, summit of El Volcán de Chiriquí, elevation 11,300 ft.; collected 26 May 1901 by W. W. Brown, Jr.

Distribution.-High mountains of western Panamá and probably of extreme eastern Costa Rica. Known only from the vicinity of the Volcán de Chiriquí, from 4400 feet in open grassland on the flanks of the Volcán to about 11,400 feet on the summit.

Habitat.-Most of the specimens examined were collected in grass, occurring as open llanos, on rocky slopes, or in a dry stream bed. Four specimens were trapped at the edge of a pond.

Comparisons.-Compared with australis (topotypes of vulcanius; topotypes of australis): Similar in body size. Tail apparently relatively longer (averages 121 per cent of head and body length in 18 topotypes of vulcanius; its length about equal to that of head and body in 9 topotypes of australis at hand and in another series of topotypes mentioned by Goodwin, 1946: 383). More black on upper parts, and subterminal bands of cover hairs of head and shoulders slightly paler (but see Remarks below). Cranium slightly larger on the average, with relatively greater values for interorbital breadth (40 per cent of cranial depth in vulcanius, 37 per cent in australis), breadth of rostrum, zygomatic plate, mesopterygoid fossa, and length of palate (respectively 40 and 38 per cent of depth of cranium in vulcanius and australis); molar teeth broader and longer; incisive foramina broadest near their middle rather than posteriorly as in australis.

Remarks.-The specimens from Panamá and Costa Rica are readily separable and indicate that the populations of the 2 areas are subspecifically distinct. The characters that justify here the recognition of vulcanius are principally those of the skull. There are differences, too, in color of pelage of the 2 series, but these may be partly or entirely seasonal differences. The pelages. are not strictly comparable. The specimens from Panamá were collected in. July and August. Those from Costa Rica represent January and February. $R$. s. vulcanius is known only from western Panamá; however, it probably ranges into the Cordillera de Talamanca of Costa Rica and intergrades with. R. s. australis.

Specimens examined.-Thirty-eight from the vicinity of Volcán de Chiriquí, 5000-11,000 ft., Chiriquí, Panamá (PM).

\section{Reithrodontomys chrysopsis}

(Maps 4, 12; Pls. II-V; Figs. 9, 14-16)

In size of body and skull $R$. chrysopsis is the largest species of the subgenurs 
Reithrodontomys. It inhabits the high mountains of central México. Its total range is small and highly discontinuous; it corresponds rather closely to that of the fir Abies religiosa (Martinez, 1948: 59), although $R$. chrysopsis has not yet been taken in the fir forests of Guerrero or of eastern Hidalgo. All situations from which it is now known are cool and moist and are 9000 feet or more above sea level. Externally and cranially it varies little from place to place, thus giving scant morphological evidence of the great insularity of its populations. Two geographic races are here recognized.

Distribution.-The high mountains of central México, from the Volcán de Orizaba and Cofre de Perote, Puebla and Veracruz, west to the Nevado

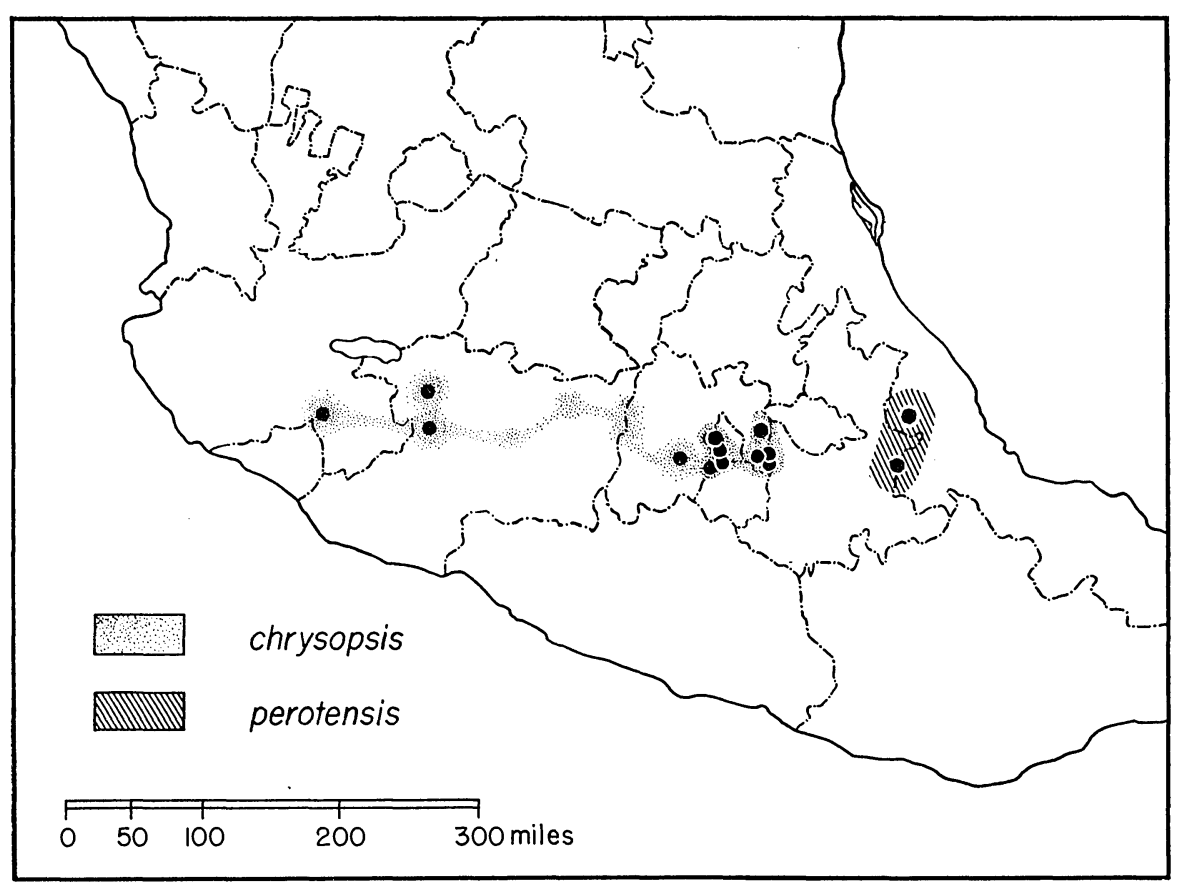

MaP 4. Distribution of the subspecies of Reithrodontomys chrysopsis, as determined from specimens examined.

de Colima, Jalisco. The lowest record of occurrence is 9300 feet at San Mateo near Mexico City. Most of the records are for altitudes above 9500 feet; 12,200 feet, near timber line, on the Volcán de Toluca is the highest recorded occurrence.

Habitat.-The species appears to have a narrow tolerance. It has been taken in few ecological situations, all generally similar. Its ecological requirements certainly do not encompass the broad range of environmental conditions obtaining for fulvescens, megalotis, and other widely ranging species. It 
is associated with fir forests (Abies religiosa) and with sacatón. It may be scansorial in habit.

Comparisons.-In size of body, hind foot, cranium, and molar teeth $R$. chrysopsis resembles $R$. hirsutus, $R$. mexicanus cherriei, and $R$. m. mexicanus (see measurements). It is smaller than creper and tenuirostris. The tail is longer than head and body and it is paler ventrally than dorsally in juveniles and subadults; in adults it is usually sharply bicolored and well covered with hair. Pelage is long and soft, cover hairs of rump being 8-10 mm. in length. In general, chrysopsis resembles tenuirostris in coloration. Most of the variations in pelage coloration appear to be correlated with age and season. In juveniles and subadults upper parts are blackish brown. Underparts are dark plumbeous, the tips of the hairs pale cinnamon; they do not completely obscure the plumbeous basal bands. In adults upper parts are a mixture of cinnamon and black; black is predominant in both fresh and well-worn pelages; cinnamon is the dominant color in moderately worn pelages. Underparts of adults are rufescent. A black eye ring usually is present. The epidermis of the ears is fuscous or black; it is sparsely or well covered with long hairs, each of which is entirely black. Upper surfaces of feet are entirely white or white peripherally and dusky medially.

The characters of Aporodon distinguish chrysopsis from all species of that subgenus. Within the subgenus Reithrodontomys, chrysopsis is most likely to be confused with $R$. sumichrasti. Although chrysopsis averages larger than sumichrasti, some individuals of one or the other of those species cannot be identified by size alone (Figs. 14, 15). In Table I are tabulated some of the contrasting features of the 2 species, as observed in specimens from México.

Relationships.-Morphologically $R$. chrysopsis belongs with $R$. megalotis, $R$. rufescens, and the other species of the subgenus Reithrodontomys rather than with species of Aporodon where Howell (1914) placed it. Externally it resembles tenuirostris and microdon, 2 species of Aporodon that live, as does chrysopsis, in comparatively cool, moist, forested areas at high altitudes. Those morphological similarities, however, probably are parallel responses to similar environments because the skulls of chrysopsis on the one hand and tenuirostris and microdon on the other are greatly different. In general appearance and in the several precise features that, by virtue of constancy among several species, characterize natural supraspecific groups in Reithrodontomys, the skull of chrysopsis must be placed with megalotis and the other species of the typical subgenus. That of tenuirostris and microdon belongs with mexicanus and the other species of Aporodon. R. chrysopsis is one of the more specialized kinds in the subgenus, just as are tenuirostris and microdon in Aporodon. It has a narrow ecologic range; the places where it lives are strikingly similar throughout its known geographic range, which is small compared with that of other species of the subgenus. Its large body and large skull, 
TABLE I

External and Cranial Characteristics of Reithrodontomys chrysopsis and $R$. sumichrasti in CENTRaL MÉXICo

\begin{tabular}{|c|c|c|}
\hline & chrysopsis & sumichrasti \\
\hline Hind foot. & $\begin{array}{l}\text { 20-22 mm.; dusky and } \\
\text { whitish }\end{array}$ & $\begin{array}{l}\text { 19-21 mm.; buffy, uncommonly } \\
\text { dusky }\end{array}$ \\
\hline Length of skull........ & $\begin{array}{l}23.0-25.3 \mathrm{~mm} . \\
\text { (see Fig. } 14 \text { ) }\end{array}$ & $\begin{array}{l}21.4-24.7 \mathrm{~mm} . \\
\text { (see Fig. } 14 \text { ) }\end{array}$ \\
\hline Zygomatic breadth.... & $11.5-12.8 \mathrm{~mm}$. & $10.8-12.3 \mathrm{~mm}$. \\
\hline Tail. & $\begin{array}{l}\text { Shorter (see Fig. 15); } \\
\text { hairs long; sharply bicolor }\end{array}$ & $\begin{array}{l}\text { Longer (see Fig. 15); hairs shorter; } \\
\text { indistinctly bicolor or monocolor }\end{array}$ \\
\hline Pinnae... & $\begin{array}{l}\text { Hairs of inner surface en- } \\
\text { tirely black }\end{array}$ & $\begin{array}{l}\text { Some, usually many, hairs of } \\
\text { inner surface cinnamon colored } \\
\text { (either entirely cinnamon or } \\
\text { banded cinnamon and black) }\end{array}$ \\
\hline Auditory bullae...... & Large & Smaller \\
\hline Zygomatic notch. & Moderate & Anteroposteriorly shallow \\
\hline Brain case.. & Broad & Narrower \\
\hline Interorbital diameter. & Relatively small & Relatively large \\
\hline Rostrum. & Narrow & Broader \\
\hline Teeth. & $\begin{array}{l}\text { Mesolophs (short or reach- } \\
\text { ing labial border of tooth) } \\
\text { always present in } \mathrm{M}^{1-2} \text {; } \\
\text { posterior border of para- } \\
\text { cone of } \mathrm{M}^{1} \text { and/or } \mathrm{M}^{2} \\
\text { evenly round }\end{array}$ & $\begin{array}{l}\text { Mesolophs usually short or absent; } \\
\text { posterior border of paracone of } \\
\mathrm{M}^{1} \text { and/or } \mathrm{M}^{2} \text { sometimes evenly } \\
\text { rounded, but often (in } 70 \text { per } \\
\text { cent of specimens) keeled and } \\
\text { fused with the mesostyle }\end{array}$ \\
\hline
\end{tabular}

with large brain case and long, narrow rostrum, and its high-crowned teeth with deep mesolophs and usually well-developed mesostyles in $\mathrm{M}^{1-2}$ in my opinion are specializations in the subgenus.

\section{Reithrodontomys chrysopsis chrysopsis Merriam}

Reithrodontomys chrysopsis Merriam, 1900: 152.

Reithrodontomys tolucae Merriam, 1901: 549. México, México, El Volcán de Toluca, 11,500 feet.

Reithrodontomys colimae Merriam, 1901: 551. México, Jalisco, El Nevado de Colima, 12,000 feet.

Reithrodontomys chrysopsis colimae, Howell, 1914: 59.

Reithrodontomys chrysopsis tolucae, Howell, 1914: 68.

Reithrodontomys chrysopsis chrysopsis, Howell, 1914: 66; Davis, 1944: 393; Hooper, 1947: 49; Hall and Villa, 1949c: 459; 1950: 194.

Reithrodontomys chrysopsis seclusus Hall and Villa, 1949a: 164 (part); 1949b: 175 (part); 1949c: 459 (part); 1950: 195 (part).

TyPe.-Adult male, skin and skull; U. S. Nat. Mus. Biol. Surv. Coll. No. 
52031; México, Volcán Popocatépetl, 11,500 feet elevation; collected 25 February 1893 by E. W. Nelson and E. A. Goldman; original No. 4405.

Distribution.-High mountains of central México in the states of Puebla, México, Michoacán, Morelos, and Jalisco. Known range from Volcán Popocatépetl, Monte Río Frío, and other mountains bounding the Valley of Mexico west, interruptedly, to El Nevado de Colima, extreme southeastern Jalisco. Known vertical range from 9300 feet at San Mateo, near Mexico City, to about 12,200 feet on Volcán de Toluca.

HABITAT.-Cool, shaded, and comparatively moist canyons and slopes that are dominated by fir or short-needled pine forests and frequently are enshrouded in clouds. In Cañón Contreras all specimens were trapped within or adjoining stands of fir and other trees on the steep, north-facing slope of the canyon. Places of capture of a few of those specimens follow: In a tubular runway through moss on the side of a rotten log in a brushy clearing; among moss, ferns, brush, small firs, and clumps of bunch grass; on a moss-covered rock shelf ( $5 \mathrm{ft}$. above ground) at the base of a cliff; in herbaceous cover at the foot of a fir ( $1 \mathrm{ft}$. diameter); among herbs, moss, and logs on the banks of a small creek; in brush (Baccharis, Salvia, and other shrubs) at the base of a cliff. Specimens from other localities were obtained in situations as follows: In the vicinity of La Cima and Kilometer 46 on the México-Cuernavaca highway the species was fairly common on the sacatón-covered plains and on adjoining rock hillsides that were covered with a mixed growth of short-needle pine, oak, and madrone, with an understory of sacatón and brush. On Volcán de Toluca 2 specimens were trapped in a second-growth fir forest; 3 were found in sacatón near a spring in an open pine forest above the fir zone on the mountain. On El Nevado de Colima one was trapped in a lush growth of moss, ferns, grass, herbs, and shrubs in the moist bottom of a cool, narrow canyon; 2 specimens were obtained under treelike Solanum that bordered a sacatón-covered clearing in an alder forest (trees up to 3 feet in diameter and 50-75 feet in height).

Characters.-Size: Large; head and body of all subadults and adults examined over $70 \mathrm{~mm}$., the average over $80 \mathrm{~mm}$; hind foot length 20-22 mm.; range in length of molar row $3.5-3.9 \mathrm{~mm}$. Ears large, $17-21 \mathrm{~mm}$. from notch, measured when fresh. Tail moderate in length, about 25 per cent longer than head and body.

Color: Fresh adult pelage of dry season (February specimens from Distrito Federal): Upper parts a mixture of bright orange buffy and black, the black predominant on back and muzzle, the buffy purest on sides; ground color slightly more vivid than Cinnamon, individual cover hairs Blackish Plumbeous for about $4 / 5$ their length and Cinnamon for the apical $1 / 5$; guard hairs (providing the black overlay) Blackish Plumbeous for their basal half, black in medial fourth, and silvery apically. Underparts between Pinkish 
Cinnamon and Light Pinkish Cinnamon, that color restricted to the terminal fourth of the hairs, the basal part Blackish Plumbeous. Black ring around eye. Ears glossy black, all hairs entirely black; the underlying epidermis Fuscous. Ankles Fuscous. Upper surfaces of forefeet and hind feet usually Fuscous medially, rimmed with white, rarely entirely white. Toes white. Tail sharply bicolor, Fuscous-Black dorsally and silvery ventrally or only slightly paler ventrally than dorsally. Worn adult pelage of dry season (May specimen from Volcán Popocatépetl): As described above, but head and back duller (the distal bands of the hairs worn away exposing the plumbeous basal band); ears Fuscous, hairs shorter and not so intensely black; and hind feet paler. Fresh adult pelage of wet season (June specimen from Distrito Federal): As described for fresh adult pelage of dry season except for differences as follows: Upper parts blackish, ground color similar, but black overlay much greater on head, back, and sides and forming a broad black dorsal stripe that extends from muzzle to base of tail. Underparts Light Pinkish Cinnamon. Upper surface of hind feet whitish with a few Fuscous hairs on mid-line. Fresh subadult pelage of wet season (July specimen from Cerro Tancítaro, Michoacán): Distinctly less brightly colored dorsally than adult pelages; ground color paler in tint and slightly more buffy (near Pinkish Cinnamon, or between that and Cinnamon-Buff); black overlay greater. Underparts similar to those of adults, but Pinkish Cinnamon tips of the hairs not obscuring Blackish Plumbeous basal parts; the plumbeous shows through. Upper surfaces of forefeet white, of hind feet Fuscous; toes white. Tail Fuscous dorsally, scarcely paler ventrally.

Skull: Brain case large (see measurements) and oval in shape, markedly less elongate than in tenuirostris, mexicanus, and hirsutus. Frontal bones small and strongly constricted interorbitally; here there is particular contrast with all species of Aporodon and with sumichrasti, fulvescens, hirsutus, and humulis in Reithrodontomys (see Pls. II, IV, and measurements of interorbital constriction). Rostrum long and moderate in breadth, much broader than the interorbital constriction. Zygomatic notch moderate in size, about as in $R$. fulvescens; deeper (anteroposteriorly) than in the species of Aporodon, also deeper than in sumichrasti of Reithrodontomys but shallower than in megalotis. Incisive foramina long (about equally narrowed posteriorly and anteriorly). Posterior palatine foramina long narrow slits. Sphenopalatine vacuities well developed, crescent-shaped and about as broad as is $\mathrm{M}^{2}$. Auditory bullae moderately large, about the size of the bullae in $R$. megalotis, thus relatively smaller in chrysopsis; much larger than in the species of Aporodon. Pterygoid fossae large, each much broader than the mesopterygoid fossa. Molars high-crowned. Mesolophs present in $\mathrm{M}^{1-2}$ but variable in height and length; no mesolophids; ectolophids often present. $\mathrm{M} \frac{3}{3}$ as in the other species of the subgenus Reithrodontomys. 
REMARks.-There is no sound reason for the recognition of colimae and tolucae. Topotypes of each fall well within the range of variation obtaining in the series from the neighborhood of the type locality of chrysopsis. The small size, small brain case, short rostrum, and other characters ascribed to colimae are based on 2 skins and a single skull of a young adult; both are examples of the species $R$. chrysopsis. The 3 older topotypes at hand are not smaller than topotypes (of comparable age) of chrysopsis, as the original specimens of colimae were reported to be (Howell, 1914). Instead, they average slightly greater in skull length, cranial breadth, and rostral length and breadth. In the small sample at hand these slight differences cannot be interpreted safely as differential characters of populations. The characters ascribed to tolucae, principally those of coloration, are founded on a single subadult specimen in worn pelage. The 5 topotypes now at hand cannot be separated externally or cranially from the series of chrysopsis from the vicinity of Mexico City and Volcán Popocatépetl.

Two species, chrysopsis and sumichrasti, are represented in the series from Cerro Tancitaro that is the basis for the description of seclusus Hall and Villa. Two specimens are chrysopsis. The type and the remaining 19 individuals are examples of sumichrasti (see accounts of $R$. sumichrasti).

Specimens EXAmined.-Sixty-nine from the following localities in México: Distrito Federal: Ajusco, 11,000 ft., 3 (US); Cañón Contreras, 9300-10,400 ft., 12; La Venta, 10,200 ft., 1 (CM); San Mateo, 9300 ft., 1; Santa Rosa, 9500 ft., 1. México: 8 mi. ESE Amecameca, 11,500 ft., 1 (KU); 28 mi. ESE Mexico City, Monte Río Frío, 10,500 ft., 1 (KU); 19 mi. E Amecameca, Paso Cortés, 11,300 ft., 1 (KU); Salazar, 9000 ft., 1 (US); Volcán Ixtaccíhuatl, 13,500 ft., 1 (US); Volcán Popocatépetl, 11,500-13,500 ft., 5 (2 MVZ, 3 US); W and SW slopes El Volcán de Toluca, 11,400-12,200 ft., 6 (2 MVZ, 1 US). Morelos: near Huitzilac, 10,000 ft., 1 (US); Km. 46, Mexico City-Acapulco highway, 10,000 ft., 9. Michoacán: Cerro Patambán, 11,000 ft., 8 (US); Cerro Tancítaro, 10,00012,000 ft., 9 (2 CM, 7 US). Jalisco: N and NW slopes El Nevado de Colima, 9500-12,000 ft., 5 (2 US).

\section{Reithrodontomys chrysopsis perotensis Merriam}

Reithrodontomys perotensis Merriam, 1901: 550; Howell, 1914: 69.

Reithrodontomys orizabae Merriam, 1901: 550. México, Puebla, El Volcán de Orizaba, 9500 feet.

Reithrodontomys chrysopsis orizabae, Howell, 1914: 69.

Reithrodontomys chrysopsis perotensis, Davis, 1944: 393.

Type.-Adult male, skin and skull; U. S. Nat. Mus. Biol. Surv. Coll. No. 54424; México, Veracruz, Cofre de Perote, 9500 feet elevation; collected 21 May 1893 by E. W. Nelson and E. A. Goldman; original No. 4912.

Distribution.-Known only from elevations above 9500 feet on the Cofre de Perote, Veracruz, and the Volcán de Orizaba, Veracruz and Puebla. 
Habitat.-Similar to that for $R$. c. chrysopsis. A specimen now in the Museum of Zoology of the University of Michigan was trapped among mosscovered boulders in a dense stand of second-growth fir on Cofre de Perote. Four specimens recorded by Davis (1944: 394) from the Cofre and the Volcán de Orizaba were taken in sacatón.

Comparisons.-Compared with chrysopsis (specimens of perotensis from the Cofre de Perote; specimens of chrysopsis from Cañón Contreras, Distrito Federal): Essentially a small replica of chrysopsis (see measurements). Tail possibly relatively longer; its length averages 136 per cent of that of head and body in the 7 known specimens of perotensis (including 4 listed by Davis, 1944: 393) and 118 per cent in 22 specimens of chrysopsis. Similar in coloration and in most cranial proportions, but auditory bullae smaller.

REMARKs.-The present estimates of the morphological characteristics of perotensis are based on exceedingly small samples and therefore are inconclusive. As now understood perotensis is distinguishable from chrysopsis in size of body and skull, in tail length, and in size of auditory bullae. It resembles $R$. sumichrasti, which lives at lower elevations in the same mountains, in size and coloration. But in sumichrasti the fur is shorter; there are ochraceous hairs on the inner faces of the pinnae; the rostrum, interorbital space, and mesopterygoid fossa are broader (the pterygoid fossae, thus, are smaller). Also, in sumichrasti of Veracruz there are no well-defined mesolophs in $\mathrm{M}^{1-2}$ and the posterolateral border of the paracone of $\mathrm{M}^{1-2}$ is often dorsoventrally keeled and fused with the mesostyle. In perotensis there are mesolophs in $\mathrm{M}^{1-2}$, and the posterior face of the paracone is evenly convex.

In the specimens available to him, Davis (1944: 393) found no satisfactory basis for the recognition of both orizabae and perotensis. He also pointed out that there are no obvious ecological or physical barriers interposed between the type localities of those 2 nominal forms. In the specimens at hand I find no differences that signify that 2 races are represented. Therefore, I agree with Davis that orizabae should be relegated to the synonymy of perotensis which has priority.

Specimens examined.-Three from the following localities in México: Puebla: El Volcán de Orizaba, 9500 ft., 1 (US). Veracruz: Cofre de Perote, 9500 ft., 1 (US); $N$ slope Cofre de Perote, Los Conejos, 10,600 ft., 1.

Reithrodontomys fulvescens

(Maps 5, 12; Pls. II-VII; Figs. 4, 5, 16, 18, 24)

Reithrodontomys fulvescens is a well-differentiated species of the subgenus Reithrodontomys. Its closest relative appears to be $R$. hirsutus, and the 2 kinds are here considered to comprise the fulvescens group. That group differs from other groups in characters of the molar teeth; the topographic patterns of the third molars are especially diagnostic. The species has an extensive 
geographic range which centers in México, but extends into the south-central United States and into northern Central America (Map 5). It is geographically variable; 15 subspecies are here recognized.

Distribution.-South-central and southwestern United States south to Honduras, but principally or entirely excluding: the desert proper of northwestern Sonora, Arizona, and north-central México; the humid tropical lowlands of southeastern México, northern Guatemala, and northern Honduras; and the lowlands of southern Chiapas, Guatemala, El Salvador, and Honduras. Marginal occurrences in the northern part of the range are in western Mississippi, extreme southern Missouri, southeastern Kansas, central Oklahoma, central and southwestern Texas, and southern Arizona. The vicinity of Tegucigalpa, Honduras, is the southern limit as now known. Like R. megalotis the species has a broad altitudinal range. It is known from many localities near sea level in south-central United States and on both coasts of México. The highest known record of occurrence is 8500 feet, in Cañon Contreras, near Mexico City.

Haвiтat.-The species inhabits both temperate and tropical climates. In Central America it is known from arid interior valleys where the temperatures are high, the soil typically sandy and rocky, and where cactus, thorny shrubs, and grass are conspicuous in the flora. In central México it occurs in warm, moderately humid lowlands, dominated by tropical deciduous vegetation and savannas; in moist, tropical evergreen forests of the rainy slopes of the Sierra Madre; on the dry cactus- and mesquite-studded interior plateau; and locally in the cool coniferal belts of the mountains. In northern México and southwestern United States it occurs principally in brush-covered areas and on mesquite-dotted grasslands. In south-central United States it is found in weedy fields, along fence rows, and in prairies lying in or at the edge of broadleaf or coniferal forests. Although its range encompasses a broad span of environmental conditions, fulvescens occurs predominantly in regions where there is a pronounced dry season. Over much of its range it is found with mesquite (Prosopis), prickly pear cactus (Opuntia), and various species of grasses. Where their ranges coincide, mesquite may be considered a plant indicator for fulvescens.

Comparisons.-Characters of $\mathrm{M} \frac{3}{3}$ distinguish fulvescens from all other species of the subgenus Reithrodontomys except hirsutus. In $\mathrm{M}^{3}$ of fulvescens and hirsutus there are 3 prominent enamel folds: major, first primary, and second primary (Figs. 4, 24). The first and second primary folds are about equal in length; each extends labially about halfway across the tooth. The first is sometimes confluent with the major fold, the 2 thus separating the protocone and anterior cingulum from the remainder of the tooth. Until it is entirely eroded the major fold is continuous with the margin of the tooth. The primary folds, however, become separated from the margin as enamel 
islands of approximately equal size. In the other species of the subgenus, the major fold is but a shallow indentation on the labial side of the tooth, and the first primary fold is much shorter than the second. With erosion of the tooth the major fold quickly disappears and the 2 primary folds become enamel islands of unequal size (Fig. 24). The anterior island (first primary fold) is much smaller than the posterior island and disappears after moderate wear. The posterior island persists for much of the life of the tooth.

In $\mathrm{M}_{3}$ of fulvescens and hirsutus the major and the first primary folds are the conspicuous folds (Figs. 5, 24). They are nearly equal in length, each extending about halfway across the tooth. Both retain connection with the margin of the tooth and persist to a late stage of wear. In the other species of the subgenus the first primary fold is the only conspicuous fold. The major and other folds are usually short and indistinct. Wear of the tooth results in one large central enamel island, the remnant of the first primary fold.

$R$. hirsutus is larger than $R$. fulvescens (hind foot length $20-22 \mathrm{~mm}$., head and body length over $75 \mathrm{~mm}$.); its skull is much larger (see measurements, particularly of zygomatic breadth, interorbital breadth, and length of skull); the zygomatic plate is relatively narrower; the rostrum is relatively shorter and broader. In hirsutus there apparently are always mesolophs in $\mathbf{M}^{1-2}$; they are present or absent in $\mathrm{M}^{3}$. In fulvescens they are often lacking in $\mathrm{M}^{1-2}$ (Fig. 16) and insofar as is known are always absent in $\mathrm{M}^{3}$. The race of fulvescens that occurs in the areas inhabited by hirsutus resembles hirsutus in pelage coloration. The tail of hirsutus, however, is usually monocolored, while that of fulvescens is distinctly paler ventrally than dorsally.

The 15 subspecies of $R$. fulvescens are moderate to small (in the genus) in size of body and cranium. Head and body length varies from about $65 \mathrm{~mm}$. in amoenus to $80 \mathrm{~mm}$. in toltecus, and average length of skull varies from approximately $20 \mathrm{~mm}$. to $23 \mathrm{~mm}$., respectively, in those subspecies. The tail is from 10 to 50 per cent longer than the head and body. The pelage is coarse in texture in comparison with most other species of the genus. The upper parts have a peculiar "streaked" or "salt-and-pepper" aspect which defies lucid description but which is nevertheless real. A similar quality is observable in $R$. gracilis and Oryzomys fulvescens. Apparently the quality results from the contrast of the black guard hairs and the paler, banded cover hairs. It is less apparent in the intensely pigmented races, difficilis and aurantius for example. The subterminal bands of the cover hairs, which provide the ground color of the upper parts, are a blend of red and buffy (near Pinkish Cinnamon). Pelage coloration is geographically variable. In humid areas the upper parts are a mixture of black and reddish brown, the pinnae are dark externally and internally, and the underparts are buffy. In arid environments the upper parts are pale buff, the ears drab externally and clothed with buffy hairs internally, and the underparts are pale buff or whitish. A 


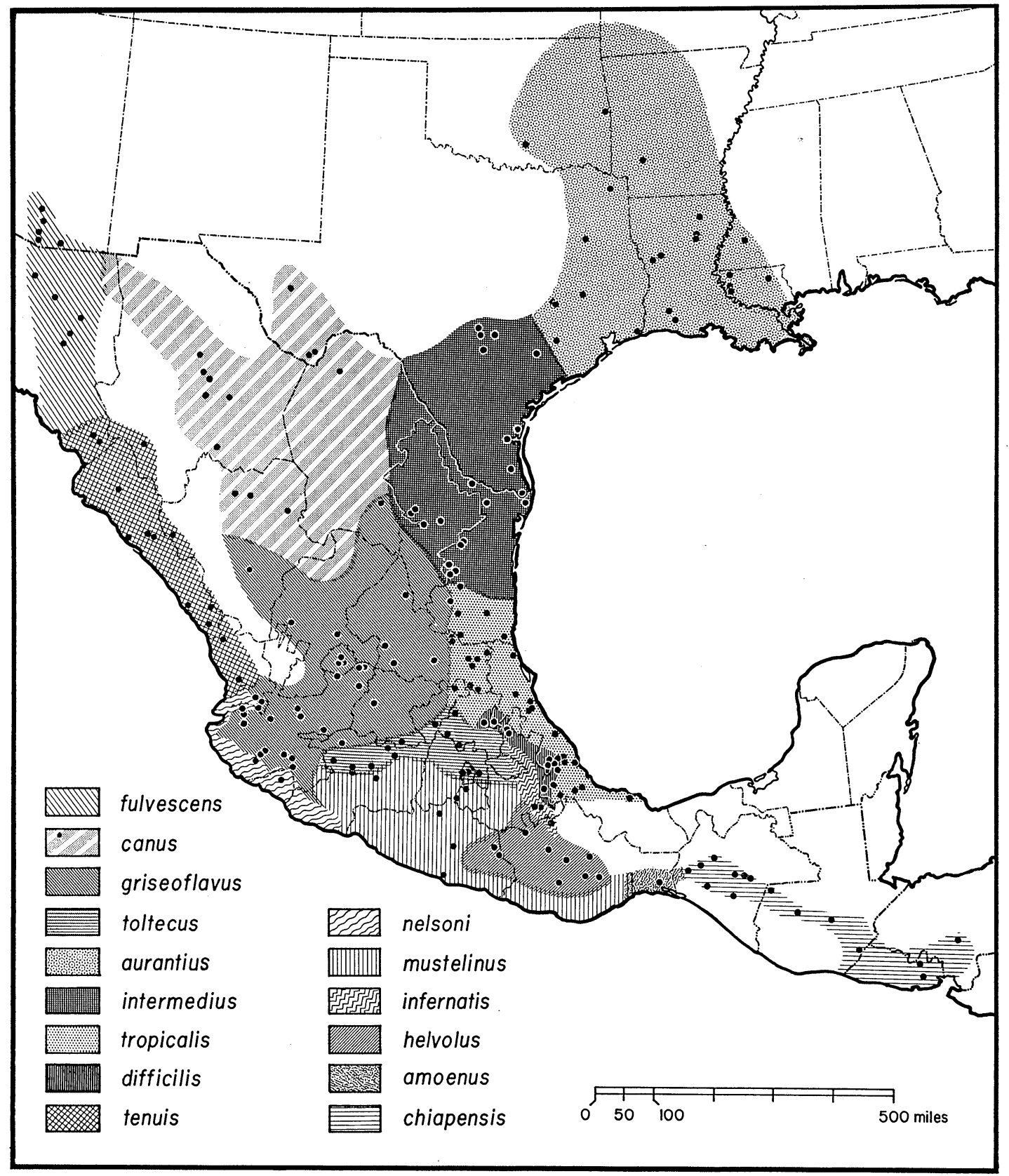

MaP 5. Distribution of the subspecies of Reithrodontomys fulvescens, as determined from specimens examined. 
lateral line may be present or absent. The upper surfaces of the feet are whitish or buffy, not dusky. There is no blackish eye ring. The subadult pelage is paler and less brightly colored than the fully adult pelage, as is true of other species of the genus. Color variations with age are less pronounced in fulvescens, however, than in most other species of the genus.

The cranium of fulvescens has a characteristic appearance. The rostrum is comparatively gross; the ascending branches of the premaxillae are broad dorsally, contributing a larger surface of bone to the dorsal face of the rostrum than is seen in the other species of the subgenus. The brain case is elongate. The frontals are inflated at their junction with the premaxillae, maxillae, and lachrymal bones. The zygomatic plate is broader than the mesopterygoid fossa, and the zygomatic notch is almost as shallow as in $R$. sumichrasti. The incisive foramina are but slightly longer than the rostrum is broad. There are oblong sphenopalatine vacuities.

Relationships.-Affinities of $R$. fulvescens are discussed in the accounts of $R$. hirsutus and $R$. gracilis. The species is morphologically nearer the species of the subgenus Reithrodontomys than those of Aporodon, but some of its characters appear to connect it, through $R$. hirsutus, with species of Aporodon.

\section{Reithrodontomys fulvescens fulvescens Allen}

Reithrodontomys mexicanus fulvescens Allen, 1894: 319.

Reithrodontomys fulvescens, Allen, 1895a: 139.

Reithrodontomys fulvescens fulvescens, Howell, 1914: 43 (part).

Trpe.-Adult male, skin and skull; Amer. Mus. Nat. Hist. No. $\frac{8411}{6736}$; México, Sonora, Oposura, 2000 feet elevation; collected 1 June 1894 by B. C. Condit.

Distribution.-Arid plains and mountains of southeastern Arizona and the eastern half of Sonora, north of the Río Mayo. Known geographic range from the vicinity of Tucson, Arizona, south to the vicinity of Nacori, Sonora. Altitudinal range from 2000 feet at Oposura, Sonora, to 5300 feet in the Huachuca Mountains, Arizona.

Habitat.-Well-drained situations supporting grass and other low-lying cover at the base of shrubs or trees, among rock outcrops, in fence rows, and in overgrown fields; principally in the mesquite-grassland belt. Specimens are recorded from situations as follows: among weeds, grass, and willows along irrigation ditches bordering cotton fields (Continental). In grass and Senecio (Huachuca Mts.).

Characters.-Size: Medium; in specimens examined hind foot and head and body length average $19 \mathrm{~mm}$. and $73 \mathrm{~mm}$., respectively; range in skull length of subadults and adults $20.4-22.1 \mathrm{~mm}$., the average $21.3 \mathrm{~mm}$. Tail of moderate length, about one-fourth longer than head and body.

Color: Adult winter pelage (January specimens from near Tucson, Arizona): Upper parts pale grayish buff; sides of legs and body Pinkish Buff or Light Ochraceous-Buff, sharply demarked from the white underparts; back 
sprinkled lightly with black, forming a faint diffuse stripe that extends from nose to rump and which becomes progressively less distinct toward a lateral line of essentially pure Light Ochraceous-Buff. Basal bands of hairs of upper parts and of underparts Blackish Plumbeous or Plumbeous-Black; those of throat white throughout. Face, forehead, and shoulders distinctly grayish. Pectoral area sometimes Light Ochraceous-Buff. Ears Hair Brown clothed internally with long Cinnamon-Buff hairs and externally with blackish and buffy hairs, black hairs predominant anteriorly. Preauricular tuft CinnamonBuff. Upper surfaces of forefeet and hind feet white or Pinkish Buff. Tarsi dusky bordered by a narrow line of Pinkish Buff. Tail Hair Brown or Dusky Drab above, whitish below, not sharply bicolored. Subadult winter pelage (January specimen from near Tucson): As that of adult, described above, but upper parts paler and more buffy, the buffy hues about Warm Buff to Light Buff, and the black hairs apparently less abundant, yielding distinctly paler, grayer upper parts and sides. Lateral line scarcely less distinct than in adult pelage. Adult summer pelage (July specimens from Huachuca Mts.): Upper parts distinctly less grayish than in winter pelage; head, shoulders, back, and sides rufescent (the ground color-subterminal bands of cover hairs-about Pinkish Cinnamon).

Skull: Brain case comparatively narrow and shallow (breadth of brain case and depth of cranium average, respectively, $10.0 \mathrm{~mm}$. and $8.2 \mathrm{~mm}$. in the specimens examined). Frontals narrow interorbitally (interorbital diameter much less than breadth of the rostrum). Zygomata comparatively strong. Rostrum broad and short, its length less than twice its breadth. Zygomatic plate broad, 1.9-2.0 mm. in diameter. Mesopterygoid fossa of medium width. Zygomatic notch broad and anteroposteriorly shallow. Auditory bullae moderate. Incisive foramina broad and long, much longer than the hard palate. Molar teeth strong, the individual teeth especially broad although the molar row is of moderate length. Sphenopterygoid vacuities large, the area of each about equal to that of the crown surface of $\mathrm{M}^{1-3}$.

Remarks. $-R$. $f$. fulvescens is separable from tenuis on the basis of its broader and longer molariform teeth and its darker and more rufescent coloration. The characters of coloration distinguish series of specimens, not each individual. The character of the teeth appears to be constant and clearcut; all specimens at hand of fulvescens and tenuis are separable on that trait alone. $R$. $f$. fulvescens is less distinct from $R$. $f$. canus. On the average, in fulvescens the upper parts are warmer in hue (not as buffy) and the shoulders and head are more nearly the color of the back and sides, not distinctly gray as in canus. The characters differentiating fulvescens and canus are few and slight. When adequate samples have been accumulated it may be found that they are best treated under one name.

Central Sonora, including the type locality of fulvescens, apparently lies 
near the center of a gradient in pelage coloration. That gradient extends from the highlands of Durango, Chihuahua, and western Texas through Sonora to the lowlands of Sinaloa. Specimens from the interior highlands are pale, buffy, gray-shouldered, and large-toothed. Those from the coastal lowlands of Sinaloa are comparatively dark, rufescent dorsally and ventrally, and small-toothed. The samples from those 2 areas are distinct externally and cranially; there is no difficulty in identifying each specimen as to its geographical origin. In areas between those 2 regions various degrees of morphological intermediacy obtain. The transition from large to small molar teeth apparently is abrupt and takes place in southern Sonora near the latitude of the Río Mayo. All specimens from localities to the north have large molars; those from localities to the south have small molars. Coloration evidences no abrupt change at that level or, so far as the specimens indicate, at any other geographic level between the aforementioned extremes. Instead, there is a decrease in intensity of pigmentation (greater to lesser amount of black on upper parts, change in the cinnamon hues from the red toward the yellow end of the spectrum, and apparently a decrease in amount of the cinnamon tones on the head and shoulders) from the coastal lowlands to the interior highlands. Specimens from central Sonora are similar in color to those from southern Sonora and to some specimens from southern Arizona. Other specimens from Arizona more nearly resemble examples from Chihuahua in regard to pallor of pelage and amount of gray on the head and shoulders. If there is a change in slope of the color cline, it probably occurs in northeastern Sonora and western Chihuahua. There are no adequate samples from that region at hand. In size of molar teeth the central Sonora specimens, including topotypes of fulvescens, cannot be grouped with the southern Sonora (and Sinaloa) specimens; they fit with the specimens of canus from the interior highlands. In color they are intermediate, fitting well with neither series, yet separable from both by their very intermediacy. Therein, and in the possibility of a steepening of the color gradient in northeastern Sonora and western Chihuahua, is the justification for recognizing both canus and fulvescens. More nearly adequate material than that now at hand may indicate a course to the contrary.

Specimens Examined.-Twenty from the following localities: México, Sonora: 10 mi. N Matape, Rancho Banochari, 2700 ft., 2 (MVZ); 6 mi. N Nacori, La Estancia, 2150 ft., 1 (MVZ); 2 mi. SW Magdalena, La Misión, 2900 ft., 1 (MVZ); Nogales, 3900 ft., 1 (MVZ); Oposura, 2000 ft., 1 (CM); Providencia Mines, 3000-3500 ft., 2 (CM).

United States. Arizona: Cochise Co., Huachuca Mts., mouth of Miller Canyon, 5300 ft., 2. Pima Co., 8 mi. SW Tucson, 2400 ft., 2 (MVZ); 25 mi. S Tucson, Continental, 2700 ft., 6. Santa Cruz Co., Tubac, 1 (CM); Tumacacori Mts., 2 mi. E Peña Blanca, 4000 ft., 1 (MVZ). 
Reithrodontomys fulvescens canus Benson

Reithrodontomys fulvescens fulvescens, Howell, 1914: 44 (part).

Reithrodontomys fulvescens canus Benson, 1939: 149.

Type.-Adult male, skin and skull; Univ. Calif. Mus. Vert. Zool. No. 76664; México, Chihuahua, 5 miles SE of Chihuahua, elevation 5750 feet; collected 20 May 1937 by Margarito Delgadillo; original No. 4446, Seth B. Benson.

Distribution.-Northern part of the Mexican Plateau in Durango, Coahuila, Chihuahua, and western Texas. Known geographic range from the Davis Mountains, Texas, and the vicinity of Chihuahua City south to the latitude of Gómez Palacio, Durango. Altitudinal range from 3800 feet at San Juan, Durango, to 6650 feet near Zarca, Durango.

HaвiтAT.-Arid grassland and mesquite-dotted plains and ridges; principally in the mesquite-grassland belt. The specimen from San Juan was collected in a mesquite-dotted river bottom.

Comparisons.-Compared with aurantius (specimens of canus from Chihuahua; examples of aurantius from Louisana): Size similar, canus possibly slightly larger; tail absolutely and relatively longer (see measurements). Color much paler, the upper parts pale grayish buff (ground color about Pinkish Buff) rather than reddish brown (ground color near Cinnamon) and lacking a distinct blackish dorsal stripe; shoulders and head pale gray rather than reddish brown. Underparts pale buff (Pale Pinkish Buff) rather than rufescent (Light Pinkish Cinnamon). Crania of the 2 forms similar in size, but rostrum of canus longer and narrower (relative to its length), hard palate longer (averages $3.7 \mathrm{~mm}$. compared with $3.4 \mathrm{~mm}$.), molar teeth and auditory bullae larger.

Compared with intermedius (specimens of canus from Chihuahua; examples of intermedius from southern Texas): Similar in size and in most cranial dimensions; tail relatively longer; on the average palate longer, auditory bullae larger, and molar teeth slightly broader and longer. Differential characters principally those of coloration: Upper parts paler and less rufescent; shoulders and head paler gray, distinctly differentiated in hue from back and sides (in intermedius head and shoulders not markedly different in color from back and sides). Underparts paler on the average.

Compared with fulvescens (specimens of canus from Chihuahua; examples. of fulvescens from central Sonora): Similar in size, tail length, and cranial. characters. Coloration of upper parts paler and more buffy, the ground color (subterminal bands of cover hairs) near Pinkish Buff rather than Pinkish Cinnamon and the head and shoulders grayish, differentiated from the remainder of the upper parts (their color more similar to that of back and sides in fulvescens).

Remarks.-The race canus is the palest in $R$. fulvescens, approached closely only by infernatis of Oaxaca. Both of those forms are inhabitants of arid 
areas and the dilute pelage colors apparently are responses to conditions imposed in those environments. Coloration is perhaps the most striking character for distinguishing canus from adjoining subspecies, but the long tail, large molar teeth, large auditory bullae, and long palate are also characteristics that set canus apart from other races, particularly those ranging in lowlands to the east.

For evidence of intergradation with fulvescens, intermedius, and griseoflavus see the accounts of those races.

Specimens examined.-Thirty from the following localities: México. Chihuahua: 7 mi. W El Saúz, Cañón del Potrero, 5750 ft., 2 (MVZ); Casas Grandes, $4800 \mathrm{ft}$., 5 (US); 5 mi. SE Chihuahua, $5250 \mathrm{ft}$., l (MVZ); $9 \mathrm{mi}$. NW Chihuahua, Cañón Gotera, 5550 ft., 2 (MVZ); Parral, 5500 ft., 1 (US); 30 mi. S Chihuahua, 1 mi. SW Pozo Mangiay, $5200 \mathrm{ft}$., 1 (MVZ); 9 mi. SE San Lucas, Río San Pedro, 5300 ft., 2 (MVZ). Coahuila: Sierra del Carmen, 2 (US). Durango: Indé, $6100 \mathrm{ft}$., 1 (US); 12 mi. W Gómez Palacio, San Juan, 3800 ft., 1; 14 mi. E Zarca, 6650 ft., 5 (MVZ).

United States. Texas: Brewster Co., Chisos Mts., Juniper Canyon, $4800 \mathrm{ft}$., 1 (CM); Pine Canyon, 4700 ft., 3 (2 MVZ). Jeff Davis Co., 15 mi. N Fort Davis, Davis Mts., Limpia Canyon, $4300 \mathrm{ft}$., 3.

\section{Reithrodontomys fulvescens griseoflavus Merriam}

Reithrodontomys griseoflavus Merriam, 1901: 553.

Reithrodontomys tenuis, Allen, 1906: 248.

Reithrodontomys fulvescens tenuis, Howell, 1914: 45 (part); Hall and Villa, 1949c: 457 (part); 1950: 192 (part).

TyPE.-Adult male, skin and skull; U. S. Nat. Mus. Biol. Surv. Coll. No. 82196; México, Jalisco, Ameca, 4000 feet elevation; collected 9 February 1897 by E. W. Nelson and E. A. Goldman; original No. 10501.

Distribution.-Plains and mountains of the southwestern part of the Mexican Plateau. Known range from the vicinity of Jaral, Coahuila, and Jaumave, Tamaulipas, south and west to Santa Isabel, southeastern Nayarit, and to the vicinity of Talpa and Autlán, Jalisco. Vertical range from about 2700 feet at Jaumave, Tamaulipas, to 6800 feet near Punta, Jalisco.

Habitat.-Desert grassland with open stands of cactus, mesquite, and thorny trees and shrubs. Specimens were obtained in situations as follows: In dense grass (2-4 ft. in height) on rolling hills studded with lava outcrops; in brush bordering a tree-lined barranca $(2 \mathrm{mi}$. N Santa Isabel). On a 45 -degree slope covered with deciduous brush 5-8 feet in height but generally with no low-lying plant cover (4 mi. N Santa Isabel). In grass at the base of cactus, mesquite, other thorny vegetation, and rock outcrops on an overgrazed hillside; in dense grass along a rock fence that bounded hay and cornfields (Ixtlán). In several situations near Ameca, all having sparse or dense stands of grass (about $4 \mathrm{ft}$. in height), and in deciduous shrubs and small trees; all 
these situations well drained, whether in fallow fields, on overgrazed hillsides, or among lava outcrops. In sparse or dense grass $(3-5 \mathrm{ft}$. in height) growing between thorny trees and shrubs on a rocky hillside and about rocky cliffs (San Gabriel). At the lower edge of the pine belt, among oak and brush (including wild rose and blackberry) on the banks of a shallow barranca (10 mi. W Guzmán). On rolling grasslands dotted with candelabra cactus, mesquite, a tall Solanum, and other small trees (4 mi. NE Autlán). Among scrub oak and scattered clumps of bunch grass at the edge of a tropical canyon $(6 \mathrm{mi}$. SSW Autlán). Along a rock wall in pasturelands surrounded by pine and oak forests (Rancho Manantlán). In grass and brushy hedges on the border of wheat and corn fields; on dry, rocky, comparatively barren slopes (Jaumave). In grass (2-4 ft. in height) at the bases of opuntia cactus and thorny trees on a lava outcrop (near Zamora).

Comparisons.-Compared with canus (specimens of griseoflavus from Ameca, Jalisco; specimens of canus from Chihuahua): Similar in body size. Upper parts rufescent with a moderate suffusion of black forming a distinct clorsal stripe (upper parts buffy and not as blackish in canus); ground color near Pinkish Cinnamon or Cinnamon rather than Pinkish Buff. Head and shoulders with a faint grayish cast, paler than sides, yet darker and less contrasted with remainder of upper parts than in canus. Tail darker dorsally. Underparts more rufescent on the average (Light Pinkish Cinnamon rather than Pale Pinkish Buff). Frontal part of skull broader (see measurements of interorbital constriction); palate shorter; auditory bullae and molar teeth smaller and postpalatal spine longer.

Compared with toltecus (specimens of griseoflavus from Ameca; examples of toltecus from Mexico City): Smaller (see measurements). Upper parts much brighter, less blackish; the ground color similar in the 2 races (Pinkish Cinnamon), but in toltecus the black overlay (of the guard hairs) predominant and the mass effect is dark grayish brown. Head and shoulders brighter and buffy, not dark gray as in toltecus. Cranium smaller in all dimensions, and on the average, rostrum relatively broader and palate relatively longer. Incisive foramina average shorter; molar teeth much smaller; a well-developed postpalatal spine in both races.

Remarks. $-R . f$. griseoflavus is an inhabitant of the desert grasslands of the highlands of west-central México. It is quite distinct externally and cranially from both nelsoni and tenuis of the Pacific lowlands. It intergrades with nelsoni in western Jalisco and southern Nayarit where tropical and temperate conditions of climate and vegetation merge. The zone of intergradation may be exceedingly narrow where tropical valleys extend as fingers into more temperate highlands. For example, near Santa Isabel, Nayarit, the only specimen that was obtained on the brushy slopes of a tropical barranca has all the characters of nelsoni. Four other examples that were trapped on grasslands 
which adjoin the barranca are referable to griseoflavus. Similarly, near Autlán, Jalisco, coastal tropical vegetation extends up some stream valleys almost to the summit of the mountain range which roughly separates tropical deciduous vegetation to the west from desert shrub and grasslands to the east. Specimens from the eastern slopes, the cactus-studded grasslands 4 miles northeast of Autlán, show but slight evidence of the geographical proximity of the nelsoni set of characters. In a series from the crest of the mountain range -the head of a tropical canyon and the adjoining grassland and encinal-6 miles south-southwest of Autlán the contrasting features of griseoflavus and nelsoni are variously mixed and blended. Specimens from the lower western slopes (tropical conditions about 10 miles to the south, near La Resolana) are typical of nelsoni. All of the specimens from localities fringing the highlands in western Jalisco and southern Nayarit are morphologically between griseoflavus and nelsoni. This is true of specimens from Rancho Palo Amarillo, Mascota, Talpa, San Sebastián, and Platanar. All except those from San Sebastián are here referred to griseoflavus, although with about equal reason they could be assigned to nelsoni. Specimens from Río Verde, San Luis Potosí, grade toward tropicalis.

Statements regarding the distribution of the characters of griseoflavus and toltecus are given in the accounts of toltecus. Additional evidence of intergradation of the 2 is supplied by examples from Ocotlán, Jalisco, and Zamora, Michoacán. They are clearly intermediate in characters. Both samples are referred to griseoflavus. Those from Zamora could be identified with either race; to my eye they are slightly nearer griseoflavus in size and coloration. Near Zamora the arid grassland and semidesert, in which the city is situated, give way to mesic pine and oak-covered mountains of the Michoacán highlands. In specimens from Aguascalientes and San Luis Potosí the pelage averages slightly paler, the tail longer, and the molars and bullae larger, than in the examples from central Jalisco. In those respects the material from Aguascalientes and San Luis Potosí grades toward canus of Durango. Two specimens from Jaral, Coahuila, are tentatively identified with griseoflavus. The examples from Jaumave grade toward tropicalis in size and coloration. In tail length they fit with specimens from the interior highlands. They are referred to griseoflavus.

SPECIMENS EXAMINED.-Two hundred and twenty-one from the following localities in México: Aguascalientes: 3 mi. N Aguascalientes, about 6200 ft., 4 (MVZ); 3 mi. NE Aguascalientes, about 6,200 ft., 5 (MVZ); vicinity of Chicalote, 6,200 ft., 3 (2 MVZ, 1 US). Coahuila: 1/2 mi. S San Antonio de Jaral, 4,400 ft., 2 (MVZ). Durango: Durango, 6,200 ft., 3 (US). Guanajuato: Silao, 5800 ft., 2 (US). Michoacán: vicinity of Zamora, 5500-6000 ft., 11 (8 MVZ, l US). Nayarit: 1 mi. E Ixtlán del Río, 4000 ft., 6; Rancho Palo Amarillo, $2500 \mathrm{ft}$. ?, 1 (CM); 2-4 mi. N Santa Isabel, $3800 \mathrm{ft}$., 5. Jalisco: 
Ameca to 7 mi. W Ameca, 4000-4300 ft., 68 (5 US); Atemajac, between 4000 and 4500 ft., 2 (US); 4 mi. NE Autlán, 3000 ft., 9; 6 mi. SSW Autlán, 4500 ft., 9; Charco Hondo, 1 (CM); Ciudad Guzmán, 5000 ft., 10 (US); 10 mi. W Giudad Guzmán, 6500 ft., 2; 9 mi. N Encarnación de Díaz, 6200 ft., 2 (MVZ); Etzatlán, 4000 ft., 7 (US); 8 mi. S Guadalajara, 5100 ft., 1; Lagos de Moreno, $6400 \mathrm{ft}$., 1 (US); Sierra de Autlán, Manantlán, $5000 \mathrm{ft}$., 1; Mascota, 3900 ft., 1 (US); Ocotlán, 5000 ft., 2 (1 CM, 1 US); near Platanar, 4000 ft., 3 (US); 6 mi. SE Punta, 6800 ft., 1 (MVZ); 1 mi. N San Gabriel, 4000 ft., 24; Talpa, $4000 \mathrm{ft} ., 1$ (US). San Luis Potosí: vicinity of La Parada, $6000 \mathrm{ft}$., 6 (3 MVZ, 3 US); Río Verde, 3200 ft., 6 (US); 71/2 mi. S Matehuala, Potrero Santa Ana, 5000 ft., 1 (MVZ); near Villa de Reyes, 1 (LSU). Tamaulipas: Jaumave, 2700-3300 ft., 13. Zacatecas: Berriozábal, 6800 ft., 1 (US); Valparaíso, near $6500 \mathrm{ft} ., 6$ (US).

\section{Reithrodontomys fulvescens toltecus Merriam}

Reithrodontomys levipes toltecus Merriam, 1901: 555.

Rhithrodontomys inexpectatus Elliot, 1903: 145. México, Michoacán, Pátzcuaro.

Rhithrodontomys $g$ [riseoflavus] helvolus, Elliot, 1903: 146.

Reithrodontomys fulvescens toltecus, Howell, 1914: 51; Davis, 1944: 392 (part); Hooper, 1947: 49.

Reithrodontomys fulvescens inexpectatus, Hall and Villa, 1949c: 458; 1950: 193.

Trpe.- Adult female, skin and skull; U.S. Nat. Mus. Biol. Surv. Coll. No. 50746; México, Distrito Federal, Tlalpam, elevation 7500 feet; collected 1 December 1892 by E. W. Nelson and E. A. Goldman; original No. 3935.

Distribution.-Mountains and valleys bordering the southern part of the Mexican Plateau. Known geographic range from Zimapán, Hidalgo, and localities in Distrito Federal west to Los Reyes, Michoacán. Vertical range from 4400 feet near Uruapan, Michoacán, to 8500 feet near Contreras, Distrito Federal.

Habitat.-Grass, brush, and cactus in comparatively dry, well-drained situations such as steep, rocky hillsides and lava flows. Specimens were collected in situations as follows: On a steep hillside densely covered with grass, opuntia cactus, mesquite, jasmine, tall sage, and other shrubs; in an open, opuntia cactus-mesquite formation with scattered grass and shrubs (Cuitzeo). Among scattered grass, shrubs, and cactus on a lava flow (San Gerónimo). In grass and shrubs, including Baccharis, that separated a brushcovered barranca from a fruit orchard with a grassy understory (Pátzcuaro). Among scattered shrubs and stands of grass on a lava flow (Cupatitzio Park, Uruapan). In a mixed stand of grass and dense brush at the edge of an airfield (Uruapan). On a steep north-facing rocky slope covered with tall bunch grass and brush (2-4 ft. in height); in sparse grass under pines on rocky ground above a canyon (Tzararacua Falls, near Uruapan). In grass and 
sparse brush bordering cultivated areas and adjoining mesquite-cactus desert (Zimapán).

Comparisons.-Compared with difficilis (specimens of toltecus from the vicinity of Mexico City; specimens of difficilis from Huauchinango, Puebla): Larger (head and body length averages $78 \mathrm{~mm}$., as against $69 \mathrm{~mm}$. in difficilis). Tail longer. Head and foreback distinctly grayer than in difficilis; remainder of upper parts a mixture of cinnamon and black, the mass effect grayish brown rather than dark chestnut as in difficilis. Ground color of back and sides near Pinkish Cinnamon rather than Orange-Cinnamon. Underparts averaging paler, about Light Pinkish Cinnamon compared with Pinkish Cinnamon. A pectoral spot usually present in both forms. Ankles less extensively dusky in toltecus. Cranium larger and differently proportioned: zygomatic spread and breadth of brain case less on the average (relative to cranial length, 49 and 45 per cent in toltecus and 52 and 47 per cent in difficilis, respectively); rostrum relatively narrower and molar teeth much larger.

For comparison with griseoflayus see accounts of that race.

REMARKs. $-R$. $f$. toltecus is the largest and one of the darker races of the species. $R$. f. griseoflavus, of plains and mountains to the north and west of the range of toltecus, and $R$. f. helvolus, of highlands of Oaxaca, most closely approach toltecus in size of body and skull. In color tone of the pelage toltecus resembles difficilis, of the eastetrn flank of the Sierra Madre Oriental, and aurantius, of southern United States.

Size and intensity in pigmentation, which attain maxima for the species in the populations here known as toltecus, apparently are distributed independently over the highlands of central México and, indeed, throughout much of the range of the species. Largest size apparently obtains in populations in the southeastern part of the Mexican Plateau, as is well exemplified by specimens from Distrito Federal. In all directions from that area size of body and skull decreases in proportions which do not relate closely to linear distance from that center of maximum size. It diminishes rapidly to the south. Specimens from Tepotzlán, Morelos--about 20 miles south of Mexico City across a mountain range-average $10 \mathrm{~mm}$. shorter in length of head and body and $2 \mathrm{~mm}$. less in skull length. To the north and west the size gradient is more gentle. Specimens from localities up to 200 miles west of Mexico City (e.g. Uruapan and Los Reyes, Michoacán) and 250 miles to the northwest (e.g. Aguascalientes) average $5 \mathrm{~mm}$. less in body length and $1 \mathrm{~mm}$. less in skull length. A series from Cuitzeo, Michoacán, about 150 miles northwest of Mexico City, is almost identical with the Mexico City samples in regard to skull size.

While Distrito Federal represents a focal point for maximum size, the highlands of central Michoacán appear to be a center for intense pigmenta- 
tion. In specimens from Los Reyes, Uruapan, and Pátzcuaro the pelages are dark reddish brown, more deeply pigmented than in other specimens from the Plateau. To the south and west paler colors obtain; there is less black in the pelage; the orange and buffy hues, however, are approximately the same as in the central Michoacán material. The pelages from localities to the north also are paler. They, too, have less black than those from Michoacán; in addition the orange and buffy ground color of the subterminal bands of the cover hairs is distinctly more buffy. The increase in pallor toward the north appears to be gradual. It culminates in the pale grayish and buffy coat colors of the populations of the northern highlands, known by the name canus.

As indicated above, specimens from Pátzcuaro (the type locality of inexpectatus) and from Los Reyes and Uruapan on the average are more rufescent dorsally, are not so distinctly grayish on the head and foreback, and are slightly smaller than those from the type locality of toltecus. Nevertheless, in contrast to specimens of adjoining races, nelsoni and mustelinus to the south and griseoflavus to the west and north, they fit well with topotypes of toltecus. As now understood, inexpectatus is considered to be subspecifically identical with toltecus.

Specimens from Zamora grade toward toltecus in coloration, but still fit best with griseoflavus. Specimens from Zimapán, Hidalgo, are smaller than examples from Mexico City. A specimen from Temascal and another listed from 15 miles east-southeast of Morelia (possibly also Temascal) are paler and their teeth are smaller than is true of the examples from near-by Cuitzeo and Pátzcuaro; in those respects they approach specimens from Tacámbaro, Michoacán, and from Tepoztlán, Morelos, which here are referred tentatively to mustelinus.

Since the above accounts were prepared, the check list of Hall and Villa of the mammals of Michoacán and the specimens of Reithrodontomys that they examined have come to hand. The facts on variation in their samples of $R$. fulvescens (Hall and Villa, 1949c: 457-59; 1950: 192-94) are in agreement with the data presented here. Their interpretations of the data, however, are somewhat different. They observed maximum size in specimens from the Valley of Mexico and deepest rufescent pelage coloration in their material from central Michoacán. Outside of those areas smaller size and paler colors obtained. Thus, of the lot they studied, their specimens from Pátzcuaro are the most intensely pigmented dorsally and are but slightly smaller than specimens from the Valley of Mexico. Those from Zamora are smaller and grayer. Those from the flanks of the Balsas Basin (Tacámbaro) are the smallest; their upper parts are less blackish and more reddish dorsally than the specimens from Zamora, Pátzcuaro, and the Valley of Mexico. These facts accord with the present analysis, which originally was based on different material from the same region. This recently received lot of specimens provides addi- 
tional corroborative evidence. For their specimens from Pátzcuaro they revived the name inexpectatus, by way of emphasizing the dark reddish pelages that apparently characterize the populations of that part of Michoacán. In view of the size and color gradients in the mice of Michoacán and México, that emphasis does not seem warranted. Specimens from Uruapan and Los Reyes resemble the Pátzcuaro specimens in color and they are but slightly smaller. Specimens from near Cuitzeo, about 40 miles to the northeast of Pátzcuaro, agree closely with the specimens from Pátzcuaro and with those from the Valley of Mexico. All can justifiably be treated under the name toltecus.

Hall and Villa referred their specimens from Zamora to a smaller, paler race, known to them as tenuis but known here as griseoflavus. Their Tacámbaro specimens seemed to them to be morphologically between inexpectatus and a small, reddish form which they suspect is nelsoni. Compared with nelsoni from Resolana, Jalisco, the Tacámbaro specimens average larger and less reddish dorsally; the rostrum is longer, incisive foramina shorter, and frontals broader interorbitally. The specimens are clearly between the large, dark form of the highlands (toltecus) and a smaller, brighter form of the adjacent lowlands. What that lowland form should be called is a moot question. Some of its characteristics, however, seem reasonably clear. It resembles nelsoni in many features, but it is not as reddish dorsally and is slightly larger; the rostrum is longer and broader, the incisive foramina are relatively shorter, and the frontals are broader and are flat interorbitally. These are features that obtain in the series from Tacámbaro, Teloloapan (Guerrero), and Tepoztlán (Morelos). As indicated in the accounts of mustelinus, they can be interpreted (1) simply as evidences of intermediacy between already named highland and lowland forms, (2) as characteristics of an unnamed race that inhabits the perimeter of the Balsas Basin, or (3) primarily as characteristics of mustelinus of which there are no known adequate samples from coastal Guerrero and Oaxaca where its characters should be fully expressed. Until the characters of mustelinus are better known through adequate series of specimens, I prefer to apply the name mustelinus to the aforementioned sampled populations of the Balsas Basin as well as to those of coastal Guerrero and Oaxaca. The Tacámbaro series, then, is considered to be between toltecus and mustelinus and is nearer the latter. In one respect the series resembles samples of griseoflavus and nelsoni from the localities 6 miles NNE Autlán, Jalisco, and 2 to 4 miles N Santa Isabel, Nayarit. In each series the characters of the upland and the coastal subspecies are variously mixed and blended.

SPECIMENS EXAMINED.-Eighty-five from the following localities in México: Distrito Federal: near Contreras, 8500 ft., 1; San Gerónimo, 7800 ft., 7; Tlalpam, 7600 ft., 4 (1 CM, 3 US). Guanajuato: Acámbaro, 6100 ft., 2 (US). 
Hidalgo: Marqués, 8132 ft., 1 (US); Tula, 6700 ft., 1 (CM); Zimapán, 6000 6400 ft., 6 (1 US). México: Hacienda Córdoba, 8300 ft., 2; 10-13 mi. SE Mexico City, 7500 ft., 2 (Tex). Michoacán: 4 mi. S Cuitzeo, 5900-6000ft., 20; Los Reyes, $5000 \mathrm{ft.,} 6$ (US); 15 mi. ESE Morelia, 7300 ft., 1 (MVZ); Pátzcuaro, $7000 \mathrm{ft} ., 2$ (1 CM); $3 \mathrm{mi}$. N and NW Pátzcuaro, 6700-6800 ft., 9 (MVZ); 2 mi. W Pátzcuaro, 7600-7700 ft., 6 (MVZ); Temascal, 7000 ft., 1; Uruapan, 5300 ft., 8; 7 mi. S Uruapan, Tzararacua Falls, 4400-4700 ft., 4. Querétaro: Tequisquiapam, $6200 \mathrm{ft} ., 2$ (US).

\section{Reithrodontomys fulvescens aurantius Allen}

Ochetodon mexicanus, Coues, 1874: 186 (part); 1877: 128 (part); True, 1884: 598 (part).

Reithrodontomys mexicanus aurantius Allen, 1895a: 137.

Reithrodontomys chrysotis Elliot, 1899: 281. Oklahoma, Murray Co., Dougherty.

Reithrodontomys aurantius, Bailey, 1905: 105.

Reithrodontomys fulvescens aurantius, Howell, 1914: 48; Lowery, 1943: 243.

Type.-Adult male, skin and skull; U. S. Nat. Mus. Biol. Surv. Coll. No. $\frac{33963}{45998}$; Louisiana, Lafayette Parish, Lafayette, collected 24 May 1892 by R. J. Thompson.

Distribution.-South-central United States. Kown range from Cherokee and Chautauqua counties, southeastern Kansas (Hibbard, 1944: 78), Ozark County, southern Missouri, and Cleveland County, central Oklahoma, south to Copiah County, Mississippi, and Colorado County, Texas. Altitudinal range from near sea level at several localities in Texas and Louisiana to 1500 feet at Noble, Oklahoma.

Habitat.-Prairie, grass- and weed-covered fields, grassy flats, fence rows, and brushy growths. Specimens were collected in situations as follows: In Johnson grass (near Tyler and Wellborn). In broom sedge at the edge of a pine forest (Huntsville). In Andropogon (College Station and near Hallettsville). On a grassy prairie in a heavy cover of Andropogon and in a low mat of other grasses (near La Belle). In grass bordering a cotton field (Vowells Mill). In a brush-covered ditch (Iowa).

Comparisons.-Compared with intermedius (specimens of aurantius from southern Louisiana; examples of intermedius from southeastern Texas): Similar in size, tail length (relatively short in both forms), and cranial characters. Adult and especially subadult pelages darker and more rufescent. Adult pelage: Upper parts reddish brown, a mixture of Cinnamon of the cover hairs and black of the guard hairs, the black concentrated dorsally and forming a distinct broad stripe (in intermedius ground color nearer Pinkish Cinnamon and the dorsal stripe indistinct and less blackish). Underparts more rufescent, Light Pinkish Cinnamon or Pinkish Cinnamon. Ears and upper surface of tail darker, near Fuscous (rather than Drab or Hair Brown as in intermedius). Buffy area on tarsi darker (near Pinkish Cinnamon). Subadult pelage: Upper parts much darker in aurantius, a mixture of Pinkish Cinnamon and black, 
the black predominant (in intermedius, Pinkish Buff with comparatively little black, the mass effect buffy gray). Underparts rufescent, about Pinkish Cinnamon or Light Pinkish Cinnamon (Pale Pinkish Buff in intermedius). Color of ears, feet, and tail as in adult pelage.

REMARKs.-The dark color of this form is its chief distinguishing character. The deep tones are best developed in the northeastern part of its range, in Louisiana, Mississippi, Arkansas, and Oklahoma. In specimens from that region, including those from the type locality of chrysotis, there is no evidence of population differences worthy of subspecific recognition. In eastern Texas aurantius grades into intermedius. It becomes largely a matter of opinion where the series of specimens at hand, arranged geographically, should be divided. The examples from Smith, Bowie, and Walker counties are clearly referable to aurantius, although they are less intensely pigmented on the average than those from Louisiana. The specimens from Brazos, Colorado, and Hays counties could be grouped about as well with those of intermedius from Willacy, Aransas, and Cameron counties as with the series from northeastern Texas. They are here identified with aurantius and mark the southern limit of the race as now known (Map 5). A specimen from Ozark County, Missouri, is comparatively pale; it resembles examples from Brazos County, Texas.

Specimens examined.-Ninety-seven from the following localities in the United States: Arkansas: Pike Co., Delight, 400 ft., 2 (1 CM). Louisiana: Calcasieu Par., Iowa, 4 (LSU). Caldwell Par., 1 mi. N Clarks, I (LSU); Columbia, 130 ft., 9 (CM). Cameron Par., Lowry, 4 (LSU). East Baton Rouge Par., vicinity of Baton Rouge, $50 \mathrm{ft} ., 18$ (LSU); Zachary, $100 \mathrm{ft}$., 1. Jefferson Davis Par., Mermentau, $14 \mathrm{ft} ., 5$ (CM). Natchitoches Par., vicinity of Vowells Mill, 7 (LSU). Ouachita Par., Monroe, 75 ft., 5 (4 LSU, 1 MVZ). Sabine Par., Many, 6 (LSU). Washington Par., 12 mi. E Franklinton, 1 (LSU). West Feliciana Par., 1 mi. N Corner, 6 (LSU). Mississippi: Copiah Co., Burnell, 3 (CM). Missouri: Ozark Co., 5 mi. N Gainesville, Cavey Mt. Refuge, 1 (MVZ). Oklahoma: Cleveland Co., Noble, 1500 ft., 1 (CM). Murray Co., Dougherty, 750 ft., 3 (CM). Texas: Bowie Co., 1 mi. NE Simms, 1 (Tex). Brazos Co., vicinity of College Station, 6 (Tex); 71/2 mi. S Wellborn, 1 (Tex). Colorado Co., Eagle Lake, 1 (Tex). Hays Co., 4 mi. NE San Marcos, $600 \mathrm{ft}$., 1 (Tex). Jefferson Co., 20 mi. SSW Beaumont and 7 mi. S La Belle, 1. Smith Co., 4 mi. N Tyler, 2 (Tex). Walker Co., vicinity of Huntsville, 6 (Tex); 20 mi. W Huntsville, 1 (Tex).

\section{Reithrodontomys fulvescens intermedius Allen}

Ochetodon mexicanus, Allen, $1891 b: 223$.

Reithrodontomys mexicanus intermedius Allen, 1895a: 136; 1896a: 66. Reithrodontomys intermedius, Bailey, 1905: 104. 
Reithrodontomys laceyi Allen, 1896b: 235. Texas, Bexar Co., 15 miles south of San Antonio, Watson's Ranch.

Reithrodontomys fulvescens intermedius, Howell, 1914: 47; Hooper, 1947: 48.

Reithrodontomys fulvescens tenuis, Howell, 1914: 47 (part); Dice, 1937: 253; Davis, 1944: 392.

TYPE.-Adult female, skin and skull; Amer. Mus. Nat. Hist. No. $\frac{4267}{323 i}$; Texas, Cameron Co., Brownsville; elevation near sea level; collected 3 September 1891 by F. B. Armstrong.

Distribution.-Plains and hills of southern Texas and northeastern México. Known range from Kerr County, Texas, south to Santa Engracia, Tamaulipas, and to localities near Monterrey, Nuevo León. Altitudinal range from near sea level at several localities in Texas to 2400 feet near Santa Catarina, Nuevo León.

Habitat.-Grasslands and brush-covered terrain. Specimens were trapped in situations as follows: In high grass growing at the edge of a dry stream bed; in a mixed growth of grasses, sedges, and rushes below a reservoir; thorny shrubs were predominant around both trapping stations (Sierra San Carlos). In brush near the Rio Ramos.

Comparisons.-Compared with tropicalis (specimens of intermedius from southern Texas; examples of tropicalis from central Veracruz): Size moderate and tail relatively short in both forms. Upper parts paler in intermedius, ground color of adult pelage Light Pinkish Cinnamon or Cinnamon (rather than Cinnamon or Ochraceous-Tawny as in tropicalis) and the black overlay less. Underparts including pectoral spot averaging paler. Subadult pelage correspondingly paler and much grayer with distinctly less black on the upper parts. Cranium similar in the 2 forms but the brain case of intermedius broader and shallower than that of tropicalis and the molar teeth relatively heavier.

Compared with difficilis (specimens of intermedius from southern Texas; examples of difficilis from the vicinity of Orizaba, Veracruz): Similar in size. Greatly different in color (upper parts dark reddish brown and underparts buffy in difficilis). Cranium smaller, the brain case relatively much narrower and shallower, and the molar teeth relatively broader and longer.

For comparisons with canus and aurantius see accounts of those forms.

Remarks.-Like aurantius and tropicalis, intermedius is a moderate-sized, relatively short-tailed form of the Gulf lowlands. So far as can be determined from the present samples, it is distinguishable from aurantius and tropicalis principally in coloration. The color characters of intermedius are not strictly between those of aurantius and tropicalis; both of those are distinctly darker and more rufescent. Rather a grayish cast on the dorsum and sides of intermedius seems to be an influence from the Mexican Plateau (from populations of canus) that spills into the lowlands of northern Nuevo León and Tamaulipas. It is probable that the populations of $R$. fulvescens are more 
continuous in that area. Hence, the flow of genes between upland and lowland populations should be less interrupted than at lower latitudes where the lofty Sierra Madre is a more effective barrier to the mice. Nevertheless, all specimens examined from Nuevo León and northern Tamaulipas are moderately dark, relatively short tailed, and small toothed; these are characters of the lowland forms intermedius and tropicalis.

The gradation in color from typical intermedius to typical tropicalis apparently takes place over a large area. The specimens from most of Tamaulipas and Nuevo León are between intermedius and tropicalis in characters of coloration. The artificial line delimiting the ranges of the 2 forms is placed just north of the Sierra de Tamaulipas. Specimens from localities to the south average darker and more rufescent than those from localities to the north. Specimens from the vicinity of San Antonio, the type locality of laceyi, fit well in a series of topotypes of intermedius. For remarks concerning intergradation of intermedius and aurantius see the accounts of aurantius.

Specimens examined.-Sixty-one from the following localities: México. Nuevo León: Cerro de la Silla, somewhere between 2000 and 3000 ft., 3 (US); 12 mi. NW General Terán, 700 ft., 5.14 mi. N Monterrey, 1950 ft., 6 (MVZ); 12 mi. N Montemorelos, Río Ramos, 1000 ft., 1 (Tex); 7.3 mi. S Santa Catarina, Rancho Rodeo, 2400 ft., 1 (MVZ); Santa Catarina, 2200 ft., 3 (US). Tamaulipas: Camargo, $200 \mathrm{ft} ., 5$ (US); 20 mi. S Reynosa, Charco Escondido, 1 (MVZ); 29 mi. N Ciudad Victoria, Cruz y Cruz, 800 ft., 1 (MVZ); Matamoros, 30 ft. ?, 5 (US); 5.7 mi. S Matamoros, 2 (MVZ); Hacienda Santa Engracia, 800 ft., 8 (CM); Sierra San Carlos, El Mulato, 700 ft., 1; Tamaulipeca, $1500 \mathrm{ft} ., 1$.

United States. Texas: Aransas Co., Aransas Refuge, 20 ft., 6 (Tex). Bexar Co., vicinity of San Antonio, $650 \mathrm{ft} ., 2$ (1 CM). Cameron Co., Brownsville, 20 ft., 3 (2 CM). Kerr Co., 20 mi. SW Hunt, 1 (Tex); 20 mi. W Mountain Home, 1 (Tex). Kleberg Co., 2 mi. S Riviera, 3 (Tex). Lavaca Co., 14 mi. WSW Hallettsville, 1 (Tex). Willacy Co., 20 mi. E Raymondville, Red Fish Bay, near sea level, 1 (Tex).

\section{Reithrodontomys fulvescens tropicalis Davis}

Reithrodontomys fulvescens tenuis, Howell, 1914: 47 (part).

Reithrodontomys fulvescens tropicalis Davis, 1944: 393.

Type.-Adult male, skin and skull; Texas A. and M. Coll. No. 3084; México, Veracruz, 5 miles $\mathrm{S}$ Veracruz, Boca del Río, elevation 10 feet; collected 22 July 1942 by David M. Donaldson; original No. 72.

Distributron.-Coastal lowlands and foothills of eastern México. Known range from Presidio and Catemaco, Veracruz, north to the Sierra de Tamaulipas and the vicinity of Gómez Farías, Tamaulipas. Known altitudinal range from near sea level at Boca del Río and Tampico Alto to 3600 feet in the Sierra de Tamaulipas. 
Habitat.-Grassy areas among arid tropical shrubs and trees, or essentially pure savanna. Specimens were collected in situations as follows: In sparse grass and weeds growing among arborescent cactus and sparse, thorny brush on a rocky hillside (Plan del Río). In marshy, semitropical situations (Boca del Río). In a thick growth of herbaceous vegetation in a fallow field in terrain dominated by tall brush (near Gómez Farías). In dense herbaceous vegetation bordering a cornfield and near large trees, some of which were figs (Antiguo Morelos).

Comparisons.-Compared with difficilis (specimens of tropicalis from Veracruz lowlands; a series of difficilis from Huauchinango): Body size similar, perhaps slightly smaller in tropicalis. Tail shorter (its length averages respectively 121 and 141 per cent of head and body length in tropicalis and difficilis). Upper parts brighter, not so blackish; ground color similar in each form, but in difficilis that color is largely obscured by black guard hairs on the back, head, and upper sides. Ears paler. Color of underparts, feet, and tail as in difficilis. Cranium smaller (see measurements), with relatively smaller brain case and relatively larger molar teeth.

Compared with infernatis (specimens of tropicalis from Veracruz lowlands; examples of infernatis from Teotitlán, Oaxaca). Similar in body size and tail length. Coloration much more rufescent (upper parts CinnamonBuff in infernatis); a stronger admixture of black on the nape, back, and sides; shoulders scarcely paler than sides (distinctly paler than sides in infernatis). Underparts darker on the average (Pinkish Cinnamon in tropicalis and Pale Pinkish Buff in infernatis). Ears and upper surface of tail darker. Brain case shallower and narrower (see measurements); zygomatic plate averaging relatively broader.

REMARKs:-The small cranium, short tail, and comparatively bright rufescent coloration are the principal identifying characteristics of this subspecies. In coloration tropicalis resembles nelsoni of western México. Both occur in tropical lowlands and appear to have similar ecological requirements, but there is no known direct continuity of their populations. The characters of tropicalis are best developed in the southern part of its range, as evidenced by the specimens from localities on that part of the coastal plain south of the latitude of Tuxpan. In the northern part and in the foothills of the Sierra Madre Oriental its characters grade respectively into those of intermedius and difficilis. The bright rufescent tones of the upper parts, characteristic of the race, are present in specimens from southeastern Tamaulipas and northeastern Veracruz. In those specimens the underparts are paler, and the cranium, brain case, and molar teeth average larger than in specimens from coastal areas to the south. Intergradation of tropicalis and difficilis is clearly indicated in the samples from Plan del Río, Cerro Gordo, Tlacotepec, and Potrero Viejo. The order in which those localities are listed represents 
degrees of morphological similarity to tropicalis and dissimilarity to difficilis. Although averaging slightly larger than specimens considered typical of tropicalis, the examples from Plan del Río and Cerro Gordo are referable to tropicalis on the basis of tail length, color, and size of brain case. Those from Tlacotepec and Potrero Viejo, intermediate in all characters, are here identified with difficilis. The same may be said of specimens from Pujal, Xilitla, and Tamazunchale. They are here included with tropicalis, but in a larger series the name difficilis might be required for the populations they represent. The specimens from Jalpán, Querétaro, are between tropicalis and griseoflavus. They are referred here to tropicalis. The specimen from Presidio has a monocolored tail.

Specimens EXAmined.-One hundred and fifteen from the following localities in México: Querétaro: Jalpán, 2500 ft., 4 (US). San Luis Potosí: Apetsco, $2500 \mathrm{ft}$., 6 (LSU); $10 \mathrm{mi}$. W Ebano, Hacienda Limón, 1 (LSU); $3 \mathrm{mi}$. W Naranjos, 1200 ft., 1 (LSU); Pujal, 300 ft., 2; Rancho Martínez, 500 ft., 1 (CM); Tamazunchale, $400 \mathrm{ft} ., 1$; vicinity of Tamuín, $160 \mathrm{ft}$., 4 (LSU); Valles, $300 \mathrm{ft}$., 1 (LSU). Tamaulipas: Sierra de Tamaulipas, vicinity of Acuña, 1600-3600 ft., 15; Altamira, 75 ft., 11 (US); Antiguo Morelos, 800 ft., 1; Ciudad Victoria, somewhere between 1100 and $3500 \mathrm{ft} ., 5$ (US); 5 mi. NE Gómez Farías, 1100 ft., 4; Hidalgo, 1000 ft., 9 (US). Veracruz: Boca del Río, 10 ft., 2 (Tex); Carrizal, $1000 \mathrm{ft}$., 5 (US); Catemaco, $1100 \mathrm{ft}$. ?, 1 (US); $4 \mathrm{mi}$. NNW Cerro Gordo, 1500 ft., 20 (KU); Nautla, 75 ft., 1; 9 mi. W Piedras Negras, 300 ft., 1 (KU); vicinity of Plan del Río, 900-1000 ft., 4 (1 Tex); Potrero Llano, $350 \mathrm{ft}$., 3 (KU); Presidio, 1000 ft., l; 12 mi. WNW Piedras Negras, Río Blanco, 3 (KU); San Carlos, 25 ft., 3 (CM); San Isidro, 100 ft., 2 (KU); Tampico Alto, $50 \mathrm{ft} ., 2$ (KU); 3 mi. S Tehuatlán, $700 \mathrm{ft} ., 1$ (KU).

\section{Reithrodontomys fulvescens difficilis Merriam}

Ochetodon mexicanus, Coues, 1877: 128 (part).

Reithrodontomys mexicanus, Allen, 1895a: 135 (part); Allen and Chapman, 1897b: 199.

Reithrodontomys difficilis Merriam, 1901: 556.

Reithrodontomys fulvescens difficilis, Howell, 1914: 50.

Type.-Adult male, skin and skull; U. S. Nat. Mus. Biol. Surv. Coll. No. 63735; México, Veracruz, Orizaba, 4500 feet elevation; collected 20 February 1894 by E. W. Nelson and E. A. Goldman; original No. 5868.

Distribution.-Humid eastern slopes of the Sierra Madre Oriental of eastern México. Known range from the vicinity of Orizaba north to the vicinity of San Agustín Hidalgo. Altitudinal range from 1500 feet near Tlacotepec to 6500 feet near Zacualpilla, Veracruz.

Habitat.-Moderately open stands of grass or brush in or bordering tropical evergreen and cloud forests. Specimens were collected in situations as follows: In open stands of sparse grass and brush on a hilltop adjoining a deep tropical barranca (near Jalapa). In grass and other low-lying vegetation on 
a south-facing slope; pine forests grew on surrounding hills and banana groves and pasturelands were present in the valley bottoms (Huauchinango). In low grass and widely spaced shrubs on the border of a stony cornfield; in tall grass and low shrubs bordering pine forest and cornfields (Pahuatlán).

CoMPARISONS.-See accounts of tropicalis, toltecus, and infernatis.

REMARKs.-The race difficilis is one of the darkest in $R$. fulvescens. Its dark reddish brown upper parts and cinnamon-colored venter are not unique in the species, for aurantius of southern United States and toltecus of Michoacán are similarly colored. Those features, however, distinguish difficilis from all known adjoining races and are comparatively constant over the range ascribed to the race. In coloration specimens from Huauchinango and Pahuatlán, Puebla, are quite similar to examples from Orizaba, Veracruz. They are also similar in size of brain case and of molar teeth. The tail averages relatively longer in the series from Huauchinango than in the samples from Orizaba. Intergradation with tropicalis, clearly evident in specimens at hand, occurs along the western border of the coastal lowlands, and the incidence of the characters of tropicalis or of difficilis in a sample appears to be related to distance from the base of the mountains (see accounts of tropicalis). Evidence of direct intergradation of difficilis with infernatis is lacking. A specimen from the vicinity of Zacualpilla agrees well enough externally with other specimens of difficilis, but cranially it belongs with toltecus.

Specrmens Examined.-One hundred from the following localities in México: Hidalgo: San Agustín, 3500 ft., 3. Puebla: Huauchinango, $5000 \mathrm{ft}$,, 38 (19 CM); Pahuatlán, $4500 \mathrm{ft} .$, 3. Veracruz: 6 mi. SW Jacales, $6500 \mathrm{ft} ., 1$ (KU); 11/2 mi. N Jalapa, 4500 ft., 2; 4 mi. SE Jalapa, $4800 \mathrm{ft} ., 1$ (MVZ); Jico, $4300 \mathrm{ft}$., 3 (CM); Mirador, $3500 \mathrm{ft}$. ?, 4 (1 NM, 2 US); Orizaba, 4000-4200 ft., 16 (US); Potrero Viejo, 1700 ft., 3 (KU); Río Blanco, 4200 ft., 1 (CM); Teocelo, 4500 ft., 22 (KU); 9 mi. ENE Tlacotepec, 1500 ft., 2 (KU); 4 mi. WSW Zacualpilla, $6500 \mathrm{ft} ., \mathrm{l}(\mathrm{KU})$.

\section{Reithrodontomys fulvescens tenuis Allen}

? Ochetodon mexicanus, Thomas, 1882: 372.

Reithrodontomys tenuis Allen, 1899: 15; 1906: 210.

Reithrodontomys fulvescens tenuis, Howell, 1914: 45 (part).

Type.-Adult female; British Mus. Nat. Hist.; México, Sinaloa, Rosario, elevation about 200 feet; collected 11 March 1897 by P. O. Simons.

Distribution.-Pacific coastal plain and adjoining foothills and valleys of southern Sonora, Sinaloa, extreme western Chihuahua and Durango, and northern Nayarit. Known geographic range from the vicinity of Álamos, Sonora, south to the vicinity of Tepic, Nayarit. Vertical range from near sea level at Mazatlán to 3000 feet near Tepic.

Habitat.-Presumably arid, tropical, deciduous forests and intermixed 
grasslands. Specific ecological information concerning the specimens examined is lacking.

Comparisons.-Compared with fulvescens (speciments of tenuis from southern Sinaloa; examples of fulvescens from north-central Sonora): Slightly smaller (head and body length averages $69 \mathrm{~mm}$. as against $73 \mathrm{~mm}$. in fulvescens): tail length similar. Coloration darker and more rufescent; general ground color of upper parts Pinkish Cinnamon or Cinnamon (compared with Pinkish Buff in fulvescens), darkened by an overlay of black on back and sides; underparts slightly more pigmented in tenuis (about Pale OchraceousBuff). Cranium similar in shape and most dimensions; molar teeth smaller in length (molar row length usually less than $3.4 \mathrm{~mm}$. in tenuis and more than $3.4 \mathrm{~mm}$. in fulvescens) and especially in breadth.

Compared with canus (specimens of tenuis from southern Sinaloa; examples of canus from Chihuahua): Slightly smaller. Darker and more rufescent dorsally and lacking the distinctly grayish color on head and shoulders; a slightly stronger cinnamon wash on underparts. Cranium similar in most dimensions, but rostrum shorter, hard palate shorter (averages $3.4 \mathrm{~mm}$. in tenuis, $3.7 \mathrm{~mm}$. in canus), and molar teeth shorter and narrower.

Compared with griseoflavus (specimens of tenuis from southern Sinaloa; examples of griseoflavus from Ameca, Jalisco): Size similar, perhaps slightly smaller. Coloration similar, but shoulders not markedly paler than back and sides, as in griseoflavus, and underparts more rufescent on the average. Similar in most cranial dimensions, but rostrum shorter and relatively broader. Zygomatic spread less, incisive foramina longer and broader (relative to length), and molar teeth slightly smaller. Postpalatal spine indistinct or lacking (prominent in griseoflavus).

REMARKs. $-R$. f. tenuis is a northern counterpart of $R$. f. nelsoni, though larger. Both are small, have distinctly reddish tones dorsally and ventrally, and are inhabitants of tropical lowlands. The 2 forms intergrade in Nayarit. Specimens from Alamos and Guirocoba, Sonora, are paler and less rufescent dorsally and ventrally than those from Agua Nueva and other localities in Sinaloa. In those features they grade toward examples of fulvescens from northern Sonora. Cranially, particularly in size of molars, they definitely are referable to tenuis. Externally tenuis is similar to griseoflavus, the 2 differing mainly in size and in intensity of the rufescent hues of the upper parts and underparts. The longer, narrower rostrum and incisive foramina and presence of a postpalatal spine set griseoflavus apart from tenuis. Specimens reported from Ciudad, Durango, by Thomas (1882: 372) under the name Ochetodon mexicanus are likely examples of $R$. megalotis zacatecae or $R$. fulvescens tenuis. I have not seen the specimens. If they are referable to tenuis they probably came from Ventanas, the other locality represented in Thomas' collection, rather than from Ciudad. Ventanas lies in the lowlands at an 
elevation of about 2000 feet. Ciudad is situated at an elevation of about 8000 feet northwest of San Dimás on the western slopes of the Sierra Madre in the drainage of the Río Piaxtla.

Specimens examined.-Thirty-five from the following localities in México: Chihuahua: near Batopilas, Las Guasimas, $2800 \mathrm{ft}$., 1 (US). Durango: Chacala, 1800 ft., 8 (US). Nayarit: Acaponeta, 200 ft., 1 (US); Tepic, 3000 ft., 2 (US). Sinaloa: 4 mi. NW Agua Nueva, 50 ft., 1 (MVZ); Altata, near sea level, 1 (US); 6 mi. E Mazatlán, Castillo, 300 ft., 4 (US); Culiacán, 1 (US); Escuinapa, 130 ft., 1 (MVZ); 21 mi. NE Rosario, Hacienda San José, 350 ft., 2 (MVZ); Sinaloa, $200 \mathrm{ft}$., 2 (US). Sonora: Guirocoba, $1500 \mathrm{ft}$., 3 (MVZ); vicinity of Álamos, in range $1500-4500 \mathrm{ft} ., 8$ (6 US, $2 \mathrm{MVZ}$ ).

\section{Reithrodontomys fulvescens nelsoni Howell}

Reithrodontomys fulvescens nelsoni Howell, 1914: 53.

Type.-Adult female, skin and skull; U. S. Nat. Mus. Biol. Surv. Coll. No. $\frac{\mathbf{3 3 4 0 9}}{45432}$; México, Colima, Colima, elevation about 1300 feet; collected 9 March 1892 by E. W. Nelson; original No. 2050.

Distribution.-Coastal valleys and adjoining lower slopes of the mountains of southern Nayarit, extreme western Jalisco, Colima, and probably southwestern Michoacán. Known range from the vicinity of Santa Isabel (intergrading area), 3800 feet, Nayarit, south at least to the vicinity of Colima, 1700 feet, Colima.

Habitat.-Tropical situations. Specimens from La Resolana were obtained in and adjoining a weed-covered, fallow cornfield in the midst of a tropical forest; the vegetation there was a mixture of broad-leafed deciduous and evergreen trees.

CoMPARIsOns.-Compared with griseoflavus (specimens of nelsoni from La Resolana; examples of griseoflavus from Ameca): Smaller (see measurements). Tail actually but not relatively shorter. Rufescent hues of pelage more intense; upper parts Orange-Cinnamon or Vinaceous-Cinnamon, darkened on the back by black hairs, but essentially the pure hue on the cheeks and sides; head and shoulders not paler than sides. Underparts rufescent, Pinkish Cinnamon or Vinaceous-Cinnamon on the average (compared with Light Pinkish Cinnamon in griseoflavus). Skull smaller (well seen in skull length and in zygomatic breadth); rostrum shorter (averages respectively 87 and 92 per cent of skull length in nelsoni and griseoflavus); incisive foramina relatively longer on the average.

Compared with tenuis (specimens of nelsoni from La Resolana; specimens of tenuis from southern Sinaloa): Similar in body size. Contrasts with tenuis in coloration in much the same way as it does with griseoflavus; the buffy hues of the upper parts and underparts more rufescent. Cranium smaller 
on the average, but the incisive foramina relatively longer and narrower; a postpalatal projection present (indistinct or absent in tenuis).

Compared with toltecus (specimens of nelsoni from La Resolana; examples of toltecus from Uruapan, Michoacán): Much smaller; tail actually and relatively shorter. Much less black over entire upper parts and sides; dorsal stripe narrower and less blackish. Ground color similar, perhaps nearer Orange-Cinnamon rather than Cinnamon as in toltecus. Cranium much smaller in all dimensions (see measurements).

REMARKs.-The small body and skull, orange-cinnamon pelage coloration, and long incisive foramina distinguish nelsoni from adjoining races of $R$. fulvescens. In coloration nelsoni resembles tropicalis which lives on the coastal plain of eastern México. Both are forms of coastal lowlands where the vegetation and climate are tropical. The similar characters of the 2 races appear to be parallel responses to like enviroments. $N$. f. nelsoni apparently occurs only on the coastal tropical slopes of the Sierra Madre. Toward the interior it gives way to griseoflawus; for further discussion on this point see the accounts of griseoflavus. The northern and southern limits of the range of nelsoni are yet to be determined.

Specimens examined.-Fifty-two from the following localities in México: 3 mi. W Colima, Rancho del Ralcón, 1700 ft., 6 (US). Jalisco: 2 mi. N La Resolana, 1200 ft., 38; San Sebastián, 8 (US).

\section{Reithrodontomys fulvescens mustelinus Howell}

Reithrodontomys fulvescens mustelinus Howell, 1914: 54; Davis, 1944: 392; Hooper, 1947: 49. Reithrodontomys fulvescens tenuis, Hall and Villa, 1949c: 457 (part); 1950: 192 (part).

Type.-Adult female, skin and skull; U.S. Nat. Mus. Biol. Surv. Coll. No. 71549; México, Oaxaca, Llano Grande, elevation 300 feet; collected 18 February 1895 by E. W. Nelson and E. A. Goldman; original No. 7483.

Distribution.-Pacific coastal slopes of the Sierra Madre del Sur in southwestern Oaxaca and southern Guerrero and the slopes bounding the Balsas Basin in Michoacán, Morelos, Puebla, and Guerrero. Known range from Llano Grande, Oaxaca, northwest to Chilpancingo, Guerrero, thence north to Tepoztlán and Yautepec, Morelos. Altitudinal range from 300 feet at Llano Grande to 6000 feet at Tepoztlán.

Habitat.-Specimens were collected in situations as follows: Along rock fences and in fallow cornfields (the tall weeds in the fields formed a canopy about 6 feet above ground but left much open space near ground level); in brush at the base of a cliff (Tepoztlán). On grassy rolling hills; in a dry barranca sparsely covered with short grass and with a few shrubs and cypress trees (vicinity of Chilpancingo).

Comparisons.-Compared with helvolus (specimens of mustelinus from Chilpancingo; topotypes of helvolus): Similar in size and tail length. Colora- 
tion of upper parts and underparts darker and richer (rufescent) in mustelinus. Sides, rump, and cheeks Pinkish Cinnamon to Orange-Cinnamon; foreliead, nape, and back a mixture of black and Pinkish Cinnamon, the black predominant in fresh pelages and forming a broad dorsal stripe (less black on upper parts in helvolus). Underparts Pinkish Cinnamon, compared with Pale Pinkish Buff in helvolus. Brain case relatively larger, frontals narrower interorbitally, and molar teeth smaller.

Compared with nelsoni (specimens of mustelinus from Chilpancingo; specimens of nelsoni from La Resolana, Jalisco): Similar in body size; tail longer (averages 141 per cent of head and body, compared with 124 per cent in nelsoni). Coloration similar in tone but that of mustelinus less intensely orange dorsally and ventrally than that of nelsoni. Cranium larger (well seen in length of skull and breadth of brain case); rostrum relatively longer (averages 91 per cent and 88 per cent of brain case depth respectively in mustelinus and nelsoni); palate relatively longer; incisive foramina relatively shorter (the averages respectively 52 and 54 per cent of brain case depth); auditory bullae relatively smaller. Posterior border of palate convex and usually prolonged medially into a spine (as in nelsoni).

REMARKs.-Information concerning variation in $R$. fulvescens in the Río Balsas Basin and adjoining areas is scanty and thus the variations cannot be completely understood until many more localities are sampled. Like some other regions in Latin America it is topographically and climatically diverse. Distinctly different enviroments, small or large in extent, lie in juxtaposition and interlace in many areas. In such regions many adequate samples are necessary for a satisfactory appraisal of geographic variation. Few are here available.

Color, size, and some cranial proportions seemingly not entirely a function of skull size apparently are distributed independently in the region. Palest tones obtain in the specimens from southeastern Puebla and northern Oaxaca (Tepanco, Tehuacán, and Teotitlán). In those the upper parts are distinctly buffy, the shoulders and nape grayish buff, the midback scarcely darker than the sides, and the underparts pale buff. Deeper tones are observed in specimens from areas to the west-the Balsas Basin (Tepoztlán, Tetecala, and Teloloapan and Tacámbaro), the central highlands of Oaxaca (Oaxaca City and Sola de la Vega), and the backbone of the Sierra Madre del Sur (Chilpancingo)-culminating in rich orange-buffy upper parts (including shoulders), blackish midback and rufescent underparts, as seen in specimens from La Resolana, Jalisco, and Colima, Colima. Between the 2 extremes-Teotitlán and La Resolana-various intermediate stages are represented. The specimens from Oaxaca City are near the midpoint in characters of coloration. Those from Tepoztlán, Tetecala, Teloloapan, and Tacámbaro have more red and black on the upper parts, thus falling nearer the colora- 
tion obtaining at La Resolana. The Chilpancingo series is quite variable. Some examples are as richly pigmented dorsally and ventrally as specimens from La Resolana; others match specimens from Oaxaca City. That series indicates that Chilpancingo lies in an intergrading area where coastal populations with characters of coloration (and of size and cranium as pointed out below) like those of the Resolana and Colima material intermix with highland populations that morphologically resemble those at Oaxaca City.

Variations in size of body and skull fall into a different geographic pattern. The samples from the Pacific lowlands (La Resolana and Colima), the fringe of the Balsas Basin (Tacámbaro, Teloloapan, Tetecala, Tepoztlán) and the eastern interior (Tepanco, Tehuacán, and Teotitlán) are small, with a body length of $65-70 \mathrm{~mm}$. and a skull length centering around $21.0 \mathrm{~mm}$. The molar teeth in those samples are narrow and short. Larger size obtains in specimens from the central highlands (Oaxaca City and Sola de la Vega), in which the body length is $77 \mathrm{~mm}$. and the skull length over $22.0 \mathrm{~mm}$. on the average; the molars are comparatively large. The sample from Chilpancingo is as variable in size as it is in color, and probably for the same reason as indicated above.

The distribution of some cranial features apparently does not always correspond to that of size and color traits. In the specimens from the Oaxacan highlands the frontal bones of the skull are flat and broad; in some instances they project as a narrow shelf over the orbits. This condition also obtains in specimens from Teloloapan and to a lesser degree in examples from Tacámbaro, Tepoztlán, and Tehuacán. The frontals are relatively narrower in the Chilpancingo sample and narrowest and dorsally most convex in the samples from Teotitlán and Resolana. The specimens from Resolana have relatively broad rostra and long incisive foramina as do those from Chilpancingo, Sola de la Vega, and Oaxaca City. The rostrum is narrow and the foramina are relatively short in the specimens from Teotitlán. The Balsas Basin material is intermediate in these features. In the series from Chilpancingo the brain case is relatively larger than in any other sample from the region.

In terms of geographical forms (subspecies or lesser units) the variation in skin and skull in the region around the Balsas Basin appears to be as follows: There is a form in the eastern interior (Teotitlán, Tehuacán, and Tepanco) characterized by pale coloration, small size, and narrow rostrum and frontals. It is formally recognized under the name infernatis. Another form occupies the Oaxacan highlands. It is larger and darker; it has a long tail, broad flat frontals, and a long broad rostrum; it is unique in size of the molar teeth. It is known by the name helvolus. A still more intensely pigmented form, small in size of body and skull and with a short broad rostrum, comparatively convex frontals, short palate, and long incisive 
foramina, occupies that part of the Pacific lowlands which is to the west and north of the Balsas Basin. It is $R$. f. nelsoni. On the Pacific slopes of Guerrero there is another form that probably resembles nelsoni more than is indicated by the samples from Chilpancingo. As now known it is characterized by orange-buffy pelage tones, a pronounced blackish dorsal stripe, moderate size, relatively broad brain case, moderately broad frontals, and long broad rostrum. The name mustelinus is applied to it. Finally, on the flanks of the Balsas Basin there are populations that in the characters of skin and skull are variously intermediate between those of adjoining populations; some characters may be peculiar to them. As now sampled they appear to be small in body and skull, to be moderately rufescent in pelage coloration, and to have broad frontals and small teeth. Pending acquisition of adequate material from the Basin they are here identified with mustelinus.

From the preceding remarks it should be clear that the specimens from Chilpancingo are considered atypical of mustelinus. They are employed in the diagnosis of that race simply because they constitute the only large sample from the area where the characters of mustelinus are to be expected. An adequate sample from the Llano Grande should be more satisfactory, not because that is the type locality, but because it is situated in the coastal lowlands where the characters of mustelinus probably are best developed.

SPECIMENS ExAmINED.-Sixty-four from the following localities in México: Guerrero: Acapulco, near sea level, 1 (US); vicinity of Chilpancingo, 43004500 ft., 33 (8 CM, 4 MVZ, 5 Tex); Cuapongo, 1 (MVZ); Teloloapan, 5400 ft., 4. Michoacán: 11/2-6 mi. S Tacámbaro, 4000-5700 ft., 19 (MVZ). Morelos: Cuernavaca, $5000 \mathrm{ft}$., 2 (1 NM, 1 US); 1 mi. W Tepoztlán, $6000 \mathrm{ft}$., 6; Tetecala, 4000 ft., 1 (CM); Yautepec, 4000 ft., 1 (US). Oaxaca: Llano Grande, $300 \mathrm{ft.?,} 2$ (US).

\section{Reithrodontomys fulvescens infernatis Hooper}

Ochetodon mexicanus, Coues, 1877: 128 (part); Alston, 1879: 151 (part).

Reithrodontomys mexicanus, Allen, 1894: 319; 1895a: 135.

Reithrodontomys fulvescens difficilis, Howell, 1914: 51 (part).

Reithrodontomys fulvescens helvolus, Hooper, 1947: 49.

Reithrodontomys fulvescens infernatis Hooper, 1950b: 167.

Type.-Young adult male, skin and skull; Univ. Mich. Mus. Zool. No. 91470; México, Oaxaca, Teotitlán, 3100 feet elevation; collected 26 February 1947 by Helmuth O. Wagner; original No. 2728.

Distribution.-Extreme southeastern Puebla and northern Oaxaca. Known range confined to the areas drained by the Salado and Quiotepec rivers, from the vicinity of Teotitlán, 3100 feet, Oaxaca, north to Tepanco, 5700 feet, Puebla.

Habitat.-Mesquite-cactus desert. Specimens were obtained in situations as follows: In the grassy border of a cornfield in mesquite desert (Tepanco). 
Along fence rows bordering cultivated areas; the terrain around the cultivated areas is arid, the ground sandy and rocky, sparsely covered with cactus, mesquite and other xerophytic plants (Tehuacán). Among short grass, shrubs, and cactus (Teotitlán).

Comparisons.-Compared with helvolus (topotypes of infernatis; topotypes of helvolus): Smaller (see measurements). Pelage paler dorsally (distinctly a warmer, more rufescent tone of buff in helvolus and a greater admixture of black on head and back). Interorbital diameter less (respectively 37 and 40 per cent of depth of cranium); rostrum relatively narrower and molar teeth narrower and shorter on the average.

Compared with mustelinus (topotypes of infernatis; specimens of mustelinus from Chilpancingo): Smaller (see measurements). The contrast in coloration obtaining between infernatis and helvolus is emphasized as regards infernatis and mustelinus; the latter is decidedly rufescent dorsally and ventrally and has a distinct dorsal stripe and rufescent shoulders. Cranium smaller in infernatis, with relatively smaller rostral and interorbital diameters and smaller molar teeth.

Compared with difficilis (topotypes of infernatis; topotypes of difficilis): Similar in size. Contrasting greatly in coloration; upper parts buffy (Cinnamon-Buff) instead of rich reddish brown (Orange-Cinnamon heavily intermixed with black in difficilis); ears and upper surface of tail paler (Hair Brown rather than Fuscous or Fuscous-Black). Underparts similarly less pigmented (Pale Pinkish-Buff rather than Orange-Cinnamon). Brain case distinctly smaller, particularly in length and depth; frontal bones narrower interorbitally.

Compared with toltecus (topotypes of infernatis; specimens of toltecus from Distrito Federal): Smaller (see measurements). Less black on upper parts; color of head, nape, and foreback scarcely different from that of remainder of back (head, nape, and foreback dark gray in toltecus); underparts slightly more rufescent in toltecus. Cranium much smaller in all dimensions; length of rostrum, incisive foramina, and molar row each relatively less in infernatis.

Remarks.-As now known the range of infernatis is restricted to the interior basin drained by several streams which join to form the Río Tuxtepec and Río Santo Domingo and, farther eastward, the Río Papaloapan (Map 5). Lying in the rain shadow of moisture-laden winds from the Gulf of Mexico, the basin is exceedingly dry and warm. The desert-like aspect of its flora and fauna stands in strong contrast to that of the biota found in rain and cloud forests a few miles away on the eastern side of mountains. Among the species of $R$. fulvescens the pale coloration of infernatis is equaled or exceeded only in canus and fulvescens.

The specimens from Tehuacán and Tepanco average slightly larger than 
those from Teotitlán; otherwise those samples match closely. For discussion of intergradation with races to the west see the accounts of mustelinus.

SPECIMENS EXAMINED.-Eighteen from the following localities in México: Oaxaca: Teotitlán, 3100 ft., 8. Puebla: Tehuacán, 5400 ft., 5 (l US); Tepanco, $6000 \mathrm{ft} ., 5$.

\section{Reithrodontomys fulvescens helvolus Merriam}

Reithrodontomys griseoflavus helvolus Merriam, 1901: 554.

Reithrodontomys fulvescens helvolus Howell, 1914: 52; Hooper, 1947: 49.

TrPe.-Adult female, skin and skull; U.S. Nat. Mus. Biol. Surv. Coll. No. 68387; México, Oaxaca, Oaxaca, about 5000 feet elevation; collected 14 August 1894 by E. W. Nelson and E. A. Goldman; original No. 6576.

Distribution.-Sierra Madre del Sur in Oaxaca and probably in eastern Guerrero. Known range from the vicinity of Oaxaca City south to Sola de la Vega and east to Nejapa. Vertical range from 1900 feet at Nejapa to 5000 leet at Oaxaca City.

Habitat.-Semiarid lands sparsely covered with mesquite, thorny shrubs, brush, scrub oak, and juniper. Specimens were obtained in situations as follows: In sparse grass under scattered oaks and junipers on a dry slope (Sola de la Vega). In short grass and brush on sandy soil (Nejapa).

Comparisons.-Compared with toltecus (topotypes of helvolus; specimens of toltecus from Distrito Federal): Similar in body size and tail length. Upper parts of helvolus paler; ground color Pinkish Cinnamon, intermixed with black on back and head; shoulders paler than sides, their ground color near Light Pinkish Cinnamon. In toltecus ground color between Pinkish Cinnamon and Cinnamon-Buff, intermixed abundantly with black on forehead, nape, back, and upper sides; forehead, nape, and foreback dark gray. Underparts slightly less rufescent than in toltecus. Cranium smaller (see measurements); frontal bones actually and relatively broader (averaging 40 per cent of depth of cranium compared with 37 per cent in toltecus); incisive foramina relatively much shorter (respectively 53 and 57 per cent of depth of cranium); molars actually and relatively smaller; postpalatal spine less distinct.

For other comparisons see accounts of mustelinus, infernatis, and amoenus.

REMARKs.-The large body, long tail, broad frontals, and large molar teeth are the principal distinguishing characters of helvolus. An inhabitant of the central highlands of Oaxaca, it probably occurs chiefly within the altitudinal range 3000-6000 feet and at lesser elevations intergrades with lowland forms. Two specimens from Nejapa, 1900 feet, are slightly smaller and more rufescent than topotypes of helvolus, in which features they approach amoenus. Their broad frontals, long palates, and large molar teeth, however, require that they be referred to helvolus. A juvenile, skin without skull, from Nochixtlán is identified with helvolus on geographic grounds 
only. Other remarks pertaining to helvolus are to be found in the accounts of mustelinus.

Specimens examined.-Twenty-nine from the following localities in México: Guerrero: Tlalixtaquilla, 4200 ft.?, 1 (US); Tlapa, 3000 ft., 1 (US). Oaxaca: Huajuapan, 5000 ft., 2 (1 US); Nejapa, 1900 ft., 2; Nochixtlán, $6200 \mathrm{ft} ., 1$; vicinity of Oaxaca, $5000 \mathrm{ft}$., 18 (US); Sola de la Vega, $5000 \mathrm{ft}$., 2; 6 mi. SE Totolapan, 4000 ft.?, 1 (US); near Yalalag, 3000 ft., 1 (US).

\section{Reithrodontomys fulvescens amoenus Elliot}

Rhithrodontomys amoenus Elliot, 1905: 234.

Reithrodontomys amoenus, Howell, 1914: 55.

Type.-Adult female, skin and skull; Chicago Nat. Hist. Mus. No. 14064; México, Oaxaca, Reforma, about 500 feet elevation: collected 6 April 1904 by Edmund Heller; original No. 3823.

Distribution.-Known only from the type locality but probably ranging to the west and east on the Pacific coastal lowlands of Oaxaca and of southwestern Chiapas.

Habitat.-Presumably grass and brush in tropical deciduous forest. No information on habitat is available.

CoMPARISONs.-Compared with helvolus (topotypes of amoenus; topotypes of helvolus): Much smaller. Tail actually and relatively shorter (see measurements). Upper parts similar in hue but darker in tone (between Cinnamon and Orange-Cinnamon rather than Pinkish Cinnamon as in helvolus); head, sides, and back similarly colored (head and back grizzled in helvolus); mass effect of upper parts distinctly more rufescent than in helvolus. Underparts and remainder of pelage similar in the 2 forms. Cranium much smaller in all dimensions (see measurements). Relative to depth of cranium, rostrum broader, incisive foramina longer, and mesopterygoid fossa broader than in helvolus.

Compared with mustelinus (topotypes of amoenus; specimens of mustelinus from Chilpancingo, Guerrero); Body size and tail length less in amoenus (see measurements). Upper parts brighter (with less intermixture of black) and underparts paler (Pale Pinkish Buff). Coloration otherwise similar to that of mustelinus. Smaller in all cranial dimensions but rostrum and mesopterygoid fossa relatively broader, incisive foramina relatively longer, and palate relatively shorter. The 2 skulls of amoenus at hand lack a postpalatal spine.

REMARks.-Clearly examples of $R$. fulvescens, the 2 known specimens from Reforma, including the type of amoenus, appear to represent a distinct geographic race that inhabits the lowlands of southeastern Oaxaca and perhaps of southwestern Chiapas. Amoenus apparently is well differentiated from chiapensis, of the interior valleys and mountains of Chiapas, but no more 
than other coastal races of $R$. fulvescens are distinct from near-by inland subspecies (nelsoni versus griseoflavus and tenuis versus canus, for example). In its morphological characters and geographic position it relates to chiapensis as nelsoni pertains to griseoflavus. Compared to their inland neighbors, each of those coastal races, amoenus and nelsoni, is small in size of body and of skull, is rufescent dorsally, and has a short rostrum and relatively long incisive foramina. That amoenus probably intergrades with chiapensis is suggested by specimens from Cintalapa, in the arid lowlands of western Chiapas. These are referable to chiapensis, but they average smaller and brighter dorsally (less black overlay) than the specimens from localities in Chiapas that are higher altitudinally and climatically. In size and coloration the Cintalapan specimens grade toward amoenus.

Three specimens from Villa Flores and one from Jaltenango have come to hand after detailed comparisons were completed and borrowed specimens were returned to museums. The 4 examples resemble the specimens from Cintalapa in coloration and they are further like all but one of those specimens in being smaller than topotypes of chiapensis. In size they fall between chiapensis and amoenus. All are referred to chiapensis, but larger samples obtained later may indicate that the name amoenus better applies to the populations of the foothills south of the Río de Chiapa Valley.

Insofar as known, $R$. fulvescens does not occur on the Pacific slopes of Guatemala and southeastern Chiapas. The specimens recorded from $\mathrm{Ha}$ cienda California, near Ocós, Guatemala (Goodwin, 1934: 35) under the name $R$. f. chiapensis are examples of Oryzomys.

Specimens examined.-Mexico, Oaxaca, Reforma, 500 ft., 2 (GM).

\section{Reithrodontomys fulvescens chiapensis Howell}

Reithrodontomys fulvescens chiapensis Howell, 1914: 53; Goodwin, 1934: 35; 1942: 158; Hooper, 1947: 49.

Type.-Adult male, skin and skull; U.S. Nat. Mus. Biol. Surv. Coll. No. 132865; México, Chiapas, Canjob, elevation about 5000 feet; collected 2 May 1904 by E. W. Nelson and E. A. Goldman; original No. 16741.

Distribution.-Arid interior valleys and slopes of Chiapas, Guatemala, El Salvador, and Honduras. Known range from the vicinity of Cintalapa and Bochil, Chiapas, southeast to Volcán San Miguel, El Salvador, and to the vicinity of Tegucigalpa, Honduras, but excluding the Pacific coastal drainages of southern Chiapas and western Guatemala. Known vertical range from 1800 feet at Cintalapa to 5700 feet in the vicinity of Comitán.

HaBitat.-Arid situations-in cactus and thorny shrub desert, dry oak forests, and savanna. Specimens were obtained in places as follows: In grass and oak brush near a cornfield (Bochil). In a thicket in an abandoned cornfield (Chanquejelve). On dry, heavily-grazed grassland dotted with scrub 
oak, pines, and small thickets (near Salamá). In broom sedge among scrub oak, thorny vines and shrubs, and arborescent cacti (Lago Atescatempa). In a rock fence; in stands of dry grass among acacia, cactus, and other xerophytic plants (near Sacapulas). In high grass in an overgrown cornfield; on a dry slope dotted with brush (Villa Flores).

Comparisons.-Compared with amoenus (topotypes of chiapensis; topotypes of amoenus): On the average larger and darker dorsally. Cranium averages larger, with larger molar teeth and auditory bullae, longer rostrum, larger brain case, and relatively shorter incisive foramina.

Compared with helvolus (topotypes of chiapensis; topotypes of helvolus): Smaller (see measurements). Apparently indistinguishable in coloration. Cranium shallower (its depth averages $8.2 \mathrm{~mm}$., compared with $8.6 \mathrm{~mm}$. in helvolus); frontals narrower interorbitally; incisive foramina shorter and relatively broader; molar teeth smaller; mesopterygoid fossa relatively broader.

Remarks.-In specimens from Salamá and Lake Atescatempa, Guatemala, and from localities in El Salvador and Honduras, the tail is actually and relatively longer than it is in material from Sacapulas, Guatemala, and from localities in Chiapas. In addition the specimens from the Central American localities are paler on the average than those from Chiapas. In 2 individuals from El Salvador, one from Volcán San Miguel and the other from Cerro Cacaguatique, the rostrum is relatively broader than in most other specimens of $R$. fulvescens. Whether any of those items are characteristics of the populations that the samples represent cannot be clearly estimated from the material at hand. Apparent color differences, as between the Central American and the Mexican specimens, cannot be trusted because most of the specimens are molting and many are young.

Examples from Cintalapa on the average are smaller, less blackish dorsally, and slightly more pigmented ventrally than those from Canjob and other localities to the south. Two of the 3 skulls approach topotypes of amoenus in size of bullae, brain case, and rostrum; in these same features the third resembles specimens from Canjob and from localities in Guatemala. When the range of individual variation of amoenus is better known, that range may well include the Cintalapan populations.

SPecimens ExAmined.-Thirty-nine from localities as follows: Guatemala. Baja Verapaz: 6 mi. NNE Salamá, $5500 \mathrm{ft}$., 2 (US). El Quiché: 41/2 mi. W Sacapulas, $4300 \mathrm{ft}$., 5 (US). Huehuetenango: Chanquejelve, $5000 \mathrm{ft}$., 5 (AM); Jutiapa: Lago Atescatempa, 2500 ft., 1 (US). El Salvador. San Miguel: Cerro Cacaguatique, 3500 ft., 1 (MVZ); Volcán San Miguel, 4300 ft., 2 (MVZ). Honduras. Francisco Morazán: La Flor Archaga, 4500-5000 ft., 1. México. Chiapas: near Bochil, 4300 ft., 2; Canjob, 5000 ft., 4 (US); Cintalapa, 1800 ft., 7; vicinity of Comitán, $5700 \mathrm{ft.}, 2$ (1 US); Jaltenango, $2300 \mathrm{ft}$., 1; Ocozoco- 
autla, 2300 ft., 1; San Bartolomé, 2600 ft., 1 (US); San Vicente, 4000 ft. ?, 1 (US); Villa Flores, 2000 ft., 3.

\section{Reithrodontomys hirsutus}

(Maps 6, 12; P1s. II, III; Fig. 16)

Reithrodontomys hirsutus is a monotypic species. As now known it occurs only in a small segment of west-central México in the states of Jalisco and Nayarit. It is a distinctive species of the genus; externally and cranially it largely bridges the morphological gap between Reithrodontomys and Aporodon. Some of its characters are shared only with species of Aporodon, especially $R$. gracilis. Other characters are seen also in fulvescens of the subgenus Reithrodontomys. Hirsutus is here treated as a specialized member of the latter subgenus. Its nearest extant relative appears to be $R$. fulvescens. The 2 species comprise the fulvescens group.

Comparisons. $-R$. hirsutus is approximately as large as $R$. mexicanus cherriei or $R$. sumichrasti luteolus (see measurements). In coloration it resembles pale races of $R$. fulvescens and $R$. gracilis. The peculiar "streaked" appearance of the upper parts that is so characteristic of those species is accented even more in hirsutus. The monocolor or faintly bicolor tail and slightly dusky hind feet are essentially matched in species of Aporodon and are seen in some specimens of sumichrasti and chrysopsis. The coarse scalation of the tail is also observed in fulvescens. In general, the shape and proportions of the skull are those of an enlarged fulvescens, although there are features that are peculiar to hirsutus and there are other details that call to mind skulls of mexicanus or gracilis. It is distinguishable from all species of the genus except fulvescens in characters of $\mathrm{M}_{3}$. In that tooth there are 2 long enamel folds, the major and the first primary. They are about equal in length. Neither the major fold nor the second primary fold, if present, forms an internal fold which with wear is isolated as an enamel island. $\mathbf{M}_{3}$ of hirsutus is essentially identical with that of fulvescens and unlike that of any other species of the genus (Figs. 5, 24). $\mathrm{M}^{3}$ likewise is similar in those 2 species (Figs. 4, 24); however, slight mesolophs sometimes occur in hirsutus. Insofar as is known mesolophs are always lacking in $\mathrm{M}^{3}$ in fulvescens, although they may be present in $\mathrm{M}^{1-2}$ in fulvescens as well as in hirsutus (Fig. 16). The large size, monocolor tail, faintly dusky hind feet, narrow zygomatic plate, and small auditory bullae distinguish hirsutus from fulvescens. $R$. fulvescens is the only species known to occur in the same habitat with hirsutus. R. megalotis and $R$. sumichrasti also are found within the geographic range of hirsutus but not in its habitat. The following characters of hirsutus will distinguish it from megalotis: large size, long monocolor and essentially bare tail, dusky hind feet, narrow zygomatic plate, small auditory bullae, and mesolophs in $\mathrm{M}^{1-2}$. Characteristics of $\mathrm{M}_{3}^{\frac{3}{3}}$ are absolutely diagnostic (see ac- 
counts of the subgenus Reithrodontomys). $R$. sumichrasti is much more intensely pigmented dorsally and ventrally than is hirsutus. It is further distinct from that species in breadth of zygomatic plate, length of rostrum, size of auditory bullae, and in characters of the molar teeth. The pattern in $M \frac{3}{3}$ of sumichrasti is like that of megalotis and all other species of the subgenus Reithrodontomys save hirsutus and fulvescens.

Relationships.-There is some question about the systematic position and affinities of hirsutus. It exhibits diagnostic characters of both subgenera. Morphologically it appears to lie near the midpoint between Aporodon and Reithrodontomys. In size of zygomatic plate, pterygoid fossae, auditory bullae, brain case, and in a characteristic of the tail, hirsutus resembles gracilis and mexicanus of Aporodon rather than any species of the subgenus Reithrodontomys. On the basis of those characters, some of which are key characters of the subgenera, hirsutus should be referred to Aporodon. I doubt that it belongs in Aporodon. Its assignment there probably would express unnatural relationships. The other morphological characteristics of hirsutus and the few facts known of the ecology of that species suggest that it is most closely related to fulvescens. It seems probable that both species stemmed from a common ancestral stock that was itself nearer the Reithrodontomys line than that of Aporodon. I believe that the resemblances of hirsutus and species of Aporodon are not as indicative of close relationships as the nature of those resemblances might first suggest. They seem to be parallel specializations in the 2 phyletic lines of the genus. In both Aporodon and Reithrodontomys, excluding hirsutus for the moment, apparently there is an evolutionary trend toward reduction in size of the zygomatic plate, zygomatic notch, and pterygoid fossae, and toward increase in size of body and skull (particularly the brain case), and in length of tail. I interpret these as evidences of increasing specialization obtaining in a parallel fashion in those 2 phyletic lines. $R$. hirsutus appears to me as a specialized fulvescens. In attempting to visualize the appearance of $R$. fulvescens, were it to become much more specialized in accordance with the observed trends in specialization, I come up with a structural plan that closely resembles that of hirsutus. Those 2 species bear about the same structural and distributional relationship to each other as chrysopsis bears to megalotis or as tenuirostris bears to mexicanus. Accordingly, hirsutus and fulvescens are here assembled as the fulvescens species group which, it is inferred, represents a separate offshoot from the Reithrodontomys phyletic line.

\section{Reithrodontomys hirsutus}

Reithrodontomys hirsutus Merriam, 1901: 553; Howell, 1914: 66.

Reithrodontomys levipes Merriam, 1901: 554; Howell, 1914: 64. México, Jalisco, San Sebastián.

Type.-Adult male, skin and skull: U. S. Nat. Mus. Biol. Surv. Coll. No. 
82200; México, Jalisco, Ameca, 4000 feet elevation; collected 15 February 1897 by E. W. Nelson and E. A. Goldman; original No. 10537.

Distribution.-Moderate elevations in the mountains of western Jalisco and southern Nayarit. Known range from Santa Isabel, Nayarit, south to the

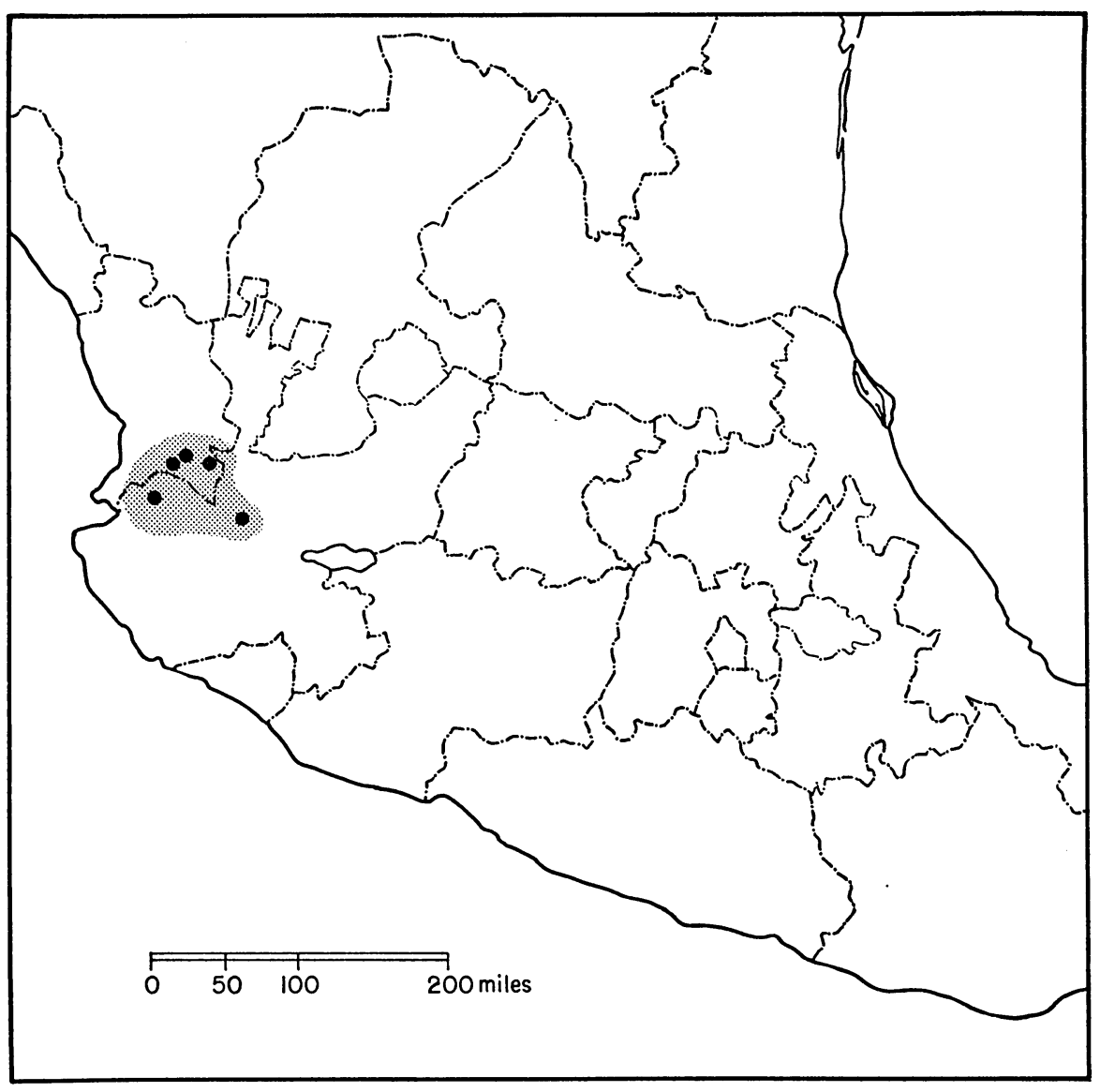

MaP 6. Distribution of Reithrodontomys hirsutus, as determined from specimens examined.

Sierra de San Sebastián and east to Ameca, Jalisco. Altitudinal range from 3000 feet near San José del Conde to 4000 feet at Ameca.

HABITAT.-Well-drained situations on steep, rocky hillsides and cut-banks with sparse, brushy, and mostly deciduous ground cover. The specimens were collected in situations as follows: On open ground and among lava boulders and deciduous brush (4-8 ft. in height) on a $30-40$ degree slope of a canyon, in the bottom of which was a permanent stream lined with tropical evergreen trees (near Santa Isabel). On bare ground among well-spaced, small, 
thorny trees (San José del Conde). One specimen on a fallen tree and another at the foot of a banana tree, both bordering a small stream at the base of a dry cut-bank (Ixtlán). Among sparse grass, brush, and small trees (some thorny and deciduous), on the slopes of a dry barranca (Ameca). $R$. fulvescens occurs in the same areas with $R$. hirsutus, and specimens of each species may be collected a few feet apart in a trap line. $R$. fulvescens apparently prefers moderately dense cover close to the ground, such as is provided by grass 3 to 4 feet high and by low-growing shrubs, while hirsutus is found in open situations, as under brush with little or no immediate ground cover.

Characters.-Size: Large (see measurements). Tail length usually over $100 \mathrm{~mm}$., about one-third greater than head and body length.

Color: Fresh adult pelage (May) from Santa Isabel: Upper parts Cinnamon or Clay Color streaked with black, the black hairs few and rather evenly distributed over entire dorsum and sides but absent in a lateral line extending from the base of the vibrissae posteriad across cheeks and lower sides to the base of the tail. Circumorbital area same color as forehead and back. Underparts and undersides of hind legs varying from Pinkish Cinnamon or Light Pinkish Cinnamon to Cinnamon-Buff or Pinkish Buff. Under surface of forelegs Pale Pinkish Buff. Hairs of throat Pale Pinkish Buff throughout, elsewhere on body Blackish Plumbeous basally. Pinnae Chaetura Drab, sprinkled externally with blackish hairs and internally with Cinnamon and black hairs. Tail Fuscous dorsally, scarcely or not at all paler below; its scalation coarse as in fulvescens (unlike the fine annulations seen in Aporodon), scarcely obscured by the few short whitish hairs. Forefeet whitish or Pinkish Buff. Ankles Fuscous or Fuscous-Black bordered laterally and medially by a narrow band of Pinkish Buff. Upper surface of hind foot with a wedgeshaped area of Fuscous rimmed with Pinkish Buff extending almost or entirely to the toes; toes and remainder of upper surface whitish or Pinkish Buff. Fresh subadult pelage (April) from Ameca: Similar to adult pelage but paler dorsally (Cinnamon-Buff to Pinkish Buff) and ventrally (Pinkish Buff to Pale Pinkish Buff).

Skull: Brain case large (see measurements). Rostrum broad (4.1-4.6 mm.) and moderately long. Zygomata broad, the spread from the skull slightly less anteriorly than posteriorly. Interorbital area narrow (its least diameter about $0.5-1.5 \mathrm{~mm}$. less than the rostral breadth). Supraorbital border shelflike and sometimes beaded, particularly in old individuals. Zygomatic plate narrow, slightly broader than the mesopterygoid fossa. Zygomatic notch shallow, as in $R$. sumichrasti and often in $R$. fulvescens. Sphenopalatine vacuities narrow slits. Auditory bullae small, about the same size as in $R$. fulvescens, thus relatively much smaller in hirsutus. Molar teeth comparatively small, about the same absolute size as in the large-sized races of $R$. fulvescens; thus relatively smaller in hirsutus. Mesolophs in $\mathrm{M}^{1-2}$ usually extending to 
the labial margin of the tooth and fused with mesostyles; mesoloph present or absent in $\mathrm{M}^{3}$. Primary folds of $\mathrm{M}^{1-2}$ usually divided into labial and lingual (internal) segments. Ectostylids present. No mesolophids.

Remarks. -I can find no characters which will permit the recognition of levipes. The 3 specimens from San Sebastián, the type locality of that nominal form, are smaller than most of the other examples at hand, but they are also younger than most of those examples. While not falling definitely within the known size range of the series from Ameca, the San Sebastián specimens do fit within the large series from Santa Isabel, a series which is not significantly different from the Amecan sample. It is clear that hirsutus and levipes are one and the same species and on the basis of present samples the populations from the vicinity of San Sebastián cannot justifiably be treated as subspecifically different.

Howell's evidence of hybridization of hirsutus and fulvescens has been reviewed in light of the more complete data on variation now available. He thought that mesostyles and mesolophs occur in hirsutus but not in fulvescens; therefore he interpreted (1914: 65) the presence of mesostyles and mesolophs in 3 specimens of fulvescens from San Sebastián as evidence of interbreeding of the 2 species. It is highly improbable that those specimens are hybrids. Mesostyles and incomplete mesolophs occur in many specimens of undoubted fulvescens from several localities in México. It is clear that those structures are incompletely fixed in the species (Fig. 16). There is no evidence at hand that hirsutus and fulvescens interbreed.

Specimens examined.-Twenty-four from the following localities in México: Jalisco: vicinity of Ameca, $4000 \mathrm{ft}$., 6 (4 US); San Sebastián, $4000 \mathrm{ft}$., 3 (US). Nayarit: 1 mi. E Ixtlán del Río, 4000 ft., 2; 1 mi. SW San José del Conde, $3000 \mathrm{ft} ., 1$; 2-4 mi. N Santa Isabel, $3800 \mathrm{ft} ., 12$.

SUBGENUS APORODON HOWELL

Type.-Reithrodontomys tenuirostris Merriam, Howell, 1914:13.

\section{Subgeneric Characters}

External.-Size medium to large (hind foot about 18-23 mm.). Pelage usually long and lax. Dorsal coloration dark and reddish, consisting of various hues and tones near tawny. Lateral line present or absent. Ventral coloration variable, usually white, gray, or cinnamon. Tail longer than head and body, usually monocolor, infrequently paler below or white-tipped; scantily covered with short hairs, the scales scarcely obscured. Dorsal surface of forefeet and hind feet usually dusky to base of toes; whitish in a few forms. Ears variable in size; unicolor, usually blackish. (The toes of the hind feet appear to be longer and the digital pads larger, relative to length of foot, in Aporodon 
than in Reithrodontomys. These apparent differences cannot be accurately measured on study skins, the only sort of specimen available for study.)

Cranial.-Outstanding diagnostic cranial characters are to be seen in the anterior-posterior proportions of the skull, in the brain case, in the zygomatic arches, and in the pterygoid region. Rear part of skull, posterior to interorbital constriction, longer than forepart. Brain case elongate, large, and greatly inflated, extending laterally beyond anterolateral limits of zygomatic arches. Incisive foramina usually broad, varying in length, sometimes shorter than palate. Zygomatic plate narrow, its breadth less than breadth of mesopterygoid fossa. Mesopterygoid fossa broad-about equal to or broader than crown length of $\mathrm{M}^{1}$. Pterygoid fossae narrow, each usually much less than twice the breadth of the mesopterygoid fossa. Hamuli of pterygoids well inflated and reflexed laterad; club-shaped in ventral view. Angular process of mandible inflected mediad but scarcely dorsad, forming a narrow shelf. Zygomasseteric musculature distinct from that in Reithrodontomys (see Rinker and Hooper, 1950).

Dental.-Diagnostic characters are present on all molar teeth (Figs. 4, 5, 16, 24). Cusps, particularly those of upper molars, almost opposite in position. Molar pattern complex. Originally, or after slight tooth wear, primary and secondary folds in each molar separated from the marginal enamel as one or more inner folds forming at least 2 enamel islands. Anterior and posterior cingula well developed on all molar teeth and often terminating as distinct cusplets. Mesolophs (ids) and mesostyles (ids) on all molar teeth except possibly $\mathrm{M}_{3}$. Enterostyles, enterolophs, ectostyles, and ectolophs present or absent.

$\mathrm{M}^{3}$ : About three-fourths the size of $\mathrm{M}^{2}$ and essentially a more compact replica of that tooth. The 4 major cusps present, protocone the largest, followed in order of size by paracone, hypocone, and metacone; hypocone and metacone often less than one-half the size of the anterior cusps. All lophs and styles joined serially early in tooth wear, isolating several internal folds. Major fold short and deep. Minor fold usually indistinct. First and second primary and secondary folds well developed; each originally, or as a result of wear, contributing to an internal fold of varying degrees of permanence; first and second internal folds always present for most of the life of the tooth.

$M_{3}$ : About three-fourths the size of $M_{2}$ and essentially a replica of that tooth. Protoconid and hypoconid of about equal size. Entoconid smaller than metaconid and continuous with the posterior cingulum. Major and minor folds relatively as long and deep as in $\mathbf{M}_{2}$. First primary fold-the only prominent lingual fold-long and deep, demarking the protoconid and metaconid and remaining for most of the life of the tooth as one of 2 internal folds. Second internal fold always present, distinct from the major fold, and remaining long in the life of the tooth. 


\section{Reithrodontomys gracilis}

(Maps 7, 12; Pls. VI-IX; Fig. 16)

The 5 forms treated here all exhibit characters of the subgenus Aporodon. Within that subgenus they resemble the species mexicanus more than any species in the tenuirostris group. Some of their characters set them apart from the species mexicanus and brevirostris, however, and indicate that they and mexicanus are reproductively isolated. The 5 forms are gracilis, anthonyi, pacificus, harrisi, and darienensis. The first 4 appear to be races of one species, to which the name gracilis applies. The fifth is treated as a full species although it is no more strongly differentiated from the races of gracilis than those races are from one another. Together these 5 allopatric forms may be considered a superspecies, as the term is defined by Mayr (1947).

Distribution.-From semiarid lowlands of the Yucatan Peninsula, southward interruptedly through arid, interior valleys of Guatemala to the Pacific Ocean, thence on the Pacific coastal plain and adjoining slopes north to southern Chiapas and south to extreme eastern Panamá. This superspecies is an inhabitant of lowlands. Most of the localities from which it is known are less than 1000 feet in elevation. Where conditions are favorable, as in the arid interior valleys of Guatemala, it extends to higher elevations. Its highest known station of occurrence is at Sacapulas, 4500 feet in the upper reaches of the Río Negro of Guatemala. As now known, its range to the south of Guatemala is restricted to Pacific slopes, but in Guatemala and southern México it extends to the Caribbean drainage as well, the range bifurcating in southeastern Guatemala (Map 7). There is no known connection in México and western Guatemala between the Caribbean and Pacific versants of its range except by way of southeastern Guatemala. The species is unknown from most of Chiapas, from Tabasco, and from southern Campeche.

HaвiтAт.-Details, as they are readily available, regarding habitat in which specimens have been collected are given in the accounts of subspecies. Like most other kinds of Reithrodontomys, gracilis is associated with grass and other plants that provide cover near the surface of the ground. It apparently prefers semiarid and arid situations. In this respect it resembles $R$. fulvescens, and the 2 species sometimes occur in the same locality. To judge from records. of occurrence, it is found in open tropical deciduous forests, on dry pine ridges, in oak scrub and acacia savanna, and on cactus-studded desert.

Whether the species is as rare in its preferred habitat as the few specimens. in museums seem to indicate, or whether most collections of Reithrodontomys have been made outside the hot, tropical environments it inhabits, I do not know. From field notes and conversations with collectors who have worked in the tropical lowlands of México and Central America, I am led to believe that the species is nowhere abundant.

Comparisons.-The known forms of the superspecies gracilis are small to 
medium in size (hind foot about $17-20 \mathrm{~mm}$., skull length about 20-23 $\mathrm{mm}$.). The tail is usually longer than the head and body (tail length 97-155 per cent of head and body length), thinly haired, and usually uniformly fuscous. The upper parts are moderately pale and have a characteristic quality in texture and color which defies lucid description, but to which the terms "streaked" or "peppered" seem to me to apply. This same quality is seen in $R$. hirsutus and in some races of $R$. fulvescens. The color of the underparts varies from white to bright Orange-Cinnamon. The ears are blackish or brown and sparsely haired. A lateral line may be present. Most of the specimens of gracilis have whitish feet, but some have a dusky area on each foot as in mexicanus, and in others the entire upper surface is dusky. Most but not all of the specimens collected in the dry season have pale feet; the converse holds for the wet season. Coloration of the feet in the species may vary seasonally. It also varies geographically.

The skull is comparatively flat in dorsal profile. The zygomata are broad and essentially parallel to each other throughout their length. The frontals are exceptionally broad, and flat interorbitally. The brain case is broad, shallow, and long. The rostrum and incisive foramina are short and broad. The palate is long. The auditory bullae are small and the upper incisors are strongly recurved.

The presence of complete mesolophs in the molars, the full complement of parts (albeit compressed) in the third molars, and the anteriorly squared zygomata with an indistinct zygomatic notch distinguish most specimens of gracilis from examples of all other forms except those which, with gracilis, comprise the subgenus Aporodon, namely mexicanus, brevirostris, microdon, tenuirostris, rodriguezi, and creper. The last 4 species, all inhabitants of the cool, moist forests of highlands, have long, thick fur, a conspicuous black eye ring, deep brown or blackish upper parts, a much larger brain case (depth not less than $8.4 \mathrm{~mm}$. and usually over $9.0 \mathrm{~mm}$.), and a long, narrow rostrum (not less than $7.9 \mathrm{~mm}$. in adults). $R$. brevirostris is similar in size, but it has a long tail (about 150 per cent of head and body length), narrower zygomatic plate, narrower frontals, and erect incisors. Most of the races of mexicanus are much larger than any forms of gracilis (see especially length of hind foot, tooth row, and skull in table of measurements). Also, the tail is longer, rostrum longer, and auditory bullae larger in these races of mexicanus. Some of the smaller races, $R$. m. potrerograndei, for example, resemble gracilis in many features, but they differ from it in coloration, tail length, breadth of frontals, shape of brain case and zygomata, and size of auditory bullae.

Relationships.-The closest extant relative of $R$. gracilis appears to be $R$. mexicanus. Both are southern Mexican and Central American species. The former inhabits arid tropical lowlands. The latter is associated with oak-pine forests and subtropical forests at higher elevations. The morpho- 


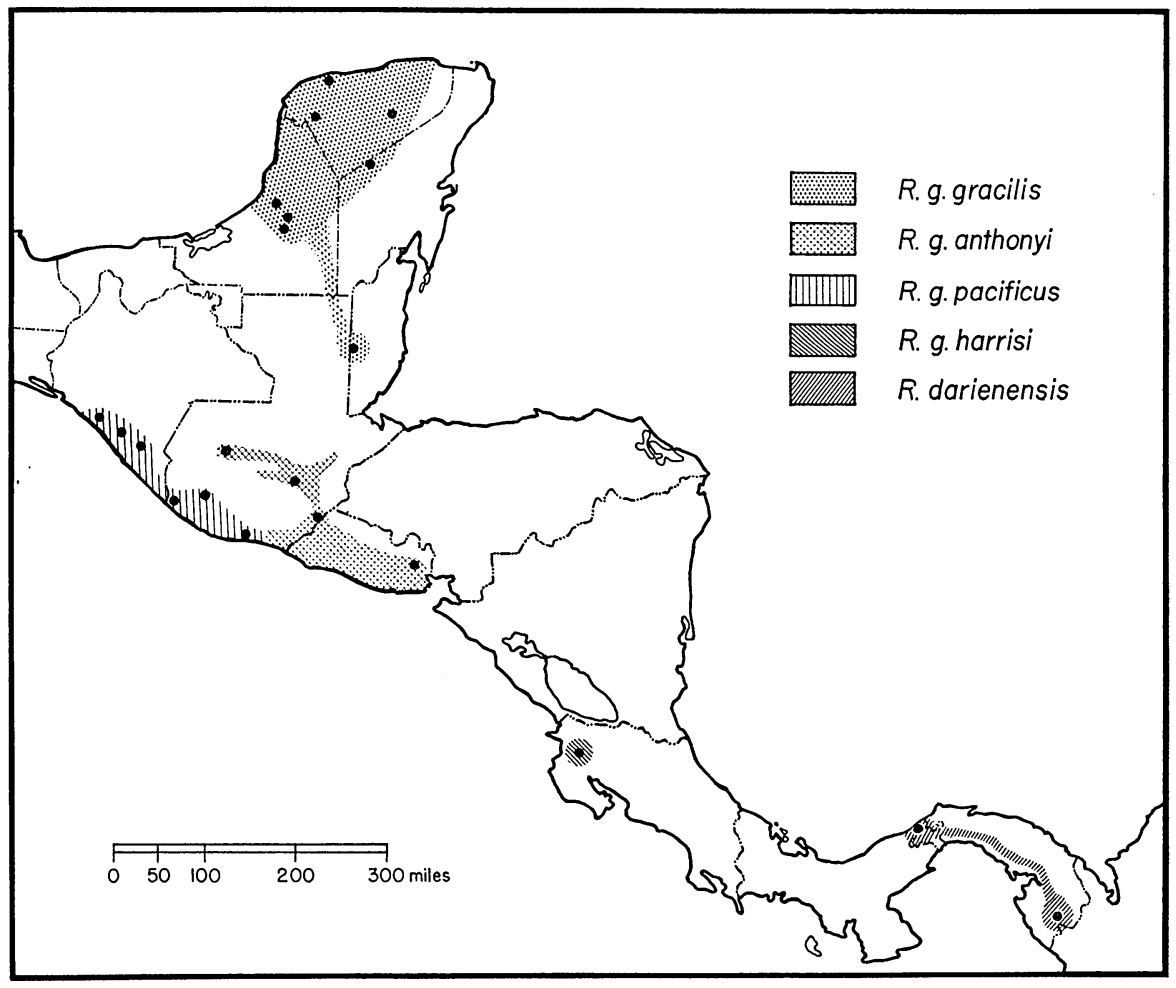

MAP 7. Distribution of the subspecies of Reithrodontomys gracilis and of Reithrodontomys darienensis, as determined from specimens examined.

logical differences between them are not great, particularly in the forms darienensis, potrerograndei, pacificus, and scansor. $R$. gracilis is quite distinct from each species in the tenuirostris group.

$R$. gracilis is perhaps the most generalized species of Aporodon. In ranking the species of that subgenus according to amount of specialization, I see no characters in gracilis that would place it above the other species. It closely approximates a hypothetical morphotype from which all species of the subgenus can be derived. It may well be the modern representative of the ancestral stock that gave rise to the species of the subgenus. Howell (1914: 77) pointed out that gracilis bears a striking resemblance to fulvescens, which is a generalized species of the subgenus Reithrodontomys. The resemblance of gracilis to fulvescens, and to hirsutus as well, may represent parallel responses to the similar environments in which the 3 species live. On the other hand, they also may be taken to indicate kinship. It is clear that such overlap as exists between characters of the subgenera obtains almost entirely in these species of the mexicanus and fulvescens groups. They tend to bridge the morphological gap between the subgenera. 


\section{Reithrodontomys gracilis gracilis Allen and Chapman}

Reithrodontomys mexicanus gracilis Allen and Chapman, 1897a: 9.

Reithrodontomys gracilis, Allen and Chapman, 1897b: 199; Howell, 1914: 76.

Type.-Female, skin and skull; Amer. Mus. Nat. Hist. No. $\frac{12018}{10451}$; México, Yucatán, Chichén Itzá; 75 feet altitude, collected 10 March 1896 by Frank M. Chapman.

Distribution.-Semiarid parts of the Yucatan Peninsula. Known range from near sea level at Progreso, Yucatán, south to the vicinity of Cayó, 1000 feet, British Honduras, and Apazote, 300 feet, Campeche.

Habitat.-Savanna or grassy areas in pine, scrub, thorn, or deciduous forests. Specimens were collected in situations as follows: Among sedges and other low-lying vegetation at the edge of a marsh (Mountain Pine Ridge). In a rock fence between henequin fields and pastureland (Calcehtok). In a patch of weeds and brush beside a highway (Santa Rosa).

Characters.-Size: Medium for the species $R$. gracilis; hind foot 16-20 mm., averaging $17 \mathrm{~mm}$.; range in skull length $21.4 \mathrm{~mm}$. (in subadults) to 22.2 $\mathrm{mm}$. (in adults); length of molar row usually $3.2 \mathrm{~mm}$. or less. Tail long, over 130 per cent of head and body length in all specimens examined.

Color: Adult pelage of February specimens from Yucatán and British Honduras: Ground color of upper parts near Tawny or Ochraceous-Tawny, purest on the sides and cheeks and darkened dorsally by black guard hairs which give a characteristically grizzled or "peppered" appearance to the upper parts. Underparts varying from white to Tawny or Ochraceous-Tawny. Ears fuscous, scantily sprinkled with brown or black hairs. No black eye ring. Upper surface of forefeet white or Ochraceous-Tawny, with or without middorsal dusky stripe of varying length; toes white. Upper surface of hind feet similarly variable; dingy white to dusky, the dusky diffused over the surface or restricted to a dorsal stripe; toes whitish. Tail fuscous, monocolor, or slightly paler ventrally.

Subadult pelage of February and March specimens from Yucatán: Similar to adult pelage but ground color of upper parts paler (nearer OchraceousBuff or Pinkish Cinnamon), the black guard hairs relatively more abundant. Juvenile pelage of October specimen from Yucatán: Upper parts grayish brown (about Hair Brown), the effect produced by the blending in the viewer's eye of the predominant black guard hairs and the narrow bands of Light Ochraceous-Buff of the cover hairs. Ears brown, densely clothed with long black hairs. Wrists and ankles dusky, the remainder of the forefeet and hind feet white. Tail monocolor. Eye ring absent. Underparts dingy white, the white tips of the hairs not concealing the basal plumbeous bands.

Skull: Somewhat similar in shape to the skull of $R$. fulvescens, but with relatively broader, longer brain case, broader frontals, flatter cranium, narrower zygomatic plate, and broader mesopterygoid fossa. Cranium low and 
long. Zygomata appearing to be parallel and depressed principally ventrad, scarcely laterad. Frontals broad between the orbits. Rostrum short and broad, molar row and incisive foramina short, and palate moderately long (see measurements).

REMARKs.-The range of $R . g$. gracilis is probably highly discontinuous, particularly in the basal part of the Yucatan Peninsula where the vegetation is predominantly quasi rain forest (Lundell, 1937). In that region the species may be confined to clearings and to so-called "pine ridges." Such pine ridges are semiopen avenues within dense forests; they are not necessarily elevated above surrounding areas. There is a population on Mountain Pine Ridge in British Honduras. That ridge is an open, parklike area in the midst of a wet forest. The trees are widely spaced and consist principally of tall pines, interspersed with scrub oak. Sedges comprise a chief understory plant. The soil is rocky and shallow. The ridge is one of many such semiarid islands in the expanse of quasi rain forest that dominates the lowlands of northern Guatemala and of the southern part of the Yucatan Peninsula of México. $R$. gracilis does not occur in dense wet forests insofar as known. The examples from Mountain Pine Ridge contrast in color with those from Yucatán and Campeche. They are darker dorsally and are bright buffy orange ventrally; in one specimen the buffy is as intense (Orange-Cinnamon) as on the upper parts. These examples apparently represent a slightly differentiated population that, as now appraised, does not warrant a formal name. Other local variants of $R$. gracilis can be expected on other pine ridges in the region.

SPECimens EXAMINED.-Fifteen from localities as follows: British Honduras. 12 mi. S Cayó, Mountain Pine Ridge, 1000 ft., 3. México. Campeche: near Yahaltun, 300 ft., 1 (US); Apazote, 300 ft., 1 (US); 50 mi. S Campeche, San Juan, 100 ft., l (CM). Quintana Roo: Santa Rosa, 1. Yucatán: Calcehtok, 2; Chichén Itzá, 75 ft., 5 (4 AM, 1 US); Progreso, 10 ft., 1 (US).

\section{Reithrodontomys gracilis anthonyi Goodwin}

Reithrodontomys gracilis anthonyi Goodwin, 1932: 3; 1934: 39.

Type.-Female, skin and skull; Amer. Mus. Nat. Hist. No. 79093; Guatemala, Dept. El Quiché, Sacapulas, 4500 feet elevation; collected 2 March 1928 by A. W. Anthony.

Distribution.-Arid valleys and slopes of central and southeastern Guatemala and of El Salvador. Known geographic and vertical range from Monte Cristo mine, 700 feet, El Salvador, to Sacapulas, 4500 feet, Guatemala.

Habiтat.-Insofar as is known, grass among clumps of cactus and thorny shrubs on dry, well-drained soils. Specimens were collected in situations as follows: In a cactus hedge (El Rancho). Four to 6 feet above ground on heavy vines in dense thorn brush; in grass under thick brush (Monte Cristo mine). On the ground in a clump of thorny shrubs, one of the few tangles that com- 
posed the sparse understory of a dry, scrub-oak and thorn forest (Lago Atescatempa).

Comparisons.-Compared with gracilis (specimens of anthonyi from Sacapulas and El Rancho; examples of gracilis from Yucatán): Similar in size, perhaps slightly larger (see measurements). 'Tail moderately long as in gracilis, 127-155 per cent of head and body length. Adult pelage of anthonyi unknown. Subadult pelage paler in anthonyi than in gracilis; ground color of upper parts Pinkish Cinnamon to Orange-Cinnamon interspersed with black hairs; a lateral line of Pinkish Cinnamon or Orange-Cinnamon; underparts whitish, the hairs plumbeous basally except on the throat where they are white throughout; forefeet and hind feet white; tail fuscous and monocolor or slightly paler ventrally. Cranium larger than in gracilis (well seen in dimensions of the brain case); no zygomatic notch (present, although shallow, in gracilis); frontals broad and essentially plane interorbitally, making the dorsal surface of the skull appear much more flattened than in gracilis; incisive foramina relatively narrower and longer, in which respect anthonyi is between gracilis and pacificus; hard palate longer (90-105 per cent of length of incisive foramen in anthonyi, and usually less than 90 per cent in gracilis).

Compared with pacificus (specimens of anthonyi from Sacapulas and El Rancho; a series of pacificus from Finca El Ciprés): Larger (see measurements). Tail longer, amounting to 127-155 and 97-136 per cent of head and body length, respectively, in the 2 subspecies. Ears larger. Pelage longer, not short and crisp as in pacificus. Color of the tail, ears, and underparts as in pacificus. Upper parts paler, more buffy. Hind feet paler, whitish instead of dusky. Cranium larger; dimensions of brain case and of rostrum closely comparable in the 2 races but palate longer and incisive foramina shorter in anthonyi (length of palate usually over 90 per cent of the length of foramina in anthonyi, usually less than 85 per cent in pacificus); zygomata relatively narrower; auditory bullae absolutely and relatively larger.

REMARKs. $-R$. g. anthonyi bears closest resemblance to $R$. g. gracilis, from which it differs chiefly in paler upper parts and hind feet, larger brain case, and longer palate. In size of brain case and size and shape of incisive foramina it resembles pacificus more than it does gracilis. The topotypes of anthonyi exceed the other specimens in body size and in dimensions of the brain case. In one of those specimens the enamel pattern of $\mathrm{M}^{3}$ approaches that obtaining in the subgenus Reithrodontomys; in it the posterior parts of the tooth are reduced in size and number and appear to consist only of a posterior cingulum of the protocone. In this specimen there is no major fold, and the second primary fold is essentially confluent with the internal fold; the tooth consists of a paracone and protocone with a long posterior cingulum. The 2 specimens from Monte Cristo mine are the smallest and darkest of the 
lot; in size and color they approach examples of pacificus from Finca El Ciprés.

Specimens EXAMINED.-Seven from the following localities: El Salvador. Morazán: Monte Cristo mine, 700 ft., 2 (MVZ). Guatemala. El Quiché: Sacapulas, 4500 ft., 2 (AM). El Progreso: El Rancho, 700 ft., 2 (CM). Jutiapa: Lago Atescatempa, $2500 \mathrm{ft} ., 1$ (US).

\section{Reithrodontomys gracilis pacificus Goodwin}

Reithrodontomys pacificus Goodwin, 1932: 2; 1934: 38.

TyPe.-Female, skin and skull; Amer. Mus. Nat. Hist. No. 79331; Guatemala, Dept. San Marcos (?), 6 miles northeast of Ocós, Hacienda California, elevation near sea level; collected 12 November 1927 by A. W. Anthony.

Distributron.-Pacific coastal plain and slopes in Chiapas and Guatemala. Known range from the vicinity of Pijijiapan, Chiapas, to San José, Guatemala. Vertical range from near sea level at San José and Hacienda California, Guatemala, to about 2000 feet at Finca El Ciprés, Guatemala.

Habitat.-Grass and other low-lying cover in tropical evergreen and deciduous forests. The specimens were collected in situations as follows: Eight feet above ground in a rough-barked tree (11/2 feet in diameter) in a cutover humid, broadleaf evergreen forest (Pijijiapan). In a tree in a cutover humid forest (Mapastepec). In a dense tangle of vines and shrubs in a secondgrowth tropical evergreen forest (San José).

Comparisons.-Compared with $R . g$. gracilis (specimens of pacificus from Finca El Ciprés; examples of gracilis from Yucatán): Smaller (see length of hind foot and length of molar row). Tail shorter (97-136 per cent and 137145 per cent of head and body length, respectively, in the 2 subspecies). Fur of wet season (specimens representing July and November) coarse and short (about $4 \mathrm{~mm}$. long on midback). Color of upper parts similar in the 2 races, slightly darker in pacificus. Sides essentially pure Tawny or OchraceousTawny, sharply demarked from the white or Pale Pinkish Cinnamon underparts. Hind feet dusky bordered by white, the dusky stripe apparently broader than in gracilis. Cranium small, but the brain case relatively larger than in gracilis. Zygomata relatively broader, deflected markedly laterad as well as ventrad (ventrad only in gracilis); incisive foramina relatively longer; palate long; zygomatic notch shallower anteroposteriorly.

Remarks. $-R$. g. pacificus inhabits the Pacific coastal plain and adjoining lower slopes of the mountains of Guatemala and Chiapas. As now known its range is separated from that of gracilis by the Sierra Madre in which habitat suited to the species is lacking. Intergradation with anthonyi is suggested by 2 specimens from San José, Guatemala. Those 2 specimens resemble anthonyi from El Rancho in coloration, but they are like pacificus in having a dusky stripe on the hind feet, small auditory bullae, a short palate, long incisive 
foramina, and broad zygomata. Here they are listed with pacificus. The specimen from Finca Esperanza is an ill-preserved juvenile; its characters cannot well be appraised. In the example from Mapastepec the patterns of $\mathrm{M} \frac{3}{3}$ are those otherwise exclusively seen in $R$. fulvescens and $R$. hirsutus. Apparently the genetic factors effecting the dental patterns in $\mathrm{M} \frac{3}{3}$ are less completely fixed in gracilis than in the other species of Aporodon.

The short crisp pelage and the broad dusky stripe on the hind feet of the specimens from Finca El Ciprés, Hacienda California, Pijijiapan, and Mapastepec may be seasonal characteristics rather than racial traits; all specimens from those localities were collected in the months July to November.

Its small size, short tail, peculiar pelage coloration, short broad rostrum, broad frontals, short broad incisive foramina, small molars, and small auditory bullae indicate that pacificus is more closely related to gracilis, anthonyi, harrisi, and darienensis than to the $R$. mexicanus chain of races. More complete material than is now available is necessary for a completely satisfactory understanding of the characteristics and relationships of pacificus.

Specimens ExAmined.-Fourteen from localities as follows: México. Chiapas: near Escuintla, Finca Esperanza, 1500 ft., 1; Mapastepec, 200 ft., 1; Pijijiapan, 50 ft., 1. Guatemala. Escuintla: San José, 15 ft., 2 (US). San Marcos (?): Hacienda California, near sea level, 1 (AM). Suchitepéquez (?): Finca El Ciprés, $2000 \mathrm{ft}$., 8 (AM).

\section{Reithrodontomys gracilis harrisi Goodwin}

Reithrodontomys harrisi Goodwin, 1945: 2; 1946: 386.

Type.-Adult male, skin and skull: Univ. Mich. Mus. Zool. No. 65220; Costa Rica, Dept. Guanacaste, 18 miles northeast of Liberia, Hacienda Santa María, 3200 feet elevation; collected 27 January 1932 by Austin Smith.

Distribution.-Known only from the type locality, but probably ranging on the Pacific coastal slopes and plain northward into Nicaragua and southward in Costa Rica.

Habitat.-The type specimen was caught by hand on the ground in a forest.

Comparisons.-The only known specimen of this race resembles examples of the subspecies gracilis from the Yucatan Peninsula. It differs from them as follows: Paler and brighter upper parts, the Ochraceous-Tawny bands obscured by fewer black guard hairs. Underparts extensively white; basal bands of hairs near Pale Neutral Gray, scarcely darker than distal bands. Tail distinctly paler ventrally than dorsally. Brain case narrower and longer, strongly depressed posteriorly; palate longer, incisive foramina narrower, and auditory bullae much smaller.

Compared with pacificus (the type of harrisi; specimens of pacificus from Finca El Ciprés): Similar in size. Much paler and brighter colored dorsally 
(bright Ochraceous-Tawny), lacking the chestnut color on the back and rump that is seen in pacificus; tail pale below, instead of monocolor. Cranium relatively longer and narrower; zygomata depressed principally ventrad (as in gracilis), rather than laterad and ventrad (as in pacificus); palate actually and relatively longer; auditory bullae small as in pacificus.

REMARKs.-The specimen herein described, although superficially resembling some examples of $R$. fulvescens, is certainly a representative of the subgenus Aporodon. Its affinities within that subgenus appear to be with $R$. gracilis, from which it is distinguishable by minor differences which are at best subspecific in sort and magnitude. It apparently represents a brightcolored but pale geographic race of $R$. gracilis which inhabits the arid Pacific slopes of Costa Rica and perhaps of western Nicaragua.

SPECIMENS EXAMINED.-The type only.

\section{Reithrodontomys darienensis Pearson}

(Maps 7, 12; Pls. VIII, IX; Fig. 16)

Reithrodontomys darienensis Pearson, 1939: 1.

Type.-Adult male, skin and skull; Acad. Nat. Sci. Phila. No. 19672; Panamá, Prov. Darién, Cana, elevation 2000 feet; collected 15 April 1938 by Oliver P. Pearson; original No. 288.

Distribution.-Known only from the type locality, but probably occurring elsewhere in the lowlands of Panamá and Colombia. A specimen from Gatún, Panama Canal Zone, may be an example of darienensis.

HabiтAт.-All of the specimens of darienensis at hand were collected in a house in Cana. The vegetation in the immediate vicinity may be described as tropical deciduous forest in which dense stands of oak are interspersed with shrubs and clumps of grass.

Comparisons.-Compared with $R$. g. harrisi (topotypes of darienensis; type of harrisi): Similiar in size; possibly slightly smaller (see measurements). Tail actually and relatively longer (greater than 148 per cent of head and body length in darienensis, 131 per cent in type of harrisi). Color differences not known; the pelages of specimens at hand are not comparable as to season or age. The type of harrisi is in fresh adult pelage (January); the examples of darienensis are all in worn subadult or juvenile pelage (April). Brain case relatively shorter and oval rather than obovoid in shape; rostrum relatively shorter (averages 82 per cent of depth of cranium in darienensis, 90 per cent in harrisi); zygomatic plate narrower (16 and 21 per cent of cranial depth, respectively); auditory bullae relatively smaller.

Compared with $R$. m. garichensis (topotypes of darienensis; specimens of garichensis from the vicinity of Bóquete): Smaller (see measurements). Color paler, the upper parts dappled or "streaked" as in $R$. gracilis. Underparts white; basal plumbeous bands (present everywhere except on throat) well 
obscured by long, white distal bands; hind feet less pigmented than in garichensis, the dorsal dusky stripe reduced or absent. Cranium much smaller in all dimensions. Brain case relatively broader, rostrum relatively much shorter (averages 82 per cent and 92 per cent of cranial depth, respectively, in the 2 forms), incisive foramina relatively shorter and broader, and molars and auditory bullae much smaller.

Compared with R. m. milleri (topotypes of darienensis; specimens of milleri from Cocal, Colombia): Distinguishable from milleri by essentially the same external and cranial characters that distinguish it from garichensis.

REMARKs.-Clearly a member of the mexicanus group of species, $R$. darienensis appears to be more closely related to $R$. gracilis than to $R$. mexicanus. The following characters of darienensis also are observed in examples of R. gracilis from México, Guatemala, El Salvador, and Costa Rica: small size; whitish hind feet; peculiar "peppered" or streaked upper parts that are sharply demarked from white underparts; small molar teeth; broad short rostrum and incisive foramina; long palate; strongly recurved upper incisors; broad frontals; and parallel-sided, ventrally-depressed zygomata. Its zygomatic plate is narrower and its tail is relatively longer than in examples of $R$. gracilis; in those 2 features it resembles some races of $R$. mexicanus, potrerograndei for example. Its tiny auditory bullae are not matched by any other known form of the mexicanus group, save possibly $R$. $m$. scansor. At least until its geographic, ecological, and variational ranges are better known, it should be treated as a full species.

A specimen labeled Gatún, Panama Canal Zone, is too young for positive identification. It consists of a skull only of an apparently new-born juvenile; the molar teeth are not emerged, and the cranium is misshapen. It is referred to darienensis on a geographical basis only.

Specimens examined.-Nine from localities as follows: Panamá, Darién, Cana, 2000 ft., 8 (PM). Panama Canal Zone, Gatún, 1 (US).

\section{Reithrodontomys mexicanus}

(Maps 8, 12; Pls. IV-IX; Figs. 6, 16, 21, 24)

The subgenus Aporodon consists of the tenuirostris and mexicanus species groups. Both groups center in Central America. The species of the tenuirostris group are all specialized kinds with generally small geographic ranges (Map 12). Three of them are monotypic; in the fourth species 3 geographic races are recognized. The species of the mexicanus group have fewer specializations and larger ranges. $R$. gracilis and $R$. darienensis are discussed on preceding pages. The other species of the mexicanus group are $R$. mexicanus and $R$. brevirostris. The latter is restricted to Costa Rica. It is not well known. It appears to be a somewhat specialized offshoot from mexicanus, but present evidence indicates that it is not a race of that species. $R$. mexicanus exceeds 
all species of Aporodon in extent of geographic range and in geographic variability. Twelve subspecies are here recognized.

Distribution.-Eastern México south to northern Ecuador (Map 8). In México the species is restricted to Atlantic slopes from southwestern Tamaulipas south through Chiapas. In Central America it occurs on both Pacific and Atlantic slopes. In South America it is known from the Western and Central Andes of Colombia and Ecuador as far south as Quito, Ecuador. It is usually found in the altitudinal range 4000-6000 feet, but where conditions are locally favorable it occurs at higher and lower elevations. The lowest record of occurrence is at Metlaltoyuca, near 1000 feet, Puebla. One specimen from 11,000 feet altitude in the crater of Volcán de Chiriquí, Panamá, is the highest record.

Habitat.-Typically a species of moderate elevations, mexicanus is usually associated with humid oak-pine and tropical broadleaf forests, but locally it is found in quasi rain forests, lowland savanna, and arid deciduous forests. For suitable niches it probably is as dependent on grass, herbs, shrubs, and other plant forms offering food and close ground cover as it is on trees which may be the dominant plants in an area. In México and Central America it has been collected in both mesic and humid forests; in sparse to dense growths of grass, herbs, and shrubs bordering cultivated areas, streams, and marshes; on rocky hillsides; in coffee groves; and in trees. In southern México and Central America it is commonly associated with $R$. sumichrasti. Trapping records indicate that it is scansorial in habit. Information on places of capture of specimens is included in the accounts of the subspecies.

Comparisons.-The 12 subspecies of $R$. mexicanus are moderate to large as regards body size in the genus. The hind foot measures about 19 or $20 \mathrm{~mm}$. The molar row varies in length from about $3.2 \mathrm{~mm}$. in the smaller forms, as howelli and potrerograndei, to $3.7 \mathrm{~mm}$. in cherriei, eremicus, and söderströmi, 3 of the larger subspecies. The tail is much longer than the head and body (amounting to 130-160 per cent of head and body length). It is usually dark brown or blackish, and monocolor; rarely is it distinctly paler below or white tipped. Body coloration varies geographically. In intensely pigmented races, as mexicanus and söderströmi, the upper parts are heavily suffused with black over a tawny ground color. In paler races the upper parts are nearly pure tawny. The basic color of the upper parts is tawny or orange-cinnamon, from which there are slight variations in hue and tone. The underparts vary from whitish to a pale cinnamon or orange-cinnamon. The epidermis of the ears is fuscous and is sparsely covered with black hairs. The duskiness of the tarsus extends onto the foot as a longitudinal stripe of varying width and length. In the northern races it covers most of the upper surface of the hind foot, leaving only a narrow rim of white. Toward the south, the stripe is narrower and wedge-shaped; its apex does not extend to the base of the toes. In some 
specimens from South America the dusky stripe is entirely lacking and the upper surface is whitish or pale cinnamon. In all forms the toes are whitish.

Cranially, $R$. mexicanus is typical of Aporodon; all the characters of that subgenus are well seen in the species. The brain case is broad and comparatively shallow, and the anterior part of the zygomatic arch is weak, with a narrow zygomatic plate and without a distinct zygomatic notch. The rostrum is comparatively broad, somewhat resembling that of $R$. fulvescens. The frontals are broad anteriorly (when the skull is viewed from directly above, the posterior part of the molar row is not visible). The palate is usually about as long as the molar row and shorter than the incisive foramina. The incisors are moderately recurved and the molars ( $\mathrm{M} \frac{3}{3}$ no exceptions) are comparatively large as in other species of Aporodon (Figs. 4, 5).

Relationships.-The affinities of $R$. mexicanus with $R$. gracilis and with the tenuirostris group of species are discussed in the accounts of those forms. Outside of the subgenus Aporodon the nearest relatives of $R$. mexicanus appear to be $R$. hirsutus and $R$. fulvescens, for a discussion of which see the accounts of those species.

\section{Reithrodontomys mexicanus mexicanus de Saussure}

Reithrodon mexicanus de Saussure, 1860: 109.

Ochetodon mexicanus, Coues, 1874: 186 (part); 1877: 128 (part). Alston, 1879: 151 (part). True, 1884: 598 (part). (Not of Thomas, 1882: 372; and Allen, 1891 b: 223.)

Reithrodontomys mexicanus, Trouessart, 1897: 531 (part). (Not of Allen, 1894: 319; 1895a: 135; and Allen and Chapman, 1897b: 199).

Reithrodontomys costaricensis jalapae Merriam, 1901: 552. México, Veracruz, Jalapa, 4000 feet elevation.

Reithrodontomys goldmani Merriam, 1901: 552. México, Puebla, Metlaltoyuca, 800 feet elevation.

Reithrodontomys cherriei jalapae, Miller, 1912: 130.

Reithrodontomys mexicanus mexicanus, Howell, 1914: 70 (part).

Reithrodontomys mexicanus goldmani, Howell, 1914: 72.

TyPE.-Skin and skull; Mus. Hist. Nat. Genève No. $\frac{510}{100}$; México, mountains of Veracruz (herewith fixed at Mirador, Veracruz); purchased from Sumichrast.

Distribution.-Moderate elevations on the slopes of the mountains of eastern México entirely within the drainage of the Gulf of Mexico. Known range from the mountains near Gómez Farías, southwestern Tamaulipas, south to Totontepec, Oaxaca. Altitudinal range from 800 feet at Metlaltoyuca to 6000 feet at Totontepec.

HaBitat.-The subspecies apparently is an inhabitant of the comparatively humid lower part of the oak and pine belt and of the adjoining subtropical forests of eastern México. Specimens have been collected in situations as follows: In grass and shrubs bordering cultivated areas and surrounded by stands of oak (Altotonca and Teziutlán). In a clearing that had been a banana 


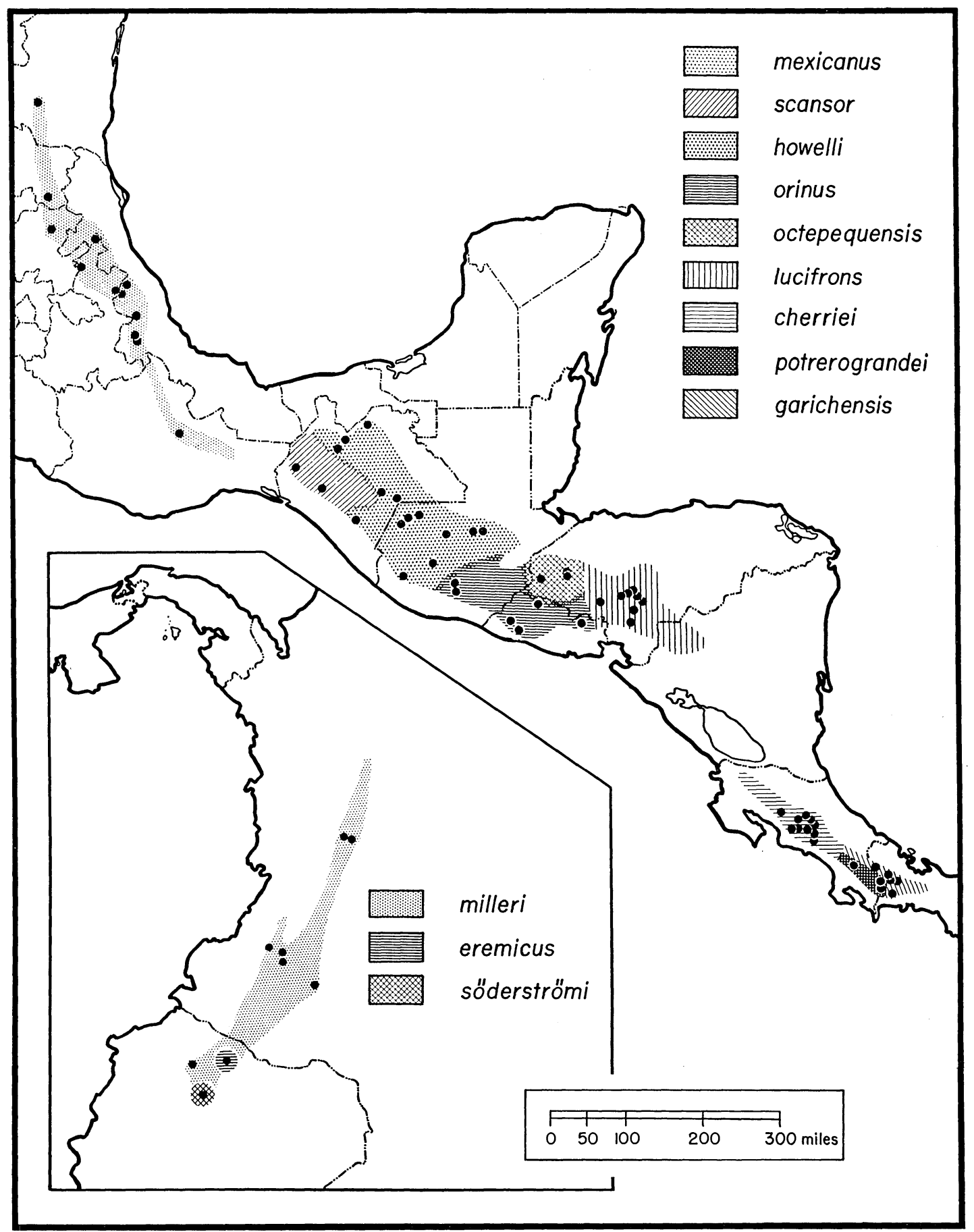

Map 8. Distribution of the subspecies of Reithrodontomys mexicanus, as determined from specimens examined. 
grove in a broadleaf forest (Río Atoyac). Among scattered boulders in a coffee grove at the base of a cliff (near Jico). In undergrowth at the edge of a moist oak-sweetgum forest (Rancho del Cielo). In an alder tree growing on the border of a cultivated field (Molango).

Characters.-Size: Medium; in the subadults and adults examined the hind foot measure 18-21 mm., averages $19 \mathrm{~mm}$.; skull length $22.8-23.9 \mathrm{~mm}$., averages 23.5 in adults; molar length, $3.4-3.6 \mathrm{~mm}$., averages $3.5 \mathrm{~mm}$. Tail about 50 per cent longer than head and body.

Color: Fresh adult pelage of wet season (July specimen from Totontepec): Upper parts Tawny or Sayal Brown, purest on sides and much darkened dorsally by many blackish guard hairs that form a longitudinal stripe extending from forehead to rump. Sides demarked from underparts by a lateral line of pure Tawny or Orange-Cinnamon. Cheeks Ochraceous-Tawny. A black ring around the eye. Hairs of underparts Plumbeous-Black basally, white distally. Ears Fuscous, sparsely covered with black hairs which are concentrated anteriorly as a preauricular black tuft. Tail Fuscous-Black above and below. Wrists and toes of forefeet white. Upper surface of hind feet dusky from ankles to base of toes; toes and periphery of upper surface of feet whitish. Fresh subadult pelage of dry season (January specimen from Altotonca): As above, but black hairs more abundant on sides and head, effecting a darker and duller over-all tone, and the pale bands of the cover hairs more buffy (near Cinnamon or Ochraceous-Tawny).

Skull: Brain case large (see measurements) and ovoid in outline (appearing longer than broad). Frontals sharply constricted interorbitally to a breadth less than that of the rostrum. Zygomata rectangular in outline (when the skull is viewed from above), the anterior parts slightly nearer the mid-line of the skull than are the posterior parts. Rostrum moderate in dimensions, about twice as long as it is broad. Auditory bullae small. Incisive foramina long (their length greater than breadth of rostrum). Molar teeth small, the entire row of moderate length (about equal to length of hard palate).

REMARKs.-The history of the name mexicanus, as applied to American harvest mice, has been reviewed by Howell (1914: 70-72). Only the essentials need to be given here. Between 1860, when de Saussure described the species, and 1914, when Howell conclusively clarified the previously muddled situation, authors applied the name mexicanus to several species as they are currently known. References to mexicanus by Coues (1874, 1877), Alston (1879), True (1884), and Trouessart (1897) pertain variously to the species mexicanus and fulvescens. The specimens from Durango listed by Thomas (1882) under the name mexicanus probably are examples of fulvescens or megalotis as now known; I have not seen them (see accounts of $R$. $f$. tenuis). Allen $(1891 b, 1894,1895 a, 1896 a)$ repeatedly used the name mexicanus in referring to specimens of the species fulvescens. This procedure, commend- 
able for its consistency but not for its accuracy, was in harmony with his observations of 24 November 1890, when Allen, Merriam, and True compared the type specimen of mexicanus with a specimen of $R$. fulvescens from Tehuacán, Puebla, that is contained in the collections of the U. S. National Museum. To Allen's eye the 2 examples-the type of mexicanus and the specimen of fulvescens-agreed in all essential details, and Allen thereafter associated the name mexicanus with the characters observed in the Tehuacán specimen. In contrast to those of Allen, Merriam's notes indicate trenchant differences between the type and the Tehuacán specimen. Howell (1914) recognized the importance of those differences. He saw that the Tehuacán specimen is an example of the well-known species fulvescens, while the type of mexicanus is an example of the species then known by the name jalapae. He recognized that the names jalapae and mexicanus applied to one and the same species. Accordingly, he relegated the name jalapae to the synonymy of the earlier-named mexicanus.

R. mexicanus is identified correctly. Dr. P. Revilloid, director of the Museum of Natural History of Geneva, has kindly provided me with a full description, including measurements and photographs of the skull, of the specimen on which de Saussure based his description of Reithrodon mexicanus. Without question the skull belongs to the above-mentioned group of mice. The grooved incisors, full mesostyles (ids) and mesolophs (ids) on all molars, broad mesopterygoid fossa, and narrow zygomatic plate are clearly visible; these and other characters described by Revilloid make correct association of the specimen and its name with living populations quite certain.

Mirador, Veracruz, is a logical choice as the type locality of $R$. mexicanus. It is situated in "mexicanus country" and it is one of the places in the uplands of Veracruz whence probably came material described by de Saussure. Mirador has long been-and still is, according to Dalquest (in litt., 19 December 1949)-the home of the Sartorius family. About 1860 C. and F. Sartorius made extensive collections of plants and animals in the vicinity of Mirador. Many of those specimens have served as the basis for descriptions of new forms. De Saussure (fide Osgood, 1909: 199) and Sumichrast (Dalquest, in litt.), from whom de Saussure obtained the type specimen of $R$. sumichrasti, are known to have stopped at the Sartorius ranch. It is probable that many, possibly all, of the specimens available to de Saussure from the "mountains of Veracruz" came from the vicinity of Mirador.

The specimens at hand provide insufficient basis for the recognition of goldmani. The type specimen of goldmani, from Metlaltoyuca, Puebla, and 5 examples from the vicinity of Xilitla (Apetsco and Miramar Grande), San Luis Potosí, average slightly paler in color of the upper parts and larger in dimensions of the cranium than those from localities in Veracruz and Oaxaca. In view of the considerable individual variation observed in $R$. mexicanus, 
it is doubtful that the above-mentioned differences are characteristic of the populations that the specimens represent. Certainly the type of goldmani is no more distinct from specimens from central Veracruz, whence probably came the type of mexicanus, than are the examples from Totontepec, Oaxaca. At present all of those specimens and the populations they represent are best treated under the one subspecific name mexicanus.

Specimens exAmined.-Twenty-seven from the following localities in México: Hidalgo: Molango, $5200 \mathrm{ft}$., 1. Oaxaca: Totontepec, $6000 \mathrm{ft} ., 2$ (US). Puebla: Huauchinango, $4900 \mathrm{ft} ., 2$ (US); Metlaltoyuca, $800 \mathrm{ft} ., 1$ (US); Teziutlán, 6500 ft., 6. San Luis Potosí: Apetsco, 2700 ft., 4 (LSU); Miramar Grande, $5000 \mathrm{ft}$., 1 (LSU). Tamaulipas: Rancho del Cielo, $3500 \mathrm{ft}$., 1. Veracruz: Altotonca, 6000 ft., 4 (1 CM); Córdoba, $3000 \mathrm{ft}$., 1 (AM); 1 mi. W Jico, $4200 \mathrm{ft}$., 2 (KU); 5 mi. NW Potrero, Río Atoyac, about $4500 \mathrm{ft}$., 1 (KU); Tlapacoyán, $1700 \mathrm{ft} ., 1$ (KU).

\section{Reithrodontomys mexicanus scansor Hooper}

Reithrodontomys mexicanus scansor Hooper, 1950a: 418.

Type.-Adult male, skin and skull; Univ. Mich. Mus. Zool. No. 96816; México, Chiapas, Villa Flores, elevation 2000 feet; collected 22 March 1950 by Helmuth O. Wagner; original number 6023 .

Distribution.-Interior arid valleys of southwestern Chiapas. Known range from Cintalapa, 1700 feet, southeast to Villa Flores, 2000 feet.

Habitat.-Trees and shrubs along stream courses and in marshy areas in arid tropical climates. Specimens were collected in places as follows: Seven feet above ground in a tree; 7 to 8 feet above ground in trees which were about 20 yards from swampy pastureland; under a clump of shrubs and trees (Cintalapa). All 5 examples from Villa Flores were trapped in trees; 3 of the 5 were taken in "colorins" (genus Erythrina), which were in flower at the time.

Comparisons.-Compared with mexicanus (specimens of scansor from Chiapas; specimens of mexicanus from Veracruz): Smaller skull, well seen in the measurements of cranial length, zygomatic breadth, and length of molar row. Incisive foramina shorter and palate relatively longer (on the average the length of palate is 93 per cent of length of incisive foramina in scansor and 81 per cent in mexicanus). Fur of upper parts shorter and paler, with much less blackish overlay (of the guard hairs); cover hairs basally near Dark Plumbeous rather than Plumbeous-Black; their distal bands paler (near Pinkish Cinnamon or Ochraceous-Tawny in subadult pelage and OrangeCinnamon or Cinnamon in adult pelage; subadult pelage of mexicanus Ochraceous-Tawny or Cinnamon and adult pelage Tawny).

Compared with howelli (specimens of scansor from Cintalapa and Villa Flores; examples of howelli from Guatemala and Prusia, Chiapas): Upper 
parts paler, with less black throughout; the buffy bands slightly less reddish. Auditory bullae less inflated; palate longer; incisive foramina shorter (on the average the length of palate amounts to 93 per cent of the length of the incisive foramina in scansor and 81 per cent in howelli). Sphenopalatine vacuities present as well-defined elongate slits (in most specimens of howelli the vacuities are minute and irregular in outline).

Remarks. $-R$. $m$. scansor inhabits arid tropical lowlands in the rain shadow of the Sierra Madre. Dr. Wagner states (in litt.) that at Cintalapa and Villa Flores the form was found only near stream courses and in swampy areas. $R$. mexicanus is known to be semiarboreal in habit. The scansorial tendency is evident in scansor. Seven of the 9 specimens were trapped in trees, 3 in flowering Erythrina and 4 in trees of undetermined kind.

In coloration and other characters of the pelage scansor resembles $R$. pacificus. In both the coloration of the upper parts is comparatively drab and "streaked" in appearance and the fur is short and coarse. All specimens of pacificus that I have seen, however, are smaller than those of scansor; the smallness is well seen in the length of hind foot, breadth of brain case, and length of molar row. In further contrast the tail of pacificus is shorter, the interorbital diameter of the skull is relatively greater, and the rostrum is relatively broader. The external resemblances in those 2 forms appear to be responses to somewhat similar environments. Other characters of scansor suggest consanguinity with $R$. mexicanus; the form appears to be a geographic race of that species.

Specimens examined.-Nine from localities in Chiapas, México, as follows: Cintalapa, 1700 ft., 4; Villa Flores, 2000 ft., 5.

\section{Reithrodontomys mexicanus howelli Goodwin}

Mus tazamaca Gray, 1843: 79 (a nomen nudum applied to specimens of Ochetodon mexicanus De Saussure from Cobán, Guatemala, fide Alston, 1879: 151).

Reithrodon mexicana, Tomes, 1861: 284.

Ochetodon mexicanus, Coues, 1874: 186 (part); 1877: 128 (part). Alston, 1879: 151 (part). True, 1884: 598 (part).

Reithrodontomys mexicanus mexicanus, Howell, 1914: 71 (part); Goodwin, 1934: 37 (part). Reithrodontomys mexicanus howelli Goodwin, 1932: 1; 1934: 37.

Type.-Female, skin and skull; Amer. Mus. Nat. Hist. No. 70500; Guatemala, Dept. El Quiché, (Santo Tomás) Chichicastenango, 6500 feet elevation; collected 12 February 1925 by A. W. Anthony.

Distribution.-Mountains of eastern and central Chiapas and of western and central Guatemala. Known range from the vicinity of Bochil, Chiapas, southeast to San Pedro Yepocapa and the Sierra de las Minas, Guatemala. Vertical range from approximately 3500 feet near Prusia, Chiapas, to 6400 feet near Chajul, Guatemala. 
Habitat.-Predominantly in and adjoining moist forests. Specimens were collected in situations as follows: In a thicket of brush that bordered an abandoned grass-covered cornfield; examples of sumichrasti and fulvescens were trapped in the same thicket (Chanquejelve). In grass on a rocky hillside; specimens of sumichrasti were collected in the same trap line (Barrillas). In a small corn patch surrounded by many blocks of paved streets and closely packed houses in the center of Chichicastenango. On a northeast-facing slope in a lush growth of ferns, moss, and grass in a wet forest (Chajul). On a steep slope in a dense growth of ferns and vines in a wet forest (Finca Helvetia). In a tree adjoining a stand of swamp cypress along a river; the uncultivated slopes of the river valley were covered with oak scrub (Bochil). In vegetation bordering a swamp among stands of oak and pine (Pueblo Nuevo). In bushes and tall grass adjoining a stream in moist pine-oak forests; in a virgin cloud forest; 9 feet above ground in a tree in a second-growth cloud forest (Prusia). At the end of a rotted moss-covered $\log$ in a streamside, damp, broadleaf forest (San José).

Comparisons.-Compared with R. m. mexicanus (specimens of howelli from Chiapas; examples of mexicanus from Puebla and central Veracruz): Smaller (see measurements). Paler; buffy bands of cover hairs of the back and sides near Cinnamon or Orange-Cinnamon (near Tawny in mexicanus); a lesser admixture of the black overhairs; dorsal stripe less blackish and more diffuse. Brain case relatively shorter; zygomatic diameter relatively less (on the average less than 135 per cent of cranial depth in howelli; usually over 140 per cent in mexicanus); incisive foramina shorter (length of foramen about equal to rostral breadth, not distinctly greater than rostral breadth as in mexicanus); auditory bullae actually larger.

Compared with ocotepequensis (specimens of howelli from Chiapas; specimens of ocotepequensis from Honduras): Similar in size, but tail possibly longer (see measurements). Slightly paler dorsally, with fewer black hairs; buffy hues similar in tone. Brain case larger and oval in outline as viewed dorsally (smaller and strongly constricted posteriorly in ocotepequensis); frontals inflated dorsally, concave in profile (essentially flat in ocotepequensis); rostrum averages relatively shorter (length of rostrum usually less than 90 per cent of cranial depth in howelli and over 90 per cent in the examples of ocotepequensis); incisive foramina average shorter.

REMARKs.-The specimens listed here give evidence of 3 centers of differentiation within the range ascribed to howelli. Those centers are: The mountains of Chiapas, the Sierra Cuchumatanes, and the highlands of southern Alta Verapaz. All now can be grouped conveniently and logically, by reason of their common characteristics of large auditory bullae and relatively narrow zygomata, under the one name, howelli. A larger series of specimens from 
each of those areas possibly would emphasize rather than obscure the morphological differences that are seen in the samples at hand. The specimens from Chiapas are all small and moderately pale; they have relatively short incisive foramina and slight molar teeth. Those from the Cuchumatanes and adjoining foothills to the northwest (specimen from San José) are consistently larger and are slightly darker dorsally; they have longer foramina, a longer rostrum and comparatively heavy teeth. They resemble some specimens of mexicanus from Veracruz. The specimens from southern Alta Verapaz (Cobán and Finca Panzamalá) resemble those from the Cuchumatanes in color, but are like most of the Chiapan samples in size and cranial details.

The 2 topotypes of howeili lack dark pigment in the terminal part of the tail. In all other examples of the subspecies, as here understood, the tail is entirely concolor; however, a white tip is observed on other specimens of the mexicanus group of species and races. A specimen of $R$. m. potrerograndei from Costa Rica, 2 examples of $R$. m. söderströmi, 3 individuals of $R$. $m$. eremicus from Ecuador, and 2 specimens of $R$. darienensis from Panamá lack pigment in the tip of the tail. The character apparently occurs sporadically in $R$. mexicanus and related species and is nowhere a population characteristic. In $R$. creper, of the tenuirostris group, a white-tipped tail is of common occurrence.

Specimens ExAminfid.-Thirty-six from the following localities: Guatemala. Alta Verapaz: Cobán, 4500 ft., 4 (CM); Finca Panzamalá, 4100 ft., 1. Chimaltenango: San Pedro Yepocapa, 4800 ft., 1 (CM). El Quiché: Chajul, $6400 \mathrm{ft}$., 2 (US); (Santo Tomás) Chichicastenango, 5000 ft., 1 (AM). Huehuetenango: Barrillas, 4700 ft., 2 (AM); Chanquejelve, $5050 \mathrm{ft} ., 1$ (AM); Jacaltenango, $4600 \mathrm{ft} ., 1$ (US). Quezaltenango: Finca Helvetia, $5500 \mathrm{ft} ., 1$ (US). Zacapa: Sierra de las Minas, Santa Clara, $5500 \mathrm{ft} ., 2$ (CM). México. Chiapas: Bochil, $4300 \mathrm{ft}$., 2; valley of Comitán, $5700 \mathrm{ft}$., 1 (US); Prusia, 3500-4500 ft., 12; 40 mi. NNW San Cristóbal, Pueblo Nuevo, 5600 ft., 1; 28 mi. ESE Comitán, San José, 4900 ft., 1 (MVZ); Tumbalá, 4000 ft., 3 (US).

\section{Reithrodontomys mexicanus orinus Hooper}

Reithrodontomys mexicanus orinus Hooper, 1949: 169.

Type.-Adult, skin and skull; Univ. Calif. Mus. Vert. Zool, No. 98459; El Salvador, Dept. Sonsonate, about 12 miles southeast of Sonsonate, near summit of Balsam Range, Hacienda Chilata, elevation 2000 feet; collected 12 May 1942 by M. Hildebrand; original No. 1465 .

Distribution.-Mountainous slopes of El Salvador and of southeastern Guatemala. Known range from San Rafael and Lago de Amatitlán, Guatemala, southeast in the coastal chain of volcanoes to the Balsam Range, El Salvador, and southeast on the southern flanks of the interior highlands of 
El Salvador as far as Cerro Cacaguatique. Vertical range from 2000 feet at Hacienda Chilata to 7000 feet at San Rafael, Guatemala.

HaвiтAт.-Typically moist situations in pine-oak and subtropical broadleaf forests. Specimens were collected in situations as follows: In a thicket of thorny shrubs and blackberries at the edge of a fallow, grass-covered cornfield; among rocks in a dry, oak forest (Lago de Amatitlán). In a pile of old roofing from a coffee nursery in semihumid forest (Volcán de Santa Ana). In trees in coffee groves and a coffee-balsam forest; under a $\log$ in a coffeebalsam forest; about 10 feet from the ground in thick brush (Hacienda Chilata). In brush on the banks of a small stream; in a house (Los Esesmiles). Under banana leaves on the ground in a banana grove; at the base of a banana tree; on the roof of a banana-leaf shed; in a nest in dense brush on a mountainside; in a house (Cerro Cacaguatique).

Comparisons.-Compared with lucifrons (specimens of orinus from Los Esesmiles; specimens of lucifrons from central Honduras): Similar in size and in color of upper parts. Underparts usually white, instead of Light Pinkish Cinnamon as in lucifrons. Cranium flattened dorsally and relatively shallower; rostrum actually and relatively longer (length of rostrum averages 91 and 87 per cent of the cranial depth, respectively, in the 2 series); palate slightly shorter; incisive foramina actually and relatively longer (their length 50 and 47 per cent of cranial depth, respectively, in orinus and lucifrons); auditory bullae relatively smaller.

Compared with howelli (specimens of orinus from Los Esesmiles; examples of howelli from Chiapas): Larger (see measurements). Upper parts much brighter, the mass effect of the fur on the back bright tawny or orange-cinnamon; the black hairs comparatively inconspicuous; buffy bands similar in hue, perhaps slightly more ochraceous in howelli. Skull averages larger in all dimensions; zygomata relatively broader, rostrum narrower and longer, palate longer, and auditory bullae relatively smaller.

Remarks. $-R$. $m$. orinus differs from neighboring races of $R$. mexicanus in a combination of characters, of which the bright tawny upper parts of the adult pelage, the white underparts, shallow cranium, long rostrum and incisive foramina, and small auditory bullae are noteworthy. It lives in comparatively arid areas in El Salvador and southeastern Guatemala. The diagnostic characters of the race apparently are best developed in southwestern El Salvador, as indicated by specimens from Hacienda Chilata and Volcán de Santa Ana. Those from Chilata are the palest and have the most distinctive crania: Relatively broad zygomata; shallow, posteriorly depressed brain case; long rostrum and incisive foramina; slight molar teeth and small auditory bullae. The examples from Volcán de Santa Ana have larger molars and are slightly darker dorsally, but are otherwise similar. In the specimens from localities to the north (Los Esesmiles), east (Cerro Cacaguatique), and west 
(San Rafael and Lago de Amatitlán) of Chilata and Santa Ana the pelage is slightly darker, the cranium deeper, and the rostrum shorter than in topotypes. Intergradation of orinus with howelli and lucifrons is indicated. The relationships with ocotepequensis are not clear. Both forms apparently occur on Los Esesmiles but at different elevations and probably in different ecologic associations. The specimens from the middle slopes (6400 feet) on that mountain are all referable to orinus. Three young examples from a collecting station at 7500-8000 feet elevation in or at the edge of the cloud forest have the dense pelage, deep color tones, small size, and peculiar cranium as seen in topotypes of ocotepequensis. As judged from the material at hand, representing few localities, orinus ranges exclusively on the chain of coastal volcanoes and on the Pacific slopes of the central highlands. The form ocotepequensis apparently is an inhabitant of the interior highlands and Caribbean slopes.

Specimens EXAmINED.-Fifty-two from the following localities: El Salvador. Chalatenango: Los Esesmiles, 6400 ft., 12 (MVZ). Morazán: Cerro Cacaguatique, 3700-4800 ft., 11 (MVZ). San Miguel: Cerro Cacaguatique, 3500-3750 ft., 11 (MVZ). Sonsonate: Hacienda Chilata, 2000-2600 ft., 7 (MVZ); Volcán de Santa Ana, 4500-5000 ft., 4 (MVZ). Guatemala. Guatemala: Lago de Amatitlán, 4200 ft., 4 (US). Sacatepéquez: Finca San Rafael, 7000 ft., 2 (CM).

\section{Reithrodontomys mexicanus ocotepequensis Goodwin}

Reithrodontomys mexicanus ocotepequensis Goodwin, 1937: 1; 1942: 159.

Type.-Male, skin and skull; Amer. Mus. Nat. Hist. No. 124860; Honduras, Dept. Ocotepeque, 30 miles northeast of Ocotepeque, Monte Verde, elevation 4500 feet; collected 23 July 1936 by C. F. Underwood.

Distribution.-Interior highlands of western Honduras and extreme northwestern El Salvador. Known geographic and vertical range from Monte Verde west to Monte Linderos, 5700 feet, Honduras, and south to Los Esesmiles, 8000 feet, El Salvador.

HaвiтAт.-Apparently cloud forest. The specimens were collected in situations as follows: In oak cloud forest under a rotten log; by a hole in moss among ferns and brush (8000 ft. on Los Esesmiles). In a straw hut in a clearing in brush (7500 ft. on Los Esesmiles). In dense forest (Monte Verde).

Comparisons.-Compared with orinus (topotypes of ocotepequensis; specimens of orinus from western El Salvador): Smaller (see measurements). Tail relatively short, possibly slightly shorter than in orinus. Pelage longer. Upper parts much more somber. Skull narrow and relatively long; smaller in all dimensions and relatively smaller in zygomatic breadth, breadth of brain case, and breadth of rostrum; auditory bullae similar in absolute size, relatively larger in ocotepequensis.

Compared with lucifrons (topotypes of ocotepequensis; specimens of lucifrons from the vicinity of Tegucigalpa): Smaller (see measurements). 
Tail possibly relatively shorter. Upper parts darker, the back chestnut rather than bright tawny. Basal bands of cover hairs darker, near Plumbeous-Black. Terminal bands of hairs of underparts shorter (the basal bands longer) and creamy white (usually Pinkish Cinnamon in lucifrons). Cranium smaller in all dimensions; disproportionately smaller in depth and in rostral breadth.

Remarks.-The specimens from Monte Linderos and Cerro Pucca have broader rostra than those from Monte Verde but the 2 series agree in external and other cranial characters. Three immature specimens, one without skull, from the cloud forest near the summit of Los Esesmiles apparently are referable to ocotepequensis. They are smaller and darker dorsally and have larger black facial markings and longer fur than the series of orinus from the dry oak and brush belt at 6400 feet on the same mountain. Although no absolute characters are known for distinguishing ocotepequensis from adjoining subspecies of $R$. mexicanus, the occurrence of orinus and ocotepequensis on the same mountain but apparently in different ecologic situations suggests that ocotepequensis may be specifically distinct from orinus. The 2 forms require further study to determine their precise relationships. As now understood ocotepequensis appears to be a race of $R$. mexicanus. Its differential characters are of no more than subspecific value and its range complements that of races of $R$. mexicanus.

Specimens eXAmined.-Fourteen from the following localities: El Salvador. Chalatenango: Los Esesmiles, 7500-8000 ft., 3 (MVZ). Honduras. Lempira: Cerro Pucca, $6600 \mathrm{ft}$., 2 (AM); Monte Linderos, $5700 \mathrm{ft}$., 3 (AM). Ocotepeque: Monte Verde, $4500 \mathrm{ft} ., 6$ (AM).

\section{Reithrodontomys mexicanus lucifrons Howell}

Reithrodontomys mexicanus lucifrons Howell, 1932: 125; Goodwin, 1942: 159.

Reithrodontomys mexicanus minusculus Howell, 1932: 125; Goodwin, 1942: 160. Honduras, Dept. Francisco Morazán, Comayaguela, 3000 feet elevation.

Type.-Adult female, skin and skull; U. S. Nat. Mus. No. 257086; Honduras, Dept. Francisco Morazán, about 15 miles (air line) north-northwest of Tegucigalpa, Cerro Cantoral; collected 7 February 1932 by C. F. Underwood; original No. 709.

Distribution.-Highlands of central and eastern Honduras and northwestern Nicaragua. Known range from the vicinity of Muya, Honduras, southeast to the Río Coco (probably headwaters near Ocotal), Nicaragua. Vertical range from approximately 3500 feet at Comayaguela to 6000 feet on Cerro Cantoral, Honduras.

Habitat.-The specimen from Comayaguela was collected on scrubby land 400 or 500 feet higher than the city (Goodwin, 1942: 109). The interior highlands of Honduras are characterized by deciduous hardwood forests, by oak and pine, and by brush and savanna; cloud forests occur on the higher moun- 
tains (Carr, 1950). There is no information on habitats of the other specimens examined.

Comparisons.-Compared with howelli (specimens of lucifrons from the vicinity of cerros Cantoral and Archaga; specimens of howelli from Chiapas): Larger (see measurements). Upper parts much brighter, the Tawny bands of the cover hairs prominent over entire dorsum and sides, much less obscured by black guard hairs than in howelli. Underparts Light Pinkish Cinnamon, rarely whitish as in howelli. Cranium larger in all dimensions; proportions similar in the 2 series, but the palate in lucifrons relatively longer on the average.

Compared with cherriei (specimens of lucifrons from central Honduras; specimens of cherriei from central Costa Rica): Slightly smaller (see measurements); indistinguishable in tail length. Coloration similar, particularly in subadult pelage. Full adult pelage similar in hue, but slightly darker in tone dorsally (Tawny or Ochraceous-Tawny rather than Zinc Orange or Ochraceous-Orange as in cherriei). Cranium large as in cherriei, but relatively smaller in length of brain case, rostrum (respectively 87 and 92 per cent of depth of cranium in lucifrons and cherriei), and incisive foramina (respectively 47 and 51 per cent of depth of cranium in the 2 races); auditory bullae slightly larger on the average.

Compared with $R$. brevirostris (specimens of lucifrons from central Honduras; specimens of brevirostris from Villa Quesada and Zapote): Larger (see measurements of hind foot and molar row especially). Upper parts brighter and less blackish in both subadult and adult pelages; the buffy bands of the hairs broader and much less obscured by the black tips; fur of dorsum about Tawny in adult pelage (near Russet in brevirostris) and Warm Sepia or Natal Brown in subadult pelage (Fuscous in brevirostris); tips of hairs of underparts usually Light Pinkish Cinnamon (creamy white in brevirostris); the forms indistinguishable in color of sides, ears, feet, and tail. Cranium more convex dorsally and averaging larger in all dimensions in lucifrons; rostrum relatively narrower, averaging 46 per cent (lucifrons) and 50 per cent (brevirostris) of brain-case depth in adult specimens; molars and auditory bullae much larger; incisive foramina relatively narrower and absolutely, if not relatively, longer.

REMARKs. - R. m. lucifrons is a large, bright-colored subspecies that inhabits the central highlands of Honduras. It apparently intergrades with neighboring subspecies: with ocotepequensis to the northwest, as indicated by specimens from Cerro Pucca; with orinus to the southwest, as seen in specimens from Cerro Cacaguatique. The ranges of lucifrons and of cherriei, as now known, are separated by the lowlands of Nicaragua where harvest mice of the species mexicanus probably are rare or are entirely absent. The 2 forms probably do not interbreed freely at the present time level, but through 
individual variation they do intergrade and are clearly part of the chain of intergrading forms that comprise the species mexicanus.

Specimens from the vicinity of Comayaguela, the type locality of minusculus, are matched by examples from Cerro Cantoral, the type locality of lucifrons, and it seems clear from the material at hand that the former must be considered synonymous with lucifrons. The type and topotypes of minusculus are in bright adult pelage, but they are subadults as judged by cranial criteria. In all specimens from the northern and extreme southern parts of the range of $R$. mexicanus, the full-colored adult pelage occurs only in obviously old individuals - those that fulfill all specifications of adults as defined on other pages of this report. In the examples from central Honduras (lucifrons) and central Costa Rica (cherriei), however, the bright adult pelage is repeatedly associated with skulls that must be classed as of subadult age. If my age criteria for the crania are reliable and if the skins and skulls are correctly matched, it would appear that in $R$. mexicanus the adult pelage colors may be acquired at an earlier age in Honduras and Costa Rica.

A single fragmented skull in $R$. mexicanus labeled as from the Río Coco, Nicaragua, is referred to this race on geographic grounds only. If the specimen was collected on the Río Coco, it likely came from the headwaters of that river, possibly in the vicinity of Ocotal. The species is to be expected there but not in the lowlands toward the east.

SPECimens EXAMINED.-Thirty from the following localities: Honduras. Francisco Morazán: Cerro Cantoral, 6000 ft., 9 (7 AM, 2 NM); near Comayaguela, about $3500 \mathrm{ft} ., 2$ (1 AM, $1 \mathrm{NM}$ ); El Derrumbo, $4000 \mathrm{ft}$. (?), 1 (AM); Hatillo, 4800 ft., 1 (AM); La Flor Archaga, 4500-5000 ft., 5 (2 AM); Montaña Vásquez, 6000 ft., 3 (CM); Monte Redondo, 3500-4000 ft., 2 (AM); Sabana Grande, 3500 ft., 2 (AM). La Paz: Humuya [=Muya, 4000 ft. ?], 4 (AM). Nicaragua. Río Coco, 1 (AM).

\section{Reithrodontomys mexicanus cherriei Allen}

Hesperomys (Vesperimus) cherrii Allen, 1891a: 211.

Sitomys cherriei, Allen, 1893: 238.

Reithrodontomys costaricensis Allen, 1895a: 139; 1904: 45, 70. Costa Rica, Prov. Cartago, La Carpintera, 5000 feet elevation.

Reithrodontomys cherriei, Osgood, 1907: 50.

Reithrodontomys cherriei cherriei, Miller, 1912: 129.

Reithrodontomys mexicanus cherrii, Howell, 1914: 73; Goodwin, 1946: 383.

Type.-Male?, skin only; Amer. Mus. Nat. Hist. No. 3648; Costa Rica, Prov. San José, San José; collected 9 June 1889 by G. F. Underwood.

Distribution.-The Cordillera Central and northern part of the Cordillera de Talamanca, Costa Rica. Known range from the vicinity of Zarcero (Tapesco), Prov. Alajuela, southeast to Volcán de Irazú in the Cordillera Central and to El Copey de Dota in the Cordillera de Talamanca. Vertical 
range from approximately 3000 feet at Villa Colón and San José to 7000 feet at Estrella de Cartago.

Habitat.-Specimens from El Copey de Dota were collected in a thick growth of herbs along a stream and in a wet meadow. One from the foothills of El Volcán de Irazú, was taken in a stone fence.

Comparisons.-Compared with brevirostris (specimens of cherriei from central Costa Rica; topotypes of brevirostris): Much larger (see measurements of hind foot, skull length, and length of molar row). Tail averages shorter ( 135 per cent of head and body length compared with 153 per cent in brevirostris). Coloration brighter in subadult and adult pelages, the orange hues more prominent, particularly dorsally (near Zinc Orange or OchraceousOrange in adults). Cranium deeper, its dorsal profile strongly convex (comparatively flat in brevirostris); larger in all dimensions except breadth of mesopterygoid fossa; relatively larger in depth of palate and of molar row.

Compared with potrerograndei (specimens of cherriei from central Costa Rica; topotypes of potrerograndei): Distinguishable by much the same set of characters (indicated above) that separate cherriei and brevirostris. Much larger (see measurements). Coloration similar. Crania of the 2 forms greatly different in absolute size: similar in most proportions, but brain case and molars relatively larger, zygomata broader, and rostrum and incisive foramina longer in cherriei.

REMARKs. - R. m. cherriei is one of the largest and brightest colored of the subspecies of Reithrodontomys mexicanus. Its body size and length of skull are comparable to those of some races of Peromyscus maniculatus. In full adult pelage it resembles Peromyscus nuttalli nuttalli, the bright orange hues closely matching. As now known it is restricted in range to the highlands of central Costa Rica, but it probably occurs in the mountains to the northwest and in the Cordillera de Talamanca, where it may be expected to intergrade with $R$. m. garichensis of western Panamá. As is true in some other regions, specimens from higher altitudes average larger than those from lower elevations. The examples from El Copey and from the slopes of Volcán de Irazú (6000-7000 feet) average slightly larger than those from San José and San Pedro (3000-4000 feet), but with the present samples the differences are not significant.

The original description of cherriei (Allen, 1891a) is based on a mixture of specimens of 2 genera, namely Reithrodontomys and Peromyscus. Allen based the name cherriei on 6 specimens as follows: a study skin without skull collected at San José by C. F. Underwood and 5 alcoholic specimens collected by G. K. Cherrie at La Carpintera. He designated no type specimen but apparently had one particular specimen in mind. This was an adult male, alcoholic, the external measurements of which are listed in the original description and on which his detailed description of pelage coloration may 
have been based. The free skull associated with that skin, however, is that of a Peromyscus maniculatus. It probably belongs with a skin of a Peromyscus which was contained in the same jar with the Reithrodontomys and which Allen referred to $P$. sonoriensis. The skull is the one measured and described by Allen in the original account of cherriei. Allen believed that he was describing a form of the genus Peromyscus when he named his new form Hesperomys (Vesperimus) [=Peromyscus] cherriei; he compared it with Peromyscus nuttalli aureolus. Actually, he described the skin of a new form of Reithrodontomys and the skull of a well-known species of Peromyscus. Before the error was discovered he described Reithrodontomys costaricensis, basing his description (1895a: 139) again on a series of specimens from La Carpintera; all of these specimens are harvest mice. This action makes it more certain that Allen placed much weight on the characters of the skulls of cherriei and costaricensis, and that he considered cherriei a form of Peromyscus, and costaricensis a representative of Reithrodontomys. Because his intent seems clear, the name cherriei should be associated with the skull rather than with the skin and should be treated in the nomenclature of the genus Peromyscus. Osgood (1907: 51), however, consigned it to Reithrodontomys and designated a lectotype. He selected the skin without skull from San José that was contained in Allen's original series. Osgood's solution of the problem should stand.

SPECIMENS EXAMINED.-Forty-seven from the following localities in Costa Rica: Alajuela: vicinity of Alajuela, 3200-3500 ft., 2 (AM); Tapesco, 5000 ft., 1 (AM). Cartago: Cartago, 4500 ft., 1; El Copey de Dota, 6000-6500 ft., 4; Estrella de Cartago, 4500 ft., 1; slopes of El Volcán de Irazú, 6 (CM); foothills of El Volcán de Irazú, $4800 \mathrm{ft}$., 1; La Carpintera, $5000 \mathrm{ft}$., 5 (AM). San José: vicinity of Escazú, 3000-4000 ft., 5 (AM); Las Nubes, 5000 ft., 6 (AM); Los Higuerones, Escazú, 4500 ft., 2 (AM); Sabanillas de Montes de Oca, 4000 ft., 1 (AM); San Indro, 4700 ft., 1 (AM); San José, 3100 ft., 2 (1 CM, $1 \mathrm{NM}$ ); vicinity of San Pedro, $4000 \mathrm{ft}$., 6 (AM); Tibas, 2 (AM); Villa Colón, Río Grande, $3000 \mathrm{ft} ., 1$ (CM).

\section{Reithrodontomys mexicanus potrerograndei Goodwin}

Reithrodontomys mexicanus potrerograndei Goodwin, 1945: 1; 1946: 384.

Reithrodontomys mexicanus cherrii, Enders and Pearson, 1940: 2 (part).

Type.-Subadult male, skin and skull; Amer. Mus. Nat. Hist. No. 142464; Costa Rica, Prov. Puntarenas, Sabanna de Potrero Grande, Agua Buena (locally known as Cañas Gordas, but about 30 airline miles north of the Cañas Gordas near the Panamanian national boundary, fide Goodwin, 1946), elevation about 3500 feet; collected 29 December 1944 by C. F. Underwood.

Distribution.-Pacific slopes of the Cordillera de Talamanca of eastern Costa Rica and extreme western Panamá. Known range from Agua Buena, Costa Rica, to localities on the slopes of Cerro Pando, Panamá. Vertical range 
from 3500 feet at Agua Buena to about 4000 feet on the Río Colorado (Siola) and Río Chebo, Panamá.

Habitat.-No habitat notes are available.

Comparisons.-Compared with $R$. darienensis (subadult topotypes of potrerograndei; subadult topotypes of darienensis): Slightly larger (see measurements). Coloration of upper parts brighter and of the $R$. mexicanus type (not "streaked" or "peppered" as in the $R$. gracilis series of forms); dusky stripe of hind foot much longer and broader. Cranium longer and narrower; brain case relatively narrower (the breadth averages 123 per cent of depth of cranium, as against 130 per cent in darienensis); interorbital area relatively narrower; rostrum broad in both forms, relatively longer in potrerograndei (its length averages 86 per cent of cranial depth compared with 82 per cent in darienensis; incisive foramina relatively longer; auditory bullae much more inflated.

Remarks. $-R$. $m$. potrerograndei is a small form that inhabits the lower slopes of the Cordillera de Talamanca on the Pacific side (Map 8). Similar in coloration to $R$. $m$. cherriei and $R$. m. garichensis which range at higher elevations in the mountains to the northwest and southeast, respectively, it is quite distinct from them in size and cranial characters. Its distributional limits are unknown. At higher elevations, say above 5000 feet, it may be replaced by a larger form similar to or identical with either cherriei or garichensis. Externally and cranially it resembles $R$. brevirostris from the Caribbean slopes of the mountains of central Costa Rica, a form which apparently is specifically distinct from $R$. mexicanus. Until it is better known, its taxonomic status cannot be clearly determined, but if the interpretation of the variations seen in the specimens from extreme western Panamá is correct, it interbreeds with garichensis, which is a geographic race of $R$. mexicanus. The specimens from Siola, Río Chebo, Wald, and Cerro Punta, Panamá, are variously between potrerograndei and garichensis in characters of skin and skull. The majority of the specimens from the first 3 localities fit best with potrerograndei. Those from Cerro Punta, although morphologically intermediate, are referred to garichensis. For further details on the relationships of these 2 forms, see the account of garichensis.

Specimens examined.-Thirty-nine from the following localities: Costa Rica. Puntarenas: Agua Buena (Cañas Gordas), 3000 ft., 7 (AM). Panamá. Chiriquí: Río Chebo, 14 (PM); Siola, Río Colorado, $4100 \mathrm{ft}$., 16 (PM); Río Santa Clara, 4150 ft., 1 (PM); Río Chiriquí Viejo, Wald, 3800 ft., 1 (PM).

\section{Reithrodontomys mexicanus garichensis Enders and Pearson}

Reithrodontomys mexicanus garichensis Enders and Pearson, 1940: 1.

Reithrodontomys costaricensis, Bangs, 1902: 39; Allen, 1904: 70.

Reithrodontomys mexicanus cherrii, Howell, 1914: 74 (part); Enders and Pearson, 1940: 1 (part). 
Trpe.-Subadult male, skin and skull; Acad. Nat. Sci. Phila. No. 18614; Panamá, Prov. Chiriquí, 5 miles southwest of El Volcán (post office), Río Gariché, elevation 3200 feet; collected 14 June 1937 by Samuel Cresson; original No. 2607a (R. K. Enders).

Distribution.-The Cordillera de Talamanca of western Panamá and possibly of extreme southeastern Costa Rica. As now known, confined to the Volcán de Chiriquí and slopes of adjoining mountains. Altitudinal range from 3200 feet on the Río Gariché to 7000 feet at Casita Alta, near Bóquete; one subadult specimen known from 11,000 feet in the crater of the Volcán.

Habitat.-Most of the specimens obtained by R. K. Enders and associates in Panamá (those listed from PM in the lists of specimens examined were collected by that group) were trapped along banks or in clearings in forests (Enders, in litt.). The specimens from Río Gariché were collected among grass and brush.

Comparisons.-Compared with cherriei (specimens of garichensis from the vicinity of Bóquete; a series of cherriei from central Costa Rica): Averaging slightly smaller and darker dorsally in all pelages; the 2 forms indistinguishable in color of feet, tail, and underparts. Cranium of the 2 forms similar in size, but brain case and zygomata of garichensis narrower; rostrum narrower and flat in dorsal profile (not strongly depressed anteriorly as in cherriei); upper incisors erect (strongly decumbent in cherriei).

Compared with potrerograndei (subadults of garichensis from the vicinity of Bóquete; subadult topotypes of potrerograndei): Larger (see measurements). The 2 forms similar in coloration. Cranium of garichensis larger in all dimensions; rostrum relatively narrower and longer (its length 92 per cent of depth of cranium in garichensis compared with 86 per cent in potrerograndei); incisive foramina relatively longer; molar teeth much larger; auditory bullae relatively much more inflated.

Compared with $R$. brevirostris (specimens of garichensis from the vicinity of Bóquete; specimens of brevirostris from central Costa Rica): Larger; range in cranial length and length of molar row of subadults $22.8-23.6 \mathrm{~mm}$. and $3.2-3.6 \mathrm{~mm}$., compared respectively with $22.1-22.5 \mathrm{~mm}$. and $3.0-3.1 \mathrm{~mm}$. in adults of brevirostris. The 2 forms similar in coloration. Cranium of garichensis larger in all dimensions; brain case well inflated (dorsal profile of cranium comparatively flat in brevirostris); rostrum relatively longer and narrower; molar teeth much larger; auditory bullae absolutely, if not relatively, larger.

REMARKs. $-R . m$. garichensis is quite distinct cranially from brevirostris and potrerograndei, the other forms of the mexicanus group known to inhabit the slopes of the Cordillera de Talamanca. Its larger size, large molar teeth, and long narrow rostrum distinguish it from those forms. It is much less distinct from cherriei, and additional material from properly spaced locali- 
ties in the Cordillera may indicate that the form is insufficiently differentiated to warrant a formal name. On the basis of the material now at hand, however, garichensis and cherriei are separable, principally on the basis of the dorsal profile of the skull and on the shape of the rostrum and upper incisors. All of the known forms of the mexicanus group from Costa Rica and western Panamá are similar in coloration. $R$. $m$. cherriei is the brightest colored in all pelages and $R$. brevirostris is the most drab in the subadult pelage. The color differences between the forms are slight.

There is much variation in the series from western Panamá. The specimens from the higher elevations on the Volcán de Chiriquí-Bóquete, Casita Alta, and the interior of the crater-are large. They are comparatively dark dorsally, and they have long dense fur and long narrow rostra. Both externally and cranially they are generally similar to cherriei from central Costa Rica; they differ from cherrie $i$ in the few characters mentioned above. The example from the crater of the Volcán, a young individual in subadult pelage with unworn molar teeth, somewhat resembles specimens of $R$. microdon and $R$. tenuirostris of Guatemala in its exceptionally long pelage, long narrow rostrum, narrowly spread zygomata, and narrow zygomatic plate. In the general appearance of its skull, however, it resembles $R$. mexicanus. All of the examples from the Río Gariché are young. With the type, which is not at hand, they form the basis for the description of garichensis. Only 2 are clearly subadults; the remainder are younger and are in the process of molting the worn juvenile pelage and acquiring the brighter subadult fur. In common with the specimens from stations on the upper slopes of the Volcán those from the Río Gariché are large and moderately dark dorsally and have long narrow rostra, gross molar teeth, and large auditory bullae. To my eye and on the basis of their measurements all of these specimens stand apart from those from the western side of the Río Chiriquí Viejo.

The Río Chiriquí Viejo appears to be a barrier to harvest mice of the species R. mexicanus. Dr. Enders suggested (in litt.) that the 4800 -foot level would approximate the upper limit of effectiveness of the stream as a barrier. The specimens from 2 localities on the western side of the Río Chiriquí Viejo, namely Río Chebo and Siola, on the average show the following features in contrast to those from collecting stations east of the river: Smaller size, slightly paler dorsal color, relatively smaller auditory bullae and molar teeth, and much heavier rostrum, in which the nasals are narrow proximally and expanded distally and the ascending branches of the premaxillae are broadly exposed dorsally. These are features also observed in specimens of potrerograndei from Agua Buena, about 30 miles to the northwest in Costa Rica. The specimens from the localities west of the river, namely Río Chebo, Río Santa Clara, Siola, and Wald are not uniform in regard to these characters. 
In size, shape of brain case, zygomatic breadth, and size of bullae and of molar teeth, 4 specimens from Siola, 2 from Río Chebo, and the example from Wald fit well in a series of potrerograndei from Agua Buena. Two examples from Siola and 4 from Río Chebo, in contrast, resemble specimens from Río Gariché and Bóquete. The characters of the remainder are intermediate or fall variously to one group or the other. Considering all characters and specimens, the sample from Siola tends to resemble that of potrerograndei from Agua Buena and is least like the series from localities east of the Río Chiriquí Viejo. The sample from Río Chebo and the specimen from Wald are somewhat closer morphologically to the samples from the localities across the river, but they still are distinct in a sufficient number of characters to warrant placement with the series from Agua Buena.

The variation in the series from Panamá is great enough to make one suspect that several forms, perhaps more than one species, are represented. The specimens in the series can be segregated into distinct lots. Those lots appear to represent only one species; the gap between extremes in all characters is completely bridged by intermediates. It is concluded, therefore, that the comparatively great variation obtaining in the samples from western Panamá is a result of the interbreeding of 2 morphologically distinct forms, one of large size of the highlands and of areas east of the Río Chiriquí Viejo, the other a small form of lower elevations to the west of that river. The former may be known as garichensis, the latter as potrerogrande $i$; both are treated as races of $R$. mexicanus.

Two specimens labeled "Boqueron" probably came from slopes above that village; the one old enough for positive identification resembles specimens from Río Gariché. A skin only from Cerro Pando is referred tentatively to garichensis; the cranium is needed to permit positive subspecific identification.

One of 2 specimens from Cerro Punta has the heavy rostrum and small bullae and teeth seen in most of the specimens from Siola. The other specimen resembles examples of garichensis from Bóquete and Río Gariché. Both are large and are referred to garichensis.

Specimens examined.-Twenty-one from the following localities in Chiriquí, Panamá: near Boquerón, 2 (1 AM, 1 CM); Bóquete, 3500-4000 ft., 6 (3 AM, 1 CM, 2 US); Casita Alta, 7000 ft., 2 (PM); Cerro Pando, 1 (PM); Cerro Punta, 6000 ft., 2 (PM); Río Gariché, 3200 ft., 7 (PM); El Volcán de Chiriquí, 11,000 ft., l (PM).

\section{Reithrodontomys mexicanus milleri Allen}

Reithrodontomys milleri Allen, 1912: 77; Howell, 1914: 74.

Reithrodontomys söderströmi, Howell, 1914: 75 (part).

Reithrodontomys mexicanus milleri, Hershkovitz, 1941: 2.

Reithrodontomys mexicanus söderströmi, Hershkovitz, 1941: 3 (part). 
Type.-Male, skin and skull; Amer. Mus. Nat. Hist. No. 32596; Colombia, Prov. Cauca, Munchique, elevation 8325 feet; collected 28 May 1911 by Leo E. Miller.

Distribution.-Moderate elevations in the Andes of western Colombia and northwestern Ecuador. Known range from El Roble and Laguneta southwest in the Central Andes to Valle de las Papas, Colombia, and in the Western Andes to the vicinity of Peñaherrera, Ecuador. Altitudinal range from 6000 feet at Cocal to 10,300 feet in Laguneta, Colombia.

Habitat.-Subtropical forests (Hershkovitz, 1941).

Comparisons.-Compared with garichensis (topotypes of milleri; examples of garichensis from Panamá): Slightly smaller; about the size of potrerograndei. Similar in coloration. Upper parts of May-taken specimens about Tawny in adults and Mikado Brown to Verona Brown in subadults. Underparts whitish to Light Pinkish Cinnamon, the hairs dark gray basally. Forefeet white dorsally, lightly clouded with dusky on the mid-line from the wrists approximately to the base of the toes. Upper surfaces of hind feet whitish with a faint to distinct, dusky, wedge-shaped stripe extending from the tarsus approximately to the base of the toes. Tail and ears as in garichensis. Rostrum relatively broader and shorter; frontals relatively broader interorbitally; palate longer and auditory bullae larger.

Compared with eremicus (topotypes of milleri; topotypes of eremicus): Smaller (see measurements). Much darker dorsally; upper parts dark brown (Tawny to Verona Brown) instead of tan (Cinnamon to Pinkish Cinnamon). Tail Fuscous instead of grayish brown. Dusky stripe of hind feet broader and longer. Cranium smaller; zygomata much more delicate anteriorly, the zygomatic plate actually and relatively narrower; frontals relatively broader interorbitally; palate relatively longer; molar row actually and relatively smaller.

Remarks. $-R$. m. milleri is a well-marked race that inhabits Andean valleys and slopes at moderate elevations in Colombia and northwestern Ecuador. It occurs both in the Western and Central Andes, but as now known it is absent from the Cordillera Oriental. It is more strongly differentiated from the southern forms, söderströmi and eremicus, than it is from garichensis and some other races to the north. This is clearly evident when the skins and skulls from Costa Rica, Panamá, Colombia, and Ecuador are arranged in geographical order on the laboratory table. The most evident "break" in the series comes in northern Ecuador. Both externally and cranially the specimens from the inter-Andean plateaus near Pimanpiro and Quito stand apart from the rest of the series. The remainder of the specimens from South America form a second, moderately uniform group to which the name milleri is applied. Size increases toward the south, but the geographical series are too few to determine if the decrease is gradual. The specimens 
from El Roble and Laguneta, all subadults, are the smallest. Subadults from the vicinity of Munchique are intermediate in size, and those from Quito and Pimanpiro (respectively typical of söderströmi and eremicus) are the largest. The specimens from Peñaherrera and Valle de las Papas differ somewhat from the samples taken at localities to the north, but they are clearly more similar to topotypes of milleri than to topotypes of eremicus or söderströmi. Each of those series from Peñaherrera and Valle de las Papas probably represents a microrace which, as now sampled, does not warrant formal recognition. The 3 specimens from Valle de las Papas have exceedingly long fur, Russet upper parts, and Vinaceous-Cinnamon underparts. Externally they somewhat resemble $R$. tenuirostris which lives at high altitudes in Guatemala. The cinnamon underparts are essentially matched in 2 specimens from Peñaherrera and in one from Pimanpiro, and their skulls fit well in the topotypal series of milleri. The specimens from Peñaherrera grade toward söderströmi in size and interorbital dimension of the frontals, but in characters of the rostrum, zygomata, zygomatic plate, molars, and palate they resemble milleri from west-central Colombia. The range of milleri as here outlined, in bridging several broad, tropical lowland valleys, does not make good distributional "sense," but it fits the morphological facts.

A skull labeled "Noanama, Cauca," a locality on the Río San Juan in the Pacific coastal lowlands, actually may have been obtained in highlands. It is similar to specimens from the highland localities, El Roble and Laguneta. There is no undoubted record of $R$. mexicanus from the Pacific lowlands of South America.

Specimens eXAmined.-Thirty-two from localities as follows: Colombia. Caldas (?): El Roble, 7000-7200 ft., 6 (AM). Cauca: Cocal, 6000 ft., 2 (1 AM, 1 CM); Munchique, 8325 ft., 12 (AM). Huila: near San Agustín, 5000 ft., 1 (AM); Valle de las Papas, 10,000 ft., 3 (AM). Tolima (?): Laguneta, 10,300 ft., 1 (AM). Ecuador. Imbabura: near Peñaherrera, $6500 \mathrm{ft}$., 7.

\section{Reithrodontomys mexicanus eremicus Hershkovitz}

Reithrodontomys mexicanus eremicus Hershkovitz, 1941: 4.

Type.-Subadult male, skin and skull; Univ. Mich. Mus. Zool. No. 77250; Ecuador, Prov. Imbabura, Valle de la Chota, near Pimanpiro, San Nícolas; elevation 6500 feet; collected 14 June 1934 by Philip Hershkovitz; original No. M-255.

Distribution.-Insofar as known restricted to the Valle de la Chota, an arid subtropical valley on the inter-Andean plateau in northern Ecuador.

Habitat.-Open situations in light sandy soil in the arid subtropical Valle de la Chota (Hershkovitz, 1941: 5).

Comparisons.-Compared with söderströmi (topotypes of eremicus; topo- 
types of söderströmi): Similar in size and in most cranial details. Distinct in coloration. Upper parts (of moderately abraded June pelage) tan (near Vinaceous-Cinnamon) instead of dark reddish-brown (near Tawny or Ochraceous-Tawny) as in söderströmi; buffy hues purest on sides, cheeks, and in a faint lateral line. Underparts pale cinnamon (varying from VinaceousCinnamon to Pale Cinnamon-Pink), the bases of the hairs lead-colored. Forefeet and hind feet whitish or Pale Pinkish Cinnamon; hind feet with a narrow dusky line extending from the ankles about halfway to the base of the toes; toes white. Tail fuscous, slightly paler ventrally. Cranium similar to that of söderströmi, with heavy zygomata, narrow frontals, short palate, and large molar teeth. Zygomatic plate and notch broader and auditory bullae more inflated than in söderströmi.

REMARKs.-From a distributional standpoint the specimens from Pimanpiro might be expected to resemble those from Peñaherrera almost as much as they resemble those from Quito. The 3 localities are about equidistant from one another (nearly 50 air-line miles) and are separated by intervening high ridges. The Pimanpiro and Quito series clearly must be grouped together, however, on the basis of size and cranial characters. They are distinguishable principally in characters of coloration; they form the basis for the names eremicus and söderströmi, respectively. The Peñaherrera specimens, in contrast, fit better with examples of milleri from localities several hundred miles to the north and across inhospitable lowlands. Hershkovitz (1941) indicated that eremicus is unique in its large ears. This character should be checked in more complete material than is now at hand. I am unable to appreciate significant differences in ear size among the races of R. mexicanus in South America. In 3 specimens of eremicus the tail is tipped with white. For mention of other examples of a white-tipped tail in the subgenus Aporodon see the accounts of $R$. m. söderströmi, potrerograndei and howelli, and $R$. creper.

SPECIMENS EXAMINED.-Six from the type locality.

\section{Reithrodontomys mexicanus söderströmi Thomas}

Reithrodontomys söderströmi Thomas, 1898: 451; Howell, 1914: 75.

Reithrodontomys mexicanus söderströmi, Hershkovitz, 1941: 3.

Type.-British museum No. 98.5.1.9; Ecuador, Prov. Pichincha, Quito, elevation 9200 feet; collected in August, 1897, by Ludovic Söderström.

Distribution.-The inter-Andean valley and adjoining slopes in the vicinity of Quito, Ecuador.

Habitat.-Consul Ludovic Söderström, who collected all but one of the known examples of söderströmi, noted that in Quito the species feeds on flowers and seeds in the garden and comes out from among the climbing plants every evening about seven o'clock (Thomas, 1898). 
Comparisons.-Compared with milleri (topotypes of söderströmi; topotypes of milleri): Larger (see measurements). Coloration similar; in adult pelage upper parts Ochraceous-Tawny with a heavy overlay of black except on the sides; underparts Light Pinkish Cinnamon, the hairs everywhere Dark Mouse Gray basally except on the throat where they may be white or Light Pinkish Cinnamon throughout; tail Fuscous, monocolor or slightly paler ventrally; upper surfaces of forefeet whitish; upper surfaces of hind feet whitish, with or without a short, narrow, median stripe (in no specimen at hand does the stripe extend distally more than halfway to the base of toes). Cranium broader, well seen in breadth of brain case and zygomatic breadth; molars larger (see measurements); auditory bullae relatively smaller; zygomatic plate actually and relatively broader (visible as a slight keel projecting anteriorly when the skull is viewed dorsally); palate relatively shorter; and frontals relatively narrower.

REMARks.-The morphological characters and geographic range of $R . m$. söderströmi cannot be known satisfactorily until many more specimens are available from Ecuador. Earlier authors (Howell, 1914; Allen, 1916; Hershkovitz, 1941) have included specimens from southern Colombia (e.g. Valle de las Papas) with söderströmi, basing their determinations largely on external characters. Hershkovitz pointed out that the Colombia specimens cranially resembled topotypes of milleri rather than those of söderströmi, yet he identified those from Valle de las Papas with söderströmi. As I see the external and cranial characters in the material before me, the South American specimens are divisible into 2 principal groups, each of which has a set of well-marked characters peculiar to it. One of these includes the specimens from Quito and Valle de la Chota, here known by the names söderströmi and eremicus, respectively. The other group consists of the remaining specimens from South America which, although differing from place to place, nevertheless form a relatively homogeneous group here treated under the name milleri. The specimens from Valle de las Papas fall in this latter group (see account of milleri for further details).

In 2 of the topotypes at hand the terminal part of the tail is white. A white-tipped tail is observed in a few specimens of eremicus and in examples of the other races of $R$. mexicanus from Costa Rica and Guatemala, but apparently that character is not fixed in any known population. Variation in the breadth and length of the dusky stripe on the upper surface of the hind feet is not completely understood. It is known to vary geographically, and there is some evidence in specimens of söderströmi and other races of $R$. mexicanus that it varies seasonally. In 2 specimens from Quito (the one of known date was collected April 25) replacement of the hairs of the hind feet is complete except in a small area on the left foot; there the hairs are well worn. The new hairs are long and white; the old hairs are dusky.

SPECIMENS EXAMINED.-Five from the type locality. 


\section{Reithrodontomys brevirostris Goodwin}

(Maps 9, 12; Pls. VIII, IX; Fig. 16)

Reithrodontomys brevirostris Goodwin, 1943: 1; 1946: 385.

Type.-Adult female, skin and skull; Amer. Mus. Nat. Hist. No. 139727; Costa Rica, Prov. Alajuela, canyons above Villa Quesada; elevation 5000 feet; collected 16 September 1941 by C. F. Underwood.

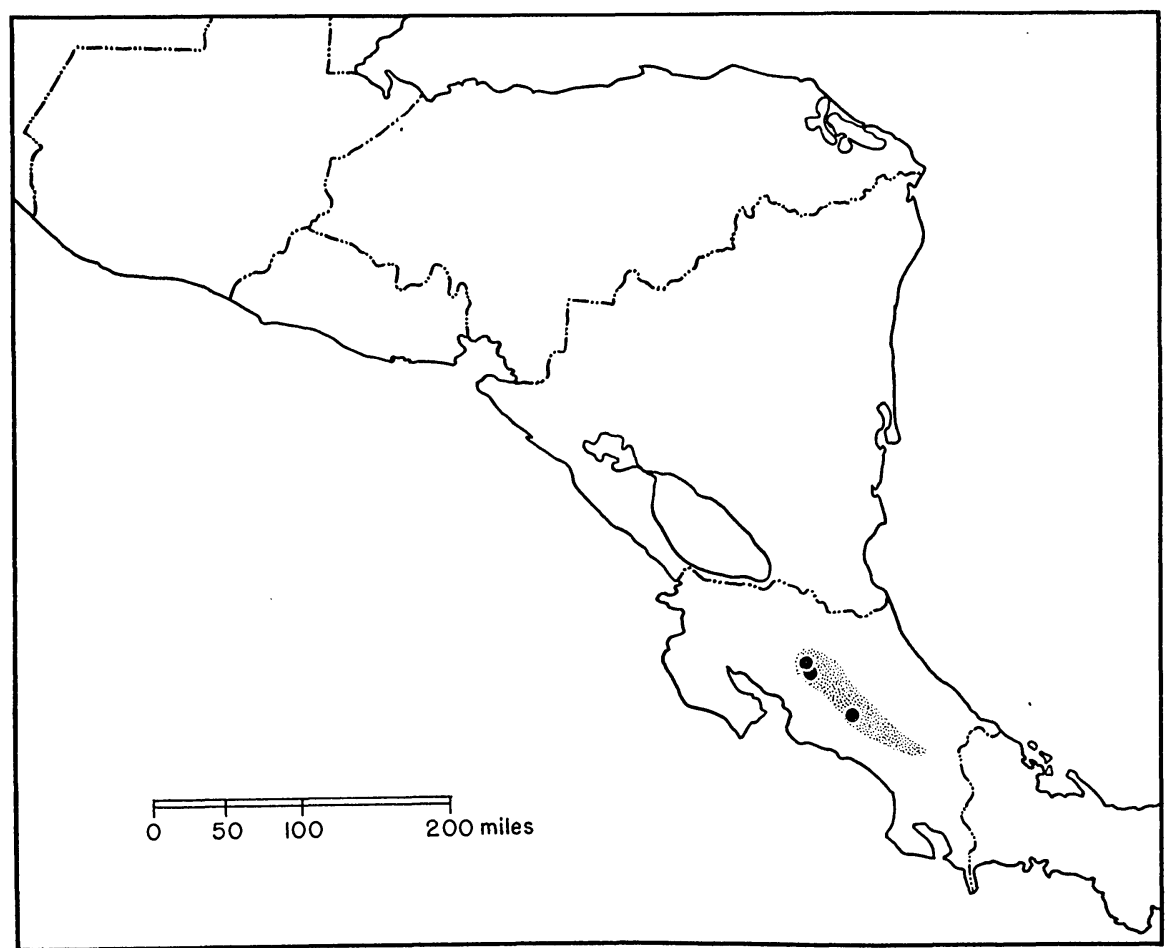

Map 9. Distribution of Reithrodontomys brevirostris, as determined from specimens examined.

Distribution.-The Cordillera Central of Costa Rica. Known range confined to the Caribbean watershed from Villa Quesada south to Estrella de Cartago. Vertical range 5600 feet at Zapote to approximately 7500 feet near Villa Quesada.

Habitat-Apparently cloud forest. The specimens from Estrella de Cartago were collected in humid subtropical situations. Those from the vicinity of Villa Quesada were taken in deep rocky canyons southeast of the town on the northwestern flanks of the Cordillera (Goodwin, 1943).

Comparisons.-Compared with $R$. m. cherriei (specimens of brevirostris from central Costa Rica; specimens of cherriei from central Costa Rica): Much smaller (see measurements). Coloration similar; upper parts more 
somber, effected by heavier suffusion of black on the back and sides. Pelage dense, long, and lax. Tail possibly relatively longer. Cranium much smaller in all dimensions but similar in most proportions to that of cherriei. Brain case low and dorsally flattened, the frontals relatively broader interorbitally; molar teeth relatively smaller; auditory bullae absolutely, and apparently relatively, smaller.

Compared with $R$. $m$. potrerograndei (topotypes of brevirostris; topotypes of potrerograndei): Similar in size and tail length. Upper parts more dusky, heavily suffused with black in juvenile, subadult, and adult pelages; the orange hues similar in the 2 forms. Pelage longer. Brain case and zygomata relatively broader; rostrum as broad as in potrerograndei but relatively longer (the length averages 93 and 86 per cent of cranial depth, respectively, in the 2 forms); incisive foramina relatively longer; auditory bullae larger.

Compared with $R$. darienensis (topotypes of brevirostris; topotypes of darienensis): Similar in size and tail length. Pelages of the specimens at hand not strictly comparable, and the fully adult pelage of darienensis is not represented. In subadult pelage upper parts darker in brevirostris, the mass effect dark brown instead of cinnamon; buffy hues nearer Ochraceous-Tawny or Tawny than Orange-Cinnamon or Cinnamon as in darienensis. Upper parts of juvenile pelage blackish brown instead of mouse gray, the buffy pigments, again as in the subadult pelage, distinctly more rufescent. Dorsal stripe prominent. A broad wedge-shaped dusky area on upper surface of hind feet, extending to base of toes (in darienensis reaching middle of hind foot or entirely absent). Cranium similar in size and most proportions in the 2 forms; brain case broad and deep; rostrum broad, relatively longer in brevirostris; incisive foramina relatively longer (average 51 per cent and 44 per cent of cranial depth, respectively, in the 2 species); auditory bullae much larger; palate shorter in relation to molar row length; molars small in both forms.

REMARks.-That brevirostris is specifically distinct from the mexicanus chain of geographic races seems reasonably certain. The few specimens of the species resemble some examples of $R$. mexicanus (for example $R$. $m$. howelli from Cobán, Guatemala, and Prusia, Chiapas, and R. m. potrerograndei from southeastern Costa Rica), but no intergradation with races of that species is known. The 2 forms occur in the same mountain range and both have been taken at Estrella de Cartago. $R$. brevirostris clearly belongs in the mexicanus group. Apparently its affinities are principally with R. mexicanus. A specimen at hand is labeled simply "Talamanca," which is the term applied to much of eastern Costa Rica. It was obtained by Professor Gabb, who secured many of his specimens from the vicinity of Sipurio in the Caribbean lowlands (Carriker, 1910: 354). I suspect that the present specimen was obtained in the Cordillera de Talamanca rather than in lowlands.

Specimens EXAmined.-Seven from the following localities in Costa Rica: 
Alajuela: near Villa Quesada, 5000-7000 ft., 3 (AM); Zapote, 5600 ft., 1 (AM). Cartago: Estrella de Cartago, 6000 ft. ?, 2. Limón: Talamanca, 1 (NM).

\section{Reithrodontomys tenuirostris group}

Four species that inhabit the high mountains of Central America and southern México stand apart morphologically and ecologically from other kinds of Reithrodontomys. Those species are as follows: microdon, tenuirostris, rodriguezi, and creper. They form a compact series that is here treated as the tenuirostris group. $R$. microdon is polytypic. The other species are monotypic.

Distribution.-The upper slopes of high volcanoes and adjoining highlands, from eastern Michoacán and Distrito Federal south, interruptedly, to the vicinity of Volcán de Chiriquí, western Panamá; but unknown in El Salvador, Honduras, and Nicaragua. Known vertical range of the tenuirostris group 7300-11,000 feet.

Habitat.-Cool, moist forests of fir, pine, cypress, or hardwoods and adjoining clearings and grasslands. The species of this group apparently are arboreal or scansorial in habit. In many places its native habitat has been drastically reduced or diluted as a result of man's activities. In such areas the populations are likely to be low in number. The comparative rarity of specimens in collections, however, is probably partly attributable to the failure of collectors to seek the species in trees.

Comparisons.-The species tenuirostris, rodriguezi, and creper are the largest in the genus, with a hind foot length of over $20 \mathrm{~mm}$., a skull length as much as $27.6 \mathrm{~mm}$., and a molar row as long as $4.5 \mathrm{~mm}$. $R$. microdon is smaller; the linear dimensions of its hind feet, skull, and tooth row are matched in other species, in $R$. mexicanus for example. All have long dense fur. The upper parts are dark reddish brown. The underparts vary from white to bright orange-cinnamon. The fuscous epidermis of the ears is clothed with black hairs. There is a blackish eye ring. The hind feet are blackish, sometimes rimmed with white. The tail is blackish and essentially monocolor; in creper and rodriguezi it may be white tipped. The brain case is long, deep, and broad. The zygomata are comparatively weak; their lateral limits scarcely exceed those of the brain case, and anteriorly they are markedly contracted toward the mid-line of the cranium. The incisors are comparatively erect; the incisive foramina are long with respect to the length of the palate; the auditory bullae are moderately inflated.

As in all species of Aporodon the brain case is large, the mesopterygoid fossa is broad at the expense of the pterygoid fossae and the zygomatic plate is narrow (its least breadth is about equal to, not markedly greater than, the width of the mesopterygoid fossa). There is no distinct zygomatic notch. The molar pattern is complex; mesolophs (ids) and mesostyles (ids) are present 
on all teeth. The third molars are essentially smaller replicas of the second. Those characters distinguish the tenuirostris group from all other species except those also in Aporodon.

The exceedingly long narrow rostrum, strongly constricted frontals, and bulbous brain case are features that set the tenuirostris group apart from the other species of Aprodon. $R$. tenuirostris and $R$. creper are larger (see especially length of hind foot and of skull in table of measurements). $R$. microdon and $R$. rodriguezi are variously matched in body and skull size and in length of molar row by $R$. brevirostris and by some races of $R$. mexicanus, but in none of these is the depth of cranium and length of rostrum relatively as great as in microdon or rodriguezi.

RELATIONSHIPS.-I consider the species of the tenuirostris group to be the most specialized in the genus. They appear to be ecologically intolerant. Unlike some other species, megalotis and fulvescens for example, they do not occur in widely diverse environments. They are confined to a few generally similar situations in cool moist forests on high mountains. Trapping records and some of their morphological characteristics strongly suggest that they are scansorial or even arboreal in habit, more so than are other species of the genus. The long dense fur, dark reddish coloration, long tail and toes should adapt them for life in humid forests. Certain cranial features, too, are interpreted as specializations. Among them are the highly inflated brain case, long rostrum, weak zygomatic arches, narrow zygomatic plate, small pterygoid fossae, and complex molar teeth. They constitute a fairly compact and apparently natural group that is set apart from $R$. mexicanus and $R$. brevirostris, the nearest relatives in the genus.

Affinities within the tenuirostris group are not clear. The species microdon and tenuirostris occur in Guatemala and southern México. $R$. rodriguezi and $R$. creper live in Costa Rica and Panamá. The latter 2 species may be southern ecological counterparts, respectively, of microdon and tenuirostris, but it is doubtful that they are morphologic counterparts. In Table II the 4 species are compared in 14 differential characters.

$R$. creper is the most distinct. It is unique in 4 characters, possibly in 6 if the characteristics of the feet and tail of creper do not agree with those of rodriguezi. It resembles rodriguezi alone in 3 characters, possibly in 5 . It fits well with tenuirostris alone in 4 characters. It agrees with microdon in none. All characters considered, creper stands apart from the other species, especially from microdon. $R$. rodriguezi is unique in none of the characters. It resembles microdon and tenuirostris in more characters than are common to it and creper; however, the examples of rodriguezi are too few to permit satisfactory appraisal of its characteristics. $R$. tenuirostris also is unique in none of the characters. $R$. microdon is unique in one. Eight are common to tenuirostris and microdon. Considering all characters and weighing them 


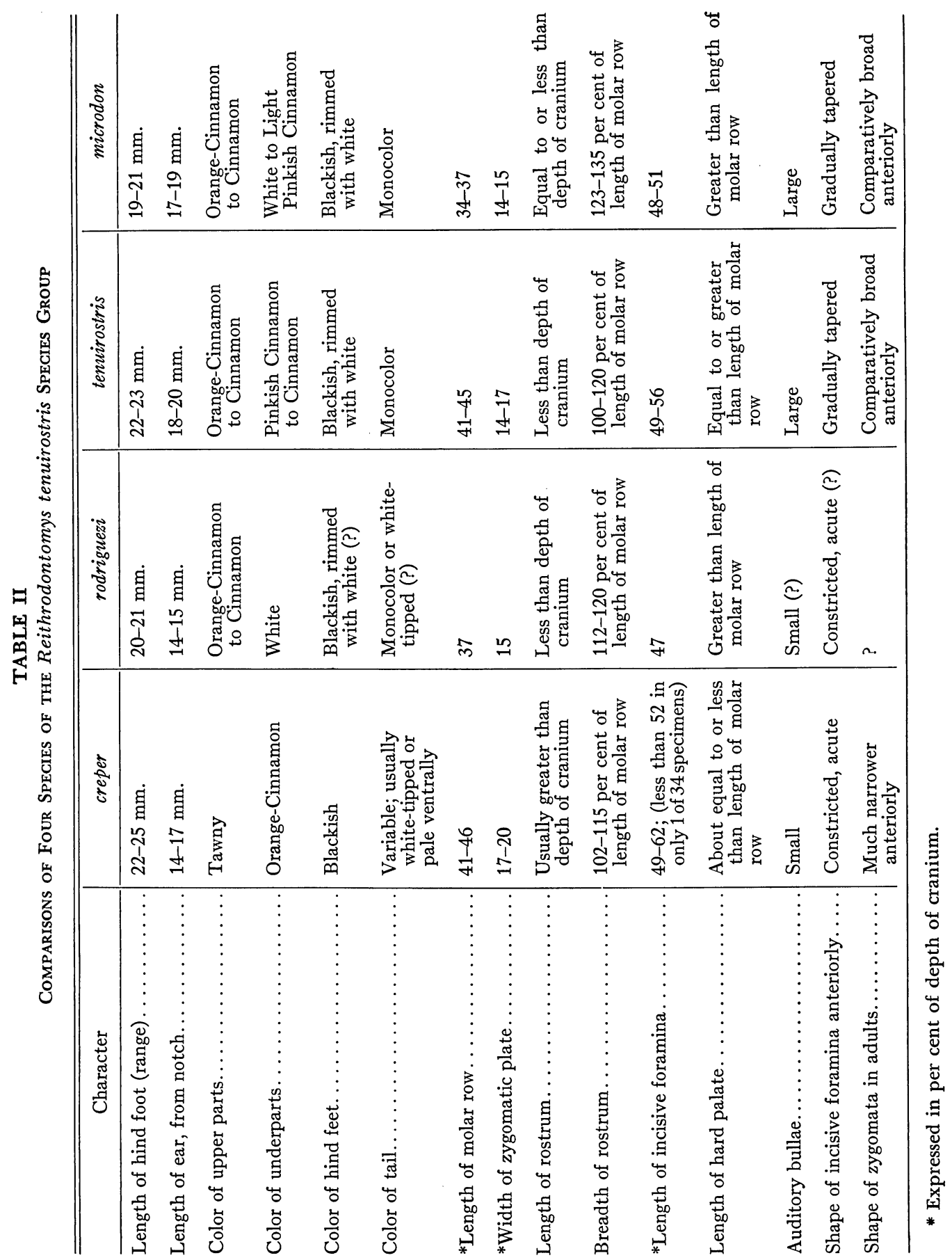


differentially as seems appropriate, I judge that affinities of the species are in the following order: microdon, tenuirostris, rodriguezi, and creper. All 4 apparently were derived from common parental stock; creper has diverged farthest from it.

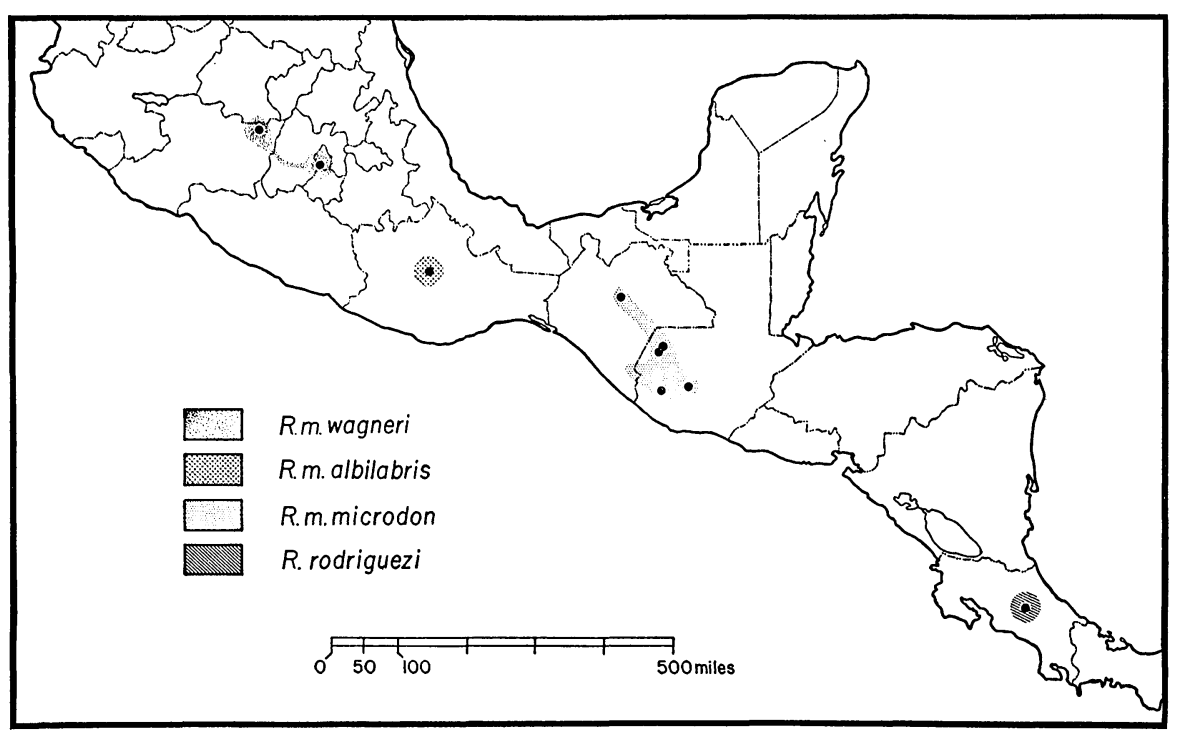

MAP 10. Distribution of the subspecies of Reithrodontomys microdon and of Reithrodontomys rodriguezi, as determined from specimens examined.

\section{Reithrodontomys microdon wagneri Hooper}

Reithrodontomys microdon wagneri Hooper, 1950b: 169.

Type.-Adult female, skin and skull; Univ. Mich. Mus. Zool. No. 94185; México, Michoacán, about 10 miles northwest of Ciudad Hidalgo, western flanks of Cerro San Andrés, 9400 feet elevation; collected 19 March 1949 by Helmuth O. Wagner; original number 463, W. B. McIntosh.

Distribution.-Known only from 2 localities in Distrito Federal and state of Michoacán, but probably occurring elsewhere on the mountains rimming the southern end of the Mexican Plateau. Known altitudinal range 930010,000 feet in Cañón Contreras near Mexico City.

Habitat.-Cool, moist situations supporting natural stands of fir, Abies religiosa. The specimens were obtained in situations as follows: One specimen at the base of a large fir, with no other cover near by; another example on moist ground near spring seepages among a mixed growth of young fir, sacatón, and shrubs in a fir forest (Cañón Contreras). At the base of a fir (1 ft. diameter) in a mixed forest of fir, pine, and oak, with a moderately dense herbaceous understory; another specimen 5 feet above ground on an old 
nest of sticks in a crevice of a fir tree in the above-mentioned forest (Cerro San Andrés).

Comparisons.-Compared with microdon (specimens of wagneri from Michoacán and Distrito Federal; specimens of microdon from Guatemala).

Size: Slightly smaller than microdon (see measurements).

Color: Much paler dorsally; near Ochraceous-Tawny rather than Cinnamon-Rufous in adult pelage of dry season, and Cinnamon rather than Tawny or Russet in subadult pelage, and in both of those pelages with less blackish wash dorsally than in microdon. Sides of face and body nearly pure Ochraceous-Tawny or Cinnamon. Underparts whitish or Pale Pinkish Buff, the bases of the hairs white throughout on the throat, elsewhere on the body Plumbeous-Black. Ears Fuscous, sparsely sprinkled internally and externally with brownish or blackish hairs; oblong in shape and longer than in microdon (from notch about $19 \mathrm{~mm}$. fresh and $17 \mathrm{~mm}$. dry, compared with $17 \mathrm{~mm}$. fresh and $15 \mathrm{~mm}$. dry in microdon). Tail as in microdon, Fuscous dorsally, scarcely or not at all paler ventrally. Forefeet whitish with or without a dusky stripe; toes white. Hind feet from ankles to base of toes Fuscous bordered by whitish, the Fuscous area usually wedge-shaped; toes white.

Skull: Cranium small, shallower than in microdon (absolutely and relative to cranial length); palate longer (molar row length about 80 per cent of length of palate in wagneri compared with 90 per cent in microdon); auditory bullae much smaller, and disc-shaped rather than spherical.

R. m. wagneri differs from $R$. m. albilabris much as it does from microdon; albilabris apparently is larger, has slightly darker upper parts, smaller ears, a deeper cranium, and larger, oval auditory bullae.

$R$. chrysopsis and $R$. rufescens, which may occur with $R$. m. wagneri, resemble that form in color of upper parts and of the ears; but the tail of chrysopsis is well covered with hairs and usually is distinctly bicolored. Both chrysopsis and rufescens have cinnamon-colored underparts. The species is distinguishable from all other species of the highlands of México in cranial characters, of which its long narrow rostrum, bulbous brain case, narrow zygomatic plate, weak zygomatic arches, and full mesolophs in $\mathrm{M}^{1-3}$ are noteworthy.

REMARKs.-Reithrodontomys microdon is known from few specimens and localities. It is restricted to local pockets and apparently is uncommon even in its preferred habitat. It is an inhabitant of fir and short-needled pine forests of cool, shaded canyons and mountainous slopes of southern Mexico and Guatemala. It is semiarboreal in habit; at least 2 of the 10 known specimens were collected well above ground. It is probable that it spends much of its life in trees, for which reason it may frequently escape detection by collectors. Its spotty distribution, rarity, and arboreal habits give the impression 
that the present known populations of the species are residuals from a time when fir and pine forests were more widespread and continuous than they are now. Inhospitable terrain now isolates the populations of Guatemala, Oaxaca, and the Distrito Federal-Michoacán area.

Specimens examined.-Four from the following localities in México: Distrito Federal, 15 mi. SW Mexico City, Cañón Contreras, 9300-10,000 ft., 2. Michoacán, 10 mi. NW Ciudad Hidalgo, Cerro San Andrés, 9400 ft., 2.

Reithrodontomys microdon albilabris Merriam

Reithrodontomys microdon albilabris Merriam, 1901: 549; Howell, 1914: 80.

TyPe.-Subadult female, skin and skull; U. S. Nat. Mus. Biol. Surv. Coll. No. 68393; México, Oaxaca, Cerro San Felipe, 10,000 feet elevation; collected 25 August 1894 by E. W. Nelson and E. A. Goldman; original No. 6629.

Distribution.-Known only from Cerro San Felipe, 10,000 feet, Oaxaca, but probably also occurring on Cerro Zempoaltepec and other high peaks of Oaxaca.

Comparisons.-For comparisons with wagneri, see accounts of that race. To judge from the only known example of the race, albilabris is dorsally paler and more buffy than microdon, by an amount that places albilabris about at the mid-point between the dark tawny microdon and the buffy cinnamon wagneri; underparts whitish like wagneri but unlike microdon; brain case larger than in either of those races; auditory bullae slightly smaller than in microdon.

REMARKs. $-R$. m. albilabris is isolated from $R . m$. microdon by the Isthmus of Tehuantepec and by other arid lowland areas. Unsuitable terrain also restricts it from wagneri to the north. Although the 3 forms are now reproductively isolated from one another, the morphological differences between them are average, not absolute, and are of no more than subspecific value. It is clear that the 3 forms are slightly differentiated geographic races of one species.

SPECimens EXAMINED.-The type only.

\section{Reithrodontomys microdon microdon Merriam}

Reithrodontomys microdon Merriam, 1901: 548.

Reithrodontomys microdon microdon, Howell, 1914: 80.

Type.-Adult female, skin and skull; U. S. Nat. Mus. Biol. Surv. Coll. No. 76923; Guatemala, Dept. Huehuetenango, Todos Santos, 10,000 feet elevation; collected 31 December 1895 by E. W. Nelson and E. A. Goldman; original No. 8977.

Distribution.-High mountains of Guatemala and extreme southern México. Now known from 4 localities in western Guatemala and one in México. Altitudinal range from approximately 7300 feet near San Cristóbal, Chiapas, to 10,500 feet at Chemal, Guatemala. 
Habitat.-Cool, moist areas in coniferal forests. The specimen from Chemal was trapped in a Microtus runway through a growth of herbs, grass, and moss that formed the dense ground cover in a cool, second-growth, shortleaf pine forest. The example from Chichavac was obtained in a "tree top." The specimen from San Cristóbal was trapped among ferns, moss, and vines in a damp, broadleaf forest.

Comparisons.-Somewhat similar to $R$. brevirostris of Costa Rica in size, coloration, and type and length of fur, but ears larger and skull distinct in many characters, of which the greater dimensions of the brain case, longer narrower rostrum, relatively narrower zygomatic spread, longer incisive foramina and hard palate, and much larger bullae are outstanding. Smaller than $R$. mexicanus and even more distinct from that species in the abovementioned features than is brevirostris.

Externally a replica of tenuirostris, but much smaller (see measurements). Molar row relatively shorter and rostrum relatively narrower (see Table II). Adult and subadult pelages for the most part similar in the 2 species, but the underparts paler in microdon (distal bands of cover hairs varying from Light Pinkish Buff in the subadults from Todos Santos and Volcán Santa Maria to whitish in the adult from Chichavac. For comparisons with $R . m$. albilabris and wagneri see the accounts of those subspecies.

REMARKs.-Variations in color of the underparts are mentioned above. The specimen from Chichavac is the smallest of the lot and has a short and relatively deep brain case. The specimen from San Cristóbal has a distinctly bicolor tail. In color of upper parts it is paler than the specimens from Guatemala; it grades toward albilabris.

Specimens exAmined.-Six from the following localities: Guatemala. Chimaltenango: near Tecpán, Chichavac, $8800 \mathrm{ft}$., 1 (CM); Todos Santos, 10,000 ft., 2 (US). Huehuetenango: Chemal, 10,500 ft., 1 (US). Quezaltenango: Volcán Santa María, I (US). México. Chiapas: 6 mi. SE San Cristóbal, 7300 ft., 1 (MVZ).

\section{Reithrodontomys tenuirostris Merriam}

(Maps 11, 12; Pls. VI, VII; Figs. 4, 5, 16)

Reithrodontomys tenuirostris Merriam, 1901: 547.

Reithrodontomys tenuirostris tenuirostris, Howell, 1914: 78.

Reithrodontomys tenuirostris aureus Merriam, 1901: 548; Howell, 1914: 78. Guatemala, Dept. Totonicapán, Calel, 10,200 feet elevation.

Type.-Adult male, skin and skull; U. S. Nat. Mus. Biol. Surv. Coll. No. 76919; Guatemala, Dept. Huehuetenango, Todos Santos, 10,000 feet elevation; collected 29 December 1895 by E. W. Nelson and E. A. Goldman; original No. 8917.

Distribution.-Highlands of Guatemala and probably of southeastern 
Chiapas, México. Known from one locality in the Sierra Cuchumatanes and several localities in the Sierra Madre from Volcán de Tajumulco south to Mataquescuintla. Known altitudinal range 8000-10,400 feet on Volcán de Tajumulco.

Habitat.-Apparently similar to that of $R$. microdon. A specimen from

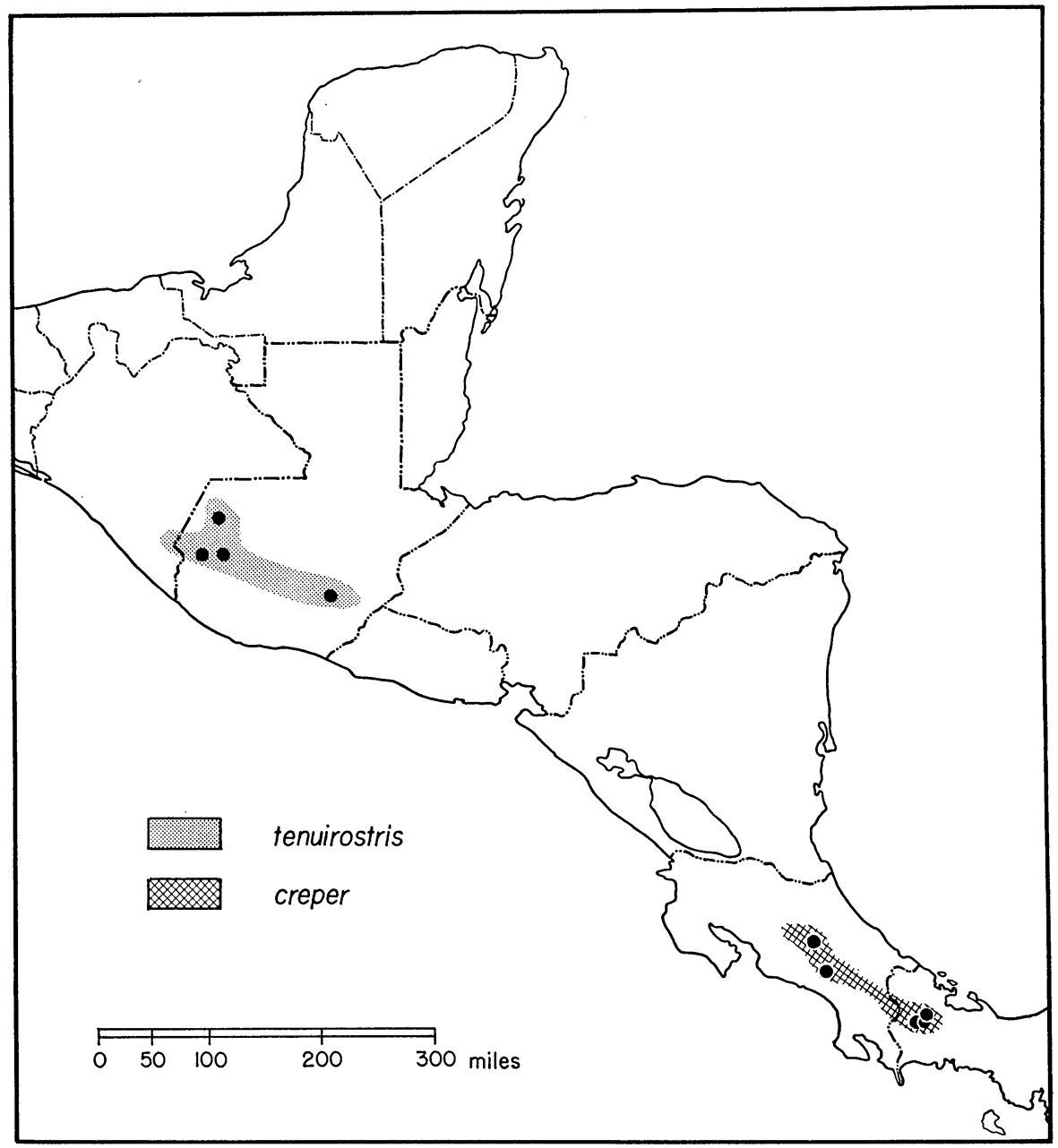

MAP 11. Distribution of Reithrodontomys tenuirostris and Reithrodontomys creper, as determined from specimens examined.

Volcán de Tajumulco was collected in a tree. The example from Mataquescuintla was trapped on the ground among ferns and forbs in a virgin broadleaf cloud forest.

ChARACTERS AND COMPARISONS. $-R$. tenuirostris is the largest and one of 
the darkest harvest mice known from Guatemala. $R$. microdon is similar in color and also has long, lax pelage (about $10 \mathrm{~mm}$. long on midback), large ears, large, inflated brain case, and long rostrum. Size alone will distinguish the 2 species (see measurements of hind foot and molar row, for example). The races of $R$. mexicanus that occur in the region inhabited by tenuirostris are smaller in size of body and skull; also they have shorter fur, brightercolored upper parts and whitish underparts. $R$. brevirostris resembles tenuirostris externally, but it is about as small as microdon and the skulls of the 2 species differ in proportions (see especially measurements of brain case, rostrum, and interorbital constriction). The Guatemalan lowland forms of Aporodon, namely gracilis, pacificus, and anthonyi, are much smaller than tenuirostris. They are pale and short tailed and have broad short rostra, small molar teeth, and broad flat frontals. The other species found within the geographic range of tenuirostris are members of the subgenus Reithrodontomys and are distinguishable from tenuirostris in the characters of the subgenera.

Size: Large (see measurements). Known range in length of hind foot 22-23 mm.; in tail length, 105-129 mm.; in length of skull, 23.2-26.1 mm.; in length of molar row, 3.9-4.1 mm.

Color: Adult pelage of February specimen from Volcán de Tajumulco: Ground color of upper parts near Tawny or Orange-Cinnamon, obscured everywhere except on lower sides by numerous black guard hairs, the mass effect near Ochraceous-Tawny or Cinnamon-Brown. Underparts PinkishCinnamon, the cinnamon-colored bands of the hairs obscuring most of the long Dark Mouse Gray basal bands. No sharp demarcation in color of sides and underparts. A black eye ring. Ears blackish, sparsely covered with black hairs which are much longer on the anterior face of the ear. Toes and sides of forefeet white, remainder of upper surface dusky. Ankles and upper surface of hind feet brownish black except for white toes and a narrow area of dingy white along the sides. Tail blackish brown, monocolor and well covered with hairs. Subadult pelage of January and February specimens from Volcán Tajumulco and Calel: Dorsum duller and more blackish than in the adult pelage, the ground color nearer Ochraceous-Tawny than Tawny. Underparts Pale Pinkish Buff to Light Pinkish Cinnamon, the basal bands of the hairs Dark Mouse Gray, scarcely obscured by the pinkish tips. Coloration otherwise similar to that of adult pelage.

Skull: Brain case broader and deeper, rostrum and incisive foramina longer, and molars broader and longer than in all other harvest mice except those of the tenuirostris group. Essentials of the cranium of tenuirostris are described on preceding pages (see especially accounts of the $R$. tenuirostris group).

REMARks.-The 2 specimens from Calel upon which Merriam based his 
description of aureus are subadults. They resemble specimens of comparable age from Volcán de Tajumulco near the type locality of tenuirostris. I fail to appreciate the characters ascribed to aureus. The specimen from Mataquescuintla is the largest (length of skull $26.1 \mathrm{~mm}$.) and the brightest colored of the lot before me. Its brain case is shallower posteriorly and relatively shorter than in the other specimens.

SPECIMENS EXAMINED.-Eight from the following localities in Guatemala: Huehuetenango: Todos Santos, 10,000 ft., 2 (US). Jalapa: Cerro near Mataquescuintla, $8400 \mathrm{ft} ., 1$ (US). San Marcos: Volcán de Tajumulco, 8000-10,400 ft., 3 (CM). Totonicapán: near Calel, 10,200 ft., 2 (US).

\section{Reithrodontomys rodriguezi Goodwin}

(Maps 10, 12; Pls. VIII, IX; Fig. 16)

Reithrodontomys rodriguezi Goodwin, 1943: 1; Goodwin, 1946: 385.

Type.-Subadult female, skin and skull; Amer. Mus. Nat. Hist. No. 141195; Costa Rica, Prov. Cartago, Volcán de Irazú, 9400 feet elevation; collected 21 August 1941 by C. F. Underwood.

Distribution.-Known only from the Volcán de Irazú, 9400 feet elevation.

Habitat.-The type was collected in grasslands near the edge of a wet forest.

Characters And COMParisons.-Size: Medium, for the tenuirostris group, nearest tenuirostris (see Table II). Compared with the other species known from Costa Rica: rodriguezi is larger than sumichrasti, gracilis, and brevirostris; similar in size to some races of mexicanus; and smaller than creper (see measurements). Tail long, about 1.5 times head and body length.

Color: Fully adult pelage not known. Subadult pelage of August specimen: Much brighter and less blackish than comparable pelage of creper. Ground color of upper parts between Pinkish Cinnamon and Cinnamon, darkened on back by black guard hairs but less dark and with a less distinct dorsal stripe than in creper. Underparts whitish or Pale Pinkish Cinnamon. Basal bands of cover hairs of body fur paler (about Deep Mouse Gray). Black eye ring indistinct. Ears as in creper. Upper surfaces of hind feet dusky, narrowly rimmed with white. In the 2 specimens examined, tail monocolor as in microdon and tenuirostris; tail of type specimen white tipped (Goodwin, 1943).

Skull: Proportioned as in other species of tenuirostris group, with large brain case, long rostrum (its length about 93 per cent of cranial depth). Smaller than microdon (see measurements of length of skull and of molar row).

REMARKs. - No satisfactory appraisal of $R$. rodriguezi can be made from the material at hand. The species is discussed in the general accounts of the tenuirostris group. 
Specimens examined.-Two (1 AM, $1 \mathrm{CM}$ ) from the type locality.

\section{Reithrodontomys creper Bangs}

(Maps 11, 12; Pls. VIII, IX; Fig. 16)

Reithrodontomys creper Bangs, 1902: 39; Howell, 1914: 79; Goodwin, 1946: 386.

Type.-Subadult female, skin and skull; Mus. Comp. Zool. No. 10284; Panamá, Dept. Chiriquí, El Volcán de Chiriquí, 11,000 feet elevation; collected 2 June 1901 by W. W. Brown.

Distribution.-Mountains of Costa Rica and western Panamá. Known range from the Volcán de Irazú, Costa Rica, south in the Cordillera de Talamanca to the vicinity of the Volcán de Chiriquí, Panamá. Altitudinal range 7500-11,000 feet on the Volcán de Chiriquí.

Habitat.-Moist temperate forests and adjoining grasslands. Specimens from the Volcán de Chiriquí and vicinity were obtained in various situations along trails and in glades deep in forests: At the bases of trees and logs; under moss; in runways through grass and litter on the forest floor; on a log five feet off the ground; in grass on rocky ground; at the base of a rocky cliff. The specimens from Cerro de la Muerta were collected in sacatón. The type specimen was obtained on the "cold, barren summit of the Volcán de Chiriquí" (Bangs, 1902: 40).

Characters ANd comparisons.-Size: The largest known form in the genus. Known range in length of hind foot $22-25 \mathrm{~mm}$. and in skull length 25.7-27.6 $\mathrm{mm}$. Breadth of brain case and length of molar row not less than $11.7 \mathrm{~mm}$. and $4.0 \mathrm{~mm}$., respectively, in any specimen examined.

Color: Similar to tenuirostris but darker throughout and with a paler tail. Adult pelage of July specimens from the Volcán de Chiriquí: Ground color of upper parts Tawny; that color purest on sides, partly obscured dorsally by black guard hairs; total fur mass of upper parts near Russet or Prouts Brown. Basal bands of hairs of upper parts and underparts Dark Mouse Gray, darker than in tenuirostris. Underparts Orange-Cinnamon or Cinnamon, that color contained in the terminal bands which mostly obscure the basal gray bands. Ears and feet slightly darker than in tenuirostris, the hind feet lacking the white border. Eye ring and that area between eye ring and vibrissae black. Tail coloration variable, in a few specimens paler below than above, but usually uniformly fuscous or blackish proximally and white or flesh-color terminally. Subadult pelage of July specimens from the Volcán de Chiriquí: Similar to adult pelage but more blackish dorsally and with a more sharply defined dorsal stripe. Mass effect of upper parts near Mars Brown or Warm Sepia. Juvenile pelage of July specimens from the Volcán de Chiriquí: Upper parts darker than in subadult pelage, the fur Fuscous Black scantily sprinkled with Tawny. Ears blacker than in other pelages. Underparts, feet, and tail as in adult pelage. 
Skull: Larger in all dimensions than that of tenuirostris (see Table II). Brain case similar in proportions, broad and deep. Rostrum heavier (the nasals broadly expanded distally) and much longer (rostral length usually exceeds depth of cranium in creper but not in tenuirostris). Auditory bullae of similar absolute size in the 2 species, thus relatively larger in tenuirostris. Frontals broad interorbitally (interorbital constriction amounts to 44-47 per cent of cranial depth in creper and 40-42 per cent in tenuirostris). $R$. rodriguezi and $R$. microdon are similar to $R$. creper in some cranial proportions, but each is smaller (see measurements of hind foot and molar row, for example) and each differs from creper in other details, for which see Table II and the accounts of microdon and rodriguezi. The species mexicanus, gracilis, brevirostris, and darienensis are much smaller; in them the rostrum is short and broad and the brain case is small (see measurements). $R$. sumichrasti is another species that occurs within the geographic range of creper. Size and characters of the subgenus Reithrodontomys distinguish it from creper.

REMARKs.-I find no significant differences between the series from Irazú, Costa Rica, and Chiriquí, Panamá. The examples from Hortigal average slightly paler than the other specimens from Panamá; most if not all of this paler color is attributable to the greater.amount of abrasion and fading of the fur in those specimens.

The observed variation in tail coloration in the species warrants comment. The variations here described have no apparent connection with sex or age; the traits appear in juvenile, subadult, and adult males and females. The proximal two-thirds of the tail is usually uniformly fuscous. In 7 of 59 skins it is slightly paler ventrally than dorsally. The variation in the coloration of the distal part is more striking. The distal part is variously blackish, fuscous, flesh-color and white. Dilution in color occurs both in the scales and in the hairs and apparently takes place independently in the 2 structures, insofar as can be determined by macroscopic examination. In some specimens pigment occurs in the scales but not in the hairs. The length of the pale area varies from 1 or $2 \mathrm{~mm}$. to as much as $50 \mathrm{~mm}$.; the average is about $20 \mathrm{~mm}$. Disregarding minor variations in tone, in 42 specimens the tail is light-tipped; in 17 it is dark throughout its length. The ratio of pale to dark is about one to two and one-half. This ratio suggests that white-tipping in creper may be a simple Mendelian character involving a dominant gene and its recessive allelomorph.

SPEcimens examined.-Sixty-three from the following localities: Costa Rica. Cartago: Cerro de la Muerta, 11,000 ft., 4 (NM); El Volcán de Irazú, 9400 ft., 6 (AM). Panamá. Chiriquí, vicinity of El Volcán de Chiriquí: Casita Alta, 7500 ft., 3 (PM); Copeta, 10,000 ft., 15 (PM); Cilindro, 4 (PM); Hortigal, $9(\mathrm{PM})$; crater of El Volcán, 11,000 ft., $2(\mathrm{PM})$; potrero, S slope El Volcán, 10,200-11,000 ft., 20 (PM). 


\section{CONFIGURATIONS OF THE MOLAR TEETH}

There are 2 basic patterns in the molar teeth of Reithrodontomys. The patterns differ from each other in kind and amount much as do those of Akodon and Oryzomys or those of Haplomylomys and Peromyscus (s.s.), and as in Haplomylomys and Peromyscus extremes in dental configuration are connected by an almost complete series of intermediate stages. These stages are represented by one or more species in entirety or by subspecies of a species.

The simplest Akodon-like configuration obtains in R. humulis and R. montanus and to a lesser degree in some other species. The molars of humulis well illustrate the basic plan. In the upper molars there are no secondary lophs or styles to complicate the primary plan of 4 cusps separated by 3 folds, one lingual and 2 labial in position (Fig. $4 a$ ). There are no internal folds except those formed in a late stage of wear; the major (lingual) and the first and second primary (labial) folds retain connection with marginal enamel for much of the life of the tooth. The major and second primary folds tend to coalesce, thus separating the metacone and hypocone from the anterior parts of the tooth. The primary cusps of $\mathrm{M}^{1-2}$ are usually opposite in position. The anterocone of $\mathrm{M}^{1}$ is simple, usually with no indication of a division into conules. The anterior cingulum is low throughout its length. There is no posterior cingulum, unless the posterior cone on $\mathrm{M}^{3}$ be so considered. $\mathrm{M}^{3}$ is minute and peglike. The folds between the protocone, paracone, and hypocone (or posterior cingulum) are erased early in wear, and the underlying dentine forms a crescent around an enamel peninsula. The lower molars are similarly simple, although on $\mathrm{M}_{1-2}$ there is a unique external ridge, or shelf, from which arise one or more styles (Fig. $5 a$ ). There are no mesolophids or ectolophids. The configuration of the molars of $R$. montanus is no more elaborate than that of $R$. humulis. There may be slight traces of mesolophs in $\mathrm{M}^{1-2}$; the incidence in specimens is exceedingly low. The tendency for the major and second primary folds in $\mathrm{M}^{1-2}$ to coalesce and for the cusps to oppose each other is less in montanus than in humulis. Usually there is no external cingulum; when present it is much less distinct than in humulis.

The most complex pattern in the genus is illustrated by $R$. tenuirostris (Figs. $4 d, 5 d$ ). This configuration is typical of the species of Aporodon. There are minor variations, but none of them are peculiar to any one species of the subgenus (save possibly $R$. gracilis). The configuration is basically like that of Oryzomys and some other oryzomyine rodents (see Hershkovitz, 1944). In the complex pattern there are numerous structures not seen in the simple molar pattern. In each molar tooth a secondary fold cuts off a mesoloph (id), which is enlarged distally as a rounded mesostyle (id). Enterostyles and, less commonly, ectostylids are present in the major folds; these sometimes are prolonged toward the mid-line of the tooth as small enterolophs and ecto- 
lophids. The primary folds are deep. They are divided by an enamel septum into internal and external parts; each worn molar is characterized by 2 or more enamel islands. The second primary fold in $\mathrm{M}_{3}$ is always divided into a large internal fold and a minute external fold. The anterocone of $\mathrm{M}^{\mathbf{1}}$ also is divided by an anteromedian fold and an anterointernal fold into distinct conules. The anterior and posterior cingula are well developed in each tooth; often the distal part of each is enlarged as a distinct conule (id) or style (id). $\mathrm{M} \frac{3}{3}$ are large and are essentially compact replicas of $\mathrm{M} \frac{2}{2}$.

The 2 extremes in molar pattern, as exemplified by humulis and tenuirostris, stand at opposite ends of a series of intermediate stages. In the configuration of the upper molar teeth the series of those stages is essentially continuous. All degrees of intermediacy likely also obtain in the lower molars, although I am not prepared to demonstrate them. The various combinations and blendings of the characteristics of the upper molars in humulis and tenuirostris are demonstrable in the species hirsutus, fulvescens, chrysopsis, and sumichrasti, and to a lesser extent in megalotis and gracilis. In one or more of those species are seen partial or complete mesolophs, partial or complete subdivision of the secondary folds, slight or well-developed anteroconules, and anterior and posterior cingula, complete or incomplete mesostyles (which may be completely or not at all fused with mesolophs), and other combinations and blendings of the characteristics of the 2 extremes.

The mesolophs in $\mathrm{M}^{1-2}$ well illustrate the stages of intermediacy that obtain among and within the species of the genus. The condition of the mesolophs was analyzed in 2486 specimens. In the analysis 5 stages of mesolophal development were recognized. These stages, indexed from zero to 5, range from no development (absence) of a mesoloph in any of the first and second upper molars to full development (mesoloph extending from the mure to the labial border) in each of the 4 teeth. In the analysis it was assumed that the stages are roughly equivalent morphologically, and that they are progressive, one grading into the next. These are justifiable assumptions. Often it was difficult to decide to which of 2 contiguous categories, 0 or 1 , 1 or 2 , and so forth, a specimen should be assigned.

After all specimens were indexed, the samples were pooled by subspecies and the percentage of specimens that occurred in each index category was determined for each species. This was done by dividing each category total by the total for the species. The percentages are indicated graphically in Figure 16. It is clear that the degree of development of mesolophs in the several species varies progressively from absence (index 0) to completeness (index 4).

A mean index for each species was calculated. Such indices are estimates of the state of development of mesolophs in entire species. They are not 


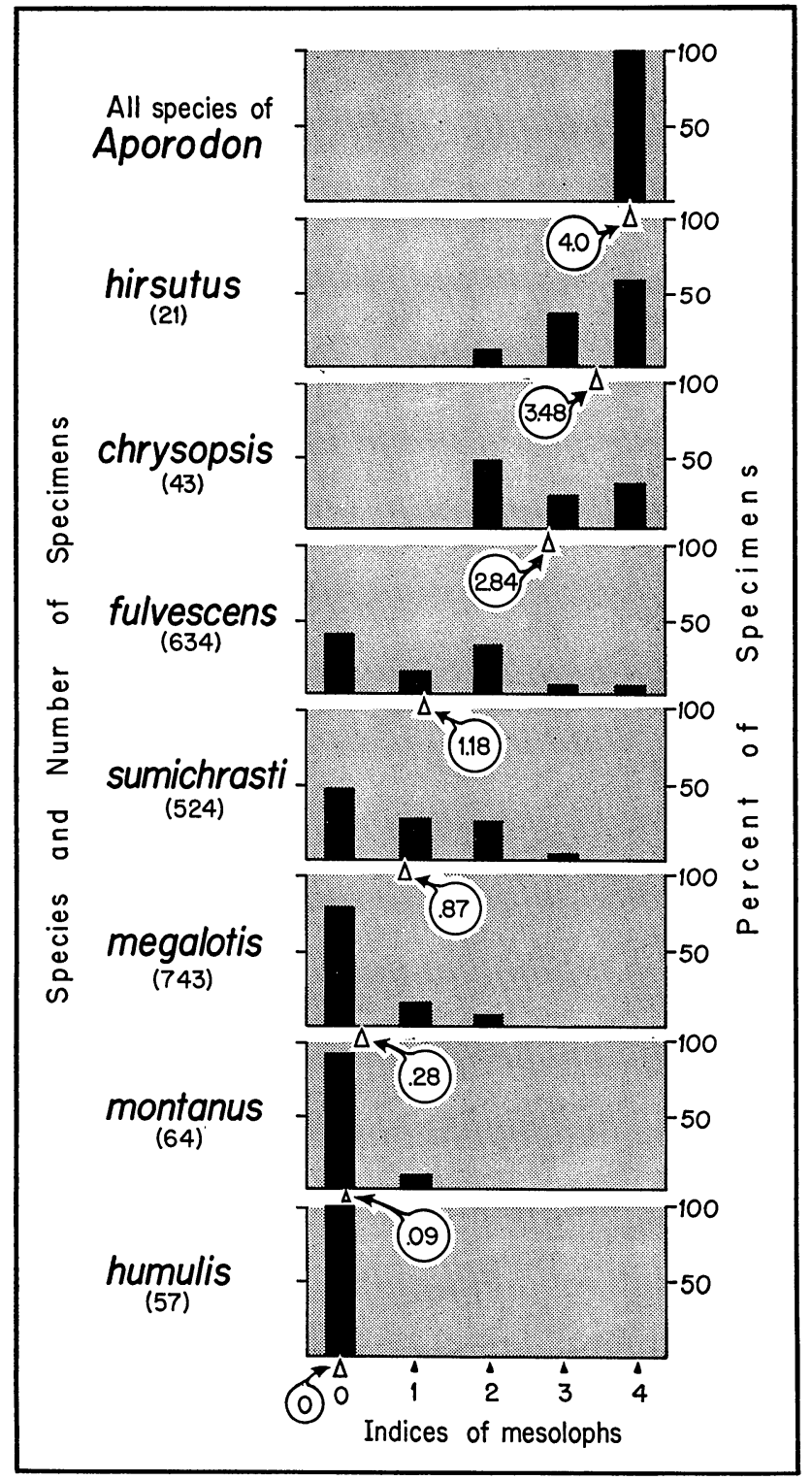

Fig. 16. The condition of mesolophs in the first and second upper molar teeth of 15 species of Reithrodontomys. Five stages of mesolophal development are recognized; they range from no development in which there are no mesolophs of any length in any of the first and second upper molars (index 0 ) to complete development in which there are full mesolophs in each of the 4 teeth (index 4). The vertical black bars represent the percentage of specimens in each index category. The circled numbers are the mean indices for the species. 
means of category totals. Rather they are averages of the mean indices of the subspecies. Those indices are indicated in Figure 16.

In some species there are significant variations geographically in the degree of development of mesolophs. Variations in the mean indices of the species fulvescens, sumichrasti, and megalotis are discussed in the following paragraphs. A mean of a sample of a subspecies is considered significantly different from the mean of the species when it departs more than 2 standard

- errors from the mean of the species.

TABLE III

Mean Indices of Mesolophs in Subspecies of Reithrodontomys fulvescens

\begin{tabular}{|c|c|c|c|}
\hline Locality & Subspecies & $\begin{array}{l}\text { Number of } \\
\text { Specimens }\end{array}$ & Mean Index \\
\hline 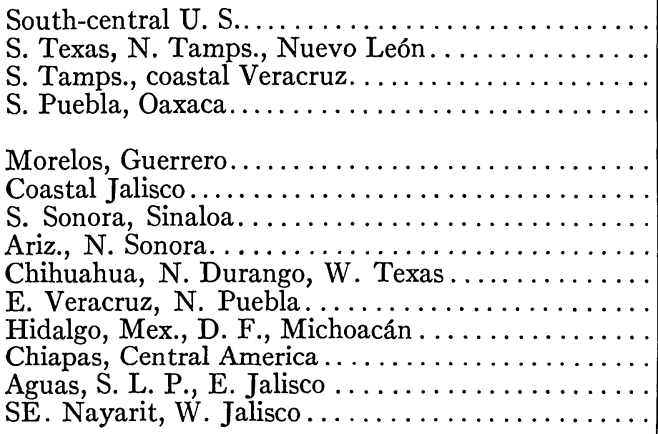 & $\begin{array}{l}\text { aurantius } \\
\text { intermedius } \\
\text { tropicalis } \\
\text { helvolus, } \\
\quad \text { infernatis } \\
\text { mustelinus } \\
\text { nelsoni } \\
\text { tenuis } \\
\text { fulvescens } \\
\text { canus } \\
\text { difficilis } \\
\text { toltecus } \\
\text { chiapensis } \\
\text { griseoflavus } \\
\text { griseoflavus }\end{array}$ & $\begin{array}{r}79 \\
41 \\
53 \\
23 \\
\\
25 \\
34 \\
15 \\
18 \\
25 \\
64 \\
92 \\
25 \\
22 \\
118\end{array}$ & $\begin{array}{l}1.32 \\
1.44 \\
1.15 \\
1.44 \\
\\
1.56 \\
1.56 \\
0.67 \\
0.89 \\
0.60 \\
0.78 \\
0.86 \\
0.48 \\
1.27 \\
1.59\end{array}$ \\
\hline $\begin{array}{l}\text { Totals. . } \\
\text { Mean Index of Species } \\
\quad \text { (and standard error of mean)... }\end{array}$ & & 634 & $\begin{array}{l}15.61 \\
1.11 \pm .11\end{array}$ \\
\hline
\end{tabular}

In $R$. fulvescens there appear to be 3 geographic centers in mesolophal development. In one of them mesolophs tend to be present and are long. In 2 they tend to be short or are entirely absent. The mean indices for the sample groups and the species are given in Table III. The values are large in the samples from the regions that skirt the central highlands of México and extend along the Gulf coast into the south-central United States. That is the semitropical region inhabited by the races nelsoni, mustelinus, helvolus, infernatis, tropicalis, intermedius, and aurantius. The mean index for each of those races exceeds the mean index of the species. The index is significantly greater for nelsoni, mustelinus, helvolus, infernatis, and intermedius. The means for aurantius and tropicalis are border-line cases at the level of probability here employed. The mean indices are low in the samples from the southwestern United States, the highlands of México, and the region south of the Isthmus of Tehuantepec-in Chiapas, Guatemala, Honduras, and El Salvador. Those samples represent the races fulvescens, tenuis, canus, 
toltecus, difficilis, and chiapensis. The mean index of each of those samples is significantly less than the mean index of the species. The race griseoflavus appears to be morphologically, as well as geographically, between the regions of high and low mesolophal development. The sample of that race from the southern part of the Mexican Plateau-San Luis Potosí, Aguascalientes, and eastern Jalisco-has a mean index approximately the same as that of the species. On the other hand, the sample of griseoflawus from areas that border the semitropical lowlands-southeastern Nayarit and western Jalisco-has a mean index that significantly exceeds the mean index of the species. In that sample the mesolophs are generally as long as in the series from the adjoining lowlands. Highest means obtain in the samples from semitropical areas in Guerrero, Morelos, and coastal Jalisco. In them mesolophs tend to be present and to be long. Lowest means obtain in the samples from arid-temperate areas in (1) Arizona, western Texas, Chihuahua, and Durango, and (2) Chiapas and northern Central America. In them mesolophs tend to be absent or, if present, to be short and on few teeth.

TABLE IV

Mean Indices of Mesolophs in Subspecies of Reithrodontomys sumichrasti

\begin{tabular}{|c|c|c|c|}
\hline Locality & Subspecies & $\begin{array}{l}\text { Number of } \\
\text { Specimens }\end{array}$ & Mean Index \\
\hline 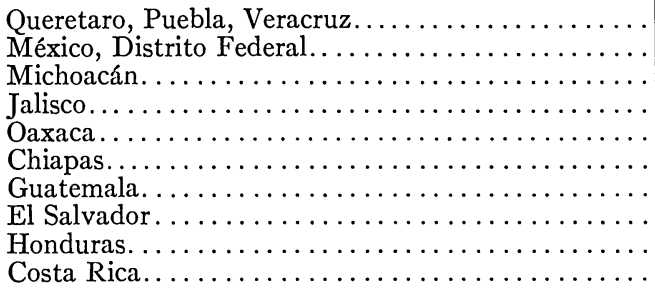 & $\begin{array}{l}\text { sumichrasti } \\
\text { sumichrasti } \\
\text { nerterus } \\
\text { nerterus } \\
\text { luteolus } \\
\text { dorsalis } \\
\text { dorsalis } \\
\text { modestus } \\
\text { modestus } \\
\text { australis }\end{array}$ & $\begin{array}{r}67 \\
17 \\
61 \\
57 \\
7 \\
129 \\
73 \\
79 \\
26 \\
8\end{array}$ & $\begin{array}{l}0.40 \\
0.24 \\
0.72 \\
0.83 \\
1.14 \\
1.49 \\
0.84 \\
0.66 \\
0.65 \\
0.13\end{array}$ \\
\hline $\begin{array}{l}\text { Totals.............. } \\
\text { Mean Index of Species } \\
\quad \text { (and standard error of mean) }\end{array}$ & & 524 & $\begin{array}{l}7.10 \\
.71 \pm .13\end{array}$ \\
\hline
\end{tabular}

In $R$. sumichrasti there appears to be higher incidence of mesolophs in the populations found near the center of the range of the species than in those of northern and southern parts of its range. Mean indices for the species are listed in Table IV. The mean indices for the samples from Chiapas and Oaxaca are significantly higher than the mean index of the species. Those for the samples from east-central México (the first 2 listed in Table IV) and the index for the sample from Costa Rica are significantly less than the mean index of the species. The degree of development of mesolophs also apparently varies geographically in $R$. sumichrasti. There is a slight indication that the degree of development varies clinally to the north and south from a maximum in Chiapas. 
In $R$. megalotis as well as in $R$. fulvescens and $R$. sumichrasti mesolophal development appears to differ from place to place. The observed range of variation in $R$. megalotis is narrow and is confined to index categories $0-2$. Mean indices for the species are given in Table $\mathrm{V}$. The mean indices for the samples from the Great Plains and from the southwestern United States are significantly less than the mean index for the species. The index for the sample from Jalisco also is less than the total mean, but the difference is of doubtful significance. The indices for the samples from the Sierra Madre Occidental and Oriental significantly exceed the mean index for the species.

TABLE V

Mean Indices of Mesolophs in Subspecies of Reithrodontomys megalotis

\begin{tabular}{|c|c|c|c|}
\hline Locality & Subspecies & $\begin{array}{l}\text { Number of } \\
\text { Specimens }\end{array}$ & Mean Index \\
\hline 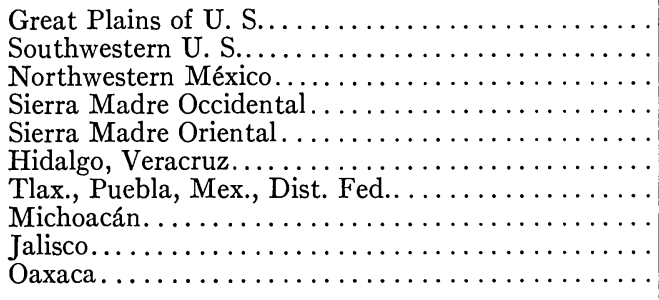 & $\begin{array}{l}\text { dychei } \\
\text { megalotis } \\
\text { megalotis } \\
\text { zacatecae } \\
\text { saturatus } \\
\text { saturatus } \\
\text { saturatus } \\
\text { saluratus } \\
\text { saturatus } \\
\text { alticolus }\end{array}$ & $\begin{array}{r}114 \\
138 \\
16 \\
26 \\
19 \\
91 \\
136 \\
79 \\
85 \\
39\end{array}$ & $\begin{array}{l}0.03 \\
0.12 \\
0.38 \\
0.92 \\
1.21 \\
0.35 \\
0.40 \\
0.32 \\
0.24 \\
0.18\end{array}$ \\
\hline $\begin{array}{l}\text { Totals............. } \\
\text { Mean Index of Species } \\
\quad \text { (and standard error of mean) } \ldots\end{array}$ & & 743 & $\begin{array}{l}4.15 \\
.41 \pm .06\end{array}$ \\
\hline
\end{tabular}

These estimates suggest that in $R$. megalotis the tendency to develop mesolophs is greater in the mesic mountains of México than on the arid plains and deserts of the western United States.

The data on variation in the molar teeth of Reithrodontomys may be summarized as follows: There are 2 principal molar patterns in the genus. One is simple. The other is characterized by numerous additional flexures in the enamel and dentine. The 2 are quite different. Their dissimilarity is the sort that distinguishes some genera of cricetine rodents. While the 2 types of configuration are individually distinct in Reithrodontomys, nevertheless they are connected by an almost complete series of intermediate types. A complex pattern is characteristic of Aporodon. Many of the structures which constitute that complex pattern are expressed rather uniformly in all species of the subgenus. Genetic variability in those structures apparently is essentially fixed. Other structures that contribute to the complex pattern, however, are less stable. Nothwithstanding the variations, the molar patterns of all species of Aporodon are fundamentally alike. Those of the species of the subgenus Reithrodontomys, on the other hand, tend to be dissimilar. In 2 
species the molar dentition tends to be almost as complex as in Aporodon. In other species it is usually simple. There is an array of intermediate types in which almost all dental characters of the genus are variously combined. Some of those combinations are seen only in one or more subspecies of a species. Others are characteristic of an entire species or of groups of species. Numerous stages in the evolution of dental patterns are represented. The generally simple configurations in the species of the subgenus Reithrodontomys appear to be trending toward complex patterns as seen in Aporodon.

The characteristics of the molar teeth are exceedingly useful systematic tools, but there is a tendency to overrate their importance in natural classifications. For example, features pertaining to mesolophs (ids) and mesostyles (ids) loom large in importance in characterizations of cricetine rodents. The features involve presence or absence of one or both of the structures, the length of the lophs, and the fusion or discreteness of the loph and style in a molar tooth. They have been considered diagnostically important at several systematic levels, for example, at the subgeneric (Osgood, 1909) and generic (Winge, 1924; Thomas, 1917) and also for suprageneric groupings (Hershkovitz, 1944). In some instances authors apparently infer that the state of these so-called accessory lophs and styles is indicative of natural groupings of species, and they hinge their classifications largely on characteristics of those structures. I am convinced that a classification of the genus Reithrodontomys based primarily on those accessory structures would be an unnatural one. Mesolophs (ids), mesostyles (ids), and other accessory structures occur in several phyletic branches of the genus. They are independent acquisitions in the different branches and are not necessarily indicative of immediate relationship.

\section{SIZE, ALTITUDE, AND LATITUDE}

\section{ANALYSES OF FOUR SPECIES}

In many species of birds and mammals body size increases as latitude or altitude increases. The races of small body size occur at low elevations or in the southern part of the range of the species, and the large subspecies live at higher latitudes and altitudes. Temperature usually is singled out as the important environmental agent in such correlations. It tends to vary with altitude and latitude, and there is reason for believing that in some way it affects body size. Accordingly, the observed connection between size and altitude or latitude is usually interpreted as a relationship of size and environmental temperature. The relationship is expressed in Bergmann's rule which states that among closely related warm-blooded forms body size is related to climate; the larger forms live in colder climates. The rule applies to intraspecific variation. Whether it extends above the specific level has not been satisfactorily demonstrated. 
The applicability of Bergmann's rule to Reithrodontomys is discussed below. In any test of the rule 2 sets of basic data are needed, namely sizes of the animals and temperatures of the animals' environments. Perhaps the most satisfactory data for the purpose are measures of mass or of surface area of the body and of temperatures of the actual habitats in which the animals live. Such indices are not available for any species of Reithrodontomys. In the analyses that follow altitude and latitude scales are employed in lieu of habitat temperatures. It is assumed that temperature decreases as altitude and latitude increase. Cranial length is used as an index of size. It is a more nearly accurate measurement than head and body length or than any body measurement for which there are data at hand. At the same time it provides an estimate of body size. The 2 dimensions are correlated (Fig. 17), although their rate of change in growth may differ.

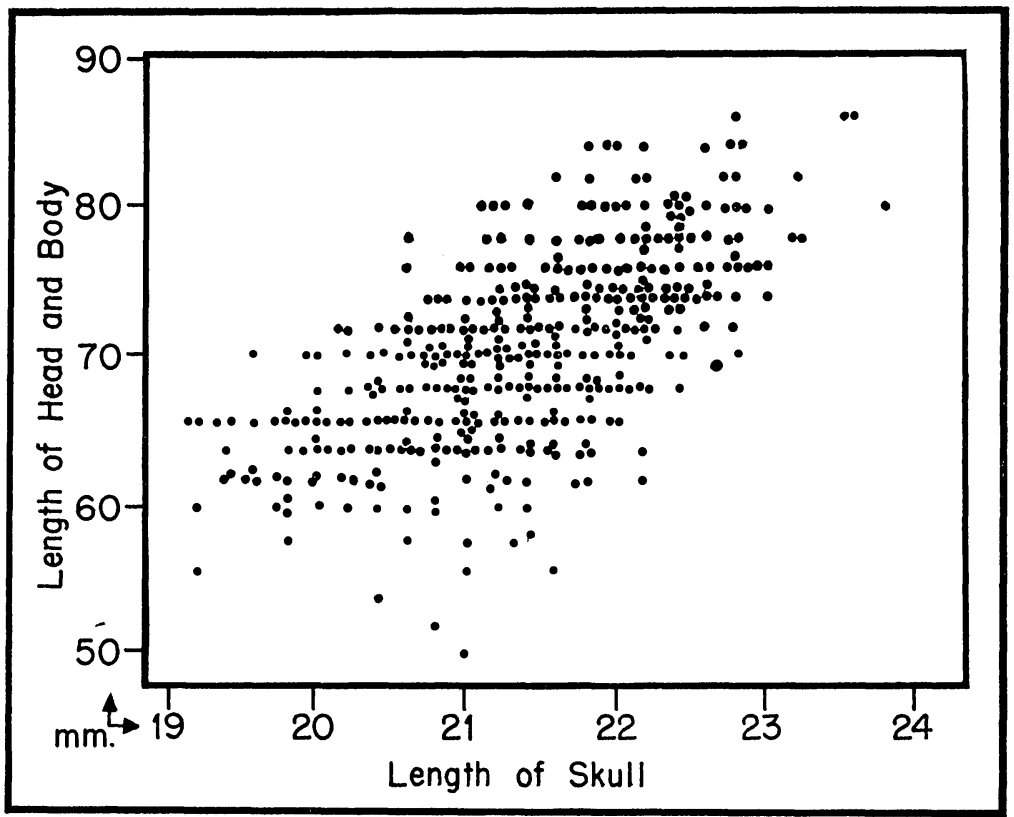

FIG. 17. The correlation of length of skull and length of head and body as observed in specimens of Reithrodontomys megalotis.

Data on 4 species, namely fulvescens, mexicanus, sumichrasti, and megalotis, were analyzed in detail. Those species have broad altitudinal and latitudinal ranges which encompass diverse climates. Any altitudinal or latitudinal effects on skull size should be evident in them. Moreover, the samples of those species are generally larger and more numerous than are the samples of the other geographically wide-spread species. Even so, the most nearly complete set of samples leaves much to be desired. The purpose 
of the analyses is to determine whether length of skull is related to altitude and/or latitude and, if so, to analyze the relationship.

The method of treatment of the data is similar for each species. The procedures followed in the analysis of $R$. fulvescens are described below. For each specimen the following data were recorded: relative age, length of skull, and altitude and latitude at which the specimen was taken. Altitude was recorded to the nearest 1000 feet and latitude was registered to the nearest whole degree. Those are the basic data. To reduce possible effects of age, the total usable sample was subdivided into 3 groups: (1) adults, (2) subadults, and (3) juveniles. The juvenile group was disregarded. Group 1 yielded a sample of 183 items. Group 2 yielded a sample of 345 specimens. Next, the items within each of those 2 groups were distributed by altitudes and latitudes. Then mean cranial length was calculated for each (1) latitude, (2) altitude, (3) altitude at each latitude, and (4) latitude at each altitude. Standard errors of the mean also were determined when they were needed.

Then, to determine possible correlation of cranial length and latitude, scatter diagrams were prepared for each altitude; in those diagrams the cranial values were plotted against latitudes. Because altitude is controlled in such diagrams, marked effects of latitude on skull size should be apparent. This diagram series indicates that either there is no effect of latitude on cranial length in fulvescens or that it is so small that it may reasonably be disregarded in investigating the effect of altitude on cranial size. Accordingly, the relationship of latitude to cranial length in $R$. fulvescens was not investigated further. The range of cranial measurements is so great and the samples at each altitude level are so small that it is doubtful that correlations, if calculated, would be reliable.

The possibility that size is related to altitude was then investigated. A second set of scatter diagrams was prepared. The cranial measurements were first plotted against altitude for each of the several latitudes. Secondly, another diagram was made for each age group in which the cranial measurements, irrespective of the latitudes they represented, were plotted against altitudes. All of these diagrams indicate a definite relationship between size and altitude in the samples of $R$. fulvescens. The nature of this relationship, that is, whether it involves a simple or a second degree correlation, is not clear because of the large range of skull measurements at each altitude. The diagrams indicate that the relationship of size to altitude is quite similar in both subadults and adults.

The mean skull length of subadults and adults at each altitude is given in Figure 18. Shown also are the ranges of 2 standard errors each side of the means and the grand mean skull length for each age group. The mean skull length for the sample of 183 adults is $22.2 \mathrm{~mm}$. and for the sample of 345 subadults it is $21.5 \mathrm{~mm}$. If the distribution of the items about the mean 
at any altitude is normal-and there is no reason to assume that it is notthen the means of approximately 95 per cent of all samples of the same size will fall within the range of 2 standard errors. Because the samples of fulvescens are unequal in size, the standard errors indicated in Figure 18 cannot be compared too closely. Nevertheless it seems clear that within each age group the means for the higher altitudes, 6000-8000 feet for example, are

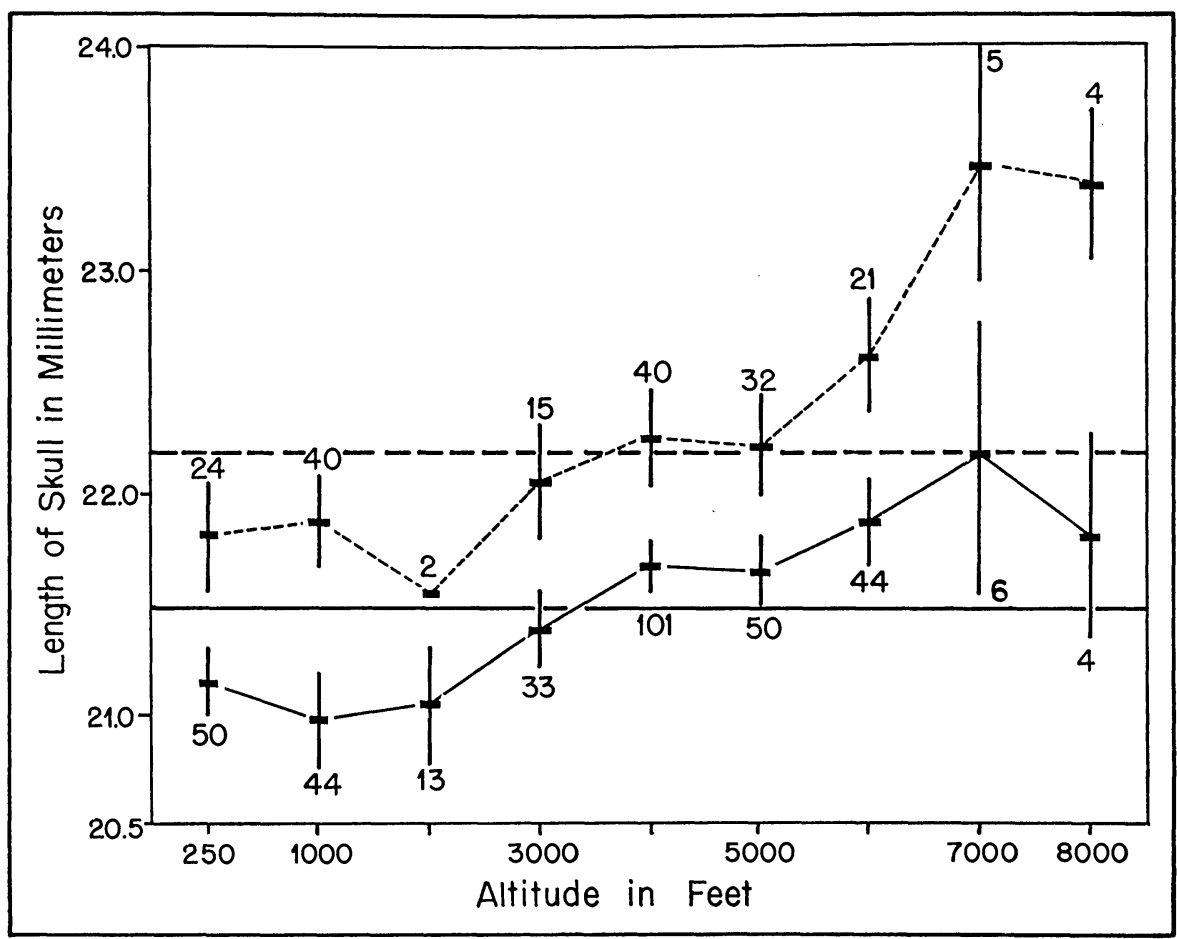

Fig. 18. Graph of the relationship of cranial length to altitude above sea level in samples of Reithrodontomys fulvescens. Latitude is disregarded. The position of the mean cranial length for each sample is indicated by a cross bar; the vertical line marks off 2 standard errors on each side of the mean; the number of specimens is indicated by figures above or below that line. The means of the samples of adults are connected by a broken line and those of subadults by a solid line. The horizontal broken line marks the position of the mean cranial length for all adults; the horizontal solid line indicates the grand mean for subadults.

significantly larger than those for the low altitudes. Moreover, the slope of the lines connecting the means is clearly upward. A positive relationship of size and altitude is indicated. The diagram suggests that the rate of increase in skull length is slight from sea level to 2000 or 3000 feet, then more rapid at higher elevations.

It is inferred, then, that in $R$. fulvescens cranial length increases with increasing altitude. The diagrams suggest that mean skull size increases on 
an average of approximately $0.2 \mathrm{~mm}$. with every increase of 1000 feet in elevation. If there is a relationship between latitude and skull length, that relationship is not clearly evident in the data at hand.

In the analysis of $R$. sumichrasti the total sample of subadults of sumichrasti amounts to 236 specimens; the mean cranial length is $22.1 \mathrm{~mm}$. The sample of adults totals 105 specimens with a mean skull length of $23.1 \mathrm{~mm}$.

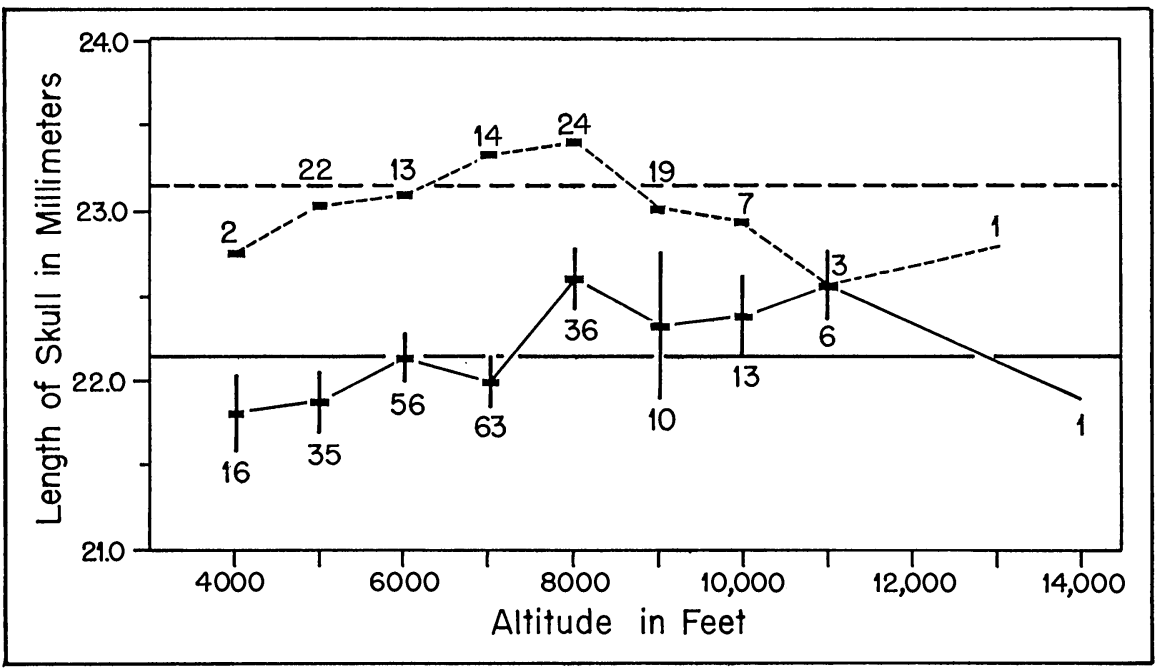

Fig. 19. The relationship of cranial length in samples of Reithrodontomys sumichrasti to altitude above sea level. Latitude is disregarded. For explanation of graph see Figure $18^{\circ}$ and text.

The distributions within each age group of the mean skull lengths for the various altitudes are shown in Figure 19. It will be noted that up to about 8000 feet both subadults and adults show a slight tendency to increase in size and then to decrease. This might seem to suggest that environmental conditions are optimum for maximum size in the species at 7500 to 8500 feet and are less suitable at both higher and lower elevations. This may well be true; however, the trends in size as indicated in the figures are doubtfully significant with the present samples.

A better check of the relationships of size and altitude is provided in the diagrams prepared for each latitude. In these, where latitude is controlled, effects of altitude on size appear to be slight or lacking. At some latitudes size increases with altitude while at others it decreases, and the results are not always similar at the same latitude for subadults and adults. To judge from the samples, any relationship of size and altitude in sumichrasti is at best slight.

When size is plotted against latitude without regard to altitude, both sub- 
adults and adults show a tendency to increase in size as latitude increases. This is indicated in Figure 20. The tendency is strong from latitude 14 degrees to latitude 20 or 21 degrees. It is notably similar for both subadults and adults. When altitude is controlled the tendency is even more obvious, especially in subadults, of which the samples are larger. Size was plotted

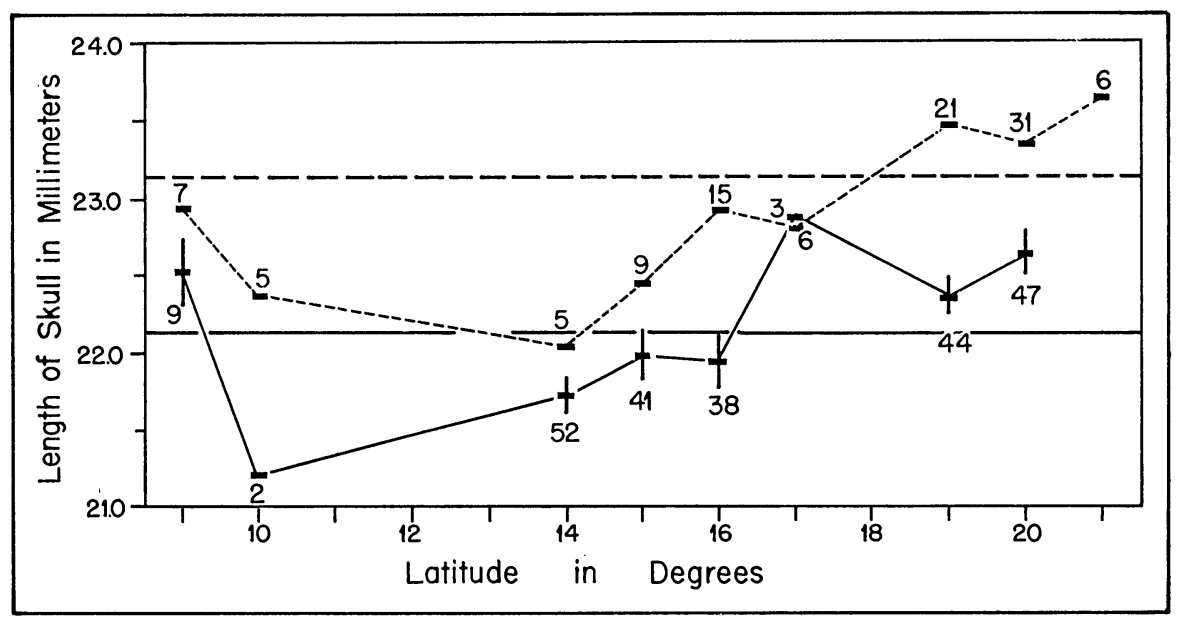

FIG. 20. The relationship of cranial length to latitude in samples of Reithrodontomys sumichrasti. Altitudes represented by the samples are disregarded. For explanation of graph see Figure 18 and text.

. against latitude at 3 different altitudes, 4000, 6000, and 7000 feet. For each of these altitude levels the line connecting the mean cranial lengths slopes upward without exception. A linear relationship between size and latitude in those samples of $R$. sumichrasti seems clearly to be indicated.

The procedure in analyzing $R$. mexicanus is the same as that followed for $R$. fulvescens. Unfortunately, the samples are exceedingly small and they represent few parts of the species' range. The total sample of subadults consists of 102 specimens having a mean skull length of $22.8 \mathrm{~mm}$. There are 48 adults with a mean skull length of $23.3 \mathrm{~mm}$.

The cranial length-altitude diagram (wherein latitude is disregarded) for adults shows an apparently linear increase of size with altitude in the range 3000-6000 feet (Fig. 21). There is a distinct upward trend in the curves within those altitudes. Moreover, the standard errors of the means computed in this range indicate that the differences between the mean at 6000 feet and those at 3000 and at 4000 feet are statistically significant. This conclusion is further supported by subdiagrams of size against altitude at 9 degrees and 14 degrees latitude, the only latitudes in which samples are large enough to consider at all. In each of them the mean line slopes upward much as in Figure 21. The sample of adults is too small to have any statistical 
significance alone; however, the same trends are indicated which are seen in the subadults. Both in the plots at single latitudes and in the plot of all latitudes an upward trend in size between 3000 and 6000 feet is indicated.

The conclusions reached in the analysis of the samples of $R$. mexicanus are as follows: No definite relationship of size and latitude is indicated. There is a tendency for size to increase with altitude, at least up to the

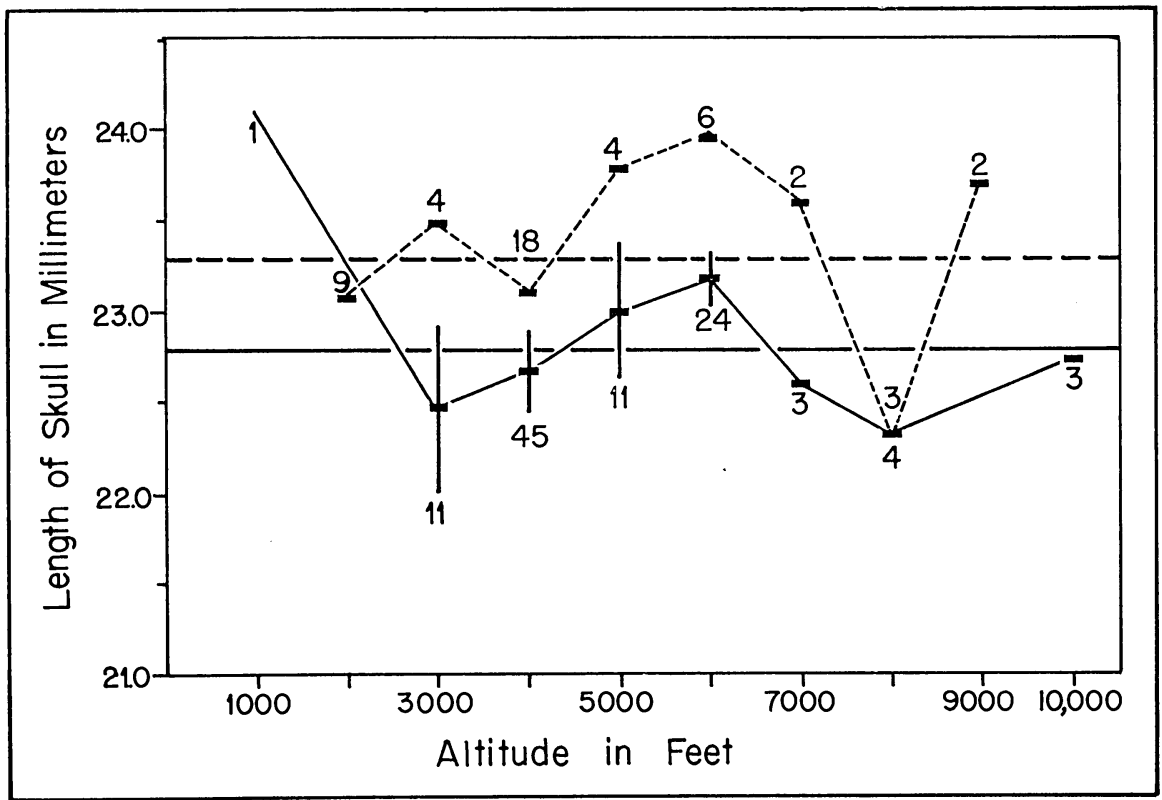

Fig. 21. The relationship of cranial length in samples of Reithrodontomys mexicanus to altitude above sea level. Latitudes represented by the samples are disregarded. For explanation of graph see Figure 18 and text.

6000 -foot level. There is a faint suggestion that it may then decrease at higher elevations. The results are considered to be barely indicative.

In the analysis of $R$. megalotis the data were handled in the same way as for the other species. In addition the subadults were analyzed with certain specimens omitted as follows: All samples of zacatecae, amoles, and arizonensis, and those of saturatus from the Sierra Madre Oriental in Nuevo León and Tamaulipas. All of those are moderately small, mountain-dwelling forms. The reason for deleting the samples was to determine whether they significantly influenced the slopes of the size-altitude-latitude curves that were drawn for the total sample. The total sample consists of 285 subadults with a mean cranial length of $21.3 \mathrm{~mm}$. and 136 adults with a mean skull length of $22.0 \mathrm{~mm}$.

Cursory examination of the diagrams indicates a possible correlation of 
size with both altitude and latitude. In the size-altitude diagram where latitude is disregarded (Fig. 22) there is indicated approximately constant or possibly slightly decreasing size from 4000 to 8000 feet, then an increase with increasing altitude up to 10,000 feet. Both subadults and adults show the same trend. The samples are all fairly large in this range and the differences in means are significant statistically. Subdiagrams of size plotted against

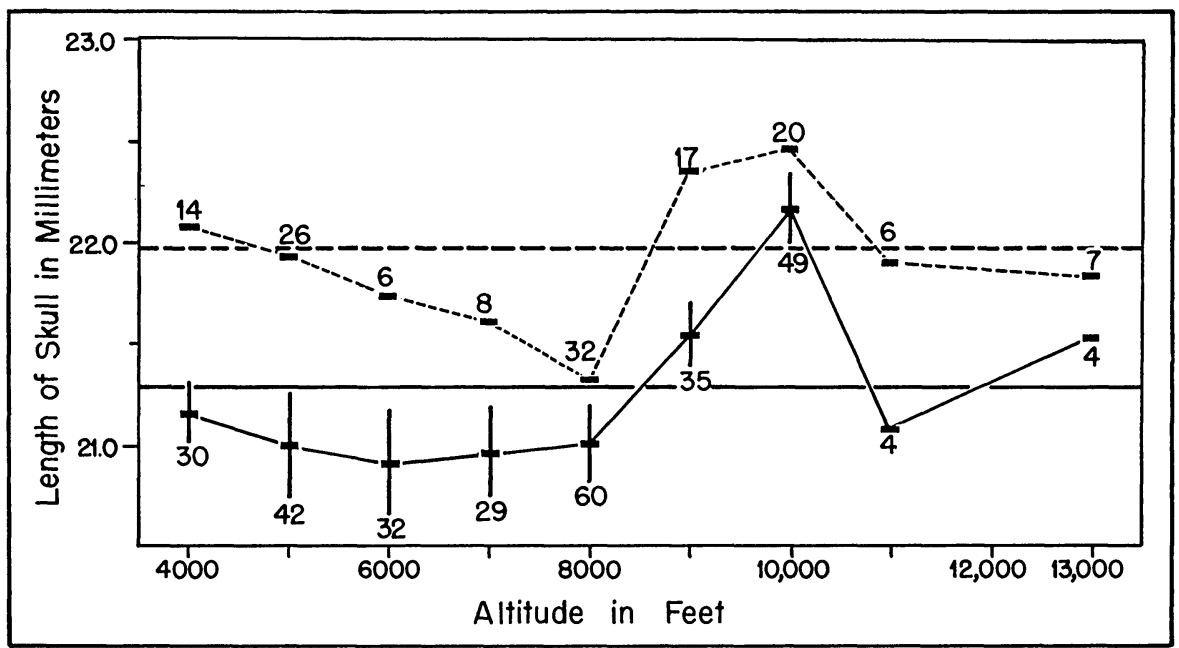

Fig. 22. The relationship of cranial length in samples of Reithrodontomys megalotis to altitude above sea level. Latitudes represented by the samples are disregarded. For explanation of graph see Figure 18 and text.

altitude (the latitude constant in each diagram), however, do not clearly indicate a relationship of size and altitude throughout all latitudes. In them a clear upward trend in skull size with respect to altitude is indicated only in the plots for latitudes 19 and 20 degrees. That trend is between 8000 and 10,000 feet for both age groups. Specimens from those latitudes alone account for the strong upswing in the curve in Figure 22. When those specimens are removed, the size-altitude curve becomes relatively horizontal.

When size is plotted against latitude, disregarding altitude, a unique curve results (Fig. 23). This curve is fairly similar for both subadults and adults. It shows an increase in cranial length from latitude 16 or 17 degrees to 20 or 21 degrees, a group of intermediate skull sizes from latitudes 23 to 26 degrees, and again an increase in size from 27 to 33 degrees but with much smaller means than obtain in the 17- to 21-degree bracket. The intermediate skull sizes all belong to the examples of the small mountain-dwelling forms that are mentioned above. When those values are removed, the relationship between size and latitude becomes almost exactly linear in 2 areas, namely 
in the range 17 to 21 degrees and in the range 27 to 33 degrees. In those 2 areas of the graph, size tends to increase as the latitude increases.

The following conclusions are drawn for $R$. megalotis: First, a possible relationship of size to altitude is suggested for some but not for all latitudes. The observed large size at latitudes 19 and 20 degrees appears to be connected with the fact that the sample there comes from high altitudes (9000 and

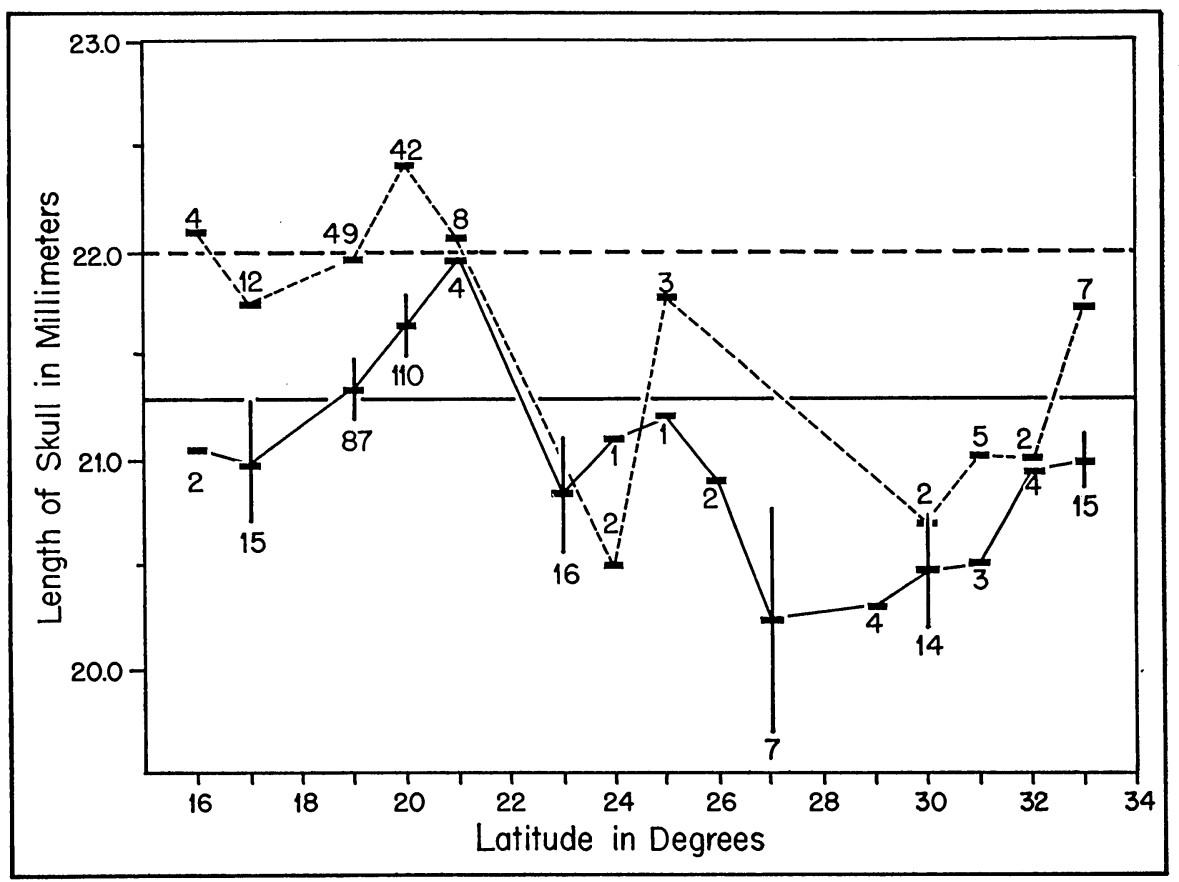

Fig. 23. The relationship of cranial length to latitude in samples of Reithrodontomys megalotis. Altitudes represented by the samples are disregarded. For explanation of graph see Figure 18 and text.

10,000 feet). The large size at altitudes 9000 and 10,000 feet, however, may be related to the fact that the sample from that altitude comes entirely from latitudes 19 and 20 degrees where some other size-influencing factors may be especially effective. Secondly, a linear relationship of size and latitude is suggested at 2 latitudinal ranges, one between 17 and 21 degrees, which embraces the highlands of south-central México, the other between 27 and 33 degrees, which covers the arid region of northwestern México and adjoining parts of the United States. The unusual curve in the size-latitude diagram suggests that 2 distinctly different segments of the species are represented, which is indeed the case (see the accounts of saturatus and zacatecae). Both of these segments appear to be similarly affected by latitude, but some factors 
other than those associated with latitude apparently affect them so that their mean size differs by about one millimeter, a clearly significant difference. None of the correlations are as clear-cut as might be desired. They appear to be obscured by important factors that were not considered in these analyses.

\section{SUMMARY AND CONCLUSIONS}

The 4 species have different altitudinal and latitudinal ranges within which body size, as indexed by cranial length, varies appreciably. In the analysis of $R$. fulvescens the available samples encompass a range of altitude from sea level to 8000 feet and 20 degrees of latitude (13-33 degrees). Maximum size is observed in the range 7000-8000 feet and 19-20 degrees. Minimum size obtains at elevations below 2000 feet. The analysis indicates that in fulvescens size tends to increase with increasing altitude. Changes in latitude have no demonstrable effects on size. The samples of $R$. sumichrast $i$ span 10,000 feet of altitude (4000 to nearly 14,000 feet) and 12 degrees of latitude (9-21 degrees). Large size is seen at 8000 feet and 20 degrees. Minimum size centers at 4000 feet and 14 degrees. In sumichrasti there apparently is a tendency for size to increase with increasing altitude up to 8000 feet and a similar tendency with respect to latitude at least within the bracket 14-21 degrees. The samples of $R$. mexicanus are small and few, and the results of the analysis are inconclusive. The samples cover 9000 feet of altitude (100010,000 feet) and 21 degrees of latitude (0-21 degrees). There is an indication of an increase in size with altitude up to $6000 \mathrm{feet}$; the situation above that level is essentially unknown. Changes in latitude have no demonstrable effect on size. The samples of $R$. megalotis that were analyzed represent 9000 feet of altitude (4000-13,000 feet) and 17 degrees of latitude (16-33 degrees). Maximum size is observed at 9000 to 10,000 feet, with 2 latitudinal peaks, one at 20 degrees and the other at 33 degrees. The small individuals in the samples mostly come from elevations below 8000 feet and from latitudes 24 to 27 degrees. The data indicate that there is an increase in size with altitude at least in the range 8000-10,000 feet and an increase in size with latitude in 2 separate areas.

For the purpose of these analyses it was necessary to assume that environmental temperature decreases as either altitude or latitude increases. According to Bergmann's hypothesis a decrease in temperature should be accompanied by an increase in size. To accord with that hypothesis, then, it may be presumed that size in these species of Reithrodontomys should increase with increasing latitude and altitude.

There is evidence in support of the presumption that this size-temperature rule does apply to the 4 species of Reithrodontomys, even to those species, fulvescens, mexicanus, and sumichrasti, which range into tropical climates. Moreover, none of the evidence definitely contradicts the presumption. That 
is to say, in none of the 8 examinations does size consistently decrease where it should increase. In the 2 instances where absolutely no effect was indicated there is not a linear relationship of any sort; rather, there is distinct irregularity.

The fact that the correlations are not all clear-cut and similar may have several explanations, none of which can be adequately documented. Undoubtedly, some of the irregularity in the correlations is attributable to the size and number of the samples. For none of the species do the samples provide complete geographic and altitudinal coverage. On the other hand, even if the samples were as large and complete as could be desired, their size-altitude-latitude curves likely would still show marked irregularities.

Such irregularities would seem to be inherent in the type of data used. Latitude and altitude scales are poor substitutes for temperature readings of the habitats in which the animals live, especially in Latin America. When those scales are used in lieu of habitat temperature, it is surprising that correlations of size with altitude and latitude are evident at all. In the analyses it was observed that the places where a relationship between size and latitude was indicated are over relatively short spans of latitude, for example 14-21 degrees, 16-21 degrees, and 27-33 degrees, rather than over the entire latitudinal range of the species. Also, there is considerable similarity at the same latitude in the diagrams of size and altitude among the various species. Another point is of possible significance in explaining the irregular curves: At a given altitude the distance required for a change of one degree of latitude is great, about 70 miles; at a given latitude, altitude may vary through almost the entire altitudinal range of the species in 70 miles. In that distance there would seem to be more opportunity for other factors to disrupt a theoretical linear relationship between size and latitude than between size and altitude.

It may be inferred from the analyses that close correlations of size with latitude and altitude can not be expected throughout the extent and types of terrain that are inhabited by these species. There are many factors that may distort a theoretical linear relationship between size and altitude or latitude. For example, it is well known that environmental conditions may vary greatly from place to place at a given altitude or latitude, depending upon slope exposure, topography, distance from the ocean, direction of air currents, and many other items (Grinnell, 1908; Grinnell and Swarth, 1913). Moreover, the microclimate experienced by the species in its habitat may be quite different from the macroclimate of that habitat, and even within a single small area of low relief there may be several widely dissimilar climates. (Wolf, et al., 1949). Thus, the fact that the correlations in these analyses are not always precise probably means that altitudes and latitudes in the region ranged by these species are not reliable indices of temperatures. It does not mean necessarily that size variation in these species fails to conform to the 
size-temperature rule. There is positive evidence in support of the rule and no evidence definitely counter to it.

A few remarks regarding application of the rule to interspecific variation in Reithrodontomys are in order. In the genus all of the species of large body and skull size occur at high altitudes and the small species are predominantly inhabitants of lowlands. These statements apply to each natural category, whether it be a species group, a subgenus, or the entire genus. Thus $R$. creper, the largest species of the genus, is restricted to high altitudes while $R$. humulis, perhaps the smallest, occurs predominantly on low coastal plains and piedmonts. In the subgenus Aporodon the 3 large species, creper, tenuirostris, and rodriguezi live on lofty mountains; gracilis and darienensis, the small species of the subgenus, are found predominantly in lowlands. Similarly, in the subgenus Reithrodontomys the large species, chrysopsis and sumichrasti, are high-mountain species while the small species of the subgenus, namely humulis, montanus, and burti, occur principally in lowlands. Within species groups, also, the highland species are larger than those of lowlands. Of the 4 species in the mexicanus group the 2 that are typically lowland kinds, namely gracilis and darienensis, are smaller than the 2 highland species mexicanus and brevirostris. In the megalotis group the large chrysopsis and sumichrasti, inhabitants exclusively of highlands, contrast with the small lowland species montanus, humulis, burti, and raviventris.

These facts might seem to indicate that the size-altitude relationship, and inferentially the size-temperature rule, transcends the specific level in Reithrodontomys. Although it is evident that the small species tend to inhabit lowlands and the large species are highland forms, it is not clear that environmental temperatures have any close connection with these tendencies. Temperature probably is one of the many factors that have influenced the distributions of the species as they are observed today. Whether it has been paramount in sorting the species by size and altitude, concentrating the small species in lowlands and the large species in highlands, is a moot point. If temperature has been an important sorting agent and if in the past it tended to vary inversely with latitude as it does at the present time, then it must have influenced size differently for this reason: Although there is no clear-cut latitudinal stratification of the several species of the genus according to their body size, nevertheless the large species are restricted to low latitudes and most of the small species are confined to the northern part of the range of the genus. The reverse would be expected under the size-temperature rule. The large species should cluster in the north and the small ones in the south. In view of these circumstances it seems doubtful that the sizetemperature rule extends to intraspecific variation in Reithrodontomys. The available evidence either for or against it is inconclusive. 


\section{EVOLUTION IN THE GENUS}

\section{PALEONTOLOGY}

The data accumulated in the present study indicate that the species of Reithrodontomys quite properly constitute a unit that excludes all other known species. I know of no other species that could be grouped with the present species without expanding the scope of the genus to unreasonable limits, and I am satisfied that all of the species of the genus belong together, although some are highly dissimilar. $R$. creper and $R$. humulis, for example, are sufficiently distinct that standing alone they could well be treated as different genera. They are extremes, however. They stand at opposite ends of the series of species in which there are essentially all stages of morphological intermediacy. There is adequate basis for believing, and no good reason for disbelieving, that the genus Reithrodontomys is a natural group derived with modification from a single common parent form.

The fossil record of harvest mice is so scanty as to be of practically no help in an assessment of the interrelationships and phyletic history of the species of the genus. Remains of harvest mice have been recovered from Quaternary cave deposits in Nuevo León (Cushing, 1945). I have examined those remains and I find no evidence in them that the species they represent is dissimilar to the species $R$. megalotis which inhabits the region of the cave today. I strongly suspect that the cave specimens of Reithrodontomys are of Recent age (see the accounts of $R$. m. saturatus).

The Recent species humulis is known as a fossil. It is recorded from Pleistocene deposits in Florida (Simpson, 1930). Two fossil species have been described. These are $R$. simplicidens Brown (1908) from the Conard Fissure of Arkansas and $R$. pratincola Hibbard (1941) from deposits in Kansas, both attributed to Pleistocene time. These species have the simple dental pattern of the subgenus Reithrodontomys. Apparently they were fairly similar to species that inhabit the same regions today. These are the sub-Recent records of Reithrodontomys to my knowledge. They provide few facts to support the data derived from contemporary species. They indicate that there were harvest mice in Pleistocene time in the southern United States which are not greatly dissimilar to modern inhabitants of the same region.

\section{THE DISTRIBUTION OF SPECIALIZATIONS}

The species of the genus are all derivable from one archetypal form. That hypothetical form is small and short tailed. Its skull is short and broad and its molar teeth are simple in pattern. It inhabits semiarid grasslands. Conceivably, such a form was the basic ancestor of Reithrodontomys, but whether or not it was is beside the point at the moment. The point to be made here is that the morphological and ecological traits of the form are 
such that the characteristics of the modern species can be derived from it. It is a basic morphotype. Deviations from that morphotype are here considered specializations when they involve an increase in size or complexity or when they seem to restrict a form to a particular habitat. I interpret the characters listed below as specializations in the genus. Most of them involve the teeth, the zygomasseteric structures, and parts of the body that seem to point toward scansorial or arboreal habits. The characters follow: Large body, feet, ears, and skull; long tail and toes; large brain case; long rostrum; weak zygomatic arches; narrow, unkeeled zygomatic plate; narrow pterygoid fossae and a proportionately broad mesopterygoid fossa; and a narrow shallow fossa on lingual surface of angular process of dentary. Small internal pterygoid and large temporal muscles (see Rinker and Hooper, 1950). Complex enamel pattern of the molar teeth as evidenced by the presence of: long mesolophs (ids) on all molars, each extending to the labial border of the tooth and there fused with a mesostyle (id); enterolophs and styles; distinct anterior and posterior cingula; divided anterocone (id); and internal enamel folds. Scansorial or arboreal (as contrasted to terrestrial) habits. A narrow ecologic or geographic range, suggesting narrow environmental tolerances.

On the basis of these characters the species of the genus may be arranged in order of increasing specializations or of increasing dissimilarity to the generalized morphotype. The species of the subgenus Reithrodontomys are generalized in contrast to those of Aporodon. As in other polytypic genera, however, there are varying degrees of specialization within each subgenus, species group, and polytypic species. A list of the species of the subgenus Reithrodontomys arranged approximately in order of increasing specialization follows: humulis, burti, montanus, megalotis, raviventris, fulvescens, sumichrasti, chrysopsis, and hirsutus. The fossil species, simplicidens and pratincola, apparently fit somewhere near montanus and megalotis. The species of Aporodon in order of increasing specialization are as follows: gracilis, darienensis, mexicanus, brevirostris, microdon, tenuirostris, rodriguezi, and creper.

There is geographic order in the distribution of the specialized and generalized traits. The generalized species concentrate in the northern part of the range of the genus and specialized species in the southern part of that range. All of the northern species are generalized in comparison with the southern species. Considering the entire genus it seems clear that there is generally progressive increase in specialization with decreasing latitude.

The most specialized forms of the genus or of either subgenus are not found farthest south, however. Rather, they are concentrated in 2 regions, each situated short of the southern limits of the genus. These regions may be termed the major specialization centers for Reithrodontomys. 
The mountainous highlands of central México constitute the principal specialization center for the subgenus Reithrodontomys. All of the highly specialized species of the subgenus occur there and all other species that range into the region tend to be more specialized there than elsewhere. Southward and northward from that region the species, and subspecies as well, are progressively more generalized. Thus, in the fulvescens group, the specialized $R$. hirsutus is restricted to the mountains of central México, while the generalized $R$. fulvescens ranges to the north and south of the central highlands (Map 5). Moreover, least specialization in fulvescens occurs farthest from the central highlands. Its central populations, known by the names toltecus, griseoflavus, difficilis, and nelsoni, tend to be more specialized than those to the north and south. Similar trends are observed in the other species of the subgenus. The most specialized species of all, namely $R$. chrysopsis, is confined to the mountains of central México. The species ranked second to chrysopsis in specialization, namely $R$. sumichrasti, is more specialized in central México than elsewhere in its range; in a scale of specialization I rank the races sumichrasti and nerterus above the extreme southern subspecies vulcanius and australis. Another point regarding $R$. sumichrasti is pertinent here. Of all species of the subgenus it ranges farthest south. Perhaps significantly, it stands in strong contrast to the generalized species that are confined to the north. $R$. megalotis is another species of the subgenus that inhabits the central highlands. Its specialized subspecies, alticola and especially saturatus, are confined to these highlands. Its generalized races, for example $d y c h e i$ and caryi, are found far to the north, in the United States. Finally, all of the generalized species of the subgenus, namely humulis, montanus, and burti, live far to the north of the region of specialization of the subgenus. None ranges into the mountainous highlands of central México.

In Aporodon specialization centers in the highlands of Central America, specifically in the mountains of Costa Rica and western Panamá. The highlands of Central America are the home of the highly specialized tenuirostris group, creper and rodriguezi being confined to Costa Rica and Panamá and tenuirostris and microdon occurring in Guatemala and southern México. The latter 2 species are slightly less specialized than creper and rodriguezi. The species microdon, which ranges farthest from the center of specialization, is, significantly, the least specialized of the 4 in the tenuirostris group. Next in order of decreasing specialization in Aporodon are the species of the mexicanus group. Of those brevirostris and mexicanus top the list. The former is restricted to Costa Rica, insofar as is known. The latter ranges southward to Ecuador and northward to northeastern México. In the highlands of Costa Rica it, too, is specialized, as evidenced in its race cherriei. The comparatively generalized species of Aporodon inhabit the lowlands of 
Central America. $R$. darienensis is known only from lands of low elevation in eastern Panamá. $R$. gracilis inhabits the lowlands of southern México and Central America south to northwestern Costa Rica. Thus, in Aporodon the specialized traits cluster in the highlands of Central America, and they are concentrated slightly more in the mountain masses of Costa Rica and Panamá than in those of Chiapas, Guatemala, and Honduras.

In Reithrodontomys, then, there are 2 major centers of specialization, each situated in the southern part of the range of its subgenus and each characterized by specialized forms, whether those forms be taken as representatives of the genus as a whole, of species groups, or even of species. They are the areas in which specialized characters are concentrated. There are other areas of specialization but all are much less important. They pertain to few forms and lesser degrees of specialization.

\section{DIFFERENTIATION AREAS}

These major specialization centers also are the principal areas of differentiation for Reithrodontomys. In these 2 centers-the southern end of the Mexican Plateau and the mountains of Central America-are found the greatest number of species and the greatest amount of differentiation of polytypic species. Of the 17 Recent species of Reithrodontomys 7 occur on the southern fringe of the Mexican Plateau, the major differentiation center for the subgenus Reithrodontomys. The 7 species constitute 55 per cent of the species of that subgenus and 25 per cent of the species of Aporodon. Sixty per cent (10 of 17 ) of the species in the genus occur in the Central American region of differentiation. These include all of the species of Aporodon and 22 per cent ( 2 of 9 ) of the species of the subgenus Reithrodontomys. In no other areas are there as many species represented. Elsewhere in the range of the genus the usual number of species per area is one or 2. Moreover, as indicated above, the number of species of each subgenus increases with progression toward the centers of differentiation. Progressing southward on a line from the northern limits of the genus, the number of species of the subgenus Reithrodontomys increases to a maximum (55 per cent) on the southern part of the Mexican Plateau. Then toward the south, while the number in that subgenus decreases, the number in Aporodon increases to a maximum in southern Central America. Thus, in Guatemala and Honduras there occurs 22 per cent ( 2 of 9 ) of the species of Reithrodontomys and 50 per cent ( 4 of 8 ) of Aporodon. In Costa Rica and Panamá there is 11 per cent ( 1 of 9 ) of the species of Reithrodontomys and 75 per cent (6 of 8 species) of Aporodon. Farther southward Reithrodontomys drops out and one species of Aporodon extends on to Ecuador.

There is a high degree of subspeciation in these major differentiation 
centers (see distribution maps). Each polytypic species that occurs in one or both of the areas is differentiated there into one or more subspecies. Those subspecies (of generalized species of each subgenus, in particular) are strongly marked morphologically. The impressive subspeciation observed in the species mexicanus, gracilis, fulvescens, and megalotis is an example in point. The differences between $R$. fulvescens toltecus and $R$. f. nelsoni, between $R$. megalotis megalotis and $R$. m. saturatus, and between $R$. mexicanus cherriei and $R$. m. potrerogrande $i$ are of the same sort and fully as great as those which characterize undoubted species. Each of the above pairs still appears to have reproductive continuity. If that continuity is broken, there are produced 6 well-differentiated species. The amount of distinctness of the subspecies and the number of them in the differentiation areas strongly suggest that those are active differentiation areas at the present time. Subspeciation and, inferentially, speciation appear to be proceeding rapidly there.

The generalized species rather than those highly specialized are providing the materials for the evolution of new species. It is in the wide-spread and moderately generalized species of each subgenus that the large amount of subspeciation and the impressive differences between subspecies occur. The highly specialized species tend to be monotypic. When they are polytypic their subspecies are weakly differentiated. Each highly specialized species has a small geographic range situated near the primary centers of specialization and differentiation. Each appears to have a narrow ecological range. The species in mind are: creper, rodriguezi, tenuirostris, microdon, chrysopsis, and hirsutus. All but hirsutus appear to be scansorial or even arboreal in habit. Under the present conditions of their environments they appear to be evolutionally static in comparison with more generalized species. The generalized species of each subgenus, namely gracilis and mexicanus in Aporodon, and humulis, montanus, megalotis, and fulvescens in Reithrodontomys, are polytypic. They range widely in different environments, and their differentiation to subspecies probably is related to those 2 facts. The morphological characters of their subspecies probably are largely responses to the different environments in which the species occur. In general, the amount of morphological difference between 2 subspecies of any one of these species seems roughly proportional to the degree of dissimilarity of the environments inhabited by the subspecies.

\section{ESTIMATE OF PHYLETIG DEVELOPMENT IN THE GENUS}

In the absence of an adequate fossil record of harvest mice, one can only speculate on their phyletic history. Following is an estimate of the interrelationships and phyletic history of the species based exclusively on observations of Recent species. I consider that specializations tend to be modern 
traits acquired with modification from a more primitive and generalized ancestor. This view accords with the fossil evidence of evolution in rodents in general (Wood, 1947). It is not entirely in harmony with the opinion of Hinton (1926) or Ellerman (1941), who contend that complexity in pattern of the molariform teeth, as observed in Oryzomys for example, is primitive. Past events in the history of the genus are inferred from current distributions and morphologies. Because those are products of past events they should give clues to some of the geographic and morphologic courses followed in the evolution of the species. The 2 sets of facts, distributional and morphologic, accord excellently in support of the scheme that is set forth below.

If it be assumed that the region of origin and center of dispersal of a group of animals is characterized by (1) the greatest number of species, (2) the greatest number of specialized species, (3) a strong tendency toward specialization in comparatively generalized species, and (4) strong differentiation among subspecies, then the southern part of the Mexican Plateau and the mountains of Central America are the regions of origin and centers of dispersal for the subgenera of Reithrodontomys. The southern part of the Mexican Plateau is the area of origin and center of dispersal of the subgenus Reithrodontomys and the highlands of Central America constitute the counterpart for Aporodon, the other principal phyletic line of the genus. Other areas are of less importance. They mark lesser levels of differentiation, specialization, and abundance of species, and they probably date from later periods in the history of the genus.

The interrelationships of the species, as I see them, are outlined schematically in Plate I. The present-day species are indicated on the uppermost level. That is the factual level. From it the remainder of the scheme is inferred. Emphasis is placed on the relative amount of space, particularly in a generally north-south direction, that may have been covered by the forms at various time levels. The lengths of the horizontal bars are intended as rough estimates of the relative positions and geographical extents of the various forms. Exception is made of the extent of range of modern forms, for which see Map 12. The center of Plate I, marked by the gap between the Reithrodontomys and Aporodon blocks, is intended to approximate the Isthmus of Tehuantepec in southern México. The gap between the Guatemalan and Costa Rican segments approximates the Nicaraguan lowlands. To give attention to geographic distribution in this phyletic scheme seems important. The facts of distribution of the modern species and of their specialized and generalized traits strongly suggest that geographic differentiation has played a major role in the evolution of each modern species. Much of the differentiation that led to the formation of the phyletic lines apparently took 
place in a north-south direction. The isolating of segments of polytypic species, followed by further differentiation and enlargement of the ranges of those independent segments, appears to have been a standard sequence of events in the history of Reithrodontomys. Such a sequence repeated again and again, with a series of consequent migrations and countermigrations of the evolving stocks, will account for the diversity and geographic position of the species as they are seen today.

The primitive ancestral stock of Reithrodontomys is thought to have been most like humulis or montanus of present-day species. From the northern part of the range of the ancestral polytypic form, it is postulated, evolved the Reithrodontomys segment. From the southern part evolved the Aporodon segment. The 2 segments probably have remained geographically isolated for much of their subsequent evolution, Aporodon developing in Central America and Reithrodontomys evolving largely in México. The focal point in differentiation and geographic distribution of those subgenera is clearly Central America for Aporodon and México, particularly the southern part of the Mesa Central, for Reithrodontomys. The initial isolation of those 2 segments may well have been effected by the Tehuantepecan water gap, which existed in late Miocene or Pliocene time (Schuchert, 1935) and which is estimated to have closed in middle Pliocene time (Schuchert, ibid.) or earlier (Olson and McGrew, 1941). The fact that the level of differentiation involved in Reithrodontomys is no higher than subgeneric suggests, however, that the initial separation of the Aporodon and Reithrodontomys stocks may have taken place later than the middle Pliocene period. The place of initial separation seems logical enough. The time seems early. Types of barriers other than aquatic may have isolated the stocks in, say, late Pliocene or Pleistocene time. For example, as suggested by Berry (1918), a blanket of tropical rain forest across the Isthmus could have effectively prohibited the exchange of forms that cannot tolerate rain forest conditions. No known species of Reithrodontomys inhabits true rain forest.

Subsequently, the primitive Aporodon and Reithrodontomys stocks were each divided latitudinally into 2 or more secondary parts. Other similar divisions followed later. A southern secondary segment of the primary Aporodon stock gave rise to the tenuirostris group of species. As I visualize it, much of the evolutionary history of that group took place in southern Central America, possibly in the nuclear land masses of Costa Rica. Fairly late in the history of this southern segment, barriers that limited its spread toward the north were temporarily lifted and the stock of the tenuirostris group spread northward to Honduras and Guatemala. From this northern stock evolved tenuirostris and microdon, while creper and rodriguezi are the modern derivatives of the residual Costa Rican segment. The occurrence of 

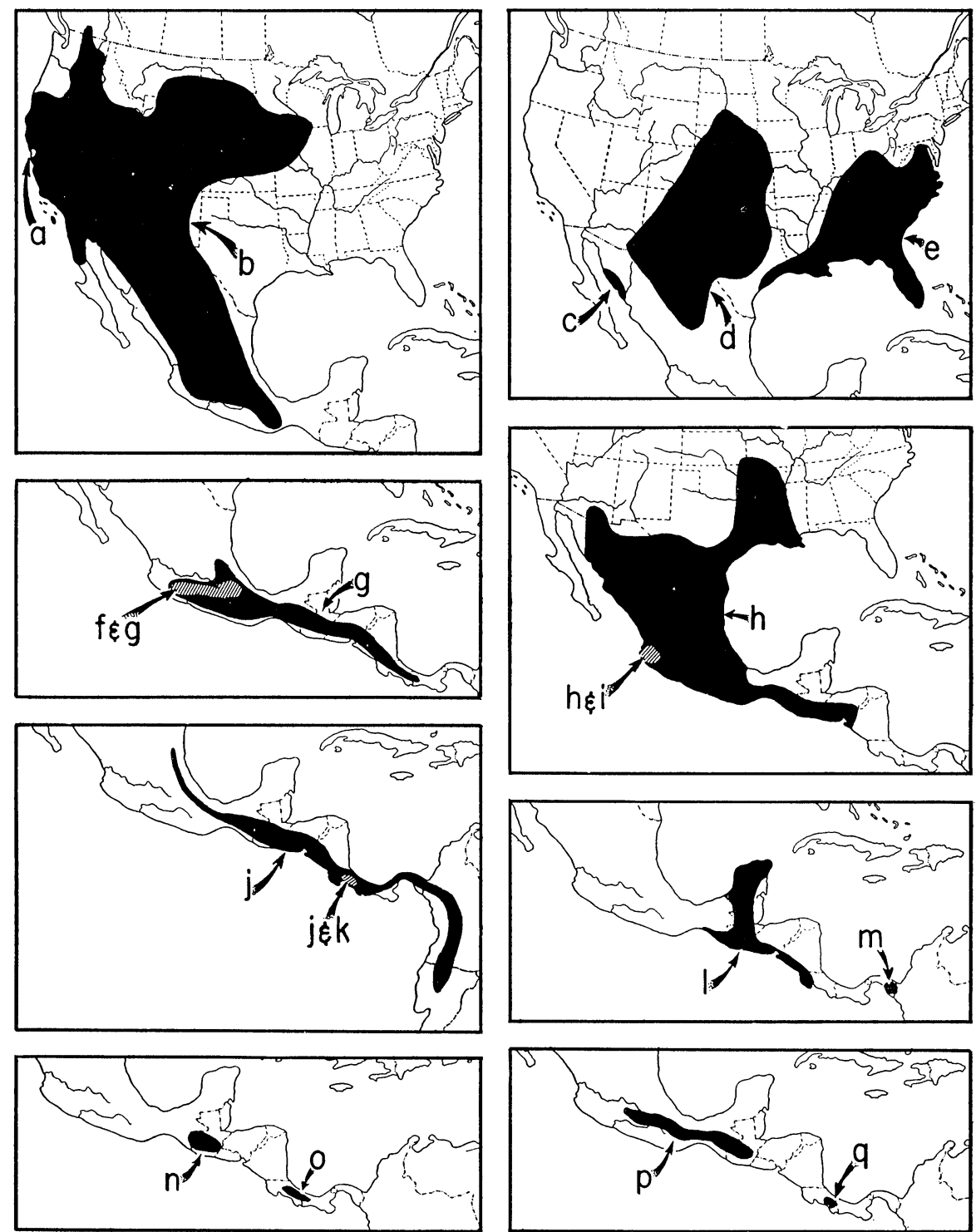

MAP 12. Distribution of the Recent species of Reithrodontomys: $(a)$ raviventris, $(b)$ megalotis, (c) burti, (d) montanus, (e) humulis, $(f)$ chrysopsis, $(g)$ sumichrasti, $(h)$ fulvescens, (i) hirsutus, $(j)$ mexicanus, $(k)$ brevirostris, $(l)$ gracilis, $(m)$ darienensis, $(n)$ tenuirostris, (o) creper, $(p)$ microdon, $(q)$ rodriguezi. 
colonies of microdon on the Mexican highlands probably is evidence of one of the latest movements of the tenuirostris group. The northern populations of microdon are but slightly differentiated from those in Guatemala, which suggests that their present separation is a comparatively recent event. It seems likely that microdon spread northward into México at about the same time that mexicanus migrated northward from Guatemala. This may have occurred in some period in Pleistocene time when conditions were suitable for the spread of those species.

The northern segment of the primitive Aporodon stock gave rise to the mexicanus group. Of modern species $R$. gracilis is estimated as structurally nearest that primitive stock. This segment centers and probably evolved in Guatemala and adjoining parts of México and Central America. The 3 species of the mexicanus group are only moderately differentiated from one another. In essence $R$. mexicanus is a larger, somewhat more specialized counterpart of gracilis that is adapted to moister and cooler environments. $R$. gracilis, now found in lowlands, may well have been there originally. If so, its habitat should have been enlarged as a result of epeirogenic movements in Pleistocene time (Schuchert, 1935: 319), which probably increased rather than diminished the extent of aridity in northern Central America. $R$. darienensis is a late minor offshoot from mexicanus or gracilis, probably the latter. Similarly, brevirostris is a late derivative from mexicanus-like stock. $R$. mexicanus appears to be a late immigrant to central México on the one hand and to South America on the other. Pleistocene time, with its fluctuations in climate and correlative movements of floral and faunal elements, would seem adequate to account for the amount of differentiation that has taken place in the species in México and South America. The populations in eastern México (R. m. mexicanus) are but slightly differentiated from those of the Sierra Cuchumatanes of western Guatemala $(R$. $m$. howelli). Similarly those of Colombia (R. m. milleri) are morphologically close to the populations of Panamá (R. m. garichensis).

The Reithrodontomys subgeneric stock likewise became divided into northern and southern segments, as did that of Aporodon. In addition, in northern México and the United States where the available land area was longitudinally broad, division occurred on an east-west basis. From the northern part of the range of the primitive Reithrodontomys (subgenus) stock came humulis, montanus, and burti. It is postulated that these species retain many characteristics of that ancestral stock. $R$. humulis is well differentiated from montanus. The 2 probably were early segregated. The easternmost segment, humulis, likely has inhabited the southeastern states since the time (late Pliocene is a guess) when the original stock entered that region. Present occurrence of the species to the west of the Mississippi River in 
coastal Louisiana and Texas is thought to be a comparatively recent event, to judge from the amount of difference between merriami, the trans-Mississippi race, and humulis of the southeastern states (see Hooper, 1943). The western segment, inhabiting the Great Plains, became montanus. Although there may have been repeated fluctuations in its range, it probably has inhabited those plains for as long a time as humulis has been a resident of the southeastern states. $R$. burti is related to $R$. montanus, but there are dental characters which connect it directly with humulis and suggest that it may be a relict closely similar to the Reithrodontomys primitive stock.

From the northwestern part of the range of the primitive stock of the subgenus came megalotis. Isolation afforded by the Rocky Mountains and inhospitable terrain on the Central Plateau of northern México could account for the specific segregation of megalotis from the eastern montanushumulis stock. If megalotis originally was excluded from the region east of the Rocky Mountains, its presence on the Great Plains probably is a recent event, possibly dating from an interglacial period in Pleistocene time. The present plains race, dychei, is fairly distinct from megalotis and from other western subspecies.

Other evidences of recent movements and countermovements of megalotis stock are afforded elsewhere in the range of the species. At the present time all contiguous populations of the species megalotis do not appear to be completely interfertile. In west-central México, for example, the populations of saturatus and zacatecae appear to intermingle but to maintain their identities. Any genetic continuity between the 2 forms must be in a geographically roundabout way through the race megalotis. The present geographic and morphologic relationships of the 2 forms suggest that formerly they were separated geographically and only recently have their ranges come together. $R$. raviventris is an offshoot of $R$. megalotis that has become adapted to conditions in salt marshes around San Francisco Bay, California. There is some evidence that it evolved entirely in Recent time (Hooper, 1944: 70).

The southern segment of the Reithrodontomys (subgenus) primitive stock gave rise to chrysopsis and sumichrasti. One of the highly specialized species in the subgenus, $R$. chrysopsis, probably has long been a resident of the southern part of the Mexican tableland. Its nearest relatives are sumichrasti and megalotis, but it is well differentiated from both. Its present discontinuous distribution indicates that it, like $R$. microdon, formerly occurred over a larger part of the southern tableland than it now does. Increasing aridity in Recent time probably has had to do with contraction of the range of the species and of its associated fir forests to their present insular states. The activities of man with his axe and plow have accelerated the process. $R$. sumichrasti also is a specialized species which probably evolved from the primitive southern stock of the subgenus. It and chrysopsis are clearly more similar 
to megalotis than to montanus and the other northern derivatives. $R$. sumichrast $i$, however, more nearly qualifies as a subtropical species than do all of these. In view of its characteristics, I consider it to have evolved as a species in the southern part of the Mexican Plateau. Its spread into Central America probably is a recent event contemporaneous with, or not much earlier than, the extension of $R$. mexicanus northward into eastern México. The races of sumichrasti in Central America are "weak" as regards amount of differentiation. This may indicate comparatively recent genetic continuity of all populations of sumichrasti in Central America. Differentiation to the east and west of the Isthmus of Tehuantepec is stronger. The differences between dorsalis, south of the Isthmus of Tehuantepec, and luteolus and nerterus to the north of that present lowland barrier are more pronounced. Other influences disregarded, this fact suggests that the Central American and Mexican segments of sumichrasti may have been separated longer than any 2 of the Central American races.

The fulvescens group of species stands apart from the other species of the subgenus Reithrodontomys. Some characters of the group approach characters of mexicanus and gracilis in Aporodon. This is particularly true of $R$. hirsutus, in which the structure of the zygomatic arches and the pterygoid region of the skull agree with comparable structures in mexicanus. Other features of the skull and skin, however, appear to relate it to the less specialized fulvescens; fulvescens on the whole is more similar to undoubted species of Reithrodontomys than to species of Aporodon. Accordingly, the fulvescens group is here considered a separate derivative of the primitive generic stock which gave rise to Aporodon and to the remainder of Reithrodontomys. This early segregation seems necessary to accord with the unique characters of the group.

The present range of the fulvescens group occupies an intermediate position between Aporodon and Reithrodontomys, just as the characters of the group are also somewhat between the 2 subgenera. The focal point in differentiation in the group lies in central México, in the latitude of Jalisco, Michoacán, and México. $R$. hirsutus is considered to have evolved from fulvescens-like stock. The number and kind of characters that distinguish the 2 species suggest that they diverged fairly early, about the time, say, that the megalotis stock was segregated from the basic humulis-montanus stock. The occurrence of fulvescens in Central America may be a late event in the history of the species, if the amount of differentiation of the southern subspecies is indicative of lapse of time. The populations of the species in Chiapas, Guatemala, El Salvador, and Honduras are morphologically similar; they are all treated under one subspecific name, chiapensis. Chiapensis is moderately distinct from amoenus and mustelinus, the neighboring races in Oaxaca. 
In summary, it is postulated that the phyletic branches of Reithrodontomys developed from geographic segments of polytypic species. The interposition of barriers facilitated the processes of subspeciation and subsequent speciation of the ancestral forms. The early development of the group took place in México and Central America, where much of the speciation that figured in the history of the modern species took place in a generally north-south direction. Later, secondary divisions occurred on an east-west basis in northern México and the United States. There were successive movements and countermovements of the evolving species, probably in response to changing climates. These migrations are necessary to account for the diverse geographic overlapping of species, closely and distantly related, that is seen today. In addition to those tidal movements, there seems to have been a general latitudinal shift of the generalized or primitive forms with respect to the assumed primary regions of origin and centers of dispersal. Primitiveness of the forms increases as the distance from those primary areas increases. All species considered, the generalized ones are found in the northern part of the range of the genus and the specialized species occur in the southern part. In the primary regions of differentiation the specialized species now appear to be evolutionally static while the more generalized species found there are actively evolving. 
TABLE VI

External Measurements of Reithrodontomys

\begin{tabular}{|c|c|c|c|c|c|}
\hline Species and Locality & $\begin{array}{c}\text { Number } \\
\text { of } \\
\text { Specimens }\end{array}$ & $\begin{array}{l}\text { Total } \\
\text { Length }\end{array}$ & $\begin{array}{c}\text { Tail } \\
\text { Vertebrae }\end{array}$ & $\begin{array}{l}\text { Hind } \\
\text { Foot }\end{array}$ & $\begin{array}{l}\text { Ear, from } \\
\text { Notch }\end{array}$ \\
\hline 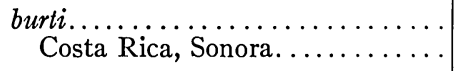 & 20 & $\begin{array}{c}128 \\
116-136\end{array}$ & $\begin{array}{c}58 \\
52-66\end{array}$ & $\begin{array}{c}16 \\
16-17\end{array}$ & $\begin{array}{c}16 \\
14-17\end{array}$ \\
\hline \multicolumn{6}{|l|}{ montanus } \\
\hline 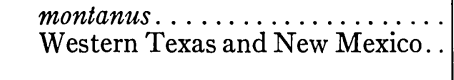 & 6 & $\begin{array}{c}120 \\
114-130\end{array}$ & $\begin{array}{c}55 \\
48-63\end{array}$ & $\begin{array}{c}16 \\
15-17\end{array}$ & $\begin{array}{c}14 \\
13-16\end{array}$ \\
\hline \multicolumn{6}{|l|}{ megalotis } \\
\hline 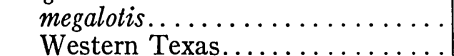 & 15 & $\begin{array}{c}133 \\
120-152\end{array}$ & $\begin{array}{c}68 \\
61-78\end{array}$ & $\begin{array}{c}17 \\
16-18\end{array}$ & $\begin{array}{c}14 \\
12-15\end{array}$ \\
\hline saturatus......... & 13 & 150 & 79 & 18 & 15 \\
\hline Las Vigas, Veracruz. & & $130-170$ & $65-96$ & $18-20$ & $13-16$ \\
\hline 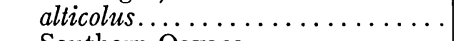 & 11 & 144 & 73 & 17 & 14 \\
\hline Southern Oaxaca............. & & $135-154$ & $64-83$ & $15-18$ & $13-15$ \\
\hline $\begin{array}{l}\text { zacatecae } . \ldots \ldots \ldots \ldots \ldots \\
\text { Valparaiso Mts. Zacatecas. }\end{array}$ & 7 & $\begin{array}{c}147 \\
136-157\end{array}$ & $\begin{array}{c}80 \\
72-87\end{array}$ & $\begin{array}{c}19 \\
18-20\end{array}$ & ․ \\
\hline 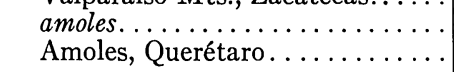 & 3 & $\begin{array}{c}146 \\
137-154\end{array}$ & $\begin{array}{c}80 \\
76-83\end{array}$ & $\begin{array}{c}16 \\
16-17\end{array}$ & $\begin{array}{c}\because \ddot{14} \\
14-14\end{array}$ \\
\hline \multicolumn{6}{|l|}{ sumichrasti } \\
\hline sumichrasti.... & 20 & 166 & 96 & 18 & 15 \\
\hline Teziutlán, Puebla. & & $147-190$ & $82-107$ & $17-20$ & $14-18$ \\
\hline 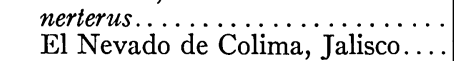 & 37 & $\begin{array}{c}184 \\
169-206\end{array}$ & $\begin{array}{c}105 \\
95-123\end{array}$ & $\begin{array}{c}20 \\
19-22\end{array}$ & $\begin{array}{c}17 \\
16-18\end{array}$ \\
\hline luteolus..................... & 7 & 176 & 101 & 20 & \\
\hline Juquila, Oaxaca. & & $158-190$ & $91-112$ & $20-21$ & \\
\hline dorsalis.......... & 43 & 159 & 85 & 19 & 14 \\
\hline Southeastern Chiapas....... & & $143-176$ & $75-96$ & $17-20$ & $13-16$ \\
\hline modestus............... & 46 & 161 & 88 & 19 & 14 \\
\hline Los Esesmiles, El Salvador. & & $148-176$ & $81-98$ & $18-20$ & $13-15$ \\
\hline australis............ & 9 & 170 & 86 & 19 & $\ldots$ \\
\hline Volcán de Irazú, Costa Rica. & & $159-179$ & $80-92$ & $18-20$ & \\
\hline vulcanius.............. & 18 & 165 & 90 & 19 & 14 \\
\hline Volcán de Chiriquí, Panamá & & $157-173$ & $82-97$ & $17-20$ & $12-15$ \\
\hline \multicolumn{6}{|l|}{ chrysopsis } \\
\hline chrysopsis. & 22 & 181 & 98 & 21 & 18 \\
\hline Distrito Federal. & & 170-192 & 89-108 & $20-21$ & $17-19$ \\
\hline perotensis...... & 2 & 178 & 104 & 19.5 & 17 \\
\hline Cofre de Perote, Veracruz. & & $176-180$ & $102-106$ & $19-20$ & 17 \\
\hline \multicolumn{6}{|l|}{ fulvescens } \\
\hline fulvescens. & 6 & 165 & 92 & 19 & 15 \\
\hline Central Sonora. & & $153-179$ & $81-104$ & $18-21$ & $15-15$ \\
\hline canus. & 8 & 160 & 89 & 19 & 15 \\
\hline Central Chihuahua. & & $150-173$ & $82-96$ & $18-20$ & $14-16$ \\
\hline griseoflavus... & 44 & 166 & 93 & 19 & 15 \\
\hline Ameca, Jalisco. & & $148-185$ & $81-105$ & $18-21$ & $14-17$ \\
\hline toltecus.... & 5 & 180 & 102 & 21 & 15 \\
\hline Distrito Federal. . . & & $166-189$ & $94-105$ & $20-22$ & $14-15$ \\
\hline aurantius.... & 20 & 159 & 88 & 20 & 15 \\
\hline Baton Rouge, Louisiana. & & $138-173$ & $76-99$ & $17-21$ & $13-16$ \\
\hline intermedius........... & 8 & 153 & 81 & 19 & 13 \\
\hline Southern Texas.. & & $145-161$ & $73-90$ & $18-21$ & $13-13$ \\
\hline
\end{tabular}


TABLE VI (Cont.)

\begin{tabular}{|c|c|c|c|c|c|}
\hline Species and Locality & $\begin{array}{c}\text { Number } \\
\text { of } \\
\text { Specimens }\end{array}$ & $\begin{array}{l}\text { Total } \\
\text { Length }\end{array}$ & $\begin{array}{c}\text { Tail } \\
\text { Vertebrae }\end{array}$ & $\begin{array}{l}\text { Hind } \\
\text { Foot }\end{array}$ & $\begin{array}{l}\text { Ear, from } \\
\text { Notch }\end{array}$ \\
\hline 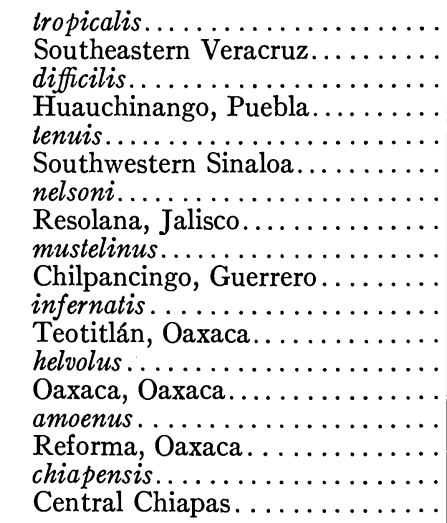 & $\begin{array}{r}22 \\
7\end{array}$ & $\begin{array}{c}158 \\
152-171 \\
166 \\
154-177 \\
163 \\
145-177 \\
153 \\
134-175 \\
167 \\
150-185 \\
161 \\
159-165 \\
184 \\
172-200 \\
148 \\
\\
169 \\
163-183\end{array}$ & $\begin{array}{c}86 \\
83-90 \\
97 \\
90-105 \\
94 \\
82-102 \\
85 \\
72-96 \\
97 \\
91-106 \\
94 \\
92-96 \\
107 \\
97-116 \\
81 \\
96 \\
92-101\end{array}$ & $\begin{array}{c}18 \\
16-20 \\
18 \\
17-20 \\
20 \\
20-21 \\
19 \\
18-20 \\
19 \\
17-20 \\
18 \\
17-20 \\
20 \\
19-21 \\
18.5 \\
\\
20 \\
19-20\end{array}$ & $\begin{array}{c}13 \\
13-14 \\
14 \\
13-16 \\
15 \\
14-16 \\
14 \\
14-16 \\
13 \\
11-16 \\
15 \\
13-16 \\
\ldots \\
\ldots \\
\ldots \\
15 \\
15-15\end{array}$ \\
\hline 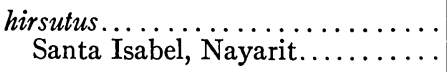 & 12 & $\begin{array}{c}189 \\
175-202\end{array}$ & $\begin{array}{c}108 \\
100-115\end{array}$ & $\begin{array}{c}21 \\
20-22\end{array}$ & $\begin{array}{c}17 \\
16-17\end{array}$ \\
\hline 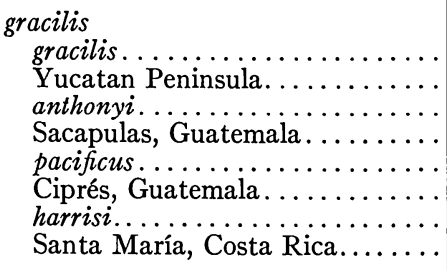 & 9 & $\begin{array}{c}182 \\
175-191 \\
175 \\
\ldots \\
165 \\
152-175 \\
162 \\
\ldots\end{array}$ & $\begin{array}{c}107 \\
104-113 \\
98 \\
\dddot{87} \\
75-101 \\
92 \\
\ldots .\end{array}$ & $\begin{array}{c}19 \\
18-20 \\
20 \\
\ldots \\
17 \\
15-18 \\
18 \\
\ldots\end{array}$ & $\begin{array}{l}14 \\
\ldots \\
\ldots \\
\ldots \\
\ldots \\
\ldots \\
14 \\
\ldots\end{array}$ \\
\hline 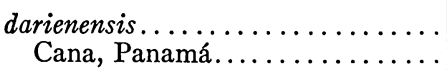 & 6 & $\begin{array}{c}172 \\
167-177\end{array}$ & $\begin{array}{c}107 \\
100-112\end{array}$ & $\begin{array}{c}18 \\
17-19\end{array}$ & $\begin{array}{c}14 \\
14-15\end{array}$ \\
\hline 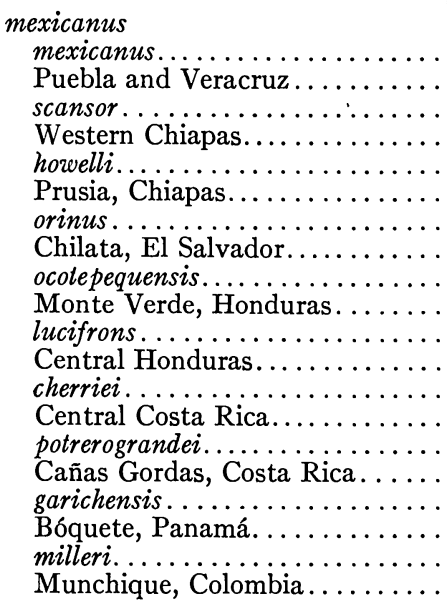 & $\begin{array}{l}15 \\
24\end{array}$ & $\begin{array}{c}181 \\
167-190 \\
180 \\
174-195 \\
179 \\
168-191 \\
181 \\
175-187 \\
169 \\
164-185 \\
177 \\
160-193 \\
187 \\
164-203 \\
183 \\
180-188 \\
196 \\
190-200 \\
179 \\
172-190\end{array}$ & $\begin{array}{c}107 \\
101-114 \\
105 \\
100-105 \\
107 \\
101-115 \\
108 \\
100-126 \\
97 \\
92-105 \\
106 \\
100-115 \\
106 \\
93-120 \\
110 \\
107-114 \\
118 \\
110-120 \\
106 \\
101-112\end{array}$ & $\begin{array}{c}19 \\
18-20 \\
19 \\
18-21 \\
19^{*} \\
18-19 \\
19 \\
18-21 \\
19^{*} \\
18-19 \\
19^{*} \\
17-20 \\
19^{*} \\
18-21 \\
18^{*} \\
18-18 \\
20 \\
20-20 \\
19 \\
18-20\end{array}$ & $\begin{array}{c}15 \\
15-16 \\
15 \\
15-16 \\
13 \\
12-15 \\
15 \\
15-15 \\
\ldots \\
\ldots \\
15 \\
15-16 \\
15 \\
14-16 \\
13 \\
13-13 \\
16 \\
15-18 \\
\ldots \\
\ldots\end{array}$ \\
\hline
\end{tabular}


TABLE VI (Cont.)

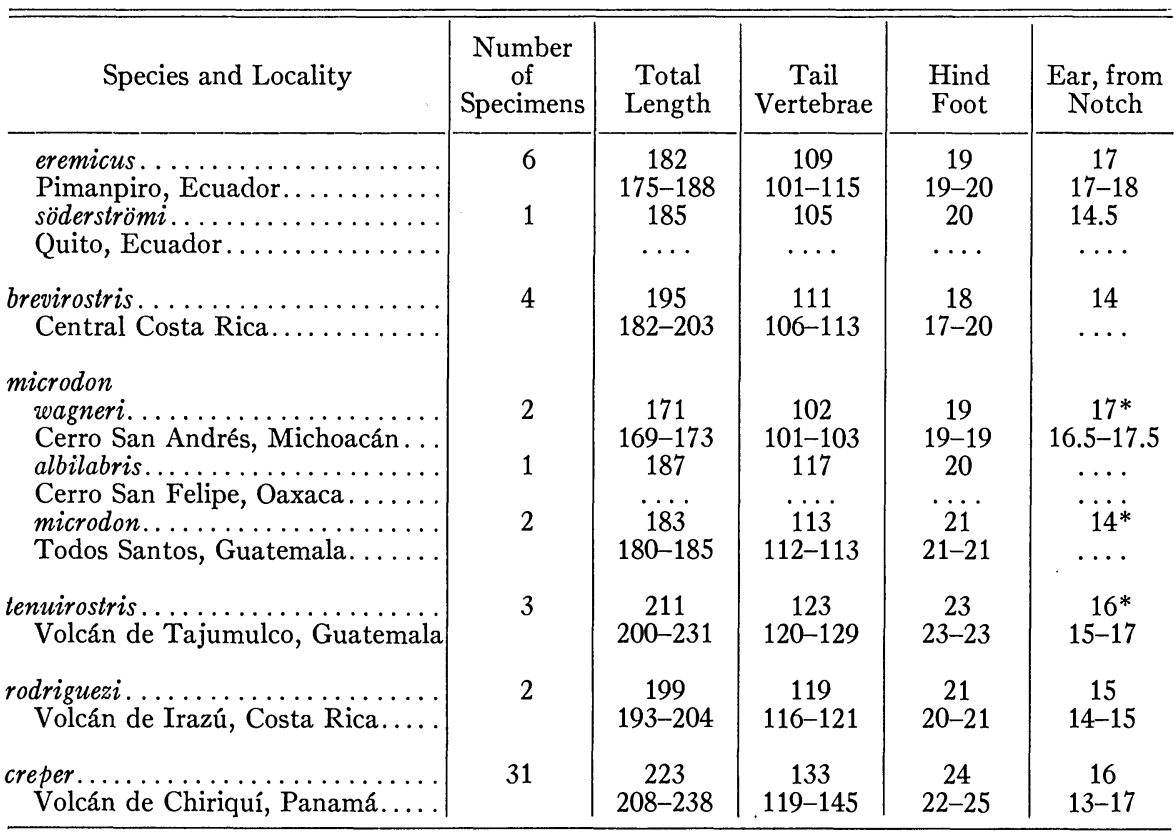

* Measurements of dry skin. 
TABLE VII

Cranial Measurements of Reithrodontomys

\begin{tabular}{|c|c|c|c|c|c|c|c|c|c|c|c|c|}
\hline $\begin{array}{l}\text { Species, } \\
\text { Locality, } \\
\text { and } \\
\text { Number of } \\
\text { Specimens }\end{array}$ & $\begin{array}{l}\text { Length } \\
\text { of } \\
\text { Skull }\end{array}$ & $\begin{array}{c}\text { Zygo- } \\
\text { matic } \\
\text { Breadth }\end{array}$ & $\begin{array}{l}\text { Breadth } \\
\text { of } \\
\text { Brain } \\
\text { Case }\end{array}$ & $\begin{array}{l}\text { Depth } \\
\text { of } \\
\text { Cranium }\end{array}$ & $\begin{array}{l}\text { Inter- } \\
\text { orbital } \\
\text { Breadth }\end{array}$ & $\begin{array}{l}\text { Breadth } \\
\text { of } \\
\text { Rostrum }\end{array}$ & $\begin{array}{l}\text { Length } \\
\text { of } \\
\text { Rostrum }\end{array}$ & $\begin{array}{l}\text { Length } \\
\text { of } \\
\text { Palate }\end{array}$ & $\begin{array}{l}\text { Length } \\
\text { of } \\
\text { Molar } \\
\text { Row }\end{array}$ & $\begin{array}{l}\text { Length } \\
\text { of } \\
\text { Incisive } \\
\text { Foramen }\end{array}$ & $\begin{array}{l}\text { Breadth } \\
\text { of } \\
\text { Zygo- } \\
\text { matic } \\
\text { Plate }\end{array}$ & $\begin{array}{l}\text { Breadth } \\
\text { of } \\
\text { Mesop- } \\
\text { terygoid } \\
\text { Fossa }\end{array}$ \\
\hline $\begin{array}{l}\text { burti } \\
\text { Costa Rica, } \\
\text { Sonora, 20 }\end{array}$ & $\begin{array}{c}20.2 \\
19.5-21.3\end{array}$ & $\begin{array}{c}10.3 \\
9.8-11.1\end{array}$ & $\begin{array}{c}9.4 \\
8.9-10.0\end{array}$ & $\begin{array}{c}7.6 \\
7.2-8.1\end{array}$ & $\begin{array}{c}3.0 \\
2.8-3.4\end{array}$ & $\begin{array}{c}3.7 \\
3.4-3.8\end{array}$ & $\begin{array}{c}7.1 \\
6.7-7.7\end{array}$ & $\begin{array}{c}3.6 \\
3.4-3.8\end{array}$ & $\begin{array}{c}3.5 \\
3.4-3.8\end{array}$ & $\begin{array}{c}4.4 \\
4.1-4.9\end{array}$ & $\begin{array}{c}2.0 \\
1.8-2.3\end{array}$ & $\begin{array}{c}0.8 \\
0.5-0.9\end{array}$ \\
\hline $\begin{array}{l}\text { montanus } \\
\text { montanus } \\
\text { Western Texas } \\
\text { and New Mexico, } 6\end{array}$ & $\begin{array}{c}19.6 \\
19.1-20.1\end{array}$ & $\begin{array}{l}10.1 \\
9.9-10.4\end{array}$ & $\begin{array}{c}9.0 \\
8.6-9.2\end{array}$ & $\begin{array}{c}7.5 \\
7.2-7.7\end{array}$ & $\begin{array}{c}2.8 \\
2.7-3.0\end{array}$ & $\begin{array}{c}3.7 \\
3.5-3.9\end{array}$ & $\begin{array}{c}6.6 \\
6.2-6.9\end{array}$ & $\begin{array}{c}3.6 \\
3.4-3.9\end{array}$ & $\begin{array}{c}3.3 \\
3.2-3.5\end{array}$ & $\begin{array}{c}4.0 \\
3.9-4.1\end{array}$ & $\begin{array}{c}2.0 \\
1.8-2.2\end{array}$ & $\begin{array}{c}0.7 \\
0.4-0.9\end{array}$ \\
\hline $\begin{array}{l}\text { megalotis } \\
\text { megalotis } \\
\text { Western Texas, } 15\end{array}$ & $\begin{array}{c}20.5 \\
19.6-21.2\end{array}$ & $\begin{array}{c}10.4 \\
10.0-11.0\end{array}$ & $\begin{array}{c}9.9 \\
9.5-10.3\end{array}$ & $\begin{array}{c}7.8 \\
7.3-8.3\end{array}$ & $\begin{array}{c}3.0 \\
2.9-3.2\end{array}$ & $\begin{array}{c}3.7 \\
3.6-4.0\end{array}$ & $\begin{array}{c}7.1 \\
6.5-7.5\end{array}$ & $\begin{array}{c}3.4 \\
3.2-3.7\end{array}$ & $\begin{array}{l}3.3 \\
3.2-3.5\end{array}$ & $\begin{array}{c}4.3 \\
4.1-4.8\end{array}$ & $\begin{array}{c}1.9 \\
1.8-2.1\end{array}$ & $\begin{array}{c}0.9 \\
0.8-1.1\end{array}$ \\
\hline $\begin{array}{l}\text { saturatus } \\
\text { Las Vigas, } \\
\text { Veracruz, } 15\end{array}$ & $\begin{array}{c}21.5 \\
20.4-22.9\end{array}$ & $\begin{array}{c}10.8 \\
10.3-11.4\end{array}$ & $\begin{array}{l}10.2 \\
9.7-10.7\end{array}$ & $\begin{array}{l}8.3 \\
8.1-8.6\end{array}$ & $\begin{array}{c}3.1 \\
3.0-3.3\end{array}$ & $\begin{array}{c}3.8 \\
3.7-4.0\end{array}$ & $\begin{array}{c}7.6 \\
7.0-8.3\end{array}$ & $\begin{array}{c}3.3 \\
3.1-3.6\end{array}$ & $\begin{array}{l}3.4 \\
3.2-3.6\end{array}$ & $\begin{array}{c}4.8 \\
4.4-5.1\end{array}$ & $\begin{array}{c}2.0 \\
1.9-2.2\end{array}$ & $\begin{array}{c}1.0 \\
0.8-1.2\end{array}$ \\
\hline $\begin{array}{l}\text { alticolus } \\
\text { Southern } \\
\text { Oaxaca, } 11\end{array}$ & $\begin{array}{c}21.3 \\
20.0-22.5\end{array}$ & $\begin{array}{c}10.5 \\
10.1-10.8\end{array}$ & $\begin{array}{c}9.7 \\
9.0-10.1\end{array}$ & $\begin{array}{c}8.1 \\
7.7-8.9\end{array}$ & $\begin{array}{l}3.0 \\
2.8-3.2\end{array}$ & $\begin{array}{l}3.8 \\
3.5-4.1\end{array}$ & $\begin{array}{c}7.5 \\
7.0-8.2\end{array}$ & $\begin{array}{l}3.3 \\
2.9-3.5\end{array}$ & $\begin{array}{l}3.3 \\
3.0-3.4\end{array}$ & $\begin{array}{c}4.7 \\
4.3-4.9\end{array}$ & $\begin{array}{l}2.0 \\
1.8-2.1\end{array}$ & $\begin{array}{l}1.0 \\
0.7-1.1\end{array}$ \\
\hline $\begin{array}{l}\text { zacatecae } \\
\text { Valparaíso Mts. } \\
\text { Zacatecas, } 7\end{array}$ & $\begin{array}{c}20.3 \\
20.0-20.6\end{array}$ & $\begin{array}{c}10.4 \\
10.1-10.7\end{array}$ & $\begin{array}{l}9.8 \\
9.7-10.0\end{array}$ & $\begin{array}{l}7.7 \\
7.6-7.9\end{array}$ & $\begin{array}{l}2.9 \\
2.7-3.1\end{array}$ & $\begin{array}{l}3.7 \\
3.5-3.8\end{array}$ & $\begin{array}{c}7.1 \\
6.9-7.5\end{array}$ & $\begin{array}{l}3.1 \\
3.0-3.3\end{array}$ & $\begin{array}{l}3.2 \\
3.1-3.5\end{array}$ & $\begin{array}{l}4.4 \\
4.2-4.7\end{array}$ & $\begin{array}{l}1.8 \\
1.7-1.8\end{array}$ & $\begin{array}{c}0.9 \\
0.8-1.0\end{array}$ \\
\hline $\begin{array}{l}\text { amoles } \\
\text { Amoles, Querétaro, } 3\end{array}$ & $\begin{array}{c}20.2 \\
19.9-20.5\end{array}$ & $\begin{array}{c}10.0 \\
9.6-10.3\end{array}$ & $\begin{array}{c}9.5 \\
9.4-9.6\end{array}$ & $\begin{array}{l}7.7 \\
\ldots\end{array}$ & $\begin{array}{l}3.0 \\
2.9-3.1\end{array}$ & $\begin{array}{l}3.7 \\
3.5-3.9\end{array}$ & $\begin{array}{c}7.0 \\
6.6-7.4\end{array}$ & $\begin{array}{c}3.2 \\
3.1-3.3\end{array}$ & $\begin{array}{c}3.0 \\
2.9-3.2\end{array}$ & $\begin{array}{l}4.3 \\
4.2-4.5\end{array}$ & $\begin{array}{l}1.7 \\
1.6-1.8\end{array}$ & $\begin{array}{c}1.1 \\
1.0-1.1\end{array}$ \\
\hline $\begin{array}{l}\text { sumichrasti } \\
\text { sumichrasti } \\
\text { Teziutlán, } \\
\text { Puebla, } 20\end{array}$ & $\begin{array}{c}22.7 \\
22.1-23.9\end{array}$ & $\begin{array}{c}11.4 \\
11.1-12.0\end{array}$ & $\begin{array}{c}10.7 \\
10.4-11.2\end{array}$ & $\begin{array}{c}8.7 \\
8.3-8.9\end{array}$ & $\begin{array}{c}3.2 \\
3.1-3.3\end{array}$ & $\begin{array}{c}3.9 \\
3.8-4.1\end{array}$ & $\begin{array}{c}8.1 \\
7.7-8.7\end{array}$ & $\begin{array}{c}3.6 \\
3.5-3.9\end{array}$ & $\begin{array}{c}3.6 \\
3.4-3.7\end{array}$ & $\begin{array}{c}4.9 \\
4.6-5.2\end{array}$ & $\begin{array}{c}2.0 \\
1.7-2.2\end{array}$ & $\begin{array}{l}1.2 \\
1.1-1.5\end{array}$ \\
\hline
\end{tabular}




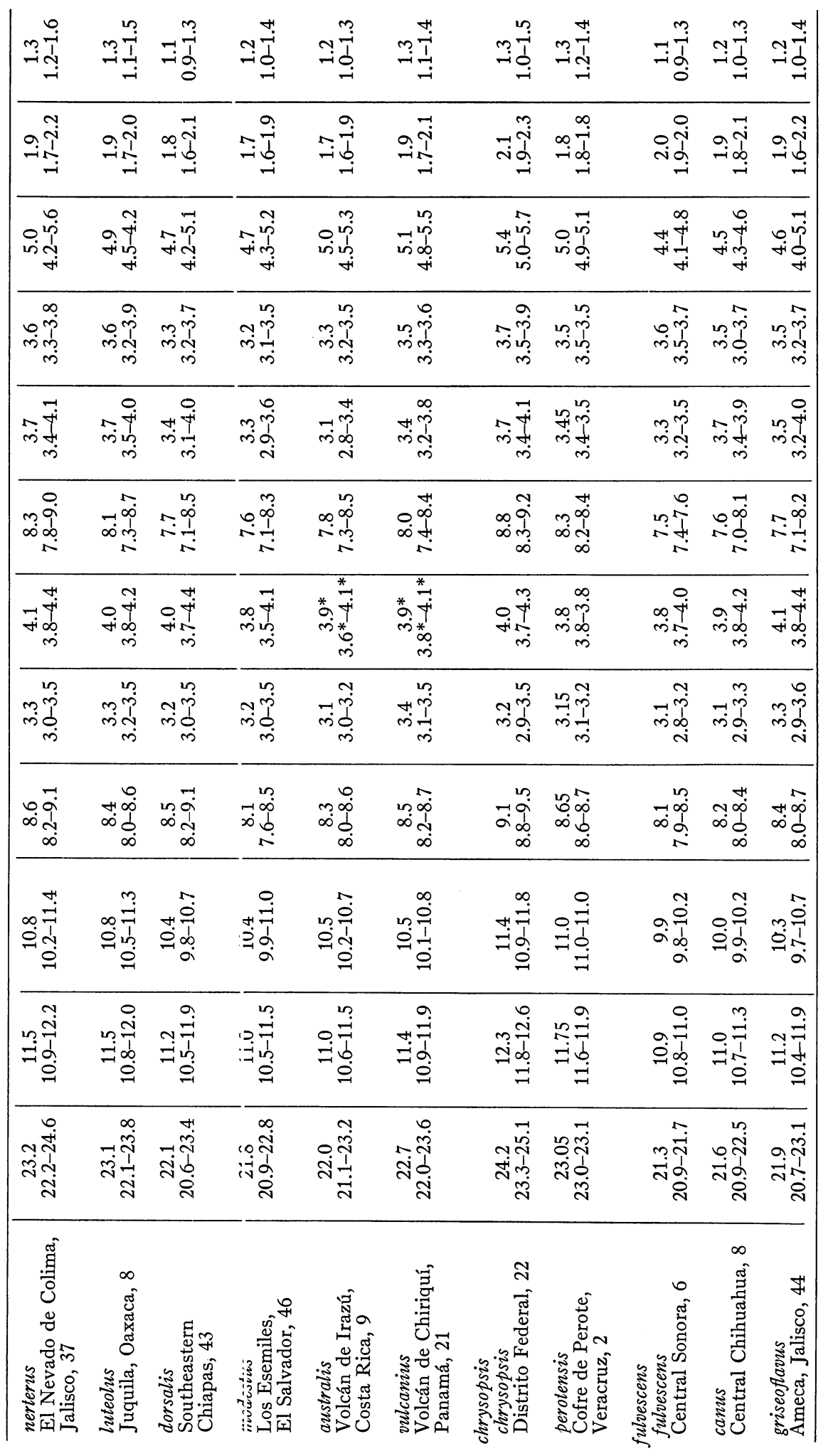


TABLE VII (Cont.)

\begin{tabular}{|c|c|c|c|c|c|c|c|c|c|c|c|c|}
\hline $\begin{array}{l}\text { Species, } \\
\text { Locality, } \\
\text { and } \\
\text { Number of } \\
\text { Specimens }\end{array}$ & $\begin{array}{l}\text { Length } \\
\text { of } \\
\text { Skull }\end{array}$ & $\begin{array}{c}\text { Zygo- } \\
\text { matic } \\
\text { Breadth }\end{array}$ & $\begin{array}{l}\text { Breadth } \\
\text { of } \\
\text { Brain } \\
\text { Case }\end{array}$ & $\begin{array}{l}\text { Depth } \\
\text { of } \\
\text { Cranium }\end{array}$ & $\begin{array}{l}\text { Inter- } \\
\text { orbital } \\
\text { Breadth }\end{array}$ & $\begin{array}{l}\text { Breadth } \\
\text { of } \\
\text { Rostrum }\end{array}$ & $\begin{array}{l}\text { Length } \\
\text { of } \\
\text { Rostrum }\end{array}$ & $\begin{array}{l}\text { Length } \\
\text { of } \\
\text { Palate }\end{array}$ & $\begin{array}{l}\text { Length } \\
\text { of } \\
\text { Molar } \\
\text { Row }\end{array}$ & $\begin{array}{l}\text { Length } \\
\text { of } \\
\text { Incisive } \\
\text { Foramen }\end{array}$ & $\begin{array}{c}\text { Breadth } \\
\text { of } \\
\text { Zygo- } \\
\text { matic } \\
\text { Plate }\end{array}$ & $\begin{array}{l}\text { Breadth } \\
\text { of } \\
\text { Mesop- } \\
\text { terygoid } \\
\text { Fossa }\end{array}$ \\
\hline $\begin{array}{l}\text { toltecus } \\
\text { Distrito Federal, } 5\end{array}$ & $\begin{array}{c}23.1 \\
22.0-23.6\end{array}$ & $\begin{array}{c}11.3 \\
11.0-11.9\end{array}$ & $\begin{array}{c}10.5 \\
10.3-10.8\end{array}$ & $\begin{array}{c}8.7 \\
8.5-8.9\end{array}$ & $\begin{array}{l}3.2 \\
3.1-3.2\end{array}$ & $\begin{array}{c}4.1 \\
3.9-4.4\end{array}$ & $\begin{array}{c}8.2 \\
7.7-8.4\end{array}$ & $\begin{array}{l}3.6 \\
3.4-3.7\end{array}$ & $\begin{array}{l}3.7 \\
3.5-3.9\end{array}$ & $\begin{array}{c}5.0 \\
4.8-5.0\end{array}$ & $\begin{array}{l}1.9 \\
1.8-2.0\end{array}$ & $\begin{array}{l}1.2 \\
1.1-1.4\end{array}$ \\
\hline $\begin{array}{l}\text { aurantius } \\
\text { Baton Rouge, } \\
\text { Louisiana, 23 }\end{array}$ & $\begin{array}{c}21.8 \\
20.4-23.0\end{array}$ & $\begin{array}{c}11.1 \\
10.7-11.4\end{array}$ & $\begin{array}{c}10.2 \\
9.8-10.6\end{array}$ & $\begin{array}{c}8.5 \\
7.9-8.9\end{array}$ & $\begin{array}{c}3.2 \\
2.9-3.4\end{array}$ & $\begin{array}{c}4.0 \\
3.8-4.3\end{array}$ & $\begin{array}{c}7.7 \\
6.8-8.5\end{array}$ & $\begin{array}{l}3.5 \\
3.3-3.8\end{array}$ & $\begin{array}{l}3.4 \\
3.2-3.5\end{array}$ & $\begin{array}{l}4.4 \\
4.0-4.9\end{array}$ & $\begin{array}{c}2.0 \\
1.8-2.2\end{array}$ & $\begin{array}{c}1.3 \\
1.0-1.4\end{array}$ \\
\hline $\begin{array}{l}\text { intermedius } \\
\text { Southern Texas, } 12\end{array}$ & $\begin{array}{c}21.3 \\
20.8-21.9\end{array}$ & $\begin{array}{c}10.8 \\
10.6-11.2\end{array}$ & $\begin{array}{c}10.1 \\
9.9-10.5\end{array}$ & $\begin{array}{c}8.4 \\
8.1-8.7\end{array}$ & $\begin{array}{l}3.2 \\
3.0-3.4\end{array}$ & $\begin{array}{l}3.9 \\
3.6-4.2\end{array}$ & $\begin{array}{c}7.4 \\
7.0-7.7\end{array}$ & $\begin{array}{l}3.4 \\
3.1-3.6\end{array}$ & $\begin{array}{l}3.3 \\
3.1-3.5\end{array}$ & $\begin{array}{l}4.3 \\
4.0-4.6\end{array}$ & $\stackrel{1.8}{1.6-2.1}$ & $\stackrel{1.1}{1.0-1.3}$ \\
\hline $\begin{array}{l}\text { tropicalis } \\
\text { Southeastern } \\
\text { Veracruz, } 7\end{array}$ & $\begin{array}{l}21.1 \\
20.7-21.6\end{array}$ & $\begin{array}{c}10.6 \\
10.3-10.9\end{array}$ & $\begin{array}{l}9.8 \\
9.3-10.2\end{array}$ & $\begin{array}{c}8.1 \\
7.8-8.3\end{array}$ & $\begin{array}{c}3.1 \\
3.0-3.3\end{array}$ & $\begin{array}{c}3.9 \\
3.8-4.0\end{array}$ & $\begin{array}{c}7.3 \\
7.1-7.6\end{array}$ & $\begin{array}{l}3.2 \\
3.1-3.5\end{array}$ & $\begin{array}{c}3.2 \\
3.0-3.3\end{array}$ & $\begin{array}{c}4.3 \\
4.1-4.4\end{array}$ & $\begin{array}{l}1.8 \\
1.7-1.9\end{array}$ & $1.0-1.3$ \\
\hline $\begin{array}{l}\text { difficilis } \\
\text { Huauchinango, } \\
\text { Puebla, } 29\end{array}$ & $\begin{array}{c}21.9 \\
20.4-22.8\end{array}$ & $\begin{array}{c}11.0 \\
10.3-11.8\end{array}$ & $\begin{array}{c}10.4 \\
10.0-11.6\end{array}$ & $\begin{array}{c}8.3 \\
7.8-9.0\end{array}$ & $\begin{array}{l}3.2 \\
2.9-3.4\end{array}$ & $\begin{array}{l}4.0 \\
3.7-4.3\end{array}$ & $\begin{array}{c}7.8 \\
7.2-8.2\end{array}$ & $\begin{array}{c}3.3 \\
2.9-3.5\end{array}$ & $\begin{array}{l}3.2 \\
2.9-3.4\end{array}$ & $\begin{array}{l}4.5 \\
4.2-4.8\end{array}$ & $1.6-1.9$ & $\begin{array}{l}1.3 \\
1.1-1.4\end{array}$ \\
\hline $\begin{array}{l}\text { tenuis } \\
\text { Southwestern } \\
\text { Sinaloa, } 7\end{array}$ & $\begin{array}{c}21.1 \\
20.2-22.2\end{array}$ & $\begin{array}{c}10.7 \\
10.1-11.0\end{array}$ & $\begin{array}{l}9.9 \\
9.7-10.2\end{array}$ & $\begin{array}{c}8.1 \\
7.9-8.3\end{array}$ & $\begin{array}{l}3.1 \\
3.0-3.2\end{array}$ & $\begin{array}{l}3.9 \\
3.6-4.1\end{array}$ & $\begin{array}{c}7.3 \\
6.8-7.5\end{array}$ & $\begin{array}{c}3.3 \\
3.1-3.5\end{array}$ & $\begin{array}{l}3.4 \\
3.2-3.5\end{array}$ & $\begin{array}{c}4.4 \\
4.1-4.6\end{array}$ & $\begin{array}{l}2.0 \\
1.6-2.1\end{array}$ & $\begin{array}{l}1.3 \\
1.0-1.4\end{array}$ \\
\hline $\begin{array}{l}\text { nelsoni } \\
\text { Resolana, Jalisco, } 32\end{array}$ & $\begin{array}{c}20.8 \\
19.3-21.9\end{array}$ & $\begin{array}{l}10.6 \\
9.9-11.2\end{array}$ & $\begin{array}{l}9.9 \\
9.5-10.2\end{array}$ & $\begin{array}{c}8.2 \\
7.8-8.5\end{array}$ & $\begin{array}{l}3.1 \\
2.8-3.4\end{array}$ & $\begin{array}{l}3.9 \\
3.6-4.3\end{array}$ & $\begin{array}{l}7.2 \\
6.5-7.8\end{array}$ & $\begin{array}{l}3.3 \\
2.8-3.7\end{array}$ & $\begin{array}{l}3.3 \\
3.1-3.5\end{array}$ & $\begin{array}{l}4.4 \\
3.9-4.9\end{array}$ & $\stackrel{1.7}{1.5-1.9}$ & $\begin{array}{c}1.2 \\
1.0-1.3\end{array}$ \\
\hline $\begin{array}{l}\text { mustelinus } \\
\text { Chilpancingo, } \\
\text { Guerrero, 17 }\end{array}$ & $\begin{array}{c}22.4 \\
21.1-23.3\end{array}$ & $\begin{array}{c}11.2 \\
10.5-12.2\end{array}$ & $\begin{array}{c}10.6 \\
10.0-11.1\end{array}$ & $\begin{array}{l}8.6 \\
8.4-9.0\end{array}$ & $\begin{array}{l}3.3 \\
3.1-3.5\end{array}$ & $\begin{array}{l}4.1 \\
3.8-4.4\end{array}$ & $\begin{array}{l}7.8 \\
7.1-8.2\end{array}$ & $\begin{array}{l}3.7 \\
3.3-4.1\end{array}$ & $\begin{array}{l}3.5 \\
3.2-3.7\end{array}$ & $\begin{array}{c}4.5 \\
4.1-4.8\end{array}$ & $\begin{array}{l}1.9 \\
1.6-2.1\end{array}$ & $\begin{array}{l}1.3 \\
1.1-1.5\end{array}$ \\
\hline $\begin{array}{l}\text { infernatis } \\
\text { Teotitlán, Oaxaca, } 5\end{array}$ & $\begin{array}{c}21.3 \\
20.9-22.1\end{array}$ & $\begin{array}{c}10.6 \\
10.5-10.7\end{array}$ & $\begin{array}{l}10.2 \\
9.9-10.5\end{array}$ & $\begin{array}{c}8.4 \\
8.0-8.7\end{array}$ & $\begin{array}{c}3.1 \\
3.0-3.2\end{array}$ & $\begin{array}{l}3.8 \\
3.7-4.0\end{array}$ & $\begin{array}{c}7.3 \\
7.2-7.8\end{array}$ & $\begin{array}{c}3.6 \\
3.4-3.7\end{array}$ & $\begin{array}{l}3.3 \\
3.1-3.5\end{array}$ & $\begin{array}{c}4.3 \\
4.1-4.6\end{array}$ & $\begin{array}{l}1.7 \\
1.5-1.8\end{array}$ & $1.1-1.2$ \\
\hline
\end{tabular}




\begin{tabular}{|c|c|c|c|c|c|c|c|c|c|c|c|c|}
\hline $\begin{array}{l}\text { helvolus } \\
\text { Oaxaca, Oaxaca, } 9\end{array}$ & $\begin{array}{c}22.3 \\
21.4-22.9\end{array}$ & $\begin{array}{c}11.2 \\
10.9-11.7\end{array}$ & $\begin{array}{c}10.4 \\
10.1-10.5\end{array}$ & $\begin{array}{c}8.6 \\
8.3-8.8\end{array}$ & $\begin{array}{l}3.4 \\
3.2-3.5\end{array}$ & $\begin{array}{c}4.1 \\
3.8-4.2\end{array}$ & $\begin{array}{c}7.9 \\
7.5-8.2\end{array}$ & $\begin{array}{l}3.6 \\
3.3-3.9\end{array}$ & $\begin{array}{l}3.5 \\
3.4-3.7\end{array}$ & $\begin{array}{c}4.6 \\
4.4-4.9\end{array}$ & $\begin{array}{l}2.0 \\
1.9-2.2\end{array}$ & $\begin{array}{l}1.3 \\
1.2-1.5\end{array}$ \\
\hline amoenus & 19.6 & ..... & $\ldots \ldots$ & $\ldots \ldots$ & $\ldots$ & 4.0 & 6.8 & 3.0 & 3.2 & 4.4 & 1.6 & 1.3 \\
\hline Reforma, Oaxaca, 2 & $\ldots$ & $\cdots$ & $\cdots \cdots$ & $\cdots \cdots$ & $\cdots$ & $\ldots$ & $\cdots$ & $\cdots$ & $\cdots$ & $\cdots$ & $\cdots$ & $\cdots$ \\
\hline $\begin{array}{l}\text { chiapensis } \\
\text { Central Chiapas, } 7\end{array}$ & $\begin{array}{c}21.8 \\
20.7-22.9\end{array}$ & $\begin{array}{c}11.0 \\
10.5-11.7\end{array}$ & $\begin{array}{l}10.1 \\
9.8-10.6\end{array}$ & $\begin{array}{c}8.2 \\
8.0-8.5\end{array}$ & $\begin{array}{l}3.3 \\
3.1-3.5\end{array}$ & $\begin{array}{c}4.1 \\
4.0-4.3\end{array}$ & $\begin{array}{l}7.5 \\
6.9-7.8\end{array}$ & $\begin{array}{l}3.4 \\
3.3-3.6\end{array}$ & $\begin{array}{l}3.3 \\
3.2-3.4\end{array}$ & $\begin{array}{c}4.5 \\
4.2-4.7\end{array}$ & $\begin{array}{l}1.9 \\
1.9-2.0\end{array}$ & $\begin{array}{c}1.3 \\
1.0-1.6\end{array}$ \\
\hline $\begin{array}{l}\text { hirsulus } \\
\text { Santa Isabel, } \\
\text { NTaynrit, 12 }\end{array}$ & $\begin{array}{c}23.8 \\
22.9-24.6\end{array}$ & $\begin{array}{c}12.4 \\
12.0-12.8\end{array}$ & $\begin{array}{c}11.1 \\
10.4-11.5\end{array}$ & $\begin{array}{c}9.0 \\
8.7-9.5\end{array}$ & $\begin{array}{l}3.6 \\
3.1-3.8\end{array}$ & $\begin{array}{c}4.5 \\
4.2-4.8\end{array}$ & $\begin{array}{c}8.3 \\
7.7-8.7\end{array}$ & $\begin{array}{l}3.8 \\
3.4-4.5\end{array}$ & $\begin{array}{l}3.7 \\
3.5-3.8\end{array}$ & $\begin{array}{c}4.8 \\
4.3-5.3\end{array}$ & $\begin{array}{l}1.8 \\
1.6-2.0\end{array}$ & $\begin{array}{c}1.6 \\
1.4-1.8\end{array}$ \\
\hline $\begin{array}{l}\text { gracilis } \\
\text { gracilis } \\
\text { Yucatan Peninsula, } 3\end{array}$ & $\begin{array}{c}21.8 \\
21.4-22.2\end{array}$ & $\begin{array}{c}10.6 \\
10.0-11.2\end{array}$ & $\begin{array}{c}10.6 \\
10.5-10.6\end{array}$ & $\begin{array}{c}8.4 \\
8.2-8.5\end{array}$ & $\begin{array}{l}3.5 \\
3.4-3.6\end{array}$ & $\begin{array}{c}4.1 \\
3.9-4.3\end{array}$ & $\begin{array}{c}7.6 \\
7.1-8.2\end{array}$ & $\begin{array}{l}3.5 \\
3.2-3.7\end{array}$ & $\begin{array}{l}3.3 \\
3.2-3.4\end{array}$ & $\begin{array}{l}3.9 \\
3.8-4.0\end{array}$ & $\begin{array}{l}1.7 \\
1.5-1.8\end{array}$ & $\begin{array}{c}1.4 \\
1.4-1.5\end{array}$ \\
\hline $\begin{array}{l}\text { anthonyi } \\
\text { Sacapulas, } \\
\text { Guatemala, } 1\end{array}$ & $\begin{array}{l}22.7 \\
\ldots \ldots\end{array}$ & $\begin{array}{l}11.8 \\
\cdots\end{array}$ & $\begin{array}{l}11.4 \\
\cdots\end{array}$ & $\begin{array}{c}9.0 \\
\cdots\end{array}$ & $\begin{array}{l}3.9 \\
\ldots\end{array}$ & $\begin{array}{l}4.2 \\
\cdots\end{array}$ & $\begin{array}{l}7.7 \\
\cdots\end{array}$ & $\begin{array}{l}4.0 \\
\cdots\end{array}$ & $\begin{array}{l}3.4 \\
\cdots\end{array}$ & $\begin{array}{l}3.8 \\
\cdots\end{array}$ & $\begin{array}{l}1.7 \\
\cdots\end{array}$ & $\begin{array}{l}1.3 \\
\cdots\end{array}$ \\
\hline $\begin{array}{l}\text { pacificus } \\
\text { Ciprés, Guatemala, } 9\end{array}$ & $\begin{array}{c}21.7 \\
21.2-22.0\end{array}$ & $\begin{array}{c}11.2 \\
10.8-11.7\end{array}$ & $\begin{array}{c}10.4 \\
10.2-10.6\end{array}$ & $\begin{array}{c}8.2 \\
7.9-8.4\end{array}$ & $\begin{array}{l}3.6 \\
3.4-3.7\end{array}$ & $\begin{array}{c}4.1 \\
3.8-4.4\end{array}$ & $\begin{array}{c}7.2 \\
7.0-7.4\end{array}$ & $\begin{array}{c}3.3 \\
3.0-3.6\end{array}$ & $\begin{array}{l}3.0 \\
2.8-3.1\end{array}$ & $\begin{array}{l}4.0 \\
3.6-4.2\end{array}$ & $\begin{array}{ll}1.6 \\
15-1.7\end{array}$ & $\stackrel{1.6}{1.3-1.8}$ \\
\hline $\begin{array}{l}\text { harrisi } \\
\text { Santa María, } \\
\text { Costa Rica, } 1\end{array}$ & $\begin{array}{l}22.1 \\
\ldots \ldots\end{array}$ & $\ldots$ & $\begin{array}{l}10.5 \\
\cdots\end{array}$ & $\begin{array}{c}8.4 \\
\cdots\end{array}$ & $\begin{array}{l}3.6 \\
\cdots\end{array}$ & $\begin{array}{l}4.3 \\
\cdots\end{array}$ & $\begin{array}{l}7.6 \\
\cdots\end{array}$ & $\begin{array}{l}3.9 \\
\cdots\end{array}$ & $\begin{array}{l}3.2 \\
\cdots\end{array}$ & $\begin{array}{l}3.7 \\
\cdots\end{array}$ & $\begin{array}{l}1.8 \\
\cdots\end{array}$ & $\begin{array}{l}1.6 \\
\cdots\end{array}$ \\
\hline $\begin{array}{l}\text { darienensis } \\
\text { Cana, Panamá, } 6\end{array}$ & $\begin{array}{c}20.4 \\
20.0-20.7\end{array}$ & $\begin{array}{c}10.7 \\
10.5-10.9\end{array}$ & $\begin{array}{c}10.6 \\
10.2-10.9\end{array}$ & $\begin{array}{c}8.1 \\
7.9-8.4\end{array}$ & $\begin{array}{l}3.5 \\
3.3-3.6\end{array}$ & $\begin{array}{l}3.8 \\
3.6-4.1\end{array}$ & $\begin{array}{l}6.7 \\
6.4-6.8\end{array}$ & $\begin{array}{l}3.5 \\
3.5-3.6\end{array}$ & $\begin{array}{l}3.0 \\
2.9-3.0\end{array}$ & $\begin{array}{l}3.6 \\
3.4-3.7\end{array}$ & $\begin{array}{l}1.3 \\
1.2-1.4\end{array}$ & $\begin{array}{l}1.5 \\
1.3-1.7\end{array}$ \\
\hline $\begin{array}{l}\text { mexicanus } \\
\text { mexicanus } \\
\text { Puebla and } \\
\text { Veracruz, } 8\end{array}$ & $\begin{array}{c}23.2 \\
22.8-23.9\end{array}$ & $\begin{array}{c}12.3 \\
11.8-12.8\end{array}$ & $\begin{array}{c}11.2 \\
10.8-11.6\end{array}$ & $\begin{array}{c}8.7 \\
8.4-8.9\end{array}$ & $\begin{array}{c}3.8 \\
3.6-3.9\end{array}$ & $\begin{array}{c}4.2 \\
3.9-4.4\end{array}$ & $\begin{array}{c}8.0 \\
7.1-8.3\end{array}$ & $\begin{array}{l}3.8 \\
3.5-4.1\end{array}$ & $\begin{array}{c}3.5 \\
3.4-3.6\end{array}$ & $\begin{array}{c}4.7 \\
4.4-4.9\end{array}$ & $\begin{array}{l}1.7 \\
1.6-1.8\end{array}$ & $\begin{array}{l}1.6 \\
1.4-1.7\end{array}$ \\
\hline $\begin{array}{l}\text { scansor } \\
\text { Western Chiapas, } 6\end{array}$ & $\begin{array}{c}22.7 \\
21.5-23.7\end{array}$ & $\begin{array}{c}11.8 \\
11.4-12.3\end{array}$ & $\begin{array}{c}11.1 \\
10.8-11.3\end{array}$ & $\begin{array}{c}8.7 \\
8.4-9.0\end{array}$ & $\begin{array}{c}3.5 \\
3.4-3.7\end{array}$ & $\begin{array}{c}4.2 \\
4.0-4.5\end{array}$ & $\begin{array}{c}7.6 \\
7.4-8.2\end{array}$ & $\begin{array}{l}3.8 \\
3.5-4.2\end{array}$ & $\begin{array}{c}3.3 \\
3.1-3.4\end{array}$ & $\begin{array}{l}4.1 \\
3.9-4.2\end{array}$ & $\begin{array}{l}1.5 \\
1.4-1.7\end{array}$ & $\begin{array}{l}1.5 \\
1.4-1.6\end{array}$ \\
\hline
\end{tabular}


TABLE VII (Cont.)

\begin{tabular}{|c|c|c|c|c|c|c|c|c|c|c|c|c|}
\hline $\begin{array}{l}\text { Species, } \\
\text { Locality, } \\
\text { and } \\
\text { Number of } \\
\text { Specimens }\end{array}$ & $\begin{array}{l}\text { Length } \\
\text { of } \\
\text { Skull }\end{array}$ & $\begin{array}{c}\text { Zygo- } \\
\text { matic } \\
\text { Breadth }\end{array}$ & $\begin{array}{l}\text { Breadth } \\
\text { of } \\
\text { Brain } \\
\text { Case }\end{array}$ & $\begin{array}{l}\text { Depth } \\
\text { of } \\
\text { Cranium }\end{array}$ & $\begin{array}{l}\text { Inter- } \\
\text { orbital } \\
\text { Breadth }\end{array}$ & $\begin{array}{l}\text { Breadth } \\
\text { of } \\
\text { Rostrum }\end{array}$ & $\begin{array}{l}\text { Length } \\
\text { of } \\
\text { Rostrum }\end{array}$ & $\begin{array}{l}\text { Length } \\
\text { of } \\
\text { Palate }\end{array}$ & $\begin{array}{l}\text { Length } \\
\text { of } \\
\text { Molar } \\
\text { Row }\end{array}$ & $\begin{array}{l}\text { Length } \\
\text { of } \\
\text { Incisive } \\
\text { Foramen }\end{array}$ & $\begin{array}{c}\text { Breadth } \\
\text { of } \\
\text { Zygo- } \\
\text { matic } \\
\text { Plate }\end{array}$ & $\begin{array}{l}\text { Breadth } \\
\text { of } \\
\text { Mesop- } \\
\text { terygoid } \\
\text { Fossa }\end{array}$ \\
\hline $\begin{array}{l}\text { howelli } \\
\text { Prusia, Chiapas, } 6\end{array}$ & $\begin{array}{c}22.4 \\
21.8-23.0\end{array}$ & $\begin{array}{c}11.4 \\
10.9-11.6\end{array}$ & $\begin{array}{c}10.7 \\
10.3-11.3\end{array}$ & $\begin{array}{c}8.4 \\
8.2-8.6\end{array}$ & $\begin{array}{c}3.5 \\
3.5-3.7\end{array}$ & $\begin{array}{c}4.2 \\
3.8-4.4\end{array}$ & $\begin{array}{l}7.7 \\
7.5-8.1\end{array}$ & $\begin{array}{l}3.4 \\
3.2-3.6\end{array}$ & $\begin{array}{c}3.2 \\
3.1-3.3\end{array}$ & $\begin{array}{c}4.2 \\
4.0-4.4\end{array}$ & $\begin{array}{l}1.5 \\
1.2-1.6\end{array}$ & $\begin{array}{c}1.6 \\
1.4-1.7\end{array}$ \\
\hline $\begin{array}{l}\text { orinus } \\
\text { Chilata, El Salvador, } 6\end{array}$ & $\begin{array}{c}23.1 \\
22.6-23.4\end{array}$ & $\begin{array}{c}12.0 \\
11.5-12.6\end{array}$ & $\begin{array}{c}11.0 \\
10.7-11.4\end{array}$ & $\begin{array}{c}8.6 \\
8.2-8.9\end{array}$ & $\begin{array}{l}3.6 \\
3.4-3.7\end{array}$ & $\begin{array}{c}4.2 \\
3.9-4.3\end{array}$ & $\begin{array}{c}8.3 \\
8.0-8.8\end{array}$ & $\begin{array}{ll}3.4 \\
3.2-3.5\end{array}$ & $\begin{array}{ll}3.2 \\
3.2-3.3\end{array}$ & $\begin{array}{c}4.3 \\
4.1-4.6\end{array}$ & $\begin{array}{l}1.6 \\
1.4-1.7\end{array}$ & $\begin{array}{c}1.5 \\
1.4-1.8\end{array}$ \\
\hline $\begin{array}{l}\text { ocotepequensis } \\
\text { Monte Verde, } \\
\text { Honduras, } 6\end{array}$ & $\begin{array}{c}22.4 \\
21.9-22.8\end{array}$ & $\begin{array}{c}11.0 \\
10.7-11.4\end{array}$ & $\begin{array}{c}10.6 \\
10.5-10.8\end{array}$ & $\begin{array}{c}8.2 \\
8.1-8.4\end{array}$ & $\begin{array}{ll}3.6 \\
3.4-3.8\end{array}$ & $\begin{array}{l}3.9 \\
3.8-4.0\end{array}$ & $\begin{array}{c}7.9 \\
7.6-8.1\end{array}$ & $\begin{array}{l}3.6 \\
3.4-3.8\end{array}$ & $\begin{array}{l}3.2 \\
3.0-3.3\end{array}$ & $\begin{array}{c}4.4 \\
4.1-4.7\end{array}$ & $\begin{array}{l}1.4 \\
1.3-1.6\end{array}$ & $\begin{array}{l}1.5 \\
1.5-1.6\end{array}$ \\
\hline $\begin{array}{l}\text { lucifrons } \\
\text { Central Honduras, } 14\end{array}$ & $\begin{array}{c}22.9 \\
21.7-23.7\end{array}$ & $\begin{array}{c}11.8 \\
11.3-12.3\end{array}$ & $\begin{array}{c}11.2 \\
11.0-11.4\end{array}$ & $\begin{array}{c}8.8 \\
8.5-9.1\end{array}$ & $\begin{array}{l}3.7 \\
3.5-3.9\end{array}$ & $\begin{array}{c}4.1 \\
3.8-4.3\end{array}$ & $\begin{array}{l}7.6 \\
7.1-8.2\end{array}$ & $\begin{array}{l}3.8 \\
3.6-4.0\end{array}$ & $\begin{array}{l}3.5 \\
3.4-3.7\end{array}$ & $\begin{array}{c}4.2 \\
3.8-4.9\end{array}$ & $\begin{array}{l}1.6 \\
1.5-1.7\end{array}$ & $\begin{array}{l}1.6 \\
1.3-1.7\end{array}$ \\
\hline $\begin{array}{l}\text { cherriei } \\
\text { Central Costa Rica, } 23\end{array}$ & $\begin{array}{c}23.7 \\
22.6-24.5\end{array}$ & $\begin{array}{c}12.1 \\
11.5-12.7\end{array}$ & $\begin{array}{c}11.3 \\
11.0-11.6\end{array}$ & $\begin{array}{c}8.8 \\
8.6-9.2\end{array}$ & $\begin{array}{l}3.6 \\
3.3-3.8\end{array}$ & $\begin{array}{c}4.2 \\
3.9-4.5\end{array}$ & $\begin{array}{c}8.1 \\
7.6-8.5\end{array}$ & $\begin{array}{c}3.9 \\
3.6-4.2\end{array}$ & $\begin{array}{l}3.6 \\
3.3-3.7\end{array}$ & $\begin{array}{l}4.5 \\
4.2-5.0\end{array}$ & $1.6-1.7$ & $1.6-1.8$ \\
\hline $\begin{array}{l}\text { potrerograndei } \\
\text { Cañas Gordas, } \\
\text { Costa Rica, } 3\end{array}$ & $\begin{array}{c}21.8 \\
21.4-22.2\end{array}$ & $\begin{array}{c}10.9 \\
10.7-11.1\end{array}$ & $\begin{array}{c}10.6 \\
10.5-10.7\end{array}$ & $\begin{array}{c}8.6 \\
8.4-8.7\end{array}$ & $\begin{array}{c}3.5 \\
3.4-3.6\end{array}$ & $\begin{array}{c}4.1 \\
4.0-4.2\end{array}$ & $\begin{array}{l}7.4 \\
7.1-7.8\end{array}$ & $\begin{array}{l}3.5 \\
3.5-3.5\end{array}$ & $\begin{array}{c}3.2 \\
3.1-3.3\end{array}$ & $\begin{array}{l}3.9 \\
3.8-4.1\end{array}$ & $1.3-1.4$ & $\begin{array}{l}1.6 \\
1.5-1.7\end{array}$ \\
\hline $\begin{array}{l}\text { garichensis } \\
\text { Bóquete, Panamá, } 4\end{array}$ & $\begin{array}{c}23.2 \\
22.8-23.6\end{array}$ & $\begin{array}{c}11.5 \\
10.9-12.1\end{array}$ & $\begin{array}{c}11.1 \\
10.9-11.4\end{array}$ & $\begin{array}{c}9.0 \\
8.8-9.1\end{array}$ & $\begin{array}{l}3.8 \\
3.6-3.9\end{array}$ & $\begin{array}{c}4.2 \\
4.1-4.3\end{array}$ & $\begin{array}{c}8.2 \\
8.0-8.6\end{array}$ & $\begin{array}{l}3.8 \\
3.6-4.0\end{array}$ & $\begin{array}{l}3.5 \\
3.2-3.6\end{array}$ & $\begin{array}{l}4.4 \\
4.2-4.5\end{array}$ & $1.3-1.5$ & $1.7-1.8$ \\
\hline $\begin{array}{l}\text { milleri } \\
\text { Munchique, } \\
\text { Colombia, } 8\end{array}$ & $\begin{array}{c}22.6 \\
22.4-22.8\end{array}$ & $\begin{array}{c}11.3 \\
11.1-11.4\end{array}$ & $\begin{array}{c}11.0 \\
10.7-11.2\end{array}$ & $\begin{array}{c}8.5 \\
8.2-8.8\end{array}$ & $\begin{array}{l}3.7 \\
3.5-3.9\end{array}$ & $\begin{array}{c}4.2 \\
4.0-4.3\end{array}$ & $\begin{array}{c}7.6 \\
7.5-7.8\end{array}$ & $\begin{array}{l}3.8 \\
3.6-4.1\end{array}$ & $\begin{array}{l}3.2 \\
3.1-3.5\end{array}$ & $\begin{array}{c}4.1 \\
4.0-4.3\end{array}$ & $\begin{array}{l}1.3 \\
1.2-1.4\end{array}$ & $\begin{array}{l}1.6 \\
1.4-1.8\end{array}$ \\
\hline $\begin{array}{l}\text { eremicus } \\
\text { Pimanpiro, } \\
\text { Ecuador, } 6\end{array}$ & $\begin{array}{c}23.5^{*} \\
23.2^{*}-23.8^{*}\end{array}$ & $\begin{array}{c}12.3 \\
10.7-12.9\end{array}$ & $\begin{array}{c}11.3 \\
11.1-11.6\end{array}$ & $\begin{array}{c}9.0 \\
8.7-9.1\end{array}$ & $\begin{array}{c}3.7 \\
3.5-3.8\end{array}$ & $\begin{array}{c}4.3 \\
4.2-4.4\end{array}$ & $\begin{array}{c}8.0 * \\
7.9 *-8.0 *\end{array}$ & $\begin{array}{c}3.7 \\
3.6-3.9\end{array}$ & $\begin{array}{l}3.7 \\
3.5-3.9\end{array}$ & $\begin{array}{c}4.4 \\
4.3-4.5\end{array}$ & $\begin{array}{c}1.8 \\
1.8-1.9\end{array}$ & $\begin{array}{l}1.5 \\
1.4-1.6\end{array}$ \\
\hline $\begin{array}{l}\text { söderströmi } \\
\text { Quito, Ecuador, } 5\end{array}$ & $\begin{array}{c}23.7 \\
23.6-23.8\end{array}$ & $\begin{array}{c}12.1 \\
11.9-12.2\end{array}$ & $\begin{array}{l}11.2 \\
10.9-11.5\end{array}$ & $\begin{array}{l}8.9 \\
8.6-9.1\end{array}$ & $\begin{array}{l}3.6 \\
3.5-3.6\end{array}$ & $\begin{array}{c}4.2 \\
4.1-4.2\end{array}$ & $\begin{array}{c}8.2 \\
8.0-8.4\end{array}$ & $\begin{array}{l}3.9 \\
3.8-3.9\end{array}$ & $\begin{array}{l}3.6 \\
3.4-3.7\end{array}$ & $\begin{array}{c}4.6 \\
4.3-4.7\end{array}$ & $\begin{array}{l}1.7 \\
1.6-1.9\end{array}$ & $\begin{array}{ll}1.5 \\
1.4-1.6\end{array}$ \\
\hline
\end{tabular}




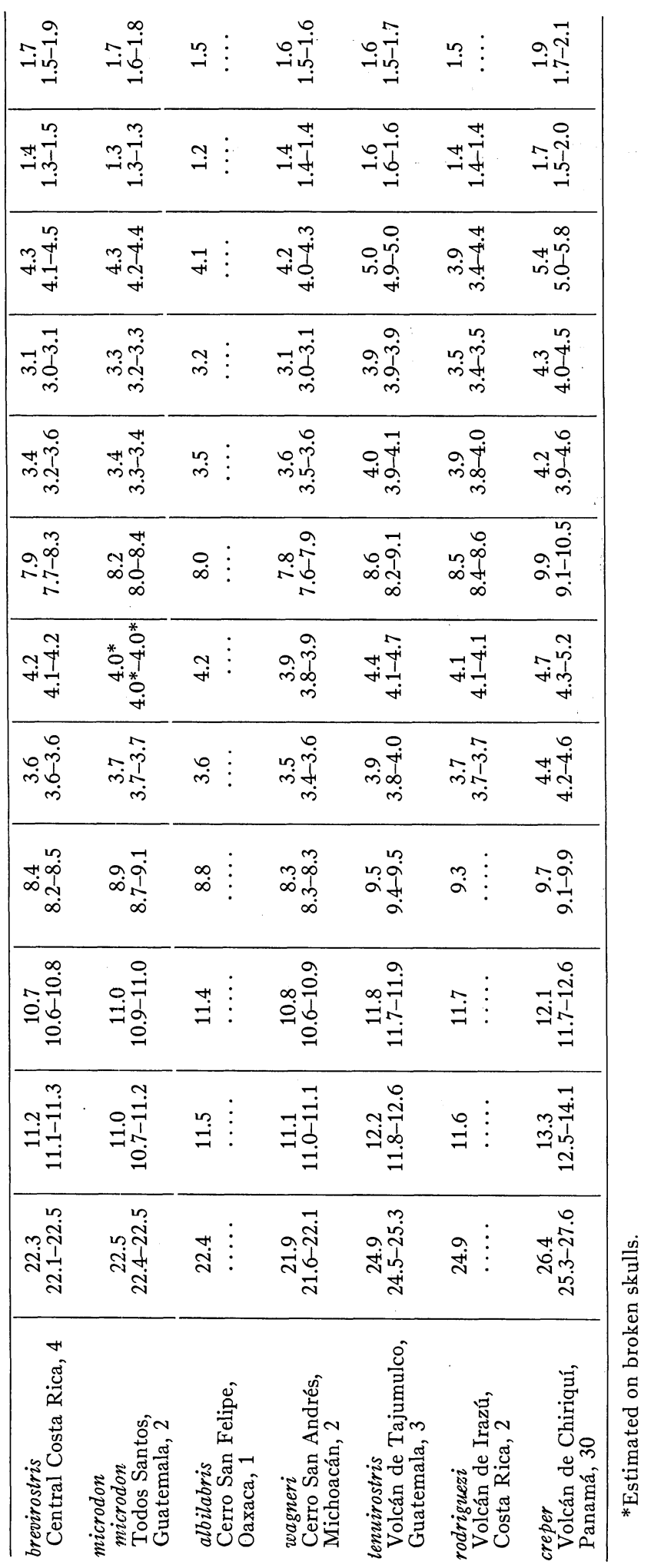



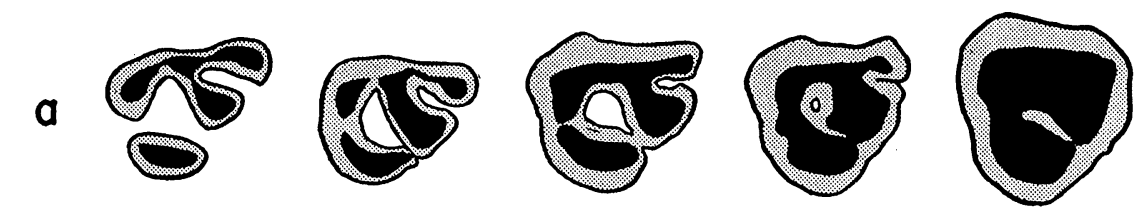

b
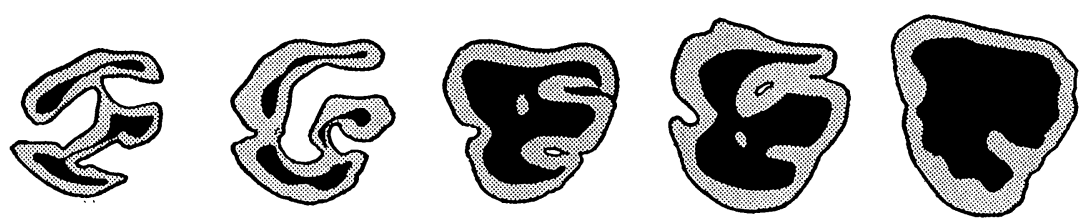

C
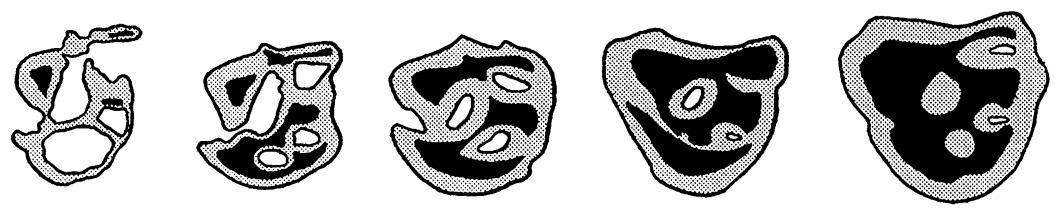

aa
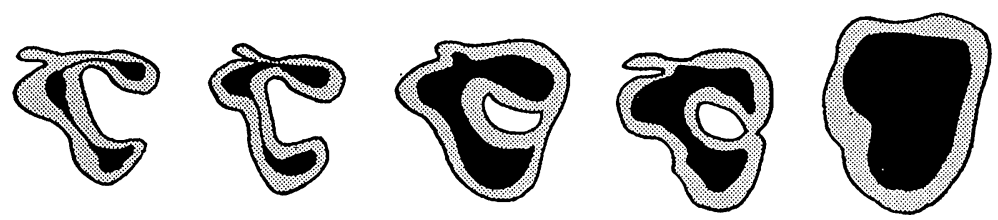

bb
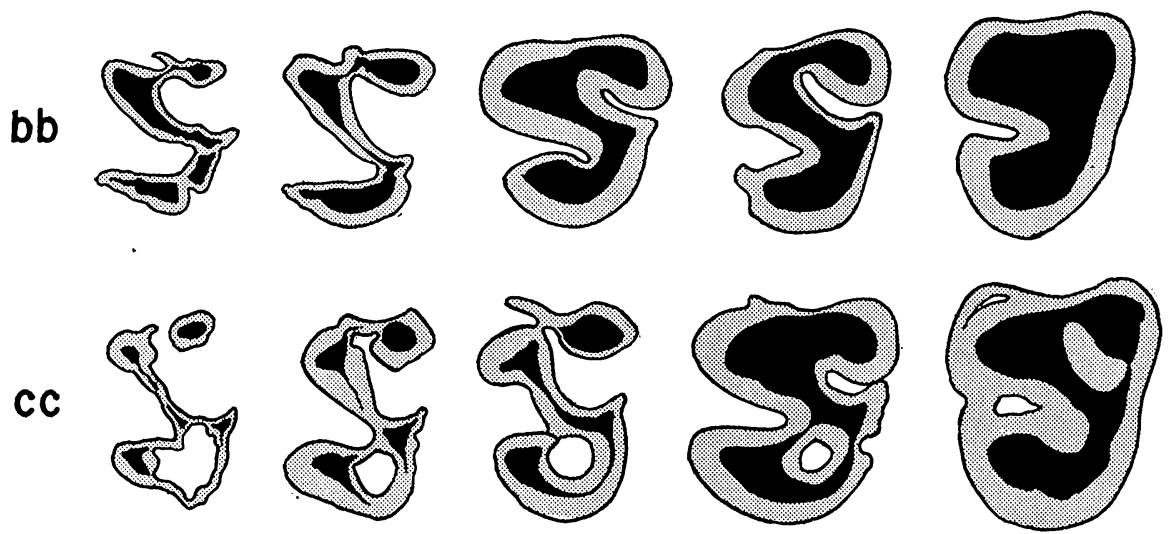

Fic. 24. Variation in the occlusal pattern of the upper $(a-c)$ and lower $(a a-c c)$ third molar teeth of 3 species of Reithrodontomys. (a, aa) R. megalotis saturatus, $10 \mathrm{mi}$. SE Pátzcuaro, Michoacán. $(b, b b) R$. fulvescens griseoflavus, Ameca, Jalisco. $(c, c c) R$. mexicanus orinus, Cerro Cacaguatique, El Salvador. 


\section{CURRENTLY RECCIGNIZED FORMS OF REITHRODONTOMYS NOT REVIE WED IN DETAIL IN THIS REPORT}

\section{Reithrodontomys simplicidens Brown}

Reithrodontomys simplicidens Brown (Mem. Amer. Mus. Nat. Hist., 9: 196, 1908).

Type locality.-Arkansas, Newton Co., $15 \mathrm{mi}$. S Harrison (Boone County), Conard Fissure, Pleistocene deposits.

\section{Reithrodontomys pratincola :Hibbard}

Reithrodontomys pratincola Hibbard (Bull. State Geol. Surv. Kans., 38: 209, 1941).

Type locality.-Kansas, Meade Co., Borchers Ranch (T. 33 S, R. 28 W, sec. 21), Borchers Fauna, Pleistocene deposits.

\section{Reithrodontomys humulis vinginianus Howell}

Reithrodontomys hum גlis virginianus Howell (Journ. Mammalogy, 21: 346, 1940).

Type locality.-Virginia, Annelia Co., Amelia Court House.

Distribution.-Piedmont and Coastal plains of eastern Virginia and southwestern Maryland.

Reithrodontomys humulis humulis Audubon and Bachman

Mus humulis Audubon and Bachman (Proc. Acad. Nat. Sci. Phila., 1: 97, 1841).

?Mus carolinensis Audt bon and Bachman (Journ. Acad. Nat. Sci. Phila., 8: 306, 1842).

Maritime districts of South Carolina.

Mus Le Contii Audubisn and Bachman (Ibid., 8: 307, 1842). Georgia; probably Le Conte's plantation near Riceboro, Liberty Co.

Reithrodontomys humulis dickinsoni Rhoads (Amer. Nat., 29: 589, 1895). Florida, Pasco Co., Willow Jak.

Reithrodontomys lecontii impiger Bangs (Proc. Biol. Soc. Wash., 12: 167, 1898). West Virginia, Greenbrier Co., White Sulphur Springs.

Reithrodontomys humulis humulis, Howell (N. Amer. Fauna, 36: 19, 1914).

Type locality.-South Carolina, Charleston Co., Charleston.

Distribution.-The southeastern United States, from Florida, Alabama, Mississippi, and eastern Louisiana (east of the Mississippi River) north and east to southern Ohio, southern West Virginia, and southwestern Virginia.

Remarks.-The species $R$. humulis is reviewed by Hooper (Occ. Papers Mus. Zool. Univ. Mich., 477, 1943).

Reithrodontomys humulis me:riami Allen

Reithrodontomys merriami Allen (Bull. Amer. Mus. Nat. Hist., 7: 119, 1895).

Reithrodontomys humulis merriami, Howell (N. Amer. Fauna, 36: 21, 1914).

Type locality.-Texas, Brazcria Co., Austin Bayou near Alvin.

Distribution.-Southeastern Texas (east of the Colorado River) and southern Louisiana (west of the Mississippi River).

Reithrodontomys montanus aibescens Cary

Reithrodontomys albescens Cary (Proc. Biol. Soc. Wash., 16: 53, 1903).

Reithrodontomys montınus albescens, Cary (N. Amer. Fauna, 33: 110, 1911).

Type locality.-Nebraska, Clierry Co., $18 \mathrm{mi}$. NW Kennedy. 
Distribution.-South-central South Dakota, central and western Nebraska, eastern Colorado, and western Kansas.

Reithrodontomys montanus griseus Bailey

Reithrodontomys griseus Bailey (N. Amer. Fauna, 25: 106, 1905).

Reithrodontomys albescens griseus, Howell (N. Amer. Fauna, 36: 23, 1914).

Reithrodontomys montanus griseus, Benson (Journ. Mammalogy, 16: 140, 1935).

Type locality.-Texas, Bexar Co., San Antonio.

Distribution.-From southeastern Nebraska south through central and eastern Kansas, Oklahoma (except eastern forested areas), and Texas (east of the Pecos River) at least as far south as San Antonio, Bexar Co.

Reithrodontomys megalotis pectoralis Hanson

Reithrodontomys megalotis pectoralis Hanson (Field Mus. Nat. Hist., Zool. Ser., 29: 205, 1944).

Type locality.-Wisconsin, Columbia Co., Westpoint.

Distribution.-Southwestern Wisconsin and southeastern Minnesota.

Remarks.-The buffy pectoral spot, the principal diagnostic character attributed to pectoralis, is inconstant in several races of megalotis. $R . m$. pectoralis may prove to be inseparable from $R . m$. dychei.

Reithrodontomys megalotis dychei Allen

Reithrodontomys dychei Allen (Bull. Amer. Mus. Nat. Hist., 7: 120, 1895).

Reithrodontomys dychei nebrascensis Allen (Ibid., p. 122). Nebraska, Cherry County, Kennedy.

Reithrodontomys megalotis dychei, Howell (N. Amer. Fauna, 36: 30, 1914).

Type locality.-Kansas, Douglas Co., Lawrence.

Distribution.-The Great Plains of the central United States in the northern half of Kansas, eastern Colorado, the southern half of Montana east of the Rocky Mountains, southern North Dakota, South Dakota, Nebraska, southern Minnesota, Iowa, and Missouri.

Reithrodontomys megalotis caryi Howell

Reithrodontomys megalotis caryi Howell (Journ. Mammalogy, 16: 143, 1935).

Type locality.-Colorado, Alamosa County, 15 mi. NE Mosca, Medano Ranch.

Distribution.-San Luis Valley of Colorado.

Remarks.-From the original description and from my data on variation in $R$. megalotis, I suspect that caryi should be listed as a synonym of $R$. m. aztecus.

Reithrodontomys megalotis aztecus Allen

Reithrodontomys aztecus Allen (Bull. Amer. Mus. Nat. Hist., 5: 79, 1893).

Reithrodontomys megalotis aztecus, Howell (N. Amer. Fauna, 36: 30, 1914).

Type locality.-New Mexico, San Juan Co., La Plata.

Distribution.-Northern New Mexico, southeastern Utah, southern Colorado, and southwestern Kansas.

Remarks.-Allen (Bull. Amer. Mus. Nat. Hist., 7: 125, 1895) and Howell (Journ. Mammalogy, 16: 144, 1935) doubt that aztecus is subspecifically distinct from megalotis. I have examined only 26 specimens, including topotypes, from localities within the range ascribed to aztecus. They average distinctly larger in skull length and in size of brain case than do specimens of megalotis from Chihuahua, Sonora, and southern New Mexico.

Reithrodontomys megalotis arizonensis Allen

Reithrodontomys arizonensis Allen (Bull. Amer. Mus. Nat. Hist., 7: 134, 1895).

Reithrodontomys megalotis arizonensis, Howell (N. Amer. Fauna, 36: 38, 1914). 
Type locality.-Arizona, Co:hise Co., Chiricahua Mountains, Rock Creek, 8000 ft. elevation.

Distribution.-Insofar as knıwn, restricted to upper parts of the Chiricahua Mountains.

Remarks.-I have examined 3 topotypes. Compared with specimens from Pinery Canyon, 5500 feet, in the Chiricahua Mountains and with other specimens from the surrounding lowlands, the topotypes are di.rker, more reddish dorsally, and more buffy ventrally, with a more distinct pectoral spot. 'The teeth are smaller (length of row 3.1-3.2 mm.) and the zygomatic notch is shorter an eroposteriorly. The specimens, therefore, are separable from specimens considered to be typical of megalotis, and provide the basis for the recognition of arizonensis. The sample is exceedingly small, however, and the pelages seasonally different from other specimens with wh ich they are here compared. A much larger sample is needed for satisfactory appraisal of arizonensis.

Reithrodontomys megalotis rayus Goldman

Reithrodontomys megaiotis ravus Goldman (Journ. Mammalogy, 20: 355, 1939).

Type locality.-Utah, Trooele Co., Stansbury Island in Great Salt Lake.

Distribution.-Stansbury Islind (which intermittently is connected with the mainland); present range limits unknown.

Reithrodontomys megalotis lo ngicaudus Baird

Reithrodon longicauda Baird (U. S. Pac. Railroad Rep., 8: 451, 1857).

Reithrodontomys pallidus Rhoads (Amer. Nat., 27: 835, 1893). California, San Diego Co., Santa Isabel.

Reithrodontomys klamathensis Merriam (N. Amer. Fauna, 16: 93, 1899). California, Siskiyou Co., Big Spring [= Mayten].

Reithrodontomys megaiotis longicauda, Grinnell (Proc. Calif. Acad. Sci., Ser. 4, 3: $303,1913)$.

Reithrodontomys megal stis longicaudus, Howell (N. Amer. Fauna, 36: 33, 1914).

Type locality.-California, Petaluma Co., Petaluma.

Distribution.-Southwestern Oregon, most of that part of California west of Sierran divides, and northwestern Bajı California as far south as about 32 degrees north latitude.

Remarks.-For reasons for the synonymizing of pallidus and klamathensis, see Howell (loc. cit.).

Reithrodontomys megalotis dis ichlis von Bloeker

Reithrodontomys megal tis distichlis von Bloeker (Proc. Biol. Soc. Wash., 50: 155, 1937).

Type locality.-California, Monterrey Co., salt marshes at mouth of Salinas River.

Distribution.-Salt marshes and sand hills along the sea coast from Elkhorn Slough, Moss Landing, south to Seaside Lagcon, Monterrey County, California.

Reithrodontomys megalotis limicola von Bloeker

Reithrodontomys megalıtis limicola von Bloeker (Proc. Biol. Soc. Wash., 45: 133).

Type locality.-California, Lus Angeles Co., Playa del Rey.

Distribution.-Coastal marshes of southern California, from Point Mugu, Ventura Co., southeast to Anaheim Bay, Orc nge Co.

Reithrodontomys megalotis catılinae Elliot

Rhithrodontomys catalinae Elliot (Field Columb. Mus., Zool. Ser., 3: 246, 1903).

Reithrodontomys megalc'tis catalinae, Grinnell (Proc. Calif. Acad. Sci., Ser. 4, 3: 304, 1913).

Reithrodontomys catalinae, Howell (N. Amer. Fauna, 36: 40, 1914); Grinnell (Univ. Calif. Publ. Zool., 4C: 170, 1933). 
Type locality.-California, Los Angeles Co., Santa Catalina Island.

Distribution.-Santa Catalina Island.

Remarks.-In his 1913 check list of the Californian mammals Grinnell treated catalinae as a subspecies of $R$. megalotis. Later he followed Howell in assigning it specific status. The characters of catalinae, as observed in topotypes before me, are those of $R$. megalotis. The form warrants only subspecific status.

\section{Reithrodontomys megalotis peninsulae Elliot}

Rhithrodontomys peninsulae Elliot (Field Columb. Mus. Zool. Ser., 3: 165, 1903).

Reithrodontomys megalotis peninsulae, Howell (N. Amer. Fauna, 36: 35, 1914).

Type locality.-Baja California, San Quintín.

Distribution.-West coast of Baja California, at least between latitudes 30 and 31 degrees.

Reithrodontomys raviventris raviventris Dixon

Reithrodontomys raviventris Dixon (Proc. Biol. Soc. Wash., 21: 197, 1908).

Reithrodontomys raviventris raviventris, Howell (N. Amer. Fauna, 36: 41, 1914).

Type locality.-California, San Mateo Co., Redwood City.

Distribution.-Salt marshes bordering San Francisco Bay in San Mateo, Santa Clara, Alameda, western Contra Costa, and eastern Marin counties, California.

Reithrodontomys raviventris halicoetes Dixon

Reithrodontomys halicoetes Dixon (Univ. Calif. Publ. Zool., 5: 271, 1909).

Reithrodontomys raviventris halicoetes, Howell (N. Amer. Fauna, 36: 42, 1914).

Type locality.-California, Sonoma Co., $3 \mathrm{mi}$. S Petaluma.

Distribution.-Salt marshes bordering San Francisco Bay, in northeastern Marin, southern Sonoma and Solano, and northern Contra Costa counties, California.

\section{GAZETTEER}

Following is a list of localities in México, Central America, and South America from which were obtained the specimens examined in the present study. The localities are arranged alphabetically by republic, irrespective of states or departments within each republic. The localities are indexed according to the most definitive word or words in the total name of the locality. For example, La Jolla Grande, Department of Chimaltenango, Guatemala, is listed under Guatemala as Jolla Grande (La); Cerro San Felipe, Oaxaca, is listed under México as San Felipe (Cerro), Oaxaca. Insofar as the information is available to me, I have attempted to provide the following data for each locality: Brief description of its location, including geographical coordinates to the nearest minute of latitude and longitude, and elevations above mean sea level; locations and elevations of the collecting stations if different from those of the key locality; names of the species and the number of specimens represented. Authorities are cited for information preceding their names. All geographical co-ordinates are in degrees and minutes of north latitude and west longitude with one exception: Quito, Ecuador, lies south of the equator. Altitudes are in feet. Distances are in miles. All are map (air line) distances except those indicated by an asterisk $(*)$. In such instances the type of mileage, that is, whether by way of winding trail or 
road or via a straight line, was not determined. U. S. Army Air Force Aeronautical Charts, scale $1 / 1000000$, latest editions dated 1947, served as the primary source for $\mathrm{C}^{\mathrm{y}}$-ordinates, mileages, and elevations. Maps prepared by the American Geographical Society on a scale 1/1000000, editions available in 1943, were relied upon for place names. Altitudes greater than 100 feet usually are rounded to the nearest 100 feet. Distances are rounded to the nearest whole mile. Even this may be pseudo accuracy. That fact must be emphasized. A given fig ure may depart several miles in distance or several hundred feet in altitude from the true location of the place. The degree of reliability of the aforementioned maps and also of other maps of Latin America is exceedingly variable; the error is sometimes great. The geographical positions and altitudes given here, therefore, should be taken as best estimates.

\section{BRITISH HONDURAS}

Mountain Pine Ridge. A collecting station of A. Murie 12 mi.* S Cayó; near $17^{\circ} 0^{\prime}, 89^{\circ} 0^{\prime} ; 1000 \mathrm{ft}$.; 3 gracilis.

\section{COLOMBIA}

Cocal, Cauca. A camp in :he forest on the western slopes of Cerro Munchique in the Western Andes, $6000 \mathrm{ft}$. (Chapman, 1917); apparently near 2० 30', $77^{\circ} 0^{\prime} ; 2$ mexicanus.

Laguneta, Tolima (?). A posada in the Central Andes on the Quindio Trail a short distance west of the pass, about $15 \mathrm{mi}$. E Armenia, 10,300 ft. (Chapman, 1917); apparently near $4^{\circ} 30^{\prime}, 75^{\circ} 30^{\prime}$; 1 mexicanus.

Munchique, Cauca. A camp west of Popayán on Cerro Munchique in subtropical forests on the e:astern slopes of the Western Andes, $8325 \mathrm{ft}$. (Chapman, 1917); 12 mexicanus. Summit of Cerro Munchique is located at $2^{\circ}$ 28', 76 $58^{\circ}$.

Papas (Valle de las), Huila. A valley in the Central Andes south of Popayán at the border of the Alpine and Temperate zones, 10,500 ft. (Chapman, 1917); apparently near $2^{\circ} 0^{\prime}, 76^{\circ} 30^{\prime} ; 3$ mexicanus.

Roble (El), Caldas (?). A locality in the Central Andes, $3 \mathrm{mi}$. SW Salento and $25 \mathrm{mi}$. SE Cartago, $70(10 \mathrm{ft}$. (Allen, 1916: 193-96); near 4० 40', 75०40'; 6 mexicanus. Apparently not the El Roble on the trail from Bogotá to Fusugasuga in the Eastirn Andes as listed by Chapman (1917).

San Agustín, Huila. A town on the headwaters of the Río Magdalena in the Central Andes, 45 mi. Sis Popayán; $10^{\circ} 23^{\prime}, 76^{\circ} 16^{\prime} ; 5500 \mathrm{ft}$; 1 mexicanus.

\section{COSTA RICA}

Agua Buena. See Cañas Cordas.

Alajuela, Alajuela. A town $10 \mathrm{mi}$. NW San José; $10^{\circ} 01^{\prime}, 84^{\circ} 12^{\prime} ; 3100 \mathrm{ft}$; 2 mexicanus. 
Cañas Gordas (Agua Buena), Puntarenas. An airport known as Cañas Gordas or Agua Buena, on the Sabana de Potrero Grande about 1000 feet above Las Vueltas on the Río Diquis, 3,000 ft.; not the Cañas Gordas on the Panamá border (Goodwin, 1946); 7 mexicanus.

Carpintera (La), Cartago. A cerro near Cartago, the summit $4 \mathrm{mi}$. NW that city; $9^{\circ} 52^{\prime}, 83^{\circ} 58^{\prime} ; 6200 \mathrm{ft}$.; 5 mexicanus.

Cartago, Cartago. A city $12 \mathrm{mi}$. SE San José; $9^{\circ} 51^{\prime}, 83^{\circ} 55^{\prime} ; 4500 \mathrm{ft}$; 1 mexicanus.

Colón (Villa), San José. A town 10 mi. W San José; $9^{\circ} 45^{\prime}, 84^{\circ} 12^{\prime} ; 3000 \mathrm{ft}$. ?; 1 mexicanus.

Copey (El Copey de Dota), Cartago. A settlement $15 \mathrm{mi}$. S Cartago on the northwestern flanks of Cerro Las Vueltas; $9^{\circ} 33^{\prime}, 83^{\circ} 55^{\prime} ; 6000$ ft.; 4 mexicanus.

Escazú, San José. A small town 5 mi. W San José on the road to Villa Colón; $9^{\circ} 56^{\prime}, 84^{\circ} 09^{\prime} ; 3700 \mathrm{ft}$. Specimens from the vicinity of town and from the heights above town (Altos Escazú); 5 mexicanus, 1 sumichrasti.

Estrella (de Cartago), Cartago. A village 3 mi. S Cartago; $9^{\circ}$ 52', 84 03'; $6000 \mathrm{ft} . ; 2$ brevirostris, 1 mexicanus.

Higuerones (Los), San José. Small farms above the town of Escazú, $4500 \mathrm{ft}$. (Goodwin, 1946); 2 mexicanus. See Escazú.

Irazú (Volcán de), A peak near Volcán Turrialba, the summit $12 \mathrm{mi}$. E San José, $9^{\circ} 59^{\prime}, 83^{\circ} 53^{\prime} ; 12,300 \mathrm{ft}$. Collections from various elevations on the Volcán; 13 sumichrasti, 7 mexicanus, 6 creper, 2 rodriguezi.

Muerta (Cerro de la), Cartago. A peak 17 mi. WNW Cerro Chirripó Grande in the Cordillera de Talamanca; summit $9^{\circ} 03^{\prime}, 83^{\circ} 45^{\prime} ; 11,600 \mathrm{ft}$; 4 creper.

Nubes (Las), San José(?) Goodwin (1946) stated that this locality is near San Isidro, $5000-6000 \mathrm{ft}$.; San Isidro, he indicated, is 8 or $10 \mathrm{mi}$.* NE San José; 6 mexicanus.

Oca (Montes de), San José. A collecting station in the vicinity of San Pedro, $4000 \mathrm{ft}$. (Goodwin, 1946); near $9^{\circ} 56^{\prime}, 84^{\circ} 03^{\prime}$; 1 mexicanus.

Quesada (Villa), Alajuela. A town $7 \mathrm{mi}$. N Zarcero and $20 \mathrm{mi}$. NW Alajuela; $10^{\circ} 16^{\prime}, 84^{\circ} 24^{\prime} ; 3000 \mathrm{ft}$. Specimens from deep valleys in the mountains above the town (Goodwin, 1942); 3 brevirostris.

San Indro (San Isidro), San José. A town 8 or 10 mi.* NE San José, $4700 \mathrm{ft}$. (Goodwin, 1946); 9० 59', 83 59'; 1 mexicanus.

San José, San José. The capital of the Republic; $9^{\circ} 56^{\prime}, 84^{\circ} 04^{\prime} ; 3800 \mathrm{ft}$; 2 mexicanus.

San Pedro, San José. A village on the eastern outskirts of San José; $9^{\circ} 56^{\prime}$, $84^{\circ} 03^{\prime} ; 4000 \mathrm{ft}$. ?; 6 mexicanus.

Santa María (Hacienda), Guanacaste. A large ranch northeast of Liberia in the Cordillera Volcánica; $10^{\circ} 46^{\prime}, 85^{\circ} 19^{\prime} ; 4600 \mathrm{ft}$.; 1 gracilis.

Talamanca. A name applied to the whole southeastern part of Costa Rica, 
from the Caribbean Sea to the crest of the Cordillera de Talamanca (Carriker, 1910: 354). The specimen at hand labeled Talamanca was collected by Gabb. He collected principally in the Caribbean lowlands near Sipurio (fide Carriker). This specimen, 1 brevirostris, probably came from the interior highlands.

Tapezco (Tapesco), Alajuela. A settlement on the Río Tapezco, $2 \mathrm{mi}$. N Zacero on road to Villa Quesada; $10^{\circ} 11^{\prime}, 84^{\circ} 24^{\prime} ; 5100 \mathrm{ft}$; 1 mexicanus.

Tibas, San José. A cantćn near San Juan, about halfway between San José and Heredía (Goodwill, 1946); near $9^{\circ}$ 58', 84 05'; 2 mexicanus.

Zapote, Alajuela. A village on the main road between Zarcero and Villa

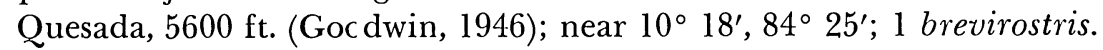

\section{ECUADOR}

Peñaherrera (San Isidro). Imbabura. A town $40 \mathrm{mi}$. W Ibarra in a valley on the western slopes of the Western Andes; $0^{\circ} 24^{\prime}, 78^{\circ} 40^{\prime}$. Specimens from 5 mi. S Peñaherrera above the Río Llurimagua in the humid subtropical forest of the Cordillera de Intag, $6500 \mathrm{ft}$. (Hershkovitz, 1941: 7); 7 mexicanus.

Pimanpiro, Imbabura. A village $15 \mathrm{mi}$. ENE Ibarra on the southern flanks of the Río Chota Valley, $6500 \mathrm{ft}$. (Hershkovitz, 1941: 7); $0^{\circ} 24^{\prime}, 77^{\circ} 55^{\prime}$; 6 mexicanus.

Quito, Pichincha. The capital of the Republic, on the western side of the inter-Andean plateau; $0^{\circ} 12^{\prime}, \mathrm{S}, 78^{\circ} 30^{\prime} ; 9200 \mathrm{ft} . ; 5$ mexicanus.

\section{EL SALVADOR}

Cacaguatique (Cerro), San Miguel and Morazán. A mountain ridge east of Ciudad Barrios in no theastern El Salvador; summit $13^{\circ} 47^{\prime}, 88^{\circ} 13^{\prime}$; $5400 \mathrm{ft}$.; 22 mexicanus, 1 fulvescens.

Chilata (Hacienda), Sons onate. A coffee finca lying near the summit of the

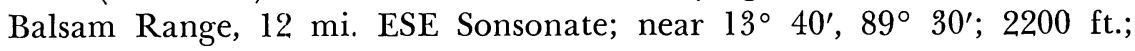
7 mexicanus.

Esesmiles (Los), Chalater ango. A local name for the short range of mountains near the Honduras boundary and east of the Río Lempa (Dickey and van Rossem, 1938); apparently near $93^{\circ} 15^{\prime}, 89^{\circ} 05^{\prime} ; 92$ sumichrasti, 15 mexicanus.

Monte Cristo mine, Morczán. A mine 5 mi. W Jocoro and 10 mi. NNE San Miguel; $13^{\circ} 35^{\prime}, 88^{\circ} 05^{\prime} ; 700 \mathrm{ft}$; 2 gracilis.

San Miguel (Volcán), Sa.a Miguel. A volcano in the coastal chain of volcanoes, the summit 7 ni. SW San Miguel; $13^{\circ} 25^{\prime}, 88^{\circ} 17^{\prime} ; 7000 \mathrm{ft} . ; 2$ fulvescens.

Santa Ana (Volcán), Sonsonate. A volcano in western El Salvador, the summit 10 mi. SW Santa Ara; $13^{\circ} 51^{\prime}, 89^{\circ} 38^{\prime}$; $7800 \mathrm{ft}$.; 4 mexicanus. 
Amatitlán (Lago de), Guatemala. A large lake 10 mi. S Guatemala City; $14^{\circ} 27^{\prime}, 90^{\circ} 35^{\prime} ; 4200 \mathrm{ft} . ; 4$ mexicanus.

Atescatempa (Lago), Jutiapa. A lake $12 \mathrm{mi}$. SE Jutiapa in extreme southeastern Guatemala; $14^{\circ} 12^{\prime}, 89^{\circ} 41^{\prime} ; 2000 \mathrm{ft}$.? Specimens from arid hill at southeast end of lake; 1 fulvescens, 1 gracilis.

Barrillas (Santa Cruz), Huehuetenango. A village $35 \mathrm{mi}$. NNE Huehuetenango, on the northeast slope of the Alto Cuchumatanes; $15^{\circ} 48^{\prime}, 91^{\circ} 19^{\prime}$; $4700 \mathrm{ft}$.; 2 mexicanus.

Calel, Totonicapán. A town and cerro respectively $17 \mathrm{mi}$. and $14 \mathrm{mi}$. N. Quezaltenango; town $15^{\circ} 05^{\prime}, 91^{\circ} 33^{\prime}, 10,000 \mathrm{ft}$; summit of Cerro $15^{\circ} 02^{\prime}$, $91^{\circ} 33^{\prime}, 10,800 \mathrm{ft}$; madrone, alder, oak-pine forests, sacatón; 22 sumichrasti, 1 tenuirostris.

California (Hacienda), San Marcos(?) A cattle ranch a few miles from the Pacific Ocean in extreme southwestern Guatemala, 6 mi.* from Ocós and the same distance from the Chiapas border (Goodwin, 1932); near $14^{\circ} 05^{\prime}$, $92^{\circ} 05^{\prime}$; 1 gracilis.

Chajul (El), El Quiché. An Indian village in the eastern Cuchumatanes, 30 mi. ENE Huehuetenango; $15^{\circ} 28^{\prime}, 91^{\circ} 0^{\prime} ; 6400 \mathrm{ft}$. Specimens from 21/2 mi. SW Chajul; 6 sumichrasti, 2 mexicanus.

Chancol (Hacienda), Huehuetenango. A hacienda in the Sierra Cuchumatanes, $15 \mathrm{mi}$. W Nebaj; $15^{\circ} 25^{\prime}, 91^{\circ} 20^{\prime} ; 9000 \mathrm{ft}$. ? Collections from grasscovered plains at Chancol and 3 mi. down SE slope; 29 sumichrasti.

Chanquejelve, Huehuetenango. A ranch on the north side of the Sierra

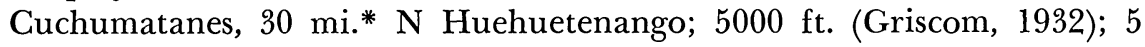
fulvescens, 1 mexicanus.

Chemal, Huehuetenango. An Indian village near the crest of the Sierra Cuchumatanes, $18 \mathrm{mi}$. NNW Huehuetenango; $15^{\circ} 33^{\prime}, 91^{\circ} 30^{\prime} ; 11,000 \mathrm{ft}$. Specimens from vicinity of Chemal and 5 mi.* $\mathrm{N}$ the village; 8 sumichrasti, 1 microdon.

Chichavac, Chimaltenango. A finca 3 mi.* N Tecpán; $14^{\circ} 48^{\prime}, 90^{\circ} 58^{\prime} ; 8600$ ft.?; 1 microdon.

Chichicastenango (Santo Tomás), El Quiché. A town 30 mi. ENE Quezaltenango; $14^{\circ} 58^{\prime}, 91^{\circ} 04^{\prime} ; 5000 \mathrm{ft}$; 1 mexicanus.

Ciprés (Finca El), Suchitepéquez? A finca on the Pacific slope at the base of Volcán Zunil, 2000 ft. (Goodwin, 1932); near 14 38', 91 ० 32'; 8 gracilis.

Cobán, Alta Verapaz. The capital and largest city of Alta Verapaz; 15 29', $90^{\circ} 20^{\prime} ; 4300 \mathrm{ft}$.; 5 sumichrasti, 4 mexicanus.

Cotzal (San Juan), El Quiché. An Indian village $10 \mathrm{mi}$. NNE Sacapulas; $15^{\circ}$ $28^{\prime}, 91^{\circ} 01^{\prime} ; 7000 \mathrm{ft}$.? Specimens from Río Cotzal Valley 31/2 mi. NE Cotzal; $4600 \mathrm{ft} . ; 6$ sumichrasti. 
Helvetia (Finca), Quezaltenango. A coffee finca on the south slope of Volcán Santa María, 12 mi. SSW Quezaltenango; near $94^{\circ} 42^{\prime}, 91^{\circ} 37^{\prime} ; 5500 \mathrm{ft}$.; 1 mexicanus.

Jacaltenango, Huehue :enango. A village on the western slope of the Alto Cuchumatanes, 30 rii. NW Huehuetenango; $15^{\circ} 38^{\prime}, 91^{\circ} 43^{\prime} ; 4600 \mathrm{ft}$; 1 mexicanus.

Jocopilas (San Pedro), El Quiché. A village $6 \mathrm{mi}$. N Santa Cruz del Quiché; $15^{\circ} 07^{\prime}, 91^{\circ} 06^{\prime} ; 700 \mathrm{Jt}$.? Specimens from $7200 \mathrm{ft}$. on a ridge $3 \mathrm{mi}$. NW Jocopilas on the roall to Sacapulas; 7 sumichrasti.

Jolla Grande (La), Chimaltenango. A finca 21/2 mi.* E Yepocapa on the southern slopes of V'olcán de Fuego; near $14^{\circ} 25^{\prime}, 90^{\circ} 55^{\prime} ; 5700 \mathrm{ft}$; 1 sumichrasti.

Mataquescuintla, Jalapa. A town $15 \mathrm{mi}$. SW Jalapa, on the road to Guatemala City; $13^{\circ} 31^{\prime}, 90^{\circ} 11^{\prime}$. Collections were made on the high ridge immediately NE of the town; $8400 \mathrm{ft}$; 1 tenuirostris.

Montserrat (Finca), Chimaltenango. A finca 5 mi. E Yepocapa on the slopes of Volcán Acatenango; near 94² 27', 90 53'; $5700 \mathrm{ft}$.; 1 sumichrasti.

Nebaj (Santa Maria), El Quiché. A town at the head of the Río Cotzal Valley, 25 mi. N Santa Cruz del Quiché; $15^{\circ} 24^{\prime}, 91^{\circ} 08^{\prime} ; 6300 \mathrm{ft}$. Specimens from $8200 \mathrm{ft}$. on ridge 3-4 mi. SE Nebaj; 20 sumichrasti.

Panzamalá (Finca), Alta Verapaz. A coffee plantation on the southern slopes of the Río Cahabón Valley, 15 mi. E Cobán; $15^{\circ} 28^{\prime}, 90^{\circ} 05^{\prime} ; 4100 \mathrm{ft}$.; 1 mexicanus.

Rancho (El), El Progres J. A village on the south banks of the Río Motagua, $30 \mathrm{mi}$. W Zacapa; $14^{\circ} 54^{\prime}, 90^{\circ} 01^{\prime}$; $700 \mathrm{ft}$.; 2 gracilis.

Sacapulas, El Quiché. A town in the arid upper valley of the Río Negro, 20 mi. N Santa Cruz del Quiché; 15 ${ }^{\circ} 19^{\prime}, 91^{\circ} 04^{\prime} ; 4500 \mathrm{ft}$. Specimens from vicinity of town, 2 gracilis; 5 fulvescens from $5 \mathrm{mi}$. W Sacapulas where Hueheutenango road crosses the Río Blanco.

Salamá, Baja Verapaz. T'he capital of Baja Verapaz, 25 mi. S Cobán; $15^{\circ} 06^{\prime}$, $90^{\circ}$ 16'; $3100 \mathrm{ft}$. Specimens from ridge $6 \mathrm{mi}$. NNE Salamá; $5500 \mathrm{ft}$; 3 sumichrasti, 2 fulvescens.

San José, Escuintla. The costal terminus of the railroad from Guatemala City; $13^{\circ} 55^{\prime}, 90^{\circ} 49^{\prime}$; near sea level; 2 gracilis.

San Rafael, Sacatepéquez. A hotel and finca $5 \mathrm{mi}$. W Guatemala City; $14^{\circ}$ $38^{\prime}, 90^{\circ} 36^{\prime} ; 7000 \mathrm{ft}$.; 8 sumichrasti, 2 mexicanus.

Santa Clara, Zacapa. A ranch in the Sierra de las Minas on the Río Teculután; $15^{\circ} 09^{\prime}, 89^{\circ} 46^{\prime}$; a jout $5500 \mathrm{ft}$; 2 mexicanus.

Santa Elena (Sierra), Cilimaltenango. A saw mill on the Pan American Highway, 36 mi. WNV/ Guatemala City; 14 49', 91 02'; 2 sumichrasti.

Santa María (Volcán), Quezaltenango. One of the large volcanoes in the 
coastal chain; summit $14^{\circ} 45^{\prime}, 91^{\circ} 32^{\prime} ; 12,400 \mathrm{ft}$. Collections $9000-11,000$ ft.; 4 sumichrasti, 1 microdon.

Tajumulco (Volcán), San Marcos. A high volcano in southwestern Guatemala; summit $15^{\circ} 02^{\prime}, 91^{\circ} 54^{\prime} ; 13,800 \mathrm{ft}$. Collections from south and east slopes; 3 sumichrasti, 3 tenuirostris.

Todos Santos, Huehuetenango. A settlement in the Sierra Cuchumatanes, $17 \mathrm{mi}$. NW Huehuetenango; $15^{\circ} 30^{\prime}, 91^{\circ} 38^{\prime} ; 8100 \mathrm{ft}$. Collections up to $10,000 \mathrm{ft}$. in grasslands and in sparse pine, cypress, and fir forest (Goldman, 1951); 10 sumichrasti, 2 tenuirostris, 2 microdon.

Yepocapa (San Pedro), Chimaltenango. A town $32 \mathrm{mi}$. WSW Guatemala City on the western flanks of Volcán Acatenango; $14^{\circ} 28^{\prime}, 91^{\circ} 02^{\prime} ; 5000 \mathrm{ft}$; 2 sumichrasti, 1 mexicanus.

Zunil, Quetzaltenango. A town in the narrow valley between the volcanoes Zunil and Santa María, 5 mi. SW Quezaltenango; 14 47', $91^{\circ} 2^{\prime \prime} ; 7600 \mathrm{ft}$;; 3 sumichrasti.

\section{HONDURAS}

Archaga (La Flor), Francisco Morazán. A village on the Talanga road east of Cerro Archaga, $4500 \mathrm{ft}$. (Goodwin, 1942); apparently near $14^{\circ} 15^{\prime}, 87^{\circ}$ 15'; 1 fulvescens, 5 mexicanus.

Cantoral (Cerro), Francisco Morazán. A mountain in central Honduras; listed by Goodwin (1942) as 12-15 mi.* NE Archaga, but probably the Cerro Cantoral situated west of Cerro Archaga and $15 \mathrm{mi}$. NNW Tegucigalpa; $14^{\circ} 22^{\prime}, 87^{\circ} 20^{\prime} ; 9$ mexicanus.

Cementerio, Lempira. A collecting locality on the slopes of Cerro Puca, $5300 \mathrm{ft}$. (Goodwin, 1942). Pico Puca lies $10 \mathrm{mi}$. N Gracias; $14^{\circ} 45^{\prime}, 88^{\circ}$ 35'; 1 sumichrasti.

Comayaguela, Francisco Morazán. A city across the Río Choluteca from Tegucigalpa; $14^{\circ} 04^{\prime}, 87^{\circ} 14^{\prime} ; 3000 \mathrm{ft}$; 2 mexicanus.

Derrumbo (El), Francisco Morazán. A locality north of Archaga; collections were made at the source of the Llama River (Goodwin, 1942); 1 mexicanus.

Hatillo, Francisco Morazán. A village 13 mi. NE Tegucigalpa, near San Juan de Flores; $14^{\circ} 15^{\prime}, 87^{\circ}$ 05'; $4800 \mathrm{ft}$.; 1 mexicanus.

Humuya. See Muya.

Linderos (Monte), Lempira. On the slopes of Cerro Puca (Goodwin, 1942); apparently near $14^{\circ} 45^{\prime}, 88^{\circ} 35^{\prime} ; 3$ mexicanus.

Muya, La Paz. A hill covered with second growth timber 4 or 5 mi.* $\mathrm{N}$ Chincala [= Chinacla?] (Goodwin, 1942). The name Humuya appears on the specimen tags but according to Goodwin the specimens actually came from Muya; near $14^{\circ} 15^{\prime}, 88^{\circ} 0^{\prime}$; the Humuya located south of La Paz apparently is not this collecting locality of Underwood; 4 mexicanus, 20 sumichrasti. 
Puca, or Pucca (Cerro (ir Pico), Lempira. A cerro 10 mi. N Gracias; 14 45', $88^{\circ} 35^{\prime} ; 2$ mexicanus.

Redondo (Monte), Francisco Morazán. Goodwin (1942) lists this as about $50 \mathrm{~km}$.* NW Tegucigalpa. Probably the Monte Redondo $15 \mathrm{mi}$. NNW Tegucigalpa; $14^{\circ} 20^{\prime}: 87^{\circ} 15^{\prime} ; 2$ mexicanus.

Sabana Grande, Francisco Morazán. A town 20 mi. S Tegucigalpa; 13 48', $87^{\circ} 15^{\prime} ; 3500 \mathrm{ft} . ? ; 2$ mexicanus.

Uyuca (Cerro), Francisco Morazán. A hill south of San Antonio de Oriente on the Tegucigalpa-Danli road, $12 \mathrm{mi}$. ESE of Tegucigalpa; $14^{\circ} 0^{\prime}, 87^{\circ} 05^{\prime}$; 3 sumichrasti.

Vásquez (Montaña), Francisco Morazán. A hamlet 15 mi.* W Monte Redondo (see Redondo), $6000 \mathrm{ft}$. (Goodwin, 1942); 3 mexicanus.

Verde (Monte), Ocotepeque. A locality about $30 \mathrm{mi}{ }^{*}$ NE Ocotepeque (Goodwin, 1942); 3 sumichristi, 6 mexicanus. Ocotepeque lies at $14^{\circ} 25^{\prime}, 89^{\circ} 13^{\prime}$.

\section{MÉXICO}

Acámbaro, Guanajuato. A large town in southeastern Guanajuato; $20^{\circ} 03^{\prime}$, $100^{\circ} 43^{\prime} ; 6100 \mathrm{ft}$;; mesquite-grassland; 2 fulvescens.

Acaponeta, Nayarit. A town on the railroad and coastal plain in northern Nayarit; $22^{\circ} 30^{\prime}, 105^{\circ} 22^{\prime}$; $200 \mathrm{ft}$.; 1 fulvescens.

Acapulco, Guerrero. The seaport at longitude $99^{\circ} 55^{\prime}, 16^{\circ} 52^{\prime}$; arid tropical, thorny trees and shrubs; 1 fulvescens.

Acultzingo, Veracruz. A town $16 \mathrm{mi}$. SW Orizaba (city) east of the pass on the Orizaba-Puebla highn'ay; $18^{\circ} 43^{\prime}, 97^{\circ}$ 18'; $7000 \mathrm{ft}$.; grassland and open oak and pine forests between the wet broadleaf forests of lower altitudes to the east and the mesquite-cactus desert found west of the pass. Specimens from the valley and the hills south of town; 27 sumichrasti.

Acuña, Tamaulipas. A village in the Sierra de Tamaulipas, $57 \mathrm{mi}$. SE Giudad Victoria; $23^{\circ} 12^{\prime}, 98^{\circ} 26^{\prime} ; 3100 \mathrm{ft}$. Specimens from various elevations, mostly below $3100 \mathrm{ft}$.; 15 fulvescens.

Agua Nueva, Sinaloa. A settlement 12 mi. SE Culiacán; $24^{\circ} 44^{\prime}, 107^{\circ} 13^{\prime}$; $50 \mathrm{ft}$. Specimens from \& mi. NW Agua Nueva; 1 fulvescens.

Agua Prieta, Sonora. A st ttlement 5 mi. S Douglas, Arizona; $31^{\circ} 15^{\prime}, 109^{\circ} 33^{\prime}$; $4100 \mathrm{ft}$. Specimens from $21 \mathrm{mi}$ * S Agua Prieta; desert grassland; 1 montanus.

Aguascalientes, Aguascalientes. The capital and largest city of the state; $21^{\circ}$ 53', 102 ${ }^{\circ} 18^{\prime} ; 6200 \mathrm{ft}$; mesquite-grassland; 7 fulvescens.

Ahumada (Villa), Chihuithua. A town on the railroad and highway between El Paso, Texas, and Chihuahua City; $30^{\circ} 37^{\prime}, 106^{\circ} 31^{\prime}$; $3800 \mathrm{ft}$.; arid plains. Specimens from 2 mi. IN Ahumada; 3 megalotis.

Ajusco, Distrito Federal. A village and cerro $15 \mathrm{mi}$. SSW Mexico City; village 
$19^{\circ} 13^{\prime}, 99^{\circ} 13^{\prime}$; $9500 \mathrm{ft} . ?$; summit of cerro $19^{\circ} 12^{\prime}, 99^{\circ} 15^{\prime}$; over $12,000 \mathrm{ft}$.; 3 chrysopsis.

Alamos, Sonora. A town in the foothills of the Sierra Madre in southern Sonora; $27^{\circ} 02^{\prime}, 108^{\circ} 56^{\prime} ; 1000 \mathrm{ft}$.? Specimens were collected in the valley in which Alamos lies and on the adjoining slopes as high as $4.500 \mathrm{ft}$. on the north slope of the Sierra de Alamos; 8 fulvescens.

Altamira, Tamaulipas. A town on coastal lowlands $13 \mathrm{mi}$. NNW Tampico; $22^{\circ} 24^{\prime}, 97^{\circ} 56^{\prime} ; 75 \mathrm{ft}$; 11 fulvescens.

Altata, Sinaloa. A railroad terminus and seacoast settlement WSW Culiacán; $24^{\circ} 38^{\prime}, 107^{\circ} 56^{\prime} ; 1$ fulvescens.

Altotonca, Veracruz. A town $27 \mathrm{mi}$. NW Jalapa, on the Perote-Teziutlán road; $19^{\circ} 16^{\prime}, 97^{\circ} 15^{\prime} ; 6000 \mathrm{ft}$. ; ; at upper edge of moist broadleaf forests; 30 megalotis, 9 sumichrasti, 4 mexicanus.

Amatenango, Chiapas. A town on the San Cristóbal-Comitán road, $20 \mathrm{mi}$. SE San Cristóbal; $16^{\circ} 29^{\prime}, 92^{\circ} 28^{\prime} ; 6000$ ft.; 23 sumichrasti. Not the Amatenango on the Chiapas-Guatemala boundary.

Ameca, Jalisco. A town in west-central Jalisco, $45 \mathrm{mi}$. WSW Guadalajara; $20^{\circ} 33^{\prime}, 104^{\circ} 03^{\prime} ; 4000 \mathrm{ft}$. Specimens from valley floor and surrounding hills to $7 \mathrm{mi}$. W Ameca; grassland, mesquite giving way to oak and pine on hills; 68 fulvescens, 6 hirsutus, 10 megalotis.

Amecameca, México. A town on the Mexico City-Cuautla highway, $30 \mathrm{mi}$. SE Mexico City; $19^{\circ} 07^{\prime}, 98^{\circ} 46^{\prime} ; 7700 \mathrm{ft}$. Specimens from slopes east of town; 9600-11,500 ft.; 1 megalotis, 1 chrysopsis.

Amoles (Pinal de), Querétaro. A town and cerro between Jalpán and Tolimán in northern Querétaro; 21 $09^{\prime}$, 99 37'; town $7900 \mathrm{ft}$; ; cerro about $9500 \mathrm{ft}$. at summit. Specimens from humid tropical canyons near town and from pine, oak, madrone forests to $9500 \mathrm{ft}$. on the cerro; 7 sumichrasti, 3 megalotis.

Angahuan, Michoacán. A Tarascan Indian village near the northeastern base of Volcán Parícutin, 15 mi. NW Uruapan; 19³3', 102 ${ }^{\circ} 14^{\prime} ; 8000 \mathrm{ft}$; ; open pine-oak forests. Specimens from 3-9 mi. (by road) E; 3 megalotis.

Antiguo Morelos, Tamaulipas. A village and important highway junction 80 mi. S Ciudad Victoria; $22^{\circ} 33^{\prime}, 99^{\circ} 05^{\prime} ; 500 \mathrm{ft}$. ?; semitropical; 1 fulvescens.

Apazote. A village $10 \mathrm{mi}$. S Yahaltun in west-central Campeche; $18^{\circ} 53^{\prime}, 90^{\circ}$ 23'; $300 \mathrm{ft}$; 1 gracilis.

Apetsco, San Luis Potosí. A ranch about $1 \mathrm{mi}$. from Xilitla and $15 \mathrm{mi}$. NW Tamasunchale; $21^{\circ} 24^{\prime}, 98^{\circ}$ 58'; $2700 \mathrm{ft}$; 4 mexicanus, 6 fulvescens.

Apixaco, Tlaxcala. A town and railroad junction at the northern base of

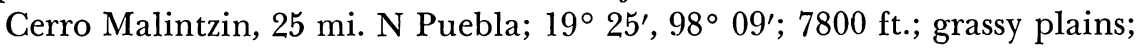
2 megalotis.

Apo, Michoacán. A village on the western flanks of Cerro de Tancítaro; $19^{\circ}$ 
$25^{\prime}, 102^{\circ} 25^{\prime} ; 7000 \mathrm{ft}$. oak-pine with epiphytes. Specimens from $1 \mathrm{mi}$. N Apo (see Escondido); (thers from $3 \mathrm{mi}$. ENE Apo, $9000 \mathrm{ft}$;; pine-oak forests at lower edge of fir kelt; 6 sumichrasti.

Apulco, Hidalgo. A villige in southeastern Hidalgo, $14 \mathrm{mi}$. N Tulancingo; $20^{\circ} 18^{\prime}, 98^{\circ} 20^{\prime} ; 7200$ ft.; 2 megalotis.

Atemajac (del Valle), Ja.isco. A settlement $5 \mathrm{mi}$. N Guadalajara on the rim of a side canyon leadir $g$ to the canyon of the Río Grande de Santiago; $20^{\circ}$ $45^{\prime}, 103^{\circ} 21^{\prime} ; 4500 \mathrm{ft} . ; 2$ fulvescens.

Atlacomulco, México. A village in northwestern México, $50 \mathrm{mi}$. WNW Mexico City; 19 47', (1953'; 8200 ft.; oak-pine, chaparral; 1 megalotis.

Atlati (Río), Puebla. A collecting station 9 mi.* NW San Martín Texmelucán;

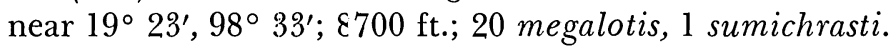

Atoyac (Río), Veracruz. A river in central Veracruz. Collecting station on headwaters of the river, $5 \mathrm{mi}$.* NW Potrero Viejo and $5 \mathrm{mi}$.* $\mathrm{N}$ Córdoba; near $18^{\circ} 58^{\prime}, 96^{\circ} 54^{\prime}$; $4.300 \mathrm{ft}$.; 1 mexicanus.

Autlán, Jalisco. A large tc'wn in southwestern Jalisco, $95 \mathrm{mi}$. SW Guadalajara; $19^{\circ} 45^{\prime}, 104^{\circ} 24^{\prime} ; 3000$ t.; cactus, thorny shrubs, grassland. Specimens from $4 \mathrm{mi}$. NE, $3000 \mathrm{ft}$., 9 fu'vescens, and $6 \mathrm{mi}$. SSW, $4500 \mathrm{ft}$., 9 fulvescens.

Autlán (Sierra de), Jalisco. Mountains to the south of Autlán; 19॰ 35', 104 20 , elevation of summit 10,300 ft. Collections from 7000-9000 ft.; oaks, pines, firs; 5 sumichrasti.

Banochari (Rancho), Sonora. A ranch 10 mi.* N Matape, $2700 \mathrm{ft}$.; 2 fulvescens. Matape is situated $60 \mathrm{mi}$. E Hermosillo; $29^{\circ} 07^{\prime}, 109^{\circ} 57^{\prime}$.

Batopilas, Chihuahua. A mining town on the Río Batopilas in extreme southwestern Chihuahua; $27^{\circ} 02^{\prime}, 107^{\circ} 45^{\prime}$; $1800 \mathrm{ft}$.; semitropical valley. Specimen from Las Gu ısimas, 2800 ft., near Batopilas (Goldman, 1951); 1 fulvescens.

Beristain, Puebla. A village in northwestern Puebla, 7 mi. SW Huauchinango; $20^{\circ} 07^{\prime}, 98^{\circ} 08^{\prime} ; 7000 \mathrm{ft}$.; 17 megalotis.

Berriozábal (Berriozába), Zacatecas. A railroad station 22 mi. SE Zacatecas; $22^{\circ} 33^{\prime}, 102^{\circ}$ 19'; $6800 \mathrm{f}$ :.; mesquite-grassland; 1 fulvescens.

Blanco (Río), Veracruz. A river in central Veracruz. Specimens from 12 mi.* WNW Piedras Negras riear the Río; near $18^{\circ} 44^{\prime}, 96^{\circ} 20^{\prime} ; 3$ fulvescens.

Bochil, Chiapas. A town $24 \mathrm{mi}$. NW San Cristóbal and $22 \mathrm{mi}$. NE Tuxtla Gutiérrez; $16^{\circ} 59^{\prime}, 92^{\circ}$.55'; $4300 \mathrm{ft}$; 2 mexicanus, 2 fulvescens.

Boco del Río, Veracruz. A village near the mouth of the Río Atoyac, $10 \mathrm{mi}$. SE Veracruz; $19^{\circ} 06^{\prime}, 96^{\circ} 05^{\prime} ; 10 \mathrm{ft}$; 2 fulvescens.

Calcehtok (Hacienda), Yucatán. A henequin plantation at the foot of low hills, 30 mi. SSW Méridiı and 7 mi. E Maxcanú; $20^{\circ} 36^{\prime}, 89^{\circ} 54^{\prime} ; 2$ gracilis.

Camargo, Tamaulipas. A town across the Rio Grande from Rio Grande City, Texas; $26^{\circ} 20^{\prime}, 98^{\circ} 50^{\prime}$; ?.00 ft.; mesquite, thorny shrubs; 5 fulvescens. 
Canjob, Chiapas. A town $12 \mathrm{mi}$. NW Comitán in southeastern Chiapas; $16^{\circ}$ 19', 92 ${ }^{\circ}$ 18'; $5300 \mathrm{ft}$; oak-pine, grassland; 2 sumichrasti, 4 fulvescens.

Canutillo, Durango. A town in extreme northern Durango; $26^{\circ} 24^{\prime}, 105^{\circ} 22^{\prime}$; $5500 \mathrm{ft}$.; desert grassland. Specimens from $3 \mathrm{mi}$ * $^{*} \mathrm{SW}$ the town, 1 megalotis, and 5 mi.* SW, 1 montanus.

Carmen (Sierra del), Coahuila. Located to the east of the Big Bend of the Rio Grande across from the Chisos Mts. of Texas; $28^{\circ} 45^{\prime}-29^{\circ} 15^{\prime}, 102^{\circ} 30^{\prime}-$ $102^{\circ} 50^{\prime}$. Juárez Canyon, $4800 \mathrm{ft}$., whence the specimens came, was not located; 2 fulvescens.

Carranza (Villa), Jalisco. See San Gabriel.

Carrizal, Veracruz. A railroad station about halfway between Jalapa and Veracruz; $19^{\circ} 22^{\prime}, 96^{\circ} 38^{\prime}$; $1000 \mathrm{ft}$.; thorny shrubs, arborescent cacti, grassland; 5 fulvescens.

Casas Grandes, Chihuahua. A town in northwestern Chihuahua, $3 \mathrm{mi}$. SW the railroad station Nuevas Casas Grandes; $30^{\circ} 22^{\prime}$, 107 $58^{\prime}$; $4800 \mathrm{ft}$.; mesquite-grassland plains and low hills at base of Sierra Madre; 4 megalotis, 5 fulvescens.

Catemaco, Veracruz. A town on the northwestern shore of Lago Catemaco in southern Veracruz; $18^{\circ} 25^{\prime}, 95^{\circ} 06^{\prime} ; 1100 \mathrm{ft}$.; arid tropical; 1 fulvescens.

Chacala, Durango. A mining town in the foothills of the Sierra Madre in extreme western Durango, $40 \mathrm{mi}$. E Culiacán, Sinaloa; $24^{\circ} 47^{\prime}, 106^{\circ} 44^{\prime}$; $1800 \mathrm{ft}$; 8 fulvescens.

Chalchicomula (San Andrés), Puebla. A town near the western base of Volcán de Orizaba, $25 \mathrm{mi}$. NW the city of Orizaba; $18^{\circ} 59^{\prime}, 97^{\circ} 27^{\prime} ; 8400 \mathrm{ft}$.; grassland, pine forests; 5 megalotis.

Charco Escondido, Tamaulipas. A town on the coastal plain, $23 \mathrm{mi}$. S Reynosa; $25^{\circ} 46^{\prime}, 98^{\circ} 21^{\prime} ; 300 \mathrm{ft}$.; 1 fulvescens.

Charco Hondo, Jalisco. A collecting locality on the Aguascalientes-San Luis Potosí highway, $15 \mathrm{mi}^{*}$ WSW Ojuelos de Jalisco; near $21^{\circ} 48^{\prime}, 101^{\circ} 49^{\prime}$; $6600 \mathrm{ft}$.; arid plains; 1 fulvescens.

Chicalote, Aguascalientes. A village on the railroad, 9 mi. N Aguascalientes; $22^{\circ} 01^{\prime}, 102^{\circ} 16^{\prime} ; 6200 \mathrm{ft}$; semiarid plains; 3 fulvescens.

Chichén Itzá, Yucatán. Mayan ruins $23 \mathrm{mi}$. W Valladolid; $20^{\circ} 40^{\prime}, 88^{\circ} 32^{\prime}$; $75 \mathrm{ft}$; 5 gracilis.

Chihuahua, Chihuahua. Capital and largest city of the state; $28^{\circ} 38^{\prime}, 106^{\circ}$ 05'; $4700 \mathrm{ft}$.; semiarid plains and low mountains; 2 megalotis. Other specimens from 5 mi.* SE Chihuahua; $5250 \mathrm{ft}$.; 3 megalotis, 1 fulvescens.

Chilpancingo (Ciudad Bravo), Guerrero. A town on the Mexico City-Acapulco highway, $55 \mathrm{mi}$. NNE Acapulco; $17^{\circ} 33^{\prime}, 99^{\circ} 30^{\prime} ; 4100 \mathrm{ft}$. Specimens from the vicinity of town to $9 \mathrm{mi}$. S; arid grassland; 33 fulvescens.

Cielo (Rancho del), Tamaulipas. A ranch in the mountains of southwestern 
Tamaulipas, 5 mi. NiW Gómez Farías; $23^{\circ} 05^{\prime}$, 99 12'; 3500 ft.; wet broadleaf forest; 14 megalotis, 1 mexicanus.

Ciénega Well (= Ciénєga), Sonora. A collecting locality of E. A. Mearns, located on the flood plcin of the Colorado River, $30 \mathrm{mi}$. SSW junction of the River and the U. S.-México international boundary (Monument 204), almost opposite Colonia Lerdo; $32^{\circ} 11^{\prime}, 115^{\circ} 04^{\prime} ; 50 \mathrm{ft}$. ?; 3 megalotis.

Cintalapa, Chiapas. A rown in an arid valley in western Chiapas, $40 \mathrm{mi}$. W Tuxtla; $16^{\circ} 42^{\prime}$, $93^{\circ}$ ' 13 '; $1700 \mathrm{ft}$.; 7 fulvescens, 4 mexicanus.

Colima, Colima. The capital city of the state; $19^{\circ} 14^{\prime}, 103^{\circ} 43^{\prime} ; 1600 \mathrm{ft}$. Specimens from Ran ho del Ralcón, 3 mi.* W Colima (Goldman, 1951); grassland, mesquite, 1horny trees; 6 fulvescens.

Colima (El Nevado de), Jalisco. A volcano lying to the southwest of Ciudad Guzmán; summit $19^{\circ} 33^{\prime}, 103^{\circ} 37^{\prime} ; 14,200 \mathrm{ft}$. Specimens from north and south slopes 7300-10,100 ft.; 52 sumichrasti, 4 chrysopsis, 2 megalotis.

Comitán, Chiapas. A large town in southeastern Chiapas; $16^{\circ} 15^{\prime}, 92^{\circ} 08^{\prime}$; $5200 \mathrm{ft}$.; oaks, pines. Sipecimens from floor of valley and from slopes above and below Comitán; ?7 sumichrasti, 2 fulvescens, 1 mexicanus. Specimens from "mountains near Comitán" were collected at about $8000 \mathrm{ft}$. approximately 21 mi.* NW Comitán on road from Teopisca to San Cristóbal (Goldman, 1951); 4 sumichrasti.

Conde (San José del), Nayarit. A settlement in extreme southern Nayarit, 32 mi. SSE Tepic and 15 mi. SE Compostela; $21^{\circ} 05^{\prime}, 104^{\circ} 44^{\prime} ; 3000 \mathrm{ft}$. Collecting station situated $1 \mathrm{mi}$. SW Conde; arid tropical, open growth thorny shrubs and trees; 1 hirsutus.

Conejos (Los), Michoacín. Another name for Nuevo San Juan. A village 4 mi. WSW Uruapan; $19^{\circ} 22^{\prime}, 102^{\circ} 07 ' ; 6000 \mathrm{ft}$.; 1 megalotis.

Conejos (Los), Veracrui. A village at $10,600 \mathrm{ft}$. on the northern slopes of Cofre de Perote. (See Perote, Cofre de.)

Contreras, Distrito Federal. A town $11 \mathrm{mi}$. SSW Mexico City; $19^{\circ} 15^{\prime}, 99^{\circ} 15^{\prime}$; $8500 \mathrm{ft}$. Specimens from the valley floor and hills above town; open oakpine forests, grassland 40 megalotis, 1 fulvescens, 14 sumichrasti.

Contreras (Cañón), Distrito Federal. A deep canyon between Cerro San Miguel and Cerro Sarta Rosa, at the mouth of which is located the town of Contreras (see Contreras). Specimens from north and south sides of canyon 9000-10,500 ft.; oak-pine forests and fir forests; 1 megalotis, 12 chrysopsis, 2 microdor.

Córdoba, Veracruz. A c.ty in central Veracruz, $12 \mathrm{mi}$. E Orizaba; $18^{\circ} 54^{\prime}$, $96^{\circ} 55^{\prime} ; 3000 \mathrm{ft}$; 1 mexicanus.

Córdoba (Hacienda), Mixico. A ranch on the old Mexico City-Puebla highway, $20 \mathrm{mi}$. ESE Mexico City; 19 17', 98 50'; $8300 \mathrm{ft}$.; open oak forests, a few pines; 40 megaiotis, 2 fulvescens, 1 sumichrasti. 
Cortés (Paso), México. A pass in the mountains 8 mi. E Amecameca; $19^{\circ} 06^{\prime}$, $98^{\circ}$ 38'; 11,300 ft.; pine forest, sacatón; 1 chrysopsis.

Corupo, Michoacán. An Indian village $18 \mathrm{mi}$. NW Uruapan; $19^{\circ} 38^{\prime}, 102^{\circ}$ 19'; $8000 \mathrm{ft}$.? Specimens from stand of Baccharis 2 mi. S Corupo; 3 megalotis.

Costa Rica (Rancho San Francisco de), Sonora. A ranch on the coastal plain and Río Sonora, 40 mi. WSW Hermosillo; $28^{\circ} 55^{\prime}, 111^{\circ} 36^{\prime} ; 200$ ft.?; 20 burti.

Cruz y Cruz (La Cruz), Tamaulipas. A locality at Kilometer 755, MéxicoLaredo highway, $29 \mathrm{mi}$. N Victoria; $24^{\circ} 07^{\prime}, 99^{\circ} 13^{\prime} ; 800 \mathrm{ft}$.; 1 fulvescens.

Cuapongo, Guerrero. Information from W. W. Brown indicates that Cuapongo is a lumber camp deep in the mountains, about $15 \mathrm{mi}$. W Chilpancingo and $5 \mathrm{mi}$. WNW Omilteme; near $17^{\circ} 33^{\prime}, 99^{\circ} 45^{\prime}$.

Cuernavaca, Morelos. A city 35 mi. S Mexico City in the Río Balsas drainage; $18^{\circ} 55^{\prime}, 99^{\circ} 14^{\prime} ; 5000 \mathrm{ft}$.; semitropical, arid scrub; 1 fulvescens.

Cuitzeo, Michoacán. A town on the northern edge of (the dry) Lago de Cuitzeo, $18 \mathrm{mi}$. N Morelia; $19^{\circ}$ 58', 101 ${ }^{\circ}$ 09'; $6000 \mathrm{ft}$; mesquite, grassland. Specimens from south shore of the lake, 4 mi. S. Cuitzeo; 20 fulvescens.

Cuitzerán (Cerro), Michoacán. See San Juan, Michoacán.

Culiacán, Sinaloa. A large town on the coastal plain of central Sinaloa; $24^{\circ}$ $48^{\prime}, 107^{\circ} 23^{\prime}$; $100 \mathrm{ft}$; low deciduous forest; 1 fulvescens.

Cumbre (La), Oaxaca. A collecting locality 5 mi.* NE Cerro San Felipe; near $17^{\circ} 12^{\prime}, 96^{\circ} 35^{\prime} ; 9000 \mathrm{ft}$; 3 sumichrasti.

Cuyutlán (Cerro Viejo), Jalisco. A mountain south of Cuyutlán, 22 mi. SSW Guadalajara; $20^{\circ} 22^{\prime}, 103^{\circ} 27^{\prime} ; 74$ specimens of megalotis from grassland on summit, $9700 \mathrm{ft}$; and 1 specimen of megalotis from $8500 \mathrm{ft}$.

Durango, Durango. The capital city in the central part of the state; $24^{\circ} 01^{\prime}$, $104^{\circ} 40^{\prime} ; 6200 \mathrm{ft}$; mesquite, agave, cactus, grassland; 3 fulvescens.

Ejutla, Oaxaca. A town in southern Oaxaca, $32 \mathrm{mi}$. S Oaxaca de Juárez; $16^{\circ}$ 34', 96 43'; $4700 \mathrm{ft}$.; 4 megalotis.

Encarnación (de Díaz), Jalisco. A town on the railroad in northeastern Jalisco, $25 \mathrm{mi}$. S Aguascalientes; $21^{\circ} 32^{\prime}, 102^{\circ} 14^{\prime} ; 6200 \mathrm{ft}$.; mesquite-grassland. Specimens from $9 \mathrm{mi}$. N Encarnación; 2 fulvescens.

Escondido (Rancho), Michoacán. A ranch and turpentine mill, $1 \mathrm{mi}$. N Apo on the western flanks of Cerro de Tancítaro; $19^{\circ} 26^{\prime}, 102^{\circ} 25^{\prime} ; 7000 \mathrm{ft}$.; humid canyons; oak, madrone, pine forests (with epiphytes) on crests; 14 sumichrasti, 5 megalotis.

Escuinapa, Sinaloa. A town near the railroad $50 \mathrm{mi}$. SE Mazatlán and $13 \mathrm{mi}$. SSW Rosario; $22^{\circ} 50^{\prime}, 105^{\circ}$ 47'; $100 \mathrm{ft}$.; 1 fulvescens.

Esperanza (Finca), Chiapas. A coffee and cattle finca $4 \mathrm{mi}$. NE Escuintla in southern Chiapas; $15^{\circ} 20^{\prime}, 92^{\circ} 36^{\prime} ; 500 \mathrm{ft}$; 1 gracilis. 
Estancia (La), Sonora. A collecting station in foothills 6 mi. N Nacori; 2150 ft.; Nacori lies at $29^{\circ}\left(15^{\prime}, 110^{\circ} 03^{\prime} ; 1\right.$ fulvescens.

Etzatlán, Jalisco. A town $41 \mathrm{mi}$. W Guadalajara and $15 \mathrm{mi}$. N Ameca; 20 46', $104^{\circ}$ 5'; $4000 \mathrm{ft}$; mesquite, cacti, grassland; 7 fulvescens.

Galeana, Nuevo León. A town in central Nuevo León $30 \mathrm{mi}$. SW Montemorelos; $24^{\circ} 40^{\prime}, 100^{\circ} 04^{\prime} ; 5500 \mathrm{ft}$. Specimens from $7000 \mathrm{ft}$. in mountains 12 mi. NNW Galeana; pines, oaks; 5 megalotis.

García (Colonia), Chihu thua. A ranch and settlement in the Sierra Madre Occidental of northwestern Chihuahua; $29^{\circ} 58^{\prime}, 108^{\circ} 22^{\prime} ; 8200 \mathrm{ft}$.; pines, oaks; 2 megalotis.

Gómez Farías, Tamaulipas. A town at the base of the Sierra Madre Oriental, $46 \mathrm{mi}$. S Ciudad Victocia; $23^{\circ} 03^{\prime}, 99^{\circ} 09^{\prime}$; $1100 \mathrm{ft}$. Specimens from $5 \mathrm{mi}$. NE Gómez Farías; cha sarral; 4 fulvescens.

Gordo (Cerro), Veracruz A village on the Jalapa-Veracruz highway, $16 \mathrm{mi}$. SE Jalapa; $19^{\circ} 25^{\prime}, 96^{\circ} 42^{\prime}$. Specimens from 4 mi.* NNW Cerro Gordo, $1500 \mathrm{ft}$.; 20 fulvescens.

Gotera (Cañón), Chihuahua. A canyon northwest of Chihuahua; near $28^{\circ}$ $45^{\prime}, 106^{\circ} 10^{\prime}$. Specimen:; from $9 \mathrm{mi}$ * NW Chihuahua; $5550 \mathrm{ft}$.; 2 fulvescens. Guadalajara, Jalisco. Tre city north of Lake Chapala; $20^{\circ} 40^{\prime}, 103^{\circ} 20^{\prime}$; $5100 \mathrm{ft}$; grassland. Spe zimens from $8 \mathrm{mi}$. S, 1 fultuescens, and from $27 \mathrm{mi}$. S and $12 \mathrm{mi}$. W of the city, 11 megalotis.

Guadalupe (Sierra), Coahuila. Goldman (1951) stated that these mountains are located about $20 \mathrm{mi}$. SW Saltillo, with a peak elevation of $9500 \mathrm{ft}$. Apparently this range is the one that lies about $15 \mathrm{mi}$. SE Generál Cepeda (or Villa de Patos); $25^{\circ} 5^{\prime}-25^{\circ} 10^{\prime}, 101^{\circ} 10^{\prime}-101^{\circ} 25^{\prime}$; 1 megalotis.

Guadalupe y Calvo, Chil uahua. A settlement in extreme southwestern Chihuahua, about $100 \mathrm{mi}$. SW Parral; $26^{\circ} 07^{\prime}, 107^{\circ} 0^{\prime} ; 7100 \mathrm{ft}$. Pine forests giving way to aspen and few fir at higher elevations; specimens from 7000 $9000 \mathrm{ft}$. in vicinity of Hacienda del Tule at east base of Cerro Mohinora (Goldman, 1951); 3 me; ; alotis.

Guirocoba, Sonora. A ra: ch in foothills $15 \mathrm{mi}^{*} \mathrm{SE}$ Alamos; near 26 $50^{\prime}$, $108^{\circ} 40^{\prime} ; 1500 \mathrm{ft}$.; 3 fuivescens.

Guzmán (Ciudad), Jalisco. Also known as Zapotlán. The second largest city in Jalisco, 70 mi. S Guidalajara; $19^{\circ} 45^{\prime}, 103^{\circ}$ 30'; $5000 \mathrm{ft}$; desert shrub, cactus, grassland. Specimens from the vicinity of the city, 10 fulvescens; others from $10 \mathrm{mi}$. W Guzmán, $6500 \mathrm{ft}$., at the lower edge of the pine belt, 2 fulvescens, 9 sumichrasii.

Hermosillo, Sonora. A city on the arid coastal plain of west-central Sonora; $29^{\circ} 05^{\prime}, 110^{\circ} 57^{\prime} ; 800 \mathrm{ft}$. Specimens from $11 \mathrm{mi}$.* W Hermosillo; 3 burti.

Hidalgo (Villa), Oaxaca. See Yalalag. 
Hidalgo, Tamaulipas. A town on the México-Laredo highway, $42 \mathrm{mi} . \mathrm{S}$ Linares; $24^{\circ} 15^{\prime}, 99^{\circ}$ 27'; $1000 \mathrm{ft}$; 9 fulvescens.

Honey, Puebla. A settlement in northeastern Puebla, 15 mi. NE Tulancingo, Hidalgo; $20^{\circ} 15^{\prime}, 98^{\circ} 13^{\prime} ; 6000 \mathrm{ft} . ? ; 4$ megalotis, 1 sumichrasti.

Huajuapan (de León), Oaxaca. A town in northwestern Oaxaca, $50 \mathrm{mi}$. SW Tehuacán, Puebla; $17^{\circ} 48^{\prime}$, 97 47'; 5000 ft.; mesquite, thorny shrubs; 1 fulvescens.

Huamantla, Tlaxcala. A town 25 mi. NE Puebla; $19^{\circ}$ 19', $97^{\circ} 55^{\prime} ; 8200 \mathrm{ft}$.; grassy plains; 1 megalotis.

Huauchinango, Puebla. A town on the edge of the Mexican Plateau in northern Puebla; $20^{\circ} 11^{\prime}$, 98 $98^{\circ}$ 03'; $4900 \mathrm{ft}$.; at lower border of oak-pine belt and upper border of humid forest. Specimens from valley and from slopes above and below the town; 10 sumichrasti, 38 fulvescens, 1 megalotis, 2 mexicanus.

Huipulco, Distrito Federal. A village near Tlalpam, 10 mi. S Mexico City; $19^{\circ} 17^{\prime}, 99^{\circ} 10^{\prime} ; 7500 \mathrm{ft}$; 3 megalotis.

Huitzilac, Morelos. A village in extreme northwestern Morelos, $7 \mathrm{mi}$. N Cuernavaca; $19^{\circ} 02^{\prime}, 99^{\circ} 16^{\prime} ; 8200 \mathrm{ft}$. Specimens from slopes above and below village; 7500-10,000 ft.; 3 megalotis, 1 chrysopsis.

Indé, Durango. A town in northern Durango, $80 \mathrm{mi}$. SSE Parral, Chihuahua; $25^{\circ} 53^{\prime}, 105^{\circ} 11^{\prime} ; 6100 \mathrm{ft}$; mesquite-grassland plains and rolling hills dotted with oak and juniper; 1 fulvescens.

Ixtaccíhuatl (Volcán), México. A volcano north of Volcán Popocatépetl, 35 mi. SE Mexico City; the summit $19^{\circ} 10^{\prime}, 98^{\circ} 38^{\prime} ; 17,300 \mathrm{ft}$. Specimens from near timber line, 13,500 ft.; 1 chrysopsis.

Ixtlán, Oaxaca. A town in the Sierra Juárez, $24 \mathrm{mi}$. NE Oaxaca City; 17 20', $96^{\circ} 29^{\prime} ; 6200 \mathrm{ft}$; 5 megalotis.

Ixtlán (del Río), Nayarit. A town in extreme southeastern Nayarit, $47 \mathrm{mi}$. SE Tepic; $21^{\circ} 03^{\prime}, 104^{\circ} 23^{\prime} ; 4000 \mathrm{ft}$. Specimens from mesquite-dotted grassland and from marshy area along a stream 1 mi. E Ixtlán; 6 fulvescens, 2 hirsutus.

Jacales, Veracruz. A village $25 \mathrm{mi}$. NNW Tulancingo, Puebla, near the Puebla state line; $20^{\circ} 26^{\prime}, 98^{\circ} 27^{\prime}$. Specimen from 6 mi.* SW Jacales, 6500 ft.; 1 fulvescens.

Jalacingo, Veracruz. A town $32 \mathrm{mi}$. NW Jalapa; $19^{\circ} 49^{\prime}, 97^{\circ} 18^{\prime} ; 6500 \mathrm{ft}$.? Specimens from vicinity of town; 18 megalotis, 8 sumichrasti.

Jalapa, Veracruz. A city in north-central Veracruz at upper edge of arid tropical belt and near lower edge of "cloud forest" belt; $19^{\circ} 32^{\prime}, 96^{\circ} 54^{\prime}$; $4500 \mathrm{ft}$. Specimens from localities within $2 \mathrm{mi}$. of Jalapa; 8 sumichrasti, 2 fulvescens, 1 mexicanus; another from 4 mi.* SE Jalapa, 1 fulvescens.

Jalpán, Querétaro. A town in the lowlands of northeastern Querétaro; $21^{\circ}$ $14^{\prime}, 99^{\circ} 29^{\prime}$; $2500 \mathrm{ft}$; mesquite, arborescent cacti; 4 fulvescens.

Jaltenango, Chiapas. A town in a valley on the northern flanks of the Sierra 
Madre, 46 mi. SW Comitán; $15^{\circ} 52^{\prime}$, $92^{\circ}$ 43'; 2300 ft.; arid, thorny shrubs and cacti; 1 fulvescens.

Jaumave, Tamaulipas. A town in an arid valley in the Sierra Madre Oriental,

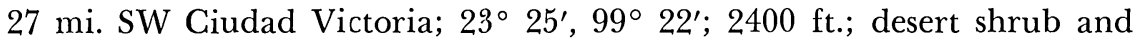
grassland; 13 fulvescer. .

Jico, Veracruz. A town a: the eastern base of the Cofre de Perote, 9 mi. SSW Jalapa; $19^{\circ} 25^{\prime}, 9^{\prime} 0^{\prime}: 4300 \mathrm{ft}$. Specimens came from the vicinity of town and upslope to about ti500 ft.; 8 sumichrasti, 3 fulvescens, 2 mexicanus.

Jimulco, Coahuila. A torwn on the railroad, $17 \mathrm{mi}$. S Torreón; $25^{\circ} 09^{\prime}, 103^{\circ}$ 21'; $4100 \mathrm{ft}$.; arid plair.s; 3 megalotis.

Juquila, Oaxaca. A towr in the Sierra Madre del Sur of extreme southern Oaxaca, $70 \mathrm{mi}$. SSW Oaxaca City; $16^{\circ} 15^{\prime}, 97^{\circ} 18^{\prime} ; 4900 \mathrm{ft}$.; moist, broadleaf forests; 12 sumichrasti.

Kilometer 46 Mexico Cily-Acapulco highway, Morelos. A collecting station near La Cima, Distrito Federal, across the line in Morelos; $19^{\circ} 05^{\prime}$, 99 ${ }^{\circ} 13^{\prime}$; 10,000 ft.; sacatón plains, oak, madrone, pines on hills; 9 chrysopsis, 7 megalotis.

Lagos (de Moreno), Jalisco. A town on the railroad in extreme northeastern Jalisco; $21^{\circ} 21^{\prime}, 101^{\circ} 55^{\prime} ; 6400 \mathrm{ft}$; mesquite-grassland; 1 fulvescens.

Lerma, México. A town $8 \mathrm{mi}$. E Toluca; 19 17', 99 32'; $9100 \mathrm{ft}$; 3 megalotis.

Limón (Hacienda), San Luis Potosí. A hacienda in extreme northeastern San Luis Potosí, $55 \mathrm{mi}$. W Tampico; 22 ${ }^{\circ} 11^{\prime}$, 98 ${ }^{\circ}$ 14'; $200 \mathrm{ft}$; 1 fulvescens.

Llano Grande, Oaxaca. A village on the coastal lowlands in southwestern Oaxaca, $18 \mathrm{mi}$. NW Pinotepa Nacional; savanna, thorny brush, and small trees (Goldman, 1951); 16 $36^{\circ}$ ', 98 ${ }^{\circ} 15^{\prime} ; 300 \mathrm{ft}$. ; ; not to be confused with the Llano Grande between Tepextla and the seacoast; 2 fulvescens.

Lobos (Puerto de), Sonorit. A village on the seacoast south of Guaymas; $30^{\circ}$ $15^{\prime}, 112^{\circ} 50^{\prime} ; 1$ megalotis.

Lulú, Zacatecas. A railroad station in extreme eastern Zacatecas, $40 \mathrm{mi}$. SSE Concepción del Oro and $10 \mathrm{mi}$. SSW the junction of Coahuila, Neuvo León, Zacatecas, and Sán Luis Potosí state boundaries; 24 28', $100^{\circ}$ 52'; $5600 \mathrm{ft}$. Specimen from $3 \mathrm{mi}$. N Lulú; 1 megalotis.

Macho de Agua, Michoacán. A locality near Kilometer 146 on the MéxicoMorelia highway, on th:e southeastern border of the Valley of Zitácuaro, 5 mi. E Zitácuaro; $100^{\circ} 17^{\prime}, 19^{\circ} 27^{\prime} ; 2$ sumichrasti.

Maltrata, Veracruz. A town $11 \mathrm{mi}$. WSW Orizaba; $18^{\circ} 49^{\prime}, 97^{\circ} 16^{\prime} ; 6000 \mathrm{ft}$.; 1 sumichrasti.

Manantlán (Rancho), Jalisco. A group of ranches in the Sierra de Autlán, 8-10 mi. S Autlán and 2-3 mi. SW Tecomatlán; 19 4.0', 104 24'; $5000 \mathrm{ft}$.; grassland, oak scrub, low thorny trees and shrubs; 1 fulvescens.

Mangiay (Pozo), Chihuahua. A collecting station of S. B. Benson, located about 30 miles by road south of Chihuahua on the Río San Pedro and on 
the power line running from Chihuahua to Horcasitos (Benson, in litt.); $5200 \mathrm{ft}$.; mesquite-grassland, desert; 1 fulvescens.

Mapastepec, Chiapas. A town on the railroad and Pacific coastal plain of southern Chiapas, $55 \mathrm{mi}$. NW Tapachula; $15^{\circ} 26^{\prime}, 92^{\circ} 54^{\prime}$; about $200 \mathrm{ft}$.; 1 gracilis.

Margaritas (Las), Chiapas. A ranch located 15 mi.* E Comitán; $16^{\circ} 20^{\prime}, 92^{\circ}$ $0^{\prime} ; 4100 \mathrm{ft}$; 10 sumichrasti.

Marqués, Hidalgo. Given by Goldman (1951) as a railroad station at $8132 \mathrm{ft}$. northwest of Tula and just north of the boundary of México; dry glassland giving way to oaks and a few pines on hills. Near $20^{\circ} 15^{\prime}, 99^{\circ} 35^{\prime} ; 1$ fulvescens.

Martínez (Rancho), San Luis Potosí. A ranch $10 \mathrm{mi}$ * $^{*} \mathrm{~S}$ Naranjas in eastern San Luis Potosí; near $22^{\circ} 25^{\prime}, 99^{\circ} 20^{\prime} ; 500 \mathrm{ft}$; 1 fulvescens.

Mascota, Jalisco. A village at the base of the Sierra San Sebastián, $30 \mathrm{mi}$. ESE Puerto Vallarta; $20^{\circ} 33^{\prime}, 104^{\circ} 49^{\prime} ; 3900 \mathrm{ft}$.? Specimen from Hacienda El Tajo at extreme NW end of valley in which Mascota is situated (Goldman, 1951); 1 fulvescens.

Matamoros, Tamaulipas. The border town on the coastal lowlands opposite Brownsville, Texas; $25^{\circ} 22^{\prime}, 97^{\circ} 31^{\prime} ; 30 \mathrm{ft}$. ? Specimens from vicinity of town, 5 fulvescens, and $6 \mathrm{mi}$.* $\mathrm{S}$ Matamoros, 2 fulvescens.

Mazatlán, Sinaloa. A city on the seacoast; $23^{\circ} 12^{\prime}, 106^{\circ} 26^{\prime}$. Collections were made at Castillo, 6 mi. E Mazatlán (Goldman, 1951); $300 \mathrm{ft} . ? ; 4$ fulvescens.

Metlaltoyuca, Puebla. A village in the lowlands of extreme northern Puebla, 35 mi. SW Tuxpan; $20^{\circ} 45^{\prime}, 97^{\circ} 51^{\prime}$; $800 \mathrm{ft}$.; dense humid tropical forest; 1 mexicanus.

Metzquititlán, Hidalgo. See San Agustín.

México, Distrito Federal. The capital of the Republic; $19^{\circ} 25^{\prime}, 99^{\circ} 10^{\prime} ; 7400$ ft. Specimens from Colonia del Valle, a colonia in the southern part of the city; 2 megalotis. Other specimens from 10-12 mi. E the city; 2 fulvescens.

Miahuatlán, Oaxaca. A town in southern Oaxaca, 50 mi. S Oaxaca de Juárez; $16^{\circ} 21^{\prime}, 96^{\circ} 35^{\prime} ; 5100 \mathrm{ft}$; 9 megalotis.

Mil Cumbres, Michoacán. A settlement and lookout on the Mexico CityMorelia highway, 15 mi. WSW Ciudad Hidalgo; 19 37', 100 46'; $9200 \mathrm{ft}$.; 1 megalotis, 1 sumichrasti.

Mirador, Veracruz. A ranch in the humid subtropics of west-central Veracruz, $27 \mathrm{mi}$. S Jalapa and $10 \mathrm{mi}$. NNE Huatusco; $19^{\circ} 17^{\prime}, 96^{\circ} 54^{\prime} ; 3000 \mathrm{ft}$; 4 fulvescens.

Miramar Grande, San Luis Potosí. A ranch 17 mi. NW Tamasunchale, a few miles west of Xilitla; $21^{\circ} 25^{\prime}, 99^{\circ} 05^{\prime} ; 5000 \mathrm{ft}$; 1 mexicanus.

Misión (La), Sonora. A collecting station 2 mi.* SW Magdalena; $2900 \mathrm{ft}$. Magdalena lies at $30^{\circ} 38^{\prime}, 111^{\circ} 0^{\prime} ; 1$ fulvescens. 
Molango, Hidalgo. A town 45 mi. N Pachuca; $20^{\circ} 48^{\prime}, 98^{\circ} 43^{\prime} ; 5400$ ft.; 14 sumichrasti, 1 mexicainus.

Monterrey, Nuevo ILeón. The capital and largest city of Nuevo León; $25^{\circ} 40^{\prime}$, $100^{\circ} 18^{\prime} ; 1800 \mathrm{ft}$. Specimens from $14 \mathrm{mi}$.* N Monterrey, $1950 \mathrm{ft}$; 6 fulvescens.

Morelia, Michoacán. A city in central Michoacán; $19^{\circ} 42^{\prime}, 101^{\circ} 11^{\prime} ; 6400 \mathrm{ft}$. The collecting station 15 mi.* ESE Morelia, $7300 \mathrm{ft}$., probably is near Temascal; 1 fulvescen.i. Other specimens from 30 mi.* E Morelia, $8500 \mathrm{ft}$., in pine and fir forest; 3 sumichrasti.

Mulato (El), Tamaulipas. A village at the northern base of the Sierra San Carlos, 30 mi. E Linares; $24^{\circ} 53^{\prime}, 99^{\circ} 05^{\prime}$; $700 \mathrm{ft}$.; thorny shrubs; 1 fulvescens.

Nahuatzin, Michoacán. A village in central Michoacán, 14 mi. SSW Zacapú; $19^{\circ} 37^{\prime}, 101^{\circ} 54^{\prime} ; 8500 \mathrm{ft}$; 10 megalotis.

Naranjos, San Luis Potosí. A settlement $15 \mathrm{mi}$. W Antiguo Morelos in the valley of the Río Mesillas; $22^{\circ} 31^{\prime}, 99^{\circ} 23^{\prime} ; 500 \mathrm{ft}$. Specimen from $3 \mathrm{mi}$. W Naranjos, $1200 \mathrm{ft}$.; 1 fulvescens.

Nautla, Veracruz. A town on the coast of central Veracruz, at the mouth of the Río Nautla; $20^{\circ} 13,96^{\circ} 45^{\prime} ; 75 \mathrm{ft}$.; 1 fulvescens.

Nejapa, Oaxaca. A town in the valley of the Río Tehuantepec, $57 \mathrm{mi}$. SE Tehuantepec; $16^{\circ} 32^{\prime}, 95^{\circ}$ 59'; $1900 \mathrm{ft}$.; 2 fulvescens.

Nochixtlán, Oaxaca. A town in north-central Oaxaca, $43 \mathrm{mi}$. NW Oaxaca City; $17^{\circ} 27^{\prime}, 97^{\circ} 14^{\prime} ; 6200 \mathrm{ft}$.; 1 fulvescens.

Nogales, Sonora. A town across the international boundary from Nogales, Arizona; $31^{\circ} 19^{\prime}, 110^{\circ}, 57^{\prime} ; 3900 \mathrm{ft}$. Specimen from vicinity of town, $1 \mathrm{ful}$ vescens; another from $14 \mathrm{mi}$ * S Nogales, 1 montanus.

Oaxaca (de Juárez), Oaxaca. The capital city of Oaxaca; $17^{\circ} 04^{\prime}, 96^{\circ} 43^{\prime}$; $5000 \mathrm{ft}$; grassland, mesıuite, thorny trees on valley floor; oak, manzanita, pine on hills; 18 fulvescens, 19 megalotis. Nelson's and Goldman's specimens from the mountains west of Oaxaca were collected in the mountains west of Cuilápan (Goldman, 1951), their camp apparently $15 \mathrm{mi}$. SW Oaxaca; near $16^{\circ} 57^{\prime}, 9 t^{\circ} 55^{\prime} ; 9300$ ft.? 1 sumichrasti, 2 megalotis.

Ocotlán, Jalisco. A city on the Río Grande de Santiago near Lago de Chapala; $20^{\circ} 21^{\prime}, 102^{\circ} 46^{\prime} ; 5000 \mathrm{ft}$; mesquite, acacias, grassland; 2 fulvescens, 3 megalotis.

Ocozocoautla, Chiapas. A rown 17 mi. W Tuxtla in western Chiapas; $16^{\circ} 46^{\prime}$, 93० 23'; $2300 \mathrm{ft}$; semiarid; 1 fulvescens.

Omilteme, Guerrero. A ra:ich on the southern slope of the Sierra Madre del Sur about $10 \mathrm{mi}$. WSW Chilpancingo; near $17^{\circ} 33^{\prime}, 99^{\circ} 40^{\prime} ; 7200 \mathrm{ft}$. ?; fir, pine, and cloud forests. Specimens from vicinity of the ranch to $3 \mathrm{mi}$. W Omilteme; 4 sumichrasti. 
Oposura (= Moctezuma), Sonora. A town on the Río Moctezuma, $90 \mathrm{mi}$. NE Hermosillo; $29^{\circ} 48^{\prime}, 109^{\circ} 41^{\prime}$; $2000 \mathrm{ft}$; 1 fulvescens.

Orizaba, Veracruz. A city in west-central Veracruz; $18^{\circ} 50^{\prime}, 97^{\circ} 06^{\prime} ; 4200 \mathrm{ft}$; wet forests, frequent clouds and fogs. Specimens from within $3 \mathrm{mi}$. of the city; 16 sumichrasti, 12 fulvescens.

Orizaba (Volcán de), Puebla and Veracruz. The highest mountain in México on the Veracruz-Puebla state boundary; summit $19^{\circ} 03^{\prime}, 97^{\circ} 16^{\prime} ; 18,700 \mathrm{ft}$. Specimens from western and southern slopes in range 9500-13,000 ft.; 3 megalotis, 1 chrysopsis.

Ozolotepec (Santa María), Oaxaca. A village $20 \mathrm{mi}$. SE Miahuatlán; 16 ${ }^{\circ}$ 13', $96^{\circ}$ 22'; $8000 \mathrm{ft} . ?$ Collections from La Cieneguía, a ranch $3 \mathrm{mi}$. N Ozolotepec, approximately 10,000 ft. (Goldman, 1951); 1 megalotis, 1 sumichrasti.

Pachuca, Hidalgo. A city in southern Hidalgo, $55 \mathrm{mi}$. NNE Mexico City; $20^{\circ} 08^{\prime}, 98^{\circ} 43^{\prime} ; 8000 \mathrm{ft}$. Specimen from $5 \mathrm{mi}$.* SW Pachuca, $8400 \mathrm{ft}$; 1 megalotis.

Pahuatlán, Puebla. A town in northern Puebla, 20 mi. NE Tulancingo, Hidalgo; $20^{\circ} 18^{\prime}, 98^{\circ} 08^{\prime}$; $4500 \mathrm{ft}$; 3 fulvescens.

Palo Amarillo (Rancho), Nayarit. A ranch in extreme southern Nayarit in the

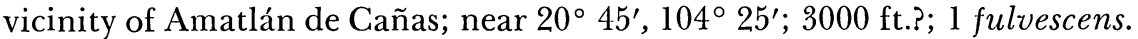

Parada (Hacienda La), San Luis Potosí. A ranch 19 mi. NW San Luis Potosí and $3 \mathrm{mi}$. S Arenal on the railroad; $22^{\circ} 20^{\prime}, 110^{\circ} 12^{\prime} ; 6000 \mathrm{ft}$.; mesquitegrassland; 6 fulvescens.

Parada (La), Oaxaca. Goldman (1951) stated that this is a hacienda situated at about $8000 \mathrm{ft}$. on the northern slopes of mountains which are west of Cerro San Felipe; 2 megalotis.

Parícutin (Volcán), Michoacán. An active volcano in western Michoacán, 15 mi. WNW Uruapan; $19^{\circ} 30^{\prime}, 102^{\circ} 16^{\prime}$. Specimen from 3 mi. NE Volcán Parícutin; $7200 \mathrm{ft}$; 1 megalotis.

Parral (Hidalgo del), Chihuahua. A large town in the foothills of the Sierra Madre in extreme southern Chihuahua; $26^{\circ} 56^{\prime}, 105^{\circ} 40^{\prime} ; 5500 \mathrm{ft}$.; semiarid plains and foothills; 1 fulvescens. Other specimens from 2 mi. W Parral; 2 megalotis.

Patambán (or Patamba), Michoacán. A town 12 mi. S Zamora at the northeastern base of Cerro Patambán; 19 48', 102 18'; $7000 \mathrm{ft}$.? Specimens from the vicinity of the town and to 12,000 ft. on the Cerro (Goldman, 1951); 8 chrysopsis, 4 megalotis, 1 sumichrasti.

Pátzcuaro, Michoacán. A town near the southeastern end of Lago de Pátzcuaro, $30 \mathrm{mi}$. WSW Morelia; $19^{\circ} 30^{\prime}, 101^{\circ} 36^{\prime} ; 7000 \mathrm{ft}$. Specimens from several collecting stations in the vicinity, from $3 \mathrm{mi}$. $^{*} \mathrm{~N}, 6700 \mathrm{ft}$., to $10 \mathrm{mi}$. SE, $9200 \mathrm{ft} . ; 78$ megalotis, 18 sumichrasti, 2 fulvescens.

Perote, Veracruz. A town at the northwestern base of the Cofre de Perote in west-central Veracruz; $19^{\circ} 34^{\prime}, 97^{\circ} 15^{\prime} ; 8000 \mathrm{ft}$.; semiarid; 6 megalotis. 
Perote (Cofre de), Veracruz. A peak in western Veracruz, $15 \mathrm{mi}$. WSW Jalapa; $19^{\circ} 30^{\prime}, 97^{\circ} 08^{\prime}$; summ it over 14,000 ft. All collections are from the northern side of the mountain $n$ the altitudinal range 9500-12,500 ft.; 15 megalotis, 2 chrysopsis.

Piedras Negras. A villag $ə$ on the coastal plain and railroad, $30 \mathrm{mi}$. S Veracruz; $18^{\circ} 46^{\prime}, 96^{\circ} 10^{\prime} ; 85 \mathrm{ft}$. Specimen from $9 \mathrm{mi}$. W Piedras Negras, $300 \mathrm{ft}$; 1 fulvescens.

Pijijiapan, Chiapas. A town on the railroad and humid tropical, Pacific coastal plain of Chiapas; located $45 \mathrm{mi}$. SW Tonalá; $15^{\circ} 41^{\prime}, 93^{\circ} 13^{\prime} ; 50 \mathrm{ft}$; 1 gracilis.

Pinabete, Chiapas. Stated by Goldman (1951) to be ranches at $8800 \mathrm{ft}$., about 48 mi.* N Tapachula and 25 mi.* NW Los Chicharras; collections made within the range 7500-8800 ft.; pines, firs, madrones; 8 sumichrasti.

Plan del Río, Veracruz. 4 settlement on the Jalapa-Veracruz highway, 20 mi. SE Jalapa; $19^{\circ} 24^{\prime}, 96^{\circ} 38^{\prime} ; 1000 \mathrm{ft}$; arid tropical, thorny shrubs, arborescent cacti. Specimens from the vicinity of the village to $3 \mathrm{mi}$. NW Plan del Río; 4 fulvescens.

Platanar, Jalisco. A towr near the railroad, 12 mi. S Ciudad Guzmán; $19^{\circ} 30^{\prime}$, $103^{\circ} 28^{\prime} ; 3200 \mathrm{ft}$. Mis spelled Plantinar on the specimen labels. Specimens from Agosto, 2 mi.* N Platanar (Goldman, 1951); 3 fulvescens.

Popocatépetl (Volcán), México. A volcano on the México-Puebla state line, the summit $11 \mathrm{mi}$. SE Amecameca; $19^{\circ} 02^{\prime}, 98^{\circ}$ 38'; 17,900 ft.; specimens from N slope, 10,800-13,000 ft.; 9 megalotis, 4 chrysopsis.

Potrero (Cañón del), Ginihuahua. An arroyo west of El Saúz. Collections from $7 \mathrm{mi}$.* $\mathrm{W}$ the town; elevation $5750 \mathrm{ft}$; 1 megalotis, 2 fulvescens. El Saúz lies at $29^{\circ} 03^{\prime}, 106^{\circ} 15^{\prime}$.

Potrero Llano, Veracruz. A collecting station on the coastal plain of northern Veracruz, 25 mi. NW 'Tuxpan; $21^{\circ} 10^{\prime}$, 97 43'; $350 \mathrm{ft}$.; 3 fulvescens.

Potrero Viejo, Veracruz. A sugar cane plantation and mill 6 mi. E Córdoba; $18^{\circ} 52^{\prime}, 92^{\circ} 50^{\prime}$; $1700 \mathrm{f}$ :.; 3 fulvescens.

Presidio, Veracruz. A railroad station $4 \mathrm{mi}$. NE Motzorongo and $17 \mathrm{mi}$. SSE Córdoba; $18^{\circ} 41^{\prime}, 96^{\circ} \triangleleft 5^{\prime} ; 1000 \mathrm{ft} . ? ; 1$ fulvescens.

Progreso, Yucatán. A town north of Mérida on the Gulf of Mexico; $21^{\circ} 18^{\prime}$, $89^{\circ} 40^{\prime} ; 1$ gracilis.

Providencia Mines, Sonora. Mines in foothills, $45 \mathrm{mi}$. NW Moctezuma and 75 mi. NNE Hermosillo; near $30^{\circ} 05^{\prime}, 110^{\circ}$. 24'; $3000 \mathrm{ft}$.?; 2 fulvescens.

Prusia, Chiapas. A coffee finca on the northern slopes of the Sierra Madre, 23 mi. NNW Mapastepec; $15^{\circ} 44^{\prime}, 92^{\circ} 44^{\prime} ; 4000 \mathrm{ft}$.; oak-pine and cloud forests; 12 mexicanus.

Pueblo Nuevo, Chiapas. A village in the mountains of northern Chiapas, 30 mi. NNW San Cristóbal; $17^{\circ} 08^{\prime}, 92^{\circ}$ 53'; 5500 ft.; 2 sumichrasti, 1 mexicanus. 
Pujal (El), San Luis Potosí. A settlement near the junction of the Río Santa María (Río Tampaón) and the México-Laredo highway, $10 \mathrm{mi}$. S Valles; $21^{\circ} 52^{\prime}, 98^{\circ} 58^{\prime} ; 300 \mathrm{ft}$; 2 fulvescens.

Punta (La), Jalisco. A village in extreme northeastern Jalisco, $24 \mathrm{mi}$. ESE Aguascalientes; $21^{\circ} 48^{\prime}, 101^{\circ} 56^{\prime} ; 6800 \mathrm{ft}$.? Specimen from 6 mi. SE Punta; 1 fulvescens.

Ramos (Río), Nuevo León. A river in northern Nuevo León. Collecting station 12 mi.* NW Montemorelos; near $25^{\circ} 19^{\prime}, 100^{\circ} 03^{\prime} ; 1000 \mathrm{ft}$; 1 fulvescens.

Ranchería, Chihuahua. A ranch in the Sierra Madre of southwestern Chihuahua. S. B. Benson, who stopped there overnight, stated (in litt.) that it is about $20 \mathrm{mi}$. E Guachochic, which would place it near $106^{\circ} 45^{\prime}, 26^{\circ} 45^{\prime}$; $6300 \mathrm{ft} . ; 1$ megalotis.

Real del Monte, Hidalgo. A mining settlement $4 \mathrm{mi}$. E Pachuca; $20^{\circ} 09^{\prime}, 98^{\circ}$ 39'; 9000 ft.; 2 megalotis.

Reforma, Oaxaca. A town on the Pacific coastal lowlands of the Isthmus of Tehuantepec, $52 \mathrm{mi}$. E Tehuantepec and $18 \mathrm{mi}$. WNW Tepantepec; $16^{\circ}$ $25^{\prime}, 94^{\circ} 28^{\prime} ; 500 \mathrm{ft} . ? ; 2$ fulvescens.

Resolana (La), Jalisco. A town in the tropical lowlands, 15 mi. SSW Autlán; $19^{\circ} 34^{\prime}, 104^{\circ} 30^{\prime}$; 1000 ft.? Specimens from 2 mi. N Resolana, $1200 \mathrm{ft}$; 38 fulvescens.

Reyes (Los), Michoacán. A town in western Michoacán, 30 mi. SSW Zamora; $19^{\circ} 35^{\prime}, 102^{\circ} 28^{\prime} ; 5000 \mathrm{ft}$.; grassland, oak, pine; 6 fulvescens.

Reyes (or Pápalo Reyes), Oaxaca. Goldman stated (1951) that this is a village at $6700 \mathrm{ft}$. on the west slope of high mountains about $10 \mathrm{mi}$.* NE Cuicatlán. The Pápalo Santos Reyes on the Amer. Geog. Soc. map lies on the south slope of mountains, $12 \mathrm{mi}$. ENE Cuicatlán; $17^{\circ} 53^{\prime}, 96^{\circ} 48^{\prime}$. Specimens from altitudinal range 6700 to $10,200 \mathrm{ft}$; 3 sumichrasti.

Reyes (Villa de), San Luis Potosí. A village 23 mi. S San Luis Potosí; 21 49', $100^{\circ} 56^{\prime} ; 6000 \mathrm{ft}$.; 1 fulvescens.

Río Blanco, Veracruz. A town on the highway $4 \mathrm{mi}$. W Orizaba; $18^{\circ} 50^{\prime}, 97^{\circ}$ 09'; $4200 \mathrm{ft}$; 1 fulvescens.

Río Frío, México. A settlement in the Monte Rio Frío Range of eastern México at about the highest point on the Mexico City-Puebla highway; $19^{\circ}$ $21^{\prime}, 98^{\circ} 40^{\prime} ; 10,000 \mathrm{ft}$. Specimens from slopes in the vicinity of Río Frío; 9500-10,500 ft.; 17 megalotis, 1 chrysopsis.

Río Verde, San Luis Potosí. A town in the broad valley of the Río Verde, 65 mi. ESE San Luis Potosí; $21^{\circ} 56^{\prime}, 100^{\circ} 0^{\prime} ; 3200 \mathrm{ft}$.; mesquite, thorny shrubs, grassland; 6 fulvescens.

Rodeo (Rancho), Nuevo León. A ranch in foothills of the Sierra Madre Oriental, 7 mi.* S Santa Catarina; near $25^{\circ} 35^{\prime}, 100^{\circ} 27^{\prime} ; 2400 \mathrm{ft}$; 1 fulvescens. 
Sabaneta, Michoacán. A collecting station 6 mi.* SSW Ciudad Hidalgo; near $19^{\circ} 37^{\prime}, 100^{\circ} 35^{\prime} ; 8000 \mathrm{ft}$; 3 megalotis.

Salado (Lago), Puebla. A.n old crater at side of Mexico City-Veracruz highway at settlement of Alchichica; $19^{\circ} 25^{\prime}, 97^{\circ} 2^{\prime} ; 8000 \mathrm{ft}$; 2 megalotis.

Salazar, México. A railroad station 17 mi. E Toluca; $19^{\circ} 1^{\prime} 9^{\prime}, 99^{\circ} 24^{\prime} ; 10,000$ $\mathrm{ft}$. Specimens from su rrounding grassy plains and adjoining fir- and pinecovered hills; 8800-10,500 ft.; 6 megalotis, 1 chrysopsis.

Saltillo, Coahuila. A cit $r$ in the Sierra Madre Oriental of southeastern Coahuila, $47 \mathrm{mi}$. WSW Nonterrey; $25^{\circ} 25^{\prime}, 101^{\circ} 0^{\prime} ; 4800 \mathrm{ft}$; arid plains, creosote bush, yucca, ancl ocotillo, giving way to oak, juniper, and piñon on low hills; 1 megalotis.

Salto (El), Durango. A settlement in southwestern Durango; $23^{\circ} 47^{\prime}, 105^{\circ} 22^{\prime}$; approximately $8300 \mathrm{ft}$; pine-oak forests; 2 megalotis.

San Agustín (= Metzqu titlán), Hidalgo. A town in eastern Hidalgo situated near the place where the Pachuca-Zacualtipán road crosses the Río Tulancingo; $20^{\circ} 32^{\prime}, 98^{\circ} 38^{\prime}$; $4700 \mathrm{ft}$. Collections were made in a deep, dry barranca at about $3500 \mathrm{ft}$; cacti of many kinds were abundant there; $3 \mathrm{ful}$ vescens.

San Andrés (Cerro), Michoacán. A mountain in northeastern Michoacán, the summit $10 \mathrm{mi}$. NNW Ciudad Hidalgo; $19^{\circ} 48^{\prime}, 100^{\circ} 35^{\prime} ; 12,900 \mathrm{ft}$. Specimens from the ridge 1:o the west of the main peak; from dry oak woods, $8000 \mathrm{ft}$., to moist pine fir forests, $9400 \mathrm{ft}$; 8 sumichrasti, 5 megalotis, 2 microdon.

San Angel, Distrito Fed(ral. A suburb of Mexico City $8 \mathrm{mi}$. SSW the center of the City; $19^{\circ} 20^{\prime}, 93^{\circ} 13^{\prime} ; 7500 \mathrm{ft}$. Specimens from the pedregal; sparse brush, cactus; 2 megalıtis.

San Antonio (de Jaral), Coahuila. A settlement $30 \mathrm{mi}$. NW Saltillo and $3 \mathrm{mi}$. S Jaral; $25^{\circ} 37^{\prime}, 101^{\circ}$ '?2'; $4000 \mathrm{ft}$.; 2 fulvescens.

San Bartolomé, Chiapas A town on the slopes of the Río de Chiapa Valley, $28 \mathrm{mi}$. WNW Comitár.; $16^{\circ} 20^{\prime}, 92^{\circ} 34^{\prime}$; $2600 \mathrm{ft}$.; 1 fulvescens.

San Bartolomé, Distrito Federal. A village $10 \mathrm{mi}$. SW Mexico City and $2 \mathrm{mi}$. NW Contreras; $19^{\circ} 20^{\prime}, 99^{\circ} 16^{\prime} ; 8500 \mathrm{ft}$. Specimen from the pine- and oakstudded hills above the village; 1 sumichrasti.

San Carlos, Veracruz. A town near the seacoast $20 \mathrm{mi}$. NNW Veracruz, 19 ${ }^{\circ}$ $24^{\prime}, 96^{\circ} 21^{\prime} ; 25 \mathrm{ft}$; 3 fulvescens.

San Cristóbal (Las Casas), Chiapas. A city in central Chiapas; $16^{\circ} 45^{\prime}, 92^{\circ} 33^{\prime}$; $7100 \mathrm{ft}$.; oak-pine. Col lections from 7000-9500 ft. in the vicinity of the city and on ridges to southeast; oak-pine forests, grassland, cloud forests; 27 sumichrasti. Specimens from $6 \mathrm{mi}$. SE San Cristóbal, 7300 ft., collected in humid forest; 4 sumichrasti, 1 microdon.

San Felipe (Cerro), Oaxica. A short range of mountains in central Oaxaca. 
The highest cerro lies $9 \mathrm{mi}$. N Oaxaca City; $17^{\circ} 11^{\prime}, 96^{\circ} 40^{\prime} ; 10,200 \mathrm{ft}$. Specimens from 8000-10,000 ft.; 3 sumichrasti, 1 megalotis, 1 microdon.

San Francisco Solano, Chiapas. A ranch situated about 25 mi.* NW Comitán; $5500 \mathrm{ft} . ? ; 23$ sumichrasti.

San Gabriel, Jalisco. Also known as Villa Carranza. A town $18 \mathrm{mi}$. W Ciudad Guzmán at the northwestern base of the Nevado de Colima; $19^{\circ} 43^{\prime}, 103^{\circ}$ 48 ; $4300 \mathrm{ft}$; ; cactus, thorny shrubs, grassland. Specimens from $1 \mathrm{mi}$. N San Gabriel; 24 fulvescens.

San Gerónimo (San Jerónimo), Distrito Federal. A village near San Ángel on

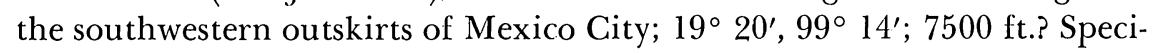
mens from the pedregal adjoining the village; shrubs, cactus, sparse grass; 7 fulvescens, 2 megalotis.

San Gregorio, Chiapas. Listed on specimen label as $30 \mathrm{~km}$. NE San Cristóbal, 2000 meters. Probably the San Gregorio situated 19 mi. E San Cristóbal; $16^{\circ} 43^{\prime}, 92^{\circ} 20^{\prime} ; 6500 \mathrm{ft}$.; 1 sumichrasti.

San Isidro, Veracruz. A village $10 \mathrm{mi}$. W Tuxpan on the south bank of the Río Tuxpan on the hot coastal plain; 20 57', 97 33'; $100 \mathrm{ft}$.; 2 fulvescens.

San José, Chiapas. A settlement near the Guatemala border, $28 \mathrm{mi}$. ESE Comitán; $16^{\circ} 07^{\prime}, 91^{\circ} 45^{\prime} ; 5000 \mathrm{ft}$; 1 sumichrasti, 1 mexicanus.

San José, Nayarit. See Conde.

San José (Hacienda), Sinaloa. A ranch 21 mi.* NE Rosario; near $23^{\circ} 05^{\prime}, 105^{\circ}$ 35 ; $350 \mathrm{ft}$.; 2 fulvescens.

San Juan, Campeche. A village on the railroad, 35 mi. S Campeche City and 15 mi. E Champotón; $19^{\circ} 18^{\prime}, 90^{\circ}$ 29'; $100 \mathrm{ft}$.; 1 gracilis.

San Juan, Durango. A village 12 mi. WSW Gómez Palacio on the Río Nazas; $25^{\circ} 29^{\prime}, 103^{\circ} 40^{\prime} ; 3800 \mathrm{ft}$; specimens from mesquite river bottom; $1 \mathrm{ful}$ vescens.

San Juan (de Parangaricutiro), Michoacán. A village destroyed by Volcán Parícutin, $14 \mathrm{mi}$. NW Uruapan; $19^{\circ} 32^{\prime}, 102^{\circ} 15^{\prime} ; 7700 \mathrm{ft}$. Specimens from open pine woods and brush 2 mi. NNW San Juan on Cerro Cuitzerán; 3 megalotis.

San Lucas, Chihuahua. A settlement $40 \mathrm{mi}$. SSE Chihuahua City on the Río San Pedro; $28^{\circ} 06^{\prime}, 105^{\circ} 45^{\prime} ; 4000 \mathrm{ft}$.? Specimens from 9 mi.* SE San Lucas on the Río San Pedro; $5300 \mathrm{ft}$.?; 2 fulvescens.

San Mateo, Distrito Federal. A village $10 \mathrm{mi}$. SW Mexico City; $19^{\circ} 20^{\prime}, 99^{\circ}$ 17'; $9000 \mathrm{ft}$.; fir, pine, oak forest in canyon; 1 chrysopsis.

San Rafael, Chiapas. A settlement 12 mi.* SE San Cristóbal; near $16^{\circ} 38^{\prime}, 92^{\circ}$ 32 '; $5000 \mathrm{ft}$.; 21 sumichrasti.

San Sebastián, Jalisco. A village in the Sierra San Sebastián, 28 mi. SE Puerto Vallarta; $20^{\circ} 46^{\prime}, 104^{\circ}$ 53'; $4000 \mathrm{ft}$. Specimens labeled San Sebastián were collected at various places and altitudes (Goldman, 1951); 8 fulvescens, 2 hirsutus. 
San Vicente, Chiapas. A hacienda at $4000 \mathrm{ft}$. near the Guatemala border on the north side of the R.io de Chiapa Valley. Collections made in altitudinal range 3500-4000 ft. (Coldman, 1951); 1 fulvescens.

Santa Ana (Potrero), San Luis Potosí. A potrero $71 / 2$ mi.* S Matehuala. Matehuala lies at $23^{\circ} .38^{\prime}, 100^{\circ} 39^{\prime} ; 5300 \mathrm{ft}$; 1 fulvescens.

Santa Catarina, Nuevo l_eón. A town on the Monterrey-Saltillo road, $10 \mathrm{mi}$. W Monterrey; $25^{\circ} 35^{\prime}, 100^{\circ}$ 27'; $2000 \mathrm{ft}$; 3 fulvescens.

Santa Engracia (Hacienda), Tamaulipas. A ranch and resort at the base of the Sierra Madre Oriental, $25 \mathrm{mi}$. N Ciudad Victoria; $24^{\circ} 02^{\prime}, 99^{\circ} 16^{\prime} ; 800$ ft.?; chaparral; 8 fulvescens.

Santa Isabel, Nayarit. A village on the Guadalajara-Tepic highway, $30 \mathrm{mi}$. SSE Tepic; $21^{\circ} 10^{\prime}, 10^{\circ} \iota^{\circ} 38^{\prime} ; 3500 \mathrm{ft}$. Specimens from grassland and shallow tree-lined barranca 2 mi. N Santa Isabel, 4 fulvescens and 3 hirsutus, and from deep, humid barranca $4 \mathrm{mi}$. N Santa Isabel, 1 fulvescens, 9 hirsutus.

Santa María, Veracruz. Goldman (1951) identified this place as a village at $1800 \mathrm{ft}$. near river of same name (= Río Pescados) about $20 \mathrm{mi}$ * NE Mirador; 4 fulvescens. The Río Pescados on my maps courses less than 10 miles from Mirador; $1800 \mathrm{ft}$. on that river would be near Jalconiulco, $19^{\circ} 20^{\prime}, 96^{\circ} 45^{\prime}$.

Santa Rosa, Distrito Ferleral. A village $11 \mathrm{mi}$. SW Mexico City and $3 \mathrm{mi}$. WNW Contreras; $19^{c} 19^{\prime}$, 99 $19^{\circ}$; $9000 \mathrm{ft}$. Specimens from fir-studded canyon near the village and on adjoining slopes; 4 megalotis, 1 chrysopsis.

Santa Rosa, Guanajuato. A mining settlement in the Sierra Guanajuato, 5 mi. NE Guanajuato; $21^{\circ} 04^{\prime}, 101^{\circ} 12^{\prime} ; 8200 \mathrm{ft}$.?; oak, madrone; 1 megalotis.

Santa Rosa, Quintana Roo. A hacienda 10 mi. S Peto, Yucatán; $19^{\circ} 58^{\prime}$, 88 53'; $100 \mathrm{ft}$; 1 gracilis.

Sauceda (La), Sonora. A settlement $15 \mathrm{mi}$. NNE Cananea; $31^{\circ} 10^{\prime}, 110^{\circ} 10^{\prime}$; $4400 \mathrm{ft}$; 6 megalotis.

Silao, Guanajuato. A town on the railroad $20 \mathrm{mi}$. N Irapuato; $20^{\circ} 57^{\prime}, 101^{\circ}$ 26'; 5800 ft.; mesquite-grassland; 2 fulvescens.

Silla (Cerro de la), Nuevo León. A mountain with a saddle-shaped crest lying to the southeast of Mo:nterrey; summit $25^{\circ} 35^{\prime}, 100^{\circ} 13^{\prime} ; 5700 \mathrm{ft}$. Specimens from altitude range 2000-3500 ft.; 3 fulvescens.

Sinaloa, Sinaloa. A town on the coastal lowlands of northern Sinaloa; $25^{\circ} 50^{\prime}$, $108^{\circ} 13^{\prime} ; 200 \mathrm{ft}$. ; 2 fulvescens.

Sola de la Vega, Oaxaca. 4 town in south-central Oaxaca, 40 mi. SSW Oaxaca City; $16^{\circ} 32^{\prime}, 96^{\circ} 58^{\prime}$; $5000 \mathrm{ft}$; 17 megalotis, 2 fulvescens.

Sombrerete, Zacatecas. A town in northwestern Zacatecas; $23^{\circ} 38^{\prime}, 103^{\circ} 39^{\prime}$; $7800 \mathrm{ft}$. Specimens from $8 \mathrm{mi}$. W and $1 \mathrm{mi}$. N Sombrerete; $7800 \mathrm{ft}$; 1 megalotis.

Sonora mesa, Sonora. A collecting locality of Nelson and Goldman located $20 \mathrm{mi}$. S U.S.-México international boundary on high bank above the Colorado River, $100 \mathrm{ft}$. (Goldman, 1951); 1 megalotis. 
Tacámbaro, Michoacán. A town south of Pátzcuaro; on U. S. Aeronautical Charts $19^{\circ} 14^{\prime}, 101^{\circ} 28^{\prime}$; $5200 \mathrm{ft}$.; on Amer. Geog. Soc. map 19॰ 06', $101^{\circ} 20^{\prime}$; $6100 \mathrm{ft}$. Specimens from vicinity of town to $6 \mathrm{mi}$. S Tacámbaro; 4000-5700 ft.; 19 fulvescens.

Talpa (de Allende), Jalisco. A town in western Jalisco, $30 \mathrm{mi}$. SE Puerto Vallarta; $20^{\circ} 23^{\prime}, 104^{\circ} 51^{\prime} ; 4000 \mathrm{ft}$; grassland, scattered pine and oak; 1 fulvescens.

Tamaulipeca, Tamaulipas. A ranch on the northwestern foothills of Sierra San Carlos, $32 \mathrm{mi}$. ESE Linares and $14 \mathrm{mi}$. NNW San Carlos; $24^{\circ} 45^{\prime}$, $99^{\circ}$ 04'; $1500 \mathrm{ft}$; thorny shrubs; 1 fulvescens.

Tamazulapan, Oaxaca. A town in northern Oaxaca, 15 mi. SE Huajuapan; $17^{\circ} 40^{\prime}, 97^{\circ} 35^{\prime} ; 6500 \mathrm{ft}$.; scrub oak, grassland; 1 megalotis.

Tamazunchale, San Luis Potosí. A town at the base of the Sierra Madre Oriental on the Río Moctezuma and México-Laredo highway; $21^{\circ} 16^{\prime}, 98^{\circ}$ 47'; $700 \mathrm{ft}$.; humid tropical forests; 1 fulvescens.

Tampico Alto, Veracruz. A town 10 mi. S Tampico; $22^{\circ} 07^{\prime}, 97^{\circ} 48^{\prime} ; 50 \mathrm{ft}$; 2 fulvescens.

Tamuín, San Luis Potosí. A town on the Río Santa María, 15 mi. E Valles; $22^{\circ} 0^{\prime}, 98^{\circ} 46^{\prime} ; 200 \mathrm{ft}$.; 4 fulvescens.

Tancítaro (Cerro de), Michoacán. A volcano in western Michoacán, the summit $15 \mathrm{mi}$. W Uruapan; $19^{\circ} 25^{\prime}, 102^{\circ} 18^{\prime} ; 12,700 \mathrm{ft}$. Specimens from the northern slopes, 6000-12,000 ft.; 21 sumichrasti, 9 chrysopsis.

Tehuacán, Puebla. A large town in southeastern Puebla; $18^{\circ} 28^{\prime}, 97^{\circ} 24^{\prime}$; $5400 \mathrm{ft}$.; mesquite, acacia, cactus desert; 5 fulvescens.

Tehuatlán, Veracruz. A village on the coastal lowlands, $18 \mathrm{mi}$. SW Tuxpan on the Tulancingo-Tuxpan highway; $20^{\circ} 44^{\prime}, 97^{\circ} 33^{\prime} ; 700 \mathrm{ft}$. Specimen from 3 mi. S Tehuatlán; 1 fulvescens.

Teloloapan, Guerrero. A town on the slopes of the Río Balsas Basin in northcentral Guerrero, 22 mi. W Iguala; 18 ${ }^{\circ} 21^{\prime}$, 99 32'; $5400 \mathrm{ft}$; 4 fulvescens.

Temascal, Michoacán. A road junction $15 \mathrm{mi}$. E Morelia; $7000 \mathrm{ft}$.; grassland, pine-oak; 1 fulvescens.

Tenejapa, Chiapas. A village $9 \mathrm{mi}$. NNE San Cristóbal on the eastern flanks of Cerro Zontehuitz; $16^{\circ} 49^{\prime}, 92^{\circ} 31^{\prime} ; 6400 \mathrm{ft}$. Specimens from slopes up to $7800 \mathrm{ft}$. above town (Goldman, 1951); 2 sumichrasti.

Teocelo, Veracruz. A village $10 \mathrm{mi}$. SSW Jalapa, and 3 mi. ESE Jico; $19^{\circ} 23^{\prime}$, $96^{\circ} 58^{\prime} ; 4500 \mathrm{ft}$.; 22 fulvescens.

Teopisca, Chiapas. A town on the road between San Cristóbal and Comitán, $18 \mathrm{mi}$. SE San Cristóbal and $2 \mathrm{mi}$. W Amatenango; $16^{\circ} 30^{\prime}, 92^{\circ} 30^{\prime} ; 5900 \mathrm{ft}$. Collections from vicinity of town and from a ranch at about $6700 \mathrm{ft}$. near Teopisca; 35 sumichrasti.

Teotitlán, Oaxaca. A village in extreme northern Oaxaca, $30 \mathrm{mi}$. SE Tehuacán, Puebla; $18^{\circ} 08^{\prime}, 97^{\circ} 07^{\prime}$; $3100 \mathrm{ft}$.; arid; 8 fulvescens. 
Tepanco, Puebla. A village on the Puebla-Tehuacán highway, $13 \mathrm{mi}$. NW Tehuacán; $18^{\circ}$ 33', 97० 34'; $6000 \mathrm{ft}$.; mesquite desert; 5 fulvescens.

Tepic, Nayarit. The carital city on the plains of the south-central part of the state; $21^{\circ} 31^{\prime}, 104^{\circ} 54^{\prime}$; $3100 \mathrm{ft}$.; grass on valley floor, scrub oak on adjoining hills; 2 fulvescens.

Tepoztlán, Morelos. A rown in northern Morelos, $10 \mathrm{mi}$. ENE Cuernavaca; $18^{\circ} 58^{\prime}, 99^{\circ} 06^{\prime} ; 6000 \mathrm{f}$ :; oak, tall shrubs, semitropical. Specimens from $1 \mathrm{mi}$. W Tepoztlán; 6 fulveiscens.

Tequisquiapam, Querétaro. A town on the Río Moctezuma, $30 \mathrm{mi}$. ESE Querétaro; $20^{\circ} 31^{\prime}, 99^{\circ} 53$ '; $6200 \mathrm{ft}$.; mesquite-grassland; 2 fulvescens.

Terán (General), Nuevo León. A town $38 \mathrm{mi}$. SE Monterrey; $25^{\circ} 15^{\prime}, 99^{\circ} 40^{\prime}$. Specimens from $12 \mathrm{mi}$ * NW Terán; $700 \mathrm{ft}$; 5 fulvescens.

Tetecala, Morelos. A town in western Morelos, 17 mi. SW Cuernavaca; $18^{\circ}$ $14^{\prime}, 99^{\circ} 24^{\prime} ; 3300 \mathrm{ft}$.; I fulvescens.

Texcoco, México. A tow $\mathrm{n}$ in the Valley of México, $25 \mathrm{mi}$. ENE Mexico City; $19^{\circ} 31^{\prime}, 98^{\circ} 35^{\prime}$; $7400 \mathrm{ft}$; arid plains. Specimens from $3 \mathrm{mi}$. NW Texcoco; 2 megalotis.

Teziutlán, Puebla. A tcwn in northeastern Puebla near the Veracruz state line; $19^{\circ} 49^{\prime}, 97^{\circ} 21^{\prime} ; 7600 \mathrm{ft}$.; 8 sumichrasti, 6 mexicanus.

Tlacotepec, Veracruz. A village on the lower slopes of the Sierra Madre Oriental, $8 \mathrm{mi}$. ENE ]Huatusco and $2 \mathrm{mi}$. NNE Córdoba; $19^{\circ} 12^{\prime}, 96^{\circ} 50^{\prime}$. Specimens from 9 mi. ESE Tlacotepec; $1500 \mathrm{ft}$.; 2 fulvescens.

Tlalixtaquilla, Guerrero. A town in the Sierra Madre del Sur in extreme eastern Guerrero, 13 mi. SSE Tlapa; $17^{\circ} 23^{\prime}, 98^{\circ}$ 29'; $5000 \mathrm{ft}$.; 1 fulvescens.

Tlalpam, Distrito Federal. A town in the southern outskirts of Mexico City; $19^{\circ} 17^{\prime}, 99^{\circ} 10^{\prime} ; 7600$ t.t.; semiarid, maguey, grassland; 4 fulvescens.

Tlapa, Guerrero. A tow'n in the Sierra Madre del Sur in extreme eastern Guerrero, 60 mi. E Chilpancingo; $17^{\circ}$ 33', 98 33'; $3000 \mathrm{ft}$.; 1 fulvescens.

Tlapacoyán, Veracruz. A village $35 \mathrm{mi}$. NNW Jalapa and $3 \mathrm{mi}$. E Puebla state line; $19^{\circ} 58^{\prime}, 97^{\circ} 13^{\prime} ; 1700 \mathrm{ft}$; 1 mexicanus.

Tlapancingo, Oaxaca. A village in the Sierra Madre del Sur, $10 \mathrm{mi}$. E Guerrero state line; $17^{\circ} 30^{\prime} .98^{\circ} 15^{\prime} ; 5200 \mathrm{ft}$; open oak, pine forest; 2 megalotis.

Tlaxcala, Tlaxcala. A town $18 \mathrm{mi}$. N Puebla; $19^{\circ} 18^{\prime}, 98^{\circ} 14^{\prime} ; 7500 \mathrm{ft} . ? ;$ grassy plains. Specime ss from 5 to $8 \mathrm{mi}$. SW Tlaxcala; 2 megalotis, 1 sumichrasti.

Toluca, México. The caj)ital of the state, $35 \mathrm{mi}$. WSW Mexico City; 19॰ 17', $99^{\circ}$ 39'; $8800 \mathrm{ft}$. Nelson's and Goldman's specimens labeled Toluca Valley probably were obtain $\epsilon$ d near San Juan de las Huertas, $10 \mathrm{mi}$. SW Toluca; 19॰ 12', 99॰ 47'; $9300 \mathrm{ft}$.; 2 megalotis.

Toluca (Volcán), Méxicc. A volcano $12 \mathrm{mi}$. SW Toluca; summit $19^{\circ} 07^{\prime}, 99^{\circ}$ $45^{\prime} ; 15,000 \mathrm{ft}$. Specimens from northern and western slopes; 10,000-12,000 ft.; oak, pine, fir, sacation; 3 megalotis, 5 chrysopsis. 
Totolapan (Totolapa), Oaxaca. A town on the Pan American Highway and Río Tehuantepec, $37 \mathrm{mi}$. SE Oaxaca City; $16^{\circ} 40^{\prime}, 96^{\circ} 18^{\prime} ; 2800 \mathrm{ft}$. Collections from Los Bichones, 6 mi. SE Totolapan (Goldman, 1951); 4000 ft.?; 1 fulvescens.

Totontepec, Oaxaca. A village on the flanks of Cerro Zempoaltepec, $40 \mathrm{mi}$. ENE Oaxaca and 9 mi. ENE Yalalag; $17^{\circ} 13^{\prime}, 96^{\circ} 03^{\prime} ; 6000 \mathrm{ft}$.; subtropical forest; 2 mexicanus.

Tula, Hidalgo. A town in southern Hidalgo, $45 \mathrm{mi}$. NNW Mexico City; $20^{\circ}$ 03'; $99^{\circ}$ 20'; $6700 \mathrm{ft}$.; semiarid, mesquite, grassland; 1 fulvescens.

Tulancingo, Hidalgo. A town in southeastern Hidalgo, 23 mi. E Pachuca; $20^{\circ} 05^{\prime}, 98^{\circ} 22^{\prime} ; 7000 \mathrm{ft} . ; 11$ megalotis.

Tumbalá, Chiapas. A settlement in northern Chiapas, $46 \mathrm{mi}$. NNE San Cristóbal and $5 \mathrm{mi}$. N Yajalón; $17^{\circ} 18^{\prime}, 92^{\circ} 18^{\prime} ; 5200 \mathrm{ft}$. Collections 5000 $5500 \mathrm{ft}$.; 33 sumichrasti, 3 mexicanus.

Tzararacua Falls, Michoacán. Waterfalls on the Río Cupatitzio, $4 \mathrm{mi}$. S Uruapan; $19^{\circ} 22^{\prime}, 102^{\circ} 04^{\prime} ; 4400 \mathrm{ft}$; oak and pine on hills, brush in canyon; 4 fulvescens.

Unión (La), Chihuahua. A ranch in the Sierra Madre of southwestern Chihuahua. S. B. Benson, who stopped there, stated (in litt.) that probably it is about $10 \mathrm{mi}$. N Guachochic; $8400 \mathrm{ft}$. On the U. S. Aeronautical Charts Guachochic is located at $107^{\circ} 04^{\prime}, 26^{\circ} 47^{\prime} ; 1$ megalotis.

Uruapan, Michoacán. A city in western Michoacán; $19^{\circ} 25^{\prime}, 102^{\circ} 03^{\prime} ; 5300 \mathrm{ft}$.; semitropical, lower border of oak and pine zone. Specimens from Cupatitzio Park and airport; 2 sumichrasti, 8 fulvescens.

Valle (Colonia del), Distrito Federal. See Mexico City.

Valles, San Luis Potosí. A town on the México-Laredo highway in northeastern San Luis Potosí; $21^{\circ} 59^{\prime}, 99^{\circ} 01^{\prime} ; 300 \mathrm{ft}$; 1 fulvescens.

Valparaíso, Zacatecas. A town on the western slopes of the Sierra Madre Occidental in southeastern Zacatecas; $22^{\circ} 46^{\prime}, 103^{\circ} 34^{\prime} ; 6400 \mathrm{ft}$.; mesquite, grassland; specimens from valley and adjoining hills, 6200-6700 ft. (Goldman, 1951); 6 fulvescens.

Valparaíso (Sierra de), Zacatecas. Mountains to the west and north of the town of Valparaíso. Nelson's and Goldman's specimens were obtained from 8200 to $8700 \mathrm{ft} ., 13 \mathrm{mi}$ * $^{*}=8 \mathrm{mi}$. ?] due west of Valparaíso (Goldman 1951); 13 megalotis.

Venta (La), Distrito Federal. A locality on the Mexico City-Toluca highway, $1 \mathrm{mi}$. E México state line; $19^{\circ} 18^{\prime}, 99^{\circ} 20^{\prime} ; 9500 \mathrm{ft}$.; 1 chrysopsis.

Victoria (Ciudad), Tamaulipas. A large town in west-central Tamaulipas at the base of the Sierra Madre Oriental; $23^{\circ} 44^{\prime}, 99^{\circ} 08^{\prime} ; 1100 \mathrm{ft}$; mesquite; 5 fulvescens.

Victoria (Guadalupe), Veracruz. A settlement in west-central Veracruz, 31/2 mi.* SW Perote; near 19 $32^{\prime \prime}, 97^{\circ} 17^{\prime} ; 8300 \mathrm{ft}$.; 1 megalotis. 
Viejo (Cerro), Jalisco. Stee Cuyutlán.

Vigas (Las), Veracruz. A town at the northern base of the Cofre de Perote, 13 mi. NW Jalapa; $19^{\circ} £ 9^{\prime}, 97^{\circ} 05^{\prime} ; 7900 \mathrm{ft}$. Specimens from vicinity of town to pedregal 2 mi. E Las Vigas; 7800-8500 ft.; 24 megalotis, 3 sumichrasti.

Villa Flores, Chiapas. A town in the Río Santo Domingo Valley, $37 \mathrm{mi}$. SSW Tuxtla Gutiérrez; $16^{\circ} 15^{\prime}, 93^{\circ} 16^{\prime} ; 2000 \mathrm{ft}$; arid; 3 fulvescens, 5 mexicanus.

Xuchil, Veracruz. A collecting station of E. Heller and C. M. Barber, apparently on the southeastern flanks of Volcán Orizaba in extreme eastern Veracruz; $18^{\circ} 53^{\prime}, 97^{\circ} 14^{\prime}: 7500-8000 \mathrm{ft}$.; 8 megalotis. Barber stated (in litt.) that he and Heller lef: the city of Orizaba by railway for Esperanza, where the railroad begins the descent from the plateau to the lowlands; thence they continued by rail to Xuchil. He believes that Xuchil is on the edge of the Plateau. Operaling from Xuchil they contacted a Mr. Chopin, who owned the short branch railroad serving the town and country around his place. Chopin provided them with mules and a guide on their trip to timber line on Volcán de Orizaba. The Esperanza that he mentioned apparently is the town and railroad junction located about 10 miles southeast of Chalchicomula, Puebla. From Esperanza junction there is (or was) a branch railroad running to the northeast through Atziziutla (or Ataiziutla), on the southeastern flanks of the Volcán, into the state of Veracruz and terminating at or near Xuchil. This appears to be Heller and Barber's collecting locality.

Yahaltun, Campeche. A village $55 \mathrm{mi}$. SSE Campeche City and $30 \mathrm{mi}$. SE Champotón; $19^{\circ} 03^{\prime}, \subseteq 0^{\circ} 22^{\prime} ; 300 \mathrm{ft}$.; 1 gracilis.

Yalalag (Villa Hidalgo), Oaxaca. A town $35 \mathrm{mi}$. ENE Oaxaca City at the eastern base of Cerro 2 empoaltepec; $17^{\circ} 12^{\prime}, 96^{\circ} 10^{\prime} ; 3800 \mathrm{ft}$.; 1 fulvescens.

Yautepec, Morelos. A lar£e town in northern Morelos, 12 mi. ESE Cuernavaca; $18^{\circ} 52^{\prime}, 99^{\circ} 04^{\prime} ; 4000 \mathrm{fl}$; ; arid tropical; 1 fulvescens.

Zacatecas, Zacatecas. A city in the foothills of the Sierra Madre in southwestern part of the state; $c_{1}^{\prime} 2^{\circ} 47^{\prime}, 102^{\circ} 34^{\prime} ; 7600 \mathrm{ft}$.; grassy plains and rolling hills; 2 megalotis.

Zacualpilla, Veracruz. A village near Zacualapan, and the Puebla state line, 23 mi. N Tulancingo: Puebla; $20^{\circ} 25^{\prime}, 98^{\circ} 22^{\prime}$. Specimen from $3 \mathrm{mi}$ ** WSW Zacualpilla; 650 J ft.; 1 fulvescens.

Zacualtipán, Hidalgo. A town on the Pachuca-Molango highway, $37 \mathrm{mi}$. N Pachuca; $20^{\circ} 39^{\prime}, 98^{\circ}: 7^{\prime} ; 6000 \mathrm{ft}$.; 18 sumichrasti.

Zamora, Michoacán. A large town in northwestern Michoacán; $19^{\circ} 59^{\prime}, 102^{\circ}$ $17^{\prime} ; 5100 \mathrm{ft}$; d desert shrub, mesquite, grassland. Specimens from the vicinity of town and on lava cutcrops $4 \mathrm{mi}$. E Zamora; $5500 \mathrm{ft}$.; 12 megalotis, 3 fulvescens.

Zapotlán, Jalisco. See Guzmán, Ciudad.

Zarca, Durango. A town in northern Durango, 75 mi. WNW Gómez Palacio; 
$25^{\circ} 50^{\prime}, 104^{\circ} 43^{\prime} ; 6100 \mathrm{ft}$; mesquite, grassland. Specimens from $14 \mathrm{mi}$. E Zarca, $6700 \mathrm{ft}$; 5 fulvescens, 1 megalotis.

Zempoala (Lagos), México. Lakes $10 \mathrm{mi}$. NNW Cuernavaca, Morelos, near the boundary of the states of Morelos, México, and Distrito Federal; $19^{\circ} 03^{\prime}, 99^{\circ}$ 19'; $9400 \mathrm{ft}$; fir, pine, oak; 3 megalotis.

Zempoaltepec (Cerro), Oaxaca. A peak 50 mi. E Oaxaca City; $17^{\circ} 10^{\prime}, 96^{\circ} 0^{\prime}$; over 11,000 ft.; specimens from west side of mountain in range 8000-10,500 ft. (Goldman, 1951); 4 megalotis.

Zimapán, Hidalgo. A town on the Pan American Highway in northern Hidalgo; $20^{\circ} 44^{\prime}, 99^{\circ} 23^{\prime}$; $6000 \mathrm{ft}$.; arid, cactus, mesquite; 6 fulvescens.

\section{NICARAGUA}

Coco (Río). A large river in northern Nicaragua heading in mountains in the north-central part of the country and emptying into the Caribbean Sea at Puerto Cabo. Specimens labeled simply Río Coco; 1 mexicanus.

San Rafael del Norte, Jinotega. A town in northern Nicaragua, $70 \mathrm{mi}$. $\mathrm{N}$ Managua; $13^{\circ} 10^{\prime}, 86^{\circ} 05^{\prime} ; 3800 \mathrm{ft}$; 10 sumichrasti.

Savala. A locality said to be situated east of Matagalapa on the Atlantic slope (Allen, 1910); 1 sumichrasti.

\section{PANAMÁ}

Boquerón, Chiriquí. A village in the Pacific coastal lowlands of western Panamá, 14 mi. NW David; $8^{\circ} 32^{\prime}, 82^{\circ}$ 35'; $1000 \mathrm{ft}$.; 2 mexicanus.

Bóquete, Chiriquí. A settlement on the eastern flanks of Volcán de Chiriquí; $8^{\circ} 45^{\prime}, 82^{\circ} 27^{\prime} ; 3500 \mathrm{ft} . ? ; 6$ mexicanus.

Cana (Santa Cruz de), Darién. A town in extreme eastern Panamá, near the Colombian national boundary; $7^{\circ} 47^{\prime}, 77^{\circ} 42^{\prime}$; $2000 \mathrm{ft}$; 8 darienensis.

Casita Alta, Chiriquí. A collecting station on Finca Lerida on the eastern slopes of Volcán de Chiriquí (see Chiriquí); $7500 \mathrm{ft}$; 2 mexicanus, 3 creper.

Chebo (Río), Chiriquí. A tributary to the Río Chiriquí Viejo, entering that river from the northwest at approximately $8^{\circ} 48^{\prime}, 82^{\circ} 46^{\prime}$; specimens from stations along the river; 14 mexicanus.

Chiriquí (Volcán de), Chiriquí. A large volcano near the Costa Rica boundary; summit $9^{\circ} 30^{\prime}, 83^{\circ} 30^{\prime} ; 11,400 \mathrm{ft}$. Specimens from slopes of the Volcán and within its crater, 10,000-11,300 ft.; 38 sumichrasti, 22 creper, 1 mexicanus. Other specimens from specific localities on the Volcán as follows (information from Pearson, in litt.):

Copeta; a hill on the eastern flank somewhat separate from the main cone; $10,000 \mathrm{ft} . ; 15$ creper.

Cilindro; a structure a few miles north of Bóquete on the Caribbean slope; 4 creper.

Hortigal; a small, deep valley, richly forested, on the eastern flanks; 9 creper. 
Cerro Punta; a locality on the northwestern flanks, about $20 \mathrm{mi}$. ${ }^{*} \mathrm{~N} \mathrm{La}$ Concepción, east of the Río Chiriquí Viejo; $6000 \mathrm{ft} . ; 2$ mexicanus.

Cilindro, Chiriquí. See ('hiriquí.

Copeta, Chiriquí. See Chiriquí.

Gariché (Río), Chiriquí A stream draining the southwestern slopes of Cerro Aperzogadas (W of Volcán de Chiriquí). Specimens from the vicinity of the Río, 5 mi.* SW Volcán.(post office); $3200 \mathrm{ft}$; 7 mexicanus.

Hortigal, Chiriquí. See Dhiriquí.

Pando or Pondo (Cerro), Chiriquí. A peak on the Panamá-Costa Rica boundary; summit $8^{\circ} 32^{\prime}, 82^{\circ} 50^{\prime} ; 10,400 \mathrm{ft}$; 1 mexicanus.

Punta (Cerro), Chiriquí. See Chiriquí.

Santa Clara (Río), Chiriquí. A tributary to the Río Chiriquí Viejo; near $8^{\circ}$ $48^{\prime}, 82^{\circ} 46^{\prime} ; 1$ mexicanus.

Siola, Chiriquí. A collecting station on the Río Colorado, a tributary (from the northwest) to Río Chiriquí Viejo, $10 \mathrm{mi}$.* WNW El Volcán post office (Pearson, in litt.); 410 ) ft.; 16 mexicanus.

Wald, Chiriquí. A colecting station $3800 \mathrm{ft}$. on the Río Chiriquí Viejo (Pearson, in litt.); 1 mexicanus.

PANAMA GANAL ZONE

Gatun. A town at the north end of Gatun Lake; $9^{\circ} 18^{\prime}, 79^{\circ} 55^{\prime}$; near sea level; 1 darienensis.

\section{LITERATURE CITED}

Allen, Joel A.

$1891 a$ Notes on a Collection of Mammals from Costa Rica. Bull. Amer. Mus. Nat. Hist., 3: 203-18.

$1891 b$ On a Collection of Mammals from Southern Texas and Northeastern Mexico. Ibid., 3: 219-cis.

1893 List of Mammals Collected by Mr. Charles P. Rowley in the San Juan Region of Colorado, Neiv Mexico and Utah, with Descriptions of New Species. Ibid., 5: $69-84$.

1894 Descriptions of Ten New North American Mammals, and Remarks on Others. Ibid., 13: 317-32.

$1895 a$ On the Species of the Genus Reithrodontomys. Ibid., 7: 107-43.

$1895 b$ Descriptions of Ne:w American Mammals. Ibid., 7: 327-40.

$1896 a$ On Mammals Collected in Bexar County and Vicinity, Texas, by Mr. H. P. Attwater, with Field Notes by the Collector. Ibid., 8: 47-80.

$1896 b$ Descriptions of New North. American Mammals. Ibid., 8: 233-40, 2 pls.

1899 Descriptions of Five New American Rodents. Ibid., 12: 11-17.

1903 List of Mammals Cillected by Mr. J. H. Batty in New Mexico and Durango, with Descriptions of New Species and Subspecies. Ibid., 19: 587-612.

1904 Mammals from Southern Mexico and Central and South America. Ibid., 20: 29-80, 18 figs.

1906 Mammals from the: States of Sinaloa and Jalisco, Mexico, Collected by J. H. Batty During 1904 a ad 1905. Ibid., 22: 191-262, 14 pls. 
1908 Mammals from Nicaragua. Ibid., 24: 647-70.

1910 Additional Mammals from Nicaragua. Ibid., 28: 87-115.

1912 Mammals from Western Colombia. Ibid., 31: 71-95.

1916 List of Mammals Collected in Colombia by the American Museum of Natural History Expeditions, 1910-1915. Ibid., 35: 191-238.

Allen, Joel A., and F. M. Chapman

$1897 a$ On Mammals from Yucatan, with Descriptions of New Species. Bull. Amer. Mus. Nat. Hist., 9: 1-12.

$1897 b$ On a Collection of Mammals from Jalapa and Las Vigas, State of Vera Cruz, Mexico. Ibid., pp. 197-208.

Alston, Edward R.

1879 Mammalia. In Biologia Centrali-Americana. (Ed. by F. D. Godman.) 1: 1-220, 22 pls.

Audubon, John J., and J. Bachman

1841 Descriptions of New Species of Quadrupeds Inhabiting North America. Proc. Acad. Nat. Sci. Phila., 1: 92-103.

1842 Descriptions of New Species of Quadrupeds Inhabiting North America. Journ. Acad. Nat. Sci. Phila., 8: 280-323.

1849 The Quadrupeds of North America. New York: George R. Lockwood. 11: 1-334, 50 pls.

1851 The Viviparous Quadrupeds of North America. New York: V. G. Audubon. 11: 1-334.

BAILEY, VERNON

1905 Biological Survey of Texas. N. Amer. Fauna, 25: 1-222, 16 pls., 24 figs.

1931 Mammals of New Mexico. Ibid., 53: 1-412, 22 pls., 58 figs.

1936 The Mammals and Life Zones of Oregon. Ibid., 55: 1-416, 52 pls., 102 figs.

BAIrd, SPENCER F.

1855 Characteristics of Some New Species of North American Mammalia, Collected Chiefly in Connection with the U. S. Surveys of a Railroad Route to the Pacific. Proc. Acad. Nat. Sci. Phila., 7: 333-35.

1857 Mammals. Part I. General Report upon the Zoology of the Several Pacific Railroad Routes. Explorations and Surveys for a Railroad Route from the Mississippi River to the Pacific Ocean. Washington, D. C. Vol. 8. Pp. xlviii $+757,43$ pls., 35 figs.

BANGS, OUTRAM

1902 Chiriqui Mammalia. Bull. Mus. Comp. Zool. Harvard Univ., 39: 17-51, 27 figs.

Benson, SETH B.

1935 The Status of Reithrodontomys montanus (Baird). Journ. Mammalogy, 16: 139-42.

1939 Descriptions and Records of Harvest Mice (Genus Reithrodontomys) from Mexico. Proc. Biol. Soc. Wash., 52: 147-50, 1 fig.

BERry, EDWARd W.

1918 Paleogeographic Significance of the Cenozoic Floras of Equatorial America and the Adjacent Regions. Bull. Geol. Soc. Amer., 29: 631-36.

BRown, BARNUM

1908 The Conard Fissure, A Pleistocene Bone Deposit in Northern Arkansas, with Descriptions of Two New Genera and Twenty New Species of Mammals. Mem. Amer. Mus. Nat. Hist., 9, pt. 4: 155-208, 12 pls., 3 figs.

BURT, William H.

1938 Faunal Relationships and Geographic Distribution of Mammals in Sonora, Mexico. Misc. Publ. Mus. Zool. Univ. Mich., 39: 1-77. 
Carr, Archie F., JR.

1950 Outline for a Classification of Animal Habitats in Honduras. Bull. Amer. Mus. Nat. Hist., 94: 563-94, 22 pls., 6 figs.

Carriker, M. A., JR.

1910 An Annotated L st of the Birds of Costa Rica Including Cocos Island. Ann. Carnegie Mu:i, 6: 314-915.

Chapman, Frank M.

1917 The Distribution of Bird-life in Colombia; a Contribution to a Biological Survey of South America. Bull. Amer. Mus. Nat. Hist., 36: x $+729,41$ pls., 21 figs.

Collins, H. H.

1923 Studies of the Pelitge Phases and of the Nature of Color Variations in Mice of the Genus Peromyscus. Journ. Exper. Zool., 38: 45-93, 7 pls., 15 figs.

Cours, Elliot

1874 Synopsis of the Muridae of North America. Proc. Acad. Nat. Sci. Phila., 26: 173-96.

1877 Muridae. Monogriphs of North American Rodentia, No. 1. Pp. i + 264, 5 pls. In Report of the United States Geological Survey of the Territories, 9: xii + $\mathrm{x}+1091,7$ pls.

Cushing, John E., JR.

1945 Quaternary Rodertts and Lagomorphs of San Josecito Cave, Nuevo Leon, Mexico. Journ. Mamm alogy, 26: 182-85.

Dalquest, Walter $W$.

1948 Mammals of Wast ington. Univ. Kans. Publ. Mus. Nat. Hist., 2: 1-444, 140 figs.

Davis, William B.

1944 Notes on Mexican Mammals. Journ. Mammalogy, 25: 370-403, 1 fig.

Dice, LEE R.

1937 Mammals of the Sin Carlos Mountains and Vicinity. In The Geology and Biology of the San Ca: los Mountains, Tamaulipas, Mexico. Univ. Mich. Studies, Sci. Ser., 12: 245-68, 3 figs.

Dickey, Donald R., and A. J. van Rossem

1938 The Birds of El Salvador. Field Mus. Nat. Hist., Zool. Ser., 23: 1-609, 24 pls.

ElLerman, John R.

1941 The Families and Genera of Living Rodents. Family Muridae. London: The British Museum. Vol. II. Pp. xii $+690,50$ figs.

Elliot, Daniel G.

1899 Description of Aprarently New Species and Sub-species of Mammals from Oklahoma Territory. Field Columbian Mus., Zool. Ser., 1: 279-82.

1901 A List of the Land and Sea Mammals of North America North of Mexico. Ibid., 2: $477-522,7$ pls.

1903 A List of a Collecion of Mexican Mammals with Descriptions of Some Apparently New For ms. Ibid., 3: 141-49.

1905 Descriptions of Apparently New Species and Subspecies of Mammals from Mexico and San Domingo. Proc. Biol. Soc. Wash., 18: 233-36.

Enders, Robert K., and O. P. Pearson

1940 A new Subspecies of Reithrodontomys mexicanus from Panama with Remarks on R. mexicanus cherrii. Notulae Nat., 60: 1-2.

Giglioli, EnRico H.

1874 Ricerche intorno a lla distribuzione geografica generale o corologie degli animali vertebrati. III Regione Boreo-Americana. Boll. Soc. Geog. Italiana, 11: $321-66$. 
Goldman, Edward A.

1920 Mammals of Panama. Smithson. Misc. Coll., 69, No. 5: 1-309, 39 pls., 24 figs.

1951 Biological Investigations in Mexico. Smithson. Misc. Coll., 113: xiii $+476,71$ pls.

Goodwin, George G.

1932 Three New Reithrodontomys and Two New Peromyscus from Guatemala. Amer. Mus. Novitates, 560: 1-5.

1934 Mammals Collected by A. W. Anthony in Guatemala, 1924-1928. Bull. Amer. Mus. Nat. Hist., 68: 1-60, 5 pls.

1937 Two New Harvest Mice from Honduras. Amer. Mus. Novitates, 921: 1-2.

1942 Mammals of Honduras. Bull. Amer. Mus. Nat. Hist., 79: 107-95.

1943 Two New Harvest Mice from Costa Rica. Amer. Mus. Novitates, 1231: 1-2.

1945 Four New Rodents from Costa Rica. Ibid., 1293: 1-4.

1946 Mammals of Costa Rica. Bull. Amer. Mus. Nat. Hist., 87: 271-474, 1 pl., 50 figs.

GraY, J.

1843 [Published Excerpts of letter from J. Gray to the Curator of the Zoological So-

GRINNELL, JOSEPH ciety of London.] Proc. Zool. Soc. London, p. 79.

1908 The Biota of the San Bernardino Mountains. Univ. Calif. Publ. Zool., 5: 1-170, 25 pls.

1933 Review of the Recent Mammal Fauna of California. Ibid., 40: 71-234.

GRINNELL, JosePh, and H. S. SWARTH

1913 An Account of the Birds and Mammals of the San Jacinto Area of Southern California with Remarks upon the Behavior of Geographic Races on the Margins of Their Habitats. Ibid., 10: 197-406, 5 pls., 3 figs.

Griscom, LudLow

1932 The Distribution of Bird-life in Guatemala. A Contribution to a Study of the Origin of Central American Bird-life. Bull. Amer. Mus. Nat. Hist., 64: ix +439 , 11 figs.

HALl, E. RAYMOND

1946 Mammals of Nevada. Berkeley and Los Angeles: Univ. Calif. Press. Pp. xi + 710. 12 pls., 485 figs.

HaLl, E. RAYmond, and B. Villa R.

1949a A New Harvest Mouse from Michoacan, Mexico. Proc. Biol. Soc. Wash., 62: 163-64.

$1949 b$ Un nuevo raton de campo genero Reithrodontomys de Michoacan, Mexico. Anuario por 1947 del Comisión Impulsora y Coordinadora de la Investigación Scientifica, pp. 173-75.

1949c An Annotated Check List of the Mammals of Michoacán, México. Univ. Kans. Publ. Mus. Nat. Hist., 1: 431-72, 2 pls., 1 fig.

1950 Lista anotada de los mammiferos de Michoacan, Mexico. Anal. Inst. Biol., 21: 159-214, 5 figs.

Hershoovitz, Philip

1941 The South American Harvest Mice of the Genus Reithrodontomys. Occ. Papers Mus. Zool. Univ. Mich. 441: 1-7.

1944 A Systematic Review of the Neotropical Water Rats of the Genus Nectomys (Cricetinae). Misc. Publ. Mus. Zool. Univ. Mich., 58: 1-88, 4 pls., 5 figs.

Hibbard, Claude W.

1938 Distribution of the Genus Reithrodontomys in Kansas. Univ. Kans. Sci. Bull., 25: $173-79,1 \mathrm{pl}$. 
1941 The Borchers Fauna, a New Pleistocene Interglacial Fauna from Meade County, Kansas. State Geol. Surv. Kans. Bull., 38: 197-220.

1944 A Checklist of Kansas Mammals, 1943. Trans. Kans. Acad. Sci., 47: 61-88.

Hill, John Eric, and C. W. Hibbard

1943 Ecological differentiation between Two Harvest Mice (Reithrodontomys) in Western Kan:ias. Journ. Mammalogy, 24: 22-25.

Hinton, Martin A. C.

1926 Monograph of the: Voles \& Lemmings (Microtinae) Living and Extinct. London: The British Museum. Pp. xvi $+488,15$ pls., 110 figs.

Hooper, EMMET T.

1943 Geographic Varia ion in Harvest Mice of the Species Reithrodontomys humulis. Occ. Papers Mus. Zool. Univ. Mich., 477: 1-19.

1944 San Francisco $\mathrm{Ba}_{r}$ as a Factor Influencing Speciation in Rodents. Misc. Publ. Mus. Zool. Univ. Mich., 59: 1-89, 5 pls.

1947 Notes on Mexican Mammals. Journ. Mammalogy, 28: 40-57.

1949 A New Subspecies of Harvest Mouse (Reithrodontomys) from Central America. Proc. Biol. So:. Wash., 62: 169-72.

$1950 a$ A New Subspecie; of Harvest Mouse (Genus Reithrodontomys) from Chiapas, Mexico. Jourrı. Wash. Acad. Sci., 40: 418-19.

$1950 b$ Descriptions of Tivo Subspecies of Harvest Mice (Genus Reithrodontomys) from Mexico. Proc. Biol. Soc. Wash., 63: 167-70.

Howell, Arthur $\mathrm{H}$.

1914 Revision of the $\Lambda$ merican Harvest Mice (Genus Reithrodontomys). N. Amer. Fauna, 36: 1-!17, 7 pls., 6 figs.

1932 Descriptions of Tro New Harvest Mice from Honduras. Proc. Biol. Soc. Wash., 45: $125-26$.

1935 The Harvest Mice of San Luis Valley, Colorado. Journ. Mammalogy, 16: 143-44.

LEConte, JoHN

1853 Descriptions of Three New Species of American Arvicolae, with Remarks upon Some Other A merican Rodents. Proc. Acad. Nat. Sci. Phila., 6: 404-15.

LILLJEBorg, Wilhelm

1866 Systematisk öfversigt af de Gnagande Däggdjuren, Glires. Uppsala: Kongl. Akad. Boktryckeriet. Pp. 1-59.

LOWERY, GEORGE H., JR.

1943 Check-list of the Mammals of Louisiana and Adjacent Waters. Occ. Papers Mus. Zool. La. State Univ., 13: 213-57.

Lundell, Cyrus L.

1937 The Vegetation of Petén. Carnegie Inst. Wash. Publ. 478: ix + 244, 39 pls.

Martinez, Maximino

1948 Los Abies Mexicanos. Ann. Inst. Biol. Mex., 19: 11-104, 82 figs.

MAYR, ERNST

1947 Systematics and the Origin of Species from the Viewpoint of a Zoologist. New York: Columbia Univ. Press. Pp. xiv + 334, 29 figs.

\section{MERRIAM, C. HART}

1892 The Geographic Listribution of Life in North America with Special Reference to the Mamma lia. Proc. Biol. Soc. Wash., 7: 1-64.

1900 Description of a N ew Harvest Mouse (Reithrodontomys) from Mexico. Ibid., 13: 152. 
1901 Descriptions of 23 New Harvest Mice (Genus Reithrodontomys). Proc. Wash. Acad. Sci., 3: 547-58.

Miller, Gerrit S., JR.

1912 List of North American Land Mammals in the United States National Museum, 1911. Bull. U.S. Nat. Mus., 79: xiv + 455.

Miller, Gerrit S., Jr., and J. A. G. Rehn

1901 Systematic Results of the Study of North American Land Mammals to the Close of the Year 1900. Proc. Boston Soc. Nat. Hist., 30: 1-352.

Olson, Everett C., and P. I. McGrew

1941 Mammalian Fauna from the Pliocene of Honduras. Bull. Geol. Soc. Amer., 52: 1219-44, 4 pls., 5 figs.

\section{OsgoOd, WiLFRED $\mathrm{H}$.}

1907 Some Unrecognized and Misapplied Names of American Mammals. Proc. Biol. Soc. Wash., 20: 43-52.

1909 Revision of the Mice of the American Genus Peromyscus. N. Amer. Fauna, 28: $1-285,8$ pls., 11 figs.

Pearson, Oliver P.

1939 Three New Small Mammals from Eastern Panama. Notulae Nat., 6: 1-5.

Poole, Arthur J., and V. S. Schantz

1942 Catalog of the Type Specimens of Mammals in the United States National Museum, Including the Biological Surveys Collection. Bull. U.S. Nat. Mus., 178: xiii +705 .

RIDGWAY, ROBERT

1912 Color Standards and Color Nomenclature. Washington, D. C.: Published by the author. Pp. iv + 44, 53 pls.

Rinker, George. C., and E. T. Hooper

1950 Notes on the Cranial Musculature in Two Subgenera of Reithrodontomys (Harvest Mice). Occ. Papers Mus. Zool. Univ. Mich., 528: 1-12, 1 pl.

DE SAussure, Henri

1860 Note sur quelques mammifères du Mexique. 3rd Art. Rev. et Mag. de Zool., Ser. 2, 12: 97-110, 4 pls.

1861 Note complémentaire sur quelques mammifères du Mexique. Ibid., 13: 3-5.

SCHINZ, HEINRICH

1845 Systematisches Verzeichniss aller bis jetz bekannten Säugethiere; oder Synopsis Mammalium nach dem Cuvier'schen System. Band II. Solothurn: Jent und Gaszmann. Pp. iv + 574 + 51 .

Schuchert, Charles

1935 Historical Geology of the Antillean-Caribbean Region. New York: John Wiley and Sons. Pp. xxvi $+811,107$ figs.

Simpson, GEORGE G.

1930 Additions to the Pleistocene of Florida. Amer. Mus. Novitates, 406: 1-14, 7 figs.

Smith, Clarence F.

1936 Notes on the Habits of the Long-tailed Harvest Mouse. Journ. Mammalogy, 17: 274-78.

Svihla, Ruth D.

1931 Notes on the Desert and Dusky Harvest Mice (Reithrodontomys megalotis megalotis and R. m. nigrescens). Journ. Mammalogy, 12: 363-65.

Thomas, OldFIELD

1882 On a Small Collection of Mammalia from Central Mexico. Proc. Zool. Soc. London. Pp. 371-72. 
1898 On Seven New Snall Marnmals from Ecuador and Venezuela. Ann. Mag. Nat. Hist., Ser. 7, 1: 451-57.

1907 On Neotropical Mammals of the Genera Callicebus, Reithrodontomys, Ctenomys, Dasypus, and Marmosa. Ibid., 20: 161-68.

1917 On the Arrangemient of the South American Rats Allied to Oryzomys and Rhipidomys. 1bid., Ser. 8, 20: 192-98.

TOMES, RoBert F.

1861 Report of a Collection of Mammals Made by Osbert Salvin, Esq., F.Z.S., at Dueñas, Guatımala; with Notes on Some of the Species, by Mr. Fraser. Proc. Zool. Soc. London. Pp. 278-88, 1 pl.

Trouessart, E. L.

1897 Catalogus Mammi.lium tam viventium quam fossilium. Fasc. III. Rodentia II (Myomorpha, Hystrichomorpha, Lagomorpha). Berolini: R. Friedländer und Sohn. Pp. 453-664.

True, Frederick W.

1884 A Provisional List of the Mammals of North and Central America, and the West Indian Islands. Proc. U. S. Nat. Mus., 7: 487-611.

WATERHouse, GeOrge R.

1837 Characters of Twc New Genera of Rodentia (Reithrodon and Abrocoma), from Mr. Darwin's Lollection. Proc. Zool. Soc. London, 1837: 29-32.

WiNGE, HERLuF

1924 Pattedyr-Slaegter. Vol. II. Rodentia, Carnivora, Primates. København: H. Hagerups Forlag. ]'p. 1-321.

Wolf, John N., R. T. WAREH.IM, and H. T. SCOFIELD

1949 Microclimates and Macroclimate of Neotoma, a Small Valley in Central Ohio.

Ohio Biol. Surv., Vol. \&, Bull. 41: viii + 267, 97 figs.

Wood, Albert E.

1947 Rodents-a Study in Evolution. Evolution, 1: 154-62, 5 figs.

Wood, Albert E., and R. W. Wilson

1936 A Suggested Nome aclature for the Cusps of the Cheek Teeth of Rodents. Journ.

Paleontol., 10: 388-91, 2 figs. 


\section{PLATE I}

An estimate of the interrelationships of species of Reithrodontomys in time and space. Relative latitudinal positions of the several phyletic branches are suggested by the positions and lengths of the rectangles. For geographic ranges of present-day species see Map 12. The several phyletic lines and branches thereof stemmed from geographically isolated segments of polytypic species. Much of the division of the stocks that gave rise to modern forms took place in a north-south direction. The basic polytypic species inhabited central and southern México and northern Central America. A barrier approximately at the present position of the Isthmus of Tehuantepec divided the ancestral polytypic species into northern and southern segments. The northern segment gave rise to Reithrodontomys. Aporodon developed from the southern part. There have been similar subsequent divisions and a series of movements and countermovements of the evolving stocks. For other explanation see text. 


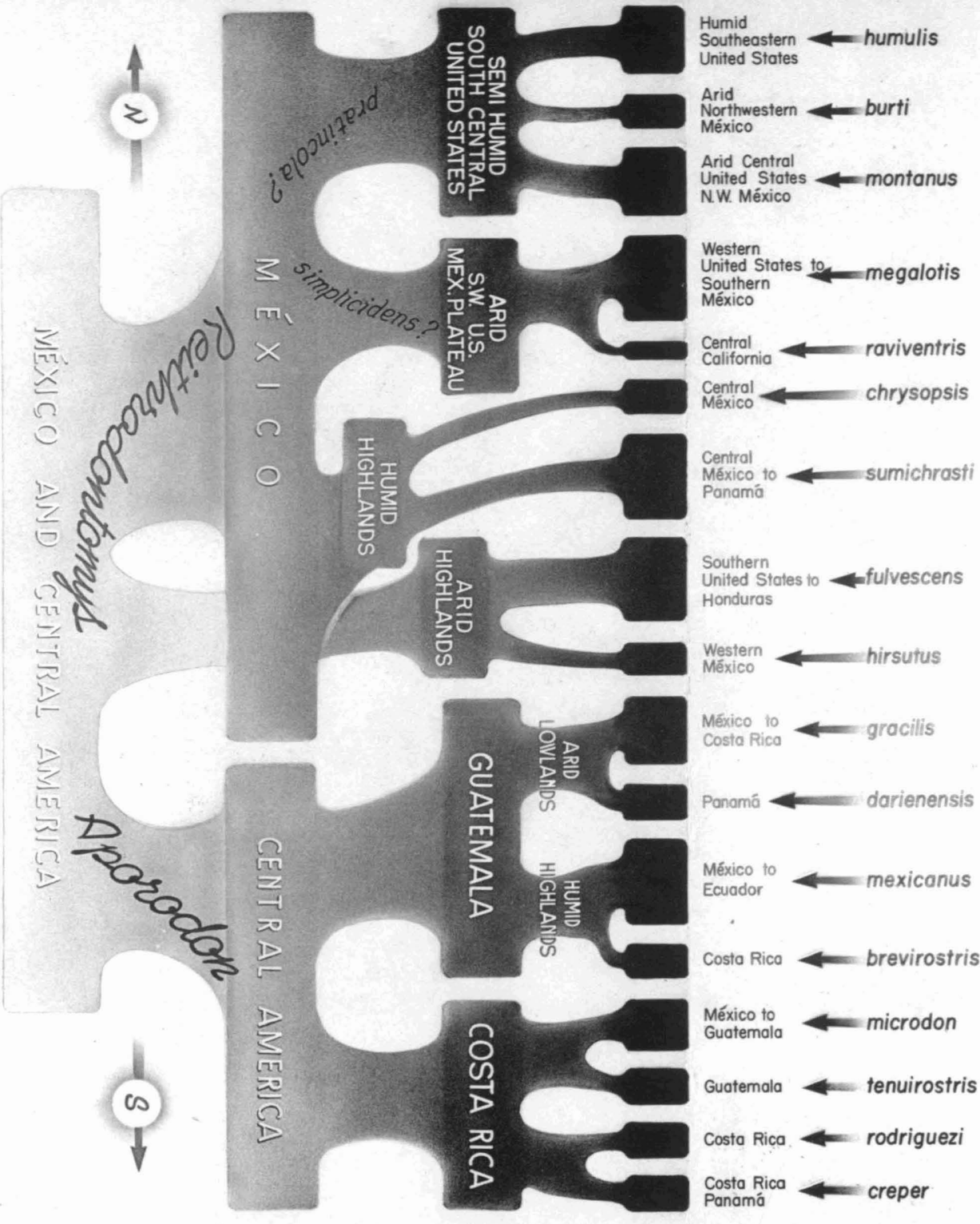




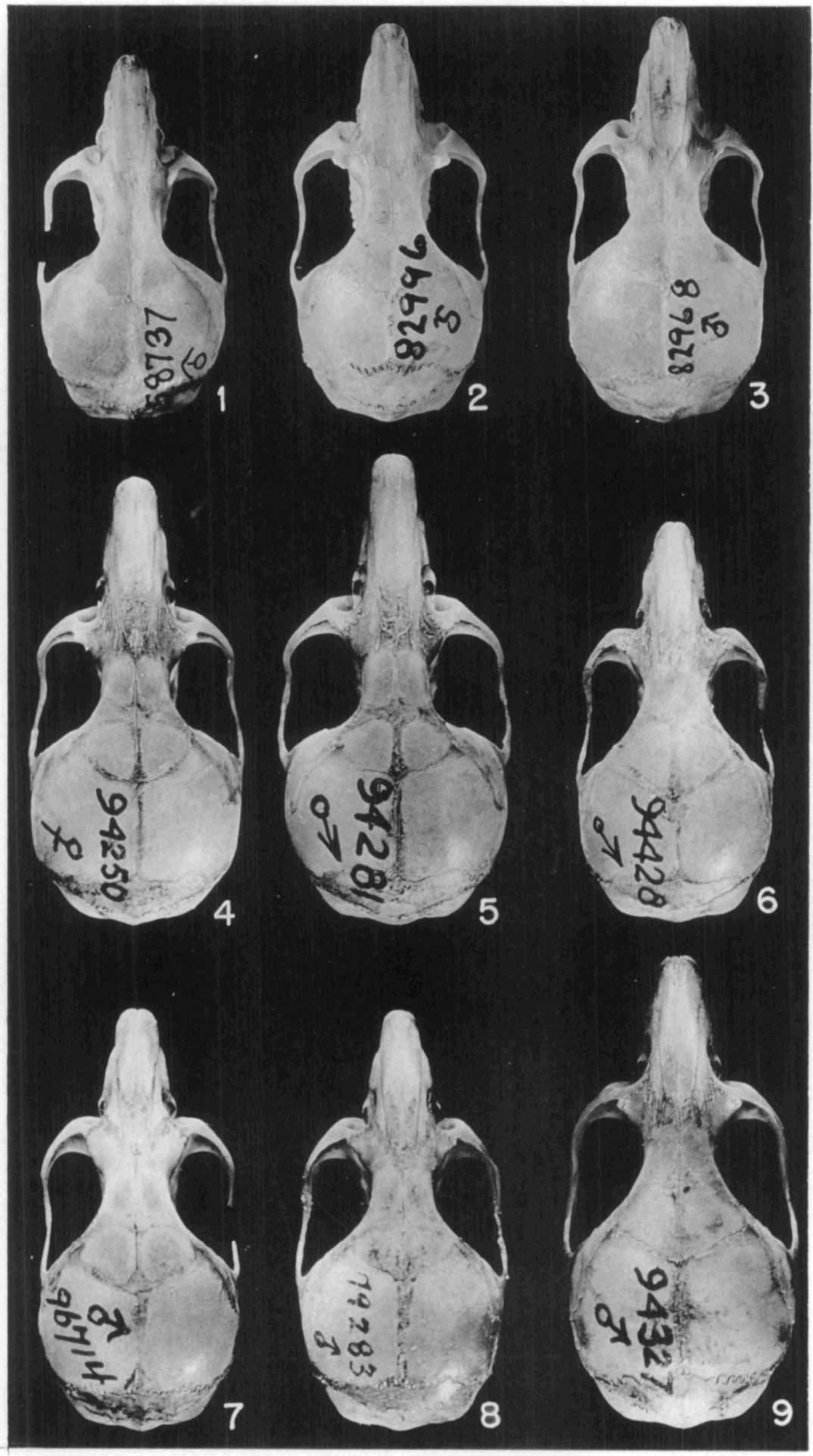




\section{PLATE II}

Dorsal aspect of crania of species inhabiting western México. Approximately $21 / 2$ times natural size.

Fig. 1. R. montanus montanus. MVZ 58737 o, 3 mi. N Socorro, New Mexico.

Fic. 2. R. burti. MVZ 82996 ð, Rancho San Francisco de Costa Rica, Sonora.

Fig. 3. R. megalotis megalotis. MVZ 82968 o , La Sauceda, Sonora.

Fic. 4. R. sumichrasti nerterus. UMMZ 94250 \%, El Nevado de Colima, Jalisco.

Fig. 5. R. chrysopsis chry'sopsis. UMMZ 94281 ơ, El Nevado de Colima, Jalisco.

Fig. 6. $R$. fulvescens nelsoni. UMMZ 94428 ơ, La Resolana, Jalisco.

Fig. 7. $R$. fulvescens tenuis. US $96714 \delta$, near Mazatlán, Sinaloa.

Fig. 8. R. fulvescens canus. UMMZ 79283 ${ }^{\star}, 15 \mathrm{mi}$. N Fort Davis, Texas.

Fig. 9. R. hirsutus. UMMZ 94327 đ', 1 mi. E Ixtlán, Nayarit. 


\section{PLATE III}

Ventral aspect of crania of species inhabiting western México. Approximately $21 / 2$ times natural size.

Fig. 1. R. montanus montanus. MVZ 58737 o, $3 \mathrm{mi}$. N Socorro, New Mexico. Fig. 2. R. burti. MVZ 82996 đ, Rancho San Francisco de Costa Rica, Sonora. Fig. 3. R. megalotis megalotis. MVZ 82968 o, La Sauceda, Sonora.

FIG. 4. R. sumichrasti nerterus. UMMZ 94250 ㅇ, El Nevado de Colima, Jalisco.

FIG. 5. R. chrysopsis chrysopsis. UMMZ 94281 o', El Nevado de Colima, Jalisco.

Fig. 6. R. fulvescens nelsoni. UMMZ 94428 ô, La Resolana, Jalisco.

Fig. 7. R. fulvescens tenuis. US 96714 đ̆, near Mazatlán, Sinaloa.

FIG. 8. R. fulvescens canus. UMMZ 79283 $\curvearrowright 15 \mathrm{mi}$. N Fort Davis, Texas.

Fıg. 9. $R$. hirsutus. UMMZ 94327 ơ, 1 mi. E Ixtlán, Nayarit. 


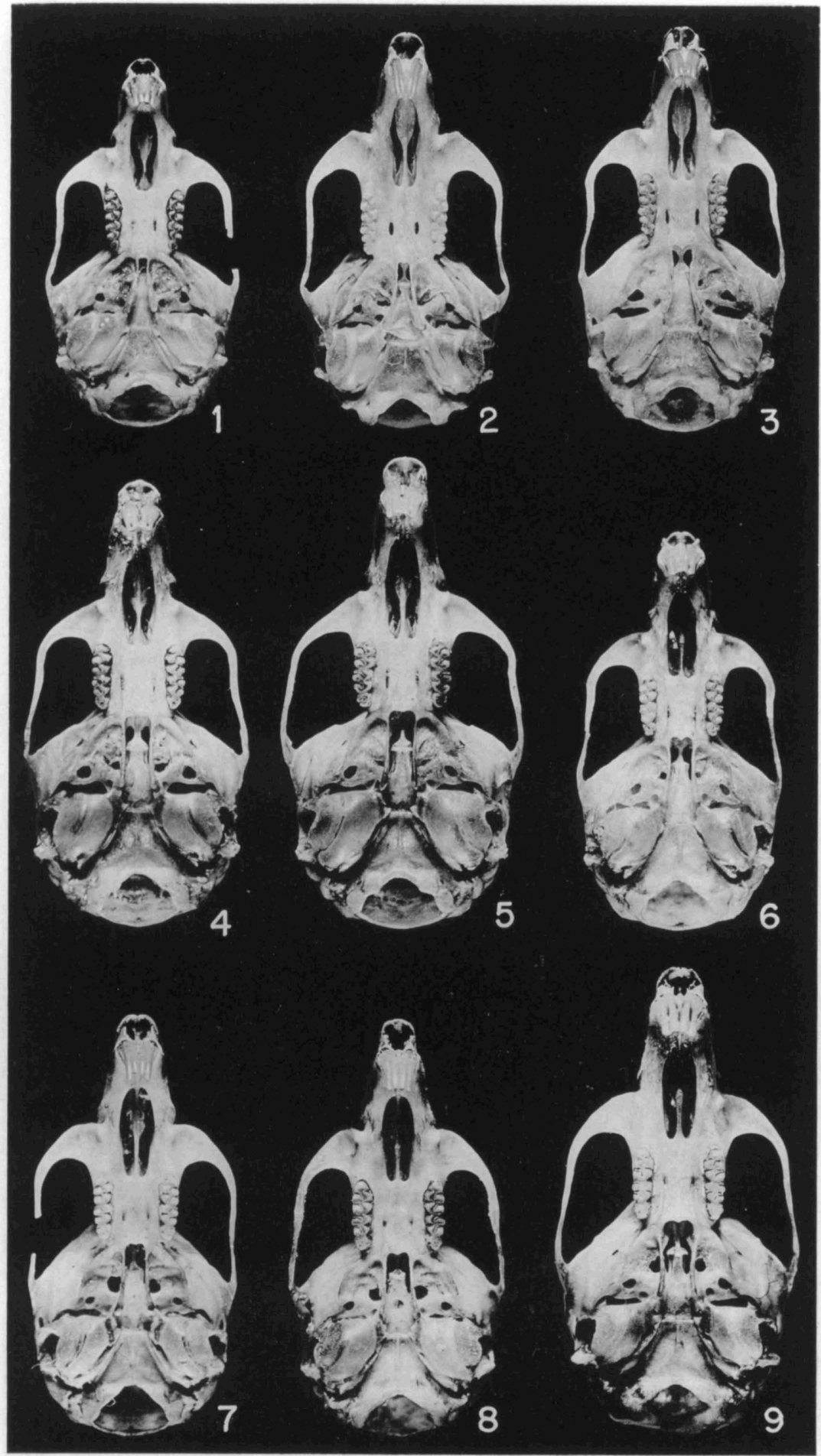




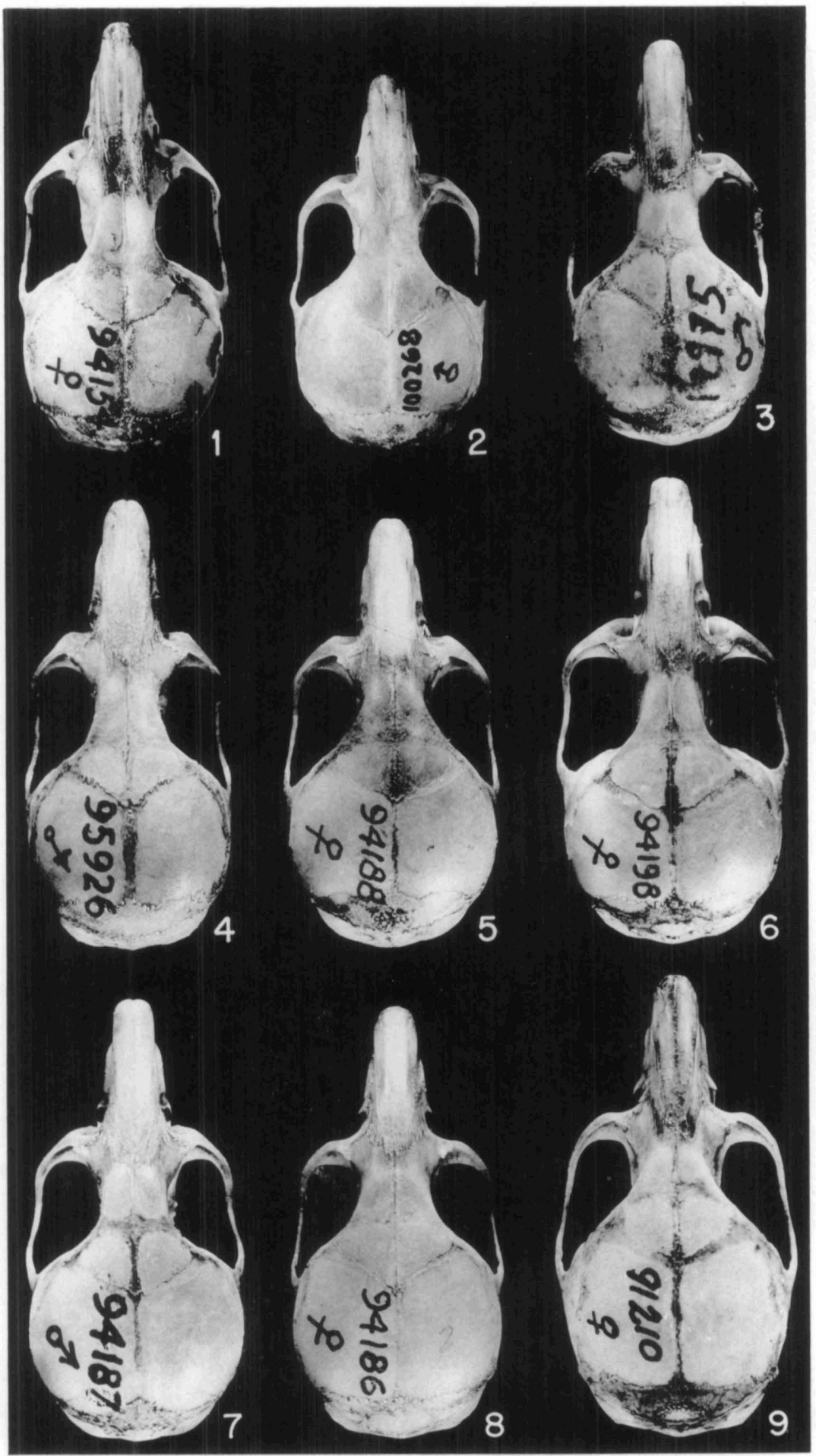




\section{PLATE IV}

Dorsal aspect of crania of species inhabiting central México. Approximately $21 / 2$ times natural size.

Fig. 1. R. megalotis saturatus. UMMZ 94154 q, $10 \mathrm{mi}$. SE Pátzcuaro, Michoacán.

Fic. 2. R. megalotis zacatecae. MVZ 100268 đ̊, 9 mi. SE Pátzcuaro, Michoacán.

Fig. 3. R. fulvescens tropicalis. KU $17975 \delta, 12 \mathrm{mi}$. WNW Piedras Negras, Veracruz.

Fig. 4. R. fulvescens toltecus. UMMZ 95926 o ${ }^{2}$, San Gerónimo, Distrito Federal.

Fig. 5. R. sumichrasti sumichrasti. UMMZ 94188 \%, 11/2 mi. N Jalapa, Veracruz.

Fig. 6. R. chrysopsis chrysopsis. UMMZ 94198, , Cañón Contreras, Distrito Federal.

Fig. 7. R. chrysopsis perotensis. UMMZ 94187 o ${ }^{2}$, Cofre de Perote, Veracruz.

FIG. 8. R. microdon wagneri. UMMZ 94186 , Cañon Contreras, Distrito Federal.

Fig. 9. R. mexicanus mexicanus. UMMZ 91210 @, Teziutlán, Puebla. 


\section{PLATE V}

Ventral aspect of crania of species inhabiting central México. Approximately $21 / 2$ times natural size.

Fig. 1. R. megalotis saturatus. UMMZ 94154 @ , 10 mi. SE Pátzcuaro, Michoacán.

Fic. 2. R. megalotis zacatecae. MVZ 100268 đ’, 9 mi. SE Pátzcuaro, Michoacán.

Fic. 3. R. fulvescens tropicalis. KU 17975 ó, $12 \mathrm{mi}$. WNW Piedras Negras, Veracruz.

Fic. 4. R. fulvescens toltecus. UMMZ 95926 ó, San Gerónimo, Distrito Federal.

Fic. 5. R. sumichrasti sumichrasti. UMMZ 94188 Q, $11 / 2$ mi. N Jalapa, Veracruz.

Fic. 6. R. chrysopsis chrysopsis. UMMZ 94198 q, Cañón Contreras, Distrito Federal.

Fig. 7. R. chrysopsis perotensis. UMMZ 94187 on, Cofre de Perote, Veracruz.

Fig. 8. R. microdon wagneri. UMMZ 94186 , Cañón Contreras, Distrito Federal.

FIg. 9. R. mexicanus mexicanus. UMMZ 91210 \&, Teziutlán, Puebla. 


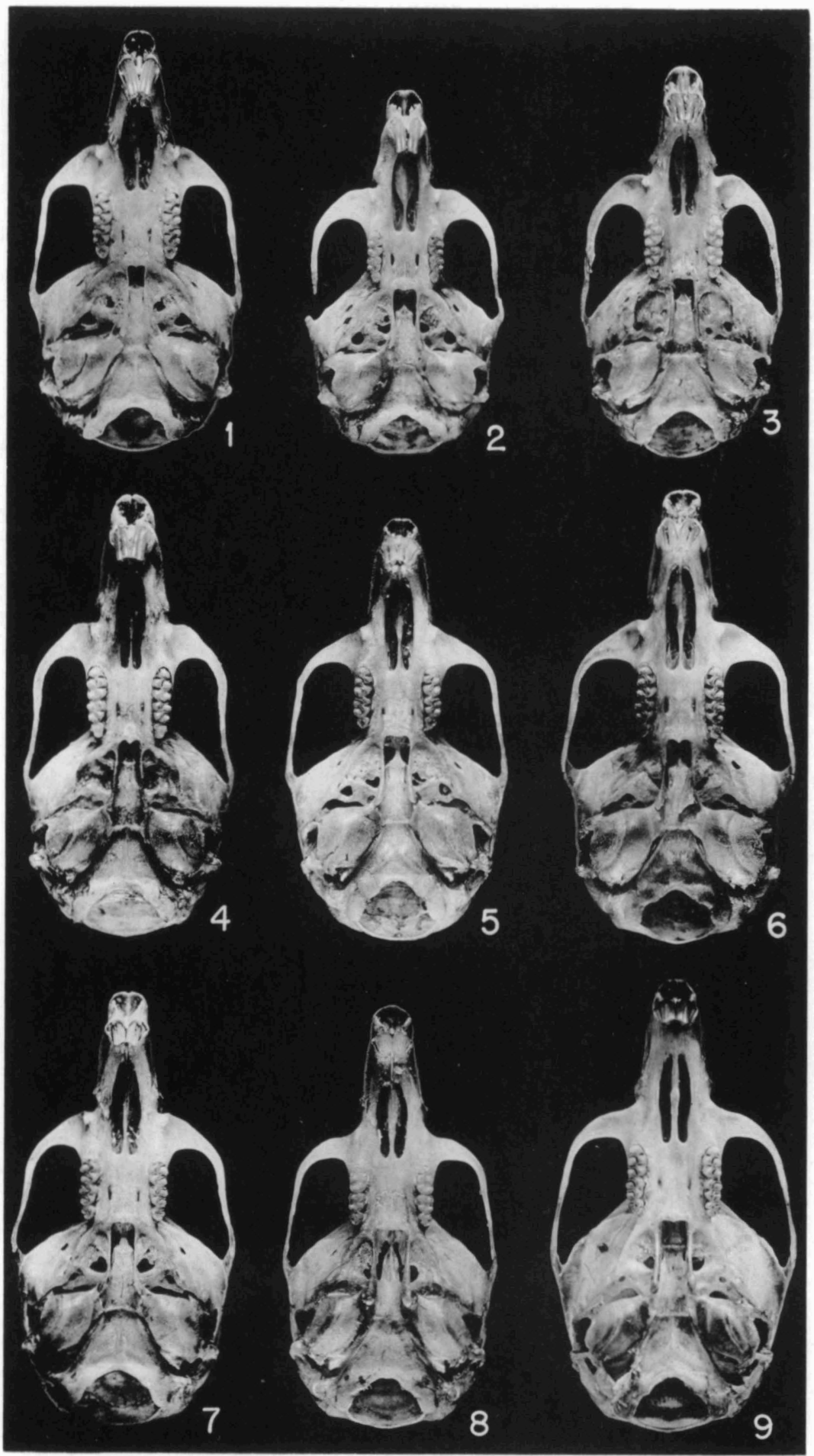




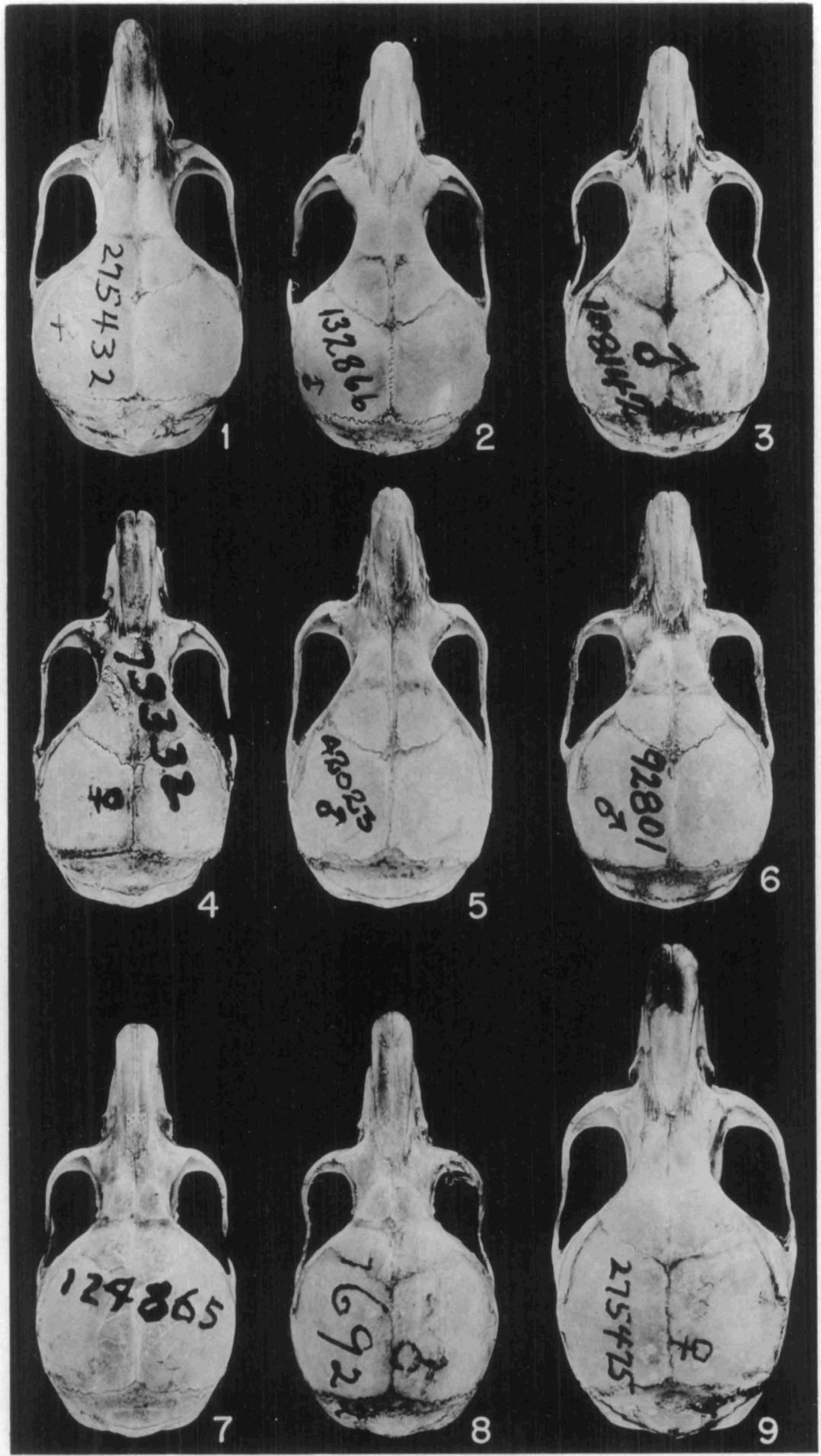




\section{PLATE VI}

Dorsal aspect of crania of species inhabiting northern (ientral America. Approximately $21 / 2$ times natural size.

FIG. 1. R. sumichrasti dorsalis. US 275432, Nebaj, Guatemala.

FIc. 2. R. fulvescens chiapensis. US 132866 ठ̊, Canjob, Chiapas.

FIG. 3. R. gracilis gracilis. US 108142 ơ, Chichén Itzá, Yucatán.

FIG. 4. R. gracilis pacificus. AM 79332 9 , Hacienda California, Guatemala.

Fig. 5. R. gracilis anthonyi. CM 42023 ơ, El Rancho, Guatemala.

Fig. 6. R. mexicanus howelli. UMMZ $92801 \sigma^{\curvearrowright}$, Pueblo Nuevo, Chiapas.

FIG. 7. R. mexicanus ocotepequensis. AM 124865 o, Monte Verde, Honduras.

Fig. 8. R. microdon microdon. US 76922 d, Todos Santos, Guatemala.

FIg. 9. R. tenuirostris. US 275475 $q$, Mataquescuintla, Guatemala. 
PLATE VII

Ventral aspect of crania of species inhabiting northern Central America. Approximately $21 / 2$ times natural size.

Fic. 1. R. sumichrasti dorsalis. US $275432 \uparrow$, Nebaj, Guatemala.

Fic. 2. R. fulvescens chiapensis. US 132866 ๙ే, Cajob, Chiapas.

Frc. 3. R. gracilis gracilis. US $108142 \AA$, Chichén Itzá, Yucatán.

FIG. 4. R. gracilis pacificus. AM 79332 ㅇ, Hacienda California, Guatemala.

Fig. 5. R. gracilis anthonyi. CM 42023 o, El Rancho, Guatemala.

Fic. 6. R. mexicanus howelli. UMMZ $92801 \delta^{\wedge}$, Pueblo Nuevo, Chiapas.

Frc. 7. R. mexicanus ocotepequensis. AM $124865 \delta^{\curvearrowright}$, Monte Verde, Honduras.

Fic. 8. R. microdon microdon. US $76922 \delta$, Todos Santos, Guatemala.

FIs. 9. R. tenuirostris. US 275475 , Mataquescuintla, Guatemala. 


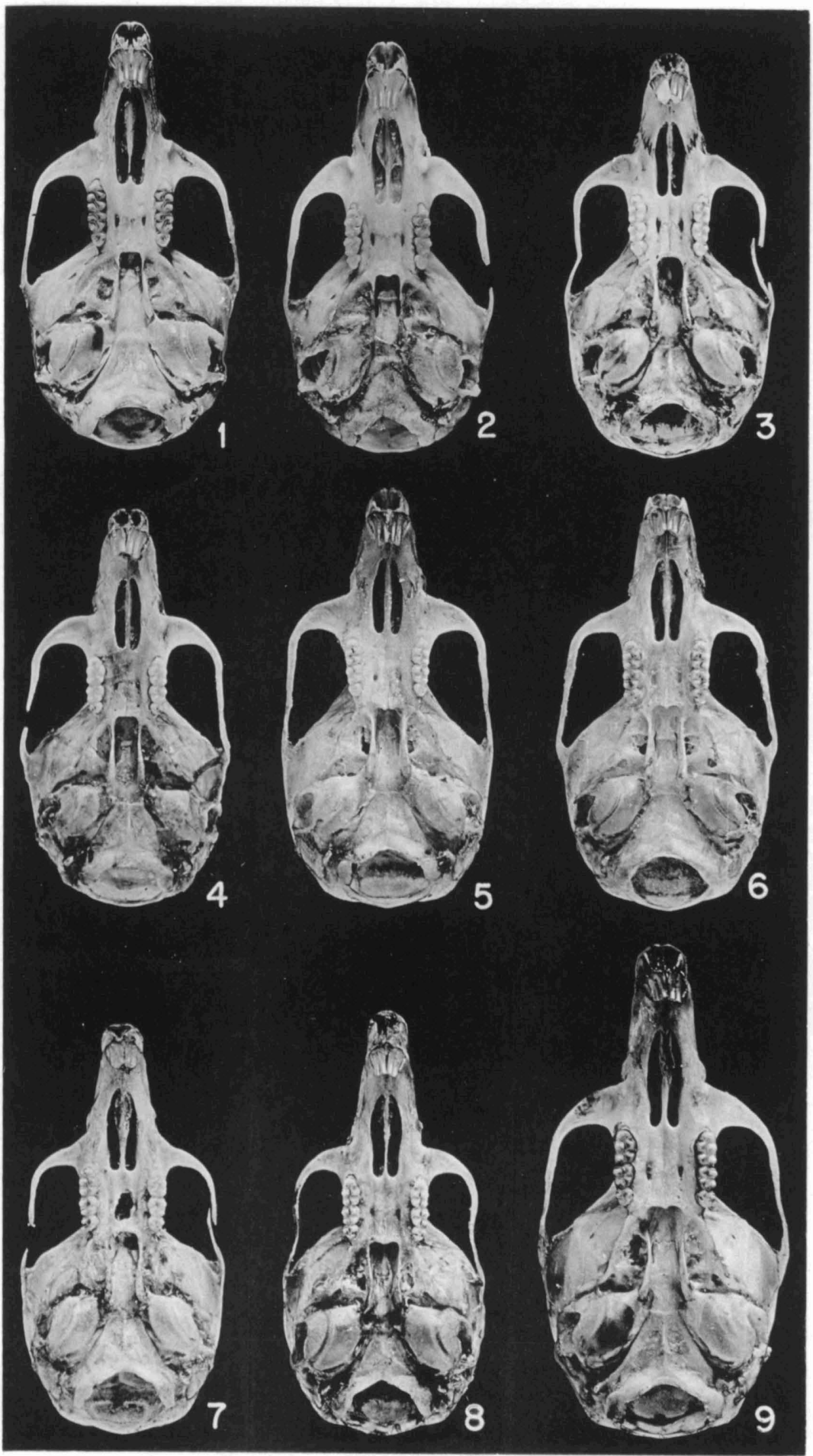




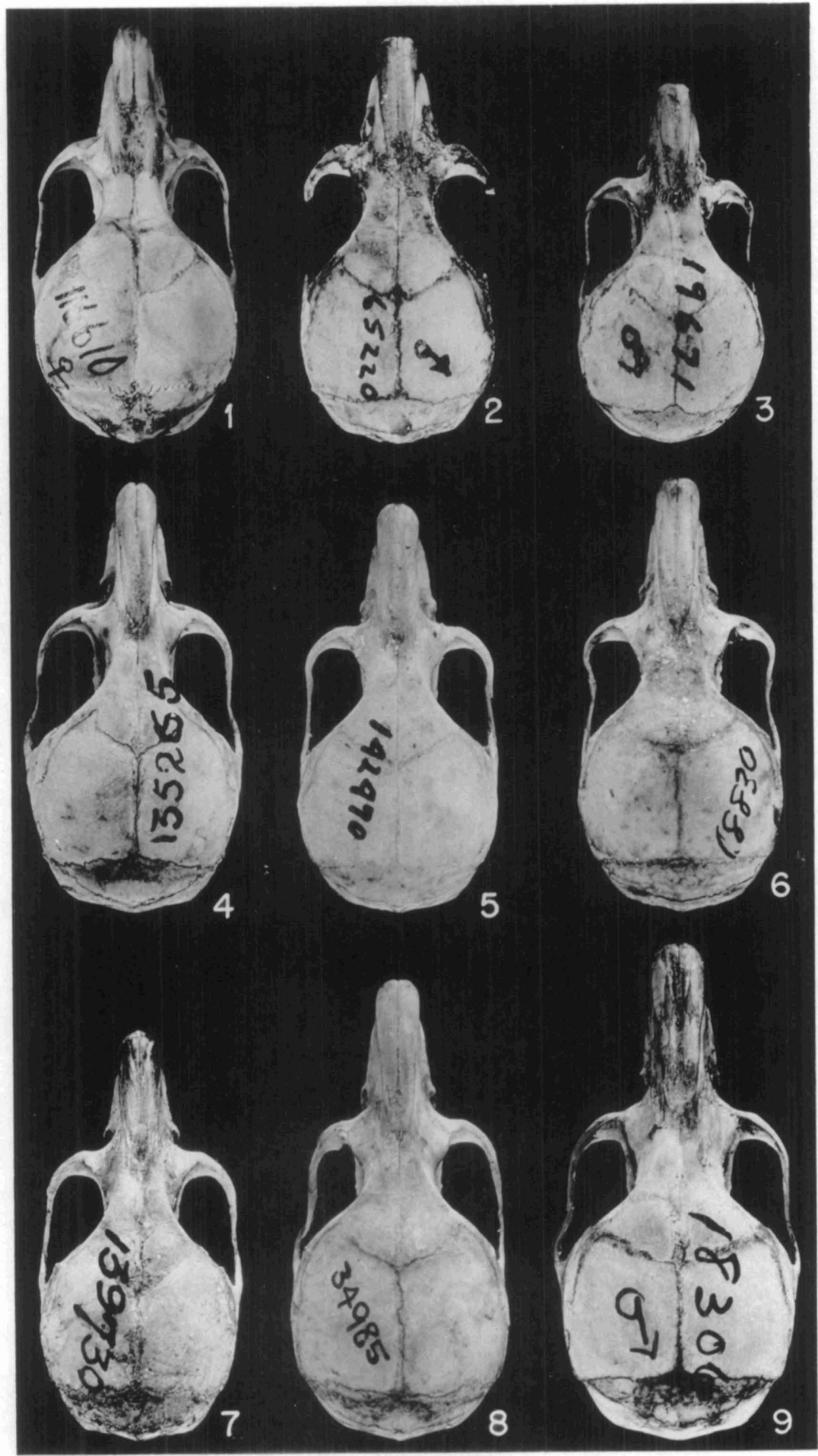




\section{PLATE VIII}

Dorsal aspect of crania of species inhabiting southern Central America. Approximately $21 / 2$ times natural size.

Fig. 1. R. sumichrasti australis. US 116610 q, Volcán de Irazú, Costa Rica.

Fig. 2. R. gracilis harrisi. UMMZ 65220 ơ, Hacienda Santa María, Costa Rica.

Fig. 3. R. darienensis. PM 19671 đ̊, Cana, Panamá.

Fig. 4. R. mexicanus cherriei. AM 135265 \%, Las Nubes, Costa Rica.

Frg. 5. R. mexicanus potrerograndei. AM $142470{ }^{\wedge}$, Agua Buena, Costa Rica.

Fig. 6. R. mexicanus garichensis. AM 18830 ó, Bóquete, Panamá.

Fig. 7. R. brevirostris. AM 139730 o, Villa Quesada, Costa Rica.

Fig. 8. R. rodriguezi. AM 34985 ð’, Volcán de Irazú, Costa Rica.

Fic. 9. R.creper. PM 18306, ơ, Volcán de Chiriquí, Panamá. 


\section{PLATE IX}

Ventral aspect of crania of species inhabiting southern Central America. Approximately $21 / 2$ times natural size.

FIG. 1. R. sumichrasti australis. US 116610 o, Volcán de Irazú, Costa Rica.

FIG. 2. R. gracilis harrisi. UMMZ 65220 $\delta$, Hacienda Santa María, Costa Rica.

Fig. 3. R. darienensis. PM 19671 đ, Cana, Panamá.

Fig. 4. R. mexicanus cherriei. AM 135265 , Las Nubes, Costa Rica.

Fig. 5. R. mexicanus potrerograndei. AM 142470 o, Agua Buena, Costa Rica.

Fig. 6. R. mexicanus garichensis. AM 18830 ơ, Bóquete, Panamá.

Fig. 7. R. brevirostris. AM 139730 o, Villa Quesada, Costa Rica.

Fig. 8. R. rodriguezi. AM 34985 đ, Volcán de Irazú, Costa Rica.

Frc. 9. R. creper. PM 18306 đ̊, Volcán de Chiriquí, Panamá. 


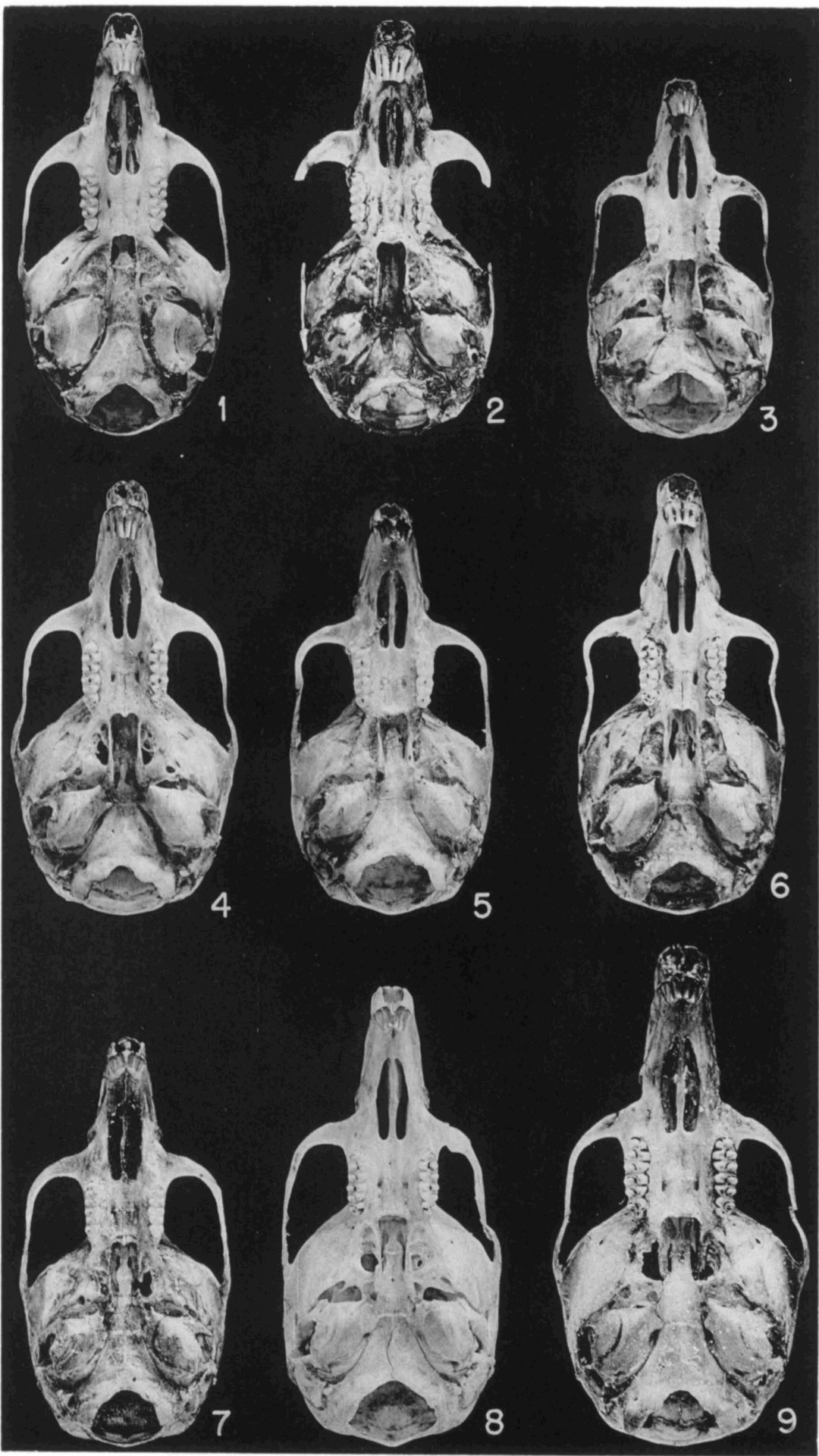




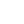


